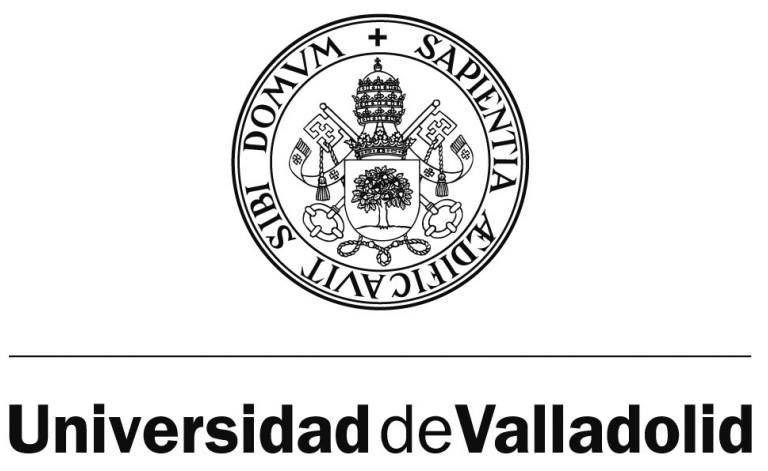

\title{
MORFOLOGÍA CONTRASTIVA DEL CHINO MANDARÍN Y EL ESPAÑOL FORMAS DE GRAMATICALIZACIÓN Y LEXICALIZACIÓN
}

TESIS DOCTORAL

Alumna: Chenling Liu

Directora: Dra. Margarita Lliteras Poncel

\begin{abstract}
Facultad de Filosofía y Letras
Departamento de Lengua Española

Programa de Doctorado: Lingüística Española y sus aplicaciones

Octubre de 2012
\end{abstract}





\section{ÍNDICE}

RESUMEN 9

$\begin{array}{ll}\text { ABSTRACT } & 11\end{array}$

$\begin{array}{ll}\text { AGRADECIMIENTOS } & 13\end{array}$

$\begin{array}{lr}\text { INTRODUCCIÓN } & 15\end{array}$

1 Breve introducción a la tipología del chino mandarín en contraste 23 con el español

1.1 Extensión y variedades del chino mandarín 23

1.2 Estructura silábica y tonos 26

1.3 Escritura y tipos de caracteres 33

1.4 Tipología morfológica de la lengua china 37

1.5 Tipología sintáctica de la lengua china 46

1.6 Orden de palabras y de sintagmas 51

1.7 Resumen y conclusiones 58

2 Unidades morfológicas 61

$\begin{array}{lll}2.1 & \text { Identificación del morfema } & 61\end{array}$

2.2 Principales clasificaciones del morfema 66

2.3 Morfemas autónomos, libres y ligados 69

2.4 Morfemas léxicos, derivativos y funcionales 71

2.5 Formantes polisémicos 81

2.6 Resumen y conclusiones 85 
4 Morfología contrastiva del chino mandarín y el español. Formas de gramaticalización y lexicalización

3 Componentes morfológicos del español: principales procesos de 89 formación léxica

3.1 Los conceptos de raíz, afijo, tema y morfema en la 89 lingüística española

$\begin{array}{lll}3.2 & \text { Flexión y derivación } & 91\end{array}$

3.2.1 Sufijación 93

3.2.2 Prefijación 98

3.2.3 Interfijación 102

3.3 Composición: compuestos morfológicos y compuestos 105 sintagmáticos

3.4 Otros procesos de formación de palabras: parasíntesis, 111 acortamiento, acronimia y siglación

3.5 Resumen y conclusiones

4 Componentes morfológicos del chino mandarín: principales 121 procesos de formación léxica

4.1 Los conceptos de sílaba, morfema y palabra en la 121 lingüística china

4.2 Flexión y derivación: problemas de reconocimiento de las 124 categorías flexivas

4.3 Afijación: sufijación, prefijación e interfijación 129

4.4 Los afijoides o pseudoafijos 139

4.5 Composición 146

$\begin{array}{ll}4.6 & \text { Los clasificadores } \\ & 164\end{array}$

$\begin{array}{lll}4.7 & \text { Reduplicación } & 168\end{array}$

4.8 Otros procesos de formación de palabras: abreviaciones, 171 aféresis, extranjerismos

4.9 Resumen y conclusiones 176 
5 Principales rasgos contrastivos entre la morfología china y la 179 morfología española

$\begin{array}{lll}5.1 & \text { Flexión } & 179\end{array}$

$\begin{array}{ll}5.2 \text { Derivación } & 186\end{array}$

$\begin{array}{lll}5.3 \text { Composición } & 197\end{array}$

$\begin{array}{lll}5.4 & \text { Formaciones híbridas } & 209\end{array}$

5.5 Otros aspectos comparables: los clasificadores, la 224 abreviación y el extranjerismo

5.6 Resumen y conclusiones 229

6 Procesos de gramaticalización y lexicalización: marco teórico 235

6.1 Gramaticalización 235

6.1.1 Principales definiciones 235

6.1.2 Gramaticalización y motivaciones pragmáticas y 239 cognitivas

6.1.3 Unidireccionalidad 247

6.1.4 Subjetivación 252

6.1.5 Reanálisis y analogía 255

6.2 Lexicalización 258

6.2.1 Principales definiciones 258

6.2.2 La cuestión de la direccionalidad 261

6.2.3 Desclitización 263

6.2.4 Desgramaticalización 265

6.2.5 Implicaciones semánticas de la lexicalización $\quad 268$

6.3 Relaciones entre gramaticalización y lexicalización 270

$\begin{array}{lll}6.4 & \text { Resumen y conclusiones } & 274\end{array}$ 

Morfología contrastiva del chino mandarín y el español. Formas de gramaticalización y lexicalización

7 Formantes gramaticalizados y lexicalizados en la morfología del 277 chino mandarín y el español

7.1 Gramaticalización en el componente morfológico

7.1.1 Gramaticalización en la morfología del español

7.1.2 Gramaticalización en la morfología del chino 280 mandarín

7.2 Lexicalización en la morfología del chino mandarín y el 285 español

7.2.1 Lexicalización de formas flexivas y derivativas

7.2.2 Lexicalización de compuestos

7.2.2.1 Carácter idiosincrásico 290

7.2.2.2 Procesos de fusión 291

$\begin{array}{ll}\text { 7.2.2.3 Idiomaticidad } 295 & 295\end{array}$

7.2.2.4 Gramaticalización y lexicalización como 298 procesos complementarios

\subsubsection{Debilitamiento sintáctico 301}

7.3 Mecanismos léxicos y gramaticales de la composición 304

7.3.1 Generalización y fusión 305

7.3.2 Analogía y reanálisis 308

$\begin{array}{ll}\text { 7.3.3 Recategorización } & 310\end{array}$

7.4 Mecanismos cognitivos de la composición 311

7.5 Resumen y conclusiones 330

8 Lexicalización de locuciones nominales 333

8.1 Características generales de la locución 333

8.2 Locuciones nominales constituidas por nombres y adjetivos 338 de color en chino mandarín y español

8.2.1 Los adjetivos de color 338

8.2.2 La estructura formal y la posición del adjetivo 340

8.2.3 Clasificación contrastiva 343 
8.2.4 Principales diferencias de productividad

8.2.5 Lexicalización formal y semántica

8.3 Locuciones nominales constituidas por nombres y adjetivos aspectuales en chino mandarín y español

8.3.1 Los adjetivos aspectuales

8.3.2 Clasificación aspectual de las locuciones nominales

8.3.3 Análisis contrastivo de la lexicalización

8.4 Locuciones nominales locativas

8.4.1 Los nombres de lugar en español y en mandarín

8.4.2 Comparación estructural

8.4.3 Análisis contrastivo de la lexicalización de los 385 nombres locativos en español y en chino mandarín

8.4.3.1 Lexicalización de las locuciones nominales locativas del español

8.4.3.2 Lexicalización de las locuciones nominales locativas del chino mandarín

8.5 Resumen y conclusiones 



\section{RESUMEN}

Con este trabajo sobre morfología contrastiva del chino mandarín y el español se ha intentado llenar, de alguna manera, el vacío existente en la actualidad en cuanto a estudios que pongan en relación los principales mecanismos de la formación de palabras en ambas lenguas. Por otra parte, el análisis de algunos esquemas de lexicalización en chino mandarín y en español desde la perspectiva del hispanista muestra que algunos principios universales y ciertos procesos cognitivos determinan una serie de congruencias o equivalencias en las formaciones morfológicas de estas dos lenguas tan distantes.

Para empezar, se introducen los principales rasgos lingüísticos del chino mandarín y las características que definen su tipología en contraste con el español. En el segundo capítulo, de carácter teórico, se revisan las principales definiciones y clasificaciones del morfema con la finalidad de valorar los tipos de estas unidades morfológicas que resultan representativos en el contraste interlingüístico del chino y el español. Especialmente útil para este propósito se considera la aplicación de los cinco principios de Nida (1965) al reconocimiento de las entidades morfológicas que intervienen en la formación de palabras en mandarín y español.

A continuación, en los capítulos tercero y cuarto, se examinan los componentes morfológicos y los principales procesos de formación léxica en ambas lenguas, primero en español -lengua cuya morfología se toma como referencia de estudio- y después en chino mandarín. A su vez, se introducen algunos fenómenos idiosincrásicos que contribuyen a la formación léxica de cada lengua, como la parasíntesis del español o los clasificadores y la reduplicación de la lengua china. 
Morfología contrastiva del chino mandarín y el español. Formas de gramaticalización y lexicalización

Desde el punto de vista de la comparación interlingüística, se es consciente de que las lenguas en contraste presentan unos rasgos comunes y otros decididamente divergentes. En esta línea, se dedica el capítulo quinto a reunir los aspectos semejantes y los específicos que caracterizan los sistemas morfológicos del chino mandarín y el español. Se ha puesto de manifiesto que un proceso habitual y productivo en una lengua puede resultar defectivo e improductivo en la otra.

En el capítulo sexto, se revisan las principales teorías propuestas acerca de los procesos de gramaticalización y lexicalización. A partir de estas nociones, se presta atención a los principales componentes morfológicos que en el estudio comparado del chino con respecto al español experimentan los procesos de gramaticalización y lexicalización para formar palabras. Asimismo, el análisis contrastivo permite comprobar el interés de considerar los procesos de gramaticalización y lexicalización como mecanismos complementarios que interactúan en la formación de palabras.

Finalmente, se examinan los principales formantes gramaticalizados y lexicalizados en la morfología de las dos lenguas contrastadas. El análisis de la lexicalización de los principales esquemas compositivos y de determinados tipos representativos de locuciones nominales en las dos lenguas contrastadas muestra el paralelismo y la convergencia de determinadas características formales y semánticas en el comportamiento de la lexicalización que experimentan las estructuras de origen sintagmático en la producción de formaciones morfológicas en chino mandarín y en español. 
With the work of contrastive morphology of Mandarin Chinese and Spanish we have tried to fill the gap in the present study about the main mechanisms of the word formation in both languages. Moreover, the analysis of some lexicalization patterns in Mandarin Chinese and Spanish from the Hispanics perspective shows that some universal principles and certain cognitive processes determine a set of congruence or equivalence in morphological formation of these two languages.

To begin, we introduce the main linguistics features of Mandarin Chinese and the characteristics that define it's typology in contrast to the Spanish. In the second chapter, by theory, we review the main definitions and classifications of the morpheme in order to assess these types of morphological units that are representative in the inter-linguistic contrast of Chinese and Spanish. It is especially useful for this purpose considering the application of the five principles of Nida (1965) on the recognition of morphological entities that involve in the word formation of Mandarin and Spanish.

In the third and fourth chapters, we examine the main morphological components and the lexical formation processes in Spanish and Mandarin Chinese. The Spanish morphology is taken as reference of the study. With this study, we introduce some idiosyncratic phenomena that contribute to the lexical formation of each language, such as the "parasíntesis" of Spanish or the classifiers and the reduplication of Chinese.

From the perspective of inter-linguistic comparison, we are aware that the language contrasts present some common features and other divergence. Following this trend, the fifth chapter is dedicated to gather some similar aspects and some specific aspects that characterize the morphological 

Morfología contrastiva del chino mandarín y el español. Formas de gramaticalización y lexicalización

systems of Mandarin Chinese and Spanish. It has been shown that a common and productive process in a language may be defective and unproductive in the other.

In the sixth chapter, we review the main proposed theories about the processes of grammaticalization and lexicalization. From these notions, we pay extra focus on the main morphological components in the comparative study of Chinese with respect to Spanish that go through the grammaticalization or lexicalization processes in order to form words. Furthermore, the contrastive analysis allows considering the processes of grammaticalization and lexicalization as complementary mechanisms that interact in the word formation.

Finally, we examine the main formant of lexicalization and grammaticalization in the morphology of the two contrasting languages. The lexicalization analysis of the major compositional schemes and certain types of representative nominal phrases in the two contrasted languages shows the parallelism and the convergence of certain formal and semantic features in the behavior of lexicalization that syntactic origin structures experience in producing morphological formations in Mandarin Chinese and Spanish. 
Deseo expresar mi más profundo agradecimiento a la profesora Dra. Margarita Lliteras por su inestimable ayuda en la dirección de este trabajo. Sus sugerencias, preguntas y correcciones me han ayudado en gran medida al desarrollo de este estudio y han despertado mi interés por otras vías de análisis para el contraste entre la lengua china y la española. Asimismo, me ha facilitado el acceso a material bibliográfico que de otra forma no me hubiera sido fácil conseguir. De manera muy especial, le agradezco la paciencia, nunca perdida en la corrección del chino mandarín, pues las modificaciones de una lengua extranjera tan distinta de la española han sido especialmente difíciles, pero siempre me ha inspirado para desarrollar posibles ideas de temas potenciales. Ella me ha ayudado de manera constante e insistente con sus críticas y sus orientaciones teóricas, formales y estilísticas. Su apoyo anímico ha sido decisivo para llevar a buen término mi trabajo.

También quiero dejar constancia de mis sentimientos de gratitud a mi madre. La comprensión y el amor recibidos de ella me han ayudado a superar los momentos más duros durante estos seis años en España.

Gracias especiales también a mi amigo, siempre joven, Eduardo Blanco Martín. Su cercanía, aun en la distancia, su cariño y su estímulo han aliviado mi nostalgia de casa. Su amistad ha sido y es el mejor regalo que he recibido durante mi estancia en España.

Gracias, finalmente, a los profesores del tribunal por su tiempo, su dedicación y su interés por mi trabajo. 



\section{INTRODUCCIÓN}

La difusión de la teoría de los universales lingüísticos había despertado el interés por analizar y contrastar lenguas, por extraer rasgos comunes y establecer diferencias. Así nació la lingüística de contraste o lingüística contrastiva que pretendía profundizar en la comprensión de los mecanismos lingüísticos mediante comparaciones sistemáticas.

Se entiende la lingüística contrastiva como una rama de la lingüística general que se ocupa de comparar, desde uno o más puntos de vista, los sistemas y los elementos de lenguas diferentes. Esta comparación sistemática tiene como objetivo la descripción de las semejanzas y las diferencias entre las lenguas. En el plano sincrónico, el objetivo de la comparación es la comprensión del lenguaje en general y también el estudio de los idiomas particulares mediante la formalización de los rasgos que los acercan y alejan de una lengua cuya descripción gramatical se toma como referencia teórica.

El desarrollo durante los últimos años de la lingüística contrastiva entre el mandarín y el inglés se ha visto canalizado con la publicación de muy diversos trabajos. No cabe duda de que los principales estudios gramaticales de la lengua china se apoyan en los resultados de los análisis contrastivos realizados entre las lenguas china e inglesa. Así, los que se dedican a la lingüística china son conscientes de que el estudio de esta lengua se basa, en general, en teorías lingüísticas inglesas, de las que recibe una gran influencia tanto en la metodología de análisis como en la descripción de las unidades del mandarín. De este modo, los estudios contrastivos entre el chino mandarín y otras lenguas indoeuropeas se ven condicionados por cierto anglocentrismo, 
Morfología contrastiva del chino mandarín y el español. Formas de gramaticalización y lexicalización

en el sentido de que la lingüística china es casi una versión de la lingüística inglesa.

Partiendo de tal situación, el estudio contrastivo entre el chino mandarín y otras lenguas parece imprescindible y necesario, pues tal comparación puede compensar los vacíos descriptivos que aún presenta el chino mandarín desde la única perspectiva del inglés y complementar la teoría lingüística de la lengua china. En esta línea, un estudio contrastivo entre el chino mandarín y el español no solo sirve para descubrir las diferencias y semejanzas de ambas lenguas, sino también para avanzar en la descripción gramatical del chino.

El presente trabajo se limita al ámbito morfológico. Se trata de realizar un análisis lingüístico contrastivo de la formación de palabras y de algunos elementos gramaticalizados y esquemas de lexicalización en chino mandarín y en español desde la perspectiva del hispanista. Nuestro objetivo último no se sitúa propiamente en el ámbito del español, pues no se alberga la pretensión de contribuir con este trabajo al desarrollo de la morfología española. La finalidad que se persigue, por el contrario, apunta hacia la descripción morfológica del chino mandarín a partir de los criterios de análisis que, en nuestra opinión, conforman en la actualidad la teoría y la descripción morfológica del español.

Sin embargo, desde el campo de la Tipología, es ineludible plantearse preguntas sobre cómo procederá el comparatista y qué comparar en el momento de comenzar el estudio morfológico contrastivo entre dos lenguas tan distintas. En realidad, pese a la distancia que las separa por su distribución geográfica y evolución histórica, aquí se defiende la hipótesis de que hay principios universales y ciertos mecanismos cognitivos que determinan rasgos comunes, congruencias o equivalencias entre ambas lenguas en el desarrollo de los procesos morfológicos. Además, la influencia de lenguas extranjeras, especialmente del inglés, condiciona la formación de neologismos a partir de préstamos o calcos semánticos, que en muchos casos resultan coincidentes en 
la morfología de las lenguas que son objeto de este estudio.

Con respecto al estado de la cuestión en la morfología contrastiva, y en particular entre el chino y el español, como se puede observar en la bibliografía, se han dedicado los estudios comparados, por lo general, a aspectos muy parciales de la gramática, como los pronombres, las oraciones compuestas, las conjunciones temporales, la negación, la voz pasiva, etc., con una orientación más bien instrumental. Sin embargo, son todavía escasos en la actualidad los trabajos contrastivos más amplios orientados a un análisis global de una disciplina en su conjunto, como es el caso de la morfología. Aunque no faltan estudios sobre algún aspecto estrictamente morfológico, como la tesis de Her (2002), que contiene una presentación de los mecanismos de formación de palabras, las contribuciones a la morfología contrastiva de las que tenemos noticia no toman en consideración algunos factores teóricos relacionados con los procesos de gramaticalización y lexicalización que pueden aplicarse al análisis morfológico con la finalidad de descubrir puntos de convergencia entre nuestras dos lenguas. Tampoco se han llegado a definir criterios para resolver con claridad los principales problemas que todavía plantea la identificación y clasificación de los componentes morfológicos, especialmente los de la lengua china. La aplicación a la morfología contrastiva de algunos principios pragmáticos y cognitivos también constituía una camino inexplorado en este tipo de investigaciones sobre la comparación de las formaciones léxicas en chino y español.

Así, a partir de estos estudios, nos pareció interesante avanzar en la línea de la morfología contrastiva, pero teniendo en cuenta un concepto integral de la morfología, entendida como el estudio de los procesos de lexicalización de las formas complejas, especialmente en la composición y las locuciones, y como el análisis de las unidades gramaticalizadas que conforman los sistemas flexivos y derivativos de ambas lenguas en contraste. Para alcanzar tales propósitos, resulta inevitable revisar las definiciones y clasificaciones de los principales formantes morfológicos $y$, en ocasiones, defender nuevas 
Morfología contrastiva del chino mandarín y el español. Formas de gramaticalización y lexicalización

explicaciones sobre todo para las unidades que en la actualidad revisten una mayor confusión.

La metodología contrastiva que aquí se aplica al estudio de la morfología china comparada con la morfología del español permite cuestionar algunos de los principales tópicos que suelen repetirse tanto en manuales de lingüística general como en algunas monografías. Se trata de la idea, escasamente fundamentada en nuestra opinión, de que el chino mandarín es una lengua aislante y analítica, carente de flexiones y pobre en la derivación. Dicho de otra forma, se suele defender el criterio desde tales ámbitos de que el chino sencillamente no tiene morfología. Esta caracterización enlaza, a su vez, con otra creencia muy generalizada sobre todo entre los lingüistas chinos, basada en la excesiva dependencia del chino escrito como única fuente posible de la descripción gramatical. La presión del código escrito lleva a defender, entre otras cuestiones, que en chino todos los morfemas son monosílabos y autónomos porque cada sílaba se escribe separada de la otra anterior y posterior. El paso siguiente consiste en confundir absolutamente el morfema con la palabra. El supuesto de que en mandarín no hay morfemas dependientes o ligados constituye una afirmación bastante generalizada en la bibliografía china. Con este argumento por el que se niega el reconocimiento de morfemas ligados o dependientes, se llega a rechazar la existencia en mandarín de procesos flexivos y derivativos.

Por nuestra parte, consideramos que este tipo de planteamientos no se corresponde con los datos que proporciona la observación del chino actual, pues el análisis morfológico de las formaciones gramaticales y léxicas usuales muestra que en mandarín no todas las unidades son el resultado de la composición, sobre todo si se siguen criterios de definición y clasificación acordes con la teoría morfológica más generalizada en la actualidad. En realidad, la morfología flexiva y derivativa son fenómenos que se dan en el chino mandarín, además de otros procedimientos que enriquecen la formación léxica. 
El análisis del componente morfológico del mandarín contrastado con el del español constituye el propósito central de este trabajo. Se ha acotado el objeto de estudio a la variedad estándar, de modo que se han limitado las consideraciones históricas de nuestras lenguas en contraste solo a los aspectos que resultan determinantes para fundamentar la descripción sincrónica. La limitación también se extiende al plano diatópico, pues se ha seleccionado la variedad del chino culto utilizado en Taiwán y el español culto peninsular, a pesar de que las variedades americanas también presentan rasgos morfológicos de interés. Solo ocasionalmente se han recogido datos morfológicos de los registros coloquiales o familiares de ambas lenguas.

Conscientes de estas y otras limitaciones, esta tesis puede considerarse como un trabajo pionero de morfología contrastiva entre el mandarín y el español. Se pretende que pueda contribuir de algún modo a la teoría morfológica, especialmente de la lengua china, pero también al desarrollo de la morfología aplicada a la enseñanza de la lengua extranjera desde una $u$ otra lengua materna. Además de este tipo aplicación, el presente trabajo también podría resultar de interés a la lexicografía bilingüe y a la traductología del chino al español, pues contiene una clasificación -relativamente exhaustiva- de los componentes morfológicos del mandarín, de los que se aporta no solo su definición categorial o marco de subcategorización, sino también su traducción literal y su equivalente en español.

El trabajo consta de ocho capítulos que se dedican al estudio descriptivo y sincrónico de los fenómenos que afectan a los procesos de formación de palabras, a la gramaticalización de unidades morfológicas y a la lexicalización de algunas estructuras en el contraste de ambas lenguas. No obstante, se ha considerado conveniente resumir en el primer capítulo las principales propiedades de la lengua china. Se presentan las variedades y la extensión del chino, sus características tipológicas más destacadas tanto en la morfología como en la sintaxis, pero también en su configuración fonológica y en el sistema de escritura. 
Morfología contrastiva del chino mandarín y el español. Formas de gramaticalización y lexicalización

El segundo capítulo contiene un análisis de las unidades morfológicas, principalmente de la unidad por excelencia que se suele identificar con el morfema. Se presta atención a las principales propuestas teóricas de definición y clasificación del morfema con la finalidad de llegar a reconocer con claridad la variada tipología de formantes morfológicos que presentan nuestras lenguas en contraste, unos comunes y otros decididamente divergentes. En esta línea de introducción teórica, los cinco principios -ya clásicos- formulados por Nida (1965) resultan de gran utilidad en su aplicación al análisis morfológico del chino comparado con el español. Al tratamiento de los problemas de definición siguen las principales clasificaciones de las unidades morfológicas de acuerdo con el contenido semántico, la capacidad léxica y la categoría funcional que desarrollan estos formantes.

En el tercer capítulo se asientan los fundamentos teóricos de los principales procesos de formación léxica del español, se definen los componentes morfológicos y se analizan las estructuras morfológicas que resultan de su combinación, la derivación y la composición. También se incluyen otros recursos de formación de palabras, como la parasíntesis, el acortamiento, la acronimia y la siglación.

A continuación, en el cuarto capítulo se definen los procedimientos fundamentales de la formación de palabras en chino mandarín mediante la aplicación de teorías morfológicas comunes a las lenguas indoeuropeas: la flexión, la derivación, la composición, la abreviación y la aféresis. También se presta atención a los procesos léxicos que son propios o prominentes en chino mandarín: los clasificadores y la reduplicación. Todos los ejemplos que se introducen en este capítulo se corresponden con el uso de Taiwán, dado que en China continental el mandarín varía en algunos aspectos fonéticos o sintácticos.

Se dedica el capítulo quinto a un análisis contrastivo propiamente dicho entre la morfología del chino mandarín y el español en relación con los componentes y las estructuras de las palabras, a fin de explorar los fenómenos 
comunes y los particulares en los procedimientos de formación de palabras en ambas lenguas. Por otra parte, también se comparan otros procesos que intervienen en la formación de palabras en ambas lenguas, tales como el problema de los clasificadores, la abreviación y el extranjerismo.

El capítulo sexto constituye una revisión de las principales teorías propuestas acerca de los procesos de gramaticalización y lexicalización. Entre ellas, se incluyen las que se formulan desde la lingüística histórico-comparada, la estructuralista y las corrientes pragmáticas y cognitivas. Se describe cómo los cambios semánticos afectan al proceso de lexicalización y, por último, se defiende la interacción entre la gramaticalización y la lexicalización como mecanismos complementarios en la formación de palabras.

En el capítulo séptimo, se examinan los principales formantes gramaticalizados y lexicalizados en la morfología de las dos lenguas contrastadas, sobre todo, en la fijación de las palabras compuestas. Por otra parte, se comprueba que los mecanismos de la generalización, la fusión, el reanálisis, la analogía y la recategorización intervienen en la formación léxica. Por último, se pone de manifiesto que la teoría de la integración y la fusión conceptual (Conceptual Blending) sirven como factores semántico-cognitivos que explican la morfología compositiva en ambas lenguas.

En el capítulo octavo, finalmente, se seleccionan tres estructuras de lexicalización muy representativas de ambas lenguas que muestran claramente las aproximaciones por las que se transforman las combinaciones sintagmáticas en unidades léxicas fijadas tanto en mandarín como en español. Se trata de tres tipos de locuciones nominales, como son las formadas por nombres y adjetivos de color, las constituidas por nombres y adjetivos aspectuales y, por último, los nombres de lugar o nombres locativos. Por otra parte, se exploran los aspectos relacionados con el desarrollo de la lexicalización en ambas lenguas y también se demuestran las diferencias estructurales y semánticas de estas locuciones. 
Morfología contrastiva del chino mandarín y el español. Formas de gramaticalización y lexicalización

En cuanto a la organización de la bibliografía, hemos distinguido dos apartados con la finalidad de facilitar la consulta y, al mismo tiempo, ordenar nuestras fuentes: el primero contiene los títulos correspondientes a los estudios de lingüística general y de lingüística española, mientras que el segundo incluye las principales aportaciones a la descripción del mandarín y a la lingüística contrastiva que toma en consideración el mandarín, sea o no el español la segunda lengua de referencia en el estudio contrastivo.

La complejidad de esta tesis ha exigido prestar especial cuidado a los aspectos formales. En general, se han seguido las indicaciones del Manual de estilo de la Universidad de Chicago (1972)', sobre todo en las convenciones que se recomiendan para los trabajos sobre lenguas con alfabetos diferentes, como es el caso de este trabajo. Así, las palabras o morfemas en caracteres chinos van precedidos de su transliteración al alfabeto latino y seguidos de la traducción literal de cada carácter al español (o, en su caso, del valor gramatical) en redonda y entre apóstrofos. Finalmente, tras la flecha $(\rightarrow)$, sigue el equivalente de traducción en cursiva, como en el siguiente ejemplo:

zhào xiàng $\bar{\jmath}$ 照相機 'reflejar' 'aspecto' 'máquina' $\rightarrow$ cámara

El subrayado de dos (o más) signos tanto en la transliteración como en los caracteres chinos indica que este grupo se corresponde con un único término de la traducción literal, como se ilustra seguidamente:

chū lái 出來 'salir'

nuè dài kuáng 虐待狂 'maltratar' 'loco, adicto' $\rightarrow$ sádico

Finalmente, se ha adoptado el criterio general de presentar en el cuerpo del texto nuestra propia traducción de las citas en inglés -salvo si se trata de fragmentos muy breves-, mientras que el original se reproduce en notas al pie de página.

\footnotetext{
${ }^{1}$ The Chicago Manual of Style, 12 th Edition completely revised. Chicago / London: The University of Chicago Press.
} 


\section{BREVE INTRODUCCIÓN A LA TIPOLOGÍA DEL CHINO MANDARÍN EN CONTRASTE CON EL ESPAÑOL}

Este primer capítulo constituye un resumen de los principales rasgos lingüísticos del chino mandarín. Se describen la extensión geográfica y las variedades de la lengua china y se analizan su estructura silábica y su escritura, que la identifican con el tipo monosilábico y logográfico. Por otra parte, se estudian las características que definen la tipología morfológica, la tipología sintáctica y el orden de palabras en el esquema sintagmático del chino mandarín en contraste con el español.

\subsection{Extensión y variedades del chino mandarín}

El término chino mandarín (o habla de Pekín) representa la lengua estándar de Pekín tal como se usa en esta ciudad de importante significación política y cultural. Esta lengua hace referencia a la mayor familia dialectal de China y ha sido reconocida actualmente como la lengua oficial de China, Taiwán y Singapur. También se habla en Indonesia y Malasia. En 1955 China estableció esta lengua común para toda la nación. Se adoptó la pronunciación del dialecto de Pekín, la gramática del mandarín del norte y el vocabulario de la literatura vernácula moderna.

El concepto de chino mandarín es en cierto modo teórico. Aunque para la civilización occidental equivale a la lengua estándar de China, para los hablantes la idea de su lengua no resulta lingüísticamente uniforme por la vasta 
Morfología contrastiva del chino mandarín y el español. Formas de gramaticalización y lexicalización

extensión geográfica de su dominio, que incluye varios países como China, Taiwán, Singapur, Indonesia y Malasia. En Taiwán, el vocablo "mandarín" se refieren a zhōng wén 中文 lengua china o guó y̌̌ 國語 lengua nacional, mientras que en la República Popular China (China continental) se utiliza el nombre hàn yǔ 漢語 lengua de los Hàn o se adopta la forma culta normalizada de la lengua, que se llama pǔ tonh huà 普通話 habla común. Esta variedad de formas de denominación se corresponde, sin embargo, con el dialecto pekinés en referencia a la mayor parte de los rasgos lingüísticos comunes, excepto en determinadas áreas del vocabulario, lo que puede ser atribuido en parte a las diferencias políticas y culturales.

La diversidad de denominación no dificulta el éxito comunicativo de esta lengua común entre hablantes de dialectos mutuamente inteligibles. Sin embargo, aunque la gramática es la misma, en cada dialecto los caracteres del chino escrito se leen y se pronuncian de manera diferente. Sobre todo, desde que el Gobierno Comunista de Pekín promovió la imposición de los caracteres simplificados en la segunda mitad del siglo XX, se rompió la tradicional uniformidad de la lengua escrita. Así, se forman dos sistemas de escritura estándar para el chino mandarín: mientras que en China continental se utiliza el chino simplificado, el mandarín tradicional continúa utilizándose en Taiwán, Hong Kong y Macao.

Básicamente, el proceso de simplificación consiste en excluir trazos y sustituir las formas de los caracteres tradicionales especialmente complejos por otros más sencillos. Normalmente se aplican ciertas reglas, por ejemplo, sustituir ciertos radicales² (subdivisión regular de un carácter) por una variante más simple y crear formas arbitrarias, de manera que la escritura simplificada es muy diferente de la tradicional y resulta prácticamente imposible deducir su

\footnotetext{
2 El término radical (bùshǒu 部首) se refiere a un grafema del sistema de escritura de los logogramas chinos, que representa a cada uno de los 214 elementos en los que se pueden descomponer los caracteres chinos. A su vez, los radicales se clasifican y ordenan según su número de trazos. El número de trazos que compone un radical varía desde 1 hasta 17. Para usar un diccionario chino hace falta recibir clases de caligrafía para poder contar los trazos.
} 
motivación (vid. tabla 5). También existen caracteres que no han sido simplificados, pues en general estos presentan relativamente pocos trazos, de modo que se escriben de la misma forma tanto en la escritura simplificada como en la escritura tradicional.

Al igual que ocurre con otras muchas lenguas, se asume como principio básico que las posibles variedades de una lengua se consideran dialectos. Así generalmente, en las distintas regiones de la lengua china, se llama dialecto a la variante del mandarín en una determinada zona geográfica. Según Li y Thompson (2003: 3), la familia de la lengua china es genéticamente clasificada como una rama independiente de la familia sinotibetana. A su vez, existen casi 60 dialectos separados a veces por distancias relativamente cortas. A continuación, se presentan en una tabla los grupos dialectales de la lengua china con sus zonas más representativos y el porcentaje de hablantes:

\begin{tabular}{|c|c|c|c|}
\hline \multicolumn{2}{|c|}{ Grupos dialectales } & \multirow{2}{*}{$\begin{array}{l}\text { Región geográfica } \\
\text { Pekín } \\
\text { Taiyuan } \\
\text { Chengdu } \\
\text { Nanking } \\
\end{array}$} & \multirow{2}{*}{$\begin{array}{c}\text { \% hablantes } \\
70 \%\end{array}$} \\
\hline MANDARÍN & $\begin{array}{l}\text { del norte } \\
\text { del nordeste } \\
\text { del sureste } \\
\text { Yangz }\end{array}$ & & \\
\hline WÚ & $\begin{array}{l}1 \\
2\end{array}$ & $\begin{array}{l}\text { Suzhou } \\
\text { Wenzhou }\end{array}$ & $8.4 \%$ \\
\hline XIAN & $\begin{array}{l}\text { Gantiguo } \\
\text { Moderno }\end{array}$ & $\begin{array}{l}\text { Shuangfeng } \\
\text { Changsha }\end{array}$ & $5 \%$ \\
\hline GAN & & Nanchang & $2.4 \%$ \\
\hline HAKKA & & Meixin & $4 \%$ \\
\hline MIN & $\begin{array}{l}\text { del norte } \\
\text { del sur }\end{array}$ & $\begin{array}{l}\text { Fuzhou } \\
\text { Chaozhou }\end{array}$ & $1.5 \%$ \\
\hline YUE & $\begin{array}{l}\text { Yue-Hai } \\
\text { Qin-Lian } \\
\text { Gao-Lei } \\
\text { Si-Yi } \\
\text { Guei-Nan }\end{array}$ & $\begin{array}{l}\text { Zhongshn } \\
\text { Lianzhou } \\
\text { Gaozhou } \\
\text { Taishan } \\
\text { Yulin y Hong Kong }\end{array}$ & $5 \%$ \\
\hline
\end{tabular}

Tabla 1: Grupos dialectales (Fuente: Li y Thompson) 
Morfología contrastiva del chino mandarín y el español. Formas de gramaticalización y lexicalización

Li y Thompson (2003: 2) indican que se suele pensar en que la diferencia entre estos dialectos y el chino mandarín es equiparable a la diferencia entre el español y otras lenguas romances, como el portugués o el italiano. Sin embargo, aunque las lenguas románicas están relacionadas entre sí, se consideran "lenguas" y no "dialectos", pues se observan, entre otros aspectos, variedades lingüísticas diferenciadas en cada región geográfica. En cambio, en el caso de las variedades chinas, se consideran "dialectos" del mandarín, aunque muchas veces sus hablantes no consiguen entenderse en los registros orales, sobre todo por las diferencias fonéticas y léxicas de cada zona. Pero la comunicación no presenta estas dificultades en el código escrito, pues todos los grupos dialectales han adoptado el mismo sistema de escritura. La delimitación entre "lengua" y "dialecto" en distintas áreas es un proceso delicado en lingüística, porque exige, entre otros aspectos, la caracterización adecuada de la lengua del territorio, el análisis de su filiación histórico-política, la valoración sociolingüística y estudios de actitudes lingüísticas por parte de los hablantes. Aquí no entramos en esta distinción teórica, pero nos interesaba dedicar atención al problema de la unidad y variedad del chino mandarín.

\subsection{Estructura silábica y tonos}

La estructura silábica del chino mandarín está constituida, según las descripciones más comunes (Li y Thompson 2003: §1.2), por dos elementos, que reciben el nombre de shēng mǔ 聲母 fonema inicial y yùn mǔ 韻母 fonema final. Sin embargo, hay cierta tendencia entre los estudiosos a identificar el fonema inicial de los caracteres monosilábicos del chino con las consonantes de las lenguas occidentales, mientras que el llamado fonema final se tiende a equiparar a las vocales. Este recurso metodológico explica que habitualmente se admita un fonema inicial "cero" para describir la estructura silábica formada solo por una o varias vocales. 
Según el Alfabeto Fonético Internacional y el sistema fonético de trascripción Pinyin ${ }^{3}$, el mandarín dispone de veintiún fonemas iniciales (incluido el fonema inicial "cero") y treinta y siete fonemas finales. En comparación con los tipos silábicos del español${ }^{4}$, las principales diferencias residen, de una parte, en la ausencia de sílabas con consonantes agrupadas en la lengua china, tanto en posición inicial como en posición final. Esta limitación explica que la única consonante o fonema inicial de la sílaba suele ser interpretada como "consonante solidaria". Por otra parte, la posición final de la sílaba china también se reduce a dos sonidos, que son el nasal alveolar [n] y el nasal velar [n]. La tabla siguiente recoge las posibles combinaciones de los dos tipos de fonemas:

\begin{tabular}{|l|l|}
\hline Fonema inicial & \multicolumn{1}{|c|}{ Ejemplos } \\
\hline Consonante solidaria + vocal & kū 哭 llorar \\
Consonante solidaria + diptongo & sāi 塞 atasco \\
Consonante solidaria + triptongo & miaò 妙 maravilloso \\
Consonante solidaria + vocal + nasal alveolar [n] & sān 三 tres \\
Consonante solidaria + vocal + nasal velar [n] & máng 忙 ocupado \\
Consonante solidaria + diptongo + nasal alveolar[n] & suān 酸 ácido \\
Consonante solidaria + diptongo + nasal velar [n] & liàng 量 cantidad \\
Consonante cero + vocal & $\bar{\imath}$ - uno \\
Consonante cero + diptongo & yé 爺 abuelo, señor \\
\hline
\end{tabular}

Tabla 2: Combinaciones silábicas de fonemas iniciales y fonemas finales

Comparado con el sistema fonológico del español, los fonemas iniciales del mandarín corresponden a los consonantes del español, mientras que los fonemas finales del mandarín pueden ser consonánticos y vocálicos.

3 En la actualidad existen varios sistemas de trascripción, como el sistema Pinyin, el Alfabeto Fonético Internacional, el sistema Wade-Giles, el sistema Yale, el sistema Francófono, el Alfabeto Fonético Chino, el Gwoyeu Romatzyh. Entre tantos tipos, el sistema más utilizado por el estudioso del chino mandarín es el Pinyin. Aquí se adoptará el sistema Pinyin para transcribir los caracteres chinos.

4 Se registran 23 tipos de sílabas en el dominio de la palabra en español según las combinaciones de vocales y consonantes. Vid. RAE (2011: § 8.4).

5 La posición posnuclear presenta restricciones consonánticas en muchas lenguas. Alarcos (1994: § 36) explica que, como consecuencia del predominio de las sílabas abiertas, en español no figura / $\hat{c} /$ y escasamente /j, f/. Además se produce la indiferenciación de sonidos, especialmente de los nasales, en esta posición. Por otra parte, este mismo autor ponía el japonés como ejemplo de lengua que no admite la combinación consonántica en posición inicial y reduce la posición final a la vocal o a la vocal más /n/. Vid. Alarcos (1976: § 60). 
Morfología contrastiva del chino mandarín y el español. Formas de gramaticalización y lexicalización

Por ejemplo, en la palabra liàng 量 cantidad se observa que la sílaba consiste en el fonema inicial de la consonante $/$ y el fonema final formado por el diptongo ia y el sonido consonántico nasal velar ng [ฤ].

Según indica Chao (1998: 7 y 16), aunque existen diferencias, los sistemas consonánticos del mandarín y del español comparten algunas semejanzas. Así, ambas lenguas configuran un sistema fonético en el que las consonantes se distinguen por su punto de articulación en sonidos bilabiales, dentales, palatales, velares, etc., tal como se ilustra en la siguiente tabla:

\begin{tabular}{|c|c|c|}
\hline \multicolumn{3}{|c|}{ Clases de consonantes } \\
\hline Articulación & Chino mandarín & Español \\
\hline Bilabiales & $\mathrm{b}, \mathrm{p}, \mathrm{m}$ & $\mathrm{b}, \mathrm{p}, \mathrm{m}$ \\
\hline Labiodentales & $\mathrm{f}$ & $\mathrm{f}$ \\
\hline Interdentales & & $\mathrm{Z}$ \\
\hline Dentales & $\mathrm{z}, \mathrm{c}, \mathrm{s}$ & $\mathrm{d}, \mathrm{t}$ \\
\hline Alveolares & $\mathrm{d}, \mathrm{t}, \mathrm{n}, \mathrm{l}$ & $\mathrm{n}, \mathrm{l}, \mathrm{r}, \mathrm{rr}, \mathrm{s}$ \\
\hline Palatales & $\mathrm{zh}, \mathrm{ch}, \mathrm{sh}, \mathrm{r}, \mathrm{j}, \mathrm{q}, \mathrm{x}$ & $\mathrm{ch}, \mathrm{ll}, \tilde{\mathrm{n}}, \mathrm{y}$ \\
\hline Velares & $\mathrm{g}, \mathrm{k}, \mathrm{h}, \mathrm{ng}$ & $\mathrm{g}, \mathrm{k}, \mathrm{j}$ \\
\hline
\end{tabular}

Tabla 3: Clases de consonantes del chino mandarín y el español (según Chao)

Respecto a la combinación silábica de fonemas vocálicos, el chino mandarín presenta los tipos vocálicos en las combinaciones silábicas que se recogen en la tabla siguiente:

\begin{tabular}{|c|c|}
\hline Tipos & Chino mandarín \\
\hline $\mathrm{V}$ & $a, e, \hat{e}, i, o, u, \ddot{u}, i_{1}, i_{2}{ }^{6}, e r$ \\
\hline VV & ai, ei, ao (au), ou, ia, ie, va, vo, üe \\
\hline VVV & iao (iau), iou, vai, vei \\
\hline$V+n[n]$ & an, en, in, ün \\
\hline $\mathrm{V}+\mathrm{ng}[\mathrm{n}]$ & ang, eng, ing, üng \\
\hline $\mathrm{VV}+\mathrm{n}[\mathrm{n}]$ & ian, van, ven, üan \\
\hline$V V+n g[n]$ & iang, vang, veng, iong \\
\hline
\end{tabular}

Tabla 4: Combinaciones vocálicas de las sílabas del chino mandarín

\footnotetext{
6 La vocal il solo se combina con los consonantes $z$, c y s y la otra vocal iz solo se combina con los consonantes zh, ch, sh y $r$ para formar la sílaba.
} 
A la vista de lo expuesto arriba, cabe reunir, por nuestra parte, los principales rasgos de contraste entre la estructura silábica del chino mandarín en relación con la del español:

1) En ambas lenguas es imprescindible la existencia de una vocal en la sílaba. Un fonema por sí solo puede formar una sílaba con tal de que este fonema sea vocálico, pues el núcleo de la sílaba consiste en un fonema vocálico.

2) Por el contrario, una sola consonante no puede constituir una sílaba ni en español ni en mandarín. Sin embargo, en español se dan combinaciones de dos fonemas consonánticos en una misma sílaba (flojo, tigre), mientras que en mandarín no se admiten dos fonemas consonánticos en la sílaba.

3) Tanto en español como en mandarín, las sílabas pueden estar formadas por diptongos (esp. aire, piedra, neutro; chin. dài 帶 llevar, gāo 高 alto) o triptongos (esp. averiguáis, buey, estudiéis; yào 藥 medicina, jiăo 미 llamar).

4) La segmentación silábica en ambas lenguas también presenta diferencias. En español, la juntura silábica de la cadena fónica puede dar lugar a varias silabaciones, como por ejemplo, la silabación /de.ló.ro/ en de loro y del oro. En cambio, en mandarín la delimitación de las sílabas está regulada por dos factores: por un lado, la tendencia a identificar cada sílaba con un elemento léxico con significado propio y, por otro, las diferencias tonales que permiten distinguir una sílaba de otra.

5) En mandarín los diptongos y triptongos son más frecuentes que en español.

6) La sílaba es el marco en que pueden determinarse las combinaciones posibles de los fonemas. En español, hay sílabas de seis fonemas (criáis), de tres vocales (buey) y de cuatro consonantes (transcribir). En cambio, las sílabas en mandarín solo pueden presentar, como máximo, 
Morfología contrastiva del chino mandarín y el español. Formas de gramaticalización y lexicalización

cuatro fonemas (xiǎng 想 pensar, la nasal velar ng [り] se considera un solo fonema) y tres vocales (yào 要 querer).

Respecto a los rasgos prosódicos, en español se basa en el acento, pues mientras que en otras lenguas europeas la posición del acento es fija (por ejemplo, en francés, con acento final obligatorio, o en checo y húngaro, con acento forzoso en la sílaba inicial), el español se considera una lengua con acento libre, que puede recaer en las tres últimas sílabas de la palabra. El cambio acentual de una misma sílaba puede dar lugar a la existencia de varios esquemas acentuales con valor distintivo (habló y hablo).

En cambio, en mandarín los rasgos prosódicos se basan en la estructura de los tonos. El chino mandarín se considera una lengua tonal, en la que el tono presenta valor distintivo o diacrítico. Los gramáticos (Chao 1968, Li y Thompson 2003, entre otros) indican que el sistema tonal del mandarín consta de cinco tonos, que determinan la melodía característica de cada sílaba. Estas propiedades fonéticas permiten distinguir los morfemas o las palabras. Señalan los autores que los tonos han de marcarse cuidadosamente al hablar, pues se pueden provocar malentendidos o formar juegos de palabras. Los tonos que dispone el mandarín son los siguientes:

1) El primer tono es un tono alto sostenido. Gráficamente está representado por una raya horizontal encima de la vocal (-).

2) El segundo tono es un tono descendente. Se representa con una raya de abajo arriba (')

3) El tercer tono empieza en el tono descendente y acaba en el tono ascendente. Se representa con un acento circunflejo invertido ( $($ ) .

4) El cuarto tono es un tono brusco descendente y se marca con una raya de arriba abajo (' ).

5) El tono quinto se conoce con el nombre de tono neutro. Es un tono ligero y breve. En el sistema de trascripción carece de marca. 
Una misma sílaba con tonos diferentes puede producir significados distintos (como en los ejemplos de 1). A su vez, una misma sílaba con un mismo tono puede referirse a signos lingüísticos diferentes según la combinación que forme con otros morfemas (como en 2). Aún, una misma sílaba de un mismo signo lingüístico puede representar distintos valores semánticos según el elemento con que se combina para formar palabra (como en 3). Tal polisemia es una de las características de la lengua china:

1) La misma sílaba "ma" presenta distintos significados según el tono:

Primer tono mā: 媽 'madre', 嘛 'monje del budismo tibetano' Segundo tono má: 麻 'cáñamo', 蟆 'rana'

Tercer tono mă: 馬 'caballo', 瑪 'ágata'

Cuarto tono mà: 罵 'maldecir'

Tono neutro ma: 嗎 'partícula interrogativa'

2) Una misma sílaba "fú" con el mismo tono puede presentar varios significados según su combinación con otros formantes léxicos en la lengua oral, pues obsérvese que varía la representación gráfica en cada caso:

sān fú huà 三幅畫 'tres' 'clasificador' 'pintura' $\rightarrow$ tres pinturas

fú shì 服飾 'ropa' 'adorno' $\rightarrow$ ropa

piaō fú 漂浮 'flotar' 'flotar' $\rightarrow$ flotar

fú qì 福氣 'suerte' 'aire' $\rightarrow$ buena suerte, felicidad

fú 氟: flúor

3) Una misma unidad léxica monosilábica puede introducir distintos valores semánticos según su composición con otros elementos léxicos:

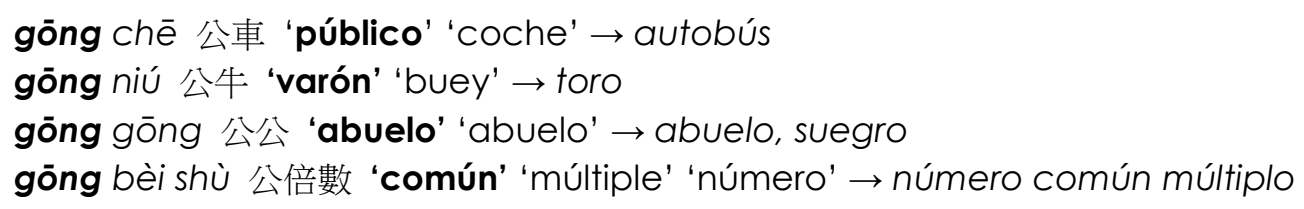


Morfología contrastiva del chino mandarín y el español. Formas de gramaticalización y lexicalización

Cabe mencionar que existe un fenómeno interesante en la alteración del tono. Normalmente, la sílaba aislada presenta su propio tono, pero este tono puede variar según el contexto tonal sin producirse por ello cambio de significado. Así, por ejemplo, cuando se suceden dos tonos terceros, el primero de ellos se articula en segundo tono ascendente, y cuando se juntan tres tonos terceros, es el segundo el que se pronuncia como ascendente. Se puede ilustrar esta variación con el siguiente cuadro propuesto por Marco Martínez y Lee (1998: 8):

\begin{tabular}{|l|l|}
\hline a) & $\cdots$ \\
\hline b) & $\cdots$ \\
\hline
\end{tabular}

Se ilustra seguidamente la alteración de tonos con estos ejemplos:

$\begin{array}{llll}\text { a) 美 酒 } & \rightarrow & \text { 美 } \text { 酒 } \\ \text { měi jiǔ } & & \text { méi jiǔ } \\ \text { bonito vino } & & \text { bonito vino } \\ \text { buen vino } & & \text { buen vino }\end{array}$
b) 品 美酒 $\rightarrow$ 品美酒 pinn měi jiǔ pinn méi jiǔ probar bonito vino probar bonito vino probar buen vino probar buen vino

En resumen, mientras en chino mandarín se enfatiza la importancia del tono en el sistema fonológico, en español la función de los rasgos prosódicos no es tan distintiva pues no se alteran significativamente en el mismo contexto. Sin embargo, en español, se puede conseguir la variación del significado de las palabras por la posición del rasgo prosódico en la secuencia. Por ejemplo, en fumo y fumó, hábito y habito, habrás y abras, la elevación del tono en la sílaba tiene una valor relativamente funcional y el incremento de la intensidad espiratoria en la sílaba determina el cambio del significado. En otras palabras, aunque el español no dispone de los cinco tonos con valor diacrítico como el mandarín, la posición del acento puede alcanzar un valor distintivo. 
Otros aspectos prosódicos que distinguen el español del mandarín son los fenómenos de enlace fónico y el llamado ér huà cí 兒化詞 (literalmente, 'hacer palabra'). En español, resultan bastante frecuentes varios tipos de enlaces fónicos que alteran la pronunciación de las sílabas, como los casos de amalgama o contracción (a el > al, de el > del), sinalefa (calle arriba, nueva ola), sinéresis (/é-roe/ o /é-rue/ en vez de /é-ro-e/ héroe, /real-mén-te/ en vez de /re-al-mén-te/ realmente), dialefa/diéresis (su-a-ve en lugar de sua-ve), etc.

En cambio, en mandarín resultan imposibles estos cambios fonéticos entre sílabas y fonemas. Como el tono de cada carácter asume el papel distintivo del significado semántico, no se da la sinalefa ni tampoco, consecuentemente, la diéresis. Los ejemplos siguientes muestran la variación léxica producida por el cambio de tonos, sin intervención de ningún tipo de amalgama o contracción:

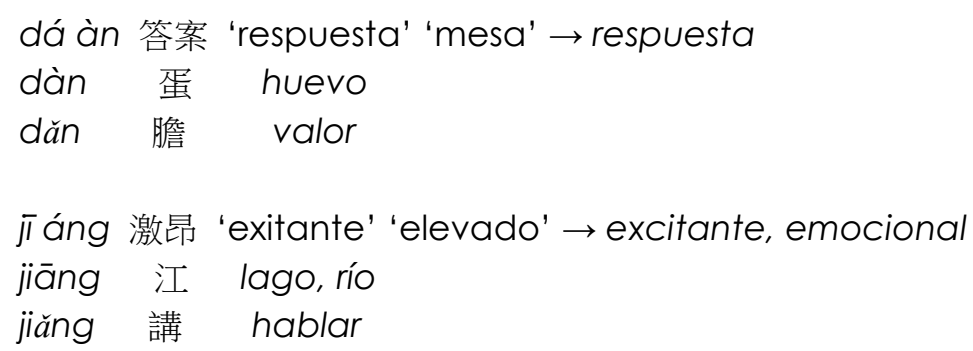

\subsection{Escritura y tipos de caracteres}

Durante seis mil años de civilización china, el sistema de los caracteres se desarrolló en formas y estilos muy diversos, con numerosas variantes para cada carácter. El estilo principal que se ha conservado hasta nuestros días proviene del último estilo caligráfico que se desarrolló durante la dinastía Wei del Norte (220-589 a.C.). Este es el estilo para los caracteres que se utilizan actualmente en periódicos y libros, así como en formatos electrónicos. Pueden distinguirse seis clases fundamentales de caracteres chinos en relación con su 
Morfología contrastiva del chino mandarín y el español. Formas de gramaticalización y lexicalización

origen y con la formación de la escritura7:

1) Xiàng xíng 象形 caracteres pictográficos. Se utilizan las líneas sencillas para dibujar la forma o el aspecto de los objetos. Por ejemplo la palabra shān 山 montaña se parece al aspecto que tiene una montaña $M$; rì 日 sol proviene del dibujo $\odot$, cuya forma se parece al sol. En la siguiente tabla se ilustran más ejemplos de caracteres pictográficos cuya forma actual imita su origen:

\begin{tabular}{|c|c|c|c|}
\hline Dibujo de origen & Forma actual & Transcripción & Significado en español \\
\hline B & 月 & yuè & Iuna \\
\hline ice. & 水 & shuěi & agua \\
\hline (1) & 目 & mù & ojo \\
\hline (iili & 雨 & yŭ & lluvia \\
\hline 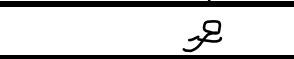 & 子 & 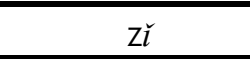 & hijo \\
\hline 斯 & 車 & chē & coche \\
\hline 8 & 角 & jiăo & cuerno \\
\hline 艧 & 果 & guó & fruto \\
\hline
\end{tabular}

Tabla 5: Origen de los caracteres pictográficos

2) Zhǐ shì 指示 caracteres ideográficos. Este sistema consiste en indicaciones diagramáticas de ideas o conceptos abstractos, como posición, movimiento, tamaño, etc. Por ejemplo shàng 上 arriba se expresa por medio de líneas que marcan hacia arriba; shià 下 abajo se manifiesta mediante líneas que marcan hacia abajo.

3) Hhuì yì 會意 caracteres ideográficos compuestos. Son palabras en las que el significado final es una simbiosis fruto de la combinación de los significados de sus partes. Es decir, este tipo comprende los caracteres

\footnotetext{
7 Para la traducción española de estos conceptos conviene mencionar el libro de Mateos F. (1975) y también Marco Martínez y Lee (1998: § 3).
} 
que son representaciones gráfico-simbólicas de los objetos o de conceptos más elaborados. Se combinan dos grafías sencillas que tienen cierta relación con el término que se quiere representar. Por ejemplo, shìn 信 honrado es el conjunto de rén 人 gente más yián 言 decir. De esta forma, se entiende que lo honrado está relacionado con "lo que dice la persona".

4) Xíng shēng 形聲 compuestos fonéticos. El compuesto fonético consiste en una parte significativa denominada radical más una parte fonética que sugiere la pronunciación, pero no el tono, que es irregular. Por ejemplo, la palabra xiăng 想 pensar consiste en el elemento fonético xiāng 相 y el radical xīn 心. El último significa 'corazón', en referencia a la antigua creencia de que tanto el espíritu como el pensamiento se hallaban alojados en el corazón.

5) Jiǎ jiè 假借 préstamos homófonos. No se trata de un préstamo lingüístico, sino de otro carácter usado con el mismo valor fonético. Es un préstamo que tiene su origen en la necesidad de expresar una nueva idea. En su desarrollo también están incluidas las erratas de los copistas debido a su ignorancia etimológica. Por ejemplo laí 來 venir en un principio se utilizaba para un tipo de cereal: gē 哥 originalmente significaba 'cantar, canción' y posteriormente se ha utilizado con el sentido de 'hermano mayor'.

6) Zhuăn zhù 轉注 caracteres de extensión etimológica. Son los caracteres que reciben una transferencia de significado, pues se amplía el sentido semántico del carácter o se adopta el de otro semejante, sinónimo u homófono. Por ejemplo, el significado de jiǔ 酒 es 'alcohol' porque es una palabra que proviene de yoú 西, la forma cambia pero el significado se mantiene. Otro ejemplo homófono es guǒ 菓 y guó 果, los dos significan igualmente 'fruto' y mantienen el mismo valor fonético. 
Morfología contrastiva del chino mandarín y el español. Formas de gramaticalización y lexicalización

Respecto a los trazos de los caracteres, difieren de la escritura alfabética de las lenguas occidentales. Es sabido que tradicionalmente los caracteres chinos se disponen en líneas verticales y se suceden de derecha a izquierda. Por ello los textos en chino empiezan por donde acaban los libros españoles, y se leen de atrás hacia delante. Pero este orden clásico ha evolucionado hasta la manera occidental, es decir, en líneas horizontales que se leen de izquierda a derecha y de delante hacia atrás.

Por otra parte, tanto para escribir los caracteres chinos como para leerlos, hay que conocer bien el número de trazos de cada carácter, su figura y el orden sucesivo de su escritura. Cada carácter es una unidad gráfica que se dibuja dentro de un cuadrado imaginario. Los trazos que componen los caracteres se reducen a ocho formas fundamentales que pueden producir 50.000 figuras individuales aisladas, combinadas o repetidas. Estas ocho formas fundamentales se encuentran en el carácter yǒng 永 'perpetuo', el cual contiene los ocho trazos de la caligrafía china. A continuación se ilustra cada trazo y su forma: 1) la tilde, 2) la raya horizontal, de izquierda a derecha, 3) la línea vertical, de arriba abajo, 4) el gancho, doblado hacia arriba, 5) el clavo, de izquierda a derecha, 6) la cola, de arriba abajo y de derecha a izquierda, 7) el rasgo corto, de arriba abajo y de derecha a izquierda y 8) la rúbrica, de arriba abajo y de izquierda a derecha (Gao 1984 y Mateos 1975: 19).

TRAZOS FUNDAMENTALES DE LOS CARACTERES CHINOS Y SU MODO DE ESCRIBIR

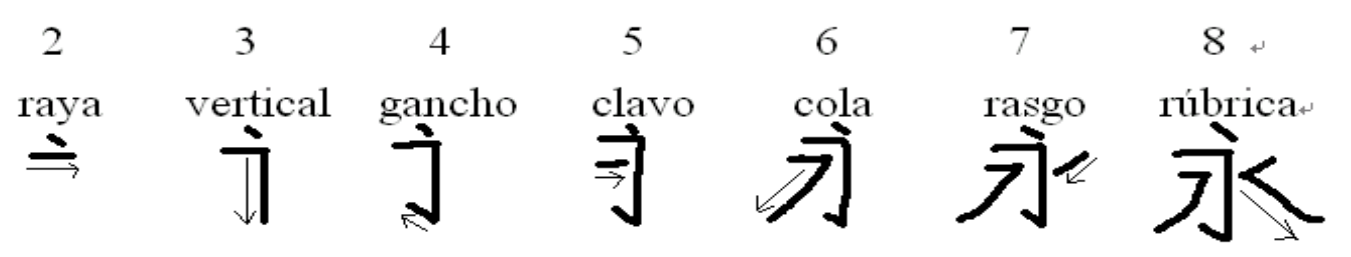




\subsection{Tipología morfológica de la lengua china}

En la clasificación tipológica, existen ciertos fenómenos que son definitivamente los que más caracterizan la esencia del idioma chino frente a un idioma indoeuropeo como el español. Un análisis básico de las modificaciones lexemáticas, las que expresan la posición en la estructura gramatical, permite comprender las peculiaridades lingüísticas de la lengua china y la tipología morfológica a la que pertenece.

En la tipología morfológica, el chino se considera una lengua aislante y analítica, mientras que el español constituye un ejemplo representativo de lengua sintética y flexiva. Esta clasificación puede ocasionar problemas debido a que resulta difícil definir con precisión qué es una lengua analítica y qué es una lengua sintética. En realidad, puede que el chino mandarín resulte ser una lengua más sintética que otras lenguas sinotibetanas en ciertos aspectos, y además cabe considerar que existe todo un gradiente entre ambos extremos. Por ejemplo, la lengua china moderna se considera altamente analítica cuyo significado está muy ligado al contexto. Este tipo lingüístico presenta pocas flexiones porque dentro de la palabra y dentro de la oración las funciones gramaticales se expresan mediante elementos que han sufrido el proceso de gramaticalización por el cual se crean flexiones nuevas. Sin embargo, la escasez de marcas morfológicas es de índole histórica y está relacionada con la evolución de la lengua. Así, el chino clásico sí que disponía de flexiones que expresaban funciones gramaticales. Por ejemplo, la palabra actual y̌n 飲 beber en chino antiguo se leía en cuarto tono yin 飲 hacer beber y expresaba un significado causativo. Esta flexión a través de la alteración fonética ha desaparecido en el uso actual, de modo que la lengua china se ha vuelto menos sintética y más analítica con el tiempo. De hecho, puede decirse que el chino mandarín se identifica relativamente como un tipo analítico desde el punto de vista diacrónico pues se trata de una lengua con un grado bajo de síntesis. 
Morfología contrastiva del chino mandarín y el español. Formas de gramaticalización y lexicalización

Frente a la clasificación morfológica de la lengua china en el tipo aislante y analííico, el español, por otra parte, se considera una lengua altamente sintética y flexiva por tener un complejo sistema de desinencias y afijos y una sintaxis simple. Sin embargo, ninguna lengua pertenece a un solo tipo sino que existen grados entre distintos tipos morfológicos. Martínez Celdrán (1995) ejemplifica que el español, por ejemplo, comparado con el inglés es una lengua fusionante, sobre todo en la conjugación verbal, ya que presenta distintas formas de un mismo verbo según las categorías de persona, número, tiempo, aspecto, modo, voz. Así, una forma verbal en primera persona del singular en futuro se expresa en inglés mediante tres palabras I will be y cada una de ellas es un morfema independiente, mientras que el español utiliza una sola forma sintética, una sola palabra seré para expresar la persona, el número, el tiempo, el aspecto y el modo. Sin embargo, comparado con el latín resulta que el español es una lengua fusionante en menor grado porque no admite declinaciones, no forma el comparativo con terminaciones, etc. Es decir, aunque por una parte el español encaja dentro del tipo fusionante, en muchos otros aspectos tiene formas analíticas. Se pueden comprobar estas diferencias al comparar el ejemplo de audacioribus del latín, que se descompone en tres partes:

[audac] lexema [ior] comparativo [ibus] dativo plural

Su equivalencia en español se expresa mediante un sintagma preposicional 'para los más audaces'.

Pese a que pertenece al tipo morfológico de lengua flexiva y sintética, la forma de expresar el género y el número en español es aglutinante frente a la del italiano que es claramente fusionante: niñ+o/a+ $\varnothing / s$ en contraste con bambin+o-i-a-e. Es decir, mientras s expresa solo la pluralidad en español, en italiano i expresa la pluralidad del género masculino, fusionando los dos morfemas en un solo morfo. Así, el español presenta estructuras aislantes (como 
la expresión de los casos), estructuras aglutinantes (como la expresión del género y el número) y estructuras fusionantes (como el sistema verbal). En suma, la comparación de unas lenguas con otras permite defender la idea de que es más apropiado distinguir grados en la clasificación tipológica de las estructuras lingüísticas.

Sería erróneo pensar que las lenguas analíticas tienen una gramática más sencilla que las lenguas sintéticas. Más bien cabría decir que las lenguas analíticas como el mandarín usan en mayor medida procedimientos analíticos para transmitir información. Así por ejemplo, el tiempo verbal se expresa en mandarín mediante diversas partículas adverbiales, mientras que en las lenguas sintéticas como el español se codifica el tiempo mediante procedimientos morfológicos como la flexión. Pero las diferencias entre lenguas analíticas y lenguas sintéticas nunca son tajantes, pues cada idioma tiene su complejidad gramatical y sus particularidades lingüisticas que aproximan y entremezclan unos tipos con otros.

Aunque la distinción tipológica entre lenguas analíticas y sintéticas es más bien gradual, normalmente el mandarín se clasifica como una lengua aislante y analítica, en la que predominan las palabras invariables y las relaciones sintácticas se suelen marcar por medio del orden de palabras o de unidades léxicas independientes. Esta clasificación tiene su explicación.

En primer lugar, como se ha mencionado anteriormente, en el chino clásico todas las palabras estaban constituidas por un solo morfema y todos los morfemas son monosilábicos. Así, la palabra y el morfema coinciden con la sílaba, de manera que no se distingue una morfología flexiva. Por otro lado, esta característica de monosilabidad de las palabras explica la importancia que asumen el orden de las palabras y los procedimientos tonales del chino mandarín para la construcción del enunciado. La monosilabidad del chino clásico también explica las confusiones entre los conceptos de zì 字 (morfema, carácter escrito) y cí 詞 (palabra) del chino moderno, creados por la teoría lingüística para la descripción de las lenguas indoeuropeas. 
Morfología contrastiva del chino mandarín y el español. Formas de gramaticalización y lexicalización

En segundo lugar, el chino mandarín tiene una escritura logográfica que presenta un claro componente fonográfico (silabográfico), en el que los logogramas pueden interpretarse como denotadores de una sílaba. Es decir, el chino mandarín presenta una escritura en la que los caracteres logográficos se escriben separados, sin que se unan mediante trazos aquellos caracteres que corresponden a una única palabra. Este sistema silabográfico hace que los morfemas se comporten como unidades fonéticamente separables y las palabras y los sintagmas no se unan independientemente de las fronteras morfológicas y sintácticas. Todas estas convenciones de monosilabidad y sistema silabográfico hacen que el chino mandarín se clasifique como una lengua aislante y analítica, que se caracteriza por la falta de casos gramaticales, desinencias y concordancia (Moreno Cabrera, 2005: 15-17). Se examinan seguidamente estas características morfológicas del chino mandarín en comparación con el español.

Como es sabido, en algunas lenguas, la función gramatical se expresa mediante el caso morfológico, que se refiere a la posibilidad de añadir una marca morfológica a sustantivos, adjetivos o pronombres según la función sintáctica que desempeñan en la oración. Por ejemplo, en turco las desinencias marcan la diversidad funcional:

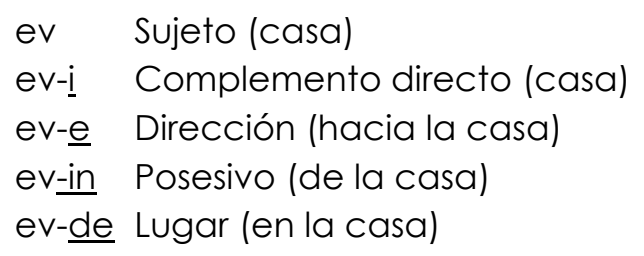

En las lenguas romances, la flexión de caso se ha perdido casi por completo y solo se conserva en el sistema pronominal. Así, el español, aunque deriva del latín, carece de marcas casuales para los sustantivos, mientras que los pronombres personales distinguen formalmente los casos rectos de los casos regidos. Sin embargo, otras lenguas, como las de la familia sinotibetana, no presentan el caso en ningún tipo de palabra. Así, en el mandarín estas 
relaciones gramaticales se expresan mediante el orden de palabras y la preposición (Li y Thompson 2003: 10):

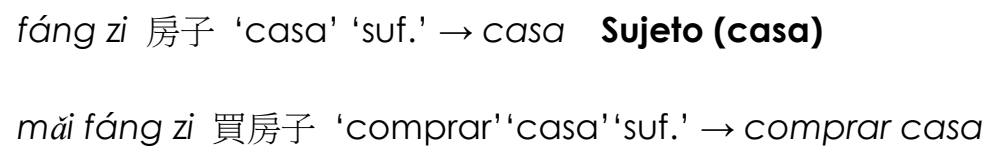

En muchas lenguas indoeuropeas, tanto los sustantivos como los adjetivos disponen de morfema de número para expresar la pluralidad. En mandarín, en cambio, la pluralidad solo se encuentra en los sustantivos, pero no se expresa mediante morfemas flexivos, sino por la agregación de otros morfemas, como los equivalentes a 'algunos/algunas' o 'muchos/muchas' antepuestos a los referentes. Otra forma de manifestar la pluralidad es con la adición de la partícula men 們, pero esta solo se utiliza para los pronombres y sustantivos personales: nĩ men 你們 '十ú' 'partícula pl.' $\rightarrow$ vosotros, tóng xué men 同學們 'junto' 'aprender' 'partícula pl.' $\rightarrow$ alumnos.

En muchas lenguas indoeuropeas se distinguen dos tipos de concordancia: la nominal y la verbal. Sin embargo, el mandarín no dispone de este recurso gramatical para marcar las relaciones sintácticas entre los diversos constituyentes. Por ejemplo, en la frase española Ellas estudian, el sujeto Ellas concuerda en número con el verbo estudian. En cambio, en la misma frase en mandarín tā men niàn shū 她們唸書 'ella' 'partícula pl.' 'leer' 'libro' $\rightarrow$ ellas estudian no se detecta que el verbo niàn shū 唸書 estudiar tome una forma determinada según el número del sujeto. Es decir, el verbo no varía con un sujeto en singular:

a) Wǒ niàn shū 我吟書 'yo' 'leer' 'libro' $\rightarrow$ yo estudio.

b) nĩ men niàn shū 你們唸書 'tú' 'partícula pl.' 'leer' 'libro' $\rightarrow$ vosotros estudiáis. 
Morfología contrastiva del chino mandarín y el español. Formas de gramaticalización y lexicalización

Respecto al tiempo y aspecto, el mandarín dispone de otro sistema para expresar estos conceptos. En las lenguas indoeuropeas el tiempo se representa mediante la conjugación verbal, como en las formas del español: vuelves, volviste, volverás. En contraste con lo que sucede en español, el mandarín carece de morfema gramatical que se añada al verbo para indicar el tiempo pasado, presente o futuro. Estos conceptos se expresan por medios léxicos. Véanse algunos ejemplos en el siguiente cuadro:

\begin{tabular}{|c|c|c|c|}
\hline & $\begin{array}{l}\text { Adverbios } \\
\text { temporales }\end{array}$ & Formas auxiliares & $\begin{array}{l}\text { Marcadores } \\
\text { temporales }\end{array}$ \\
\hline Pasado & zoú tiān 昨天 ayer & $\begin{array}{l}\text { y̌̃ qīng 已經 } \\
\rightarrow \text { haber+part. }\end{array}$ & (guò) le (過)了 \\
\hline Presente & xiàn zài 現在 ahora & $\begin{array}{l}\text { zhèng zài 正在 } \\
\rightarrow \text { estar+gerundio }\end{array}$ & \\
\hline Futuro & $\begin{array}{c}\text { míng tiān 明天 } \\
\text { mañana }\end{array}$ & $\begin{array}{c}\text { huì 會 } \\
\rightarrow \text { ir } a+\text { +infinitivo }\end{array}$ & jiāng 將 \\
\hline
\end{tabular}

Tabla 6: Ejemplos de la expresión del tiempo en chino

Véase un ejemplo de marcador temporal de futuro en la siguiente oración:

$\begin{array}{lcccc}\text { 明 天 } & \text { 我 } & \text { 將 } & \text { 回 } & \text { 來 } \\ \text { míng tiān } & \text { wǒ } & \text { jiāng } & \text { huí } & \text { laí } \\ \text { adv. de tiempo } & \text { yo } & \begin{array}{l}\text { marca de } \\ \text { tiempo }\end{array} & \text { volver } & \text { venir } \\ \text { 'mañana' } & & & \end{array}$

Mañana volveré.

Por otra parte, muchas lenguas indoeuropeas presentan la propiedad del aspecto gramatical para señalar si la acción que expresan ha concluido o no en el momento de la comunicación. Las lenguas indoeuropeas antiguas como el latín tenían formas particulares de la raíz para indicar el aspecto. En español, como en las demás lenguas románicas, y algunas lenguas germánicas occidentales, la forma de marcar el aspecto perfectivo depende 
de un verbo auxiliar, que usualmente es haber o ser. Esta manera de marcar el aspecto es una innovación surgida en latín tardío que parece haberse extendido a algunas lenguas germánicas de Europa occidental, como el inglés o el alemán. Por ejemplo, en las frases del español Estoy comiendo; He comido; Iba al cine; Comí durante el mediodía, los distintos aspectos se construyen combinando verbos auxiliares y formas no personales; en las frases del inglés I am eating; I have eaten; I was going to the movie; I ate already, los distintos aspectos se expresan de forma parecida.

El mandarín, en cambio, presenta otro sistema aspectual para expresar los diferentes modos de ver la constitución interna de una situación (ya se trate de acción, estado o proceso), que consiste en la adición de marcadores aspectuales pospuestos a los verbos. Generalmente, el aspecto es independiente del tiempo y puede aplicarse tanto al pasado como al presente o al futuro. Los marcadores aspectuales pueden manifestar las distintas fases de una acción, sea inicial, progresiva, durativa, resultativa, etc. Todos estos marcadores se asemejan formalmente a los sufijos en que aparecen inmediatamente detrás del verbo, excepto zài 在 lque se traduce habitualmente en español por un gerundio) que se considera como un prefijo por su posición. Según Li y Thompson (2003: 12, 15 y 65) y Marco Martínez y Lee (1998: 258), los aspectos que gramaticaliza el mandarín son los siguientes:

Aspecto perfectivo: le 了

Aspecto imperfectivo: zài 在 asp. progresivo (acción) zhe 著 asp. progresivo y durativo (estado)

Aspecto perfecto resultativo: daò 到, jiàn 見, le 了

Aspecto experiencial: guò 過 pasado indefinido guò 過 pasado reciente

Aspecto incoativo: qí laí 起來

Aspecto continuativo: xià qù 下去

Aspecto delimitativo: reduplicación del verbo

Forma no marcada a signo cero: $\varnothing$ 
Morfología contrastiva del chino mandarín y el español. Formas de gramaticalización y lexicalización

Véanse dos ejemplos en los que el marcador le $了$ manifiesta el aspecto perfectivo:

a) 我昨 天 吃飯後去逛街 Wŏ zuó tiān chī le fàn hòu qù guàng jiē Yo ayer comer asp. pfvo. arroz después ir pasear calle Ayer fuimos de compras después de comer.

b) 我明天吃予飯後去逛街 Wŏ míng tiān chī le fàn hòu qù guàng jiē Yo mañana comer asp. pfvo. arroz después ir pasear calle Mañana vamos / iremos de compras después de comer.

Como puede observarse, en chino moderno la partícula le $了$ ocupa una posición posterior al verbo. Además, cabe observar en a) y b) que el chino usualmente no marca el tiempo gramatical con desinencias verbales sino con adverbios de tiempo. La marca de aspecto perfectivo se aplica tanto al pasado a) como al futuro b).

Teniendo en cuanta lo expuesto arriba sobre la monosilabidad, la falta de caso gramatical, de concordancia y de desinencias del chino mandarín, en algunos aspectos la lengua china sí que parece ser más analítica y aislante que otras lenguas. Sin embargo, en opinión de Moreno Cabrera (2005: 20-26), el concepto de que el chino es una lengua aislante no es completamente adecuado, pues la consideración de la lengua escrita como medio de clasificación tipológica de las lenguas ha sesgado de modo muy pronunciado los criterios que se siguen para decidir cuándo una lengua es predominantemente sintética y flexiva o bien analítica y aislante desde el punto de vista morfológico. El autor indica que no es apropiado decir que el chino es una lengua aislante sin marcas morfológicas, ya que en el mandarín hablado se unen palabras con partículas en unidades fonéticamente inseparables. El autor destaca que es la escritura china la que es aislante y monosilábica, y que esta consideración hacia la lengua escrita induce su clasificación tipológica. Para ilustrar que hay un razonamiento defectuoso en la consideración del chino como una lengua totalmente aislante, el autor señala 
que el monosilabismo lingüístico de la lengua china es una idea solo parcialmente correcta. Es decir, lo único que puede mantenerse es que a cada carácter chino le corresponde una sílaba, y si bien hay palabras que son de una sílaba y se escriben, por tanto, mediante un único carácter, hay muchísimas palabras que al tener más de una sílaba se escriben con dos, tres o más caracteres. Véanse algunos ejemplos ilustrativos:

tú 圖 'dibujo, mapa'

tú shū 圖書 'dibujo, mapa' 'libro' $\rightarrow$ libro (con dibujos o fotos)

tú shū guăn 圖書館 'dibujo' 'libro' 'casa' $\rightarrow$ biblioteca

tú shū guăn 圖書館員 'dibujo' 'libro' 'casa' 'persona' $\rightarrow$ bibliotecario

Por otra parte, frente a la idea de que en chino no hay morfología, sería más adecuado afirmar que se trata de una lengua con una fuerte inclinación hacia la composición morfológica. Los siguientes ejemplos muestran que las palabras compuestas no se constituyen con elementos formados de raíces yuxtapuestas independientes, tal como se esperaría de una lengua aislante, pues cada componente carece de autonomía léxica y solo se usa en procesos morfológicos (derivación o composición):

yú lè yuán 遊樂園 'viajar' 'feliz' 'jardín' $\rightarrow$ parque de atracciones (pero *yú 遊) băi huò gōng sī 百貨公司 'cien' 'artículo' 'empresa' $\rightarrow$ grandes almacenes (pero * băi 百)

Además de la composición léxica, existe también derivación morfológica. Hay elementos afijales que se utilizan para la formación de sustantivos y adjetivos. Sin embargo, no se ha alcanzado el acuerdo entre los gramáticos del chino respecto al inventario y a la definición de tales afijos. He aquí unos ejemplos:

Derivación adjetival con el prefijo kè 可

kě ài 可愛 'pref. deverbal' 'amar' $\rightarrow$ encantador

kě bēi 可悲 'pref. deverbal' 'estar triste' $\rightarrow$ lamentable

Derivación nominal con el sufijo zhè 者 zoù zhè 作者 'escribir, hacer' 'suf. deverbal' $\rightarrow$ escritor dú zhě 讀者 'leer' 'suf. deverbal' $\rightarrow$ lector 
Morfología contrastiva del chino mandarín y el español. Formas de gramaticalización y lexicalización

Hay también en chino mandarín fenómenos de fusión morfológica en los que un afijo está fonológicamente integrado en una palabra y no se reconoce como morfema independiente. Es lo que ha ocurrido con el sufijo ér 兒:

shì ér 事兒 'asunto' 'suf.' $\rightarrow$ asunto

gǒu ér 狗兒 'perro' 'suf.' $\rightarrow$ perro

En conclusión, se puede afirmar que el chino mandarín se clasifica tipológicamente como una lengua aislante y analítica porque su escritura se compone de caracteres logográficos que se escriben separadamente y mantiene -solo en parte- el monosilabismo del chino clásico, en el que cada signo corresponde a una sílaba y denota una palabra con contenido léxico. Sin embargo, la escritura logográfica no puede justificar el tipo de lengua aislante, ya que en el chino mandarín se forman palabras derivadas con marcas morfológicas. Además, el chino mandarín presenta una gran riqueza en la composición morfológica, la cual se considera el proceso primordial de la formación de palabras y hace que el chino mandarín sea una lengua muy desarrollada en la morfología compositiva. Así, el chino mandarín puede identificarse como una lengua aislante y analítica, pero al mismo tiempo, también parece más sintética de lo que en realidad es. Por otro lado, tampoco es adecuado considerar que el chino mandarín es una lengua sin flexión nominal ni verbal, pues se observan algunas marcas morfológicas de contenido gramatical, como las que expresan pluralidad o variaciones temporales y aspectuales.

\subsection{Tipología sintáctica de la lengua china}

Como señala Qien (2002), el estudio de la lengua china se basa, en general, en la lingüística indoeuropea de la que recibe una gran influencia 
tanto en la teoría como en la aplicación. Así, Marco Martínez y Lee (1998: 72) indican que los modelos de las gramáticas indoeuropeas, como la tradición grecolatina, el estructuralismo europeo y americano, el generativismo, la teoría de casos etc., han sido aplicados al estudio del chino mandarín con diferentes grados de éxito. Sin embargo, existen ciertos fenómenos que no se ajustan a ninguno de estos marcos teóricos y son, en definitiva, los que mejor definen y caracterizan la esencia del idioma chino en contraste con otros, en nuestro caso, el español.

Según Marco Martínez y Lee (1998: 72-73), la idea fundamental que permite comprender algunas diferencias lingüísticas de ambas lenguas se basa en que el español (y en general las lenguas indoeuropeas) es una lengua con una sintaxis orientada a la oración mientras que el chino mandarín es una lengua con una sintaxis dirigida al discurso.

El español, como indica Alarcos Llorach (1994: 71), es una lengua en la que las categorías gramaticales (nombre, adjetivo, verbo, etc.) están bien definidas y las funciones sintácticas (sujeto, objeto, etc.), sea en forma de palabras léxicas o de pronombres, están bien presentes en la oración. Así, el concepto de oración adquiere la entidad suficiente para prestarse mejor a ser tomada como base del análisis sintáctico. En contraposición, el chino mandarín se caracteriza por un sistema confuso de clases de palabras desde el punto de vista categorial, pues muchas palabras pueden actuar como dos o más categorías diferentes según su disposición en la frase. Véase un ejemplo de la palabra guài 怪 con diferentes funciones:

a) Adj. 這 很 怪

Zhè hěn guài

Este muy raro

Esto es raro.

b) Adv. 這 怪 可怕的

Zhè guài kě pà de

Este bastante pref. miedo part.

Esto es bastante horroroso. 
Morfología contrastiva del chino mandarín y el español. Formas de gramaticalización y lexicalización

C) V. trans. 你 別 怪 我

Nĩ bié guài wŏ

Tú no culpar yo

No me eches la culpa.

La diferencia principal entre las lenguas con una sintaxis orientada a la oración y las que presentan un sistema sintáctico orientado hacia el discurso reside en que en estas últimas las funciones gramaticales pueden estar sujetas a un proceso de elipsis u omisión. Por ejemplo, en español la frase Las letras del libro son muy pequeñas y no lo compro equivale en mandarín a un enunciado donde puede observarse la debilidad de las relaciones sintácticas:

$\begin{array}{lcccccc}\text { 書 } & \text { 字 } & \text { 很 } & \text { 小 } & \text {, 我 } & \text { 不 } & \text { 買 } \\ \text { Shū } & \text { zì } & \text { hěn } & \text { xiăo } & \text {, wǒ } & \text { bù măi } \\ \text { Libro letra } & \text { muy pequeño } & \text { yo } & \text { no comprar }\end{array}$

En la segunda proposición se observa una omisión del objeto directo del verbo "comprar", que hace referencia al tópico "libro", pero no al sujeto "letra" de la primera proposición. Esta elipsis de elementos sintácticos explica la tendencia cada vez mayor a superar el marco oracional y a saltar a un marco discursivo o contexto lingüístico mayor.

Así, para entender la estructura sintáctica de las oraciones chinas se destaca la función de tópico (o tema). En chino mandarín el concepto de tópico adquiere más importancia que el de sujeto y es un rasgo esencial que distingue tipológicamente al mandarín de las lenguas europeas. Se refiere o bien a algo que el oyente ya conoce o bien a una clase de entidades. Su colocación en la oración es siempre inicial, e incluso antes del sujeto si lo hay.

En mandarín, el tópico se distingue del sujeto en el sentido de que aquel no necesita obligatoriamente establecer una relación formal con el verbo e incluso puede separarse opcionalmente del resto de la oración por una pausa o por las partículas pausales a 阿 ya 呀 ne 呢ba 吧: 


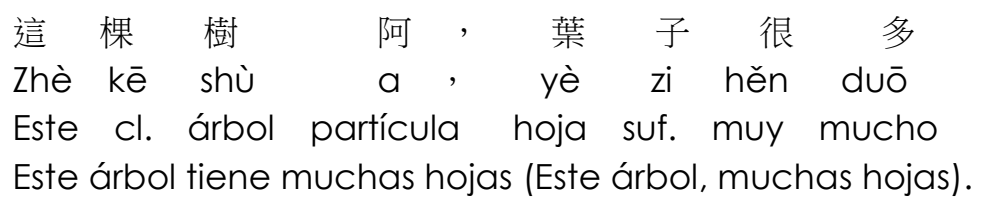

Por otra parte, el tópico no presenta restricciones sintagmáticas, pues cualquier tipo de sintagma puede desempeñar la función de tópico, como el sintagma verbal del ejemplo a), e incluso una proposición u oración entera del ejemplo b):

a) 便 宜

Pián yí

不一定

好

Ser barato

bù yi ding

hăo

S.V. (V. Cualidad)

no seguramente bueno

TÓPICO

Lo barato no siempre es bueno.

b) 出去吃 飯我 請 你

Chū qù chī fàn wŏ qing nì

Salir ir comer arroz yo invitar tú

Vamos a comer fuera y yo te invito.

En mandarín, teniendo en cuenta la presencia o no del tópico y del sujeto en una misma oración, se distinguen cuatro posibilidades:

a) Oración con tópico y sujeto

$\begin{array}{llccc}\text { 作業 } & \text { 我 } & \text { 寫 } & \text { 完 } & \text { 了 } \\ \text { Zuòyè } & \text { wŏ } & \text { xiě } & \text { wán } & \text { le } \\ \text { Deber } & \text { yo escribir } & \text { acabar } & \text { asp. perfectivo } \\ \text { He acabado los deberes. } & \end{array}$

b) Oración en la que el tópico y el sujeto coinciden

我寫完作業勇

Wŏ xiě wán zuò yè le

Yo escribir acabar deber asp. Perfectivo

He acabado los deberes.

c) Oración con tópico y sin sujeto

作業寫完的

Zuò yè xiě wán le

Deber escribir acabar asp. Perfectivo

Los deberes los han acabado. (Se han acabado los deberes) 
Morfología contrastiva del chino mandarín y el español. Formas de gramaticalización y lexicalización

d) Oración sin tópico

$\begin{array}{llllc}\text { 作業 } & \text { 呢? } & \text { 寫 } & \text { 完 } & \text { 了 } \\ \text { Zuòyè } & \text { ne } & \text { xiě } & \text { wán } & \text { le } \\ \text { Deber } & \text { part. de pausa } & \text { escribir } & \text { acabar } & \text { asp. Perfectivo } \\ \text { ¿Y los deberes? } & \text { Están acabados. }\end{array}$

Las oraciones del tipo (c) se suelen traducir al español mediante la voz media o la voz pasiva (Se han acabado los deberes), aunque en mandarín no son construcciones pasivas sino simplemente construcciones del tipo tópico-comentario en las que el sujeto del verbo no está presente. El tipo (d) a menudo se sobrentiende por el contexto comunicativo.

Una de las propiedades muy destacadas y características del tópico en chino mandarín es que cuando el tópico y el sujeto son distintos, el tópico tiene prioridad sobre el sujeto para determinar la referencia de un sintagma nominal omitido en la oración siguiente (Li y Thompson 2003: § 4.1.9). Véase el siguiente ejemplo:

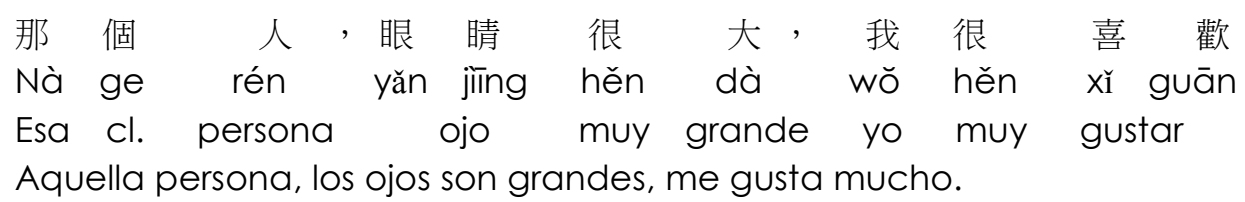

En la segunda oración el sujeto del verbo gustar se ha omitido. Este elemento solamente puede interpretarse como referido al tópico que aparece al principio de la primera oración (aquella persona), nunca como referido al sujeto del verbo ser (los ojos). En este ejemplo se observa una de las funciones principales del tópico de la lengua china, basada en la elipsis u omisión del sintagma nominal correferencial con el tópico. Sin embargo, en español, y otras lenguas indoeuropeas, suele quedar la marca de un pronombre. En el siguiente ejemplo se ilustra la diferencia entre el tópico del chino mandarín y el uso de pronombres en lenguas indoeuropeas: 
這 本 書 很 難, 我不懂, 他也不懂

Zhè běn shū hěn nán, wǒ bù dŏng, tā yě bù dŏng Este cl. libro muy difícil yo no entender él tampoco no entender Esp.: Este libro es muy difícil, yo no lo entiendo, él tampoco lo entiende.

Ing.: This book is very difficult, I don't understand it, she doesn't understand it either.

\subsection{Orden de palabras y sintagmas}

Todos los sistemas lingüísticos disponen, en mayor o menor grado, de ciertas normas para establecer el orden de las palabras en el esquema sintagmático. En general, la libertad de posición está en relación directa con el número de variaciones morfológicas que presentan las palabras. En este apartado sobre la tipología del orden de palabras y de sintagmas interesa analizar el orden de los constituyentes básicos. Comúnmente, se estudia la posición del verbo con relación a los participantes en la predicación verbal y, por otro lado, el orden relativo entre un nombre y sus complementos.

Según Greenberg (1963a), las lenguas del mundo se dividen en tres tipos en función del orden que mantienen entre sí el sujeto (S), el verbo (V) y el objeto (O). Por ejemplo, el español, el francés y el inglés son lenguas del tipo SVO; el coreano, el japonés y el vasco son lenguas del tipo SOV; el celta y el irlandés son del tipo VSO. Steele (1978), tras haber examinado 63 lenguas, indica que existen más tipos de orden básico y entre ellos, el tipo de SVO ocupa el mayor porcentaje, luego los tipos SVO, VSO, VOS y los otros sucesivamente.

Sin embargo, la clasificación de la tipología sintáctica no es tan categórica como cabría suponer. Por ejemplo, en la expresión en alemán Im Wald habe ich einen Fuchs gesehen (esp. lit. En el bosque he yo un zorro visto), el verbo se divide en una forma auxiliar (habe), por un lado, y un infinitivo o participio (gesehen), por otro, pero entre ambas formas se inserta el sujeto (ich) y el objeto directo (einen Fuchs). Así, el alemán podría considerarse tanto una lengua del tipo SOV como del tipo VSO. El latín, polaco y esperanto también se 
Morfología contrastiva del chino mandarín y el español. Formas de gramaticalización y lexicalización

consideran lenguas difíciles de clasificar, debido a que admiten varias combinaciones diferentes de verbo, objeto y sujeto.

El mandarín, igual que estas últimas lenguas, tampoco se clasifica en ninguno de los tipos con facilidad, pues el concepto de sujeto no puede ser claramente codificado como el del español, el inglés $U$ otras lenguas indoeuropeas en las que el sujeto está marcado por la posición, por la concordancia (número y persona) o por desinencias de caso. Más concretamente, en mandarín, la estructura básica de las oraciones es la relación tópico-comentario y no la de sujeto-predicado. Según indican Li y Thompson (2003: § 19-20), esta característica ha complicado la clasificación del mandarín entre las lenguas de tipo SVO, VSO o SOV de Greenberg. En el siguiente ejemplo se muestra la inconsistencia del chino mandarín respecto a los rasgos de correlación VO y OV:

\begin{tabular}{|c|c|c|c|c|c|}
\hline 那 & 田 & 他 & 們 & 加 & 肥 \\
\hline Nà & kuài & tā & men & jiā & féi \\
\hline Aquel & trozo campo & él & partícula pl. & añadir & fertilizante \\
\hline
\end{tabular}

Se observa que el verbo jiā féi 加肥 de la oración es un compuesto verbo-objeto, pero el objeto féi 肥 carece de autonomía léxica, pues no se usa independientemente como una palabra. Además, el verbo compuesto jiā féi 加肥 ('añadir fertilizante') no admite la posposición del objeto nà kuài tián 那塊田 ('aquel campo'). Así, la estructura de la frase es: N (tópico) - N (sujeto) $\checkmark$ compuesto del tipo $\mathrm{V}-\mathrm{O}$.

Otro problema para clasificar la tipología del mandarín según el orden sintagmático reside en que esta ordenación de palabras y sintagmas no depende de la función gramatical sino del sentido semántico. Así, la posición preverbal indica sintagmas definidos que pueden ser sujetos, objetos o tópicos. Estos últimos son siempre definidos y no admiten la posición posverbal. Sin embargo, los sujetos y los objetos pueden ser preverbales o posverbales. Vemos 
algunos ejemplos:

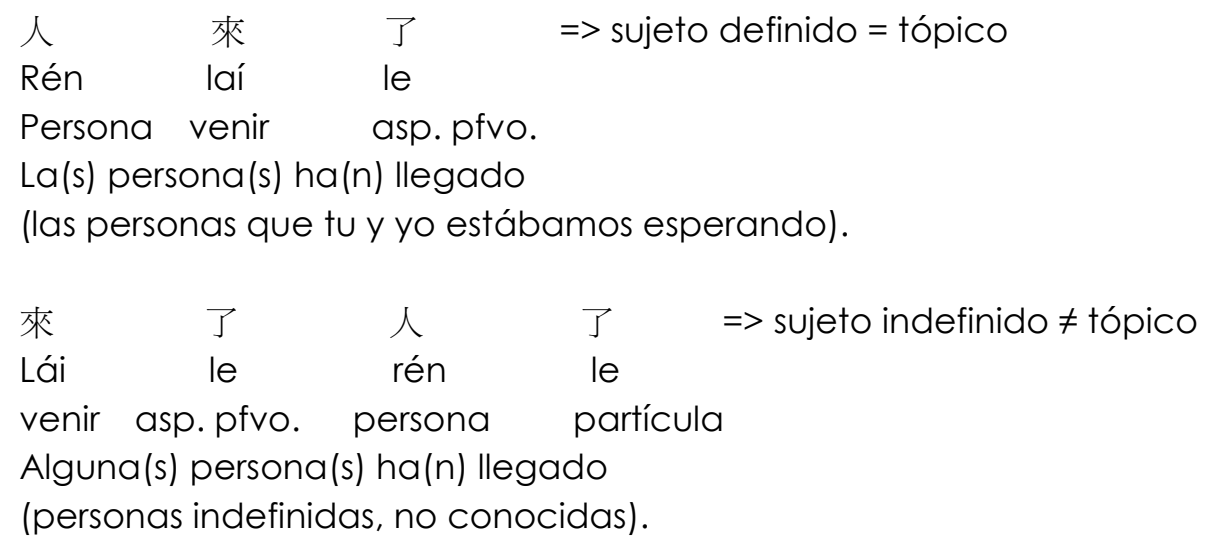

En el primer ejemplo el sujeto preverbal es definido y se corresponde con el tópico, mientras que en el segundo ejemplo el sujeto posverbal es indefinido y puede que el interlocutor no conozca su referente, por lo que no se interpreta como tópico.

Así, una lengua de estas características no puede encajar en ninguno de los tipos señalados por Greenberg. Más bien cabe decir que el mandarín es una mezcla de SOV y SVO, aunque en la conversación cotidiana la lengua china presenta más rasgos del tipo SOV y además parece que existe un proceso de cambio del tipo SVO al SOV. Li y Thompson (2003: 23) muestran las propiedades de la lengua china correspondientes a los tipos SVO y SOV:

\begin{tabular}{|c|c|}
\hline Propiedades SVO & Propiedades SOV \\
\hline $\begin{array}{l}\text { a) Construcción de VO } \\
\text { b) Uso de preposición } \\
\text { c)Los verbos auxiliares preceden al } \\
\quad \text { verbo principal } \\
\text { d)La estructura de las proposiciones } \\
\quad \text { subordinadas es SVO }\end{array}$ & $\begin{array}{l}\text { e) Construcción de OV } \\
\text { f) Adposiciones detrás del nombre al que } \\
\text { modifican } \\
\text { g) Los sintagmas posesivos preceden al } \\
\text { nombre } \\
\text { h) Los adjetivos y las proposiciones de } \\
\text { relativo preceden al nombre } \\
\text { i) Los marcadores aspectuales se posponen } \\
\text { al verbo } \\
\text { j) Algunos adverbios preceden al verbo } \\
\text { k) Las proposiciones adverbiales suelen } \\
\text { preceder a la principal }\end{array}$ \\
\hline
\end{tabular}

Tabla 7: Propiedades del tipo SVO y SOV del mandarín según Li y Thompson 
Las oraciones siguientes tratan de ejemplificar cada una de estas características:

a) 我開窗 戶

Wŏ kāi chuāng hù

Yo abrir ventana puerta

Abro la ventana.

b) 他從學 校到車站

Tā cóng xuéxiào dào chē zhàn

Él desde escuela llegar (hasta) coche parada

Él llega a la estación desde la escuela.

c) 你該回家了

Nǐ gāi huí jiā le

Tú deber volver casa part.

Debes volver a casa ya.

d) 我叫他寫信給你

Wǒ jiaò tā xiě shìn gěi nǐ

Yo llamar él escribir carta para tú

Le dije a él que te escribiera la carta.

e) 風把衣服吹乾了

Fēng bǎ yī fú chuī gān le

Viento marc. de C.D. ropa soplar seco part.

El viento ha secado la ropa (soplando).

f) 她在房裡

Tā zài fáng lĩ

Ella estar (en) habitación posposición (dentro, en)

吟 書

niàn shū

leer libro

Ella está estudiando en la habitación.

g) 學生的成績 出 來了

Xuéshēng de chéng ̄̄ chū aí le

Alumno part. posesiva nota salir venir part.

Han salido las notas de los alumnos.

h) 穿紅 衣服的 小孩

Chuān hóng yīfú de xiǎo hái

Vestir rojo ropa part. relativa niño, 


$$
\begin{aligned}
& \text { 是 我 女 兒 } \\
& \text { shì wǒ nǔ ér } \\
& \text { ser yo mujer hijo } \\
& \text { La niña que se viste en rojo es mi hija. }
\end{aligned}
$$
i) 我寫察作 業 Wǒ xiě le zuò yè He hecho los deberes.

j) 她 慢 慢 的 說 Tā màn màn de shuō Ella despacio part. hablar Ella habla despacio.

k) 小 時候 我們 住 在 xiăo shí hòu wǒ men zhù zài Pequeño conjunc. temp. nosotros vivir en

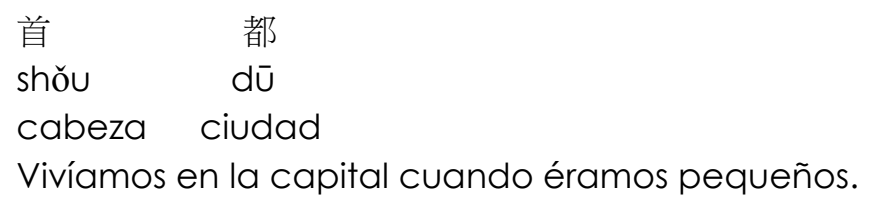

Frente al interés del orden de palabras en el chino mandarín, en que la disposición de los elementos oracionales desempeña una función gramatical y presenta un valor semántico, el tema del orden de palabras en español es una de las cuestiones que hasta periodos relativamente recientes no ha recibido un tratamiento gramatical, sino que ha sido abordado tradicionalmente desde la perspectiva de la retórica y estilística. Sin embargo, en el Curso superior de sintaxis española de Gili Gaya (1943) se encuentra un capítulo dedicado al tratamiento del orden de palabras desde puntos de vista propiamente gramaticales, pues el autor aborda el tema como un problema sintáctico y no simplemente retórico. Más adelante, autores como Prince (1981), Ulrich (1985), Reyes (1985), Ocampo (1990), Briz Gómez (1998), etc., indican que el español muestra un orden más o menos flexible y que esta relativa flexibilidad en el orden de los elementos oracionales debe abordarse desde una perspectiva funcional que tenga en cuenta fenómenos gramaticales como la entonación o la estructura semántica y fenómenos textuales relativos a la distribución de 
Morfología contrastiva del chino mandarín y el español. Formas de gramaticalización y lexicalización

información.

Según Gutiérez Ordóñez (1997: 40-61), Zubizarreta (1999: 4215-4244), RAE (2010: 2963-2985), Hernando Cuadrado (2005: 167), entre otros autores, en español el orden de palabras, tanto el de los constituyentes de la oración como el de las unidades de cada constituyente, es el fenómeno más estrechamente vinculado a la estructura informativa del esquema sintagmático oracional. Es decir, la construcción se encuentra motivada por las vivencias del hablante y responde a la función pragmática de la conversación. En este sentido, en una construcción virtual, el sujeto se colocaría antes del verbo, y, a continuación de éste, aparecerían los complementos. A su vez, en el interior de cualquier grupo sintagmático, el modificador se pospondría al núcleo. Sin embargo, por la motivación informativa, el hablante tiende a anteponer el elemento que considera más relevante, de manera que el orden de palabras responde a la función pragmática de la topicalización y al realce informativo de los elementos.

En este aspecto, hay que tener en cuenta que el español se asemeja al chino mandarín al seleccionar un elemento como tópico o tema de la predicación, que se sitúa como tal elemento topicalizado en posición inicial, separado del resto del esquema sintagmático por diferentes elementos, como los siguientes:

Por una pausa: La película, jmerece la pena verla!

Por marcadores de relación: Respecto al conserje, no le van a subir el sueldo.

Por reduplicación léxica: Listo, sí que es listo, pero debería esforzarse más.

Por su parte, el chino mandarín, al no tener bien definido el concepto sintáctico de sujeto, no puede adscribirse con facilidad a un determinado tipo de orden sintáctico, pues se rige más bien por reglas de índole pragmática y semántica. El español, en cambio, presenta variaciones morfológicas que marcan bien las diferencias de las personas gramaticales de las formas verbales. Así, en español, el orden básico predominante es SVO, que se refleja, por ejemplo, en la muestra extraída del corpus de la Base de datos sintácticos 
del español actual de López Meirama (1997: 71-72), donde el orden indicado ocupa una media del $92.28 \%$.

En los patrones tipológicos manejados por Greenberg (1963a) se proponen los siguientes esquemas como las combinaciones más representativas de la lengua española:

SVO: Juan compra un libro

auxiliar + verbo: ha comido, vamos a empezar

numeral + sustantivo: cinco libros

demostrativo + sustantivo: esta chica

adverbio + adjetivo: muy guapo

sustantivo + complemento preposicional: jersey de lana

antecedente + proposición de relativo: el regalo que me dio

adjetivo + comparante: más listo que nadie

Teniendo en cuanta lo expuesto arriba, el chino mandarín comparte algunas construcciones del orden básico de la lengua española, pero difiere de ella en otras combinaciones. Véanse algunos ejemplos:

\section{Semejanzas con el español}

SVO: tā hē shǔi 他喝水 'él' 'beber' 'agua' $\rightarrow$ él bebe agua auxiliar + verbo: wǒ jiāng qù 我將去 'yo' 'ir a' 'ir' $\rightarrow$ yo voy a ir demostrativo + sustantivo: zhè biān 這邊 'este' 'lado' $\rightarrow$ este lado adverbio + adjetivo: hěn měi 很美 'muy' 'bonito' $\rightarrow$ muy bonito

\section{Diferencias con el español}

numeral + clasificador + sustantivo:

一 本 書

Yì běn shū

Uno clasificador libro

Un libro

complemento preposicional + part. posesiva + sustantivo:

$\begin{array}{lllll}\text { 羊 } & \text { 毛 } & \text { 的 } & \text { 毛 } & \text { 衣 } \\ \text { Yáng máo } & \text { de } & \text { máo } & \text { ȳ̄ } \\ \text { Oveja pelo part. posesiva } & \text { pelo ropa }\end{array}$

Jersey de lana

proposición de relativo + part. relativa + sustantivo (antecedente)

她送我的 禮 物

Tā sòng wŏ de lì wù

Ella dar yo part. relativa regalo

El regalo que me dio ella. 
Morfología contrastiva del chino mandarín y el español. Formas de gramaticalización y lexicalización

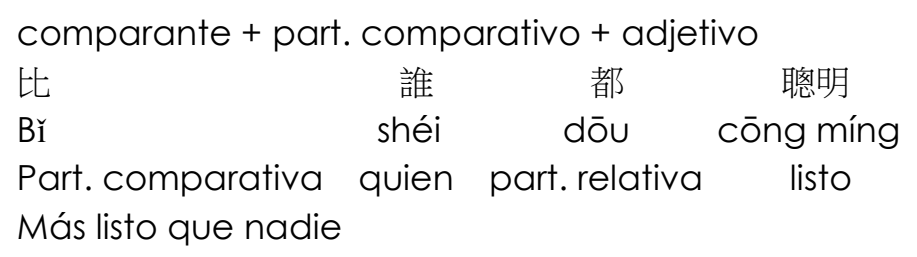

\subsection{Resumen y conclusiones}

El chino mandarín es una lengua ampliamente hablada en el sureste de Asia y genéticamente clasificada como una rama independiente de la familia sinotibetana. Su estructura silábica está constituida por un fonema inicial y un fonema final, que se equiparan a la consonante y a la vocal de las lenguas occidentales respectivamente. La segmentación silábica del chino mandarín está determinada por la tendencia a identificar cada sílaba con un elemento léxico con significado. En chino mandarín se enfatiza la importancia del tono en el sistema fonológico, pues las diferencias tonales alcanzan valor distintivo. A diferencia de la escritura alfabética de las lenguas occidentales, el chino mandarín tiene una escritura logográfica que presenta un claro componente fonográfico (silabográfico), en el que los logogramas pueden interpretarse como denotadores de una sílaba.

Desde un punto de vista tipológico, se considera el chino mandarín como un ejemplo de idioma aislante y analítico, que se caracteriza por la falta de casos gramaticales, desinencias y concordancia. Sin embargo, esta consideración no parece del todo apropiada, pues es la escritura aislante y monosilábica la que sobre todo induce la clasificación tipológica del chino mandarín. En algunos aspectos, la lengua china sí que presenta caracteres analíticos: predominan las palabras invariables y las relaciones sintácticas se marcan por medio del orden de palabras o de unidades léxicas independientes. Sin embargo, la distinción tipológica es más bien gradual y el monosilabismo lingüístico de la lengua china es una idea parcialmente correcta. En efecto, el mandarín dispone de marcas morfológicas que se unen 
a palabras, tal como ér huà cí 兒化詞 (literalmente, 'hacer palabra'). Por otro lado, frente a la idea de una gramática sencilla y una morfología pobre, sería más adecuado afirmar que el chino mandarín es una lengua con una fuerte inclinación hacia la composición morfológica. Dispone además de un sistema de afijos que desempeñan funciones gramaticales y léxicas, comparables a los procedimientos flexivos y derivativos de las lenguas que se prestan al análisis morfológico.

Con respecto a las propiedades sintácticas, mientras que el español es una lengua con una sintaxis orientada a la oración, el chino mandarín es una lengua con una sintaxis dirigida al discurso. Así, el sistema de clases de palabras del chino mandarín apenas puede clasificarse desde el punto de vista categorial, pues muchas palabras actúan como dos o más categorías diferentes según su disposición en la frase. Por otra parte, el concepto de tópico adquiere más importancia que el de sujeto y representa un rasgo esencial que distingue tipológicamente al mandarín de las lenguas europeas. En mandarín el tópico se caracteriza por tres aspectos: ocupa la posición inicial en la oración, no presenta restricciones sintagmáticas y tiene prioridad sobre el sujeto para determinar la referencia de un sintagma nominal omitido, si el sujeto y el tópico coinciden.

Respecto a la tipología del orden de palabras y de sintagmas, frente al español cuyo orden básico predominante es SVO, el chino mandarín no puede adscribirse con facilidad a un determinado tipo de orden sintáctico, pues se rige más bien por reglas de índole pragmáticas y semánticas. Más concretamente, la estructura básica de las oraciones es la relación tópico-comentario y no la de sujeto-predicado del español. En este sentido, se considera en este trabajo que las funciones sintácticas de sujeto y predicado no son relevantes para describir las propiedades tipológicas del chino. Por tanto, si se tratara de aplicar al chino los criterios de los tipólogos tradicionales, cabría afirmar que el mandarín representa una mezcla de los tipos SOV y SVO. 

2

\section{UNIDADES MORFOLÓGICAS}

Este capítulo se dedica a revisar las principales definiciones y clasificaciones del morfema en la teoría general, pero también la aplicación de tales concepciones a la morfología de ambas lenguas. Se toman en consideración, especialmente, los cinco principios de Nida a fin de identificar los morfemas y se analizan sus principales clasificaciones de acuerdo con el valor semántico, la capacidad léxica y la función gramatical que desarrollan estas unidades morfológicas.

\subsection{Identificación del morfema}

Para delimitar los elementos que podrían ser considerados morfemas, la definición de Bloomfield (1950 [1933]: 161) puede servir de referencia inicial: "Un elemento lingüístico que no tiene parcialmente semejanza fonética y semántica con ningún otro elemento es [...] un morfema"8. Partiendo de tal caracterización, Nida (1965: 6-7) afirma:

Esto significa que los morfos que pertenecen al mismo morfema no pueden estar constituidos por los mismos fonemas ni tener precisamente significados equivalentes. Pero si estos morfos de forma diferente no superponen otros conjuntos de morfos en sus significados respectivos, entonces se pueden agrupar bajo un solo morfema. Esto es porque, como

8 Texto original en Bloomfield (1950 [1933]: 161): "A linguist form which bears no partial phonetic-semantic resemblance to any other form is a [...] morpheme". Para la traducción del inglés al español, también véase Her (2002: 154). 
Morfología contrastiva del chino mandarín y el español. Formas de gramaticalización y lexicalización

señala la definición, estos no tienen parcialmente semejanza fonético-semántica con ningún otro elemento. Así, el significado de esta definición negativa se hace más fácil de percibir a la hora de aplicar los diversos principios para la identificación de morfemas?.

A partir de esta generalización, Nida (1965) plantea algunos principios a fin de identificar los morfemas. En primer lugar, los elementos que tengan la significación común y la misma forma fonémica en todas sus apariciones constituyen un solo morfema. Por ejemplo, en español, el elemento -dor constituye un morfema porque siempre se usa con los mismos tipos fonéticos y con el mismo significado de 'agente de la acción' cuando se añade a verbos para la formación de nombres como consumidor, diseñador, proveedor, etc. Su equivalente en chino mandarín es zhě 者 'agente de la acción' que presenta la misma definición morfológica, pues se trata también de un formante pospuesto al verbo:

\section{xiāo fèi zhě 消費者 'consumir' '-dor' $\rightarrow$ consumidor \\ shè jí zhě 設計者 'diseñar' '-dor' $\rightarrow$ diseñador \\ tígōng zhě 提供者 'proveer' '-dor' $\rightarrow$ proveedor}

En segundo lugar, los elementos que tienen la significación común pero difieren fonéticamente pueden constituir un solo morfema con tal de que la distribución de las diferencias formales sea fonológicamente definible. Por ejemplo, el prefijo de negación in- presenta más de una forma, como en inseguro, imposible e irreal. Pero existe parcialmente una semejanza fonético-semántica entre in-, im- e i- que depende de las condiciones fonológicas. En este caso, el tipo de consonante que sigue decide la selección de una de estas tres formas. Pues bien, en chino mandarín sucede algo parecido. Her (2002: 161-162) señala en su trabajo que, de acuerdo con Harris

\footnotetext{
9 Texto original en Eugene A. Nida (1965: 6-7): "It means that forms belonging to the same morphemes may not consist of identically the same morpheme and they may not have precisely equivalent meanings, but if these varying forms with correspondingly meanings still do not overlap on other sets of forms with their respective meanings, then they may be regarded as constituting single morpheme. This is because, as the definition states, they bear no partial phonetic-semantic resemblance, to other forms. The significance of this negative type of definition will become more obvious as we consider the various principles which determine the identification of morphemes". Para la traducción del inglés al español, también véase Her (2002: 154).
} 
(1942: 179-180) y Hockett (1947: 328-329), los alomorfos pueden considerarse un mismo morfema si: a) tienen el mismo significado; b) están en distribución no contrastiva y c) no tienen más elementos combinatorios que aquellos morfemas carentes de alomorfos. Así, los adjetivos numerales que designan las unidades pueden servir de ejemplo. En chino mandarín, estos numerales (de uno a nueve) aparecen en las siguientes posiciones:

1) Delante de las unidades de medida y de los clasificadores: liù gōng chŭ 六公尺 'seis' 'metro' $\rightarrow$ seis metros yī pī mă 一匹馬 'uno' 'clas.' 'caballo' $\rightarrow$ un caballo sān tiáo shé 三條蛇 'tres' 'clas.' 'serpiente' $\rightarrow$ tres serpientes

2) Delante y detrás de los grupos numerales: sān qiān 三千 'tres' 'mil' $\rightarrow$ tres mil yī băi bā 一百八 'uno' 'cien' 'ocho' $\rightarrow$ ciento ochenta

3) Detrás del prefijo ordinal dì 第: dì liù 第六 'pref.' 'seis' $\rightarrow$ sexto

Sin embargo, la significación de 'dos' se corresponde con dos formas distintas: èr 二 dos y liăng 兩 dos, que presentan distribuciones diferentes, pues èr 二 dos no se usa en primera posición, mientras que liăng 兩 dos no se emplea en segunda posición. Véanse algunos ejemplos:

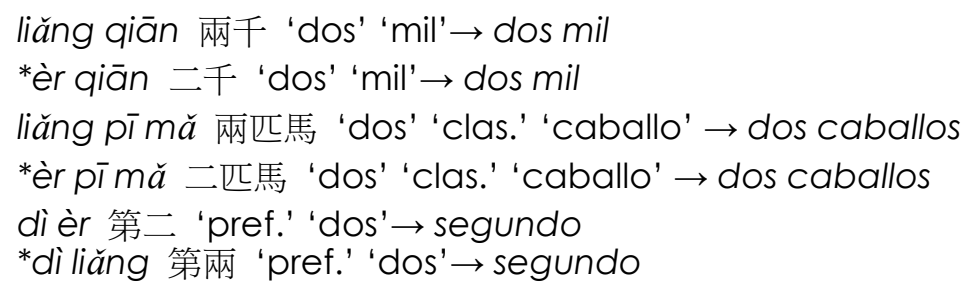

En opinión de Her (2002: 161), a pesar de las diferencias fonológicas, èr 二 dos y liăng 兩 dos pueden considerarse un mismo morfema. Según la autora, estos elementos son alomorfos o variantes pertenecientes a un mismo morfema porque están en distribución complementaria, en el sentido de que no aparecen en las mismas posiciones con la misma forma fonética.

En tercer lugar, Nida considera que los elementos de significación común que difieren en las formas fonémicas, pero de tal manera que su distribución no resulte definible fonológicamente, constituyen un solo morfema 
Morfología contrastiva del chino mandarín y el español. Formas de gramaticalización y lexicalización

si están relacionados con una serie de estructuras idénticas. Por ejemplo, los elementos formativos del plural en español no son iguales en mesas, tabúes, voces, polisíndeton. Sin embargo, se pueden considerar como una serie de alomorfos porque presentan la característica común de adjuntarse a las formas en singular como raíces. Más concretamente, partiendo del aserto de Nida (1965: 54), se identifica el mismo morfema porque la diferencia entre el singular y el plural es "abierta" o "nula". Por ejemplo, la diferencia entre voz y voces es "abierta", ya que el plural se manifiesta formalmente (-es), mientras que el contraste entre la forma singular polisíndeton y la plural polisíndeton es "nulo", pues el plural polisíndeton presenta un cero estructural parecido al singular polisíndeton y este cero se refiere a la ausencia del significante del sufijo -s /-es. Sucede lo mismo en préstamos de otras lenguas como dandis (del ing. dandy) y zarevich (del ruso tsarevich). En dandis se observa una diferencia "abierta" ya que la voz extranjera en -y precedida de consonante se adapta gráficamente al español sustituyendo la -y. Por el contrario, zarevich presenta una diferencia "nula", puesto que se mantiene invariable en plural.

En el caso del chino mandarín, la diferencia entre la forma singular chē 車 coche y la plural chē車 coches es "nula", pues el plural chē 車 coches presenta un cero estructural, como el singular chē 車 coche. Solo en el caso de los pronombres personales (y de algunos sustantivos que designan personas) se observa una diferencia "abierta", ya que el plural se expresa mediante la marca de pluralidad men 們 pospuesta, como en nǐ men 你們 'tú' + 'partícula de plural' $\rightarrow$ vosotros (vid. §4.2).

El cuarto principio hace referencia a los elementos homófonos, que, según Nida, con significados diferentes constituyen morfemas diferentes. Así, en español se identifican claramente como morfemas diferentes ola y hola, baca y vaca, etc. El chino mandarín, por su parte, lengua en la que la homofonía es un fenómeno habitual, los morfemas se distinguen del mismo modo que en español mediante la escritura y el significado léxico. Por ejemplo, la palabra ȳ̄ puede representar varios signos lingüísticos, como - uno, 衣 ropa, 醫 
medicina y 依 depender. Pese a la forma fonéticamente idéntica, todos estos elementos se consideran morfemas distintos con su propio significado y su propia forma gráfica.

Por otro lado, en opinión de Lü (1990 [1979]: 101-103), en chino mandarín, los elementos que presentan la misma forma fonética y gráfica pero difieren semánticamente, tampoco se interpretan como un mismo morfema. Este principio permite agrupar los elementos que comparten la misma significación en un mismo morfema, a pesar de que forman parte de composiciones diferentes. Por ejemplo, entre gōng rén 工人 'trabajo' 'gente' $\rightarrow$ obrero y gōng zī 工資 'trabajo' 'dinero' $\rightarrow$ salario hay una semejanza semántica en el elemento gōng 工, que aporta el mismo significado de 'trabajo, oficio' y, por tanto, se considera un mismo morfema. Sin embargo, en gōng chē 公車 'público' 'coche' $\rightarrow$ autobús y gōng niú 公牛 'varón' 'buey' $\rightarrow$ toro, aunque el elemento gōng 公 presenta la misma forma fonética en los dos casos, no se identifica con un mismo morfema ya que aporta significados diferentes. Se trata, pues, de términos homónimos o polisémicos.

El último principio que plantea Nida (1965) para identificar y definir el morfema supone que los elementos que pueden aparecer aisladamente o los que pueden entrar en múltiples combinaciones, aunque estos últimos no sean independientes, pueden considerarse morfemas siempre que los segmentos a los que se agregan tengan autonomía. Por ejemplo, río, ahora, yo, etc., pueden identificarse como morfemas porque es posible emitir todos ellos aisladamente; -tor/-dor nunca aparecen aisladamente, pero en trabajador, administrador, escritor, inventor, -tor/-dor se combinan con segmentos independientes como trabajar, administrar, escribir, inventar que tienen autonomía. Así, -tor/-dor se identifican como morfemas. Lo mismo sucede con el prefijo con- en combinaciones como concluir, consumir, contener, etc. Conse define como un morfema porque las raíces a las que se agrega pueden aparecer independientemente o combinarse con otros elementos para formar palabras, como en incluir, resumir, detener, etc. Sin embargo, una forma como 
Morfología contrastiva del chino mandarín y el español. Formas de gramaticalización y lexicalización

gre- no podría considerarse como un morfema, pues no se combina con elementos libres ni con raíces que puedan dar lugar a nuevas combinaciones (como, por ejemplo, en greca, gregario, gremio, etc.).

En chino mandarín, de modo parecido, băn 板 tabla no aparece aisladamente, pero se identifica como morfema porque las raíces independientes de 1) pueden combinarse con este morfema, como en 2) o bien combinarse con otros elementos para formar palabras, como en 3):

1) mù 木 'madera'

dì 地'tierra'

hēi 黑 'negro'

*băn 板 'tabla'

2) mù băn 木板 'madera' 'tabla' $\rightarrow$ madera

dì băn 地板 'tierra' 'tabla' $\rightarrow$ suelo

hēi băn 黑板 'negro' 'tabla' $\rightarrow$ pizarra

3) mù gōng 木工 'madera' 'trabajador' $\rightarrow$ carpintero

tǔ dì 土地 'barro' 'tierra' $\rightarrow$ terreno, tierra

yŏ hèi 䵢黑 'oscuro' 'negro' $\rightarrow$ moreno

\subsection{Principales clasificaciones del morfema}

Tradicionalmente, en chino mandarín se distinguen dos tipos de morfemas: shí cí 實詞 'morfema lleno' y xū cí 虛詞 'morfema vacío'. El primer tipo desempeña una función oracional y aporta significado léxico. Se corresponde con la raíz o el lexema de la palabra. El segundo tipo está dotado de significado gramatical, pero carece de significado nocional. Se identifica con las partículas que distinguen las funciones gramaticales de las palabras. Ahora bien, aunque estos dos tipos de morfemas representan el principio fundamental de la morfología china, se deben tomar en consideración otros factores para clasificar adecuadamente las unidades morfológicas. Por el momento, se presentan tres criterios para la clasificación de los morfemas: 
1) Según el valor semántico, los morfemas se dividen en dos tipos: morfemas llenos con significado léxico y morfemas vacíos con significado gramatical.

2) Según la capacidad léxica, los morfemas se clasifican en tres tipos: los autónomos, los libres y los ligados (§2.3).

3) Según la función de los morfemas, se distinguen tres tipos: morfemas léxicos, morfemas derivativos y morfemas funcionales (§2.4). En el análisis morfológico, la raíz se corresponde con el morfema léxico y los afijos pueden identificarse con los morfemas derivativos y con los flexivos o funcionales.

Se observa claramente que cada clasificación adopta un punto de vista diferente que da lugar a varias definiciones para la noción de morfema. En chino mandarín, la clasificación semántica de morfemas llenos y morfemas vacíos es un recurso habitual. Los morfemas léxicos y las raíces o bases del español corresponden a los morfemas llenos del mandarín, mientras que los morfemas gramaticales del español se identifican con los morfemas vacíos del mandarín. Por lo tanto, entre los distintos tipos de clasificaciones se producen correlaciones y reciprocidades. En ambas lenguas se encuentran formas que justifican estas categorizaciones diferentes. Aquí se presentan algunos ejemplos de los tipos de morfemas en las dos lenguas en contraste:

1) Un morfema vacío desempeña funciones gramaticales. Las desinencias del español (-o/-a, -s/-es, -aba, -ría, etc.) y los marcadores aspectuales del mandarín (le $了$ 'aspecto perfectivo', guò 過 'pasado indefinido', etc.) pertenecen a este tipo.

2) Un morfema autónomo es un morfema libre que aporta significado léxico. Se trata de los llamados morfemas llenos. En ambas lenguas las raíces como casa (casero, caserío, etc.) y diàn 電 electricidad (diàn năo 電腦 'electricidad' 'cerebro' $\rightarrow$ ordenador, diàn shì 電視 'electricidad' 'ver' $\rightarrow$ televisión, etc.) son de esta clase. 
Morfología contrastiva del chino mandarín y el español. Formas de gramaticalización y lexicalización

3) Un morfema vacío es un morfema ligado, como los elementos gramaticales. En ambas lenguas, algunos tipos de afijos pertenecen a esta categoría. Sin embargo, los afijos del español, en general, presentan un valor semántico más claramente que muchos afijos del mandarín, ya que todos los prefijos y sufijos derivativos del español aportan información léxica suplementaria al lexema o raíz. Sin embargo, en mandarín, algunos afijos del grupo que aquí llamamos "afijos convencionales", cuando se combinan con algunos lexemas, no aportan ni siquiera significado gramatical. Por ejemplo, los elementos lăo 老 y zi 子 sirven para cumplir la tendencia bisilábica del chino moderno, como en las palabras lăo hŭ 老虎 'pref.' 'tigre' $\rightarrow$ tigre y fáng zi 房子 'casa' 'suf.' $\rightarrow$ casa. Por su parte, los interfijos del español (cafe-l-ito, pan-nec-ito, pie-cec-ito, etc.) también pueden interpretarse como morfemas vacíos, pues desempeñan una función muy semejante a los elementos del chino mandarín anotados anteriormente.

4) En la morfología china se ha considerado también un tipo de morfema que en la actualidad se presenta como ligado, pero era un morfema libre en periodos anteriores de la lengua. Como señalan Packard (1998: §3.4) y Sun (2003), se denominan morfemas libres a estos constituyentes que admiten múltiples combinaciones, aunque no aparecen aisladamente como elementos independientes en el chino actual. Otros autores, como Deng (2002) y Huang (2003), utilizan la denominación -ciertamente contradictoria- de "morfemas libres ligados" para hacer referencia a estos formantes. Creemos, por nuestra parte, que estos elementos dependientes se encuentran en una posición intermedia entre las formas ligadas y las libres, pues eran unidades autónomas en el chino clásico. En la actualidad, estas antiguas unidades libres del chino clásico solo forman palabras compuestas. Además, pueden adoptar las dos posiciones y constituyen un recurso muy productivo en la composición. Por ejemplo, el formante guó 果 'fruto' se presenta en el chino actual como un morfema ligado que se combina con otros lexemas para formar palabras compuestas, tanto en la anteposición como en la posposición: guǒ zhī 果汁 
'fruto' 'jugo' $\rightarrow$ zumo, shǔi guǒ 水果 'agua' 'fruto' $\rightarrow$ fruta. Sin embargo, este formante actual era un morfema libre en el chino clásico. En nuestra propuesta contrastiva, cabría considerar que algunos temas cultos de origen grecolatino se comportan en la morfología española de una forma semejante a estos "morfemas libres ligados" de la morfología china. Por ejemplo, hidro, teca, podo, logo, bio, filo, fono, fago, etc., proceden etimológicamente de formas libres, pero en el español actual no suelen usarse fuera de la composición o derivación, aunque algunos de ellos recuperan su antigua condición de morfemas libres (como terapia, crono, fobia, etc.).

\subsection{Morfemas autónomos, libres y ligados}

Según la capacidad léxica, los morfemas pueden clasificarse en tres tipos: los autónomos, los libres y los ligados. Los morfemas autónomos son elementos independientes que no se combinan con otros morfemas ni se derivan ni tienen flexión. En español estos morfemas independientes son las palabras invariables, como las preposiciones en, de, hasta, etc., las conjunciones y, o, ni, etc., algunos adverbios como hoy, luego, entonces, etc., y ciertas interjecciones. En mandarín estos morfemas autónomos incluyen las preposiciones zài 在 en, jiā 加 con, wèi le 為了 para/por, etc., las conjunciones dàn shì 但是 pero, rú guǒ 如果 si, jǐn guăn 儘管 aunque, etc., los adverbios hěn 很 muy, dōu 都 completamente, etc., y las interjecciones ¡wei! ¡喂! ¡oye, oiga!, ¡ai! ¡唉! ¡ay!, etc.

No obstante, es necesario tener en cuenta que, según Chao (1998: 54), en mandarín muchos sustantivos bisilábicos y polisilábicos se identifican con los morfemas autónomos. Así, algunos arcaísmos, como biān fú 蝙蝠 murciélago y líng lóng 玲瓏 delicado, fino, etc., y extranjerismos, como mă lā sōng 馬拉松 maratón y xiē sī ď̉ lǐ 歇斯底里 histeria, etc., son morfemas autónomos, pues se 
Morfología contrastiva del chino mandarín y el español. Formas de gramaticalización y lexicalización

consideran unidades independientes que no se unen a otros morfemas y tampoco aceptan la flexión ni la derivación. Este fenómeno no es desconocido en español, pues algunos sostantivos también se comportan como elementos autónomos (lunes > *Iunesito, *Iuneses).

Los morfemas libres son los que pueden aparecer aisladamente como palabras independientes. En español estos morfemas pueden admitir flexión y también formar derivados y compuestos en combinación con otros morfemas y adoptar distintas posiciones:

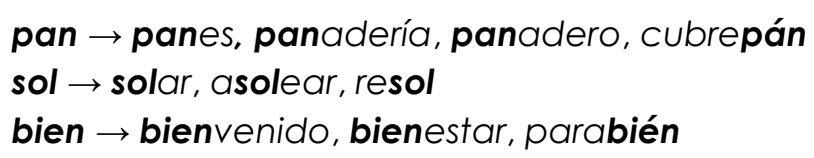

En el mandarín moderno, del mismo modo, los morfemas libres pueden combinarse con otros elementos léxicos para formar palabras compuestas. Su colocación también puede variar, como se muestra en los siguientes ejemplos:

1) tiān 天 'cielo':

tiān shēng 天生 'cielo' 'nacer' $\rightarrow$ de nacimiento

xiān tiān 先天 'primero, antes' 'cielo' $\rightarrow$ congénito

lăo tiān yé 老天爺 'viejo, mayor' 'cielo' 'señor' $\rightarrow$ Dios

2) ěr 耳 'oreja':

ěr $\bar{\jmath}$ 耳機 'oreja' 'aparato' $\rightarrow$ auriculares

nèi ěr 內耳 'interior' 'oreja' $\rightarrow$ oído interno

zhōng ěr yán 中耳炎 'medio' 'oreja' '-itis' $\rightarrow$ otitis media

3) měi 美 'bello':

mẽi wèi 美味 'bello' 'sabor' $\rightarrow$ sabroso

wuán měi 完美 'completo' 'bello' $\rightarrow$ perfecto

shěn měi guān 審美觀 'examinar' 'bello' 'concepto' $\rightarrow$ punto de vista estético

Por último, los morfemas ligados incluyen los que se combinan con otros morfemas y carecen de autonomía léxica. Unos pueden presentarse en diferentes posiciones, mientras que otros adoptan una distribución fija. El español dispone de morfemas ligados que se identifican con la raíz, dado que esta ha de construirse con afijos para formar palabras: 
-am- $\rightarrow$ amante, desamor, enamorado

-viv- $\rightarrow$ vívido, vivienda, convivencia

-busc- $\rightarrow$ buscapleitos, rebuscar, rebuscamiento

Los morfemas ligados que presentan una posición determinada son los morfemas derivativos y los morfemas flexivos. Entre los derivativos se distinguen los prefijos, los interfijos y los sufijos; los flexivos -o morfemas de cierre- son los que representan las distintas formas de 'género', 'número', 'persona', 'modo', 'tiempo', 'aspecto' y ocupan la última posición, tras los derivativos.

En mandarín, los morfemas ligados pueden ser, además de los afijos y pseudoafijos, muchas antiguas unidades libres del chino clásico que en la actualidad forman palabras con otros elementos en posición libre como en 1) y 2) (vid. §2.2.4 con el ejemplo de guǒ 果 'fruto' y §4.5). Los afijos y pseudoafijos forman palabras con otros elementos en una posición determinada como en 3) y 4):

1) ant. huàn 幺𠃌 'ilusorio':

mèng huàn 夢幻 'sueño' 'ilusorio' $\rightarrow$ fantasía

huàn jué 幻覺 'ilusorio' 'sentido' $\rightarrow$ ilusión

2) ant. băn 板 'tabla':

băn dèng 板登 'tabla' 'silla' $\rightarrow$ banco

hēi băn 黑板 'negro' 'tabla' $\rightarrow$ pizarra

3) ā 阿 'prefijo':

à bà 阿爸 'pref.' 'padre' $\rightarrow$ padre

à yí 阿姨 'pref.' 'tía' $\rightarrow$ tía

4) zhè 者 'sufijo':

zoù zhè 作者 'escribir, hacer' 'suf.' $\rightarrow$ escritor

dú zhě 讀者 'leer' 'suf.' $\rightarrow$ lector

ji zhě 記者 'acordarse, apuntar' 'suf.' $\rightarrow$ periodista

\subsection{Morfemas léxicos, derivativos y funcionales}

Según la función que desempeñan las unidades morfológicas, en español y en chino mandarín se clasifican los morfemas en tres tipos: morfemas 
Morfología contrastiva del chino mandarín y el español. Formas de gramaticalización y lexicalización

léxicos, morfemas derivativos y morfemas flexivos o funcionales. Vemos algunos ejemplos:

\begin{tabular}{|c|c|c|}
\hline $\begin{array}{l}\text { Tipos de } \\
\text { morfemas }\end{array}$ & Chino mandarín & Español \\
\hline \multirow{3}{*}{$\begin{array}{l}\text { Morfema } \\
\text { léxico }\end{array}$} & lù 綠 verde & mar \\
\hline & b̌ 筆 lápiz, bolígrafo & cas- \\
\hline & dú 毒 droga & sol \\
\hline \multirow{3}{*}{$\begin{array}{l}\text { Morfema } \\
\text { derivativo }\end{array}$} & lù huà 綠化 'verde' 'suf. -izar' $\rightarrow$ plantación & mar-ino \\
\hline & bǐ zhě 筆者 'lápiz, bolígrafo' 'suf. -tor' $\rightarrow$ autor, escritor & cas-ero \\
\hline & făn dú 反毒 'pref. anti-' 'droga' $\rightarrow$ antidroga & sol-ana \\
\hline \multirow[t]{3}{*}{$\begin{array}{l}\text { Morfema } \\
\text { funcional }\end{array}$} & $\begin{array}{c}\text { bǐ zhě men 筆者們 'lápiz, bolígrafo' 'suf. -tor' } \\
\text { 'pluralidad' } \rightarrow \text { autores, escritores }\end{array}$ & marino-s \\
\hline & $\begin{array}{c}\text { chīguò 吃過 'comer' 'asp. experiencial' } \rightarrow \text { ha } \\
\text { comido }\end{array}$ & casero-s \\
\hline & kàn zhe 看著 'mirar' 'asp. durativo' $\rightarrow$ estar mirando & solana-s \\
\hline
\end{tabular}

Tabla 1: Morfemas léxicos, derivativos y funcionales en chino mandarín y español

En primer lugar, los morfemas léxicos se refieren a la raíz de la palabra, que no puede segmentarse en más elementos. Tanto en español como en mandarín, los morfemas léxicos son los elementos nucleares de las palabras y aportan el significado léxico. Por ejemplo, en casa, casero, casilla, caserío, etc., el elemento cas- es el significante parcial común que forma la raíz de la serie de palabras y el lexema que presenta un significado autónomo y parcial también común. Tal unidad es el elemento básico y constante que constituye el punto de partida de cualquier construcción morfológica.

En chino mandarín, el morfema léxico se asemeja al del español en el sentido de que se trata del segmento básico y constante en el significante y significado de cualquier palabra morfológicamente emparentada. Así, el lexema xié 鞋 zapato puede adoptar varios tipos de afijos o elementos léxicos para formar diversas construcciones morfológicas:

xié zi 鞋子 'zapato' 'suf.' $\rightarrow$ zapato (derivado con sufijo convencional) xié jiàng 鞋匠 'zapato' 'suf. -ero' $\rightarrow$ zapatero (derivado con pseudosufijo) 
tuō xié 拖鞋 'arrastrar, fregar' 'zapato' $\rightarrow$ sandalia (compuesto subordinado) fán bù xié 帆布鞋 'Iona' 'trapo' 'zapato' $\rightarrow$ playera (compuesto complejo)

En español, hay dos tipos de morfemas léxicos: el morfema dependiente es el que va necesariamente unido a otro morfema, como el caso anterior de cas-, o la primera parte de las palabras pat-o, am-a-r, cali-graf-ía, cam-a. El segundo tipo es el morfema independiente, que no va unido a otro morfema, como azul, árbol, leche. Las palabras del segundo tipo tienen sufijo cero o vacío. Casos más claros de lexemas sin afijos son las preposiciones, como para y con; las conjunciones, como y y que; y los adjetivos numerales, como dos y cinco.

De modo parecido, en chino mandarín los morfemas léxicos pueden ser unidades dependientes que siempre se unen a otros elementos, como en los ejemplos de 1), o morfemas libres que pueden aparecer independientemente, como en los ejemplos de 2):

1) shǔi qing 水晶 'agua' 'cristal' $\rightarrow$ cristal

huàn jué 幻覺 'ilusorio' 'sentido' $\rightarrow$ ilusión

líán hé 聯合 'unir' 'juntar' $\rightarrow$ unir

2) shŭi 手 agua

zhř 紙 papel

diàn 電 electricidad

En resumen, el morfema léxico de ambas lenguas, según se ha caracterizado, puede considerarse como la unidad básica en la descripción de las distintas operaciones morfológicas (derivación, composición, etc.). Sin embargo, los morfemas léxicos del chino mandarín difieren de los del español en que aquellos siempre constituyen la parte invariable en las distintas formaciones. Es decir, en español, los morfemas léxicos o la denominada raízio no son exactamente invariables, porque puede haber alomorfos como en pod-er y pued-e. Sin embargo, el chino mandarín no manifiesta tal cambio morfológico, pues los morfemas léxicos siempre presentan un significado autónomo e independiente con significante invariable.

10 Sobre la consideración de las unidades 'raíz' 'tema' y 'base' véase Jesus Pena (1999: § 66.2.2). 
Morfología contrastiva del chino mandarín y el español. Formas de gramaticalización y lexicalización

Por otra parte, el morfema derivativo es el formante que se adjunto a la raíz o base léxica para la formación de una nueva palabra. Así, en español, las palabras primitivas como agua, azul, bien, cama, favor, pie, sol, voz, etc., son aquellas que constan de un solo lexema y ningún morfema derivativo. Este tipo de palabras alcanza un escaso porcentaje en la lengua y se caracteriza por poder usarse separadamente entre pausas o espacios en la cadena hablada o escrita, respectivamente. Al contrario, aquellas formaciones que pueden segmentarse en dos lexemas o que constan de algún morfema derivativo reciben la denominación de palabras complejas. Entre estas, se distinguen principalmente las palabras derivadas y las palabras compuestas. En español, en comparación con otros procesos morfológicos, la derivación es el procedimiento principal en la formación de palabras nuevas. Se trata de una lengua que cuenta con una gran cantidad de morfemas derivativos. En los diccionarios del español, las formas derivadas suelen tener entrada lexicográfica.

Es un supuesto bastante compartido entre los estudiosos del mandarín que se trata de una lengua con menos riqueza de morfemas derivativos que las lenguas occidentales, puesto que se considera al chino una lengua analítica en la que predomina el proceso morfológico de la composición. Pero, pese a la práctica unanimidad de estas opiniones y a las diferencias con el español, se encuentran en mandarín algunas unidades lingüísticas que no aportan el significado léxico principal, pero añaden rasgos semánticas o contenidos gramaticales al significado básico del lexema. Todos estos elementos son morfemas ligados que bien se anteponen al lexema, bien se posponen al lexema o bien se interponen entre el lexema y otros elementos. Así, tales formantes del chino se pueden relacionar con los afijos del español. Entre ellos, destaca el grupo de los afijos denominados convencionales, como ér 兒,

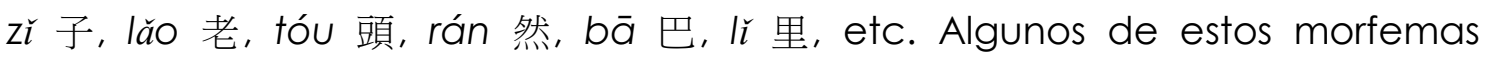
derivativos desempeñan la función morfonológica principal de satisfacer la tendencia a la bisilabidad del chino moderno, pero otros aportan significado 
léxico o gramatical. Véanse algunos ejemplos en la siguiente tabla:

\begin{tabular}{|c|c|c|}
\hline & Solo con función morfonológica & Con significado léxico o gramatical \\
\hline Prefijo & Iăo hǔ 老虎 'pref.' 'tigre' $\rightarrow$ tigre & $\begin{array}{c}\text { kè pà 可怕 'pref. -ble' 'temer' } \rightarrow \\
\text { horrible }\end{array}$ \\
\hline Sufijo & $\begin{array}{c}\text { shí tóu 石頭 'piedra' 'suf.' } \rightarrow \\
\text { piedra }\end{array}$ & $\begin{array}{c}\text { lù huà 綠化 'verde' 'suf. -izar' } \rightarrow \\
\text { plantación }\end{array}$ \\
\hline Interfijo & $\begin{array}{c}\text { gǔ lǐ gú guài 古里古怪 } \\
\text { 'antiguo' 'interf.' 'antiguo' 'raro' } \\
\rightarrow \text { raro }\end{array}$ & $\begin{array}{c}\text { kàn dé daò 看得到 'ver' 'interf. modal } \\
\text { poder' 'llegar (asp. resultativo)' } \rightarrow \\
\text { poder llegar a ver }\end{array}$ \\
\hline
\end{tabular}

Tabla 2: Formaciones derivadas con afijos convencionales

En opinión de Wang (2008: 115), por la influencia del extranjerismo y la necesidad de crear palabras para conceptos nuevos, el chino actual experimenta la tendencia hacia la derivación mediante elementos productivos antepuestos o pospuestos a las palabras tradicionales, los cuales tratan de corresponderse con las formaciones derivadas de las lenguas occidentales. Estos nuevos elementos derivativos contrastan con los afijos convencionales y se perciben como afijoides, pues se encuentran en un estado intermedio entre la afijación y la composición. Por un lado, están dotados de significado léxico, pero carecen de autonomía sintáctica y funcionan como morfemas ligados. En la tabla siguiente se ilustran algunos de estos morfemas derivativos que se corresponden en la función gramatical y el valor semántico con sus equivalentes del español:

\begin{tabular}{|c|c|c|}
\hline $\begin{array}{c}\text { Morfema } \\
\text { derivativo }\end{array}$ & $\begin{array}{c}\text { Equivalente } \\
\text { en el español }\end{array}$ & Ejemplos \\
\hline huà 化 & -ificar, -izar & yáng huà 洋化 'occidente' '-izar' $\rightarrow$ occidentalizar \\
\hline yuán 員 & -dor & jing bàn yuán 經辦員 'pasar' 'hacer' '-dor' $\rightarrow$ gestor \\
\hline diàn 店 & -ería & huā diàn 花店 'flor' '-ería' $\rightarrow$ floristería \\
\hline dān 單 & mono- & dān sè 單色 'mono-' 'color' $\rightarrow$ monocolor \\
\hline hòv 後 & $\operatorname{pos}(t)-$ & hòu zhì 後製 'pos(t)-' 'producción' $\rightarrow$ posproducción \\
\hline jiān 間 & inter- & chǐ jiān 齒間 'inter-' 'diente' $\rightarrow$ interdental \\
\hline fēi 非 & in- & fēi zhèng shì 非正式 'in-' 'formal' $\rightarrow$ informal \\
\hline qián 前 & ex & qián fū 前夫 'ex' 'marido' $\rightarrow$ ex marido \\
\hline
\end{tabular}

Tabla 3: Formaciones derivadas con afijoides 
Morfología contrastiva del chino mandarín y el español. Formas de gramaticalización y lexicalización

Sin embargo, aunque cada morfema derivativo del mandarín encuentra su equivalencia en español, la correspondencia no es bilateral, pues en muchos casos, se observan correlaciones sintáctico-semánticas entre un mismo afijo o afijoide chino y varios equivalentes del español. Las tablas siguientes recogen ejemplos que manifiestan estas correspondencias:

\begin{tabular}{|c|l|c|c|c|c|}
\hline \multicolumn{3}{|c|}{ Chino mandarín } & \multicolumn{3}{c|}{ Español } \\
\hline Morf. & \multicolumn{1}{|c|}{ Ejemplos } & Estructura & Morf. & Ejemplos & Estructura \\
\hline $\begin{array}{c}\text { fēi } \\
\text { 非- }\end{array}$ & $\begin{array}{l}\text { fēi zhèng shì 非正式 'in-' } \\
\text { 'formal' }\end{array}$ & pref. + adj. & in- & informal & pref. + adj. \\
\cline { 2 - 6 } & $\begin{array}{l}\text { fēi zhí xiàn de 非直線 'des-' } \\
\text { 'línea' }\end{array}$ & pref. + adj. & des- & desalineado & pref. + adj. \\
\cline { 2 - 6 } & $\begin{array}{l}\text { fēi jīn shǔ 非金屬 'no } \\
\text { 'metálico' }\end{array}$ & pref. + adj. & no & no metálico & pref. + adj. \\
\cline { 2 - 6 } \\
$\begin{array}{l}\text { fēi rén dào de 非人道 } \\
\text { 'anti- 'humano' }\end{array}$ & pref. + adj. & anti- & antihumano & pref. + adj. \\
\hline
\end{tabular}

Tabla 4: Formaciones con fēi 非-y sus equivalentes del español

\begin{tabular}{|c|c|c|c|c|c|}
\hline \multicolumn{3}{|c|}{ Chino mandarin } & \multicolumn{3}{c|}{ Español } \\
\hline Morf. & Ejemplos & Estructura & Morf. & Ejemplos & Estructura \\
\hline $\begin{array}{c}\text { 反ăn } \\
\text { 反ăn găn 反感 're-' } \\
\text { 'sentir' }\end{array}$ & pref. + v. & re- & resentir & pref. + v. \\
\cline { 2 - 6 } & $\begin{array}{c}\text { făn shè huì 反社會 } \\
\text { 'anti-' 'social' }\end{array}$ & pref. + adj. & anti- & antisocial & pref. + adj. \\
\cline { 2 - 6 } & $\begin{array}{c}\text { făn cháng 反常 'a-' } \\
\text { 'normal' }\end{array}$ & pref. + adj. & a- & anormal & pref. + adj. \\
\cline { 2 - 6 } & $\begin{array}{c}\text { făn fāng 反方 } \\
\text { 'contra-' 'posición' }\end{array}$ & pref. + n. & contra- & contraposición & pref. + n. \\
\hline
\end{tabular}

Tabla 5: Formaciones con făn 反-y sus equivalentes del español

\begin{tabular}{|c|c|c|c|c|c|}
\hline \multicolumn{3}{|c|}{ Chino mandarín } & \multicolumn{3}{c|}{ Español } \\
\hline Morf. & Ejemplos & Estructura & Morf. & Ejemplos & Estructura \\
\hline $\begin{array}{c}\text { Chāo } \\
\text { 超- }\end{array}$ & $\begin{array}{c}\text { chāo shì 超市 'super-' } \\
\text { 'mercado' }\end{array}$ & pref. + n. & super- & supermercado & pref. + n. \\
\cline { 2 - 6 } & $\begin{array}{c}\text { chāoxiàn dài 超現代 } \\
\text { 'ultra-' 'moderno' }\end{array}$ & pref. + adj. & ultra- & ultramoderno & pref. + adj. \\
\hline
\end{tabular}




\begin{tabular}{|c|c|c|c|c|c|}
\hline $\begin{array}{c}\text { Chāo } \\
\text { 超- }\end{array}$ & $\begin{array}{c}\text { chāo píng miàn 超平 } \\
\text { 面 'extra-' 'plano' }\end{array}$ & pref. + adj. & extra- & extraplano & pref. + adj. \\
\cline { 2 - 6 } & $\begin{array}{c}\text { chāo yīn sù de 超音速 } \\
\text { 'hiper-' 'sonido' } \\
\text { 'velocidad' }\end{array}$ & pref. + adj. & hiper- & hipersónico & pref. + adj. \\
\hline
\end{tabular}

Tabla 6: Formaciones con chāo 超- y sus equivalentes del español

\begin{tabular}{|c|c|c|c|c|c|}
\hline \multicolumn{3}{|c|}{ Chino mandarín } & \multicolumn{3}{|c|}{ Español } \\
\hline Morf. & Ejemplos & Estructura & Morf. & Ejemplos & Estructura \\
\hline \multirow[t]{5}{*}{$\begin{array}{c}\text { shŏU } \\
\text { 手- }\end{array}$} & $\begin{array}{c}\text { gē shǒu 歌手 'canción' } \\
\text { '-ante' }\end{array}$ & n. + suf. & -ante & cantante & n. + suf. \\
\hline & shǔi shǒU 水手 'agua' '-ero' & n. + suf. & -ero & marinero & n. + suf. \\
\hline & duò shǒu 舵手 'timón' '-el' & n. + suf. & $-\mathrm{el}$ & timonel & n. + suf. \\
\hline & díshǒu 敵手 'rival' '-dor' & n. + suf. & -dor & competidor & n. + suf. \\
\hline & qín shǒu 琴手 'piano' '-ista' & n. + suf. & -ista & pianista & n. + suf. \\
\hline
\end{tabular}

Tabla 7: Formaciones con shǒu f- y sus equivalentes del español

A partir de estos ejemplos puede observarse que a un mismo morfema del mandarín le corresponden varios morfemas diferentes del español. Sin embargo, la equivalencia entre ambas lenguas resulta más ajustada si se toman en consideración los rasgos semánticos que permiten identificar los principales subsistemas gramaticalizados en cada idioma, aunque en chino tales rasgos confluyan en un mismo afijo o afijoide, mientras que en español esta polisemia (vid. §2.5) tiende a reducirse considerablemente. Así, las dos lenguas en contraste disponen de afijos para la expresión de los significados privativos, de contrariedad o contraposición (tablas 4 y 5), para la designación de las nociones elativas o de superioridad (tabla 6) y para la formación de nombres agentivos (tabla 7).

En cuanto a la combinación de morfemas, los esquemas productivos en chino mandarín y en español se representan en la siguiente tabla: 
Morfología contrastiva del chino mandarín y el español. Formas de gramaticalización y lexicalización

\begin{tabular}{|c|c|c|}
\hline Combinación & Chino mandarín & Español \\
\hline \multirow{4}{*}{$\begin{array}{c}\text { Morfema } \\
\text { léxico } \\
+ \\
\text { Morfema } \\
\text { léxico }\end{array}$} & y̌̌ yán 語言 'lengua' 'habla' $\rightarrow$ idioma & \multirow{4}{*}{$\begin{array}{c}\text { coliflor } \\
\text { pelirrubio } \\
\text { altavoz } \\
\text { petróleo }\end{array}$} \\
\hline & nián qiing 年輕 'edad' 'ligero' $\rightarrow$ joven & \\
\hline & $\begin{array}{c}\text { tígāo 提高 'levantar, elevar' 'alto' } \rightarrow \text { levantar, } \\
\text { elevar }\end{array}$ & \\
\hline & shí yóu 石油 'piedra' 'aceite' $\rightarrow$ petróleo & \\
\hline \multirow{4}{*}{$\begin{array}{c}\text { Morfema } \\
\text { léxico } \\
+ \\
\text { Morfema } \\
\text { derivativo }\end{array}$} & xué zhě 學者 'estudiar' 'suf. -tor' $\rightarrow$ letrado, erudito & \multirow{4}{*}{$\begin{array}{c}\text { arrozal } \\
\text { enfermera } \\
\text { contable } \\
\text { quebradizo }\end{array}$} \\
\hline & $\begin{array}{c}\text { yáng huà 洋化 ‘occidental' ‘suf. -izar' } \rightarrow \\
\text { occidentalizar }\end{array}$ & \\
\hline & lì tóu 裡頭 'dentro' 'suf.' $\rightarrow$ dentro & \\
\hline & hái zi 孩子 'niño' 'suf.' $\rightarrow$ niño & \\
\hline \multirow{4}{*}{$\begin{array}{c}\text { Morfema } \\
\text { derivativo } \\
+ \\
\text { Morfema } \\
\text { léxico } \\
\end{array}$} & fēi jin shř 非金屬 'no, anti-' 'metálico' $\rightarrow$ metaloide & \multirow{4}{*}{$\begin{array}{l}\text { analfabeto } \\
\text { irreal } \\
\text { desigual } \\
\text { contrapaso }\end{array}$} \\
\hline & dì ȳi 第一 'pref. número ordinal' 'uno' $\rightarrow$ primero & \\
\hline & à yí 阿姨 'pref.' 'tía' $\rightarrow$ tía & \\
\hline & $\begin{array}{c}\text { kě xí 可惜 'pref.' 'Iamentable' } \rightarrow \text { lamentable, por } \\
\text { desgracia }\end{array}$ & \\
\hline \multirow{2}{*}{$\begin{array}{l}\text { Morfema } \\
\text { léxico } \\
\text { reduplicado }\end{array}$} & qiāo qiāo 悄悄 silenciosamente, secretamente & \multirow{2}{*}{$\begin{array}{l}\text { picapica } \\
\text { bullebulle }\end{array}$} \\
\hline & $\begin{array}{c}\text { Căo căo 草草 descudadosamente, } \\
\text { chapuceramente }\end{array}$ & \\
\hline
\end{tabular}

Tabla 8: Combinaciones morfémicas en chino mandarín y español

Entre las palabras complejas, la combinación de dos morfemas léxicos recibe el nombre de palabra compuesta. En cambio, la combinación de un morfema léxico con un morfema derivativo se considera una palabra derivada. Muchas veces el proceso derivativo y el proceso compositivo se mezclan y entrecruzan:

Ejemplos del español:

1) Sufijación de base prefijada: [in-mortal] -idad > inmotalidad

2) Prefijación de base sufijada: des- [esper-anza] > desesperanza

3) Compuesto con sufijación interna: vana + glori-oso > vanaglorioso

4) Compuesto con prefijación interna: re-corta + setos $>$ recortasetos

5) Sufijación externa del compuesto: [sordo + mudo]-ez > sordomudez

6) Prefijación externa del compuesto:

contra- (electro + motriz) > contraelectromotriz

Ejemplos del chino mandarín:

1) Compuesto con sufijación interna: zhăo 找 'buscar'+ [chá ér 碴兒 'problemas' 'sufijo'] > zhăo chá ér 找碴兒 buscapleitos

2) Sufijación externa del compuesto: [ài 愛 'amar' + guó 國 'país'] -zhǔ yì 主義 'suf. -ismo' > ài guó zhǔ yì 愛國主義 patriotismo 
3) Prefijación externa del compuesto: quàn 全 'todo' + [zì dòng 自動 'automático'] > quàn zì dòng 全自動 totalmente automático

4) Doble composición: [gōng 公 'público' + gòng 共 'junto' $\rightarrow$ público] + [ qì 汽 'vapor' + chē 車 'vehículo' $\rightarrow$ coche] > gōng gòng qì chē 公共汽車 autobús

La comparación de estos procesos permite comprobar el alcance de los mecanismos morfológicos en cada lengua. Así, el español presenta más variedad de esquemas derivativos $y$, en cambio, menos recursos que el chino mandarín para las composiciones complejas. En efecto, las derivaciones complejas del español, ilustradas en 1) y 2), no se dan en chino mandarín, al ser una lengua tradicionalmente pobre en recursos derivativos. Por el contrario, la composición con derivación interna y externa resulta poco frecuente en español, mientras que está bien representada en el vocabulario chino, que cuenta además con palabras de doble composición, como en 4), proceso que creemos improductivo en la morfología española.

Por otro lado, los morfemas funcionales son los morfemas flexivos. El término "flexión" en español hace referencia a los cambios en las terminaciones determinados por las relaciones sintagmáticas sin alterar la categoría gramatical de la palabra. Así, los adjetivos admiten morfemas de género, número y grado (-o, -s, -ísim-, etc.); los sustantivos también disponen de morfemas de número y de género. La vocal temática se considera parte de la flexión del verbo (am-ar, dec-ir, cog-er, etc.). En cambio, el chino mandarín no está sometido a restricciones gramaticales, como la concordancia, y carece de morfemas "flexivos". En mandarín para referirse a estos morfemas, se suele preferir la denominación de "morfema funcional", pues expresan las funciones gramaticales de otros morfemas.

En español la flexión se expresa por medio de desinencias o sufijos que no producen cambios de categoría gramatical. La presencia de diversos morfemas flexivos depende de las relaciones sintácticas que contraen las palabras en la oración. En mandarín, los morfemas funcionales pueden ser elementos interpuestos que proporcionan al verbo variaciones aspectuales. Por ejemplo, los siguientes morfemas se encuentran en una posición intercalada: 
Morfología contrastiva del chino mandarín y el español. Formas de gramaticalización y lexicalización

kàn yī kàn 看一看 'ver' 'interf.' 'ver' $\rightarrow$ ver un poco, ver de una vez, intentar a ver algo

chī bù wán 吃不完 'comer' 'interf. modal negativo (no poder)' 'terminar (asp. resultativo)' $\rightarrow$ no poder terminar de comer

kàn dé dào 看得到 'ver' 'interf. modal (poder)' 'alcanzar (asp. resultativo)' $\rightarrow$ poder llegar a ver.

En español la relación entre los morfemas léxicos, derivativos y funcionales está muy clara: el morfema léxico (raíz) se adjunta al morfema derivativo para formar la palabra: am-or, am-or-oso y el morfema funcional cierra la palabra para expresar el cambio flexivo: am-or-es, am-aban. Sin embargo, las clases de morfemas que se reconocen en chino mandarín, por ser una lengua aislante, por su naturaleza funcional o léxica no se distribuyen tan estrictamente dentro de la palabra con arreglo a este orden morfológico. Es decir, la relación entre tales morfemas no es tan precisa como la de español, de manera que hay casos en los que los morfemas funcionales se interponen, como los interfijos ȳ̄ 一, bù 不 y dé 得 mencionados arriba.

En comparación con el español, el número de los morfemas funcionales del mandarín es menor que el de los morfemas flexivos del español, pues el mandarín no dispone de las desinencias de género en el nombre, ni de las de persona verbal. Además, los cambios gramaticales se expresan mediante la adición de morfemas funcionales que pueden situarse en distintas posiciones. Seguidamente se ilustran algunos ejemplos de estos morfemas funcionales:

1) Partícula de pluralidad: wǒ 我 yo $\rightarrow$ wǒ men 我們 nosotros

2) Aspecto experiencial: lăi 來 venir $\rightarrow$ lăi guò 來過 haber venido

3) Aspecto continuativo: kàn 看 ver $\rightarrow$ kàn xià qù 看下去 seguir leyendo

4) Marcador de compl. circunstancial: fēng kuāng 瘋狂 loco $\rightarrow$ fēng kuāng di 瘋 狂地 locamente

5) Marcador posesivo: xué shēng 學生 alumno y shū 書 libro $\rightarrow$ xué shēng de shū 學生的書 $\rightarrow$ los libros de los alumnos

6) Marcador de interrogación: kě yǐ 可以 poder $\rightarrow$ kě yǐ mã 可以嗎 ¿̇se puede?

7) Marcador de petición o presuposición: bù xíng 不行 no se puede $\rightarrow$ bù xíng ba 不行吧 ; l lo mejor no se puede! 


\subsection{Formantes polisémicos}

En ambas lenguas, los morfemas polisémicos aportan significados diferentes dependiendo de la base a la que se adjuntan. Tanto en chino mandarín como en español, se observa que ni los morfemas monosémicos ni los polisémicas se corresponden entre sí. Un morfema polisémico del mandarín da lugar a un grupo de unidades morfológicas en español cuyo sentido no está relacionado con el del mandarín. Paralelamente, un morfema polisémico del español produce equivalentes en mandarín que no coinciden en la formación morfológica. Vemos algunos ejemplos:

Ejemplos de español:

peri-: 'alrededor de' en periferia, 'envolver, cubrir' en pericardio

orto-: 'recto' en ortogonal, 'correcto' en ortografía, 'corregir' en ortopedia

Ejemplos de chino:

qién 前: qién fū 前夫 'anterior' 'marido' $\rightarrow$ ex marido

qién fāng 前方 'enfrente' 'dirección' $\rightarrow$ adelante

qién jin 前進 'avanzar' 'marchar' $\rightarrow$ avanzar, ir adelante

wuài 外: wuài tào 外套 'fuera' 'funda' $\rightarrow$ abrigo, chaqueta

wuài jiāo 外交 'exterior' 'relación' $\rightarrow$ diplomático

wuài maò 外貿 'extranjero' 'comercio' $\rightarrow$ comercio internacional

Los morfemas derivativos también pueden presentar un mismo significado o ser elementos polisémicos. En las tablas siguientes se recogen ejemplos de morfemas derivativos unívocos que tiene solo un significado en ambas lenguas:

\begin{tabular}{|c|c|c|c|c|}
\hline & bi- & ante- & omni- & -avo, a \\
\hline Sign. & dos & anterioridad & todo & $\begin{array}{c}\text { numeral } \\
\text { partitivo }\end{array}$ \\
\hline Ejs. & $\begin{array}{c}\text { bilabial } \\
\text { bilingüe } \\
\text { bimensual }\end{array}$ & $\begin{array}{c}\text { anteayer } \\
\text { antebrazo } \\
\text { anteponer }\end{array}$ & $\begin{array}{c}\text { omnímodo } \\
\text { omnipresente } \\
\text { omnisciente }\end{array}$ & $\begin{array}{c}\text { seisavo } \\
\text { doceavo } \\
\text { centavo }\end{array}$ \\
\hline
\end{tabular}

Tabla 9: Morfemas derivativos unívocos del español 


\begin{tabular}{|c|c|c|c|}
\hline \multicolumn{2}{|c|}{$\begin{array}{l}\text { Morfema } \\
\text { derivativo }\end{array}$} & Sign. & Ejemplos \\
\hline \multirow[t]{2}{*}{ prefijo } & di 第 & $\begin{array}{l}\text { numeral } \\
\text { ordinal }\end{array}$ & $\begin{array}{l}\text { dì yī 第一 'num. ord.' 'uno' } \rightarrow \text { primero } \\
\text { dì èr 第二 'num. ord.' 'dos' } \rightarrow \text { segundo } \\
\text { dì wŭ 第五 'num. ord.' 'cinco' } \rightarrow \text { quinto }\end{array}$ \\
\hline & $\begin{array}{c}\text { zhŭn } \\
\text { 准 }\end{array}$ & 'casi' & $\begin{array}{c}\text { zhǔn píng yuán 准平原 'casi' 'Ilanura' } \rightarrow \text { penillanura } \\
\text { zhǔn } \underline{\text { IIn shǔ }} \text { 准金屬 'casi' 'metal' } \rightarrow \text { semimetal } \\
\text { zhǔn jūn duì 准軍隊 'casi' 'militar' } \rightarrow \text { paramilitar }\end{array}$ \\
\hline \multirow[t]{2}{*}{ sufijo } & $\begin{array}{c}\text { zhě } \\
\text { 者 }\end{array}$ & agente & $\begin{array}{c}\text { jì zhě 記者 'apuntar' 'suf.' } \rightarrow \text { periodista } \\
\text { zoù zhě 作者 'escribir, hacer' 'suf.' } \rightarrow \text { escritor } \\
\text { dú zhě 讀者 'leer' 'suf.' } \rightarrow \text { lector }\end{array}$ \\
\hline & $\begin{array}{c}\text { rán } \\
\text { 然 }\end{array}$ & '-mente' & $\begin{array}{c}\text { hū rán 忽然 'repentino' '-mente } \rightarrow \text { repentinamente } \\
\text { xiăn rán 顯然 'obvio' '-mente' } \rightarrow \text { obviamente } \\
\text { gōng rán 公然 'público' '-mente' } \rightarrow \text { públicamente }\end{array}$ \\
\hline
\end{tabular}

Tabla 10: Morfemas derivativos unívocos del chino mandarín

El chino mandarín cuenta con menos morfemas derivativos que el español, pero en las dos lenguas se comprueba claramente el fenómeno de la polisemia de los afijos y afijoides. Véanse algunos ejemplos de los morfemas derivativos polisémicos en ambas lenguas:

\begin{tabular}{|c|c|c|}
\hline Afijo & Significado & Ejemplos \\
\hline \multirow{4}{*}{ re- } & intensificación & recargar, rebuscar, renegar \\
\cline { 2 - 3 } & repetición & reconstruir, repasar, reelegir \\
\cline { 2 - 3 } & negación & reprobar \\
\cline { 2 - 3 } & oposición, resistencia & repugnar \\
\hline \multirow{3}{*}{ pro- } & por, en vez de & pronombre, procónsul \\
\cline { 2 - 3 } & ante, delante & prólogo, progenitura \\
\cline { 2 - 3 } & publicación & proclamar, proferir \\
\cline { 2 - 3 } & negación, contradicción & prohibir, proscribir \\
\hline \multirow{2}{*}{-al } & relación, pertenencia & ferrovial, cultural \\
\cline { 2 - 3 } & lugar & arrozal, pedregal \\
\hline -ismo & movimiento & socialismo, platonismo \\
\cline { 2 - 3 } & actitud & egoísmo, puritanismo \\
\cline { 2 - 3 } & actividad & atletismo, alpinismo \\
\cline { 2 - 3 } & término científico & leísmo, astigmatismo \\
\hline
\end{tabular}

Tabla 11: Morfemas derivativos polisémicas del español 


\begin{tabular}{|c|c|c|c|}
\hline \multicolumn{2}{|c|}{$\begin{array}{l}\text { Morfema } \\
\text { derivativo }\end{array}$} & Significado & Ejemplos \\
\hline \multirow[t]{6}{*}{ pref. } & \multirow[t]{3}{*}{$\begin{array}{l}\text { lăo } \\
\text { 老 }\end{array}$} & familiaridad & $\begin{array}{l}\text { lǎo zhāng 老張 'pref.' 'apellido' } \rightarrow \text { zhāng } \\
\text { lăo gōng 老公 'pref.' 'marido' } \rightarrow \text { marido }\end{array}$ \\
\hline & & $\begin{array}{l}\text { orden de edad de } \\
\text { miembros de familia }\end{array}$ & $\begin{array}{c}\text { lăo dà 老大 'pref.' 'mayor' } \rightarrow \text { el primer hijo } \\
\text { lăo èr 老二 'pref.' 'dos' } \rightarrow \text { el segundo hijo } \\
\text { (mayor) }\end{array}$ \\
\hline & & zoónimos & $\begin{array}{l}\text { lǎo ȟ̌ 老虎 'pref.' 'tigre' } \rightarrow \text { tigre } \\
\text { lăo shǔ 老鼠 'pref.' 'ratón' } \rightarrow \text { ratón }\end{array}$ \\
\hline & \multirow[t]{3}{*}{$\begin{array}{l}\text { kě } \\
\text { 可 }\end{array}$} & causativo & $\begin{array}{l}\text { kě pà 可怕 'pref.' 'temer' } \rightarrow \text { horrible } \\
\text { kě bēi 可悲 'pref.' 'triste' } \rightarrow \text { patético }\end{array}$ \\
\hline & & poder & $\begin{array}{l}\text { kě xíng 可行 'pref.' 'practicar' } \rightarrow \text { practicable } \\
\text { kě kaò 可靠 'pref.' 'depender' } \rightarrow \text { responsable }\end{array}$ \\
\hline & & cualidad positiva & $\begin{array}{c}\text { kě rén 可人 'pref.' 'persona' } \rightarrow \text { majo, guapo } \\
\text { kě kŏU 可 } \square \text { 'pref.' 'boca' } \rightarrow \text { delicioso }\end{array}$ \\
\hline \multirow[t]{9}{*}{ suf. } & \multirow[t]{4}{*}{$\begin{array}{l}\text { tóu } \\
\text { 頭 }\end{array}$} & $\begin{array}{l}\text { suf. nominal (para la } \\
\text { bisilabidad) }\end{array}$ & $\begin{array}{c}\text { shí tóu 石頭 'piedra' 'suf.' } \rightarrow \text { piedra, } \\
\text { gǔ tóu 骨頭 'hueso' 'suf.' } \rightarrow \text { hueso }\end{array}$ \\
\hline & & $\begin{array}{l}\text { suf. verbal (para la } \\
\text { bisilabidad) }\end{array}$ & $\begin{array}{c}\text { kàn tóu 看頭 'ver' 'suf.' } \rightarrow \text { interés } \\
\text { zhuàn tóu 賺頭 'ganar' 'suf.' } \rightarrow \\
\text { rentabilidad }\end{array}$ \\
\hline & & $\begin{array}{l}\text { suf. adverbial (para la } \\
\text { bisilabidad) }\end{array}$ & $\begin{array}{l}\text { hòu tóu 後頭 'detrás' 'suf.' } \rightarrow \text { detrás } \\
\text { lì tóu 裡頭 'dentro' 'suf.' } \rightarrow \text { dentro }\end{array}$ \\
\hline & & $\begin{array}{l}\text { nombre abstracto de } \\
\text { cualidad }\end{array}$ & $\begin{array}{l}\text { tián tóu 甜頭 'dulce' 'suf.' } \rightarrow \text { dulzura } \\
\text { kǔ tóu 苦頭 'amargo' 'suf.' } \rightarrow \text { amargura }\end{array}$ \\
\hline & \multirow[t]{5}{*}{$\begin{array}{l}\text { zi } \\
\text { 子 }\end{array}$} & $\begin{array}{l}\text { suf. nominal (para la } \\
\text { bisilabidad) }\end{array}$ & $\begin{array}{l}\text { zhuō zi 桌子 'mesa' 'suf.' } \rightarrow \text { mesa } \\
\text { kuài zi 筷子 'palillo' 'suf.' } \rightarrow \text { palillo }\end{array}$ \\
\hline & & $\begin{array}{l}\text { suf. adjetival (para la } \\
\text { bisilabidad) }\end{array}$ & $\begin{array}{c}\text { pàng zi 胖子 'gordo' 'suf.' } \rightarrow \text { gordo } \\
\text { xiā zi 瞎子 'ciego' 'suf.' } \rightarrow \text { ciego }\end{array}$ \\
\hline & & adjetivo deverbal & $\begin{array}{l}\text { piàn zi 騙子 'mentir' 'suf.' } \rightarrow \text { mentiroso } \\
\text { xué zi 學子 'estudiar' 'suf.' } \rightarrow \text { estudiante }\end{array}$ \\
\hline & & instrumento & $\begin{array}{l}\text { shū zi 梳子 'peinar' 'suf.' } \rightarrow \text { peine } \\
\text { zuàn zi 鑽子 'destornillar' 'suf.' } \rightarrow \text { destornillador }\end{array}$ \\
\hline & & suf. clasificador & $\begin{array}{c}\text { ȳ̄ bèi zi 一輩子 'uno' 'vida' 'suf.' } \rightarrow \text { toda la vida } \\
\text { yī zhèn zi 一陣子 'uno' 'temporada' 'suf.' } \rightarrow \\
\text { una temporada }\end{array}$ \\
\hline
\end{tabular}

Tabla 12: Morfemas derivativos polisémicos del chino mandarín

Entre los morfemas funcionales también se distingue el tipo monosémico del tipo polisémico. En chino mandarín, algunos morfemas funcionales son especialmente complejos por su variedad gramatical. Es el caso del formante de 的, que funciona como marcador posesivo, partícula de 
Morfología contrastiva del chino mandarín y el español. Formas de gramaticalización y lexicalización

relativo, marcador del aspecto perfectivo y de la atribución.

En español los morfemas funcionales también pueden dividirse en el tipo monosémico y el tipo polisémico. Sin embargo, en comparación con los del chino mandarín, los del español se caracterizan por un elevado sincretismo, pues una sola terminación del verbo, por ejemplo, desempeña varias funciones gramaticales, como las variaciones de modo, tiempo, persona, etc. Véanse ejemplos de ambas lenguas en las siguientes tablas:

\begin{tabular}{|c|c|c|}
\hline $\begin{array}{l}\text { Morfema } \\
\text { funcional }\end{array}$ & Función & Ejemplos \\
\hline men 們 & pluralidad & $\begin{array}{l}\text { Wǒmen 我們 'yo' 'plur.' } \rightarrow \text { nosotros } \\
\text { nǐmen 你們 'tú' 'plur.' } \rightarrow \text { vosotros }\end{array}$ \\
\hline di 地 & $\begin{array}{l}\text { formación } \\
\text { adverbial }\end{array}$ & $\begin{array}{l}\text { fēng kuāng di 瘋狂地 'loco' '-mente' } \rightarrow \text { locamente } \\
\text { kāi xīn di 開心地 'feliz' '-mente' } \rightarrow \text { felizmente }\end{array}$ \\
\hline \multirow[t]{5}{*}{ de 的 } & posesivo & $\begin{array}{l}\text { Wǒ de 我 的 'yo' 'pos.' } \rightarrow \text { mi } \\
\text { fáng zi de 房子的 'casa' 'suf.' 'pos.' } \rightarrow \text { de la casa }\end{array}$ \\
\hline & relativo & $\begin{array}{lccccccc}\text { 戴 } & \text { 眼 } & \text { 鏡 } & \text { 的 } & \text { 人 } & \text { 是 } & \text { 我 } & \text { 媽 } \\
\text { dài } & \text { yăn } & \text { jing } & \text { de } & \text { rén } & \text { shì } & \text { wǒ ma } \\
\text { llevar } & \text { ojo cristal } & \text { rel. persona } & \text { ser } & \text { yo } & \text { madre } \\
\text { La que lleva gafas es mi madre. } & & & \end{array}$ \\
\hline & & 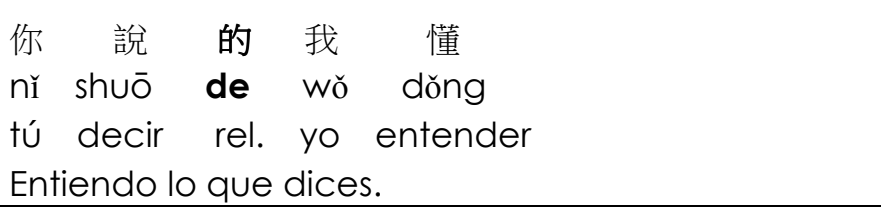 \\
\hline & $\begin{array}{l}\text { aspecto } \\
\text { perfectivo }\end{array}$ & $\begin{array}{lccl}\text { 我 } & \text { 昨 天 } & \text { 到 } & \text { 的 } \\
\text { Wó } & \text { zoú tiān } & \text { daò } & \text { de } \\
\text { yo } & \text { ayer } & \text { llegar } & \text { asp. perf. } \\
\text { Llegué ayer. } & & \end{array}$ \\
\hline & & 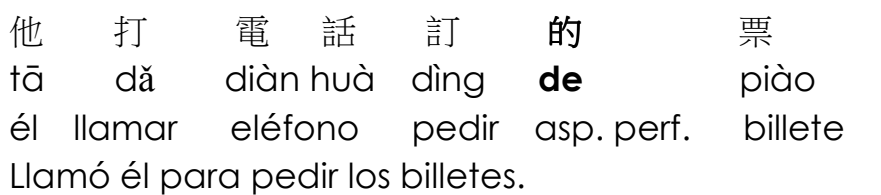 \\
\hline
\end{tabular}




\begin{tabular}{|l|l|l|}
\hline de 的 & Atribución & $\begin{array}{l}\text { měi lì de nǔ hái 美麗的女孩 'guapa' 'atr.' 'chica' } \rightarrow \\
\text { chica guapa } \\
\text { lán lán de tiān 藍藍的天 'azul' 'azul' 'atr.' 'cielo' } \rightarrow \\
\text { cielo muy azul }\end{array}$ \\
\hline guò 過 & asp. pfvo. & $\begin{array}{l}\text { jing guò 經過 'pasar' 'asp. pfvo.' } \rightarrow \text { pasé } \\
\text { cuò guò 錯過 'perder' 'asp. pfvo.' } \rightarrow \text { perdí }\end{array}$ \\
\cline { 2 - 3 } & $\begin{array}{l}\text { asp. } \\
\text { experiencial }\end{array}$ & $\begin{array}{l}\text { chì guò 吃過 'comer' 'asp. experiencial' } \rightarrow \text { haber } \\
\text { comido } \\
\text { lăi guò 來過 'venir' 'asp. experiencial' } \rightarrow \text { haber venido }\end{array}$ \\
\hline
\end{tabular}

Tabla 13: Morfemas funcionales unívocos y polisémicas del chino mandarín

\begin{tabular}{|c|c|c|}
\hline $\begin{array}{l}\text { Morfema } \\
\text { funcional }\end{array}$ & Función & Ejemplos \\
\hline$-s$ & pluralidad & sus libros, las rosas \\
\hline-5 & $2^{a}$ pers. sig. & tomas, tomabas, comes \\
\hline-0 & género masculino & bueno, chico, suyo \\
\hline-0 & $1^{a}$ pers. sing. & vivo, hago, digo \\
\hline أí & $1^{a}$ pers. sing. indefinido acabado en -er, -ir & cogí, viví \\
\hline \multirow[t]{3}{*}{$-a$} & $3^{a}$ pers. sing. presente de indicativo en -ar & canta \\
\hline & $\begin{array}{l}1^{a} \text { y } 3^{a} \text { pers. sing. presente de subjuntivo en } \\
-e r,-i r\end{array}$ & coma, viva \\
\hline & $2^{a}$ pers. sing. del imperativo en -ar & toma (tú) \\
\hline \multirow[t]{2}{*}{-éis } & $2^{a}$ pers. plur. presente de subjuntivo en -ar & escuchéis \\
\hline & $2^{a}$ pers. plur. presente de indicativo en -er & coméis \\
\hline
\end{tabular}

Tabla 14: Morfemas funcionales unívocos y polisémicas del español

\subsection{Resumen y conclusiones}

La aplicación de los cinco principios de Nida (1965) a las dos lenguas en contraste ha permitido distinguir entre el morfema y el alomorfo, como variante este último que corresponde a un mismo morfema. En definitiva, el factor fundamental de este tipo de estudios consiste en: 1) considerar como un mismo morfema a todos los elementos que comparten el mismo significado; 2) distinguir como morfema a todos los formantes que o bien puedan utilizarse aisladamente (morfemas libres o raíces) o bien resultan productivos en 
Morfología contrastiva del chino mandarín y el español. Formas de gramaticalización y lexicalización

combinaciones con formas libres o raíces.

Por otro lado, se ha explicado que la clasificación de los morfemas en llenos y vacíos no es suficiente para dar cuenta de la varidad morfológica de las dos lenguas en contraste. Además de este criterio elemental, los morfemas del chino mandarín y del español pueden ser clasificados de acuerdo con su capacidad léxica en morfemas autónomos, libres y ligados, y según la función gramatical que desarrollan en léxicos, derivativos y funcionales.

Finalmente, se ha comprobado que en las dos lenguas la relación entre el significado y el significante de los morfemas puede no ser una correspondencia unívoca, pues se constata con frecuencia el fenómeno de la polisemia, más acusado en el chino mandarín que en el español.

En cuanto a los aspectos contrastivos examinados en este capítulo, cabe recoger aquí el paralelismo entre los diferentes tipos de unidades morfológicas que se suelen reconocer para cada lengua. Así, en este sentido, hemos propuesto que algunos formantes no son tan exclusivos del chino mandarín como suele afirmarse, pues en las lenguas occidentales -y particularmente, en español-, un análisis morfológico sosegado muestra la relativa proximidad entre los procesos y las unidades de nuestras dos lenguas. Aunque se volverá sobre estas cuestiones en los capítulos siguientes, conviene adelantar ahora que un tipo de los llamados afijos convencionales del mandarín (como lăo español, dado que unos y otros desempeñan exclusivamente funciones morfonológicas y carecen de significado léxico o gramatical.

Por otra parte, el concepto de "morfema libre ligado" tampoco parece ser una característica exclusiva del chino. Del mismo modo que esta lengua oriental, también las lenguas románicas disponen de unidades morfológicas que se encuentran entre la derivación y la composición, pues se trata de formantes que fueron libres o autónomos en las lenguas originarias. Por tanto, se puede establecer cierta convergencia entre estos "morfemas libres ligados" del mandarín y los temas polimórficos cultos del español. Finalmente, 
los procesos flexivos y derivativos del mandarín también se prestan a la comparación con el español, no solo por la equivalencia de unidades en una y otra lengua, sino también porque tales recursos morfológicos no son tan extraños al mandarín como a menudo suele indicarse.

Con todo, también se han presentado brevemente en este capítulo algunas diferencias en la estructura morfológica de nuestras dos lenguas en contraste. Así, las raíces del español pueden presentar alomorfos, mientras que en chino son elementos invariables. En cuanto a la combinación de procesos derivativos y compositivos, se ha puesto de manifiesto que la doble composición y la reduplicación son procesos habituales del chino, mientras que en español resultan inexistente o sumamente raros, lo mismo que la composición con derivación interna y externa. Por el contrario, las derivaciones complejas son frecuentes en español y prácticamente inusuales en mandarín. 

COMPONENTES MORFOLÓGICOS DEL ESPAÑOL: PRINCIPALES PROCESOS DE FORMACIÓN LÉXICA

En este tercer capítulo, se examinan las definiciones de los componentes de la palabra en español. Se trata de las unidades pertinentes del análisis estructural de la palabra: raíz, afijo, tema y morfema. A continuación, se plantea una caracterización de los principales procesos morfológicos en español, como son la derivación y la composición. También se introducen las propiedades que permiten distinguir la flexión de la derivación. Finalmente, se reúnen otros tipos de formación de palabras, como la parasíntesis, el acortamiento, la acronimia y la siglación.

\subsection{Los conceptos de raíz, afijo, tema y morfema en la lingüística española}

La raíz es un constituyente de la palabra que no puede descomponerse en unidades morfológicas menores. Por ejemplo, en series de palabras como blanc-o, -a, -o-s, -a-s; blancuzc-o, -; blancot-e, -s.; blancura,-s, la raíz es el segmento básico y constante en el significante /blank-/. Se trata de un morfema léxico que aporta a la palabra el valor semántico fundamental y es la base de la que parte la primera operación morfológica ${ }^{1}$.

Al lado de este significante común, hay otros que se adjuntan para determinarlo de algún modo: blancuzc-o, -a; blancura, -s. Se trata de los

11 La unidad básica de la palabra se denomina raíz desde el punto de vista formal o del significante; recibe el nombre de lexema o semantema desde el punto de vista semántico o del significado. 
Morfología contrastiva del chino mandarín y el español. Formas de gramaticalización y lexicalización

elementos que se adjuntan directa o indirecta a la raíz y que constituyen el tema de las distintas clases de palabras: los afijos. Según que los afijos formen parte del tema o se adjunten a él, se habla de afijos derivativos y de afijos flexivos o desinencias.

Los afijos derivativos son aquellos que tienen contenido léxico y que contribuyen a derivar otras formas léxicas (blancuzc-o, blanquear). Los afijos flexivos son los que transmiten contenidos gramaticales y no contribuyen a formar nuevas palabras sino a flexionarlas (blancuzc-o, -a; blancura, -s;), es decir, a dotarlas de las desinencias de género, número, caso, persona, tiempo, aspecto y voz, propias de cada categoría gramatical. En español, los afijos flexivos se denominan morfemas de cierre porque ocupan el último lugar del proceso morfológico, tras los afijos derivativos.

El tema presenta distintos rasgos de complejidad en su estructura interna de acuerdo con el número y la naturaleza de los morfemas que lo integran. El tema puede estar constituido solo por la raíz (blanc-o) en cuyo caso tema y raíz coinciden, o puede estar constituido por raíz y afijo(s) (blanc-uzc-o ). A su vez, el significante de una palabra puede estar constituido por un único tema o por la combinación de dos o más temas.

Por otra parte, los temas cultos se corresponden con lexemas que no se realizan como palabras con la sola presencia de los afijos flexivos apropiados (*eco-s, *fil-aban). Estos formantes clásicos suelen tener su origen en el griego o el latín. Para actualizarse como palabras tienen que combinarse con otro elemento de su mismo tipo (ecó-nomo) o han de incrementarse con otra palabra (eco-sistema) o algún afijo derivativo (fób-ico, fil-ia).

Finalmente, el morfema es la unidad gramatical mínima del análisis morfológico ${ }^{12}$ que constituye la parte variable de la palabra. Así decimos que, gramaticalmente, la palabra aúna dos tipos de monemas: lexemas y

\footnotetext{
12 Véase Pena (1999: 4318). El morfema no se corresponde estrictamente con el concepto de unidad significativa mínima, puesto que no siempre atribuye un significado determinado. Por ejemplo, el segmento re- de reducir no se asocia a un significado "volver a" como el de re- en re-coger. Así, el morfema se convierte en una unidad distintiva sin un significado constante.
} 
morfemas. El morfema, con valor gramatical, aparece siempre asociado al lexema, con valor semántico. Los morfemas se suelen clasificar en formas libres y formas ligadas (o trabados): el primero puede aparecer como palabra independiente (pues, con, que), mientras que el segundo está ligado con otro(s) morfema(s) (libr-o-s, a-normal, reloj-ería).

La formación de palabras se vale de los procedimientos morfológicos de las palabras complejas. Estas palabras se forman a través de dos tipos de procesos: la derivación mediante afijos y la composición a través de la combinación de dos lexemas. La derivación puede transformar la clase gramatical de los morfemas a los que se adjuntan los afijos que producen, en todo caso, un cambio semántico respecto del primitivo; la composición se basa en combinaciones de lexemas independientes, cuya formación implica la combinación de palabras en estructuras morfológicas complejas.

Para Lang (1992: 11-12), la formación de palabras no solo incluye el mecanismo de afijación y de combinación en virtud de palabras existentes de la lengua, sino que debería referirse también a las distintas formas de combinación de las palabras y sus subunidades. Desde este punto de vista, la morfología léxica puede incluir tanto los préstamos de otras lenguas, como la formación de nuevos términos mediante la acronimia o combinación de los extremos opuestos de dos palabras, la apócope o acortamiento con la eliminación de unidades en final de palabra. Todas estas formaciones se presentarán en los siguientes apartados.

\subsection{Flexión y derivación}

El proceso morfológico que establece una distinción dicotómica con la derivación es la flexión. La flexión se semeja a la derivación por cuanto que ambos procesos consisten en la adjunción de un afijo a una base, si bien la flexión española se vale de la sufijación. Frente a la derivación, que genera 
Morfología contrastiva del chino mandarín y el español. Formas de gramaticalización y lexicalización

formas de paradigmas distintos o nuevas palabras con entrada en el diccionario (cantar > canta-ble, cant-or, cant-o), la flexión genera formas de un mismo paradigma o formas de la misma palabra (cant-o / canta-s / canta-mos / cant-áis).

Rainer (1993: 17-40) y Pena (1999: $§ 66.3$ y 68.1.3) indican que son varias las propiedades que permiten diferenciar la flexión de la derivación, las cuales son de diferentes tipos, formales, funcionales, semánticas, de frecuencia, de productovidad, etc. En primer lugar, la sufijación flexiva es el elemento de

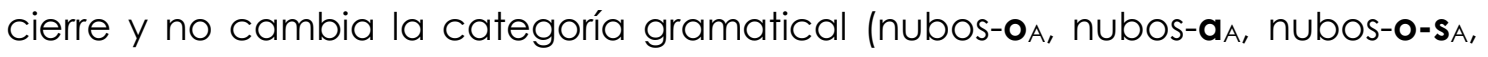
nubos-a-sA); en segundo lugar, los significados expresados en los afijos flexivos son contenidos obligatorios desde el punto de vista del componente sintáctico, imprescindibles para construir las unidades sintácticas. Por ejemplo, en El muchacho apretaba los dientes y El muchachito apretujaba los dientes, la distinción entre palabras no es relevante para la estructura sintáctica; sin embargo, en Los muchachos apretaban los dientes y los muchachitos apretujaban los dientes, todas las palabras se presentan con una determinada flexión-aquí de número y género- para formar la oración.

Por otro lado, el significado de una forma flexiva es predecible o regular, mientras que el de una palabra derivada puede adquirir significados irregulares. En otras palabras, en la derivación no hay una regularidad en la correlación entre las acepciones de la palabra base y la derivada, que sí hay en las correlaciones marcadas por la flexión del tipo "singular" / "plural", "masculino" / "femenino", "indicativo" / "subjuntivo", etc. De ahí, podemos decir que la productividad es más alta por el carácter obligatorio de las categorías o propiedades gramaticales expresadas en la forma flexiva.

Sin embargo, Rainer (1993: 41) advierte que las diferencias entre la morfología derivativa y la morfología flexiva son graduales. Siguiendo esta idea, Moreno Cabrera (2002: 420-462), Pena (1999: 4329-4331) y Ulloa (2006) explican que la flexión y la derivación son una realidad continua y gradual en la que una serie de características se pueden dar en mayor o menor grado para 
reconocerse como propiedades flexivas o derivativas.

\subsubsection{Sufijación}

En el proceso de derivación, pueden distinguirse los mecanismos afijales de los no afijales o regresivos. La afijación es el proceso morfológico mediante el cual la información gramatical o léxica se añade a un radical. Se trata, pues, de una combinación de afijos y radicales. Para Pena (1999: 4332), tres son los tipos de derivación afijal: la sufijación (cas-ero), la prefijación (re-coser) y la circunfijación (o parasíntesis: em-pobr-ecer). Varela (2005a: 32) reconoce otros dos tipos de afijos por su posición: los infijos, que se colocan dentro de la raíz o lexema (azuqu-ít-ar), y los interfijos, que se colocan entre la base léxica y el sufijo (Jose-l-ito, lod-az-al) ${ }^{13}$.

En la derivación no afijal, Varela (2005a) habla de la "formación regresiva"14, la "formación temática" y la "conversión". La formación regresiva es un fenómeno por el cual se forman nombres deverbales mediante un proceso de sustracción a la base de la derivación: como retén, sostén o desliz, derivados por eliminación de todos los morfemas flexivos del verbo respectivo (retener, sostener y deslizar) y sin la adición de sufijos nominales. Las formaciones temáticas se llaman así porque las derivaciones se forman sobre el tema verbal puro, es decir, la raíz más la vocal temática, como por ejemplo los nombres marcha del verbo marchar, carga del verbo cargar, en los que la vocal refleja la categoría y el género femenino de la formación nominal. No obstante, en español hay formaciones temáticas en las que la vocal no coincide con la del tema verbal: ligue del verbo ligar, reparto del verbo repartir; abandono del verbo abandonar. Además, puede haber varias derivaciones

\footnotetext{
13 Sobre la divergencia de opiniones para los conceptos de interfijo e infijo, véase el § 2.1.3 de nuestro trabajo.

14 Para algunos lingüistas, por ejemplo, Pena (2012: 145-156), estas derivaciones se pueden considerar como si fueran afijales, dado que, un nombre como desliz se analizaría desliz- $\varnothing$, donde - $\varnothing$ representa un sufijo nominal sin expresión fonológica o "morfo cero".
} 
Morfología contrastiva del chino mandarín y el español. Formas de gramaticalización y lexicalización

distintas de una misma base verbal, como cost-a, cost-e, cost-o del verbo costar $^{15}$. Por último, la conversión es una derivación léxica sin afijo derivativo aparente, como en sal > sal-ar o azúcar > azucar-ar, donde las bases nominales reciben solo los morfemas propios de la nueva categoría, la vocal del tema (-a-) y la desinencia verbal (-r del infinitivo).

La sufijación es el procedimiento derivativo más importante en español. Consiste en la posposición de un formante a un elemento léxico ya existente. El español dispone de un número considerable de sufijos con significados muy variados y acepta que todas las clases de palabras principales entren en este tipo de derivación con o sin cambio de la clase semántica y gramatical del

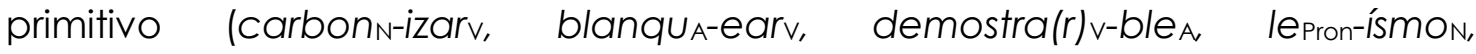

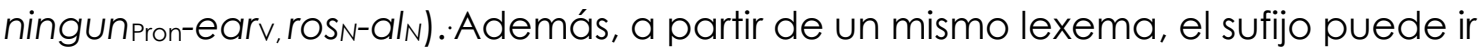
construyendo nuevas palabras mediante la aplicación sucesiva en un proceso morfológico recursivo: nación > nación-al > nación-alizar > nacion-alización.

Muchos sufijos presentan la particularidad de seleccionar la base léxica en virtud de varios factores como son: 1) la categoría gramatical, 2) los llamados "rasgos subcategoriales" y 3) el orden semántico. Así por ejemplo, -ble es un sufijo adjetivo que selecciona bases verbales (destaca-ble) y -ción, un sufijo nominal que escoge también bases verbales (demostra-ción); por su parte, el sufijo verbal -izar se agrega a nombres (capital-izar) y a adjetivos (agil-izar). En segundo lugar, según los "rasgos subcategoriales", la distribución de un sufijo puede referirse a subclases gramaticales: el mismo sufijo adjetival -ble se agrega, preferentemente, a verbos transitivos y de acción con sujeto agente, como conta-ble, venci-ble, ama-ble. De ahí que resulten agramaticales formaciones como *trabaja-ble, *ven-ible, *tene-ble. El orden semántico determina el rasgo del tipo semántico de la base o del sufijo: el sufijo -idad, cuando forma nombres de cualidad a partir de adjetivos, solo selecciona los que son calificativos (cordial > cordialidad, peligroso >

15 Por ello, consideramos que estas son formaciones afijales, a las que llamamos "posverbales", porque en ellas el sufijo $(-a,-e,-o)$ se añade directamente a la raíz verbal. 
peligrosidad), pero no los que son adjetivos de relación (aéreo > *aeridad, comarcal > *comarcalidad). Así también, solo se interpreta la familiaridad en el sentido calificativo de 'confianza en el trato', y no en la interpretación relacional con el sentido de 'ser perteneciente a la familia' (La familiaridad con mi profesora / (?) La familiaridad con mi madre).

Según Almela (1999: § 4.1), la sufijación se somete a determinadas reglas que pueden dar cuenta de los procesos más predecibles. Por ejemplo, la tendencia del adjetivo acabado en -ivo a nominalizarse en-dad, en vez de hacerlo en -ez (selectivo > selectividad, selectivo $>$ *selectivez). Otro caso de regularidad lo constituyen los verbos que acaban en -ecer, que prefieren el sufijo -miento al sufijo -ción para formar sustantivos (establecer > establecimiento, pero no establecer > *estableción).

Faitelson-Weiser (1993) propone una gradación de regularidad en virtud de la amplitud de las reglas. La autora distingue los siguientes casos:

1) Derivaciones morfológicamente regulares: la pérdida del componente postónico o pérdida del acento (montaña > montañoso, cutis > cutáneo).

2) Menos regulares: alteración del componente postónico y pérdida del acento de intensidad (tierra > terráqueo, hierba $>$ herbáceo).

3) Casi-regulares: diptongación, monoptongación, asimilación, disimilación fonética, epéntesis, supresión, etc. (cantidad > cuantitativo, decidir > decisorio).

4) Irregulares 16: alternancias peculiares como supletismo, formaciones híbridas con mezcla de integrantes cultos y patrimoniales, etc. (agua > acuático, cabello > capilar).

Sin embargo, Lang (1992: 130-131) indica que las reglas más extendidas no pueden explicar muchas irregularidades e inconsistencias que se dan en la

${ }^{16}$ Monge Casao (2012: 139) añade que las irregularidades se extienden al vocabulario en su conjunto. La invasión de cultismos provoca la covivencia de palabras cultas y populares en la misma familia de palabras, con o sin diferenciación semántica. Por ejemplo, abrir, abertura y apertura; quemar, cremación y quemadura; agua, acuoso y aguanoso; ojo, ocular y ojoso, etc. 
Morfología contrastiva del chino mandarín y el español. Formas de gramaticalización y lexicalización

alomorfía de la sufijación. Un ejemplo de la selección de los sufijos -ción y -miento demuestra el capricho: obtener > obtención, retener > retención, pero no obtener $>$ *obtenimiento o retener $>$ *retenimiento; por el contrario, someter $>$ sometimiento, contentar > contentamiento, pero no someter $>$ *sometición, contentar $>$ *contentación. No obstante, con respecto a la distribución de estos dos mismos sufijos, Lliteras (2002) analiza los casos de concurrencia (tipo relajación y relajamiento) para explicar, en última instancia, la productividad y la regla de formación específica de cada uno de estos dos sufijos nominalizadores.

Monge Casao (2012:140) expone que las irregularidades de la sufijación se manifiestan principalmente de dos formas:

1) La diversidad de valores en un mismo sufijo. Por ejemplo, el frecuentísimo -ero puede ser un sustantivo que designa personas (librero, zapatero), lugares (gallinero, granero), objetos (cenicero, paragüero), árboles (melocotonero), etc. Pero también puede formar adjetivos relacionales (callejero, dominguero).

2) La diversidad de sufijos para expresar una misma idea. Por ejemplo, las formaciones para designar 'color próximo a': azulado, azulenco, blanquecino, blancuzco, negruzco, amarillento, grisáceo, rojizo, verdoso.

Merece una mención especial la formación de verbos mediante sufijación. Los sufijos no solo sirven para crear sustantivos o adjetivos, sino que también los hay verbalizadores. Alvar (1993: 60-62) indica que son muy frecuentes los verbos resultantes de la primera conjugación, formados a partir de sustantivos o adjetivos: abonar, sentenciar, publicar. El tipo más productivo se corresponde con la formación de verbos en -ear, como bucear, pestañear, campear, vocear. También es importante el grupo de verbos derivados con el sufijo culto -izar. Muchos de estos son neologismos y palabras científicas o técnicas: capitalizar, cristalizar, rivalizar, puntualizar, legitimizar, neutralizar. 
También resulta muy productivo el sufijo -ecer, que forma verbos de tipo incoativo a partir de sustantivos y adjetivos, como florecer, humedecer. Con este sufijo son frecuentes las formaciones parasintéticas: anochecer, enriquecer, envilecer.

Respecto a la clasificación de los sufijos, existen claras divergencias entre las diversas propuestas, basadas en la multiplicidad de efectos producida por la posición del sufijo y la creación de muchos neologismos ${ }^{17}$. Tradicionalmente la clasificación más común es la que agrupa los sufijos en dos grandes clases: apreciativos y no apreciativos. Los primeros suelen dividirse en: diminutivos, que transmiten una idea de pequeñez o afectividad; aumentativos, que implican amplia dimensión, fealdad o grandiosidad; y peyorativos, que implican desagrado o ridiculez; son considerados no apreciativos todos los demás ${ }^{18}$.

La mayoría de los apreciativos, o bien mantiene la categoría de la base $\left(\right.$ peor $_{A}>$ peorcito $_{A}$, escoba pescobón $_{N}$, espanto $>$ > espantajoN) o bien altera la categoría gramatical del educto (cantarv > cantarín $N$, beberv > beberrón $n_{N}$, rico $>$ > ricachoN), pero no suele alterar el significado nocional de la base $($ montónN $>$ monton-azON = 'montón' + 'grande'; montónN $>$ monton-c-iton = 'montón' + 'pequeño'). A la vez, la sufijación apreciativa puede producir derivados de distinto género al de la base: noticia f. $\rightarrow$ notición m., a menudo con algún efecto de sentido producido por la lexicalización: avión m. $\rightarrow$ avioneta f, peluca f. $\rightarrow$ peluquín $\mathrm{m}$.

Sin embargo, según Monge Casao (2012: 136), algunas de estas formaciones llegan a perder su significado apreciativo, de modo que el sufijo contribuye a formar palabras con un significado particular, completando así el proceso de lexicalización con o sin cambio de género: camilla no se interpreta

\footnotetext{
17 Por ejemplo, para Almela (1999: 108-119), están excluidos de la lista de la sufijación los llamados sufijoides (-algia, -cracia, -fero, -cultor, -logía), los integrantes de series terminológicas (metanol, etano; morfema, fonema), los numerales (decena, millar, milésimo), y los que se crean con finalidad esencialmente provisional, episódica (apoquinean, despiporren).

18 También véase Bajo (1997: 36-71) sobre la sufijación apreciativa; en la descripción de los sufijos diminutivos y aumentativos se presta atención al contexto y se señalan diferencias entre regiones y países.
} 
Morfología contrastiva del chino mandarín y el español. Formas de gramaticalización y lexicalización

como una 'cama pequeña', sino como 'cama portátil para transportar enfermos' o 'mesa con faldas que contiene un brasero'. En esta línea, los sufijos de colilla, ventanilla, zapatilla; callejón, tapón; camarote, carreta, caseta; pañuelo, lentejuela, castañuela, etc., pierden su significado cuantitativo o cualitativo, pues no se prestan al análisis composicional cuando alteran el significado de la base. Así, el conjunto adquiere una significación nueva para designar una realidad o un concepto diferente.

En español, el sistema de los sufijos apreciativos se caracteriza por una acusada morfología recursiva: chico $\rightarrow$ chiquito $\rightarrow$ chiquitito; pobre $\rightarrow$ pobrete $\rightarrow$ pobretón. En este sentido, parece que se producen pocas restricciones con respecto a las posibilidades combinatorias de estos sufijos (Lang 1992: 128-130): aum. + aum. (tontorrón), dim. + pey. (chiquitajo), pey. + aum. (besucón), pey. + pey. (pintarrajear), etc. Así, parece imposible establecer una ordenación interna de estos sufijos, pues la morfología derivativa del español en este aspecto se muestra extremadamente flexible.

La derivación apreciativa, en conjunto, alcanza una alta productividad. Normalmente, la productividad de este proceso morfológico solo está limitada por razones de índole semántica (p. ej., los nombres abstractos no reciben diminutivos: *honestidad-ita) o fonológica (p. ej., los nombres terminados en diptongo + -s no aceptan sufijos apreciativos: *caries-ita). No obstante, el sufijo, con la capacidad de cambio de género, tiende a una utilización amplia: libro > librito, > libreta; silla > sillita, > sillín; zapato > zapatito, > zapatilla.

\subsubsection{Prefijación}

Con respecto a la prefijación del español, se llama prefijo el afijo que precede a la base del derivado: acallar, contertulio, deshacer, intolerable, preclásico, redecorar. El rasgo más destacado del prefijo es su relativa 
independencia o autonomía con respecto a la base, en el sentido de que la conexión semántica entre el prefijo y la base es menos rígida que la que se establece entre la raíz y el sufijo. Esta propiedad de los prefijos se refleja a veces en la utilización de guiones: pre-fabricado, anti-cuerpo, bi-mensual, in-visible, contra-decir, y por las vacilaciones ortográficas que pueden presentan determinadas formaciones como ex marido / exmarido; ex ministro / exministro. De hecho, el prefijo admite la separabilidad en ciertos casos de antónimos coordinados: becas pre- y posdoctorales, manifestación pro- y antiaborto. En este tipo de sintagmas los prefijos comparten la misma base y se coordinan porque presentan algún grado de autonomía.

Por otra parte, no es raro que un mismo prefijo pueda aplicarse a diferentes categorías gramaticales: super-mercadon y super-valorarv; des-contarv y des-horan. También es frecuente la recursividad entre varias formaciones prefijales: des-en-volver, des-en-caminar, anti-extra-terrestre, pro-in-migración.

Frente a los sufijos, los prefijos no suelen cambiar la categoría gramatical de la base, ya que en la mayoría de los casos, el educto de la derivación se corresponde sintácticamente con la palabra primitiva: ligarv $\rightarrow$ desligarv, sala $\rightarrow$ antesala $_{\mathrm{N}}$, famoso $_{\mathrm{A}} \rightarrow$ archifamoso $^{19}$. Una segunda diferencia se refiere a las características prosódicas: frente a los sufijos, los prefijos suelen ser átonos y no modifican la estructura acentual de la base: útil $\rightarrow$ inútil; típico $\rightarrow$ atípico; culpa $\rightarrow$ disculpa.

En el español actual, es indiscutible que se da una estrecha relación entre prefijos y preposiciones. Un determinado número de prefijos puede aparecer independientemente, como verdaderas preposiciones (sinsentido, enmarcar, antesala) o como adverbios (malquerida, bienpensante). Ahora bien, cabe pensar en el problema de si existe o no la prefijación en estos casos.

19 Según Varela (2005a: 64), hay prefijos transcategorizadores en los que el nombre prefijado tiene función adjetival, pues modifica al nombre núcleo del sintagma: máscara antigás, manifestación pro-aborto, periodo pre-constitución, vehículo monomando. La modificación no se produce sin la presencia del prefijo y, además, estos nombres prefijados pueden recibir un sufijo que los convierte en verdaderos adjetivos: periodo preconstitucional, manifestaciones proabortistas. Se ha vuelto a este mismo problema recientemente (Fábregas 201 1: 360-365). 
Morfología contrastiva del chino mandarín y el español. Formas de gramaticalización y lexicalización

Una adecuada solución a este problema tiene que partir de la distinción entre categoría y forma. Según Almela (1999: 56), la respuesta es clara:

La prefijación y la preposición son categorías distintas, son conceptos gramaticales distintos [...], aunque algunos prefijos coinciden formalmente con algunas preposiciones. La aportación semántica de la preposición no es la misma que la de la prefijación. Aquella significa subordinación nominal; ésta significa adición sémica.

Otra cuestión también controvertida de la prefijación es la separación entre prefijación y composición como procesos de formación de palabras. En las respuestas no hay unanimidad. Algunos autores consideran que la prefijación está incluida en la composición, como lordan (1972); otros la consideran como un mecanismo distinto, como Alvar (1993: 39) y Lázaro Mora (1986: 223-224). Aquí creemos más acertada la alineación de la prefijación como un mecanismo situado en el mismo nivel que la sufijación, pero de naturaleza diferente a la composición, tal como señala Bajo (1997: 13): "el hecho de que los prefijos no posean capacidad transcategorizadora no es razón suficiente para negarles el rasgo de afijos derivativos asegurando que constituyen un caso particular de la composición".

Un destacado subgrupo de prefijos en español moderno es el que se ha denominado prefijoides ${ }^{20}$, dado que muchos de ellos aparecen a menudo delante de la base léxica. Los prefijoides son morfemas derivativos de origen grecolatino que se utilizan para generar vocabulario técnico o científico de carácter internacional: tele-, radio-, video-, electro-, bio-, foto-, crono-, etc. Estos temas presentan una mayor productividad y no tienen limitada su posición a la derecha o a la izquierda del lexema, como en cambio la tienen los prefijos. E incluso pueden recibir ellos mismos prefijos (á-grafo) y sufijos (graf-ía, gráf-ico). En otras palabras, algunos de estos temas pueden actuar

\footnotetext{
20 Lang (1992: 221) y Alvar (1993: 49). Algunos autores prefieren la denominación de "temas cultos", "prefijos cultos" o "cultismo". Almela (1999: § 3.1), no obstante, no incluye los prefijoides auto-, fono-, logo-, neo-, seudo- en el inventario de los prefijos; en cambio, sí que acepta los prefijos que proceden de preposiciones griegas y latinas: hiper-, meta-, ante-, extra-, etc.
} 
como prefijo o como base léxica: cromografía y monocromo; fotografía y telefoto; logopedia y filólogo, metrónomo y termómetro, etc.

Con respecto a las propuestas de sistematización de los prefijos, cabe destacar la aportación de García-Medall (1994) para la prefijación verbal. En español los verbos autónomos prefijados, los que disponen de un correlato no prefijado en el léxico verbal, constituyen el esquema más frecuente y se especializan en el engarce pragmático-temporal del eje de la precesión/sucesión (re-, pre-, post-, retro-, etc.). En las reglas de formación de palabras próximas al nivel sintáctico, lo importante es el tipo de integración de los significados a partir de relaciones causativas, locativas y aditivas. Así, el autor clasifica la prefijación verbal en varios grupos: la transcategorizadora, la presupositiva, la negativa, la sintáctica dominante y la deíctica.

En cuanto al inventario de los prefijos, es difícil hallar cierta unanimidad entre los autores. Las principales disparidades provienen del deslinde entre los prefijos y los prefijoides antepuestos, así como de la inclusión o no de prefijos cultos. Lang (1992: §8) reduce los prefijos a cinco grupos según las nociones que contienen: negación (a-, des-), locativos (ante-, entre-), temporales (pos-, pre-), cantidad o tamaño (mono-, pluri-) e intensificación (super-, archi-). Para Almela (1999: 63-70), la reducción de Lang no está justificada. Primero, porque tales nociones no son cinco sino bastantes más y porque no están tan distantes entre sí los sentidos que presentan los prefijos. Además, el criterio de esta clasificación no parece plenamente lingüístico. Por otro lado, hay que ser consciente de lo escurridiza que es la frontera que separa el "sentido" de la "asignación". En el inventario que propone Varela (2005a: 64-67), la lengua de la ciencia y la tecnología está incluida si las correspondientes formaciones prefijadas se han extendido a la lengua común y han dado lugar a creaciones analógicas (policloruro, policolor, polideportivo etc.). No deben estar incluidos los prefijos numerales, salvo los que corresponden a 'uno' (uni-, mono-) y 'dos' (bi-, ambi-), que son bastante frecuentes y tienen uso diferenciado según señalen número de unidades o divisiones temporales: unifamiliar, monopatín, 
Morfología contrastiva del chino mandarín y el español. Formas de gramaticalización y lexicalización

bicelular, bianual / bienal, bimensual / bimestral.

\subsubsection{Interfijación}

En cuanto a la interfijación, desde que Malkiel (1958) difundió este término, se han considerado su existencia y su débil situación como los principales problemas. Alarcos (1983: 13), aunque aporta la idea de su estatuto, para calificar el carácter problemático de los interfijos recurre a su estrecha relación con los afijos. Alvar Ezquerra (1993: 62-63) considera también que los interfijos forman parte de los sufijos y "son unos elementos átonos sin función gramatical ni significativa, tan sólo morfofonemática, pues sirven de enlace entre la base léxica y los sufijos".

No obstante, se ha aceptado generalmente el concepto de interfijación, pese a que son varios los aspectos en los que se ofrecen opiniones divergentes. Para Malkiel, los interfijos son formas necesarias como paso intermedio para la formación de una variante de sufijo. Por ejemplo, el elemento -ar- de hum-ar-eda y polv-ar-eda resulta imprescindible para fundamentar la necesidad del nuevo morfema -areda, ejemplo utilizado por Malkiel para comprobar el valor de interfijo.

Es favorable la opinión de Martínez Celdrán (1978: 458) sobre el interfijo. En su opinión, se trata de un "elemento morfológico porque su función es la de servir de eslabón o enlace entre las expresiones de los distintos morfemas que entran a formar parte de la palabra". Respeto a las contradicciones de la conexión entre el morfema y la ausencia de significado, Portolés (1993) defiende nítidamente que el interfijo sí tiene significado si se considera que la función significativa del interfijo se realiza no sobre el lexema, sino sobre el sufijo.

Las funciones de los interfijos se limitan prácticamente a los mecanismos ante-sufijales. Almela (1999: 178-181) distingue tres grupos relacionados con los niveles del análisis lingüístico. En el nivel fonético, los 
interfijos sirven para evitar el hiato entre la base y el sufijo (ruso-n-iano, cafe-c-ito, mama-s-ita, bosqu-er-il), eliminar la homonimia (te-t-era, llam-ar-ada, lengu-ar-ado), hacer reconocibles algunos primitivos (vol-ad-izo, cern-id-ura), salvaguardar la estructura prosódica de la base (tierno > tiernecillo) y evitar la formación de estructuras silábicas difíciles (interfijos ínterradicales o compositivos: alt-i-plano, oj-i-negro, boqu-i-abierto).

En el nivel morfémico, los interfijos permiten que determinados sufijos se unan con determinadas bases: 1) los interfijos -ik-, -aj- hacen que el sufijo -oso se pueda unir a una base verbal: quej-ic-oso, pic-aj-oso; 2) los verbos de las conjugaciones 2. a y 3. a necesitan un interfijo para recibir el sufijo -ón, como en tem-er-ón, com-il-ón, dorm-il-ón; 3) la terminación -ear necesita un interfijo junto a determinadas bases verbales, como en correr > corr-et-ear, bailar > bail-ot-ear; 4) la unión del sufijo -ón a bases masculinas y a adjetivos es fácil con un interfijo y difícil sin él, como en beso > bes-uc-ón, hueso > hues-arr-ón, bravo > brav-uc-ón.

Con relación al nivel léxico, los interfijos colaboran en la composicionalidad de los significados para eliminar homonimias (pan-ad-era / panera, man-ot-ada / man-ada, ris-ot-ada / ris-ada, cort-ec-ito / cort-ito), y también para seleccionar un significado de entre los varios posibles sufijos muy productivos como -eta, -ada, -azo, -ón, etc., significado que generalmente es de 'burla' o 'golpe' y anuncia una categoría gramatical en el derivado (cantarv > cant-al-etan, chupar $>$ chup-et-ónN, pegarv $>$ peg-uj-ón $n_{N}$ ).

Según Portolés (1993: 342), el hecho de que el proceso de interfijación difiere de la sufijación y la prefijación es lo que ha perjudicado su reconocimiento como entidad morfológica independiente, dado que aquellas tienen como núcleo la base y, por el contrario, el interfijo depende en primer lugar del sufijo que lo selecciona y posteriormente de la base a la que se acomoda:

$$
\begin{aligned}
& \left.[[\text { BASE }]+\text { sufijo }] \rightarrow[\text { [reloj }]_{N}+\text { ero }\right]_{N} \\
& {[\text { prefijo }+[\text { BASE }]] \rightarrow\left[\text { des }+[\text { acuerdo }]_{N}\right]_{N}} \\
& {[[\text { BASE }]+[\text { interfijo }+[\text { sufijo }]]] \rightarrow[[\text { hum }(O) N]+[\text { ar }+[\text { eda }]]]_{N}}
\end{aligned}
$$


Morfología contrastiva del chino mandarín y el español. Formas de gramaticalización y lexicalización

Esta circunstancia ha favorecido la confusión con cadenas sufijales o con variantes de sufijos. De este modo, el inventario de los interfijos tropieza con dos clases de dificultades: la propia de toda identificación de ejemplares y la derivada de la naturaleza del interfijo. En la lista que propone Almela (1999: 169-176), están excluidos los interradicales por la dependencia de los tipos compositivos y los escasísimos casos de interfijados posprefijales existentes (en-s-alzar, en-s-anchar). Por otra parte, Portolés (1993: 349-357) amplía estos datos y distingue varios tipos según la dependencia del sufijo, de la información propia de la flexión y de la categoría gramatical, sin fundamentar el significado conceptual de los interfijos.

Para terminar este apartado, cabe mencionar el debatido doblete de "interfijo / infijo". Dentro del marco de los interfijos, existe la entidad lingüística que recibe el nombre de "infijo". Para algunos autores, este fenómeno es muy débil y no hay base empírica suficiente para discernir tal intercalación. El panorama lo describe así Elena Bajo (1997: 35):

Los infijos por su dudosa naturaleza gramatical, no son propiamente afijos, $y$, en rigor, no parecen unidades gramaticales mínimas, ni aportan un significado particular, ni se usan para que una base dada pase a ser una nueva palabra [...] y ni siquiera está claro que sean verdaderamente productivos.

Martínez Celdrán (1978: 457-458), no obstante, admite la denominación de infijo para algunas formaciones adverbiales (cerqu-it-a, lej-it-os, ahor-it-a) y nombres propios (Luqu-it-as, Carl-it-os). Malkiel (1958: 109-110), por otra parte, distingue claramente entre interfijo e infijo, asignándole a este el papel de "inserto dentro de un cuerpo estrechamente unido" y "acaso también al contrastar, guar-ec-er con guar-ir con menor exactitud, en español antiguo". Pena (1991: 74) define el infijo como "un morfo continuo que se inserta dentro de otro morfo, normalmente la raíz". 


\subsection{Composición: compuestos morfológicos y compuestos sintagmáticos}

La composición es otro de los principales procedimientos del español para la formación de nuevas palabras, junto con la derivación. En el proceso de composición, se unen dos o más lexemas para formar una nueva palabra con un sentido único y constante. Según Varela (2005a: 73), los lexemas que se combinan en la palabra compuesta pueden ser de dos tipos: bien palabras de la lengua (P), bien "temas cultos" de origen grecolatino (T). Todas las combinaciones posibles entre estos dos tipos de unidades léxicas forman compuestos en español:

\begin{tabular}{|l|l|l|l|}
\hline $\mathbf{P}+\mathbf{P}$ & hojalata, claroscuro, pelirrojo & $\mathbf{T + T}$ & logopeda, ecólogo, pediatra \\
\hline $\mathbf{P + T}$ & claustrofobia, musicólogo & $\mathbf{T + P}$ & geofísico, ecosistema \\
\hline
\end{tabular}

Tabla 1: Combinaciones de lexemas en la composición

Algunos autores identifican los temas cultos con los afijos, no con los lexemas, de modo que la formación resultante se clasifica como palabra derivada. Sin embargo, aquí se considera preferible la clasificación de estas unidades morfológicas como temas porque la combinación entre verdaderos afijos no produce resultados: *in-dad, *pre-ción; además, los temas pueden ocupar tanto la posición inicial como la posición final en la palabra compuesta, mientras que los afijos se clasifican en prefijos, interfijos o sufijos justamente según la posición predeterminada.

Se denomina generalmente compuesto ortográfico o léxico al compuesto que presenta sus componentes unidos gráficamente y comparte otros rasgos con las palabras simples, por los que se distingue de los sintagmas y las frases (Lang 1992: 91, Varela 2005a: 74). Estos rasgos son principalmente los siguientes:

1) El compuesto tiene un significado propio -unitario y constante- con un referente único, si bien su significado no es, por lo general, ajeno al de sus constituyentes. Por ejemplo, una palabra como vanagloria está 
compuesta del adjetivo vana que pierde su polisemia y transmite un significado específico de 'vanidad y alabanza excesiva de las propias cualidades'.

2) Las partes que forman el compuesto pueden ser palabras independientes, pero al mismo tiempo, pierden en la composición su independencia sintáctica. Tal falta de independencia se muestra en varios aspectos, todos ellos relacionados con el hecho de que los elementos que integran el compuesto son inseparables y presentan un orden fijo. Por ejemplo: El guardiamarina > * Lo marino del guardia; limpiabotas > *limpiabotas(y)zapatos; pelirrojo > *pelibarbirrojo; altavoz $>$ *vozalta.

Por lo que se refiere a las marcas morfológicas de género y número del nombre y del adjetivo, lo esperable es que se manifiesten tales desinencias solo externamente y se atribuyan al compuesto en su totalidad: *puntaspiés > puntapiés; *bocascalles > bocacalles. Quedan, sin embargo, algunos restos de compuestos con flexión interna, como quienesquiera o cualesquiera, vestigio de cuando sus constituyentes eran aún palabras independientes.

Otras características de los compuestos ortográficos son de orden fonológico. El principio general es que estas palabras funcionan como si fueran una sola, y en consecuencia siguen la regla normal de acentuación, con desplazamiento del acento al segundo constituyente: álta vóz > altavóz ; bóca cálle > bocacálle. Pero en la combinación, suele ocurrir que los elementos compositivos sufren alteración fonética o morfológica: rojo + negro da rojinegro; cabeza + baja da cabizbajo; cara + largo da carilargo. Por otra parte, no es raro que los constituyentes adopten formas especiales en el interior del compuesto, distintas de cuando aparecen como palabras independientes en la oración: Es inglés y español > Es anglo-español; Está escrito a mano > Es un manuscrito; La vaca se ha lastimado la uña del pie > Se ha lastimado la pezuña. 
En la formación de palabras, la composición y la derivación pueden presentarse conjuntamente al mismo tiempo. Dicho de otro modo, las palabras complejas pueden derivarse ulteriormente. Se trata de la llamada "derivación externa del compuesto", que se observa en barriobaj-ero, centrocamp-ista, malhumor-ado; los compuestos de dos temas también se derivan externamente: telégrafo > telegraf-ista, teléfono > telefón-ico. Por otra parte, los compuestos pueden incluir en su interior una palabra derivada; hablamos entonces de "derivación interna del compuesto", como en aguamarina (< agua + mar-ina), cazasubmarinos (< caza + sub-mar-ino-s) o aguardiente (< agua + ard-iente).

Dos son los tipos de compuestos ortográficos que resultan bastante productivos en el español actual: el que combina un verbo con un nombre y el que se estructura como nombre y adjetivo, aunque también hay otros casos como el de las formaciones adjetivales compuestas de dos adjetivos (Bustos Gisbert 1986; Alonso-Cortés 1992: 152-153; Lang 1992: § 3.3 y 3.4; García Lozano 1993: 205-214).

El primer tipo tiene mayor vitalidad y es productivo en la formación de nombres de agente, oficios, instrumentos o máquinas: rompehielos, lavaplatos, guardarropa, abrecartas, escurreplatos ${ }^{21}$. La estructura es la de un verbo que se combina con un nombre plural dando lugar a un compuesto nominal. En el compuesto, el verbo aparece en tercera persona del singular. En la mayoría de los casos el plural solo puede marcarse a través de los determinantes y el género es siempre masculino, independientemente del género que presente el constituyente nominal: el / los lavaplatos, el / los abrecartas. Solo en una pequeña porción de casos, el nombre aparece en singular, particularmente cuando se trata de un nombre no contable: el tragaluz, el ganapán, el portavoz. Este tipo de compuestos puede someterse a nuevas composiciones ulteriores: parabrisas + limpiar > limpiaparabrisas, cuentakilómetros + portar > portacuentakilómetros.

21 Para los antecedentes históricos de estos compuestos, véase Pérez Lagos (1986: 21-23). 
El segundo tipo de compuestos, con la estructura N+A, también está muy representado en español, como en carirredondo, manilargo, boquiabierto, pelicano, lengüilargo, etc. La productividad de este tipo de formaciones se revela en la preferencia por la atribución a nombres animados referida a su descripción física, siempre que el primitivo sea una parte del cuerpo. Este compuesto presenta como particularidad sintáctica que es el adjetivo el núcleo mientras que el nombre se subordina a él. Desde el punto de vista fonológico, tal nombre suele ser bisilábico y sustituye la vocal final por -i- (pelo $>$ peli[corto], cabeza > cabiz- [bajo]).

Por otra parte, los compuestos adjetivales también se dan en palabras de estructura A+A: agridulce, sordomudo, claroscuro, clarividente, decimoquinto y de estructura Adv.+A: malsano, bienintencionado. Por otra parte, en todos los compuestos adjetivales, la flexión de género y número opera externamente, lo que en términos de teoría morfológica les confiere el estatuto de compuestos: una sordomuda, colores claroscuros.

Además de los compuestos ortográficos, suelen distinguirse tres tipos de compuestos sintagmáticos: los compuestos preposicionales (el tipo $\mathrm{N}$ de N), los compuestos yuxtapuestos o apositivos (el tipo NN) y los compuestos de nombre y adjetivo (NA ○ AN). Estos tipos de combinaciones fijas también reciben los nombres de sintagma lexicalizado o lexía compleja (Almela 1999: 146-150). Se trata de formaciones que se presentan como una unidad solidaria y tienen significado único, a pesar de que sus componentes se realicen como palabras separadas.

En primer lugar, los compuestos preposicionales como pie de imprenta, ojo de buey, patas de gallo, piel de gallina se corresponden con los compuestos ortográficos en que tienen un significado global unitario y un referente único. Sus constituyentes carecen de independencia sintáctica, de ahí que no puedan recibir modificadores o complementos: *pie de imprenta [informatizada], " ojo de [gran] buey, *patas de [mucho] gallo, *piel de gallina [blanca]. 
En segundo lugar, entre los compuestos yuxtapuestos se incluyen los yuxtapuestos binominales y los yuxtapuestos de dos adjetivos. Los binominales pueden ser bien apositivos como pájaro mosca, ciudad dormitorio, o bien coordinados, como falda pantalón, café teatro. En el primer grupo, el nombre en aposición denota solo algunas de las propiedades que presenta la entidad expresada por el compuesto, mientras que en el segundo grupo, en cambio, el nombre yuxtapuesto denota la propia entidad, de manera que la construcción se asemeja semánticamente a una coordinación. Así, un pájaro mosca solo tiene de 'mosca' el significado de 'pequeño tamaño' mientras que café teatro es un 'café' que tiene todas las propiedades de un teatro y el compuesto obtiene su significado de la suma de los dos nombres.

Lang (1992: § 3.5) y Varela (2005a: 82) indican que un subtipo de los compuestos nominales apositivos es aquel en el que el nombre en aposición resalta o intensifica algunas de las propiedades del primer constituyente. Estas formaciones hiperbólicas constan de un segundo constituyente que se repite de forma paradigmática mediante nombres como estrella, clave, relámpago, cumbre, prodigio, modelo y algunos otros que se combinan recurrentemente con muchas clases de nombres para señalar que se trata de entidades que tienen una posición privilegiada o especial dentro de su clase: \{oferta / pasajero / cliente\} estrella; \{problema / decisión / hombre\} clave; \{visita / viaje / guerra\} relámpago. En estos casos, la función del segundo constituyente es comparable a la de un sufijo en la derivación, lo que remite al origen etimológico de muchos afijos provenientes de palabras latinas. En otras series, el constituyente puede presentarse a la izquierda y estas estructuras se asemejan al proceso de prefijación en la reiteración paradigmática del primer constituyente: coche \{restaurante / litera / cabina\}; hombre \{anuncio / gol / puente / rana\}.

La flexión de estos sintagmas binominales apositivos se presenta en el constituyente núcleo: horas punta, trajes sastre, decisiones relámpago, globos sonda. Por otro lado, el uso popular acepta la flexión externa sobre el segundo 
constituyente: coches camas, cenas homenajes, perros policías, guardias civiles, etc., pero tiende a la norma general sobre todo si el segundo constituyente puede interpretarse como un nombre no contable: operaciones retorno, comités anticorrupción, cupones obsequio.

Por lo que se refiere a los compuestos yuxtapuestos de dos adjetivos, mucho más usuales son los tipos de composición adjetival mediante el empleo de guiones: económico-social, jurídico-laboral, estructural-funcional, léxico-semántico, anglo-indio, franco-español.

En todos los casos, o bien el morfema de género y de número operan externamente o bien no se reconocen, lo que en términos de teoría morfológica les confiere el estatuto de compuestos. La flexión afecta a todo el conjunto: medidas político-económicas, bufandas blanquivioletas.

Por último, en los compuestos de nombre y adjetivo se da una relación entre modificado (nombre-núcleo) y modificador (adjetivo). Entre los que se componen de un adjetivo calificativo, se distinguen las estructuras que no han alcanzado aún la unión de carácter ortográfico y las que constituyen en la actualidad una sola palabra: disco duro, gota fría, cal viva; caradura, avefría, tiovivo. Lliteras (2010a: 364) indica que los adjetivos calificativos que alcanzan mayor productividad en la formación tanto de compuestos como de locuciones nominales de nombre y adjetivo pertenecen a cuatro tipos: los privativos (risa falsa, punto flaco, arco ciego), los genuinos (purasangre, tiovivo), los cuantificadores (alzaprima, terciopelo) y los antónimos de cualidades físicas y valoración (manicorto, temporada alta). A partir de las ideas de Calvo (1986: 119), Moreno Cabrera (1991: I, 250-251), Demonte (1999: § 3.2.3; 2011: § 3.2) y Cruse (2008: 245), Lliteras (2010a: 368) señala que estos adjetivos "se corresponden preferentemente con los atributos intersectivos o absolutos, cuya interpretación no depende de una norma externa, sino que relacionan los objetos con grados máximos o mínimos de la propiedad que denotan y responden a una escala cerrada representada por estos valores". 
Además de su alto grado de lexicalización, otra característica es que estos compuestos pueden recibir afijos derivativos, lo que demuestra que tienen el mismo estatuto que un compuesto ortográfico: mal humor > malhumorado. Respecto a la flexión de número, se aplica a los dos constituyentes: bomba lacrimógena / bombas lacrimógenas, fuente termal / fuentes termales, faro flotante / faros flotantes.

\subsection{Otros procesos de formación de palabras: parasíntesis, acortamiento, acronimia y siglación}

Este apartado reúne una diversidad de modelos de formación de palabras, alguno de los cuales, como la parasíntesis, se asemeja en algunos aspectos a la sufijación, mientras que otros, como el acortamiento y la acronimia se refieren a procedimientos neológicos que se apartan de forma considerable de la clásica división entre composición y derivación. También se incluye aquí alguna breve referencia a los extranjerismos y a la siglación.

En español, se origina una configuración de tres miembros, contradiciendo, en principio, la suposición de que la concatenación morfológica procede siempre de una ramificación binaria, formulada por Aronoff (1976: 85). Tal es el caso de los llamados parasintéticos (Serrano Dolader 1995), formaciones verbales o deverbales que se caracterizan por formarse mediante la aplicación simultánea de la prefijación y sufijación. Su estructura se presenta en componentes tripartitos, a base de un prefijo, una base léxica (raíz) y un sufijo [pre.+ [R] + suf.]: en-triste-cer, a-segur-ar, a-temor-izar. No hay base derivada solo mediante prefijación (*entriste-, *aseguro-, *atemor-), ni base sufijada sin la prefijación (*-tristecer, ${ }^{*}$-segurar, *-temorizar). 
Morfología contrastiva del chino mandarín y el español. Formas de gramaticalización y lexicalización

Según Varela (1990a: 59), las formaciones parasintéticas más usuales del español son las siguientes:

1) Deadjetivales: en...ar (en-dulz-ar)

en...ecer (em-bell-ecer)

a...ar (a-grand-ar)

2) Denominales: en...ar (em-polv-ar)

en...ecer (en-moh-ecer)

en...izar (en-coler-izar)

a...ar (a-caramel-ar)

a...ecer (a-tard-ecer)

a...izar (a-terror-izar)

Respecto al valor semántico, en opinión de García-Medall (1994: 51), los prefijos de la parasíntesis en español, sobre todo a- y en-, provocan una serie de neutralizaciones morfológicas de tres tipos básicos de oposiciones semánticas: parte-todo, contenedor-contenido, dimensionalidad objetual y pertenencia a clases.

Ahora bien, parece que los parasintéticos casi se han circunscrito al campo de las formaciones verbales. Existen, sin embargo, formaciones no verbales parasintéticas creadas por afijación, más concretamente dentro de la categoría de los adjetivos.

Según Serrano-Dolader (1999: §72.2), la parasíntesis por afijación en el campo no verbal queda reducida al ámbito de los adjetivos, es decir, no existen en español sustantivos ni adverbios parasintéticos. Dentro de los parasintéticos adjetivales, el tipo más frecuente es el que forma adjetivos denominales en -ado (Lang 1992: 243-244): naranja $\rightarrow$ anaranjado, niño $\rightarrow$ aniñado, caracol $\rightarrow$ acaracolado, canal $\rightarrow$ acanalado, mujer $\rightarrow$ amujerado. Estas formaciones se semejan a los adjetivos participiales, especialmente a aquellos adjetivos deverbales que se derivan de un nombre como base (yeso $\rightarrow$ enyesar $\rightarrow$ enyesado, corral $\rightarrow$ acorralar $\rightarrow$ acorralado). Otro tipo que merece mencionarse es el adjetivo con estructura "prefijo de valor local + sustantivo + sufijo": submarino, antediluviano, intercelular, postónico, etc. En 
estos casos, el prefijo indica una dirección u orientación locativo (inter-, supra-, sub-, trans-, etc.) y el sufijo suele determinar la categoría gramatical de la formación.

El concepto de parasíntesis también se utiliza en referencia a formaciones en las que afijación y composición se producen de modo simultáneo, puesto que se da también una estructura ternaria: picapedrero (picar + piedras + -ero), sietemesino (siete + mes + -ino), ropavejero (ropa + vieja + -ero).

El acortamiento consiste en la abreviación silábica del lexema base. Es la reducción de una unidad léxica, sea palabra simple, sea palabra compleja. Queda clara la definición de Almela (1999: 202):

Se llama aquí acortamiento a la reducción del significante de una palabra, generalmente concretado en la pérdida de sílabas iniciales (se llama "aféresis": violón[chelo], auto[bus]) o finales (se llama "apócope": bici[cleta], cole[gio], profe[sor]); se llama también truncamiento, braquigrafía, forma acortada, abreviamiento.

La forma truncada puede llegar a alcanzar el estatuto léxico pleno. De hecho, como indica Alvar (1983a, 1983c y 1995), los morfemas cine, moto, foto, tele, etc., han llegado a sustituir a las bases de procedencia (cinematografía, motocicleta, fotografía, televisión) y se utilizan en todos los ámbitos de la vida social, aunque tuvieran algunos un origen popular.

Las palabras acortadas, como formas léxicas de la lengua que son, pueden tomar los morfemas flexivos de la categoría correspondiente (anarqu[ista] > anarc-os; plum[íferas] > plum-a-s) y también incrementarse con morfemas derivativos (bloca[dillo] > bocata; cuba[-libre] > cubata). Por otra parte, los acortamientos también entran en composición con otras palabras de su mismo tipo formal, así en polimili (de polí[tico]-mili[tar]), o con palabras plenas, así en autoescuela (de auto[móvil]+escuela).

Por lo general, los acortamientos pertenecen a la lengua oral y en su creación suele primar una intención afectiva. Así, estas formas presentan un valor parecido a los apreciativos, lo que se hace patente en los hipocorísticos, 
114 Morfología contrastiva del chino mandarín y el español. Formas de gramaticalización y lexicalización

como en los ejemplos de Lang (1992: 261): Teresa $\rightarrow$ Teresita / Tere; Antonio $\rightarrow$ Antoñito / Toni; Guadalupe $\rightarrow$ Lupita / Lupe; María $\rightarrow$ Marieta / Mari.

Hoy día se manifiesta una tendencia cada vez mayor a aceptar otras vocales en un lenguaje ultraneológico, como analfa $\leftarrow$ analfabeto, forasta $\leftarrow$ forastero, ecolo $\leftarrow$ ecologista 22 . Se denomina acronimia a este proceso de formación de palabras. La acronimia puede definirse como la combinación de un fragmento inicial de una unidad léxica (que sufre apócope) y de un fragmento final de otra unidad léxica (que sufre aféresis), sin necesidad de la existencia de nexos. Afecta a dos unidades léxicas y da como resultado un producto léxico. Ejemplos prototípicos son pequeñecos $1<$ peque[ños] + [me]ñecos), cristañola ( < crista[lería] + [espa]ñola), informática 1 < infor[mación] + [auto]mática), secrefata (< secre[taria] + [aza]fata), cantautor $(<\text { canta[nte] }+[a] \text { utor })^{23}$. Este proceso de acronimia corresponde a lo que afirma García-Medall (1988: 130): la complejidad morfológica produce en las unidades recientes una fragmentación tan inevitable como necesaria, pues la morfología se asienta sobre esta misma fragmentación funcional y la fomenta.

La acronimia tienen un desarrollo amplio "puesto que constituye un rasgo característico del lenguaje de la publicidad, la empresa, el comercio y el periodismo" (Lang 1992: 259). Alvar (1993: 45) precisa que tal unión de los extremos opuestos de dos palabras es de carácter técnico, muchos de ellos son voces hechas en otras lenguas (como inglés) y después introducidas en el español, aunque hay algunos de carácter autóctono: motel (< mo (tor + ho) tel), apartotel (< apart (amento + h) otel), aceriales (< acer (os + industr) iales) y transistor (< transf (fer + res) istor).

En los acrónimos, los fragmentos fónicos que se combinan pueden constar de sílabas completas o incompletas (disparatario < disparate +

\footnotetext{
22 La formación de neologismos morfológicos consiste, según explica García-Medall (1997: $111-112)$, en una cierta regla de formación de palabras inexistente en otros tiempos en el estudio de una lengua, que cuenta con suficientes garantías empíricas de su productividad inherente.

${ }^{23}$ En Lang (1992: 12), también se incluyen como acrónimos palabras como tergal < [poliés[ter + [gal]o), en la cual la combinación es el constituyente final de la primera palabra y el inicial de la segunda palabra.
} 
vocabulario); y la sílaba (o el fonema) que comparte las palabras pueden alterarse: secráfono < secreto + teléfono: a por e).

Aparte del tipo prototípico -fragmento + fragmento-, también se consideran acrónimos aquellas formaciones en las que aparece reducida solo una de las dos palabras, como miniversidad ( $<$ mini + universidad), analfabestia (< analfabeto + bestia), orotelia (<oro + filatelia) y docudrama (< documental + drama) etc. Otro tipo es el que representa una formación de tinte humorístico o burlesco, en que una parte se sustituye por otra de significado opuesto, como dictablanda, con alteración de la terminación -dura.

El proceso de combinación confiere al acrónimo una similitud con el compuesto. De hecho, no es fácil diferenciar el acrónimo de un compuesto integrado por dos palabras acortadas o por temas cultos, tal como autobús de auto[móvil] + [ómni]bus. ${ }^{24}$ Un rasgo evidente es que en las formaciones de acronimia hay solapamiento de sílabas o fonemas, que no suponen un cruce de palabras sino la mera combinación de elementos léxicos. Otra evidencia de los fragmentos de palabras que se aglutinan en un acrónimo es que no coinciden con un morfema, sino que son meras agrupaciones de fonemas que pertenecen a dos palabras distintas. Además, los acortamientos de los acrónimos solo se dan en tales formaciones y no son elementos que se usen para componer otras palabras complejas de manera productiva. Por ejemplo, teleñeco se completa con una secuencia (-ñeco) que es una mera agrupación de dos sílabas y no un elemento recurrente en otras formaciones (Varela 2005a: 96-97). Un caso semejante puede ser el de trillizos, quintillizos, etc., a partir de (me)llizo.

Por otro lado, existen también acortamientos opacos, en los que el hablante apenas tiene conciencia de que proceden de una secuencia sintáctica reducida, como ovni (< Obbjeto Volante no_Identificado), sida (< Síndrome de Inmuno-deficiencia Adquirida) o grapo (< Grupos de Resistencia Antifascista Primero de Octubre). A este proceso de creación de palabras se le

24 Para los rasgos más destacados de los acrónimos con relación a los procedimientos de composición, prefijación, sufijación y siglación, véase Almela (1999: 210). 

Morfología contrastiva del chino mandarín y el español. Formas de gramaticalización y lexicalización

denomina siglación.

La siglación es un procedimiento de sustracción en el que se eliminan ciertos fragmentos y se unen las letras o grafemas iniciales de las palabras. Normalmente hay varios tipos de siglas. Uno es el que se forma nombrando o deletreando los grafemas cuando las iniciales de las palabras agrupadas componen una secuencia fónica que no es aceptable, como DNI leído [dé.éne.í]; otro es el que se compone con más de un grafema de alguna de las palabras que aparecen o se deletrea el primer grafema y se lee según su valor fónico más la secuencia: RENFE (de Red Nacional de Ferrocarril Españoles), PSOE (leído [pé.sóe]).

Cuando se crean siglas, con frecuencia se busca un carácter evocador y expresivo, con tendencia a construir unidades coincidentes con elementos léxicos ya existentes: AVE (Alta Velocidad Española), ACUDE (Asociación de Consumidores y Usuarios de España), IDEA (Instituto de Estudios Asturianos) (Alvar 1993: 47).

Las siglas pertenecen a la categoría nominal, sus referentes son sectores científicos, partidos y organizaciones de diversas clases (Rodríguez González 1987: 139). Con respecto a su carácter nominal, Almela (1999: 216-218) habla de que la mayoría de las siglas se usan como nombres propios con las siguientes características: a) el género corresponde al que presenta la palabra que constituye el núcleo de la sigla: la EMI (Escuela de Mandos Intermedios). No obstante, Almela (1999: §9.4) indica que hay que considerar otros factores como el de las asociaciones semánticas: el APRA es el partido llamado Alianza Popular Revolucionaria Americana; b) la pluralidad se manifiesta en el determinante: Los GEO (Grupo Especial de Operaciones) rescataron al secuestrado, Hubo una reunión de varios COIE (Centro de Orientación e Información de Empleo); por otra parte, hay casos de reduplicación para señalar el plural, tal como EE.UU, leído "Estados Unidos"; c) la prefijación y la sufijación son aceptables en las siglas: otanización (OTAN + -ación), onusiano 
(ONU + -ano), psoetizar ( PSOE + izar).

En proporciones diferentes y épocas distintas, el español ha incluido también en su léxico préstamos de otras lenguas. Según la procedencia de estos préstamos, hay anglicismos, arabismos, germanismos, italianismos, catalanismos o voces amerindias.

Actualmente, es el inglés la lengua moderna que más palabras se registran en español. Algunas de ellas no son propiamente inglesas, pero a través de esta lengua han llegado al español. Los préstamos se distinguen por su grado de adaptación: bien se toma la palabra directamente sin ningún cambio, como los casos de reality show, lobby, free lance, etc., bien la palabra nueva se adapta a la ortografía española, como hamburger > hamburguesa. Otro tipo de préstamo es el denominado "calco semántico", como perrito caliente sobre hot dog, hora punta sobre rush hour, donde se traduce el término inglés literalmente con una formación netamente española.

Aparte de la irrupción reciente del inglés, las dos principales aportaciones al léxico del español han sido, en épocas muy diferentes, la del árabe y la del francés. Hay muchas palabras que nos dejaron los árabes en el español, lo cual no sorprende debido a sus 700 años de presencia en España: ajedrez, almohada, alcalde, acequia, ojalá, zanahoria, etc. Las palabras que llegan al español a través del francés, como coqueta, perfume, pantalón, chalet, neceser, etc., muestran que la influencia de esta lengua y su cultura se ha introducido en la vida social y cotidiana de los españoles. Por su parte, la aportación del italiano se refleja mucho en el ámbito del arte y de la música, pero también en la gastronomía, el espectáculo, etc.: aria, romanza, ferroviario, pizza, graffiti, casino. De la influencia del alemán, existen calcos semánticos como voluntad de poder (< Wille zur Macht), visión de mundo o cosmovisión k< Weltanschauung), de adopción directa también hay casos que heredan el significante o el significado: sable, búnker, potasa, níquel. 


\subsection{Resumen y conclusiones}

Aunque es difícil hallar cierta unanimidad entre los autores respecto al inventario de los afijos, es indudable que la derivación caracteriza la morfología española, en particular, la sufijación, que se considera el proceso morfológico más productivo. Otro proceso característico de la morfología española es la parasíntesis, que se identifica con un modelo de formación de palabras circunscrito al campo de las formaciones verbales que resulta muy productivo en español pero defectivo en otras lenguas, como el chino mandarín.

Por otro lado, se observa que en español algunos procesos morfológicos no están exentos de problemas. Las principales discusiones giran en torno a los siguientes temas:

a) La distinción entre flexión y derivación.

b) La clasificación de los temas cultos en la composición o la derivación.

c) La definición del proceso morfológico mediante prefijos idénticos a las preposiciones.

En primer lugar, respecto a las diferencias entre la morfología flexiva y la morfología derivativa, algunos autores indican las propiedades que permiten diferenciar la flexión de la derivación, las cuales son de diferentes tipos, formales, funcionales, semánticas, de frecuencia, de productividad. Además, otros autores explican que la flexión y la derivación son una realidad continua y gradual en la que una serie de características se pueden dar en mayor o menor grado para reconocerse como propiedades flexivas o derivativas.

En segundo lugar, el estatuto de los temas cultos en la composición o la derivación todavía es objeto de controversia. Mientras que muchos autores excluyen estos formantes polimóficos cultos fuera de la afijación, porque alcanzan la autonomía léxica, otros autores admiten algunos temas cultos, como hiper-, meta-, ante-, extra-, en la lista de los prefijos. 
En tercer lugar, aunque algunos prefijos coinciden formalmente con las preposiciones, la función que desempañan es diferente en cada caso: mientras que los prefijos no producen una combinación sintáctica en la palabra compleja, las preposiciones indican una subordinación nominal. Además, los prefijos pueden alternar con diferentes alomorfos, mientras que esta alternancia no consta para las preposiciones. Otra cuestión polémica que atañe a la prefijación es que en el uso moderno, se encuentran algunos prefijos (como anti-) que pueden alterar la categoría gramatical del educto, lo que se considera una propiedad característica de los sufijos. 

4

COMPONENTES MORFOLÓGICOS DEL CHINO MANDARÍN: PRINCIPALES PROCESOS DE FORMACIÓN LÉXICA

En este capítulo se revisan los conceptos de los componentes morfológicos del chino mandarín, como son el morfema y la palabra. Con la finalidad de examinar los principales procesos de formación de palabras, se estudian los problemas de reconocimiento de las categorías flexivas y se describen las formaciones derivativas y compositivas de la lengua china. Se defiende que el grupo de pseudoafijos constituye una categoría productiva en la morfología del chino moderno. Finalmente, se dedica atención a ciertos fenómenos que contribuyen muy decisivamente a la formación léxica, como el uso de los clasificadores, las formas de reduplicación y el tratamiento del extranjerismo.

\subsection{Los conceptos de sílaba, morfema y palabra en la lingüística china}

La definición de los componentes morfológicos del chino es una cuestión compleja, ya que se trata de una lengua con una estructura interna muy distinta a la de las lenguas indoeuropeas cuyas unidades no siempre resultan útiles para la descripción de la lengua oriental. Normalmente se suele utilizar el término zì 字 para indicar el morfema, el componente de las palabras, que también se corresponde con el llamado "carácter escrito" en español. Así zì 字 siempre se identifica con una sílaba. Según Chang (1994: 65-70), el morfema del mandarín se define como un elemento que no puede ser 
Morfología contrastiva del chino mandarín y el español. Formas de gramaticalización y lexicalización

segmentado en otros elementos significativos. El morfema se refiere a las unidades mínimas que componen una palabra y que presentan una forma fonética y un contenido significativo. Además, todos los morfemas son monosilábicos 25 .

Tomamos el ejemplo de zhào xiàng ji 照相機 para demostrar el análisis de morfemas en mandarín. Esta es una palabra compuesta de tres caracteres. Cada carácter es un morfema con tono fonético y contenido semántico propio. El significado léxico que representa cada morfema es: zhào 照 'reflejar', xiàng 相 'aspecto' jٓ 機 'máquina'. En total son tres los elementos que componen la palabra equivalente a cámara en español. Además, se observa que los morfemas son monosilábicos.

Sin embargo, Sun (2003: 149) indica que hay morfemas bisilábicos, aunque son escasos pues solo ocupan un $3 \%$ de los morfemas del chino mandarín. Esta clase de morfemas se divide en tres tipos: a) los que pertenecen al ámbito designativo de las plantas y los animales; b) los que repiten el mismo fonema inicial o el mismo fonema final; c) los préstamos de otras lenguas extranjeras modernas. Véanse algunos ejemplos de cada tipo:

a) biān fú 蝙蝠 murciélago mù sù 苩宿 alfalfa hú dié 蝴蝶 mariposa

b) fēn fù 吩咐 orden, petición āng zāng 骯骿 suciedad líng lóng 玲瓏 delicado, fino

c) tăn kè 坦克 tanque shā lóng 沙龍 salón shā fā 沙發 sofá

En chino mandarín, al hablar de los componentes morfológicos, es indispensable distinguir bien entre el concepto de morfema y el de palabra. Desde el punto de vista sintáctico, el concepto de "palabra" equivale a cí 詞

25 Ha de destacarse que todos los "caracteres chinos" son monosilábicos. Sin embargo, un carácter no necesariamente es por sí mismo un morfema, ni mucho menos una palabra. 
en mandarín, que puede consistir en solo uno o más morfemas, los cuales aportan un significado determinado. En mandarín la relación entre el significado léxico de cada morfema y el de la palabra completa puede ser de tres tipos, que dependen del grado de composicionalidad. Así, una palabra puede estar constituida por varios morfemas que aportan, cada uno de ellos, un significado relacionado con el significado global de la palabra. Pero también hay palabras cuyo significado total no puede deducirse del sentido de cada constituyente. Por ejemplo, bing xiāng 冰箱 nevera es una palabra que está constituida de manera composicional por dos morfemas cuyos significados son 'hielo' y 'caja', respectivamente. Sin embargo, la palabra shí tóu 石頭 piedra consta del morfema shí 石, hoy anticuado, que en chino clásico significaba 'piedra', y tóu 頭, que sufre una pérdida de su contenido semántico originario 'cabeza' y adquiere un significado abstracto para denotar entidades no personales. Finalmente, los dos morfemas de la palabra compuesta chì cù 吃醋 significan 'comer' y 'vinagre', pero no guardan relación con el significado del conjunto celoso.

Los conceptos de zì 字 (morfema) y cí 詞 (palabra) han cambiado en el mandarín moderno con respecto al chino clásico. En el chino clásico no se diferenciaba entre zì 字 (morfema) y cí 詞, (palabra) porque todas las palabras constaban de un solo morfema y todos los morfemas eran monosilábicos. La mayoría de los morfemas (o caracteres) equivalía por sí mismo a una palabra y por lo tanto el idioma chino clásico se considera una lengua monosilábica. Sin embargo, Chao (1968: § 3.1.2) indica la existencia de algunas palabras bisilábicas en chino clásico, aunque son pocas y suelen proceder de préstamos antiguos, como wú gōng 蜈蚣 ciempiés, chóu chú 躊 躇 fluctuante y méi gui 玫瑰 rosa.

Por otro lado, en el chino mandarín moderno, con la evolución histórica y la influencia del extranjerismo, se dispone cada vez más de palabras bisilábicas o polisilábicas, como bō lí 玻璃 cristal, shè huì 社會 sociedad, hā mì guā 哈密瓜 melón japonés, etc. Así, se distingue el zì 字 (morfema) del cí 詞 
(palabra), pues cí 詞 (palabra) puede estar constituido por un zì 字 (morfema) o por más de un zì 字 (morfema). Dicho de otra manera, si bien antiguamente en chino clásico predominaban las palabras monosilábicas, en la actualidad existe una clara tendencia a la bisilabidad.

\subsection{Flexión y derivación: problemas de reconocimiento de las categorías flexivas}

El mandarín se consideraba tradicionalmente una lengua de morfología pobre en comparación con las lenguas indoeuropeas por la falta de accidentes gramaticales y por el escaso uso de la afijación. Sin embargo, en los estudios actuales muchos autores, como Hu (1992: 17), entre otros, han cuestionado tal teoría, pues defienden la existencia de una base morfológica en el mandarín moderno e indican que en chino mandarín las palabras se forman mediante varios procesos, entre los que se incluyen la afijación, la composición, la reduplicación y la abreviación. Estos procesos morfológicos, en general, resultan en la actualidad muy frecuentes por la expansión de los neologismos chinos que tratan de imitar formaciones de otras lenguas. Además, el uso de los clasificadores aún enriquece más el vocabulario del mandarín, al mismo tiempo que aumenta la productividad de la composición.

Ahora bien, aunque se reconocen estos procesos como recursos morfológicos para la creación de palabras, en chino mandarín pervive una cuestión controvertida sobre las diferencias entre la flexión y la afijación, pues los gramáticos, en general, como Li y Thompson (2003: 40), Dong (2004: 84), Jiang (2009: 264), entre otros, suelen situar el mecanismo de la flexión en el mismo nivel que la derivación mediante sufijos, ya que -en su opinión- se trata en ambos casos de posposiciones de determinados formantes a la base léxica. Con todo, los autores que tratan del estatuto de la flexión en mandarín apenas dedican unas pocas páginas a este problema y siempre incluyen su 
tratamiento en el tema general de la derivación. En cualquier caso, los gramáticos del mandarín no se detienen en el análisis de las propiedades diferenciales entre la flexión y la derivación.

En nuestra opinión, aunque los procesos flexivos a veces no se distingan con claridad de los derivativos, pues -como se ha indicado anteriormenteforman parte de un mecanismo continuo, consideramos que para la descripción morfológica de la lengua conviene separar los fenómenos propiamente flexivos de los derivativos. Los primeros crean nuevas formas de una misma palabra, mientras que los segundos forman palabras nuevas. Además, las desinencias flexivas presentan un contenido gramatical (como, por ejemplo, el número, el tiempo, etc.), a diferencia de los afijos que admiten una paráfrasis léxica.

Con respecto a la flexión, aquí se defiende la hipótesis de una morfología flexiva en la lengua china. Estas marcas morfológicas flexivas pueden intercalarse o posponerse a otros morfemas, según la función y los efectos que producen. En mandarín se suele distinguir entre la flexión nominal y la flexión verbal. En la flexión nominal, el formante más tratado por la mayoría de los autores es la partícula que desempeña la función de pluralidad en los sustantivos: men 們. Q.-Z. Wu (2003: 339) y Luo (1999: 184) indican que esta partícula de plural men 們 suele posponerse a los pronombres personales y sustantivos animados de persona para indicar la pluralidad: nǐ men 你們 'tú' + partícula de plural $\rightarrow$ vosotros, lăo shīmen 老師們 'profesor' + partícula de plural $\rightarrow$ profesores, rì běn rén men 旦本人們 'japonés' + partícula de plural $\rightarrow$ japoneses.

Por su colocación pospuesta, algunos gramáticos consideran men 們 como sufijo, aunque expresa la pluralidad. Sin embargo, su aplicación está condicionada por restricciones morfológicas y prosódicas, pues no se adjunta al pronombre interrogativo *shéi men 誰們 quiénes y además después de los sustantivos personales monosilábicos resulta agramatical: *zéi men 賊們 ladrones, *guān men 官們 funcionarios, *guěi men 鬼們 fantasmas. 
Morfología contrastiva del chino mandarín y el español. Formas de gramaticalización y lexicalización

Otra marca que en nuestra opinión también se corresponde con el concepto de marca flexiva nominal es el formante genitivo 的 de, que se pospone al poseedor y desempeña la función gramatical de denotar la relación de posesión. La función de este morfema consiste en indicar que el nombre antepuesto es el complemento nominal del que sigue y así puede considerarse como el caso genitivo (o el posesivo) del primer sustantivo. Seguidamente se ilustran algunos ejemplos de esta marca morfológica:

$\begin{array}{ccc}\text { a) 我 } & \text { 的 } & \text { 眼鏡 } \\ \text { Wǒ } & \text { de } & \text { yăn jing } \\ \text { Yo } & \text { posesivo } & \text { gafa }\end{array}$ Mis gafas

\begin{tabular}{|c|c|c|c|}
\hline ) 中 & 文 & 的 & 語法 \\
\hline Zhōng & wén & de & yǔ fă \\
\hline ino & lengua & posesivo & gramática \\
\hline
\end{tabular}

Respecto a la flexión verbal, Wang (2000a: 441-444) indica que hay un grupo de marcas verbales que puede expresar diferentes relaciones gramaticales. Los ejemplos más evidentes son las partículas verbales le 了, zhe 著, zài 在 y guò 過, que se posponen al verbo para expresar el significado de tiempo pasado, aspecto resultativo, aspecto durativo o la experiencia, respectivamente. La partícula le 了 se suele posponer al verbo para denotar una acción determinada en el tiempo pasado: chīle 吃了 'comer' + partícula $\rightarrow$ he comido, comí; chū qù le 出去了 'salir' + partícula $\rightarrow$ he salido, salí. Las partículas zhe 著 y zài 在 especifican el resultado o la duración de la acción o el estado expresado por el verbo. Esta última se antepone al verbo (como en b), mientras que la primera, zhe 著, se coloca entre el verbo y su complemento (como en a): 
a) 他拿著書

Tā ná zhe shū

Él coger asp.res. libro.

Tiene (cogidos) los libros.

b) 我在穿鞋子

Wǒ zài chuān xié zi

Yo asp. dur. llevar zapato

Estoy poniéndome los zapatos.

La partícula guò 過 se usa pospuesta a un verbo para expresar la experiencia. Este significado se suele traducir al español mediante las formas compuestas con haber + participio: kàn guò 看過 'ver' + partícula $\rightarrow$ haber visto, jiăn chá guò 檢查過 'examinar' + partícula $\rightarrow$ haber examinado, kăo lù guò 考慮過 'considerar' + partícula $\rightarrow$ haber considerado.

También existen partículas verbales bisilábicas que introducen modificaciones aspectuales. Entre ellas, cabe destacar las formas chǐ lái 起來 que expresa el aspecto incoativo y xià qù 下去 que marca el aspecto continuativo. La primera suele emplearse con la partícula pospuesta le 了:

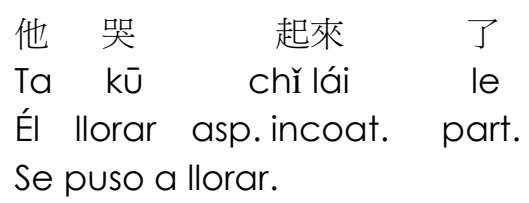

我們看 下去

Wǒ men kà xià qù

Yo pluralidad ver asp. contin.

Seguimos viendo.

Además de estas marcas morfológicas de función gramatical, el tiempo verbal del chino mandarín también puede expresarse por medios léxicos (con adverbios) y con formas auxiliares. Normalmente estos marcadores temporales se anteponen al verbo:

$\begin{array}{lcr}\text { 我 } & \text { 昨天 } & \text { 出去 } \\ \text { Wǒ } & \text { zoú tiān } & \text { chū qù } \\ \text { Yo } & \text { adv. de tiempo } & \text { salir } \\ & \text { 'ayer' } & \end{array}$

Ayer salí. 
Morfología contrastiva del chino mandarín y el español. Formas de gramaticalización y lexicalización

\begin{tabular}{lllll} 
我 & 已經 & 遞出 & 辭 & 呈 \\
Wǒ & yĩ qīng & dì chū & cí & chéng \\
Yo & adv. de tiempo & presentar & despedida & carta \\
\multicolumn{4}{r}{} \\
He presentado la carta de despedida.
\end{tabular}

$\begin{array}{lcccc}\text { 總統 } & \text { 現在 } & \text { 正在 } & \text { 演 } & \text { 講 } \\ \text { Zǒng tǒng } & \text { xiăn zài } & \text { zhèng zài } & \text { yiăn } & \text { jiăng } \\ \text { Presidente } & \text { adv. de tiempo } & \text { forma auxiliar } & \text { realizar } & \text { discurso } \\ & \begin{array}{c}\text { 'ahora' } \\ \text { El presidente ahora está dando un discurso. }\end{array} & \end{array}$

Sería una idea errónea, pero considerada tradicionalmente, que el chino mandarín es una lengua carente de flexión porque todos los morfemas son monosilábicos con significado léxico. Con lo expuesto arriba, debería admitirse la descripción del mandarín moderno como una lengua flexiva, ya que las variaciones gramaticales de una misma palabra se expresan mediante marcas sin contenido léxico. En este sentido, los formantes gramaticales que se añaden al sustantivo para indicar la pluralidad y la posesión, y los formantes funcionales que se agregan al verbo para indicar tiempo y aspecto se deben consideran -en nuestra opinión- procesos flexivos. En efecto, algunos gramáticos, como Chang (1987) Cheng (1992: 245), Hu (1992: 18) etc., han apoyado la existencia de flexión en el chino mandarín en la actualidad. Sin embargo, estos autores creen que los procesos flexivos equivalen a la interfijación o a la sufijación, dado que la morfología flexiva se expresa mediante la adición de un formante intercalado o pospuesto a otros morfemas. En general, como se ve, estos autores no toman en consideración las diferencias entre los tipos de significados, léxicos o gramaticales, que pueden aportar los afijos. De aquí que se produzca cierta confusión al clasificar estos elementos como formantes flexivos o formantes derivativos. Por ejemplo, la mayoría de los gramáticos clasifican el morfema de pluralidad men 們 en el ámbito derivativo, aunque expresa el número de los sustantivos. 
En nuestra opinión, la flexión del mandarín es indudable y no debería confundirse con el concepto de afijación, aunque ambos procesos consisten en la adición de formantes (Ulloa 2006). En la flexión, los formantes intercalados o pospuestos producen efectos funcionales y gramaticales, mientras que en la afijación los formantes añadidos producen efectos léxicos. El contenido semántico de los formantes flexivos es predecible y con fecuencia abstracto, mientras que los formantes derivativos tienden a presentar un significado más concreto e imprevisible en gran medida. Los formantes flexivos suelen formar un conjunto cerrado de elementos, frente a la arbitrariedad y variedad de los afijos derivativos. En chino mandarín, como en todas las lenguas, los formantes flexivos crean nuevas formas de palabras y regularmente alcanzan al paradigma léxico en su conjunto, mientras que los formantes derivativos crean nuevas palabras con entrada propia en los diccionarios, pero presentan un alcance limitado a determinados rasgos subcategoriales.

\subsection{Afijación: sufijación, prefijación e interfijación}

En el ámbito de la afijación, aunque el mandarín no cuenta con la riqueza de afijos que presentan las lenguas occidentales, sí que dispone de afijos que se comportan como morfemas dependientes, pues se agregan a los morfemas léxicos para formar palabras. Interesa, por tanto, destacar la importancia morfológica de este proceso derivativo.

En mandarín moderno, los sufijos son más numerosos que los prefijos y los interfijos. Aunque no se ha alcanzado todavía un acuerdo entre los gamáticos sobre su naturaleza e inventario, es incuestionable la definición de que los sufijos son morfemas dependientes que se sitúan al final del elemento léxico para formar una nueva palabra. Para la gramática tradicional del chino, aunque todavía se plantean algunas dificultades para delimitar el número de 
Morfología contrastiva del chino mandarín y el español. Formas de gramaticalización y lexicalización

sufijos, se reconocen varios tipos de estos formantes y se afirma que son más comunes que los prefijos o infijos.

Algunos gramáticos, como Chao (1968: 228-245), Chen (2001), Jiang (2009) y LU (1957), etc., indican que los principales sufijos que caracterizan la formación de palabras, preferentemente sustantivos, en chino son: ér 兒, zi 子， tóu 頭, rán 然 y bā巴. Este grupo de sufijos-que pertenecen al tipo de los afijos convencionales- es de índole más bien gramatical que léxica. Por tanto, serían sufijos próximos a los de tipo flexivo, y no tanto derivativo. El estudio que sigue a continuación de estos sufijos formativos se corresponde más propiamente con los objetivos de nuestro trabajo.

El proceso de formación de palabras con el sufijo ér 兒 se denomina ér huà cí 兒化詞 ("palabrizar", hacer palabras) y es muy frecuente. La formación se basa en la vocal retrofleja ér 兒 pospuesta a la palabra. Este es el único sufijo no silábico del mandarín porque se amalgama con la sílaba precedente. En los sustantivos, ér 兒 puede agregarse a los morfemas con o sin autonomía léxica y a las palabras compuestas. Así, a los morfemas con autonomía léxica, como niăo ér 鳥兒 pájaro, huā ér 花兒 flor， nǔ hái ér 女孩兒 chica; a los morfemas sin autonomía léxica (los llamados morfemas libres ligados, vid. §2. 2, apdo. 4), como wèi ér 味兒 sabor y yàng ér 樣兒 aspecto o forma; a las palabras compuestas, como zhăo chá ér 找碴兒 'buscar' 'problema' + sufijo (verbo-objeto-ér) $\rightarrow$ buscapleitos, dăn ér dà 膽兒大 'coraje' + sufijo 'grande' (verbo-ér-predicado) $\rightarrow$ tener mucho coraje y chàng wán ér 唱完兒 'cantar' 'terminar' + sufijo (verbo-complemento- ér) $\rightarrow$ terminar de cantar, etc.

La productividad de ér 兒 alcanza a sustantivos, verbos, adjetivos y adverbios: con los adjetivos, como fāng ér 方兒 cuadrado, liàng ér 亮兒 luminoso; con los verbos, como chàng ér 唱兒 cantar, kū ér 哭兒 llorar; con los adverbios o locuciones adverbiales, como i kuài ér 一塊兒 conjuntamente, î hŭi ér 一會兒 a ratos, īzǒu ér 一早兒 por la mañana. Por otra parte, Chao (1968: 228-229) indica que ér 兒 se ha extendido a otras formas, como los adverbios de lugar: zhè ér 這兒 aquí y nà ér 那兒 allí, y de tiempo: jīn ér 今兒 hoy, míng ér 
明兒 mañana， y a los clasificadores: ȳ̄ băn ér shū 一本兒書 'uno' '(clas.) volumen' 'suf.' 'libro' $\rightarrow$ un volumen (de libro), yī zhāng ér zhǐ 一張兒紙 'uno' '(clas.) hoja' 'suf.' 'papel' $\rightarrow$ una hoja de papel. Por los ejemplos aportados, puede comprobarse que la función principal de este sufijo convencional se limita al plano morfonológico, pues el sufijo en sí no aporta ningún contenido semántico ni tampoco desempeña una función gramatical específica. Por tanto, consideramos, por nuestra parte, que este formante no pertenece a la clase de los afijos derivativos, como habitualmente se dice, sino que su función se reduce al ámbito morfonológico, pues representa un recurso comparable -salvando las distancias- al de la paragoge (de fraque por frac, por ejemplo).

El sufijo zi 子 se combina con varios tipos de morfemas. Comparado con ér 兒, zi 子 no es tan productivo, pero también puede proporcionar el polisilabismo de las palabras, sin aportar ningún significado ni léxico ni gramatical, como en las formaciones siguientes: a) sustantivos, en general, como: zhuō zi 桌子 mesa, kuài zi 筷子 palillos, xié zi 鞋子 zapato, jiăo zi 餃子 empanada, etc.; b) compuestos del tipo verbo-objeto, como: guò rì zi 過旦子 'pasar' 'vida' $\rightarrow$ vivir, yǒu shēn zi 有身子 'tener' 'cuerpo' $\rightarrow$ estar embarazada. Pero también puede desempeñar funciones léxicas y gramaticales, sin que resulte fácil distinguir entre estos dos campos, como en los siguientes casos: a) nombres deverbales de acción o instrumento: jiá zi 夾子 'pinzar' 'suf.' $\rightarrow$ pinza, chù zi 鉅子 'serrar' 'suf.' $\rightarrow$ sierra, shū zi 梳子 'peinar' 'suf.' $\rightarrow$ peine, zuàn zi 鑽子 'destornillar' 'suf.' $\rightarrow$ destornillador, etc.; b) formaciones afectivas con nombres de parentesco como: lăo mā zi 老媽子 'madre' 'suf.' $\rightarrow$ madre, jiù zi 舅子 'hermano de la madre' 'suf.' $\rightarrow$ hermano de la madre, xīn niáng zi 新娘子 'novia' 'suf.' $\rightarrow$ novia; c) sustantivación de adjetivos de cualidades físicas o mentales de las personas, normalmente de signo negativo, como: pàng zi 胖子 'gordo' 'suf.' $\rightarrow$ el gordo, xiā zi 瞎子 'ciego' 'suf.' $\rightarrow$ el ciego, shă zi 瑷子 'tonto' 'suf.' $\rightarrow$ el tonto, fēng zi 瘋子 'loco' 'suf.' $\rightarrow$ el loco, etc.; d) formación de cuantificadores universales como: yī wū zi 一屋子 'uno' 'casa' 'suf.' $\rightarrow$ toda la 
Morfología contrastiva del chino mandarín y el español. Formas de gramaticalización y lexicalización

casa, ȳ̄ bèi zi 一輩子 'uno' 'vida' 'suf.' $\rightarrow$ toda la vida, ȳ̄ jiā zi 一家子 'uno' 'familia' 'suf.' $\rightarrow$ toda la familia, etc.

El sufijo tóu 頭 se añade a sustantivos que en el uso actual tienden a usarse como palabras bisilábicas: mán tóu 饅頭 pan, mù tóu 木頭 madera, shí tóu 石頭 piedra, y casi todas los nombres que designan partes del cuerpo (shé tóu 舌頭 lengua, gǔ tóu 骨頭 hueso). Pero además de esta función morfonológica, también desempeña funciones léxicas y gramaticales, como las siguientes: a) nombres deverbales de efecto y resultado, como: niàn tóu 念 頭 'pensar' 'suf.' $\rightarrow$ idea, zhǔn tóu 準頭 'ajustar, reglar' 'suf.' $\rightarrow$ norma, regla, modelo, kàn tóu 看頭 'ver' 'suf.' $\rightarrow$ interés, zhuàn tóu 賺頭 'ganar' 'suf.' $\rightarrow$ rentabilidad; b) nombres deadjetivales de cualidad, como: ǩu tóu 苦頭 'amargo' 'suf.' $\rightarrow$ amargura, tián tóu 甜頭 'dulce' 'suf.' $\rightarrow$ dulzura; c) adverbios de dirección, como: jián tóu 前頭 delante, hòu tóu 後頭 detrás, lǐ tóu 裡頭 dentro, wuài tóu 外頭 afuera, shàng tóu 上頭 arriba, xià tóu 下頭 abajo.

Según Li y Thompson (2003: 46), la razón de que existan tantos términos derivados en zi 子 y tóu 頭 se basa en la fuerte tendencia del mandarín moderno a formar palabras polisilábicas. Estos sufijos convencionales, que nunca pueden aparecer como palabras independientes, se omiten cuando se combinan con otros morfemas para formar compuestos: mù tóu 木 頭 madera， pero mù băn 木板 'madera' 'tabla' $\rightarrow$ tabla de madera, mù tàn 木炭 'madera' 'carbón' $\rightarrow$ carbón de leña; shí tóu 石頭 piedra, pero shí gāo 石膏 'piedra' 'grasa, manteca' $\rightarrow$ yeso, shí huī 石灰 'piedra' 'polvo' $\rightarrow$ cal, shí diāo 石雕 'piedra' 'estatua' $\rightarrow$ estatua de piedra; xié zi 鞋子 zapato, pero pí xié 皮鞋 'cuero' 'zapato' $\rightarrow$ zapato de cuero, tuō xié 拖鞋 'arrastrar, fregar' 'zapato' $\rightarrow$ sandalia, bù xié 布鞋 'trapo' 'zapato' $\rightarrow$ zapato deportivo; hái zi 孩子 niño, hijo, pero nán hái 男孩 'hombre' 'niño' $\rightarrow$ niño, nǔ hái 女孩 'mujer' 'niño' $\rightarrow$ niña, xiăo hái 小孩 'pequeño' 'niño' $\rightarrow$ niño, hijo. Esta simplificación de zi 子 y tóu 頭 en la composición demuestra, en suma, que la función fundamental que desempeñan en la formación léxica se limita al apoyo morfonológico. 
Rán 然 en chino clásico tiene el significado de 'modo, manera'. En el chino moderno se integra con otros morfemas para formar adverbios composicionales: hū rán 忽然 repentinamente, xiăn rán 顯然 obviamente, gōng rán 公然 públicamente, dāng rón 當然 supuestamente, jū rán 居然 inesperadamente. Pero también da lugar a algunas conjunciones, como sūi rán 雖然 aunque, ji rán 既然 como causal.

Finalmente, bā 巴 es el sufijo convencional tal vez el menos productivo de todos, que únicamente desempeña funciones morfonológicas dirigidas a formar palabras bisilábicas, que como tales, resultan no composicionales, como: zŭi bā 嘴巴 boca, yă bā 啞巴 mudo, ní bā 泥巴 barro, ǐ bā 尾巴 cola， yán bā 鹽巴 sal.

Respecto al inventario de los sufijos, aunque existen divergencias entre las diversas propuestas sobre la delimitación y definición, se ha reconocido un aspecto fundamental en la lingüística china sobre los sufijos: el sufijo se distingue de la raíz en que es una entidad morfológica dependiente y se somete a la regularidad de la posposición constante a un elemento léxico.

Chu (2001: 24-26) plantea cinco criterios para la adscripción de un elemento a esta categoría:

El primero se basa en la posición invariable y en su condición de elemento ligado. Los sufijos no pueden aparecer aisladamente y siempre se posponen a la base léxica para formar palabras. En comparación con los morfemas libres, los sufijos difieren de ellos en desempeñar solo una función gramatical, carecer de significado semántico y también de la libertad posicional que presentan los elementos léxicos. Según este autor, por ser una lengua casi carente de flexión y con poca riqueza de sufijos, la relación entre los elementos léxicos y los morfemas del mandarín no se expresa a través de las desinencias flexivas ni los cambios de sufijos, sino en el orden de los morfemas y la adición de elementos gramaticales. 
El segundo criterio expuesto por Chu se refiere a la determinación de la categoría gramatical. En el proceso de formación de palabras derivadas, el sufijo desempeña la función de determinar la categoría gramatical de la palabra resultante. Por ejemplo, las palabras acabadas en zi 子 son sustantivos; las palabras acabadas en rán 然 son adjetivos o adverbios, pues este morfema se utiliza para describir la forma y el estado.

El tercer factor toma en consideración la productividad morfológica. Todos los sufijos del mandarín reciben el efecto analógico que produce series de palabras. No existe ningún sufijo que seleccione solo una o dos bases léxicas. Es decir, todos los sufijos crean más de tres formas y con la influencia del extranjerismo y neologismo, se aumenta la creación de palabras derivadas con sufijos.

El criterio siguiente que introduce este autor se relaciona con la imposibilidad de intercalación. La adyacencia estricta entre la base léxica y el sufijo no permite la inserción de ningún otro elemento. Por ejemplo, el morfema měi 每, aunque presenta una posición invariable y además alcanza una alta productividad en la formación de sustantivos, no se clasifica como un prefijo típico del mandarín porque admite la interposición de los numerales, como muestran los ejemplos siguientes:

měi ȳi tiān 每一天 'cada' 'uno' 'día' $\rightarrow$ cada día měi liăng rén 每兩人 'cada' 'dos' 'persona' $\rightarrow$ cada dos personas měi wǔ nián 每五年 'cada' 'cinco' 'año' $\rightarrow$ cada cinco años

Por último, Chu trata del debilitamiento fonético. Aunque el debilitamiento fonético no es la característica principal de los sufijos, también constituye un aspecto distintivo de los sufijos en relación con los elementos léxicos libres. Por ejemplo, zi 子 y tóu 頭 responden al significado de 'hijo' y 'cabeza', respectivamente. Sin embargo, al desempeñar el papel de sufijos, estos dos formantes sufren una pérdida de contenido semántico, acompañada por el debilitamiento del tono de intensidad. Así, cuando se emplean como sufijos en palabras derivadas, se distinguen de su uso como 
raíces en el tono ligero y breve característico del debilitamiento fonético. Más evidente es el caso de ér 兒, cuyo significado original es 'hijo', pero como sufijo en palabras derivadas, se amalgama con la sílaba precedente y no llega a considerarse como una unidad silábica.

Frente a la sufijación, en chino mandarín la prefijación se considera un poceso morfológico menos productivo. Los prefijos son morfemas que se colocan delante del término léxico para formar una nueva palabra. Según Li y Thompson (2003: 37-38) y Chao (1968: §4.3), los prefijos convencionales se limitan a los siguientes: lăo 老, xiăo 小, dì 第, chū 初, $\bar{a}$ 阿 y kě 可.

El significado léxico de lăo 老 y xiăo 小 se corresponde en español con el de los adjetivos 'viejo' y 'pequeño' e incluso con el del diminutivo -ito en este último caso: lăo chē 老車 'viejo' 'vehículo' $\rightarrow$ coche viejo, xiăo māo 小貓 $\rightarrow$ gatito. Se utilizan también en el lenguaje familiar seguido de apellidos para expresar el cariño y equivalen a los hipocorísticos: lăo zhāng 老張, xiăo zhāng 小 張 (a partir del apellido zhāng). En comparación con xiăo 小, el prefijo lăo 老

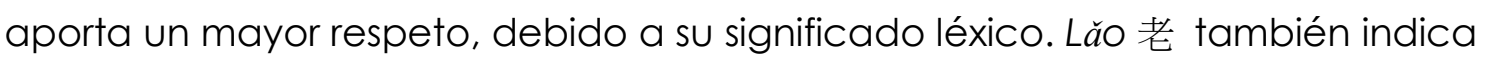
el orden de mayor a menor edad de los miembros de la familia, especialmente entre los hijos y los hermanos. Se utiliza delante de los números del dos al diez: lăo èr 老二 el segundo hijo (mayor), lăo sān 老三 el tercer hijo (mayor). El primer hijo no se expresa, sin embargo, mediante el número uno sino con el adjetivo grande: lăo dà 老大.

Tanto dì 第 como chū 初 van antepuestos a los numerales. Dì 第 se coloca delante de los numerales cardinales para formar los ordinales: dì yī 第一 primero, di liù 第六 sexto. Por su parte, chū 初 es un prefijo que precede a un número cardinal del uno al diez para denominar los primeros diez días del mes

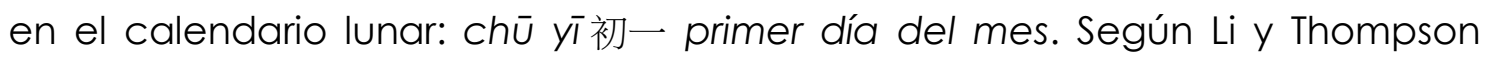
(2003: 38), aunque hay un debate sobre el estatuto de los morfemas di 第 y chū 初 como prefijos o como elementos compositivos, se adopta aquí su clasificación entre los prefijos porque desempeñan una función gramatical y, de por sí, carecen de autonomía léxica. 
Morfología contrastiva del chino mandarín y el español. Formas de gramaticalización y lexicalización

Entre los prefijos tradicionales, $\bar{a}$ 阿 es el único que no aporta un significado léxico determinado, pues se antepone exclusivamente a los nombres de persona con sentido familiar, cariñoso, burlesco o despectivo: ā bà 阿爸 'pref.' 'padre' $\rightarrow$ padre, ā Míng 阿明 'pref.' 'nombre propio de persona' $\rightarrow$ Míng, ā sān 阿三 'pref.' 'tres' $\rightarrow$ bobo, hombre torpe.

Kě 可 se antepone a los verbos para formar adjetivos. Su significado corresponde al sufijo -ble del español que designa la posibilidad pasiva, es decir, la capacidad o aptitud para recibir la acción del verbo: kě jing 可敬 'pref.' 'respetar' $\rightarrow$ respetable, kě néng 可能 'pref.' 'poder' $\rightarrow$ posible, kě pà 可怕 'pref.' 'temer' $\rightarrow$ horrible, kěxíng 可行 'pref.' 'practicar' $\rightarrow$ practicable. Sin embargo, en algunos casos, estas formaciones no resultan composicionales, pues el verbo pospuesto pierde en parte su significado léxico y el complejo se lexicaliza para usarse como en una expresión idiomática: kě xí 可惜 'pref.' 'lamentar' $\rightarrow$ dar pena, kě jiàn 可見 'pref.' 'ver' $\rightarrow$ ser evidente, kě lián 可憐 'pref.' 'lastimar' $\rightarrow$ dar lástima.

Los prefijos comparten con los sufijos algunas propiedades, como la posición invariable, el efecto analógico que produce series de palabras y la imposibilidad de intercalación. Los prefijos se asemejan a los sufijos en el hecho de que ambos son morfemas ligados que solo aportan un significado léxico o gramatical y no admiten la alteración de posición en la formación compleja. Respecto a la condición de anteposición inmediata del prefijo a la base léxica, sin elementos intercalados, Chu (2001) indica que el desacuerdo en el inventario de los prefijos del mandarín se relaciona con esta característica morfológica. Según este autor, en ocasiones, un mismo morfema puede desempeñar distintos comportamientos funcionales y semánticos según el contexto en que se encuentra. De esta forma, se plantea el problema de definir su naturaleza y, en virtud de esta, reconocer su clasificación entre los diferentes tipos morfológicos. Por ejemplo, dă 打 desempeña la función de prefijo antepuesto a verbos, como en los ejemplos de 1), que se corresponde con un auxiliar de modalidad comparable a las perífrasis españolas de infinitivo 
con 'intentar, procurar, tratar de', con valor de 'intención' (Fernández de Castro 1999: 53, Gómez Torrego 1999: §51.3.1.7). Sin embargo, en 2) se antepone a los cuantificadores que determinan a nombres continuos o de materia y también adquiere un significado verbal:

1) dă tīng 打聽 'pref.' 'escuchar' $\rightarrow$ tratar de escuchar dă bàn 打扮 'pref.' 'arreglar' $\rightarrow$ intentar arreglarse dă diăn 打點 'pref.' 'ordenar' $\rightarrow$ tratar de ordenar

2) dă diăn cài 打點菜 'coger' 'poco' 'comida' $\rightarrow$ coger algo de comida dă xiē jiǔ 打些酒 'coger' 'poco' 'alcohol' $\rightarrow$ coger algo de vino dă diăn fàn 打點兒飯 'coger' 'poco' 'arroz' $\rightarrow$ coger algo de arroz

Esta característica forma parte de las dificultades que complican la clasificación y la definición de los prefijos. Sin embargo, por nuestra parte, podríamos sugerir que se trata de un prefijo polisémico con una doble definición gramatical, y no solo léxica, comparable -solo en cierto modo- a la que, por ejemplo, se da en español con el prefijo in-.

En las descripciones morfológicas del mandarín, el término interfijo también es utilizado por algunos gramáticos para designar un fenómeno similar al de las lenguas indoeuropeas. En mandarín los interfijos son muy escasos. Por su colocación en el interior de una palabra, algunos autores como Chang (1994: 90) y Chao (1968) indican que este tipo de morfemas equivale a los auxiliares, conjunciones o adverbios según la función que desempeñan en cada caso. El llamado complemento potencial dé 得 (ejemplificado en 1) y el marcador de negación bù 不 (en 2) son los ejemplos prototípicos de interfijos que ofrecen las gramáticas chinas, aunque se corresponderían más propiamente con los auxiliares modales (especialmente de tipo epistémico) o aspectuales de las gramáticas del español. Estas partículas se colocan entre un verbo de acción y el término que indica el aspecto resultativo:

1) shuō dé gīng chǔ 說得清楚 'decir' + interf. modal ('poder') + 'claro'(asp. resultativo) $\rightarrow$ poder llegar a decir claramente

kàn dé daò 看得 到 'ver' + interf. modal ('poder') + 'llegar' (asp. resultativo) $\rightarrow$ poder llegar a ver 
Morfología contrastiva del chino mandarín y el español. Formas de gramaticalización y lexicalización

2) shūo bù qīng chǔ 說不清楚 'decir' + interf. modal negativo ('no poder') + 'claro' (asp. resultativo) $\rightarrow$ no poder llegar a decir claramente

kàn bù daò 看不到 'ver' + interf. modal negativo ('no poder') + 'llegar' (asp. resultativo) $\rightarrow$ no poder llegar a ver.

Para Guo y Qiao (2007), İ̌ 里 y yī - también se identifican con los interfijos, pues son morfemas ligados que siempre se colocan en posición interfijada. Estos elementos se caracterizan por no aportar significado léxico, no alterar la categoría gramatical del educto ni cambiar el significado nocional de la base. En los siguientes ejemplos, $l_{i}$ 里 es un enlace de repetición para expresiones fijas que presentan la forma $A \mid \check{l}$ 里 $A B$ (como en 1 ), mientras que $y \bar{l}$ - se intercala entre verbos duplicados del tipo A yī - A y presenta la significación de 'un poco', 'de una vez' o el sentido de 'intentar hacer algo' (como en 2):

1) hú lǐ hú tú 糊里糊塗 'borroso' 'interf.' 'borroso' 'pintar' $\rightarrow$ descuidado, confundido

gǔ lǐ gǔ guài 古里古怪 'antiguo' 'interf.' 'antiguo' 'raro' $\rightarrow$ raro

2) shuō ȳ̄ shuō 說一說 'decir' 'interf.' 'decir' $\rightarrow$ decir de una vez, intentar decir algo

chì yī chī 吃一吃 'comer' 'interf.' 'comer' $\rightarrow$ comer de una vez, comer un poco, intentar comer algo

Para los gramáticos que se oponen al análisis de estos elementos como interfijos, su propuesta entre los procedimientos de formación de palabras resulta difícil de determinar, pues algunos estudios defienden la idea de que tales unidades son marcadores de formaciones idiomáticas o usos especiales de palabras separables del chino mandarín. Por ejemplo, en opinión de Zhu (1991), el complemento potencial dé 得 y el marcador de negación bù 不 no son elementos opcionales, pues su supresión daría resultados agramaticales. Así, el autor considera que estos elementos no han de clasificarse entre los interfijos, sino que deben definirse como formantes necesarios para algunas formaciones complejas especiales o frases hechas: 
chī dé kāi 吃得開 'comer' + interf. modal ('poder') + 'abrir' (asp. resultativo) $\rightarrow$ tener enchufe

chī bù xiāo 吃不消 'comer' + interf. modal negativo ('no poder') + 'digerir' (asp. resultativo) $\rightarrow$ ser incapaz de aguantar o soportar

En suma, pese a que el concepto de interfijo en chino mandarín resulta polémico, se ha aceptado generalmente en la lingüística china el estatuto especial de los elementos dé 得, bù 不, $l \grave{l}$ 里 y yī- como un tipo de interfijación que mantiene una estrecha relación entre las bases léxicas y se han considerado elementos necesarias para la formación de verbos modales o expresiones específicas de repetición, como en los ejemplos mencionados.

\subsection{Los afijoides o pseudoafijos}

Además de los afijos tradicionales, conviene tratar de otros grupos de formantes que, en general, provienen de la traducción de las lenguas occidentales. Desde que Lü (1990 [1979]) adoptó la teoría de la adición de un formante morfológico híbrido delante o detrás de una base léxica, estos elementos suelen denominarse "prefijoides / pseudoprefijos y sufijoides / pseudosufijos", como en las lenguas indoeuropeas. Sin embargo, para otros autores, como Ma (1995) y Wang (2008), este grupo de elementos plantea problemas de definición y delimitación entre los tipos morfológicos de la derivación y la composición. En efecto, su estatuto gramatical resulta bastante controvertido. Por un lado, se asimilan a los afijos por su posición constante y su productividad en la formación léxica. Pero por otro lado, se asemejan a las unidades léxicas por el contenido semántico que aportan a la formación del significado de la palabra compleja. Así, en chino mandarín, todavía no existe un acuerdo mayoritario sobre el número de estos elementos ni se reconoce su identidad como categoría independiente entre los otros tipos morfológicos. 
Morfología contrastiva del chino mandarín y el español. Formas de gramaticalización y lexicalización

Pese a que no hay consenso en la definición ni en el inventario de estas unidades, la lingüística china se ha mostrado unánime al considerar que los prefijoides y los sufijoides son más productivos que los auténticos prefijos y sufijos tradicionales. En el sistema morfológico del mandarín, estas unidades ocupan una parte significativa por su alta productividad y rentabilidad en la formación léxica para la expresión de conceptos nuevos. Wang (2007: 35) y Xu (2007: 134) indican que tal productividad y rentabilidad se relacionan con la influencia de las lenguas extranjeras en el mandarín. En efecto, en chino moderno muchos prefijoides y sufijoides son producto de la traducción de los auténticos prefijos y sufijos de las lenguas foráneas. Cuando estos elementos se introducen en el chino moderno, no se consideran auténticos prefijos o sufijos porque el chino mandarín se identifica tradicionalmente con una lengua aislante que se caracteriza por las palabras monosilábicas, de manera que estos formantes, frente a los afijos, presentan autonomía léxica. Además, los prefijoides y sufijoides al traducirse al chino alcanzan una mayor frecuencia de uso y una alta productividad para la formación de nuevas palabras.

Entre los prefijoides más habituales de las lenguas extranjeras, se encuentran sobre todo los de carácter calificativo, cuantificador o deíctico, como wèi 偽 'seudo-', bàn 半 'semi-', chāo 超 'super-', cì 次 'sub-', dān 單 'mono-', duō 多 'multi-', făn 反 'anti-', hòu 後 'pos(t)-', jián 前 'pre-', etc. Véanse algunos ejemplos:

wèi zhī 偽肢 'seudo-' 'miembro' $\rightarrow$ seudópodo bàn dăo lǐ 半導體 'semi-' 'conducir' 'cuerpo' $\rightarrow$ semiconductor chāo shì 超市 'super-' 'mercado' $\rightarrow$ supermercado ci jí 次級 'sub-' 'categoría' $\rightarrow$ subcategoría dān yīn jié 單音節 'mono-' 'sonido' 'segmento' $\rightarrow$ monosílaba duō guó 多國 'multi-' 'nación' $\rightarrow$ multinacional făn dú 反毒 'anti-' 'droga' $\rightarrow$ antidroga hòu zhì 後製 'pos(t)-' 'producción' $\rightarrow$ posproducción jián zhì 前置 'pre-' 'posición' $\rightarrow$ preposición 
Del mismo modo, entre los sufijoides, los más usuales pueden ser -xué 學 '-logía', -jiā 家 '-ista', -huà 化 '-izar', kǒng jù zhèng 恐懼症 '-fobia', yuán 員 '-dor / -tor', diàn 店 '-ería', etc. De estos, Li y Thompson (2003: 42-43) se detienen en algunos casos. El sufijo xué 學 equivale al formante '-logía', 'tratado, ciencia' y se emplea para designar las especialidades de distintos campos que se introducen del mundo occidental:

xīn lǐ xué 心理學 'corazón' 'teoría' '-logía' $\rightarrow$ psicología

kăo gǔ xué 考古學 'investigar' 'antigüedad' '-logía' $\rightarrow$ arqueología

wù lǐ xué 物理學 'objeto' 'teoría' '-logía' $\rightarrow$ física

huà xué 化學 'transformar' '-logía' $\rightarrow$ química

El formante jiā 家 equivale con frecuencia a los sufijos agentivos españoles '-ista', '-ico', que designan personas que se dedican a alguna actividad profesional:

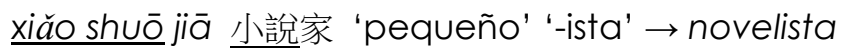

kē xué jiā 科學家 'ciencia' '-ico' $\rightarrow$ científico

zhèng zhì jiā 政治家 'política' '-ico' $\rightarrow$ político

yùn dòng jiā 運動家 'deporte' '-ista' $\rightarrow$ deportista

De los sustantivos y los adjetivos pueden derivarse verbos causativos mediante el sufijo huà 化. El significado se corresponde con el de '-izar' del español:

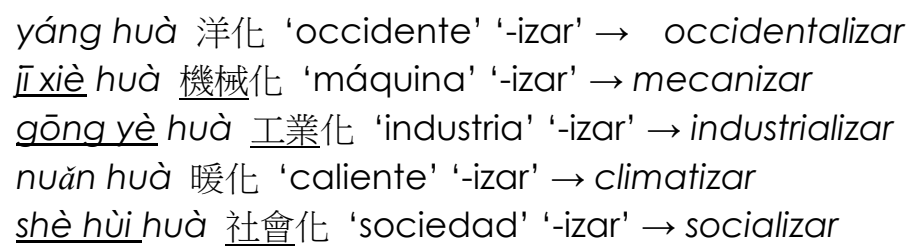

Además de la traducción literal, algunos sufijoides del chino moderno provienen directamente del préstamo y calco de las lenguas extranjeras. Estas unidades se introducen a través de la traducción fonética, luego se transforman en morfemas ligados cuyo significado, en fases iniciales de la imitación, se mantiene fiel al original, pero posteriormente puede alcanzar cierta generalización a través de procesos de gramaticalización. Por ejemplo, 
Morfología contrastiva del chino mandarín y el español. Formas de gramaticalización y lexicalización

en la creación de palabras modernas, una de las unidades más habituales es ba 吧 bar. Este elemento se introduce del inglés al mandarín y al principio se utilizaba solamente para referirse al local en que se despachan bebidas alcohólicas. Pero después, este elemento se libera del significado específico que le dio nacimiento y se generaliza en el uso común para la formación de sustantivos que designan lugares. De hecho, la lengua actual cuenta con una serie de palabras terminadas en ba 吧 que designan sitios de ocio y entretenimiento:

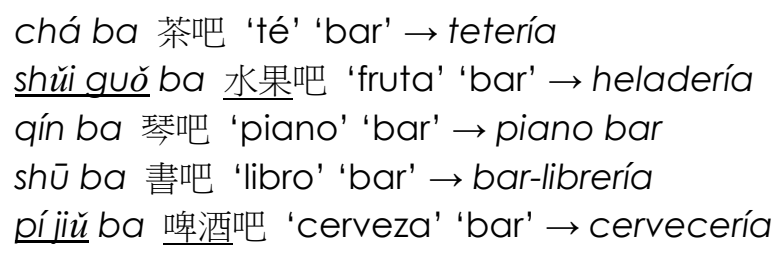

Lo mismo sucede con el desarrollo del nuevo sufijoide xiù 秀 show. Este elemento pasa a designar cualquier tipo de espectáculo:

gāng guăn xiù 鋼管秀 'barra' 'show' $\rightarrow$ pole dance show (esp. baile en barra) tuō kŏU xiù 脫口秀 'talk' 'show' $\rightarrow$ talk show (esp. programa de entrevistas) shí jìng xiù 實境秀 'real' 'condición' 'show' $\rightarrow$ reality televisión (esp. tele-realidad)

rén yāo xiù 人妖秀 'persona' 'transexual' $\rightarrow$ espectáculo de transexuales

Otro ejemplo es el prefijoide del neologismo líng 零 'no-'. Según Liu (2003: 138), a partir de líng 零 'no-' se pueden crear más de 200 formas de sustantivos o verbos que suelen utilizarse al principio en la esfera de la economía y luego se extienden a todos los ámbitos de la vida. El morfema líng 零 'no- ' se clasifica como prefijoide porque presenta una alta productividad, ocupa una posición antepuesta y aporta el significado privativo de falta 0 negación:

\footnotetext{
líng chéng zhăng 零成長 'no-' 'crecimiento' $\rightarrow$ sin crecimiento líng fēng xiăn 零風險 'no-' 'riesgo' $\rightarrow$ sin riesgo líng jù lí 零距離 'no-' 'distancia' $\rightarrow$ sin distancia líng piào fáng 零票房 'no-' 'taquilla' $\rightarrow$ sin éxito de taquilla
} 
Para Xu y Cai (2007: 134), la introducción de lenguas extranjeras en la formación de sufijoides constituye un proceso que puede esquematizarse como sigue:

Elementos
extranjeros $\rightarrow\left[\begin{array}{l}\text { Traducción fonética } \\ \text { Traducción semántica: otros fonemas o raíces } \\ \text { Préstamo directo }\end{array} \rightarrow\right.$

$\rightarrow$ Transformación en morfemas $\rightarrow$ Analogía $\rightarrow$ Prefijoide o sufijoide

Xu y Cai (2007: 134) señalan que, a través de la traducción fonética, el calco semántico y el préstamo directo de las lenguas extranjeras, estos formantes se introducen en chino mandarín como morfemas productivos que presentan capacidad combinatoria con otros elementos autóctonos para formar palabras complejas. En el proceso de transformación de elementos extranjeros a afijoides chinos, estos morfemas conservan su significado originario, de manera que aunque aparecen como miembros de una formación derivativa, se diferencian de los afijos tradicionales por conservar el significado léxico originario y en muchos casos también alcanzan la autonomía léxica.

Según Wei (2006), desde el punto de vista morfológico y semántico, se observa que la alta productividad de los prefijoides y sufijoides a través de la traducción de elementos extranjeros puede considerarse el resultado de la gramaticalización de estos elementos, como ya hemos adelantado. Así, al principio, estos elementos presentan un funcionamiento léxico-semántico como unidades independientes, pero lo van perdiendo progresivamente hasta quedar convertidos en morfemas facultativos, de manera que estas unidades alcanzan mayor frecuencia como parte de la serie derivativa. En otras palabras, tal reducción semántica provoca que el elemento pierda su autonomía y pase a depender de otra unidad. En el proceso de gramaticalización, el significado de estos elementos se va debilitando y tal generalización semántica favorece la capacidad combinatoria con otros elementos. De esta forma, se presentan formantes productivos con alta 
Morfología contrastiva del chino mandarín y el español. Formas de gramaticalización y lexicalización

rentabilidad para la formación de palabras derivativas. Esta teoría permite explicar las formaciones con xing 性 propiedad, shì 式 forma, yuán 員 persona, pinn 品 objeto, chăng 場 explanada, etc., cuyo significado original sufre un debilitamiento desde un sentido específico a otro sentido general o abstracto. Véanse algunos ejemplos:

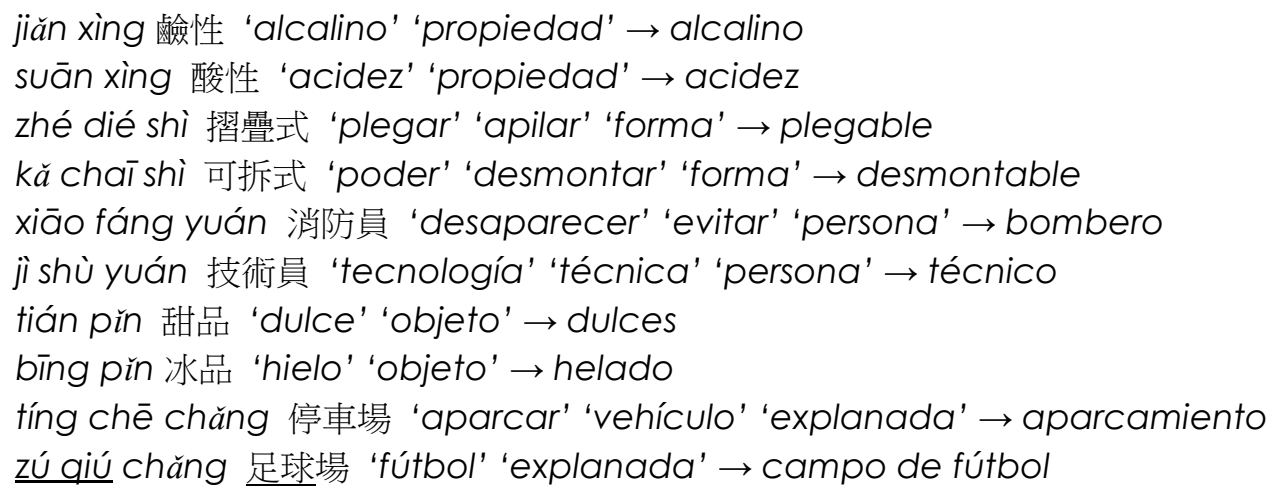

Otra característica que atañe a los sufijoides del mandarín se refiere a la pluralidad de sílabas. Normalmente los sufijoides son monosilábicos. Sin embargo, con la tendencia bisilábica del chino moderno y la influencia del extranjerismo, se utilizan cada vez más sufijoides bisilábicos y polisilábicas. En general, los sufijoides polisilábicos responden a la traducción de lenguas extranjeras. Por ejemplo, el formante bisilábico liáo fă 療法 'curar' 'forma' $\rightarrow$ tratamiento o terapia y el polisilábico kǒng jù zhèng 恐懼症 'miedo' 'temor' 'síntoma' $\rightarrow$ fobia son nuevos conceptos del mundo occidental que se introducen en el chino mandarín a través de la traducción semántica. Véanse algunos ejemplos:

fāng xiāng liáo fă 芳香 療法 'fragante' 'aromático' 'tratamiento' $\rightarrow$ aromaterapia

shǔi qīng liáo fă 水晶 療法 'Cristal' 'tratamiento' $\rightarrow$ fitoterapia miăn yì liáo fă 免疫 療法 'inmuno' 'tratamiento' $\rightarrow$ inmunoterapia yōu bì kŏng iù zhèng 幽閉恐懼症 'tranquilo' 'cerrado' 'fobia' $\rightarrow$ claustrofobia rén qún kŏng jù zhèng 人群恐懼症 'persona' 'grupo' 'fobia' $\rightarrow$ antropofobia 
En comparación con los auténticos afijos, los prefijoides y sufijoides contribuyen más productivamente a la formación léxica porque sufren un proceso de generalización de su significado semántico que favorece la combinación con otros elementos. Así, en el siguiente cuadro se observa que el porcentaje de los prefijoides y sufijoides reconocidos en la lingüística china ha superado mucho a los afijos convencionales en la formación de palabras y se percibe claramente una gran influencia de la traducción de lenguas extranjeras (Wang 2006: 71):

\begin{tabular}{|l|c|c|}
\hline & Cantidad & Porcentaje \\
\hline Afijos convencionales & 6 & $3.2 \%$ \\
\hline Total de prefijoides y sufijoides & 179 & $97.8 \%$ \\
\hline Prefijoides y sufijoides de origen chino & 110 & $61.4 \%$ \\
\hline Prefijoides y sufijoides reconocidos de lenguas extranjeras & 42 & $23.5 \%$ \\
\hline Prefijoides y sufijoides sin reconocimiento de su origen & 27 & $15.1 \%$ \\
\hline
\end{tabular}

Tabla 1: Distribución de afijos y afijoides (según Wang)

En resumen, se observa que el chino mandarín moderno ha dejado de ser la lengua aislante y sintética que era en otras épocas, en la que predominaban los morfemas monosilábicos y escaseaban considerablemente los afijos, mientras que la composición se consideraba el proceso primordial de la formación de palabras. Sin embargo, el mandarín actual, aunque no dispone de una gran variedad de afijos como marcas morfológicas, sí resultan muy frecuentes los afijoides para la creación de neologismos.

Wang (2007: 35-36) indica que en el sistema morfológico del chino actual, el uso común de los afijoides demuestra dos cambios significativos. Por un lado, la variedad de prefijoides y sufijoides se debe a la evolución social y al contacto con las lenguas indoeuropeas. Mediante esta influencia de las lenguas extranjeras, el uso de los prefijoides y sufijoides alcanza un nivel de difusión cada vez mayor, de modo que estos nuevos formantes consiguen una alta productividad en la formación léxica. De hecho, el proceso derivativo está adquiriendo una gran importancia en el sistema morfológico del chino 
Morfología contrastiva del chino mandarín y el español. Formas de gramaticalización y lexicalización

mandarín, pues se convierte en un recurso equiparable a la composición entre los procedimientos generales de formación de palabras.

Por otro lado, además del cambio en el sistema morfológico, el uso frecuente de prefijoides y sufijoides también produce cambios silábicos en el sistema léxico. Wang (2007: 35) señala que una de las características de los prefijoides y sufijoides es su gran capacidad combinatoria con distintos tipos de elementos léxicos. De hecho, como en el chino moderno predomina la tendencia bisilábica de las palabras, los prefijoides y sufijoides se añaden a estos elementos léxicos y de ahí se produce una marcada inclinación hacia palabras trisilábicas y polisilábicas, según se observa en los ejemplos anteriores.

\subsection{Composición}

La composición es uno de los procesos principales de la formación de palabras del mandarín moderno. Según Chao (1968), el término "palabra compuesta" debería restringirse a las unidades polisílabas que se pueden analizar en dos o más elementos significativos con autonomía léxica (o morfemas libres). Por ejemplo, kāi quān 開關 'abrir' 'cerrar' $\rightarrow$ interruptor, chōu yān 抽煙 'sacar' 'humo' $\rightarrow$ fumar, xiāng shǔi 香水 'aromático' 'agua' $\rightarrow$ perfume, tòng kǔ 痛苦 'doloroso' 'amargo' $\rightarrow$ angustioso.

En mandarín moderno, muchas palabras compuestas están formadas por un constituyente que proviene del chino clásico. Pero estos constituyentes de la lengua antigua han perdido su autonomía y funcionan como morfemas ligados o dependientes en el mandarín moderno. A pesar de ello, las formaciones con estos elementos clásicos no se clasifican entre los derivados sino entre los compuestos. Por ejemplo, en el chino clásico, el verbo compuesto qū zhú 驅逐 'desalojar' 'perseguir' $\rightarrow$ expulsar estaba constituido por dos morfemas libres con autonomía sintáctica y semántica que podían usarse independientemente como verbos simples. Sin embargo, en chino moderno 
ninguno de estos dos formantes se usa como morfema libre, sino que estos siempre se combinan entre sí o con otros elementos léxicos para formar verbos compuestas:

qū chú 驅除 ‘desalojar' 'eliminar' $\rightarrow$ quitar

zhuīzhú 追逐 'seguir' 'perseguir' $\rightarrow$ perseguir

Así, los morfólogos no consideran necesario para la composición que cada constituyente se interprete en la lengua actual como un morfema libre, con tal de que la forma compuesta pueda representar una palabra con autonomía léxica y funcional, y -en nuestra opinión- siempre que tales morfemas, hoy ligados, hayan formado parte en la lengua clásica de algún compuesto de dos o más formas que durante aquel periodo se comportaban como elementos libres. En §2.2.4 nos hemos referido a la denominación de "morfemas libres ligados" que utilizan algunos morfólogos para describir el comportamiento de estos formantes del tipo gǔ́ 果 'fruto'.

De acuerdo con Chao (1968) y Lü (1992a), Li y Thompson (2003) indican que la dificultad de definir y delimitar la formación compuesta se debe al origen monosilábico de las palabras del chino clásico. Estos autores señalan que en mandarín moderno los formantes de la composición mantienen o pierden la autonomía sintáctica y semántica de forma gradual cuando constituyen la base o el formante de la composición, de manera que resulta prácticamente imposible distinguir bien entre morfemas ligados y morfemas libres si no se recurre a un estudio etimológico. Por consiguiente, el estudio de la formación compuesta del mandarín moderno suele enfocarse desde una perspectiva diacrónica, pues los compuestos se contrastan con textos antiguos o palabras del chino clásico.

En cuanto a la delimitación y clasificación de las palabras compuestas, en opinión de Chao (1968: §6.1.3), se pueden tomar en consideración los siguientes factores para distinguir tipos de compuestos: 1) intensidad de tono; 2) tipo de constituyente; 3) significado composicional o lexicalizado; 4) número de morfemas; 5) construcción endocéntrica o exocéntrica; 6) estructura 
Morfología contrastiva del chino mandarín y el español. Formas de gramaticalización y lexicalización

sintáctica; 7) categoría funcional.

En primer lugar, la intensidad tonal de la palabra recae en la última sílaba, cuyo tono no puede ser neutro. Sin embargo, mediante este criterio solo se consigue distinguir entre las palabras compuestas y algunas palabras derivadas con sufijos, pero no sirve tal condición para diferenciar los compuestos de las construcciones sintagmáticas. Como se observa en los ejemplos siguientes, las palabras compuestas de 1) y las construcciones sintácticas de 2) se igualan en la intensidad tonal, pero se diferencian de las palabras derivadas de 3), pues los sufijos (zi 子 del tono neutro y la vocal retrofleja ér 兒) no aportan la intensidad tonal de la palabra:

1) aó yè 謷夜 'aguantar, soportar' 'noche' $\rightarrow$ trasnochar shō duăn 縮短 'reducir' 'corto' $\rightarrow$ reducir

2) ná xìn 拿信 'coger' 'carta' $\rightarrow$ coger carta hē shŭi 喝水 'beber' 'agua' $\rightarrow$ beber agua

3) hái zi 孩子 'niño' 'suf.' $\rightarrow$ niño zhè ér 這兒 'aquí' 'suf.' $\rightarrow$ aquí

En segundo lugar, los constituyentes del compuesto pueden ser tanto elementos de los llamados "libres ligados" (esto es, ligados en la lengua actual) como formas libres. El siguiente cuadro ilustra las combinaciones posibles de estos dos tipos de unidades. Sin embargo, si los componentes son morfemas libres, los compuestos se distinguen de las construcciones sintácticas por el contexto en que se encuentran:

\begin{tabular}{|c|c|}
\hline lig.+lig. & $\begin{array}{l}\text { xiào yǒu 校友 'escuela' 'amigo' } \rightarrow \text { antiguo alumno } \\
\text { qū zhú 驅逐 'desalojar' 'perseguir' } \rightarrow \text { expulsar }\end{array}$ \\
\hline lig.+lib. & $\begin{array}{l}\text { méi rén 媒人 'intermediador' 'persona' } \rightarrow \text { casamentero } \\
\text { fáng kè 房客 'habitación' 'huésped' } \rightarrow \text { inquilino }\end{array}$ \\
\hline lib.+lig & $\begin{array}{l}\text { fēill } \bar{l} \text { 飛機 'volar' 'máquina' } \rightarrow \text { avión } \\
\text { shǔi yuán 水源 'agua' 'origen' } \rightarrow \text { manantial }\end{array}$ \\
\hline lib.+lib & $\begin{array}{l}\text { tiě lù 鐵路 'hierro' 'camino' } \rightarrow \text { ferrocarril } \\
\text { huǒ chē 火車 'fuego' 'vehículo' } \rightarrow \text { tren }\end{array}$ \\
\hline
\end{tabular}

Tabla 2: Composición con constituyentes ligados y libres 
En tercer lugar, desde el punto de vista semántico, la mayoría de las construcciones sintácticas responde a un significado composicional, pues el significado de la expresión es la suma de los significados de los constituyentes. Solo algunas construcciones sintácticas se prestan a una interpretación escasamente composicional u opaca debido al uso lexicalizado o idiomático, tal como yǒ yì sì 有意思 'haber' 'significado' $\rightarrow$ interesante y bàn píng shŭi 半 瓶水 'media' 'botella' 'agua' $\rightarrow$ mediocre, presuntuoso. En el caso de los compuestos, según Li y Thompson (2003: 49-51), se suelen distinguir tres tipos según la relación entre el significado del compuesto y el de cada uno de los constituyentes:

1) El tipo composicional: el significado del compuesto es directo y puede deducirse de los constituyentes. Es decir, la suma de los significdos de los componentes da lugar al significdo nuevo de la palabra compuesta:

X̌̃ Zăo 洗澡 'lavar' 'baño' $\rightarrow$ bañarse, ducharse

$h \bar{u}$ X⿳亠丷厂 呼吸 'exhalar' 'inhalar' $\rightarrow$ respirar

nián qīng 年輕 'edad' 'ligero' $\rightarrow$ joven

fēill $\bar{\jmath}$ 飛機 'volar' 'máquina' $\rightarrow$ avión

2) El tipo metafórico: entre el compuesto y los constituyentes se observa una relación metafórica, figurada o inferencial. En algunos casos, el compuesto es una representación conjunta de un referente único, cuyo significado no es deducible necesariamente del significado de sus componentes, pero tampoco le es ajeno. Entre la suma de los significados de los componentes y el significado global del conjunto se advierte alguna diferencia:

rè xīn 熱心 'calor' 'corazón' $\rightarrow$ caluroso

gōng lù 公路 'público' 'camino' $\rightarrow$ carretera

qiing shì 輕視 'ligero' 'ver' $\rightarrow$ despreciar, desdeñar

3) El tipo lexicalizado: el significado del compuesto no puede deducirse de los significados parciales: 
fēng liú 風流 'viento' 'fluidez, flujo' $\rightarrow$ libertino, mujeriego

huā shēng 花生 'flor' 'nacer, crecer' $\rightarrow$ cacahuete

shāng fēng 傷風 'herir' 'viento' $\rightarrow$ gripe, catarro

xiǎo shuō 小說 'pequeño' 'hablar' $\rightarrow$ novela

Para Chao (1968), es necesario que los compuestos con significado metafórico y lexicalizado tengan entrada en el diccionario, pese a que algunos de ellos presentan un sentido deducible parcialmente por la composicionalidad de los constituyentes.

En cuarto lugar, acerca del número de constituyentes, a pesar de que la mayoría de los compuestos consta de una estructura sencilla de dos morfemas, no son pocos los compuestos complejos, especialmente los del tipo subordinado, que están formados por tres o más morfemas, o en algunos casos, con el enlace fónico ér 兒. Por ejemplo, yú zǐ 魚子 'pez’ 'hijo' $\rightarrow$ hueva, huevo de pez es un compuesto sencillo formado por dos morfemas, que contrasta con el compuesto de tres morfemas $\bar{j}$ ž ér 雞子兒 'gallina' 'hijo' 'sufijo' $\rightarrow$ huevo de gallina, en el que el segundo y el tercer constituyente ž̌ ér 子兒 'hijo' 'sufijo' se considera una unidad derivativa consistente en la raíz más el sufijo convencional no silábico. Otro ejemplo de compuesto complejo es pú táo gān ér 葡萄乾兒 'Uva' 'secado' 'sufijo' $\rightarrow$ pasa de uva, en el que los dos primeros constituyentes forman uno de esos escasos morfemas bisilábicos por su origen en un préstamo antiguo, mientras que el tercer y el cuarto constituyente se consideran una unidad derivativa consistente en el lexema más el sufijo nominal no silábico. En opinión de Chao (1968: 365), la mayoría de los compuestos complejos es del tipo subordinado. Por ejemplo, qiē cài dāo 切菜 刀 'cortar' 'verdura' 'cuchillo' $\rightarrow$ cuchillo de cocina consiste en qiē cài 切菜 'cortar' 'verdura', que es una construcción verbo-objeto, más dāo 刀 'cuchillo', que subordina a la construcción verbo-objeto antepuesta.

Por otra parte, también se ha aplicado a los compuestos la división entre estructuras endocéntricas o exocéntricas según la relación del referente y el conjunto. Los compuestos que representan una especialización con respecto a su núcleo referencial son considerados endocéntricos. Por ejemplo, 
en ji dàn 雞蛋 'gallina' 'huevo' $\rightarrow$ huevo de gallina, el núcleo recae en el segundo constituyente dàn 蛋 'huevo'; en cí zhí 辭職 'renunciar' 'trabajo' $\rightarrow$ dimitir de un cargo, el verbo transitivo cí 辭 'renunciar' es el núcleo; en cún kUăn 存款 'ahorrar' 'dinero' $\rightarrow$ ahorro, el núcleo recae en kUăn 款 'dinero'. Por su parte, aquellos compuestos que designan una realidad no referida por ninguno de los elementos componentes son considerados exocéntricos. Por ejemplo, en chī cù 吃醋 'comer' 'vinagre' $\rightarrow$ estar celoso, wài háng 外行 'fuera' 'ocupación' $\rightarrow$ profano, lego y sì hăi 四海 'cuatro' 'mar' $\rightarrow$ por todas partes, los compuestos no tienen como núcleo ninguno de los componentes, pues el núcleo es externo a la palabra. Todos estos compuestos heredan rasgos categoriales y subcategoriales del componente externo identificado como núcleo. En opinión de Yan (2008), tal clasificación semántica entre el endocentrismo y exocentrismo no es absoluta, pues advierte que sobre todo la exocentricidad es una categoría polémica y difícil de definir. El autor señala que existen múltiples tipos intermedios que obligan a concretar el grado de endocentrismo o exocentrismo de un compuesto. Por ejemplo, en wáng shǔi 王 水 'rey' 'agua' $\rightarrow$ aguafuerte, el núcleo del compuesto está representado por el contenido semántico del constituyente shǔi 水 'agua' que designa la noción genérica de 'líquido'. En este caso el grado de exocentrismo es menor que el compuesto fàng yáng 放羊 'apacentar' 'oveja' $\rightarrow$ mentir, donde el significado del compuesto difiere del de sus componentes por la transferencia metafórica. Por otro lado, Chao (1968: 365) indica que, en algunos casos, tal gradación semántica puede determinar la clasificación de una palabra compleja en compuesta o en derivada. Por ejemplo, zhèn tóu 枕頭 'apoyar' 'cabeza' $\rightarrow$ almohada puede identificase como un compuesto exocéntrico si se analiza como construcción verbo-objeto y el primer constituyente se usa en cuarto tono zhèn 枕 'apoyar'. Sin embargo, cuando el primer constituyente se utiliza en tercer tono zhěn 枕 se analizaría como construcción endocéntrica consistente en la raíz zhěn 枕 'almohada' más el sufijo nominal tóu 頭. En tal caso, no se consideraría un compuesto sino una palabra derivada. 
Morfología contrastiva del chino mandarín y el español. Formas de gramaticalización y lexicalización

Otro factor que se ha utilizado para clasificar los compuestos es la estructura sintáctica interna. Las clases habituales son el compuesto por coordinación y el compuesto por subordinación. Este último, a su vez, presenta varios tipos, como el de sujeto-predicado, verbo-objeto, verbo-complemento predicativo y el de una estructura compleja. Otros compuestos, aunque no están formdos por constituyentes que establecen tales relaciones sintacticas, son palabras analizables desde el punto de vista funcional. Solo hay una proporción escasa de compuestos cuya estructura no se considera propiamente sintáctica. De los compuestos examinados por Lu (1957: 13), se sabe que menos del $10 \%$ presentan una estructura sintáctica opaca, mientras que casi todas las formas compuestas muestran una relación sintáctica clara entre los constituyentes. Chao (1968) indica que mediante un estudio diacrónico puede revelarse el origen de muchos de estos compuestos. Pero en el nivel descriptivo sincrónico, estas palabras no muestran la relación sintáctica que media entre los constituyentes, por lo que no se puede analizar su estructura interna.

Por último, los compuestos también pueden clasificarse según su categoría gramatical. A veces, esta operación puede plantear algún problema. Por ejemplo, en Lu (1957: 104), se reúnen esquemas que tienen en cuenta la categoría gramatical del compuesto y la de sus constituyentes:

$$
\begin{aligned}
& \mathrm{A}-\mathrm{A} \rightarrow \mathrm{N} \text { : tòng ǩ̌ 痛苦 'doloroso' 'amargo' } \rightarrow \text { angustia } \\
& \mathrm{V}-\mathrm{V} \rightarrow \mathrm{A} \text { : băo shǒ } \text { 保守 'proteger' 'conservar' } \rightarrow \text { conservador }
\end{aligned}
$$

Sin embargo, en otros ejemplos, como fēng liú 風流 'viento' 'correr o moda' $\rightarrow$ mujeriego no está muy claro que el significado de liú 流 se refiera al verbo 'correr' o al sustantivo 'moda'. Otro ejemplo de compuesto en el que la categoría de los constituyentes resulta inconsistente por el efecto de la polisemia es míng guì 名貴 'nombre' 'caro' $\rightarrow$ valioso, que refleja el esquema $\mathrm{N}-\mathrm{A} \rightarrow \mathrm{A}$, según indica Lu (1957). Sin embargo, en oponión de Chao (1968), el constituyente míng 名 no funciona como sustantivo en míng rén 名人 'famoso' 
'gente' $\rightarrow$ celebridad y míng jiăo 名腳 'famoso' 'pie' $\rightarrow$ futboilista famoso, sino que se utiliza como un componente adjetivo para la formación de nombres compuestos.

De acuerdo con el diferente alcance de los factores mencionados, Chao (1994 [1980]: §6.3) y Hu (1992) indican que en la lingüística china la clasificación tradicional de la formación compuesta consiste en el análisis de las relaciones sintácticas de los componentes que forman el complejo. Para estos autores, la composición es el proceso más productivo del chino mandarín, por delante de la afijación. Señalan que pueden distinguirse varios tipos según la relación gramatical que se establece entre los constituyentes. Así, seguidamente se analizan las estructuras formales de los distintos tipos sintácticos de la formación compuesta. Entre ellos, se dedica cierta atención a los compuestos coordinados y a los compuestos subordinados.

En primer lugar, los compuestos coordinados ${ }^{26}$ son palabras constituidas por dos o más elementos de significado igual, parecido v opuesto. Generalmente, siguen manteniendo las propiedades semánticas de los constituyentes. Se corresponden, por tanto, con los compuestos composicionales. En el plano gramatical, muestran una relación que admite una paráfrasis semejante a la coordinación sintáctica entre sus componentes:

\begin{tabular}{|c|c|c|}
\hline $\begin{array}{c}\text { Significado de los } \\
\text { constituyentes }\end{array}$ & Chino mandarín & Español \\
\hline \multirow{2}{*}{$\begin{array}{c}\text { Significado igual } \\
\end{array}$} & fēn sàn 分散 'repartir' 'dispersar' & dispersar \\
\cline { 2 - 3 } & xiăng niăn 想念 'pensar' 'sentir' & echar de menos \\
\cline { 2 - 3 } & jiān nán 艱難 'difícil' 'difícil' & difícil \\
\hline \multirow{2}{*}{$\begin{array}{c}\text { Significado } \\
\text { parecido }\end{array}$} & fù mǔ 父母 'padre' 'madre' & padres \\
\cline { 2 - 3 } & gān jìng 乾淨 'seco' 'limpio' & limpio \\
\cline { 2 - 3 } & guó jiā 國家 'país' 'casa' & país \\
\hline \multirow{2}{*}{$\begin{array}{c}\text { Significado } \\
\text { opuesto }\end{array}$} & dà xiăo 大小 'grande' 'pequeño' & talla, tamaño \\
\cline { 2 - 3 } & măi mài 買賣 'comprar' 'vender' & comercio \\
\cline { 2 - 3 } & wàng ji 忘記 'olvidarse' 'acordarse' & olvidarse \\
\hline
\end{tabular}

Tabla 3: Compuestos coordinados

26 La traducción de Li y Thompson (2003: 71) es "compuesto paralelo". 
Morfología contrastiva del chino mandarín y el español. Formas de gramaticalización y lexicalización

Desde el punto de vista sintáctico, los elementos constitutivos del compuesto pertenecen a la misma categoría gramatical y el compuesto puede extenderse a distintas categorías gramaticales:

$$
\begin{aligned}
& \mathrm{N}+\mathrm{N} \rightarrow \mathrm{N} \text { : dēng huǒ 燈火 'lámpara' 'fuego' } \rightarrow \text { Iuz } \\
& \mathrm{A}+\mathrm{A} \rightarrow \mathrm{N} \text { : fán năo 煩惱 'molestado' 'enojado' } \rightarrow \text { problema } \\
& \mathrm{V}+\mathrm{V} \rightarrow \mathrm{N} \text { : hū Xī 呼吸 'expirar' 'aspirar' } \rightarrow \text { respiro/respiración } \\
& \mathrm{A}+\mathrm{A} \rightarrow \mathrm{A} \text { : xīn xiān 新鮮 'nuevo' 'fresco' } \rightarrow \text { fresco } \\
& \mathrm{V}+\mathrm{V} \rightarrow \mathrm{V} \text { : shī bài 失敗 'perder' 'fracasar' } \rightarrow \text { fracasar } \\
& \mathrm{N}+\mathrm{N} \rightarrow \mathrm{Adv} \text { : zǒu wăn 早晚 'mañana' 'noche' } \rightarrow \text { tarde o temprano }
\end{aligned}
$$

Mientras que los compuestos coordinados se caracterizan por la ausencia de núcleo, lo que explica que muchos de estos admitan la paráfrasis de la conjunción y entre los constituyentes (padre y madre = padres; comprar y vender $=$ comercio), los compuestos subordinados no se interpretan como una simple adición de las formas simples, sino que entre estas se establece una relación sintáctica de núcleo y modificador o complemento. Los compuestos subordinados se suelen clasificar de acuerdo con el tipo de función sintáctica que desempeña un formante con respecto al otro. Así, se distinguen las siguientes clases de compuestos subordinados: compuestos sujeto-predicado, compuestos verbo-objeto, compuestos verbo-complemento predicativo y compuestos complejos.

Los compuestos sujeto-predicado son aquellos que están integrados por dos elementos de los cuales el primero es el sujeto del segundo. Su estructura interna es parecida a una oración de sujeto y de predicado. Veamos ejemplos según la categoría gramatical del compuesto:

\begin{tabular}{|c|c|c|}
\hline Clase gramatical & Chino mandarín & Español \\
\hline \multirow{2}{*}{ Sustantivo } & tiān liàn 天亮 'cielo' 'iluminar' & amanecer \\
\cline { 2 - 3 } & dì zhèn 地震 'tierra' 'vibrar' & terremoto \\
\cline { 2 - 3 } & dōng zhì 冬至 'invierno' 'llegar' & solsticio de invierno \\
\hline \multirow{2}{*}{ Verbo } & huǒ shāo 火燒 'fuego' 'quemar' & quemar \\
\cline { 2 - 3 } & lù guò 路過 'camino' 'pasar' & pasar \\
\cline { 2 - 3 } & shǒu chí 手持 'mano' 'coger' & coger \\
\hline
\end{tabular}




\begin{tabular}{|c|c|c|}
\hline \multirow{2}{*}{ Adjetivo } & nián qīng 年輕 'edad' '(es) ligero' & joven \\
\cline { 2 - 3 } & ming kŭ 命苦 'vida' '(es) amargo' & desdichado \\
\cline { 2 - 3 } & dăn xiăo 膽小 'coraje' '(es) pequeño' & cobarde \\
\hline Adverbio & shì bì 勢必 'situación' 'hacer falta' & inevitablemente \\
\hline Conjunción & lì rú 例如 'ejemplo' 'parecer' & por ejemplo \\
\hline
\end{tabular}

Tabla 4: Compuestos sujeto-predicado

Otro tipo de compuestos sujeto-predicado se relaciona con las enfermedades físicas, tales como qì chuăn 氣喘 'aire' ‘jadear' $\rightarrow$ asma, tóu téng 頭疼 'cabeza' 'doler' $\rightarrow$ dolor de cabeza, ěr míng 耳鳴 'oreja' 'zumbar' $\rightarrow$ zumbidos de los oídos, năo chū xiě 腦出血 'cerebro' 'salir' 'sangre' $\rightarrow$ hemorragia cerebral, bí sāi 鼻塞 'nariz' 'atascar' $\rightarrow$ obstrucción nasal, etc.

Con respecto a los compuestos verbo-objeto, se trata, en primer lugar, de compuestos verbales cuya estructura interna equivale al verbo y a su complemento. Estos compuestos se caracterizan por su relativa composicionalidad, por el predominio del endocentrismo y por el carácter normalmente dependiente de uno de sus componentes, al menos. Según Chao (1968: §6.5.2), en las construcciones verbo-objeto, el elemento verbal o el elemento nominal pueden ser formantes ligados. En general, se distinguen tres tipos de combinación de morfemas en la composición verbo-objeto:

\begin{tabular}{|c|c|c|}
\hline Tipo de morfema & Chino mandarín & Español \\
\hline $\begin{array}{c}\text { dependiente + } \\
\text { dependiente }\end{array}$ & zhí bān 值班 'estar de servicio' 'turno' & estar de turno \\
\cline { 2 - 3 } & guò shì 過世 'dejar' 'mundo' & fallecer \\
\hline $\begin{array}{c}\text { independiente + } \\
\text { independiente }\end{array}$ & nà shuì 納稅 'entregar' 'impuesto' & pagar impuestos \\
\cline { 2 - 4 } $\begin{array}{c}\text { independiente + } \\
\text { dependiente }\end{array}$ & shuì jiăo 睡覺 'dormir' 'sueño' & comer \\
\cline { 2 - 4 } & dă liè 打獵 'golpear' 'caza' & cazar \\
\hline
\end{tabular}

Tabla 5: Compuestos verbo-objeto

Pero, en segundo lugar, la composición V-O también puede producir sustantivos. En tal caso, el compuesto nominal suele designar individuos, instrumentos, acciones o resultados del verbo: 
Morfología contrastiva del chino mandarín y el español. Formas de gramaticalización y lexicalización

\begin{tabular}{|c|c|}
\hline $\begin{array}{c}\text { Significado del } \\
\text { compuesto }\end{array}$ & Ejemplo \\
\hline individuo & dāng jú 當局 'dominar' 'situación' $\rightarrow$ autoridad \\
\hline instrumento & hù xī 護膝 'proteger' 'rodilla' $\rightarrow$ rodillera \\
\hline Acción & xíng zhèng 行政 'administrar' 'política' $\rightarrow$ administración \\
\hline resultado & zhào xiàng 照相 'fotografiar' 'foto' $\rightarrow$ fotografía \\
\hline
\end{tabular}

Tabla 6: Principales designaciones de los compuestos nominales del tipo V-O

Por su parte, los compuestos $\mathrm{V}$-O adjetivales se caracterizan por aceptar una modificación que afecta a la totalidad del conjunto, pues la mayoría de estas composiciones adjetivales se consideran compuestos de constituyentes inseparables que no toleran modificadores entre el verbo y el objeto, por ejemplo: quē dé 缺德 'carecer' 'moralidad' $\rightarrow$ inmoral, chī lì 吃力 'comer' 'fuerza' $\rightarrow$ duro, complicado, zhī jǐ 知已 'saber' 'sí mismo' $\rightarrow$ íntimo, comprensible. Sin embargo, He (2005: 52) indica que algunos otros tipos de compuestos $\mathrm{V}-\mathrm{O}$, especialmente los verbales, admiten la modificación intercalada entre el elemento verbal y el nominal. En este sentido, el autor distingue dos tipos de intercalción: 1) intercalación de elementos que expresan el aspecto del elemento verbal, como guò 過 'aspecto experiencial', le 了 'aspecto perfectivo', zhe 著 'aspecto progresivo'; 2) intercalación de elementos oracionales que separan el verbo del objeto y convierten el compuesto en una proposición. Véanse los siguientes ejemplos:

1) dă le dǔ 打了賭 'hacer' 'aspecto perfectivo' 'apuesta' $\rightarrow$ apostar pái zhe duì 排著隊 'ordenar' 'aspecto progresivo' 'cola' $\rightarrow$ hacer cola

2) chījngī 吃驚 'comer' 'susto' $\rightarrow$ estar asustado admite intercalaciones como:

\begin{tabular}{|c|c|c|c|c|}
\hline 吃 & 了 & 好 & 大 & 一 \\
\hline Chī & le & hăo & dà & ȳ̄ \\
\hline Comer & asp. perfectivo & muy & grande & uno \\
\hline
\end{tabular}


En cuanto a los compuestos $\mathrm{V}$-O adverbiales, no se permite ningún tipo de intercalación. Por ejemplo:

zhào cháng 照常 'seguir' 'costumbre' $\rightarrow$ habitualmente

*zhào le cháng 照了常 'seguir' 'aspecto perfectivo' 'costumbre'

zhuăn yăn 轉眼 'girar' 'ojo' $\rightarrow$ en un instante

*zhuăn zhe yăn 轉著眼 'girar' 'aspecto progrsivo' 'ojo'

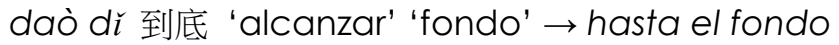

*daò le ď̌ 到了底 'alcanzar' 'aspecto perfectivo' 'fondo'

Por el último, los compuestos V-O interjectivos suelen presentar la forma reduplicada para alcanzar el tono de cortesía:

¡láo jià láo jià! i勞駕勞駕! 'molestar' 'visita' 'molestar' 'visita' $\rightarrow$ iperdone la molestia!

¡fèi xīn fèi xīn! 㵒心費心! 'costar' 'corazón' 'costar' 'corazón' $\rightarrow$ por favor

Con respecto a la idiomaticidad del significado, Chao (1968: §6.5.4) indica que esta condición puede ser el criterio para distinguir los compuestos de las construcciones sintagmáticas. Por ejemplo, măi xué 買鞋 'comprar' 'zapato' $\rightarrow$ comprar zapatos, y hē shǔi 喝水 'beber' 'agua' $\rightarrow$ beber agua son construcciones que muestran la relación sintáctica de verbo-objeto, pero no se clasifican como palabras compuestas sino como combinaciones de sintagmas libres, dado que el significado de la construcción es la suma de los significados de los elementos que la componen y la construcción presenta una estructura oracional.

Sin embargo, aunque la idiomaticidad del significado sirve como criterio para la identificación de una formación compuesta, esta característica, que normalmente se corresponde con el exocentrismo, no es una condición absoluta, sino que se puede observar cierta gradación respecto de la especialización del significado léxico. Por ejemplo, los compuestos de 1) presentan una idiomaticidad mínima, pues el significado del conjunto está determinado por el significado adicional de sus constituyentes y por el contexto limitado en el que se suele emplear el compuesto. Pero más especialización léxica se puede encontrar en los ejemplos de 2), en los que el significado del 
Morfología contrastiva del chino mandarín y el español. Formas de gramaticalización y lexicalización

compuesto ha sufrido una transformación metafórica y se observa un proceso de lexicalización:

1) duàn năi 斷奶 'cortar' 'leche' $\rightarrow$ destetar zuò huó 做活 'hacer' 'trabajo' $\rightarrow$ trabajar

2) fān liăn 翻臉 'girar' 'cara' $\rightarrow$ enfadarse

chīcù 吃醋 'comer' 'vinagre' $\rightarrow$ tener celos

gē qiăn 擱淺 'poner' 'ribera' $\rightarrow$ encallar, varar

bèi shū 背書 'cargar' 'libro' $\rightarrow$ respaldar

Otro tipo de compuestos bastante productivos en mandarín es el que responde al análisis de verbo y complemento predicativo. Según Chao (1994 [1980]: §6.6) y He (2005: 52), los compuestos verbo-complemento predicativo pueden estar constituidos por morfemas independientes o dependientes. SU combinación puede ser inseparable, pero también pueden intercalarse los interfijos modales dé 得 ('poder') y bù 不 ('no poder'). Por su parte, Chu (2002: 6) explica que cuando se admite la intercalación, el compuesto se clasifica como un tipo de lí hé cí 離合詞 "palabras intercaladas separables", en el que los interfijos dé 得 y bù不 se pueden considerar también como adverbios a fin de expresar "lo alcanzable o lo posible" y "lo no alcanzable o lo imposible" del resultado, respectivamente. En el caso de aceptar la intercalación, el significado del conjunto puede ser sintético o composicional, esto es, que admite interfijos por su bajo grado de lexicalización o bien léxico, en caso contrario. Por ejemplo, gé XĪn 革新 'revolucionar' 'nuevo' $\rightarrow$ revolucionar está constituido por dos morfemas dependientes. Es un compuesto de tipo léxico porque no acepta el interfijo y su significado está lexicalizado; en cambio, zhuā jǐn 抓緊 'agarrar' 'apretado' $\rightarrow$ agarrar está constituido por dos morfema independientes, acepta la intercalación del interfijo y su significado léxico es del tipo llamado sintético o composicional, como zhuā dé jĭn 抓得緊 ‘agarrar' 'poder' 'apretado' $\rightarrow$ poder agarrar fuerte. 
Normalmente los compuestos verbo-complemento predicativo suelen estar formados por un verbo y un adjetivo que describe la acción del verbo. Sin embargo, también se consideran una variante de este tipo compositivo las formaciones de dos verbos, en las que uno de ellos especifica el modo de la acción. En la tabla siguiente se muestran ejemplos de estas dos clases de compuestos:

\begin{tabular}{|c|c|c|}
\hline & Chino mandarín & Español \\
\hline \multirow{2}{*}{$\begin{array}{c}\text { Verbo+ } \\
\text { adjetivo }\end{array}$} & rèn qīng 認清 'conocer' 'claro' & reconocer \\
\cline { 2 - 3 } & shēng gāo 升高 'levantar' 'alto' & elevarse \\
\hline \multirow{2}{*}{$\begin{array}{c}\text { Verbo + } \\
\text { verbo } \\
\text { direccional }\end{array}$} & găi zhèng 改正 'corregir' 'correcto' & corregir \\
\cline { 2 - 3 } & păo chū lái 跑出來 'correr' 'salir' & salir \\
\cline { 2 - 3 } & zŏu jìn 走進 'andar' 'entrar' & entrar \\
\cline { 2 - 3 } & nù qù 拿去 'coger' 'Ilevar' & devar \\
\hline
\end{tabular}

Tabla 7: Compuestos verbo-complemento

Algunos de estos compuestos de verbo + adjetivo admiten la intercalación de los interfijos mencionados para expresar la modalidad epistémica positiva y negativa de la acción del verbo:

rèn bù qīng 認不清 'conocer' + interf. modal negativo ('no poder') + 'claro' (asp. resultativo) $\rightarrow$ no poder reconocer bien

shēng dé gāo 升得高 'levantar' + interf. modal ('poder') + 'alto' (asp. resultativo) $\rightarrow$ poder elevarse alto.

A propósito de los compuestos formados por verbo + verbo direccional, Chao (1994 [1980]: §6.6.6) y Li y Thompson (2003: §3.2.3) indican que los "verbos de dirección" incluyen lái 來 'venir hacia al hablante', qù 去 'alejarse del hablante', shàng 上 'subir', xià 下 'bajar', jìn 進 'entrar', chū lái 出來 'salir', húi 回 'volver', etc. Muchas veces estos verbos se combinan entre sí para precisar el sentido de la dirección, como tūi húi qù 推回去 'empujar' 'volver' 'ir' $\rightarrow$ volver a retirar (algo) del hablante, duān shàng lái 端上來 'llevar' 'subir' 'venir' $\rightarrow$ subir llevando (algo) hacia al hablante. 
Morfología contrastiva del chino mandarín y el español. Formas de gramaticalización y lexicalización

A diferencia de los compuestos coordinados tratados anteriormente (vid. ejemplos en tabla 3), en los que cada constituyente es el núcleo, los compuestos subordinados solo tienen un constituyente como núcleo y este suele ser el componente pospuesto. Según Cheng (1992: 178-179) y Hu (1992: 251), la categoría gramatical de los principales compuestos subordinados corresponde al sustantivo como constituyente nuclear, mientras que el constituyente modificador puede ser otro sustantivo, un adjetivo o un verbo:

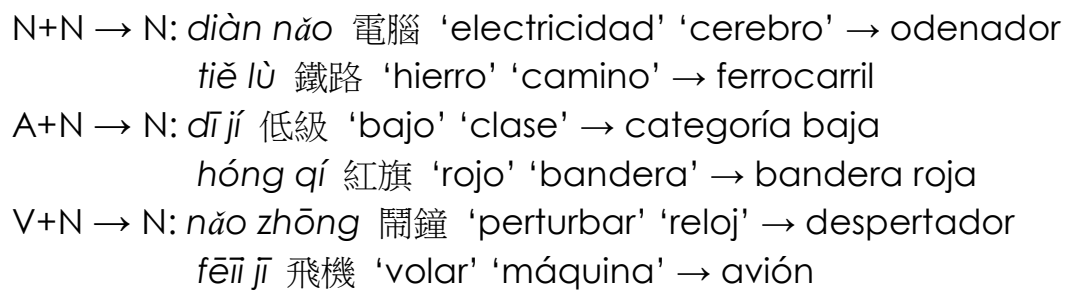

En los compuestos subordinados nominales, los constituyentes también pueden ser adjetivos determinativos, clasificadores o numerales. Los principales esquemas son los siguientes:

1) Determinativo-clasificador

2) Numeral-sustantivo

3) Sustantivo-numeral

4) Sustantivo-clasificador

La combinación del determinativo y el clasificador se considera un tipo de composición sin restricciones en la morfología china, a pesar de que -en nuestra opinión- resulta bastante dudoso el carácter morfológico de estas expresiones. Chao (1968: 389) indica que cualquier combinación del determinativo más el clasificador constituye un posible compuesto subordinado:

nà jiàn 那件 'ese' 'clas. de prenda' $\rightarrow$ esa prenda

sān běn 三本 'tres' 'clas. de libro' $\rightarrow$ tres tomos o volúmenes

jǐnián 幾年 'alguno' 'año' $\rightarrow$ algunos años 
Solo algunos demostrativos determinativos como gè 各 cada y zhū 諸 cada y el numeral èr 二 dos tienen usos restringidos. Por ejemplo, gè 各 cada puede aparecer en gè zhŏng 各種 'cada' 'tipo' $\rightarrow$ cada tipo o en gè guó 各國 'cada' 'país' $\rightarrow$ cada país, pero nunca se combina con unidades de medida *各吋 'cada' 'pulgada'. Por su parte, zhū 諸 cada mantiene sus propiedades del chino clásico y solo se aplica a formas como zhū wèi 諸位 'cada' 'clas. de persona' $\rightarrow$ todos y zhū jūn 諸君 'cada' 'caballero' $\rightarrow$ señores y caballeros. Por último, èr 二 dos no se combina con unidades de medida procedentes de lenguas extranjeras * èr bàng 二磅 'dos' 'libras'.

El segundo tipo de compuesto, formado por numeral y sustantivo alcanza una productividad limitada. En general, se trata de combinaciones relacionadas con varias tradiciones numéricas, como el uso de los meses: $\bar{y}$ yuè 一月 'uno' 'mes' $\rightarrow$ enero, èr yuè 二月 'dos' 'mes' $\rightarrow$ febrero; o la clasificación de categorías yī děng 一等 'uno' 'clase' $\rightarrow$ primera clase, èr děng 二等 'dos' 'clase' $\rightarrow$ segunda clase.

Se suele incluir en la composición el tipo compuesto formado por un sustantivo y su correspondiente clasificador para designar el carácter cuantificado o plural del sustantivo en cuestión. Por ejemplo, a partir de ȳ̄ zhāng zhǐ 一張紙 'uno' 'clas.' 'papel' $\rightarrow$ un papel se forma el compuesto sustantivo-clasificador zhǐ zhāng 紙張 'papel' 'clas.' $\rightarrow$ papel o papeles. Del mismo modo, se constituyen formaciones semejantes, como huā duǒ 花朵 'flor' 'clas.' $\rightarrow$ flores, chē liàn 車輛 'coche' 'clas.' $\rightarrow$ coches, fáng jiān 房間 'habitación' 'clas.' $\rightarrow$ habitaciónes, mă pī 馬匹 'caballo' 'clas.' $\rightarrow$ caballos, chuán zhī 船隻 'barco' 'clas.' $\rightarrow$ barcos, bù pì 布疋 'tela' 'clas.' $\rightarrow$ telas. Pero no todos los sustantivos se comportan del mismo modo con su propio clasificador. Así, por ejemplo, a partir de yī fēng xin 一封信 'uno' 'clas.' 'carta' $\rightarrow$ una carta no se produce el sust.-clas. *xin fēng 信封 'carta' 'clas.' $\rightarrow$ carta que designe la pluralidad de la carta, ya que xin fēng 信封 'carta' 'sobre' se considera un compuesto coordinado que tiene el significado de sobre (de carta). 
Morfología contrastiva del chino mandarín y el español. Formas de gramaticalización y lexicalización

Según He (2005: 50), otro tipo de composición subordinada muy productivo en el mandarín moderno se refiere a palabras provenientes de la traducción de lenguas extranjeras. Se encuentran tres tipos de combinaciones: 1) traducción semántica + traducción semántica 2) traducción fonética + traducción semántica y 3) traducción semántica + traducción fonética:

1) nuè dài kuáng 虐待狂 'maltratar' 'loco, adicto' $\rightarrow$ sádico

chāo rén 超人'super-' 'hombre' $\rightarrow$ superman

2) mínĩ qún 迷你裙 'mini-' 'falda' $\rightarrow$ minifalda

tăn kè chē 坦克車 'tanque' 'coche' $\rightarrow$ tanque

3) jiǔ ba 酒吧 'alcohol' 'bar' $\rightarrow$ bar

tuō kŏu xiù 脫口 秀 'hablar' 'show' $\rightarrow$ talk show

Como se observa en 2), mí nĭ 迷你 y tăn kè 坦克 son la traducción fonética de mini y tanque; en 3), ba 吧 y xiù 秀 reproducen los sonidos de bar y show.

Además del sustantivo, los compuestos subordinados también forman palabras verbales y adjetivales. Así, se forman verbos a partir de adjetivos antepuestos a un verbo:

dà mà 大罵 'grande' 'reñir' $\rightarrow$ reñir fuertemente xiăo păo 小跑 'pequeño' 'correr' $\rightarrow$ correr lentamente fù yin 複印 'doble' 'imprimir' $\rightarrow$ imprimir por duplicado.

Los adjetivos compuestos pueden formarse mediante un adjetivo pospuesto a un nombre o a un verbo:

fū qiăn 膚淺 'piel' 'superficial' $\rightarrow$ superficial

fěn suì 粉碎 'polvo' 'roto' $\rightarrow$ pulverizado

gǔn tàng 滾潩 'hervir' 'caliente' $\rightarrow$ hervido

tòu míng 透明 'transparentar' 'claro' $\rightarrow$ transparente

fēi kuài 飛快 'volar' 'rápido' $\rightarrow$ rápido

Los párrafos anteriores se han dedicado principalmente a los compuestos de dos constituyentes (aunque también puede participar algún interfijo). A continuación se examinan los diferentes tipos de compuestos 
complejos, constituidos por más de dos morfemas.

Los compuestos complejos más productivos son los formados por tres morfemas. Según la categoría gramatical de los constituyentes, se dividen en los siguientes tipos: (1) A-NN, (2) AN-N, (3) VN-N, (4) NNN, (5) VV-N, (6) AA-N, (7) V compl.-N, (8) otros. Veamos el siguiente cuadro con cada tipo:

\begin{tabular}{|c|c|c|}
\hline & Chino mandarín & Español \\
\hline \multirow{2}{*}{$\begin{array}{l}(1) \\
A-N N\end{array}$} & bái píxié 白皮鞋 'blanco' 'cuero' 'zapato' & calzado blanco \\
\hline & hóng shí zì 紅十字 'rojo' 'diez' 'letra' & cruz roja \\
\hline \multirow{2}{*}{$\begin{array}{l}\text { (2) } \\
\text { AN-N }\end{array}$} & gū ér yùn 孤兒院 'solitario' 'hijo' 'asilo' & Orfanato \\
\hline & xiăo shù diăn 小數點 'pequeño' 'número' 'punto' & separador decimal \\
\hline \multirow{2}{*}{$\begin{array}{l}\text { (3) } \\
\text { VN-N }\end{array}$} & qiù sēng quān 救生圈 'salvar' 'vida' 'círculo' & Flotador \\
\hline & qǐ zhòng jٓ 起重機 'levantar' 'peso' 'máquina' & Grúa \\
\hline \multirow[t]{2}{*}{ (4) NNN } & fán bù xié 帆布鞋 'Iona' ‘trapo' 'zapato' & Playera \\
\hline & hăi àn xiàn 海岸線 'mar' 'costa' 'línea' & línea de costa \\
\hline \multirow{2}{*}{$\begin{array}{l}(5) \\
V V-N \\
\end{array}$} & jiàng luò săn 降落傘 'bajar' 'caerse' 'paraguas' & Paracaídas \\
\hline & lián hé huó 聯合國 'reunir' 'colaborar' 'país' & ONU \\
\hline \multirow{2}{*}{$\begin{array}{l}\text { (6) } \\
\text { AA-N }\end{array}$} & suān là tāng 酸辣湯 'ácido' 'picante' 'sopa' & sopa agri-picante \\
\hline & hóng lù dēng 紅綠燈 'rojo' ‘verde' 'luz' & Semáforo \\
\hline \multirow{2}{*}{$\begin{array}{l}\text { (7) V } \\
\text { compl.- } \\
\mathrm{N}\end{array}$} & fàn dà jìng 放大鏡 'aumentar' 'grande' 'espejo' & Lupa \\
\hline & piăo bái shuǐ 漂白水 'blanquear' 'blanco' 'agua' $\rightarrow$ & $\begin{array}{l}\text { líquido } \\
\text { blanqueador }\end{array}$ \\
\hline \multirow{2}{*}{$\begin{array}{l}\text { (8) otros } \\
\text { tipos } \\
\text { léxicos }\end{array}$} & shī lē yuán 失樂園 'perder' 'alegría' 'parque' & El Paraíso Perdido \\
\hline & dì zhèn yí 地震儀 'tierra' 'vibrar' 'aparato' & Sismómetro \\
\hline
\end{tabular}

Tabla 8: Compuestos complejos

En el tipo (8), los compuestos están altamente lexicalizados y algunos de ellos son producto de la traducción de lenguas extranjeras, como shī lè yuán 失樂園 cuyo uso metafórico viene de la obra "Paradise Lost". 


\subsection{Los clasificadores}

Los clasificadores ocupan un lugar importante en la gramática china. Se trata de unidades léxicas, la mayoría de ellas con significado y uso autónomo, que especifican la cantidad o las porciones de unidades a las que se hace referencia y la clase de elementos de los que se habla. Se colocan entre el numeral y el sustantivo cuantificado. El clasificador chino desempeña una función comparable a la de los sustantivos cuantificativos del español, como cabeza, pedazo, pastilla, etc. (Bosque 1999: §1.2.3.4). Por ejemplo, dos cabezas de ganado correspondería en mandarín a liăng tóu yáng 兩頭羊 'dos' 'cabeza, cl.' 'oveja' $\rightarrow$ dos ovejas. Pero esta última lengua también dispone de clasificadores sin significado léxico liǎng zhī yáng 兩隻羊 'dos' 'cl.' 'oveja'.

Según Chao (1968: §7.9), muchos de los clasificadores son a su vez sustantivos que desempeñan además la función de clasificador. Por ejemplo, dāo 刀 cuchillo es sustantivo y también el clasificador del verbo kăn 砍 'hachar, cortar' en kăn yī dāo 砍一刀 'cortar' 'uno' 'cl.' $\rightarrow$ dar un hachazo; chuáng 床 cama es sustantivo y el clasificador del sustantivo mián bèi 棉被 colcha en yī chuáng mián bèi 一 床 棉被 'uno' 'Cl.' 'colcha' $\rightarrow$ una colcha.

Chao (1968: §7.9) y He (2001) distinguen tres tipos principales de clasificadores: los nominales, los individuales y los verbales. Los clasificadores nominales son sustantivos con significado léxico y uso autónomo que sirven además como clasificadores de nombres de materia. Entre estos clasificadores nominales, destacan los que indican 'recipiente' o 'contenedor': bēi 杯 vaso, dài 袋 saco, hé 盒 cajetilla, hú 鲎 vasija con asa, pén 盆 tiesto, barreño, pín 瓶 botella o frasco, tǒng 桶 cubo, wuăn 碗 tazón, guō 鍋 sartén, caldera, pán 盤 plato, dié 碟 platillo, tāng chí 湯匙 cucharada, xiāng 箱 cajón, caja, chí 池 fuente, guì 櫃 armario etc.; los de pesos, medidas o unidades temporales: gōng chǐ 公尺 metro, yīng cùn 英时 pulgada, gōng fēn 公分 centímetro, gōng ľ̌ 公里 kilómetro, guāng nián 光年 año de luz, gōng jinn 公斤 kilo, gōng shēng 公升 litro, diăn 點 / shí 時 hora，kè 刻 cuarto, fēn 分 minuto, miăo 秒 
segundo, tiān 天 día, yè 夜 noche, xīng qí 星期 semana etc.; y otros: chē 車 camión, carro, chuán 船 barco, chuáng 床 cama, dāo 刃 cuchillo, mén 門 puerta, asunto, hù 戶 ventana, casa.

Para Chao (1968) y He (2001) los clasificadores individuales también equivalen a los "numerativos" (numeratives) o a las llamadas "adjunciones numerales" (numerary adjuncts). Cada tipo de sustantivo tiene al menos un tipo propio de clasificador individual, que se aplica entre el numeral y el sustantivo para describir el aspecto, el tipo $u$ otra propiedad de los nombres de objetos. Algunos de los clasificadores individuales carecen de significado léxico. La tabla siguiente reúne algunos ejemplos tomados de Chao (1968: §7.9) y J.-M. Chao (1997: §7.1.2).

\begin{tabular}{|c|c|}
\hline Clasificador & Ejemplo \\
\hline $\begin{array}{c}\text { běn 本 volumen, aplicado a libros, } \\
\text { folletos }\end{array}$ & liǎng běn shū 兩本書 dos libros \\
\hline fú 幅 usado para pintura & sān fú huà 三幅畫 tres pinturas \\
\hline dào 道 para cosas situadas en líneas & yī dào qiáng 一道牆 un muro \\
\hline $\begin{array}{c}\text { duàn 段 aplicado a realidades que } \\
\text { se pueden fragmentar }\end{array}$ & $\begin{array}{l}\text { yī duàn huà 一段話 un trozo de } \\
\text { conversación }\end{array}$ \\
\hline ge 個 aplicado a individuos & $\begin{array}{c}\text { sìge nǔ rén 四個女人 cuatro } \\
\text { mujeres }\end{array}$ \\
\hline tiáo 條 para cosas largas & sān tiáo shé 三條蛇 tres serpientes \\
\hline gēn 根 para cosas largas y redondas & Wǔ gēn gùn zi 五根棍子 cinco palos \\
\hline jiā 家 se aplica a establecimientos & yī jiā shū diàn 一家書店 una librería \\
\hline $\begin{array}{c}\text { zhāng 張 usado para cosas con } \\
\text { superficie plana }\end{array}$ & $\begin{array}{c}\text { sān zhāng zhuō zi 三張桌子 tres } \\
\text { mesas }\end{array}$ \\
\hline zhř 只 unidad de un par & yī zhǐ ěr duō 一只耳朵 una oreja \\
\hline $\begin{array}{c}\text { bă 把 para lo que puede ser cogido } \\
\text { con la mano }\end{array}$ & Wǔ bă dāo 五把刀 cinco cuchillos \\
\hline jiàn 件 usado para prendas de ropa & bā jiàn qún zi 八件裙子 ocho faldas \\
\hline $\begin{array}{c}\text { kẽ } \text { 顆 usado para cosas redondas y } \\
\text { pequeñas }\end{array}$ & $\begin{array}{c}\text { jiǔ kē zhēn zhū 九顆珍珠 nueve } \\
\text { perlas }\end{array}$ \\
\hline $\begin{array}{c}\text { miàn 面 aplicado a cosas con lados } \\
\text { planos }\end{array}$ & $\begin{array}{c}\text { liǎng miàn jìng zi 兩面鏡子 dos } \\
\text { espejos }\end{array}$ \\
\hline pĩ 匹 aplicado al ganado equino & bā pīmă 八匹馬 ocho caballos \\
\hline
\end{tabular}

Tabla 9: Clasificadores individuales del chino mandarín 
Morfología contrastiva del chino mandarín y el español. Formas de gramaticalización y lexicalización

Los clasificadores verbales son a su vez sustantivos que designan instrumentos, como dāo 刀 cuchillo, o los objetos afectados por la acción del verbo. Indican el golpe dado con una parte del cuerpo o un movimiento de poca duración, como en los siguientes ejemplos:

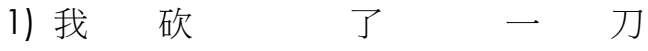
Wǒ kăn le ȳ̄ dāo
Yo hachar asp. pfvo. uno corte
Dí un cuchillazo.

2) 我開予 一 槍

Wǒ kāi le ȳì qiāng

Yo dar asp. pfvo. uno tiro

Disparé un tiro.

3) 她 看了我一 眼

Tā kàn le wǒ yī yăn

Ella ver asp. pfvo. yo uno mirada

Ella me echó una mirada.

4) 你打了我一 拳

Nǐ dă le wǒ ȳ̄ quán.

Tú pegar asp. pfvo. yo uno puñetazo

Me diste un puñetazo.

En algunos casos, los clasificadores verbales se repiten para significar que la acción del verbo se cumple en su totalidad sin excepciones:

1) 她餐餐吃素

Tā cān cān chī sù

Ella comida comida comer vegetariano

Ella es vegetariana.

2) 我 次次都失敗

Wǒ cì cì dōu shī bài

Yo vez vez siempre fracasar

Siempre fracaso.

Aunque no está muy claro que en chino mandarín los clasificadores formen parte de la morfología o de la sintaxis, en nuestra opinión se pueden distinguir dos tipos de clasificadores según su identificación gramatical: los que 
se relacionan con la composición y los que comparten alguna propiedad con la afijación. Los que se asemejan a los constituyentes compositivos aportan un significado semántico y presentan autonomía léxica como palabras autónomas. Entre ellos se incluyen los nominales y los verbales, como en los ejemplos de 1). Los que se asemejan a los afijos derivativos son los clasificadores individuales, que carecen de significado léxico y adoptan una posición fija, pues se intercalan entre el numeral y el sustantivo, como en los ejemplos de 2):

1) Clasificadores nominales:

yī chuáng mián bèi 一床棉被 'uno' 'cl. cama' 'colcha' $\rightarrow$ una colcha sì xiāng píng guó 四箱蘋果 'cuatro' 'cl. caja' 'manzana' $\rightarrow$ cuatro cajas de manzanas

Wǔ tāng chí táng 五湯匙糖 'cinco' 'cl. cuchara' 'azúcar' $\rightarrow$ cinco cucharadas de azúcar

\section{Clasificadores verbales:}

dă yī quán 打一拳 'golpear' 'uno' 'cl. puño' $\rightarrow$ dar una puñelada kàn yī yăn 看一眼 'ver' 'uno' 'cl. ojo' $\rightarrow$ echar un vistazo zǒu liăng bù 走兩步 'andar' 'dos' 'cl. paso' $\rightarrow$ dar dos pasos

\section{2) Clasificadores individuales:}

sān zhāng zhuō zi 三張桌子 'tres' 'cl.' 'mesa' $\rightarrow$ tres mesas sìge nǔ rén 四個女人 'cuatro' 'cl.' 'mujer' $\rightarrow$ cuatro mujeres bā pĩ mă 八匹馬 'ocho' 'cl.' 'caballo' $\rightarrow$ ocho caballos

Se observa que la selección del clasificador, sobre todo el de tipo individual, está regulada por la relación de hiperonimia-hiponimia, de modo que los términos hipónimos suelen combinarse con el mismo clasificador que modifica al término hiperónimo. En este sentido, una clase de sustantivos puede compartir el mismo clasificador por pertenecer al mismo campo semántico. Por ejemplo, el clasificador que se adopta con casa (jiāng 間) también marca la cuantificación de habitación, aula, cuarto, sala, oficina, residencia, etc:: 
Morfología contrastiva del chino mandarín y el español. Formas de gramaticalización y lexicalización

\section{Clasificador + hiperónimo casa:}

yī jiāng fáng zi 一間房子 'uno' 'cl.' 'casa' $\rightarrow$ una casa

Clasificador + hipónimo habitación, aula, cuarto, sala, oficina, residencia:

yī jiāng fáng jiān 一間房間 'uno' 'cl.' 'habitación' $\rightarrow$ una habitación

yī jiāng jiào shì 一間教室 'uno' 'cl.' 'aula' $\rightarrow$ un aula

yī jiāng_cè suǒ 一間廝所 'uno' 'cl.' 'cuarto de baño' $\rightarrow$ un cuarto de baño

yī jiāng kè tīng 一間客廳 'uno' 'cl.' 'salón' $\rightarrow$ un salón

yī jiāng bàn gōng shì 一間辦公室 'uno' 'Cl.' 'oficina' $\rightarrow$ una oficina

yī jiāng sù shè 一間宿舍 'uno' 'cl.' 'residencia' $\rightarrow$ una residencia

yī jiāng gōng chăng 工廠 'uno' 'cl.' 'fábrica' $\rightarrow$ una fábrica

\subsection{Reduplicación}

Según Li y Thompson (2003: §3.1), la reduplicación es un proceso morfológico que consistente en la repetición de un morfema para formar una nueva palabra, cuya estructura sintáctica y semántica difiere del morfema original ${ }^{27}$. Este tipo de formación de palabras puede analizarse desde el punto de vista silábico y también según las categorías gramaticales de los eductos.

Normalmente los verbos monosilábicos de acción que presentan un sujeto agente capaz de controlar la acción aceptan la reduplicación. Las formaciones reduplicadas expresan, por lo general, significados aspectuales, referidos a la acción que se desarrolla durante un corto periodo de tiempo o que se manifiesta con ligereza: kàn kàn 看看 ver un poco, shì shì 試試 intentar un poco, xiăng xiăng 想想 pensar un poco, zǒU zǒ U 走走 andar un poco (un rato). En algunas ocasiones, sobre todo en el mandarín de China continental, el segundo término adquiere un tono neutro: cháng chang 嚐嚐 probar un poco, xiē xie 歇歇 descansar un poco, zǒ zou 走走 andar un poco.

Otra forma de expresar la reduplicación consiste en la inserción del morfema $y \bar{\imath}$ - 'uno' de tono neutro. Los verbos monosilábicos pueden

\footnotetext{
27 Aquí nos limitamos al estudio de la repetición como proceso morfológicamente productivo, pues la repetición por sí misma constituye una regla de formación de palabra. Para el estudio sintáctico de la reduplicación resulta muy interesante el estudio de García-Medall (1992).
} 
intercalar tal elemento entre los dos morfemas reduplicados para representar una cuantificación mínima de la acción expresada por el verbo. En tal caso, el componente de repetición mantiene su tono original: shuō ȳ̄ shuō 說一說 'decir' 'uno' 'decir' $\rightarrow$ decir un poco; kàn yī kàn 看一看 'ver' 'uno' 'ver' $\rightarrow$ ver un poco; zŏU yīzǒu 走一走 'andar' 'uno' 'andar' $\rightarrow$ andar un poco.

En cuanto a la reduplicación de las palabras bisilábicas como son, por ejemplo, los verbos de lengua o comunicación, estos realizan la reduplicación sin cambiar la estructura fonológica: qǐng jiào qìng jiào 請教 請教 'preguntar' 'preguntar' $\rightarrow$ preguntar (consultar) un poco; pi píng pī píng 批評 批評 'criticar' 'criticar' $\rightarrow$ criticar un poco； kăo lù kăo lù 考慮考慮 'Considerar' 'considerar' $\rightarrow$ considerar un poco. Estos verbos no aceptan el morfema yi 'uno' en la reduplicación: *qĭng jiào yī qĭng jiào 請教一請教, *pī píng yī pī píng 批評一批評. Esta particularidad se observa más claramente cuando un mismo significado se puede expresar formalmente con una palabra monosílaba o bisílaba: zhăo 找 'buscar' / xún zhăo 尋找 'rebuscar' 'buscar', shuō 說 'decir' / sù shuō 訴說 'contar' 'decir':

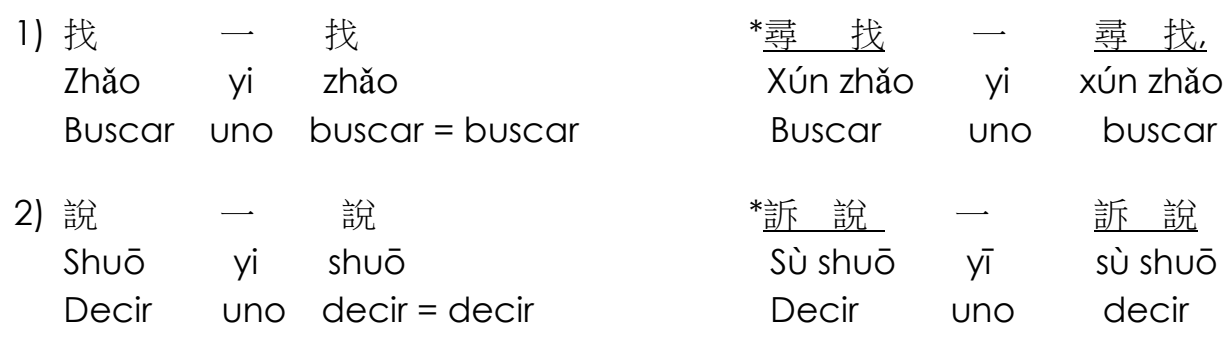

Por otra parte, los verbos que no pueden incluirse en el proceso de reduplicación son aquellos que no admiten la reducción de la intensidad o la duración de la acción que designan, como los verbos adjetivales (*fēng fēng 瘋瘋 'aficionarse' 'aficionarse'), los verbos resultativos compuestos (*mà kū mà kU 罵哭罵哭 'reñir' 'llorar' 'reñir' 'llorar') y los verbos de estado (*tòng tòng 痛痛 'doler' 'doler'). 
Morfología contrastiva del chino mandarín y el español. Formas de gramaticalización y lexicalización

En el caso de los verbos compuestos del tipo verbo-objeto, se reduplica solo el primer componente cuando cada uno de los componentes conserva su propio significado léxico. De esta manera, el morfema reduplicado adquiere el tono neutro, sobre todo en el habla de China: shui joao 睡覺 'dormir' 'sueño' $\rightarrow$ shuì shuì jiào 睡睡覺 dormir un poco; tiaò Wǔ 跳舞 'saltar' 'baile' $\rightarrow$ tiaò tiaò

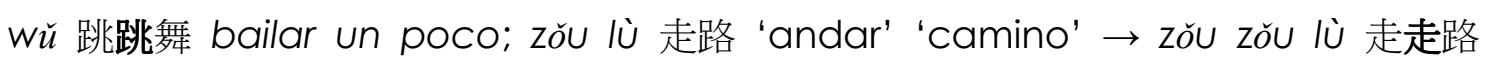
andar un poco.

Con los compuestos cuyos componentes no son separables sintácticamente, se reduplica el compuesto entero: xiăo xīn! 小心! jcuidado! $\rightarrow$ xiăo xīn xiăo xīn! 小心小心! jun poco de cuidado!; baò yuàn 抱怨 quejarse $\rightarrow$ baò yuàn baò yuàn 抱怨 抱怨 quejarse un poco; xiào liăo 效勞 esforzarse $\rightarrow$ xiào liăo xiào liăo 效勞 效勞 esforzarse un poco.

Por su parte, los adjetivos reduplicados aumentan la intensidad de las cualidades que describen del nombre. Se trata de un recurso equivalente a la formación del grado superlativo en español. En tal caso, la reduplicación exige la intercalación del marcador de atribución de 的 entre el adjetivo y el sustantivo: lán tiān 藍天 'azul' 'cielo' $\rightarrow$ lán lán de tiān 藍藍的天 'azul' 'azul' 'atr.' 'cielo' $\rightarrow$ cielo muy azul; gāo shān 高山 'alto' 'montaña' $\rightarrow$ gāo gāo de shān 高高的山 'alto' 'alto' 'atr.' 'montaña' $\rightarrow$ montaña muy alta.

Los adjetivos reduplicados se comportan como adverbios de modo cuando modifican a los verbos. En esta clase de reduplicación también se intercala el morfema de 的 entre el adjetivo y el verbo: kuài păo 快跑 'rápido' 'correr' $\rightarrow$ kuài kuài de păo 快快的跑 correr muy rápidamente; qīng pāi 輕拍 'ligero' 'golpear' $\rightarrow$ qīng qīng de pāi 輕輕的拍 golpear muy ligeramente.

Si el adjetivo es bisílabo, se ha de reduplicar cada morfema independiente: gāo xìng 高興 alegre $\rightarrow$ gāo gāo xing xìng 高高興興 muy alegre; qīng sōng 輕鬆 aliviado $\rightarrow$ qīng qīng sōng sōng 輕輕鬆鬆 muy aliviado; shū fú 舒服 cómodo $\rightarrow$ shū shū fú fú 舒舒服服 muy cómodo. Sin embargo, algunos adjetivos bisílabos encuentran más restricciones en la reduplicación. Así, no admiten la repetición: kùn nán 困難 difícil $\rightarrow$ *kùn kùn nán nán 困困難難; 
zhòng yào 重要 importante $\rightarrow$ *zhòng zhòng yào yào 重重要要; fěn hóng 粉紅 rosa $\rightarrow$ *fěn fěn hóng hóng 粉粉紅紅.

La reduplicación de los tratamientos familiares es habitual. Los sustantivos de parentesco son de por sí formas reduplicadas, como bàbà 爸爸 padre, gē gē 哥哥 hermano mayor, jiě jiě 姐姐 hermana mayor, năi năi 奶奶 abuela, etc.

Por último, la reduplicación también se constituye en un procedimiento más de formación léxica, en el que la reiteración misma forma parte de la lexicalización, pues no resulta opcional y además no puede interpretarse, como en los casos anteriores, con el significado de 'un poco' o 'muy': máo máo yǔ 毛毛雨 'vello' 'lluvia' $\rightarrow$ Iluvizna; lěng bīng bing 冷冰冰 'frío' 'hielo' $\rightarrow$ gélido; gāng gāng 剛剛 hace un rato; piān piān 偏偏 inesperadamente, al revés; cháng cháng 常常 frecuentemente. La mayoría de las onomatopeyas también se forman por este tipo de reduplicación no composicional: guā guā 呱呱 sonido de pato; jīj İ zhā zhā 嘰嘰喳喳 sonido de pájaros; bī bī bō bō 逼逼皮 皮 sonido de freír algo, hū hū 呼呼 sonido del viento.

\subsection{Otros procesos de formación de palabras: abreviaciones, aféresis, extranjerismos}

Según Chao (1968: 492), dado que la mayoría de los morfemas del mandarín son monosilábicos y están escritos con "carácter" individual, la abreviación suele formarse por medio de la selección de elementos claves de una serie de morfemas: ôu zhōu lián méng 歐洲 聯盟 'Europa' 'unión' $\rightarrow$ Unión Europea => ōu méng 歐盟; jiāo tōng ǐnng chá 交通 警察 'tráfico' 'policía' $\rightarrow$ policía de tráfico => jiāo jinng 交警; jiào yù găi gé 教育 改革 'educación' 'revolución' $\rightarrow$ revolución educativa $=>$ jiào găi 教改; qì chē wéi xiū 汽車 維修 'coche' 'arreglar' $\rightarrow$ mantenimiento del coche => qì xiū 汽修; liú xíng xing găn 
Morfología contrastiva del chino mandarín y el español. Formas de gramaticalización y lexicalización

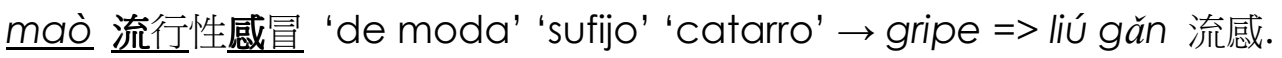

Además del morfema, J-H Wang (2001: §3.1) indica que tanto la sílaba como la palabra pueden ser unidades que constituyen la abreviación: los nombres de países o lugares suelen abreviarse en monosílabos en el lenguaje del periodismo: yì dà lì 義大利 Italia $\rightarrow$ yì 義, rì běn 日本 Japón $\rightarrow$ rì 日, sì chuān 四川 una provincia en China Continental $\rightarrow$ chuān 川, shăn XĪ 陝西 una provincia en China Continental $\rightarrow$ shăn 陝. La abreviación de palabras suele formar sintagmas de uso habitual: rén mín dài biăo dà huì 人民代表大會 'gente' 'pueblo' 'sustituir' 'presentar' 'grande' 'unión' $\rightarrow$ Congreso Nacional de Pueblo $\rightarrow$ rén dà 人大: ào lín pī kè yùn dòng huì wěi yuán huì 奧林匹克運動會委員會 'olímpico' 'transportar' 'moverse' 'miembro' 'unión' $\rightarrow$ Comité Internacional de Juegos Olímpicos $\rightarrow$ 奧委會.

Hay veces en las que la forma entera se ha olvidado o ha adquirido diferencias en el significado. En tal caso, la abreviación se convierte en un nuevo compuesto que se analiza separadamente de la palabra original. Por ejemplo, yǔ wén 語文 era anteriormente abreviación de yǔ yán wén zì 語言 文 字 'lengua' 'escritura', que significaba el habla y la escritura a la vez. Sin embargo, en la actualidad el uso de y̌̌ wén 語文 se suele referir solo a la capacidad de habla o solo a la de escritura en contextos distintos. Otro ejemplo es el sintagma wén xué yì shù de fù xing 文學 藝術 的復興 'literatura' 'arte' 'part. pos.' 'revitalización' no se abrevia en forma de wén yì fù xīng 文藝 復興, ya que el primero es una traducción literal de la expresión "la revitalización de la literatura y el arte", mientras que la forma abreviada significa el Renacimiento europeo en mandarín.

Otro tipo de abreviación se produce a través del proceso de la omisión de la sílaba, sea o no un componente directo. De ahí la palabra huā shēng 花生 'flor' 'crecer' $\rightarrow$ cacahuete, antiguamente luò huā shēng 落花生 'caer' 'flor' 'crecer' $\rightarrow$ cacahuete (flores caídas y luego crecido el fruto). El nombre antiguo todavía se conserva en japonés y mandarín de China. La palabra huó chē 火車 'fuego' 'vehículo' $\rightarrow$ tren proviene de huó lún chē 火輪車 'fuego' 
'rueda' 'vehículo' $\rightarrow$ tren (vehículo de fuego con ruedas).

Con respecto al extranjerismo, Wang (2000 [1947]) es el primer autor que introduce el estudio de los préstamos en el mandarín. En su opinión, la acusada tendencia del chino mandarín hacia las palabras polisilábicas viene determinada por la influencia de la traducción de lenguas extranjeras desde el siglo XIX, como shè huì 社會 sociedad, zī běn 資本 (el) capital, wèi shēng 衛生 sanidad, tăn kè 坦克 tanque, luó gí 邏輯 lógica, yōu mò 幽默 humor.

Principalmente, el extranjerismo suele reducirse a las palabras procedentes de inglés y del japonés. El anglicismo es importante por su influencia cultural y los préstamos del japonés son populares por la utilización de caracteres chinos.

Según Li (2004) y Shi (2000), el anglicismo se clasifica básicamente en traducciones fonéticas (o transliteraciones) y traducciones literales. Entre ellos, hay préstamos híbridos que combinan ambos procesos y otros préstamos directos que hacen referencia a los que no sufren ningún cambio.

Las palabras traducidas fonéticamente del inglés son abundantes. Este proceso comporta el cambio fonético de determinados fonemas o estructuras silábicas, como se refleja en la tabla siguiente:

\begin{tabular}{|c|c|c|}
\hline Inglés & Chino mandarín & Español \\
\hline disco & dísī kè 迪斯可 & discoteca \\
\hline coffee & kā fēi 咖啡 & café \\
\hline chocolate & qiǎo kè lì 巧克力 & chocolate \\
\hline acrylic & yiā kè lì 壓克力 & acrílico \\
\hline salad & shā lā 莎拉 & ensalada \\
\hline romantic & luó màn dì kè 羅曼蒂克 & romántico \\
\hline
\end{tabular}

Tabla 10: Anglicismos fonéticos

Mientras que las traducciones fonéticas están relacionadas con el valor fonético, las traducciones literales o calcos hacen referencia a los significados traducidos pero con la forma de la lengua receptora. La tabla siguiente contiene algunos ejemplos: 


\begin{tabular}{|c|c|c|}
\hline Inglés & Chino mandarín & Español \\
\hline democracy & mín zhǔ 民 主 'pueblo' 'estar en el poder' & democracia \\
\hline cosmetic & $\frac{\text { huà zhuāng pin 化妝 品 'maquillarse' }}{\text { 'producto' }}$ & cosmético \\
\hline surfing & chōng làng 衝 浪 'lanzarse' 'ola' & surfing, hacer surf \\
\hline abstract & chōu xiāng 抽象 'sacar' 'aspecto' & abstracto \\
\hline insurance & băo xiăn 保險 'proteger' 'riesgo' & seguro \\
\hline
\end{tabular}

Tabla 11: Calcos del inglés

Otro tipo destacado de calco se forma en chino mandarín con un hiperónimo que designa la clase semántica a la que pertenece el término extranjero. De este modo, se especifica el campo nocional correspondiente al nuevo término mediante un elemento compositivo o afijal pospuesto, como en los casos siguientes:

\begin{tabular}{|c|c|c|}
\hline Inglés & Chino mandarín & Español \\
\hline leukemia & xiě ái 血 癌 'sangre' 'cáncer' & leucemia \\
\hline buffet & zì zhù cān 自助 餐 'auto-servicio' 'comida' & bufet \\
\hline autism & zì bì zhèng 自閉 症 'autismo' 'síntoma' & autismo \\
\hline digitalize & shù wèi huà 數位化 'digital' 'transformar' & digitalizar \\
\hline psychology & xinn lĩ xué 心理 學 'psicología' 'estudio' & psicología \\
\hline gastritis & wèi yán 胃炎 'estómago' 'inflamación' & gastritis \\
\hline
\end{tabular}

Tabla 12: Calcos compuestos del inglés

Respecto a los préstamos híbridos, Lan (2004: 274) indica que existen varios tipos fundamentales, que incluyen las transliteraciones con carácter léxico (1-4) y las combinaciones de morfemas ingleses y de mandarín (5-7):

\begin{tabular}{|c|c|c|}
\hline Inglés & Chino mandarín & Español \\
\hline gram & gōng kè 公克 'público' 'gramo' & gramo \\
\hline England & yīng gúo 英國 'Inglaterra' 'país' & Inglaterra \\
\hline gin & qín jiǔ 琴酒 'gin' 'alcohol' & ginebra \\
\hline French & fà wén 法文 'Francia' 'idioma' & francés \\
\hline punk hairstyle & páng kè tóu 龐克 頭 'punk' 'cabeza' & peinado punk \\
\hline sunburn & shài bān 䃂斑 'tomar el sol' 'peca' & quemadura del sol \\
\hline talk show & tuō kŏu xiù 脫口 秀 'talk' 'espectáculo' & talk show \\
\hline
\end{tabular}

Tabla 13: Préstamos híbridos 
Por otra parte, los préstamos directos se refieren a las palabras prestadas que no sufren ningún cambio en mandarín, ni siquiera reciben la transliteración al alfabeto chino: pub, pizza, call (esp. llamada), show (esp. espectáculo o enseñar), Windows 2000, e-mail, moden, DIY (esp. hazlo tú mismo), DJ, CD, MTV (esp. televisión musical), LD (esp. disco láser), etc. Estos préstamos demuestran que en la actualidad los anglicismos (y otros préstamos indirectos) están muy extendidos en los medios de comunicación y en Internet. Su utilización refleja el avance de la alta tecnología y la globalización del conocimiento estándar.

Respecto a los préstamos de japonés, según Cheng (1992: 214-219), desde el punto de vista etimológico, muchos préstamos japoneses proceden, a su vez, del chino. El mandarín moderno los reasimila y los convierte en préstamos, como gé ming 革命 revolución, shè huì 社會 sociedad, gàn bù 幹部 miembro activo de una organización, chăng hé 場合 ocasión, situación, shǒu xù 手續 trámite, fú wù 服務 servicio, etc. Estos préstamos se caracterizan por no parecerse al extranjerismo, dado que también son "caracteres chinos"28.

En opinión de Shi (2000), los préstamos del japonés se dividen en tres grupos: a) préstamo directo; b) transliteración y traducción fonética; c) traducciones de caracteres japoneses. El primer grupo es el que produce más préstamos en mandarín. Se incluyen las palabras de conceptos del mundo occidental y se transforman del japonés mediante la utilización del carácter chino: qīng jī 經濟 economía, měi shù 美術 arte, zǔ hé 組合 combinación, shēn fèn 身分 identidad. El segundo grupo, poco frecuente, se refiere a la adaptación fonética al chino de formas occidentales pero introducidas en mandarín a través del japonés: pí jiǔ 啤酒 cerveza, jù lè bù 俱樂部 club, chǔ 呎 pie inglés, cùn 吋 pulgada. El tercer grupo reúne préstamos directos de caracteres de japonés. Se mantiene el concepto original del japonés pero se lee fonéticamente como mandarín huā dào 花道 la ceremonia japonesa de

${ }^{28}$ En japonés también se utilizan los caracteres chinos. Sin embargo, estos pueden tener diferentes significados léxicos según el contexto y, en algunas ocasiones, se emplean como vocabulario culto. 
Morfología contrastiva del chino mandarín y el español. Formas de gramaticalización y lexicalización

flor, fěi jù 俳句 poesía japonesa, ró dào 柔道 judo, shòu sī 壽司 susi, wuă sī 瓦 斯 gas.

\subsection{Resumen y conclusiones}

Para el chino moderno, se ha considerado que la composición es el proceso más productivo de la formación de palabras. Este reconocimiento se fundamenta en el origen histórico de la lengua, pues se admite que en chino clásico predominaban las palabras monosilábicas, constituidas, a su vez, por un único morfema que se identificaba con un elemento léxico. Además de la formación compositiva, los gramáticos de la lengua china están de acuerdo en que el proceso derivativo también es primordial para la formación de palabras, aunque nunca han llegado a un consenso sobre el inventario o sobre la definición de los afijos. Sin embargo, pese a estas discrepancias, se aceptan tradicionalmente las diferencias entre los afijos convencionales y los afijoides, basadas en el origen etimológico, la función gramatical y el significado léxico que aportan estos formantes.

Aparte de estos acuerdos sobre la morfología china, también se han observado varios fenómenos todavía no aclarados. En nuestra opinión, es problemática la idea de la ausencia de flexión en la lengua china, tanto en la flexión nominal como en la verbal, pues se pueden reconocer algunas marcas flexivas que expresan la pluralidad, el género, el genitivo, la temporalidad, el aspecto, etc., aunque algunas desempeñen además funciones autónomas como elementos léxicos. Por su parte, las flexiones verbales también pueden expresarse con recursos léxicos o bien mediante algunas marcas morfológicas de función gramatical, de manera que las variaciones de tiempo y aspecto se presentan con la anteposición o posposición de estos marcadores al elemento léxico verbal. 
Otros conceptos morfológicos que resultan polémicos se refieren a la identificación de los prefijos, la clasificación de los afijoides y la definición de los interfijos. Así, algunos prefijos polisémicos presentan una doble definición gramatical y léxica, de manera que se plantea el problema de definir su naturaleza en un único tipo morfológico. Por otro lado, los afijoides importados de lenguas extranjeras, por su función afijal y el significado léxico que aportan, plantean dificultades de definición y delimitación entre los tipos morfológicos de la derivación y la composición. Por último, los interfijos también son objeto de discusión porque se trata de un inventario reducido con una capacidad morfológica poco productiva, de manera que se suelen considerar más bien como auxiliares, conjunciones o adverbios, según la función que desempeñan en cada caso.

En cuanto a la composición, una propiedad que caracteriza este proceso es que no todos los constituyentes se interpretan como elementos libres en la lengua actual, pues se encuentran algunos elementos de los llamados "formantes libres ligados" que aportan significado léxico pero carecen de autonomía léxica en la formación compositiva moderna. En chino mandarín, el factor más importante para la clasificación de los compuestos es la estructura sintáctica interna. Esta relación gramatical que se establece entre los constituyentes explica la evolución de los compuestos modernos, pues todos estos reproducen construcciones sintácticas de la lengua clásica.

Por último, dos rasgos muy característicos de la lengua china son los clasificadores y la reduplicación, que alcanzan una amplia presencia en las gramáticas y los diccionarios del chino. Aunque no está muy claro que los clasificadores formen parte de la morfología o de la sintaxis, aquí se ha propuesto que los clasificadores nominales y verbales se relacionan con la composición, mientras que los individuales se asemejan más claramente a los afijos derivativos. Finalmente, la reduplicación se ha considerado como un fenómeno típicamente morfológico que afecta a la modificación aspectual de determinados verbos y a la formación del superlativo absoluto del adjetivo. 

PRINCIPALES RASGOS CONTRASTIVOS ENTRE LA MORFOLOGÍA CHINA Y LA MORFOLOGÍA ESPAÑOLA

El propósito de este capítulo consiste en reunir los aspectos comunes y los específicos que caracterizan los sistemas morfológicos de las dos lenguas en contraste. Tanto en chino mandarín como en español, las palabras se pueden formar por procesos derivativos y compositivos. Se dedican los diferentes apartados al análisis contrastivo de las correspondientes estructuras morfológicas a fin de explorar los fenómenos que en una lengua resultan procesos habituales y productivos, pero en la otra lengua se consideran como recursos defectivos o improductivos. Por otra parte, también se examinan otros procesos que intervienen en la formación de palabras en ambas lenguas, como el problema de los clasificadores, la abreviación y el extranjerismo.

\subsection{Flexión}

La lengua china usa en mayor medida que la española procedimientos analíticos para transmitir información gramatical, como el orden de palabras o la adición de unidades léxicas independientes. Sin embargo, aquí hemos defendido que los procesos flexivos no están ausentes del mandarín y que conviene distinguir con claridad entre las marcas flexivas y los afijos derivativos, a pesar de que ambos tipos de formantes comparten su dependencia con respecto a las unidades libres y, en gran medida, también su posición en el orden de las secuencias (§4.2). En este apartado se analizarán los 
Morfología contrastiva del chino mandarín y el español. Formas de gramaticalización y lexicalización

aspectos convergentes y divergentes que caracterizan los sistemas flexivos de las dos lenguas en contraste.

En cuanto a la flexión de caso, mientras que en español el caso gramatical se conserva en el sistema pronominal, en mandarín los pronombres personales solo presentan una única forma, de modo que las relaciones sintácticas se expresan a través preposiciones y del orden de palabras, lo mismo que sucede con los sustantivos, que, como ocurre en español, tampoco distinguen variaciones casuales:

Funciones sintácticas de los pronombres personales:

Sujeto (él): tā măi 他買 'él' 'comprar' $\rightarrow$ él compra

Compl. directo (lo): tā măi che 他買車 'él' 'comprar' 'coche' $\rightarrow$ él lo compra (el coche)

Compl. Indirecto (le): tā sòng che gěi tā ér zi 他送車給他兒子 'él' 'regalar' "coche" "a' "su' 'hijo' $\rightarrow$ él le regala un coche (a su hijo)

Compls. preps. (prep+él): Wǒ gān tā sàn pù 我跟他散步 'yo' 'con' 'él' 'pasear' $\rightarrow$ paseo con él

tā wuì tā gōng zuò 他為他工作 'él' "por' 'él' 'trabajar' $\rightarrow$ trabaja para él

Funciones sintácticas de los sustantivos:

Sujeto (coche): che zài zhè ér 車在這兒 'coche' 'estar' 'aquí' $\rightarrow$ el coche está aquí

Compl. directo (coche): Wǒ măi che 我買車 'yo' "comprar' "coche' $\rightarrow$ compro coche

Posesivo (de+coche): che de líng jiàn 車的零件 'coche' 'pos.' 'recambios' $\rightarrow$ los recambios del coche

Lugar (en+coche): Wǒ zài che lǐ 我在車裡 'yo' 'en' 'coche' 'dentro' $\rightarrow$ estoy en el coche

En español, tanto los sustantivos como los adjetivos disponen de morfema de número para expresar la pluralidad. En mandarín, en cambio, la flexión de pluralidad, expresada mediante el formante men 們, solo es pertinente para los pronombres personales y para determinados sustantivos que designan personas (vid. §4.2), como en 1). Con otros sustantivos, la expresión de la pluralidad requiere procedimientos sintácticos, pues normalmente recae en los cuantificadores equivalentes a 'algunos/algunas' o 
'muchos/muchas' antepuestos a los nombres, como en 2):

1) nǐmen 你們 'tú' 'partícula pl.' $\rightarrow$ vosotros

tóng xué men 同學們 'junto' 'aprender' 'partícula pl.' $\rightarrow$ alumnos

2) jǐ nián 幾年 'alguno' 'año' $\rightarrow$ (algunos) años

hěn duō shū 很多書 'mucho' 'año' $\rightarrow$ (muchos) libros

En el caso del género, el chino mandarín no dispone de ningún morfema flexivo para distinguir el masculino del femenino. Solo en la lengua escrita se usa una forma gráfica diferente para designar el sexo del referente en el pronombre de tercera persona: tā 他 él y tā 她 ella.

No obstante algunos nombres que significan clases de personas según la edad, parentesco, profesión, etc., y también ciertas clases de animales expresan la variación sexual mediante procedimientos sintagmáticos. Así, los nombres genéricos gōng 公 'macho' y mǔ 母 'madre' se usan para distinguir el sexo de los animales, y nán 男 'hombre' y nǔ 女 'mujer o hija' preceden a nombres de profesiones para distinguir el sexo de la persona referida. Se ilustran estas formaciones con los siguientes ejemplos:

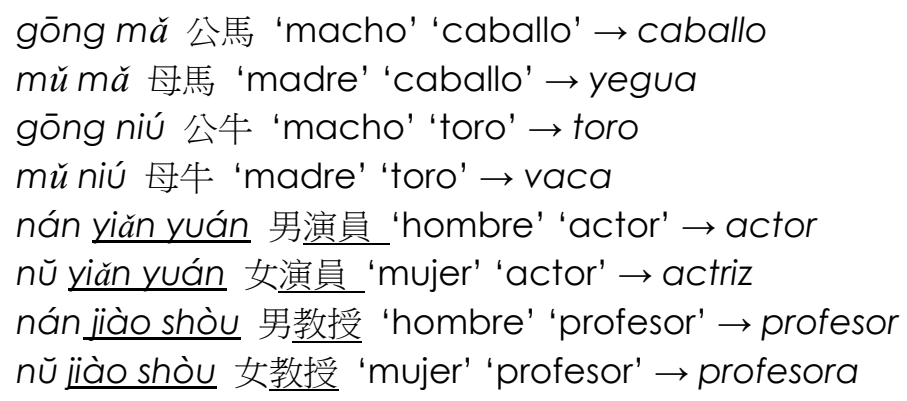

Cabría recordar que estos recursos apositivos no resultan extraños al español, especialmente con nombres epicenos que designan especies de animales cuyos rasgos sexuales son, en general, irrelevantes (la araña macho; el escorpión hembra). Por otra parte, muchos nombres de profesiones han adoptado recientemente las dos terminaciones propias de los nombres variables, lo que no impide que muchos hablantes sigan usando tales sustantivos como si se tratara de nombres invariables (ortónimos o epicenos), 
Morfología contrastiva del chino mandarín y el español. Formas de gramaticalización y lexicalización

como en tres mujeres ministros/tres ministras; varios presidentes mujeres/varias presidentas; las mujeres periodistas/las periodistas, etc. (Lliteras 2010b: 513-523).

Con respecto a la flexión verbal, mientras que en español el verbo se compone de un lexema y de morfemas constituyentes denominados desinencias, en chino mandarín las variaciones de persona, tiempo, aspecto, modo y voz se expresan principalmente mediante procesos analíticos, por la presencia de marcas gramaticales y léxicas. Cabe tener en cuenta que el chino mandarín no dispone de conjugación verbal. Así, los verbos no presentan cambios morfológicos, de manera que un mismo verbo chino sirve para todos los sujetos, tiempos, aspectos, modos y voces.

Tanto en chino mandarín como en español, el paradigma de los pronombres personales consta de tres personas gramaticales, que tienen formas específicas para el singular y para el plural. Se trata, como es sabido, de un universal lingüístico reconocido tradicionalmente. Sin embargo, el español, como es una lengua con concordancia desinencial entre el verbo y el participante sujeto, el pronombre personal puede no aparecer en el enunciado, mientras que es necesaria su presencia en la lengua china, ya que los verbos carecen de marcas flexivas para expresar la persona gramatical. Por ejemplo:

Wǒ hē shüi 我喝水 'yo' 'beber' 'agua' $\rightarrow$ bebo agua Wǒ men hē shŭi 我們喝水 'nosotros' 'beber' 'agua' $\rightarrow$ bebemos agua $n \check{n}$ hē shǔi 你喝水 '十ú' 'beber' 'agua' $\rightarrow$ bebes agua nǐmen hē shǔi 你們喝水 'vosotros' 'beber' 'agua' $\rightarrow$ bebéis agua tā hē shüi 他喝水 'él' 'beber' 'agua' $\rightarrow$ bebe agua tā men hē shǔi 他們喝水 'ellos' 'beber' 'agua' $\rightarrow$ beben agua

Respecto al tiempo verbal, mientras que en español se codifica el tiempo mediante los procedimientos morfológicos de la conjugación verbal, en chino mandarín el tiempo verbal se manifiesta por medio de diversas partículas adverbiales antepuestas al verbo. Tal como se ilustra en los siguientes ejemplos, el pasado, el presente y el futuro se expresan mediante elementos léxicos generalmente adverbiales (ayer, antes, lvego, etc.): 
Wǒ zoú tiān yŏu kè 我昨天有課 'yo' “ayer' 'tener' 'clase' $\rightarrow$ ayer tuve clase Wó xiàn zài yǒu kè 我現在有課 'yo" "ahora' "tener' "clase' $\rightarrow$ ahora tengo clase Wǒ míng tiān yŏ kè 我明天有課 'Yo' 'mañana' 'tener' 'clase' $\rightarrow$ mañana tendré clase

Sin embargo, le $\}$ puede considerarse como una marca flexiva que, además de indicar el aspecto perfectivo, expresa el tiempo pasado, como se ilustra en los ejemplos siguientes de 1). Pero no todos los verbos admiten la desinencia le $了$ para la formación del tiempo pasado, pues resultan agramaticales los enunciados con le $了$ pospuesto a los verbos de los ejemplos de 2):

1) Wǒ ná le shū 我拿了書 'yo' 'sacar' 'flexión de pasado' 'libro' $\rightarrow$ saqué el libro nǐ chuāng le xié zi 你穿了鞋子 'tú' 'poner' 'flexión de pasado' 'zapato' $\rightarrow$ te pusiste los zapatos

tā dă può le bēi zi 他打破了杯子 'él' 'romper' 'flexión de pasado' 'vaso' $\rightarrow$ rompió el vaso

2) *Wǒ xiăng le ň̌ 我想了你 'yo' 'pensar' 'marca flexiva' '十ú'

*tā guò le hăo shēn huó 他過了好生活 'él' 'llevar' 'marca flexiva' 'bueno' 'vida'

Los predicados que admiten la marca flexiva le 3 son los que designan una acción dinámica que produce un resultado y progresa hacia un límite. Es decir, la flexión verbal de tiempo pasado parece que se restringe a los predicados télicos o delimitados (Elena de Miguel 1999, cap. 46), como los enunciados de 1) que se relacionan con paráfrasis del tipo tuve sacado el libro, tuviste puestos los zapatos, quedó roto el vaso.

Por otro lado, esta marca flexiva le $了$ es compatible en el mismo enunciado con una forma adverbial de tiempo pasado. Este tipo de construcciones permite defender el carácter flexivo de este morfema ligado, que admite la presencia de los acotadores léxicos, como son los adverbios de tiempo, tal como ilustran los siguientes ejemplos:

$\begin{array}{lcccc}\text { 我 } & \text { 昨天 } & \text { 拿 } & \text { 了 } & \text { 書 } \\ \text { Wó zoú tiān ná } & \text { le } & \text { shū } \\ \text { Yo } & \text { ayer sacar } & \text { marca flexiva } & \text { libro } \\ \text { Ayer saqué el libro. } & & \end{array}$




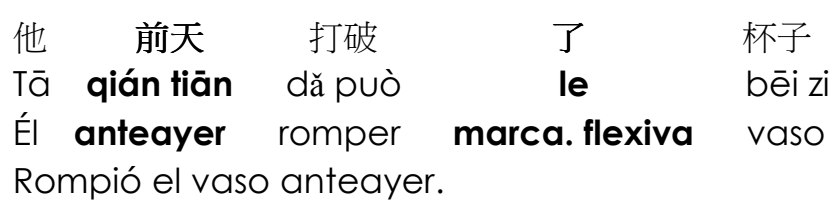

Otra marca que expresa el tiempo pasado es la forma yǐ qīng 已經. Este elemento induce a una interpretación del verbo en pretérito, equivalente a haber + participio o al indefinido del español. Comparte con le $\}$ la característca de construirse solo con verbos télicos. Sin embargo, difiere de la marca flexiva le $了$ en la colocación, pues yǐ qing 已經 se antepone a los verbos y además presenta un claro significado léxico como elemento autónomo, pues funciona como un adverbio equivalente en español a ya. Véase un ejemplo:

$\begin{array}{lcccc}\text { 我 } & \text { 已經 } & \text { 遞出 } & \text { 辭 } & \text { 呈 } \\ \text { Wǒ } & \text { y̌̃ qīng } & \text { dì chū } & \text { cí } & \text { chéng } \\ \text { Yo } & \text { adv. de tiempo 'ya' } & \text { presentar } & \text { despedida } & \text { carta } \\ \text { Ya he presentado/presenté la carta de despedida. } & \end{array}$

En cuanto al aspecto gramatical, el español utiliza las perífrasis verbales para señalar si la acción que expresan los verbos ha concluido o no en el instante de referencia indicado en la oración. Por ejemplo, la forma de marcar el aspecto pefectivo es mediante un verbo auxiliar que usualmente es haber, (han comido, habéis trabajado). Las llamadas formas no conjugadas del verbo, el participio, el infinitivo y el gerundio también presentan con valores aspectuales: tengo preparado el trabajo, vamos a estudiar, andamos pensando la solución.

Mientras que en español el aspecto se expresa por medios gramaticales, en chino mandarín estas manifestaciones temporales que expresan el desarrollo de la acción recaen en el grupo de las marcas verbales recogidas en a). Como se ha señalado anteriormente (§ 1.4), estas marcas aspectuales pueden manifestar las distintas fases de una acción, sea inicial, progresiva, durativa, resultativa, etc. Todos estos marcadores son palabras que han sufrido el proceso de gramaticalización y en la actualidad se asemejan a los sufijos, 
pues aparecen inmediatamente detrás del verbo. En este sentido, consideramos que la variación aspectual depende de un componente morfológico, creemos que típicamente flexivo, en la lengua china. Se ilustran algunos ejemplos del uso en b):

a) Aspecto perfectivo: le 了

Aspecto imperfectivo: zài 在 asp. progresivo (acción) zhe 著 asp. progresivo y durativo (estado)

Aspecto perfecto resultativo: daò 到, jiàn 見, le 了

Aspecto experiencial: guò 過 pasado indefinido guò 過 pasado reciente

Aspecto incoativo: qǐ laí 起來

Aspecto continuativo: xià qù 下去

Aspecto delimitativo: reduplicación del verbo

Forma no marcada a signo cero: $\varnothing$

b) 我在

Wǒ zài niàn shū

Yo asp. progresivo estudiar

Estoy estudiando.

$\begin{array}{lcc}\text { 我 去 } & \text { 過 } & \text { 美國 } \\ \text { Wǒ qù } & \text { guò } & \text { měi guó } \\ \text { Yo ir asp. experiencial } & \text { EE.UU. } \\ \text { He ido a EE.UU. } & \end{array}$

El modo describe la actitud del hablante, el grado de realidad o la fuerza elocutiva de la predicación verbal. En español esta categoría gramatical se expresa mediante la conjugación verbal. En cambio, en chino mandarín la modalidad se representa mediante determinadas conjunciones, como rú guó 如果 si, o auxiliares verbales que distinguen la modalidad epistémica, como en el caso siguiente:

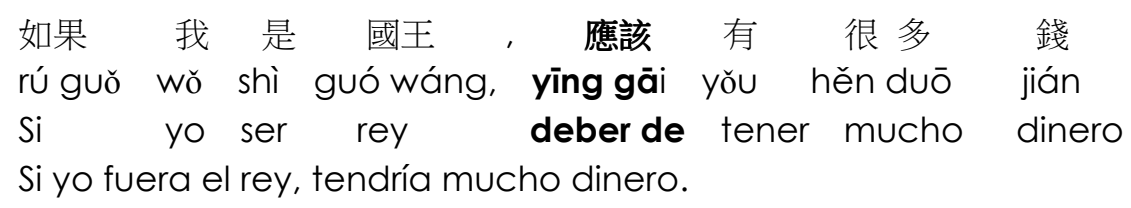


Morfología contrastiva del chino mandarín y el español. Formas de gramaticalización y lexicalización

La voz es la categoría gramatical asociada al verbo que indica la relación semántica entre el sujeto y el verbo, que permite decidir si el sujeto es agente o paciente. En este sentido, en español, por lo que respecta a la llamada voz, se distinguen la activa, la pasiva y la media. Todas estas construcciones se expresan mediante formas perifrásticas (ser/estar + participio) o verbos pronominales (con se). El chino también carece de conjugación verbal para formar construcciones pasivas y medias. Se reconoce un marcador propiamente morfológico para la pasiva, bèi 被, que se considera el más representativo y el único cuya función exclusiva en la actualidad es marcar la voz pasiva. Bèi 被 aparece normalmente detrás del sujeto paciente para introducir el agente. El esquema sería Sto. paciente + bèi 被 + Sto. agente + V, como se ilustra en el ejemplo siguiente:

\begin{tabular}{|c|c|c|c|}
\hline 被 & 他 & 騙 & 了 \\
\hline bèi & $t \bar{a}$ & piàn & le \\
\hline marca pasiva & él & engañar & asp. perf \\
\hline Sto. P & Sto. A & $V$ & \\
\hline
\end{tabular}

La voz media también se expresa mediante un recurso morfológico de tipo flexivo, pues el formante gěi 給 se antepone al verbo para introducir el significado gramatical que en español corresponde a la pasiva refleja, como en el siguiente ejemplo:

$\begin{array}{lccc}\text { 房子 } & \text { 給 } & \text { 燒 } & 了 \\ \text { Fáng zi } & \text { gěi } & \text { shaō } & \text { le } \\ \text { Casa } & \text { marca media } & \text { quemar } & \text { part. perf. } \\ \text { Se quemó la casa. } & & \end{array}$

\subsection{Derivación}

Tanto en español como en chino mandarín, la afijación es uno de los procedimientos fundamentales de la formación de palabras. Mediante la 
aplicación de un formante derivativo a una base léxica se crea una nueva forma compleja. En cuanto al número de los afijos, es difícil hallar cierta unanimidad entre los autores. En español, las principales disparidades provienen del deslinde entre los afijos y los afijoides, así como de la inclusión o no de afijos cultos. En chino mandarín, el inventario de los afijos tropieza con una dificultad: la identificación de los afijos traducidos de las lenguas extranjeras. En la lengua china, estos formantes neológicos reciben el nombre de pseudoafijos y difieren por su comportamiento de los afijos convencionales, como ér 兒, zi 子, tóu 頭， lăo 老, xiăo 小, dì 第, etc. Sin embargo, pese al desacuerdo sobre el listado de los afijos, los criterios coincidentes entre los morfólogos de ambas lenguas consisten en el reconocimiento de las funciones básicas de la afijación en la ampliación del léxico, la recategorización morfológica (nominalización, etc.) y la variación estilística.

Tanto en chino mandarín como en español los elementos afijales comparten algunas características: a) la posición fija, b) el debilitamiento del significado y c) la función emocional.

En primer lugar, los afijos se caracterizan por la estabilidad posicional. El prefijo y el sufijo reciben estos nombres por su colocación delante y detrás de la base, respectivamente. Sin embargo, en ambas lenguas, se encuentran elementos que pueden alternar entre la anteposición y la posposición. Estos elementos no se reconocen como afijos tradicionales, pues aunque funcionan como miembros de una formación compleja, se identifican con los elementos compositivos. En español estos elementos tienen origen culto y se denominan temas grecolatinos o temas polimórficos cultos (Lliteras 2010a: 363), como bio-/-bio, fono-/-fono-, cito-/-cito, lito-/-lito, morfo-/-morfo, zoo-/-zoo, entre otros, en biografía/microbio, teléfono/fonología, citología/linfocito, litografía Imonolito, morfología/isomorfo, zoología/protozoo, etc. En términos muy semejantes, el chino mandarín cuenta con un tipo de formantes productivos que se sitúan fuera de los auténticos sufijos, aunque crean series de palabras pero con el formante en las dos posiciones. Véanse algunos ejemplos: 


\begin{tabular}{|c|c|}
\hline Anteposición & Posposición \\
\hline $\begin{array}{c}\text { Iùn wén 論文 'teoría' } \\
\text { 'texto' } \rightarrow \text { tesis }\end{array}$ & $\begin{array}{c}\text { wéi wù lùn 唯物論 'solo' 'material' 'teoría' } \rightarrow \text { materialismo } \\
\text { xiāng dui lùn 相對論 'mutuo' 'enfrente' 'teoría' } \rightarrow \text { teoría de } \\
\text { la relatividad }\end{array}$ \\
\hline $\begin{array}{c}\text { jī qì 機器 'máquina' } \\
\text { 'aparato' } \rightarrow \text { máquina } \\
\text { o aparato }\end{array}$ & fēil jī 飛機 'volar' 'máquina' $\rightarrow$ avión \\
\hline
\end{tabular}

Tabla 1: Ejemplos de formantes de doble posición

En segundo lugar, los afijos de la lengua china eran unidades léxicas que presentaban autonomía sintáctica y semántica en el chino clásico. En el uso actual, estos elementos sufren la pérdida del contenido semántico y la adquisición de un valor gramatical. Así, junto con la pérdida semántica, estos elementos dejan de funcionar como unidades autónomas y se convierten en formantes ligados en la formación derivativa. Por ejemplo, según Jiang (2009:

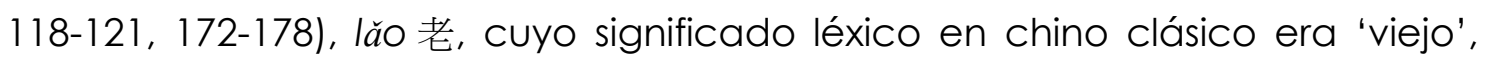
cuando se prefija a nombres propios patronímicos o a los adjetivos numerales (que aquí representan el orden de los hijos), pierde el contenido semántico relacionado con la vejez y adquiere un sentido de familiaridad y cariño, como en 1). Otro ejemplo lo constituye el elemento zi 子, que en chino clásico significaba 'hijo', pero cuando se pospone a determinados adjetivos de cualidad, especialmente negativa, adquiere este el valor de sustantivo y además pospuesto a verbos suele designar el agente, como en 2). En el uso antiguo, se sufijaba al apellido para expresar el respeto, como en 3):

1) lăo zhāng 老張 'pref.' 'apellido' $\rightarrow$ Zhang

lăo wáng 老王 'pref.' 'apellido' $\rightarrow$ Wang

lăo sān 老三 'pref.' 'tres' $\rightarrow$ el tercer hijo (mayor)

2) shăzi 俊子 'tonto' 'suf.' $\rightarrow$ el tonto

fēng zi 属子 'loco' 'suf.' $\rightarrow$ el loco

piàn zi 騙子 'mentir' 'suf.' $\rightarrow$ el mentiroso

xì zi 戲子 'actuar' 'suf.' $\rightarrow$ el actor

3) Cǒng zi 孔子 'Cóng' 'suf.' $\rightarrow$ Confucio

Mèng zi 孟子 'Mèng' 'suf.' $\rightarrow$ Mencio (discípulo de Confucio) 
En español, también se encuentran algunos sufijos que comparten esta característica del debilitamiento semántico o gramaticalización. El ejemplo más evidente es la conversión de mente en sufijo adverbializador (Dyer 1972). E elemento mente tenía un origen culto y funcionaba como una palabra autonóma: en latín clásico era el sustantivo mens, -tis y significaba 'mente, espíritu'. Se usaba en ablativo e iba acompañado de un adjetivo, sobre todo en contextos con un significado psicológico como, por ejemplo, clara-mente 'con mente clara'. Pero, ya en latín tardío, sufrió una pérdida de su significado léxico originario y ganó en significado gramatical. Así, se usaba como un elemento que servía para crear adverbios y con este sentido adverbial se convirtió en un sufijo.

En tercer lugar, la morfología derivativa del chino mandarín y la del español coinciden en que ambas lenguas disponen de un grupo de afijos que pueden expresar la subjetividad emocional, de manera que la llamada derivación expresiva, según la clasificación de Beard (1995) 29, está representada en nuestras lenguas en contraste. Para Beard, la derivación expresiva puede alterar semánticamente la base con la aportación de diversos aspectos emocionales. En este tipo de afijación suele distinguirse el diminutivo, el aumentativo, el peyorativo, el afectivo y el honorífico. En español, tal concepto está bien codificado, pues existe un extenso repertorio de sufijos denominados de esta manera a fin de expresar las ideas de tamaño (grande o pequeño), afectividad, fealdad, grandiosidad, desagrado, ridiculez, etc. En chino mandarín, creemos que algunos afijos adquieren la función de orientar el contenido semántico de la base léxica hacia sentidos apreciativos o evaluativos. Así, los prefijos xiăo 小 y lăo 老, y los sufijos zi 子 y tóu 頭 aportan la función denotativa de expresar la idea de pequeñez y de aminorar la sustancia semántica de la base de derivación. Es decir, la emotividad que

29 Beard (1995: 59) describe cuatro tipos de derivación: 1) derivación con valor desinencial, la que modifica el valor de las características gramaticales, como el género, el número y la clase de paradigma; 2) derivación expresiva, la que expresa la subjetividad del hablante; 3) derivación funcional, la que añade la función sintáctica, como el sujeto, objeto, etc., a la base del lexema; 4) derivación de transposición, la que cambia la categoría gramatical del lexema. 
Morfología contrastiva del chino mandarín y el español. Formas de gramaticalización y lexicalización

comportan tales afijos está relacionada con la idea de disminución. El hablante puede estimar o desestimar el valor según la intención y así se expresa su subjetividad hacía las entidades. Por ejemplo, Dong (2004) señala que cuando zi 子 se coloca después de una base nominal, aporta la idea de cariño. Por otro lado, Jiang (2009) explica que en la lengua vulgar o coloquial se usa el prefijo lăo despectivo. Véanse estos ejemplos en el siguiente:

jiù zi 舅子 'tío' 'suf.' $\rightarrow$ tío (hermanos de la madre)

xīn niáng zi 新娘子 'novia' 'suf.' $\rightarrow$ novia

lăo tǔ 老土 'pref.' 'vulgar, rústico' $\rightarrow$ paleto

Iăo nang 老娘 'pref.' 'madre' $\rightarrow$ designación del yo, si es mujer

Entre las distintas clases de sufijos apreciativos del español (diminutivos, aumentativos y despectivos), son los diminutivos los que más se asemejan a los afijos del chino mandarín por la capacidad de expresar diversos grados de disminución, reducción o pequeñez de lo designado. Los afijos apreciativos del chino mandarín se pueden reducir a los cuatro siguientes, que en la actualidad se han gramaticalizado, pues han perdido el significado léxico originario que consta a continuación:

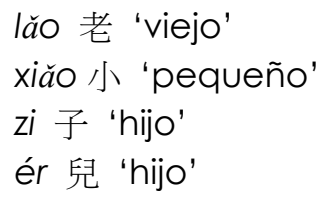

Sin embargo, en el rango semántico, los diminutivos del español expresan más tipos de significados que los afijos expresivos del chino mandarín. Según la Nueva Gramática de la Real Academia Española (2010: § 9.6), los diminutivos no lexicalizados expresan matices afectivos, de familiaridad, cercanía, ironía, cortesía, menosprecio, atenuación, tamaño o poca relevancia de algo. En cambio, los afijos expresivos del chino mandarín denotan menos variedad de significados, pues el contenido semántico de lo designado se centra en determinados tipos. El siguiente cuadro reúne los 
principales valores semánticos expresados por los afijos apreciativos de ambas lenguas:

\begin{tabular}{|c|c|c|}
\hline & Español & Chino mandarín \\
\hline familiaridad & $\begin{array}{l}\text { Juanita } \\
\text { Pablito }\end{array}$ & $\begin{array}{c}\text { lăo zǒng 老兄 'pref.' 'hermano' } \rightarrow \text { tú (apelativo } \\
\text { entre amigos) } \\
\text { xiǎo zhāng 小張 'pref.' 'apellido' } \rightarrow \text { Zhang }\end{array}$ \\
\hline tamaño & $\begin{array}{l}\text { papelito } \\
\text { pueblito }\end{array}$ & $\begin{array}{c}\text { běn zi 本子 'tomo' 'suf.' } \rightarrow \text { agenda, libreta } \\
\text { cè zi 冊子 'cuaderno' 'suf.' } \rightarrow \text { agenda, } \\
\text { cuadernillo }\end{array}$ \\
\hline menosprecio & $\begin{array}{c}\text { mediquito } \\
\text { abogadito } \\
\text { maestrillo }\end{array}$ & $\begin{array}{l}\text { chú zi 廚子 'cocinero' 'suf.' } \rightarrow \text { cocinero } \\
\text { qǔ ér 乞兒 'mendigo' 'suf.' } \rightarrow \text { mendigo }\end{array}$ \\
\hline temporalidad & viajecito, paseíto & \\
\hline eufemismo & cosita, braguita & 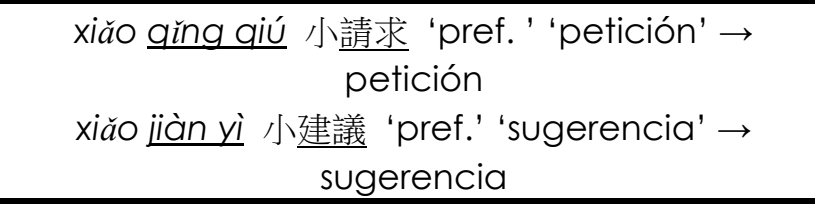 \\
\hline intensidad & solito, cerquita & \\
\hline atenuación & verdecito, ojuelos & \\
\hline ironía & dinerote, vejete & \\
\hline
\end{tabular}

Tabla 2: Principales valores de los sufijos apreciativos

Por los ejemplos de la tabla, se observa que en español la base léxica de los diminutivos puede corresponder a diferentes categorías gramaticales, como sustantivos, adjetivos e incluso adverbios. Sin embargo, en chino mandarín los derivados suelen tener raíces nominales. Por otra parte, mientras que en español los afijos apreciativos de los diminutivos son elementos sufijales, en chino mandarín los afijos expresivos pueden ser sufijos y prefijos. Respecto a la interrelación semántica, los derivados del español manifiestan más tipos de connotaciones que los sufijos afectivos del chino mandarín, pues en español, los diminutivos pueden expresar tamaño, atenuación, cercanía, intensidad, ponderación, cortesía, ironía, menosprecio y otras nociones que caracterizan la valoración afectiva que se hace de las personas, los animales o las cosas. En cambio, en chino mandarín los afijos expresivos centran los matices afectivos en la disminución y la familiaridad. Además, en ambas lenguas se usan sufijos 
Morfología contrastiva del chino mandarín y el español. Formas de gramaticalización y lexicalización

afectivos para aportar valoraciones negativas y se percibe menosprecio en los derivados de algunos sustantivos de persona, aunque no se detecta por lo general intención despectiva en estos nombres.

Según la Nueva Gramática de la Real Academia Española, (2010: 652), los sentidos concretos facilitan la formación del diminutivo en español, pues resulta más natural la derivación con el diminutivo en las nociones materiales. Por ejemplo, los sustantivos contables suelen admitir los diminutivos con mayor frecuencia que los no contables (mucho dolor frente a un dolorcito). En otras voces los sustantivos contables prefieren los diminutivos en sus acepciones más concretas, en lugar de representar las más abstractas (Guardo un buen recuerdo de este viaje frente a Quisiera sacar un recuerdito nuestro). En chino mandarín, los sentidos más claramente físicos o materiales muestran la tendencia a aceptar afijos convencionales con más naturalidad. Así, por ejemplo, el sufijo tóu 頭, aunque sin valor afectivo, forma una serie de derivados que designan una parte del cuerpo:

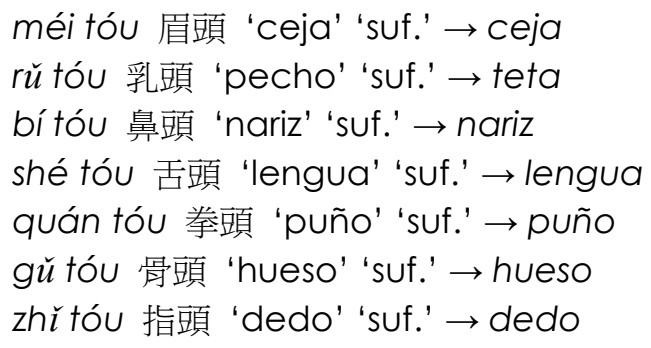

Frente a estas semejanzas, cabe tener en cuenta las principales diferencias de los elementos afijales en ambas lenguas. En primer lugar, en español, la alteración de la categoría gramatical de la palabra constituye la diferencia principal entre los prefijos y sufijos: los prefijos normalmente no alteran la categoría gramatical de la palabra (salvo quizá el prefijo anti-), mientras que los sufijos pueden mantenerla o cambiarla. En cambio, en mandarín, tanto los prefijos como los sufijos que derivan sustantivos tienen la capacidad de transcatecorizar las palabras en mayor o menor grado. Veamos los siguientes ejemplos: 
Prefijos que no alteran la categoría gramatical Chino mandarín:

lăo 老 'pref. afectivo' + shī 師 'maestro' $\mathrm{N} \rightarrow$ lăo shī 老師 profesor, maestroN xiăo 小 'pref. afectivo' + 貓 'gato' $\mathrm{N} \rightarrow$ xiăo māo 小貓 $\rightarrow$ gatito $\mathrm{N}$

dì 第 'pref. de número cardinal' + sān 三 'tres' $\rightarrow$ dì sān 第三 el terceron.

Español:

des- + colgarv $\rightarrow$ descolgarv

contra- + cultura $_{N} \rightarrow$ contraculturaN $_{N}$

Prefijos que alteran la categoría gramatical

Chino mandarín:

kě 可 'poder' + ài 愛 'amar'v $\rightarrow$ kè ài 可愛lindo, bonitoA

hoù 後 'pos-' + ji 記 'apuntar'v $\rightarrow$ hoù ji 後記 posdataN

jián 前 'pre-' + †i 提 'mencionar' $\vee \rightarrow$ jián ti 前提 precondición $\mathrm{N}_{\mathrm{N}}$

Español:

anti- + celulitis $_{N} \rightarrow$ anticelulitis $A$

anti- + niebla $_{N} \rightarrow$ antiniebla $_{A}$

Sufijos que no alteran la categoría gramatical Chino mandarín:

xié 鞋 'zapato' + zi 子 'morfofonema' $\rightarrow$ xié zi 鞋子 zapaton

shé 舌 'lengua' + + tóu 頭 'morfofonema' $\rightarrow$ shé tóu 舌頭 lengua ${ }_{N}$

zUľ 嘴 'boca'N + bā 巴 'morfofonema' $\rightarrow$ zUǐ bā 嘴巴 boca

Español:

-ada + payason $_{N} \rightarrow$ payasada $_{N}$

-ón + cobarde $_{A} \rightarrow$ cobardón $_{A}$

-ento + amarillo $_{A} \rightarrow$ amarillento $_{A}$

Sufijos que alteran la categoría gramatical

Chino mandarín:

lu 綠 'verde' ${ }_{\text {A }}$ huà 化 '-izar' $\rightarrow$ lù huà 綠化 plantarv

suān 酸 'agrio'A + xìng 性 'propiedad' $\rightarrow$ suān xìng 酸性 agrion

$j i$ 記 'apuntar'v + zhě 者 '-dor/tor' $\rightarrow$ ji zhě 記者 periodista

\section{Español:}

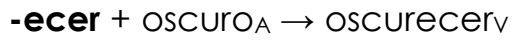

-ivo + oprimirv $\rightarrow$ opresivOA

-ción + socializarv $\rightarrow$ socialización $N$

De los sufijos del español, los que no alteran la categoría gramatical son los sufijos apreciativos; los no apreciativos, en cambio, pueden provocar o no el cambio de la categoría gramatical. En mandarín, los sufijos y los prefijos 
Morfología contrastiva del chino mandarín y el español. Formas de gramaticalización y lexicalización

que no alteran la categoría gramatical son los afijos tradicionales que forman sustantivos, mientras que la mayoría de los prefijos y sufijos capaces de cambiar la categoría gramatical pertenece a los afijos traducidos de lenguas extranjeras, los llamados "afijoides / pseudoprefijos o pseudosufijos".

Por otra parte, el sistema de los sufijos apreciativos en español se caracteriza por una acusada morfología recursiva, con acumulación de sufijos sobre la misma base. Normalmente se establece la mayor parte de las combinaciones mediante la utilización de sufijos distintos, y son todas las combinaciones posibles en función de la fantasía o el grado de emoción que el que describe o habla desee transmitir, como en 1), solo ocasionalmente el mismo tipo de sufijo se repite, como en 2).

1) chico $\rightarrow$ chiquitajo (diminutivo + peyorativo) dulce $\rightarrow$ dulzoncito (aumentativo + diminutivo) pintar $\rightarrow$ pintarrajear (peyorativo + peyorativo)

2) chico $\rightarrow$ chiquito $\rightarrow$ chiquitito

tonto $\rightarrow$ tontorro $\rightarrow$ tontorrón

Frente a la flexibilidad de la doble sufijación del español, en chino mandarín se producen restricciones con respecto a las combinaciones de los afijos expresivos. Así, los sufijos chinos carecen de las posibilidades combinatorias del español. Solo el sufijo ér 兒, al ser un elemento no silábico que se amalgama a la base, es el único que presenta capacidad recursiva. Pero los otros afijos no se aplican sucesivamente a partir de un mismo lexema. Sin embargo, difiere de los sufijos apreciativos del español en que el sufijo ér 兒 no altera semánticamente la base:

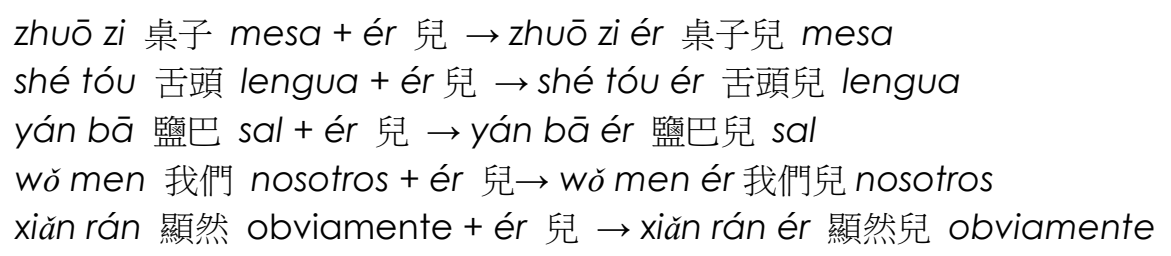


En tercer lugar, desde el punto de vista léxico-semántico, en español los sufijos apreciativos se dividen en dos grupos: las formas derivadas cuyo significado es composicional, pues se obtiene de la combinación de la base y el sufijo (arbolillo, cochazo, palacete, librote, etc.) y las voces lexicalizadas cuyo significado no se obtiene por la simple combinación de los dos componentes que los forman (centralita, cinturón, estribillo, pañuelo, lentejuela, pastilla, peluquín, etc.). Frente a estos conceptos de transparencia y opacidad, lo que sucede en chino mandarín es más sencillo: no se manifiesta este tipo de lexicalización, pues los derivados con prefijos y sufijos que designan valores afectivos son formas trasparentes en las que es posible obtener los rasgos expresivos a partir de la simple combinación de la base léxica y el formante derivativo:

lăo xiōng 老兄 'pref.' 'hermano mayor' $\rightarrow$ apelativo coloquial (= tío) jiàn ér 健兒 'fuerte, sano' 'suf.' $\rightarrow$ real mozo líng tóu 零頭 'suelto' 'suf.' $\rightarrow$ cambio, suelto xiā zi jiù zi 舅子 'hermano de la madre' 'suf.' $\rightarrow$ hermano de la madre

Por último, mientras que en chino mandarín los prefijos que expresan la valoración afectiva y la familiaridad, como lăo 老 y xiăo 小 se combinan con frecuencia con los numerales para indicar el orden de los miembros de la familia, especialmente entre los hijos y los hermanos (lăo èr 老二 'pref.' 'dos' $\rightarrow$ el segundo hijo, xiăo wǔ 小五 'pref.' 'cinco' $\rightarrow$ el quinto hijo), en español, resulta un fenómeno marginal este tipo de combinaciones. Según la Nueva Gramática de la Real Academia Española (2010: 633 y 657), algunos numerales admiten sufijos aumentativos para designar familiarmente al que ha alcanzado determinada edad, como en treintón (frente a treintañero), cuarentón, cincuentón, sesentón, etc. Por otra parte, en el español de América, se usan diminutivos con numerales en el área andina por la influencia del quechua y del aimara: unito, dosito, cuatrito, etc. También se encuentran casos particulares de sufijos apreciativos con los adjetivos ordinales: primerito, ultimito. 
Morfología contrastiva del chino mandarín y el español. Formas de gramaticalización y lexicalización

Merece una mención especial la sufijación mediante formantes que carecen tanto de significado léxico como de valor gramatical. En nuestra opinión, algunos afijos convencionales de la lengua china se identifican más bien con los morfofonemas en determinadas combinaciones, pues sirven de elementos que contribuyen al bisilabismo del chino moderno. En el chino mandarín, el prefijo lăo 老 y los sufijos ér 兒, zi 子 y tóu 頭 desempeñan funciones afijales cuando se unen a la base para formar palabras derivativas, pues aportan alguna función gramatical o léxica, como en a). Sin embargo, estos mismos elementos cuando se combinan con algunas unidades léxicas en la formación compleja, no aportan ni significado léxico ni significado gramatical, sino que su función principal es morfonológica, pues cumplen con la tendencia prosódica del bisilasiamo en el chino moderno, como en b):

a) Iăo zhāng 老張 'pref. (familiariad)' 'Zhang (apellido)' $\rightarrow$ Zhang zhè ér 這兒 'aqui' 'suf. (indicador de dirección)' $\rightarrow$ aquí xiā zi 瞎子 'ciego' 'suf. (sustantivador de persona)' $\rightarrow$ el ciego kŭ tóu 苦頭 'amargo' 'suf. (sustantivador de cualidad)' $\rightarrow$ amargura

b) lăo hŭ 老虎 'morfofonema' 'tigre' $\rightarrow$ tigre lăo shǔ 老鼠 'morfofonema' 'tigre' $\rightarrow$ ratón yàng ér 樣兒 'forma' 'morfofonema' $\rightarrow$ aspecto o forma wò men ér 我們兒 'nosotros' 'morfofonema' $\rightarrow$ nosotros xié zi 鞋子 'zapato' 'morfofonema' $\rightarrow$ zapato fáng zi 房子 'casa' 'morfofonema' $\rightarrow$ casa shí tóu 石頭 'piedra' 'morfofonema' $\rightarrow$ piedra mù tóu 木頭 'madera' 'morfofonema' $\rightarrow$ madera

Por lo tanto, en las combinaciones de b), estos formantes podrían equipararse a los interfijos del español, en el sentido de que son elementos sin función gramatical ni significativa. Tan solo ejercen funciones morfofonemáticas, pues sirven de eslabón o enlace entre las expresiones de los distintos morfemas que entran a formar parte de la palabra.

Sin embargo, en comparación con los intefijos del español, estos elementos presentan algunos comportamientos diferentes. En primer lugar, se observa que no se colocan entre la base léxica y el sufijo, pues se trata de afijos 
que solo admiten la anteposición o posposición al lexema. Además, estos formantes del chino desempeñan una única función: proporcionar el bisilabismo del chino moderno, mientras que en español los interfijos presentan varias funciones. Así, en el nivel fonético, los interfijos pueden evitar el hiato entre la base y el sufijo (cafe-c-ito, mama-s-ita); en el nivel morfémico, los verbos de las conjugaciones $2 .^{a}$ y $3 .^{a}$ necesitan un interfijo para recibir el sufijo -ón, como en tem-er-ón, com-il-ón; en el nivel léxico, los interfijos colaboran en la identificación de la base léxica al eliminar posibles homonimias (pan-ad-era / panera, man-ot-ada / man-ada, cort-ec-ito / cort-ito).

\subsection{Composición}

Tanto en español como en mandarín, las palabras compuestas parten de la unión de dos o más morfemas léxicos. Tal procedimiento es uno de los procesos principales en la formación de palabras. En ambas lenguas, los compuestos pueden agruparse en varias clases de acuerdo con distintos criterios, como los que se muestran seguidamente:

1) Las clases de palabras a las que corresponden los segmentos constitutivos de la composición.

2) La relación gramatical que se establece entre estos formantes constituyentes.

Por el primer criterio, se pueden analizar y equiparar los tipos de compuestos en español y mandarín según la categoría gramatical de los componentes. En la tabla siguiente se muestran las semejanzas categoriales de los constituyentes en la composición de ambas lenguas: 
Morfología contrastiva del chino mandarín y el español. Formas de gramaticalización y lexicalización

\begin{tabular}{|c|c|c|}
\hline & Chino mandarín & Español \\
\hline $\mathbf{N}+\mathbf{N}$ & $\begin{array}{c}\text { tiě lù 鐵路 'hierro' 'camino' } \rightarrow \text { ferrocarril } \\
\text { guó jiā 國家 'país' 'casa' } \rightarrow \text { país } \\
\text { guǒ zhī 果汁 'fruto' 'jugo' } \rightarrow \text { zumo } \\
\text { xiōng dì 兄弟 'hermano mayor' 'hermano menor' } \rightarrow \\
\text { hermanos } \\
\end{array}$ & $\begin{array}{l}\text { ferrocarril } \\
\text { compraventa } \\
\text { baloncesto } \\
\text { aromaterapia } \\
\text { madreselva } \\
\end{array}$ \\
\hline$N+A$ & $\begin{array}{c}\text { xué bái 雪白 'nieve' 'blanco' } \rightarrow \text { blanco (como la nieve) } \\
\text { dăn xiǎo 膽小 'coraje' 'pequeño' } \rightarrow \text { cobarde } \\
\text { xīng jí 心細 'corazón' 'fino' } \rightarrow \text { considerado, atento } \\
\text { xing jí 性急 'carácter' 'precipitado' } \rightarrow \text { impaciente }\end{array}$ & $\begin{array}{l}\text { camposanto } \\
\text { ojinegro } \\
\text { nochebuena } \\
\text { pelirrojo }\end{array}$ \\
\hline$N+V$ & $\begin{array}{l}\text { dì zhèn 地震 'terreno' 'moverse' } \rightarrow \text { terremoto } \\
\text { hăi yùn 海運 'mar' 'transportar' } \rightarrow \text { transporte marítimo } \\
\text { zhú kē 竹刻 'bambú' 'grabar' } \rightarrow \text { grabado en bambú } \\
\text { fă zhì 法治 'ley' 'gobernar' } \rightarrow \text { gobierno legal }\end{array}$ & $\begin{array}{l}\text { maniatar } \\
\text { manuscribir } \\
\text { perniquebrar }\end{array}$ \\
\hline$A+A$ & $\begin{array}{c}\text { CŪ xì 粗細 'gordo' 'fino' } \rightarrow \text { gordo y fino } \\
\text { xì cháng 細長 'fino' 'largo' } \rightarrow \text { fino y largo } \\
\text { xiăo qiăo 小巧 'pequeño' 'delicado' } \rightarrow \text { pequeño y } \\
\text { delicado } \\
\text { bàn zhòng 笨重 'torpe' 'pesado' } \rightarrow \text { torpe y pesado }\end{array}$ & $\begin{array}{c}\text { anchicorto } \\
\text { blanquinegro } \\
\text { latinoamericano } \\
\text { agridulce }\end{array}$ \\
\hline$A+N$ & $\begin{array}{l}\text { xiăo jìng 小徑 'pequeño' 'camino' } \rightarrow \text { sendero } \\
\text { xiăo fèi 小費 'pequeño' 'coste' } \rightarrow \text { propina } \\
\text { nián tǔ 黏土 'pegajoso' 'barro' } \rightarrow \text { plastilina } \\
\text { kuài ting 快艇 'rápido' 'canoa' } \rightarrow \text { barco }\end{array}$ & $\begin{array}{l}\text { medianoche } \\
\text { mediodía } \\
\text { salvoconducto } \\
\text { librecambio }\end{array}$ \\
\hline$V+V$ & $\begin{array}{c}\text { sàng shī 喪失 'perder' 'perder' } \rightarrow \text { perder } \\
\text { wàng jì 忘記 'olvidar' 'recordar' } \rightarrow \text { olvidar } \\
\text { kāi guān 開關 'abrir' 'cerrar' } \rightarrow \text { interruptor } \\
\text { qì shǒu 棄守 'abandonar' 'guardar' } \rightarrow \text { dejar de } \\
\text { guardar }\end{array}$ & $\begin{array}{l}\text { quitapón } \\
\text { ganapierde } \\
\text { bullebulle }\end{array}$ \\
\hline$V+N$ & $\begin{array}{c}\text { jǔ zhòng 舉重 'levantar' 'peso' } \rightarrow \text { levantar peso } \\
\text { chīfăn 吃飯 'comer' 'arroz' } \rightarrow \text { comer } \\
\text { cái yuán 裁員 'cortar' 'personal' } \rightarrow \text { reducir el personal } \\
\text { pái duì 排隊 'ordenar' 'cola' } \rightarrow \text { hacer cola }\end{array}$ & $\begin{array}{l}\text { quitasol } \\
\text { rompeolas } \\
\text { sacacorchos } \\
\text { salvavidas }\end{array}$ \\
\hline $\begin{array}{l}\text { Adv. }+ \text { V / } \\
\text { Participio } \\
\text { /Adj. }\end{array}$ & $\begin{array}{l}\text { zhǐnéng 只能 'solo' 'poder' } \rightarrow \text { solamente } \\
\text { gèng jiāa 更加 'más' 'añadir' } \rightarrow \text { más aún } \\
\text { bú jin 不禁 'no' 'aguantar' } \rightarrow \text { inconscientemente } \\
\text { bú bài 不敗 'no' 'derrotar' } \rightarrow \text { invenciblemente }\end{array}$ & $\begin{array}{l}\text { bienvivir } \\
\text { maltratar } \\
\text { bienaventurado } \\
\text { malcriado } \\
\text { maloliente }\end{array}$ \\
\hline
\end{tabular}

Tabla 3: Categorías gramaticales de los constituyentes de la composición

El segundo criterio de clasificación de los compuestos se refiere a la relación sintáctica que establecen los constituyentes. Según este criterio, los compuestos se clasifican en tipos coordinados y tipos subordinados. En ambas 
lenguas, se llaman compuestos coordinados y subordinados a los que manifiestan una relación asimilable, respectivamente, a la coordinación y subordinación sintácticas entre sus componentes, aun cuando en los compuestos coordinados del español no haya razones para asociar la vocal $-i$-, en caso de que aparezca, con una conjunción copulativa (Real Academia Española 2010: 738). Así, tomando como principio el modelo sintáctico, los compuestos en ambas lenguas se pueden dividir en los siguientes tipos:

\begin{tabular}{|c|c|c|c|}
\hline \multicolumn{2}{|c|}{$\begin{array}{l}\text { Relación sintáctica } \\
\text { entre morfemas }\end{array}$} & Chino mandarín & Español \\
\hline \multirow{3}{*}{ 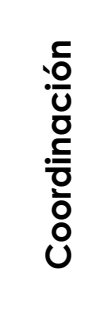 } & $\begin{array}{c}\text { Elementos } \\
\text { iguales }\end{array}$ & sàng shī 喪失 'perder' 'perder' $\rightarrow$ perder & \multirow{3}{*}{$\begin{array}{l}\text { anchicorto } \\
\text { motocarro } \\
\text { afroasiático } \\
\text { blanquinegro }\end{array}$} \\
\hline & $\begin{array}{l}\text { elementos } \\
\text { parecidos }\end{array}$ & guó jiā 國家 'país' ‘casa' $\rightarrow$ país & \\
\hline & $\begin{array}{l}\text { elementos } \\
\text { opuestos }\end{array}$ & cū xì 粗細 'gordo' 'fino' $\rightarrow$ gordo y fino & \\
\hline \multirow{4}{*}{ 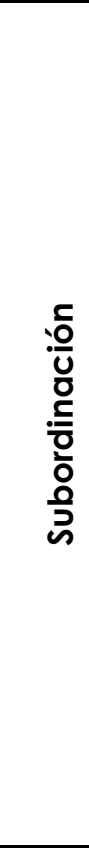 } & $\begin{array}{l}\text { Verbo- } \\
\text { compl. } \\
\text { objeto }\end{array}$ & $\begin{array}{l}\text { cái yuán 裁員 'cortar' 'personal' } \rightarrow \text { despedir } \\
\text { jǔ zhòng 舉重 'levantar' 'peso' } \rightarrow \text { halterofilia } \\
\text { kāi chē 開車 'abrir' 'coche' } \rightarrow \text { conducir }\end{array}$ & $\begin{array}{l}\text { guardacostas } \\
\text { quitasol } \\
\text { rompeolas } \\
\text { sacamuelas } \\
\text { paracaídas }\end{array}$ \\
\hline & $\begin{array}{l}\text { Verbo- } \\
\text { compl. } \\
\text { predicativo }\end{array}$ & $\begin{array}{c}\text { jí kuă 擊垮 'derrotar' 'caerse' } \rightarrow \text { caerse } \\
\text { derrotado } \\
\text { shēng gāo 升高 'levantar' 'alto' } \rightarrow \text { levantar } \\
\text { jiǎn míng 講明 'hablar' 'claro' } \rightarrow \text { aclarar }\end{array}$ & \\
\hline & $\begin{array}{l}\text { Sujeto- } \\
\text { predicado }\end{array}$ & $\begin{array}{c}\text { yăn hóng 眼紅 'ojo' 'rojear' } \rightarrow \text { envidiar } \\
\text { dì zhèn 地震 'tierra' 'vibrar' } \rightarrow \text { terremoto } \\
\text { shaān bōng 山崩 'montaña' 'desprenderse' } \\
\rightarrow \text { derrubio }\end{array}$ & \\
\hline & $\begin{array}{l}\text { Prep.- } \\
\text { término }\end{array}$ & $\begin{array}{c}\text { zì č̌ 自此 'desde' 'esto' } \rightarrow \text { desde entonces } \\
\text { dāng chăng 當場 'ante' 'ocasión' } \rightarrow \text { en } \\
\text { seguida } \\
\text { dāng minàn 當面 'ante' 'cara' } \rightarrow \text { en persona }\end{array}$ & $\begin{array}{l}\text { parabién, } \\
\text { enhorabuena } \\
\text { sobremesa }\end{array}$ \\
\hline
\end{tabular}

Tabla 4: Relaciones sintácticas de los constituyentes de la composición

Es de interés señalar que la preposición cuando entra en procesos compositivos pierde su condición de núcleo del sintagma preposicional -si es que se admite esta función- y se realiza como un morfema no nuclear, bien 
Morfología contrastiva del chino mandarín y el español. Formas de gramaticalización y lexicalización

manteniendo su significado como preposición (entremeter, sobrevolar, contraatacar, zì č̌ 自此 'desde' 'esto' $\rightarrow$ desde entonces), bien adoptando una función adverbial (entreabrir, sobrecargar, contrapesar, dāng chăng 當場 'ante' 'ocasión' $\rightarrow$ en seguida).

Por otra parte, un caso particular de los compuestos del tipo AN en ambas lenguas lo constituyen las formaciones nominales con adjetivos numerales y sustantivos. Muchos de estos compuestos designan animales y plantas. En español, este esquema resulta relativamente productivo, por ejemplo, en casos como ciempiés, cientoemboca, cuatronarices, milamores, milflores, milhojas, sietecolores, sietecueros, sietemachos, sietepellejos, etc. (Real Academia Española 2010: 779). En chino mandarín, las formaciones responden a patrones semejantes:

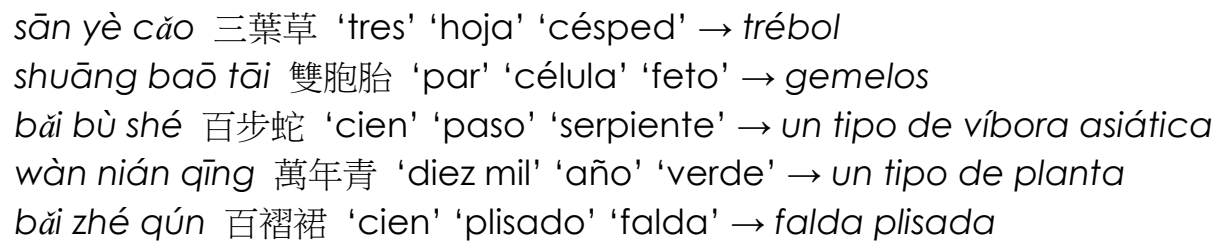

En el lenguaje científico, también es común la formación de tecnicismos en ambas lenguas a partir de un numeral cardinal y un sustantivo. En este caso, las formaciones son prácticamente idénticas:

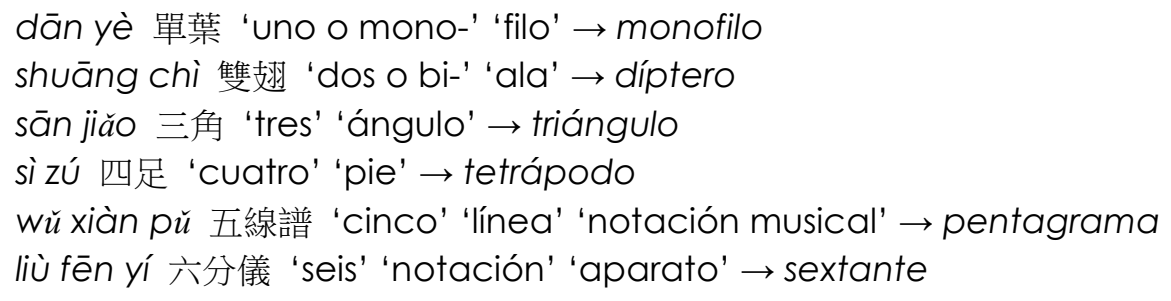

En lo que sigue, se tratará de analizar otros aspectos convergentes y divergentes de los procesos compositivos de ambas lenguas. Sin embargo, por razones metodológicas, los compuestos sintagmáticos (punto de vista, hora punta, etc.) no se tomarán, en general, aquí como muestras representativas de voces compuestas en español que puedan compararse a las formaciones 
chinas, pues los criterios utilizados para distinguir los compuestos léxicos de los sintagmáticos en español ( $\$ 3.3$ y 8) no pueden ser aplicados rigurosamente a la composición en chino. En cambio, se dedica el capítulo 8 de este trabajo al análisis contrastivo entre determinados tipos de locuciones en español y sus correspondientes formaciones en chino.

En el compuesto NN de tipo subordinado, el sustantivo que no actúa como núcleo complementa al que ejerce este papel. Dicha relación expresa a menudo la posesión o pertenencia, por lo que se corresponde en el plano sintagmático con grupos preposicionales introducidos por la preposición de en español y la partícula posesiva de 的 del chino mandarín. Cabe tener en cuanta que cambia el orden de los elementos, pues en español el núcleo del compuesto está representado por el primer constituyente, mientras que en chino el núcleo ocupa la segunda posición. Véanse algunos ejemplos:

\begin{tabular}{|c|c|}
\hline Español & Chino mandarín \\
\hline $\begin{array}{c}\text { bocacalle } \\
\text { ('la boca de la calle') }\end{array}$ & $\begin{array}{c}\text { jiē kǒu 街 } \square \text { (jiē de kǒu 街的 } \square \text { 'calle' 'part. posesiva' 'boca') } \\
\rightarrow \text { bocacalle }\end{array}$ \\
\hline $\begin{array}{c}\text { telaraña } \\
\text { ('la tela de la araña') }\end{array}$ & $\begin{array}{l}\text { zhī zhū wăng 蜘蛛網 (zhī zhū de wăng 蜘蛛的網 'araña' 'part. } \\
\text { posesiva' 'tela') } \rightarrow \text { telaraña }\end{array}$ \\
\hline $\begin{array}{c}\text { bocamanga } \\
\text { ('la boca de la } \\
\text { manga') }\end{array}$ & 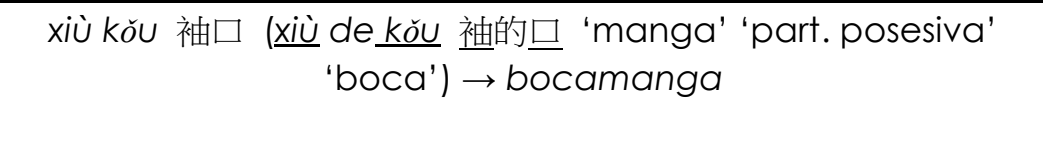 \\
\hline
\end{tabular}

Tabla 5: Composición NN de relación subordinada

Es bastante productiva en ambas lenguas la pauta AN cuando el núcleo procede de un adjetivo que designa un color y el otro segmento se refiere al tono parecido al de la cosa que representa. Así, en español, verdemar, verdemontaña, verdevejiga, etc. En los siguientes ejemplos del chino mandarín también se observa que el segmento modificador designa la entidad representativa o prototípica de la variedad cromática en cuestión:

tiān kōng lán 天空藍 'cielo' 'azul' $\rightarrow$ azul cielo

zhēn zhū bái 珍珠白 'perla' 'blanco' $\rightarrow$ blanco perla

ying táo hóng 櫻桃紅 'cereza' 'rojo' $\rightarrow$ rojo cereza

píng guó lù 蘋果綠 'manzana' 'verde' $\rightarrow$ verde manzana 
Morfología contrastiva del chino mandarín y el español. Formas de gramaticalización y lexicalización

En ambas lenguas, el esquema NA produce una serie de compuestos que calcan formaciones de lenguas extranjeras, especialmente del inglés (workaholic, acis-fastness, drug addict, sex addict, vasodilator). Así, por ejemplo, en español, acidorresistente, drogadicto, narcotraficante, vasodilatador, etc. Del mismo modo, en chino mandarín, se observa la influencia de la traducción de lenguas extranjeras en este tipo de compuestos subordinados:

\section{gōng zuò kuáng 工作狂 'trabajo' 'adicto' $\rightarrow$ trabajólico \\ bào lì kuáng 暴力狂 'violencia' 'adicto' $\rightarrow$ sádico, violento lüăn tóng pì 變童僻 'paidofilia' 'maniático' $\rightarrow$ paidófilo, pederasta \\ gòu wù pì 購物僻 'compra' 'maniático' $\rightarrow$ consumidor compulsivo}

Desde el punto de vista semántico, entre el nombre y el adjetivo se establece una relación argumental en estos compuestos adjetivales NA neológicos, en el sentido de que el sustantivo desempeña la función semántica que corresponde al argumento requerido por el verbo que sirve de base al adjetivo. Las paráfrasis que siguen muestran claramente esta relación:

\section{1) Ejemplos del español}

acidorresistente ('resistente al ácido'), catalanohablante ('hablante del catalán'), drogadicto ('adicto a las drogas'), radioaficionado ('aficionado a la radio'), vasodilatador ('dilatador de los vasos').

\section{2) Ejemplos del chino mandarín}

gōng zuò kuáng 工作狂 'trabajo' 'adicto' $\rightarrow$ trabajoadicto ('adicto al trabajo') bào lì kuáng 暴力狂 'violencia' 'adicto' $\rightarrow$ violento ('adicto a la violencia') lüăn tóng pì 變童僻 'paidofilia' 'maniático' $\rightarrow$ paidolfilo, pederasta ('maniático sexual contra los niños')

gòu wù pi 購物僻 'compra' 'maniático' $\rightarrow$ consumidor compulsivo ('maniático de la compra')

Los compuestos NA del español encuentran su equivalencia en chino mandarín, pero presentan el esquema contrario AN, pues en el orden de palabras de la lengua china, el adjetivo precede al sustantivo:

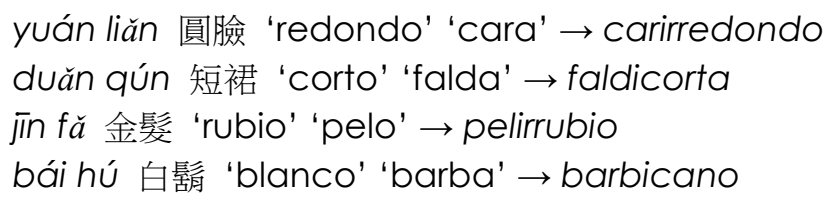


gāo ling 高領 'alto' 'cuello' $\rightarrow$ cuellilargo

Con respecto a los compuestos NV, mientras que en el chino mandarín este esquema resulta muy productivo, en español ha dejado de serlo, entre otras razones, porque la relación sintáctica "nombre-sujeto + verbo" no se lexicaliza en la composición española. Se observa, en general, que los compuestos chinos reflejan más claramente la estructura sintáctica de la lengua, pues en la composición tienen cabida tipos como el de sujeto-verbo o verbo-complemento predicativo, que no se dan en español. Así, a pesar de que en la composición de ambas lenguas se encuentran propiedades distribucionales de la sintaxis oracional en la morfología, es de notar que, en algunos casos, los compuestos del español presentan una estructura cuasi-sintáctica débil en contraste con las relaciones gramaticales sólidas y constantes de los componentes del chino mandarín. Con razón, Piera y Varela (1999: 4383) explican la gramática del compuesto español como una 'sintaxis empobrecida' que no sobrepasa el nivel de la categoría léxica.

Así, la relación nombre-sujeto + verbo no se da en la palabra compuesta del español (afilalápices, pero *máquinafila), puesto que esta relación estructural implica un contorno sintáctico que sobrepasa la mera combinación de categorías léxicas, pues queda el sujeto fuera del ámbito de rección del verbo. En cambio, en chino mandarín, se dan combinaciones de nombre-sujeto + verbo, como ilustran los ejemplos siguientes:

\footnotetext{
dì zhèn 地震 'terreno' 'moverse' $\rightarrow$ terremoto

tiān liàn 天亮 'cielo' 'iluminarse' $\rightarrow$ amanecer

dōng zhì 冬至 'invierno' 'llegar' $\rightarrow$ solsticio de invierno
}

En chino mandarín, muchas de estas construcciones suelen estar formadas por constituyentes que hacen referencia a las partes del cuerpo y a cambios de la naturaleza:

qǐshēn 起身 'levantar' 'cuerpo' $\rightarrow$ levantarse shòu shēn 瘦身 'adelgazar' 'cuerpo' $\rightarrow$ adelgazar (el cuerpo)

dòng shēn 動身 'mover' 'cuerpo' $\rightarrow$ marchar(se)

luò yè 落葉 'caer' 'hoja' $\rightarrow$ defoliar 
Morfología contrastiva del chino mandarín y el español. Formas de gramaticalización y lexicalización

En español, constituye un caso particular el compuesto crecepelo, que se relaciona con la forma causativa 'hacer crecer el pelo', en la que el sustantivo corresponde al argumento paciente de crecer. En chino mandarín, se encuentran casos parecidos como los siguientes compuestos VN:

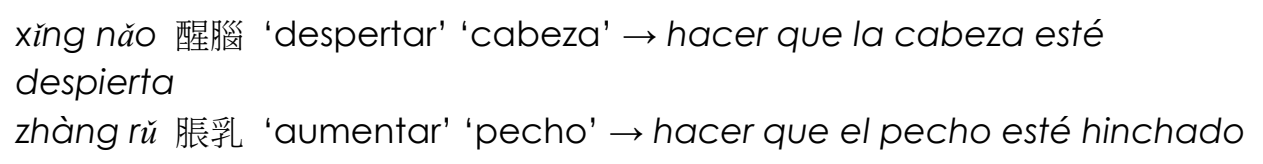

Estos compuestos verbales formados por un verbo causativo más nombre admiten en mandarín la doble composición con otro morfema léxico nominal pospuesto que corresponde al argumento agente del compuesto verbal. Así, tales formaciones se presentan claramente como endocéntricas:

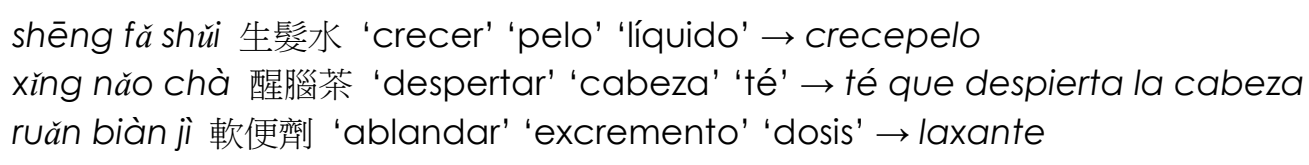

Otro caso de restricciones en relación con la combinación sintáctica que resulta defectivo en la morfología española es el tipo formado por verbo y complemento predicativo. Según Piera y Varela (1999: 4383), en la palabra compuesta del español no se dan complementos predicativos porque estos complementos dependen de dos constituyentes sintagmáticos que actúan de manera composicional (Juan duerme tranquilo; Compraron baratos los muebles), pero en la palabra no se dan constituyentes de doble dependencia. Además, los predicativos se refieren siempre a nombres determinados y en la palabra no caben nombres acotados referencialmente. En cambio, en chino mandarín, el predicativo forma parte de algunos tipos de compuestos. Por ejemplo, en las siguientes palabras, de combinación categorial verbo-adjetivo, el adjetivo equivale sintácticamente a un complemento predicativo:

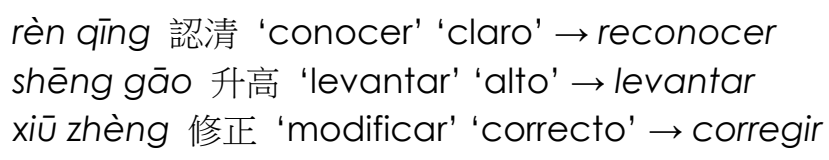


En resumen, es indudable que tanto en chino mandarín como en español se establecen conexiones entre la sintaxis y la morfología. Sobre todo, en chino mandarín, estas operaciones sintácticas constituyen el procedimiento principal para la formación de palabras compuestas. Los compuestos muestran una sintaxis interna semejante a las relaciones estructurales que rigen la gramática. Sin embargo, aunque el chino mandarín y el español coinciden en algunas propiedades sintácticas del proceso morfologico de la composición, se ha podido mostrar que el chino presenta una mayor variedad de tipos compositivos.

Con respecto a los compuestos de dos adjetivos, tanto en español como en chino mandarín estos compuestos suelen interpretarse como coordinativos, pues designan cierta propiedad resultante de mezclar o combinar otras dos. En español, el esquema AA para la designación de colores (negrirrojo, blanquiazul, rojiverde, albiceleste, etc.), los formados con el radical tonti- (tontiloco, tontipasmado, tontivano, etc.) y los formados con constituyentes relacionados (afroasiático, audiovisual, hispanoárabe, sociocultural) son pautas muy productivas. Fuera de estos grupos, son relativamente escasos los compuestos AA lagridulce, anchicorto, pavisoso, etc.).

En chino mandarín, el esquema AA forma principalmente adjetivos que expresan las propiedades y las características de las entidades. La designación semántica de estos compuestos se dispersa en varios ámbitos equilibradamente, como color, alimento, prenda de vestir, juego, cultura, etc. Los compuestos de dos adjetivos calificativos resultan polisémicos en mandarín, pues además de la interpretación composicional del adjetivo resultante, también lexicalizan el sustantivo abstracto de cualidad:

$c \bar{x}$ xì 粗細 'gordo' 'fino' $\rightarrow$ [gordo y fino] $\mathrm{A} O$ [tamaño] $\mathrm{N}$ xiăo qiǎo 小巧 'pequeño' 'delicado' $\rightarrow$ [pequeño y delicado]A O [delicdeza] $]_{N}$ bàn zhòng 笨重 'torpe' 'pesado' $\rightarrow$ [torpe y pesado $]_{\mathrm{A}} \mathrm{O}$ [pesadez $]_{\mathrm{N}}$ 
Morfología contrastiva del chino mandarín y el español. Formas de gramaticalización y lexicalización

En ambas lenguas, son productivos los compuestos AA, ambos relacionales, puesto que estos adjetivos aluden a los diversos dominios léxicos del sustantivo que forma la base de la derivación. Sin embargo, mientras que en español se forman estos compuestos mediante adjetivos denominales, muchos de sus equivalentes en chino mandarín presentan el esquema coordinado pero entre los mismos nombres primitivos:

shì tīng 視聽 'vista'N 'oído'N $\rightarrow$ [audiovisual] $]_{\mathrm{A}}$

lǐ huà 理化 'física'N 'química'N $\rightarrow[\text { [físico-químico }]_{A}$

zhèng jing 政經 'política'N 'economía' $\rightarrow$ [político-económico]A

shè jing 社經 'sociedad'N 'economía' ${ }_{N} \rightarrow[\text { socioeconómico }]_{\mathrm{A}}$

Respecto a la combinación VV, como se ilustra en los siguientes ejemplos, mientras que es muy productiva en chino mandarín la clase de los compuestos en la que se combinan dos verbos, tanto a partir de verbos de significado contrario como a partir de los que comportan un significado próximo, en español esta pauta de formación resulta bastante limitada. En español, se crean compuestos $V V^{30}$ duplicando el mismo verbo para formar sustantivos, como matamata, picapica, pegapega, pillapilla, pasapasa, etc.

\begin{tabular}{|c|c|c|}
\hline $\begin{array}{c}\text { Tipo de sigdo. del } \\
\text { constituyente }\end{array}$ & $\begin{array}{c}\text { Ejemplos del } \\
\text { español }\end{array}$ & Ejemplos del chino mandarín \\
\hline Sigdo. contrario & $\begin{array}{c}\text { alzapón } \\
\text { tejemaneje } \\
\text { tiramira }\end{array}$ & $\begin{array}{c}\text { wàng jì 忘記 'olvidar' 'recordar' } \rightarrow \text { olvidar } \\
\text { kāi guān 開關 'abrir' 'cerrar' } \rightarrow \text { interruptor }\end{array}$ \\
\hline Sigdo. próximo & salvaguarda & $\begin{array}{c}\text { sàng shī 喪失 'perder' 'perder' } \rightarrow \text { perder } \\
\text { fàng qì 放棄 'poner' 'abandonar' } \rightarrow \\
\text { abandonar, rendirse }\end{array}$ \\
\hline
\end{tabular}

Tabla 6: Compuestos VV

Entre todos los compuestos, el esquema VN (o verbo-objeto) es el más productivo de entre los que dan lugar a compuestos propios en todo el sistema morfológico del español (Real Academia Española 2010: 770). Sin embargo, en

30 Val Álvaro (1999: 4804-805) llama la atención sobre el esquema VV que no produce verbos, sino sustantivos, pero su vitalidad es muy limitada en español. 
chino mandarín, este mismo esquema ocupa el segundo puesto de productividad, por detrás del tipo AN (Bien 2000). En español, los compuestos VN exocéntricos suelen ser bastante productivos (sacacorchos, quitanieves, limpiabotas, matasanos, picapleitos, guardacostas, etc.). En cambio, los compuestos $\mathrm{VN}$ del chino mandarín se reparten porcentajes similares tanto en la construcción exocéntrica y como en la construcción endocéntrica, aunque parece dominar esta última.

Sin embargo, algunos morfólogos del español han cuestionado el carácter exocéntrico de estos compuestos, del tipo sacacorchos, pues en general la exocentricidad difícilmente se corresponde con la elevada productividad de este esquema. Por ello, se han planteado algunas hipótesis para defender la naturaleza endocéntrica, basadas en un núcleo interno representado por el nombre deverbal del primer constituyente, analizado no tanto como verbo sino como sustantivo que desempeña el papel semántico de Actor de un acontecimiento (Varela 1990a: 110).

En español, el constituyente nominal de los compuestos VN se interpreta a veces como complemento de régimen, como en guardapolvos, guardabrisas, guardabarros ('preservarse del polvo, de la brisa, del barro'). Este esquema resulta en mandarín especialmente productivo, pero con formas complejas de tres elementos, en la que el sustantivo pospuesto funciona como sujeto sintáctico:

dăng ní băn 擋泥板 'tapar' 'barro' 'tabla' $\rightarrow$ guardabarros fáng chén tào 防塵套 'evitar' 'polvo' 'funda' $\rightarrow$ guardapolvos dăng fēng zhào 擋風罩 'tapar' 'viento' 'tapa' $\rightarrow$ guardabrisas

Respecto a los compuestos del tipo AdvV, en español estos se forman sobre todo con los adverbios de modo bien y mal (bienestar, bienvenida, bienaventuranza; malacostumbrar, malcasar, malcriar, maldecir, maleducar, malentender, malgastar, malherir, malinterpretar, maltratar, malvender, malvivir, etc.). Se ha observado en ocasiones que resultan más frecuentes las formaciones lexicalizadas a partir del sentido negativo de mal, probablemente 
Morfología contrastiva del chino mandarín y el español. Formas de gramaticalización y lexicalización

porque la sociedad codifica la transgresión a una expectativa de comportamiento: malversar/*bienversar (Company Company 2009: 29-45). En nuestra opinión, la misma observación puede aplicarse a las formaciones correspondientes del chino mandarín. Aunque estas voces se interpretan también en ocasiones como formas prefijadas en español, la idea de la composición parece más acertada, pues el primer elemento de estas formaciones no muestra diferencias sustanciales con los adverbios léxicos correspondientes en la sintaxis: bienvivir-vivir bien, malentender-entender mal, maltratar-tratar mal, etc. (Val Álvaro 1999: 4834-4836). En chino mandarín también resulta bastante productiva esta estructura con el mismo tipo de adverbios que el español. Como muestran los siguientes ejemplos, las formaciones son muy semejantes en una y otra lengua, salvo por la presencia en mandarín del interfijo modal dé 得 'posibilidad', que, en nuestra opinión, obliga a analizar estas formaciones no como compuestos morfológicos, sino como sintagmas:

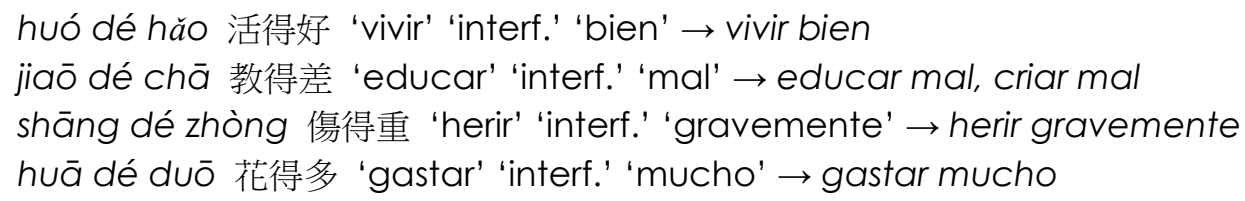

Finalmente, en ambas lenguas, se forman compuestos de estructura compleja. En español, estas formaciones representan casos de lexicalización de un grupo verbal que contiene nombres, artículos, preposiciones y otros elementos: acabose ( $\mathrm{V}+$ Pron), besalamano $(\mathrm{V}+\mathrm{Art}+\mathrm{N})$, bienmesabe $(A d v+$ Pron $+V)$, curalotodo $(\mathrm{V}+$ Pron $+N)$, hazmerreír $(\mathrm{V}+$ Pron $+\mathrm{V})$, mataporgusto $(\mathrm{V}+\operatorname{Prep}+\mathrm{N})$, metomentodo $(\mathrm{V}+$ Pron+Prep $+\mathrm{N})$, parlaembalde $(\mathrm{V}+\operatorname{Prep}+\mathrm{N})$, pésame (V+Pron), quehacer (Pron+V), sabelotodo $(\mathrm{V}+$ Pron $+\mathrm{N})$, siguemepollo $(\mathrm{V}+$ Pron $+\mathrm{N})$, tentempié $(\mathrm{V}+$ Pron $+\mathrm{N})$, etc. Algunos de estos compuestos designan personas a partir de los atributos que las caracterizan (hazmerreír, sabelotodo), por lo que se relacionan con los compuestos $\mathrm{V}+\mathrm{N}$ (del tipo matasanos, picapleitos). 
Por su parte, en chino mandarín estos compuestos de estructura compleja son mayoritariamente trisílabos y también responden a la lexicalización de un grupo verbal que contiene varios elementos de distintas categorías gramaticales, como muestran los ejemplos de 1). Además del grupo verbal, el chino mandarín, que es -como se ha indicado- una lengua con fuerte tendencia hacia la composición morfológica, dispone de más variedad combinatoria que el español para la creación de compuestos de estructura compleja, como muestran los ejemplos de 2):

1) qiù sēng quān 救生圈 'salvar' 'vida' 'círculo' $\rightarrow$ flotador $(\mathrm{V}+\mathrm{N}+\mathrm{N})$ jiàng luò săn 降落傘 'bajar' 'caerse' 'paraguas' $\rightarrow$ paracaídas ( $\mathrm{V}+\mathrm{V}+\mathrm{N})$ fàn dà jìng 放大鏡 'aumentar' 'grande' 'espejo' $\rightarrow$ lupa ( $\mathrm{V}+\mathrm{A}+\mathrm{N})$ dì zhèn yí 地震儀 'tierra' 'vibrar' 'aparato' $\rightarrow$ sismómetro $(\mathrm{N}+\mathrm{V}+\mathrm{N})$ wù wàng wò 勿忘我 'no' 'olvidar' 'yo' $\rightarrow$ nomeolvides (Adv+V+Pron) duà jiăng jٓ 對講機 'entre' 'hablar' 'aparato' $\rightarrow$ interfono (Prep+V+N)

2) hóng shí zi 紅十字 'rojo' 'diez' 'letra' $\rightarrow$ Cruz Roja (A+numeral+N) hóng lù dēng 紅綠燈 'rojo' 'verde' 'luz' $\rightarrow$ semáforo $(A+A+N)$ yì shēng jùn 益生菌 'beneficioso' 'vida' 'bacteria' $\rightarrow$ probióticos $(A+N+N)$ yī dà zăo 一大早 'muy' 'mucho' 'mañana' $\rightarrow$ de madrugada (Adv+A+N)

\subsection{Formaciones híbridas}

Tanto en chino mandarín como en español existe un grupo de morfemas dependientes que se sitúan al final de la base léxica y que suelen clasificarse como sufijoides (o pseudosufijos) por sus especiales características morfológicas. En este apartado se desarrolla un análisis contrastivo de estos formantes híbridos del español y chino mandarín ${ }^{31}$. Tras revisar críticamente las principales teorías sobre los sufijoides, se defiende en primer término el carácter común de la morfología léxica de ambas lenguas en este punto, a pesar de la

${ }^{31}$ Este párrafo 5.4 constituye un resumen reelaborado de nuestro artículo Liu (2010): "Formantes morfológicos híbridos en contraste: los pseudosufijos del chino y los sufijoides del español" en IX Congreso Internacional de Lingǘstica General celebrado en Valladolid del 21 a 23 de junio de 2010. 
distancia tipológica que las separa.

Se plantea la hipótesis de que los formantes chinos que se clasifican tradicionalmente como sufijoides, como zú 足 '"-podo', $j \bar{l}$ 機 'aparato, máquina', lùn 論 'tratado', lèi 類 'tipo, especie', jiè 界 'ámbito, sector', etc., pueden compararse a determinadas unidades pospuestas a bases léxicas del español que presentan diferentes grados de autonomía, como -terapia, -génesis, -fobia, -cultura, -crono, etc., y de productividad, como -fono, -landia, -teca, -cracia, etc. Pero, a partir de esta comparación, también se propone una clasificación más rigurosa del conjunto de los sufijoides, puesto que, según el comportamiento de cada forma, conviene distinguir en una y otra lengua entre los elementos que únicamente admiten la posposición (sufijoides) y los que alcanzan cierta autonomía léxica o admiten la doble posición (temas). A continuación, antes de desarrollar el análisis contrastivo, se introduce el concepto de sufijoide en ambas lenguas y se examina la intervención del sufijoide en la formación léxica del chino y del español.

Sobre el concepto de sufijoide, se acepta comúnmente que algunos formantes pospuestos a bases léxicas del mandarín y del español no se clasifican exactamente entre los sufijos por sus especiales características y, por tanto, el proceso morfológico en el que intervienen oscila entre la composición y la derivación, pues, por una parte, tales elementos pueden funcionar como palabras independientes, pero, por otra parte, pueden aparecer también como miembros de una formación derivativa. En ambas lenguas este tipo de formantes, que suelen denominarse sufijoides, pseudosufijos o semisufijos, presenta algunas características comunes:

1) Los sufijoides aportan un significado léxico, mientras que los sufijos presentan un significado gramatical (agente, lugar, acción, efecto, etc.). Por ejemplo, en español -itis 'inflamación' en otitis, hepatitis, etc., y su correspondiente en chino yán 炎 'inflamación' en năo yán 腦炎 'cabeza' '-itis' $\rightarrow$ encefalitis y wèi yán 胃炎 'estómago' 'inflamación' $\rightarrow$ gastritis. 
2) Los sufijos son morfemas ligados, que carecen de autonomía léxica. Sin embargo, algunos sufijoides, especialmente los de origen culto, también están presentes en la lengua como sustantivos plenos. Por ejemplo, en español -terapia 'tratamiento' / terapia (sust.) 'remedio para el tratamiento'; -fobia 'temor' / fobia (sust.) 'aversión obsesiva'; -crono 'tiempo' / crono (sust.) 'tiempo medido con cronómetro en pruebas de velocidad'. Lo mismo sucede con algunos de sus correspondientes en chino: -liaó -療 'tratamiento' / (zhi) liaó (治) 療 (sust.) 'remedio para el tratamiento'; -kóng jù zhèng -恐懼症 'temor' / kǒng jù zhèng 恐懼症 (sust.) 'aversión obsesiva'.

En la morfología española, los sufijoides se consideran elementos de origen latino o griego que intervienen en procesos de formación léxica. Reciben varias denominaciones diferentes: Manuel Seco (1972: 194) habla de «raíces sufijas». Esta denominación se aplica a aquellos elementos constitutivos de palabras de origen grecolatino que resultan altamente productivos en el léxico moderno y que dan lugar a formaciones cuyo estatuto gramatical ha sido objeto de controversia. Alba de Diego (1983), Rebollo Torío (1997), García Platero (1998), entre otros autores, describen los sufijos cultos con el nombre de "sufijoide», "pseudosufijo» y "semisufijo», pues, tal como afirma Alvar Ezquerra (1993: 49), estos elementos se posponen a la base léxica, pero son morfemas falsos debido a su origen culto y a su introducción reciente en palabras creadas artificialmente en el lenguaje científico y técnico. En lo que respecta a su origen, Alba de Diego (1983: 18) indica que estos elementos «se liberan del modelo etimológico que les dio nacimiento para pasar a depender del modelo funcionalı, de hecho, se vulgarizan y penetran en la lengua estándar. Así, el autor indica que elementos como -grafía (del gr. 'descripción, tratado, representación gráfica') y -logía (del gr. 'tratado, estudio, ciencia') están independizados de su contexto primitivo, pues en el español actual los compuestos que se forman con esta base solo designan 'escritura' y 'estudio', 
Morfología contrastiva del chino mandarín y el español. Formas de gramaticalización y lexicalización

respectivamente. De esta forma, se convierten en elementos aislados que llegan a comportarse como auténticos afijos y crean toda una serie de morfemas léxicos.

Mientras que algunos autores localizan los afijoides en la derivación, otros, como por ejemplo Guerrero Ramos (1995), incluyen en la composición culta las palabras formadas mediante elementos tomados del griego o del latín. En esta línea se sitúa también el DRAE (2003), que denomina «elementos compositivosı a estos formantes. Algunos lingüistas como Rebollo Torío (1997), Val Álvaro (1999) y Varela y Martín García (1999) emplean el término «tema» para referirse a estos elementos, ya que se trata de unidades morfológicas que se diferencian en varios aspectos de los afijos:

1) Algunos temas pueden aparecer tanto a la izquierda como a la derecha de la palabra compleja (filosoviético / bibliófilo, grafomanía / reprografía). Sin embargo, los afijos presentan una posición fija.

2) Los temas pueden combinarse entre sí para formar palabras (telepatía). Sin embargo, la combinación de afijos no da resultados léxicos (*reción).

3) Los verdaderos afijos son adjuntos que modifican el significado de la formación compleja, mientras que los temas se consideran lexemas que intervienen en el sentido de la formación compleja.

4) Los sufijos son tónicos, mientras que los sufijoides pueden ser tónicos (telepatía) y también átonos (bibliómano).

En esta misma línea, la denominación de «temas polimórficos cultos», utilizada por Lliteras (2010a: 363), hace referencia a las principales características distintivas de estos formantes grecolatinos. Con este término se alude, en primer lugar, a la condición morfológica propia de estos temas, diferente de los afijos y de los falsos afijos, según la idea que aporta el sufijo -oide utilizado por otros autores. Pero además, la noción de polimorfismo responde a la libertad de posición, a la capacidad combinatoria y a las 
variaciones morfonológicas y de acentuación que experimentan estos elementos de origen culto.

Por otro lado, Almela (1999: 154-160) también ofrece un tratamiento particular para el «pro-compuesto», término que hace referencia a las unidades lingüísticas que proceden de los sustantivos o adjetivos grecolatinos. El estatuto de pro-compuestos se justifica porque tales formaciones alcanzan autonomía léxica y aportan un significado léxico específico.

En resumen, aunque el fenómeno del sufijoide en la morfología española es muy discutido y no está universalmente aceptado, estos formantes se diferencian claramente tanto de los sufijos como de los constituyentes de la composición (tipo sacacorchos). Por el proceso de debilitación semántica, por su elevada productividad y por su estatuto intermedio, los llamados sufijoides ocupan una posición híbrida en la morfología del español.

Por su parte, en las descripciones morfológicas del chino mandarín se suele considerar el estatuto del sufijoide como una categoría híbrida entre la composición y la derivación, que todavía plantea algunas dificultades de delimitación. Lü (1990 [1979]) fue el primero que adoptó el marco teórico del llamado sufijoide para referirse al fenómeno que consiste en la adición de un formante morfológico híbrido tras una base léxica, que da como resultado un nuevo sustantivo. Más adelante, Shen (1986) señala que, aunque no existe acuerdo en el número de los sufijoides, el chino dispone de un número considerable de estos elementos con significados muy diversos. Mediante este proceso, se forman palabras que se emplean en todo tipo de lenguaje, en todos los registros idiomáticos y tanto en la modalidad oral como en la escritura. Así, Xu (1999) indica que en las lenguas sinotibetanas los sufijos auténticos no son los que desempeñan la función principal en la derivación, pues la utilización de estos elementos parece servir principalmente solo para facilitar la acusada tendencia hacia las formaciones polisilábicas de las palabras, en sustitución del monosilabismo del chino clásico. Por el contrario, son los sufijoides los que contribuyen más productivamente a la formación léxica 
214 Morfología contrastiva del chino mandarín y el español. Formas de gramaticalización y lexicalización

porque sufren un proceso de debilitación de su significado originario que favorece la combinación con otros elementos.

Con respecto al problema de la delimitación entre la sufijación y la composición, hay autores que no incluyen la categoría sufijoide en la derivación. Así, Chu (1982) considera que el fenómeno descrito podría clasificarse en la composición porque los sufijoides se comportan más bien como lexemas que, al unirse a otros, aunque pierdan algo de su contenido semántico primitivo, aportan un significado léxico que constituye una parte del significado final del compuesto. Además, muchos sufijoides -o mejor, afijoidespresentan la posibilidad de anteposición y posposición en la formación de palabras complejas. En mandarín, según los estudios de Ma (1995), Chen (2001) y Wang (2005), los sufijoides son más numerosos que los sufijos. Aunque no se ha alcanzado todavía un cierto consenso mayoritario sobre el inventario de estos elementos, en la gramática china se reconoce el estatuto de los sufijoides y se admite que estas unidades dan lugar a procesos morfológicos especiales que se sitúan entre los tipos derivativos y compositivos.

Sin embargo, como muchos de los llamados sufijoides se producen por la influencia de las lenguas extranjeras y por la necesidad de creación de palabras para conceptos nuevos, en la gramática china se observa una tendencia a extender este fenómeno hasta incluir a todos los elementos léxicos productivos que se posponen a la palabra. Para restringir la ampliación de estas unidades morfológicas que están a medio camino entre los afijos y las formas libres, Wang (2007: 34-35) define los sufijoides como elementos morfológicos que deben concebirse como un continuum entre la derivación y la composición. Su presencia constituye un proceso de superposición y coexistencia del mecanismo derivativo y del mecanismo compositivo. Se consideran elementos que han sufrido una especie de debilitación de su significado primitivo y que se caracterizan por su alta productividad y su posposición a otros constituyentes léxicos para formar la nueva palabra. 
Por su parte, Ren (2002) y Chang (2003) establecieron algunos criterios en relación con el estatuto del sufijoide. Señalan que solo los elementos que cumplen las características siguientes pueden considerarse sufijoides:

1) Posición determinada: los sufijoides solo se posponen a la palabra.

2) Determinación de la categoría gramatical: los sufijoides son transcategorizadores en el sentido de que forman sustantivos a partir de otras categorías gramaticales.

3) Productividad elevada.

4) Debilitamiento semántico: los sufijoides sufren una pérdida progresiva del significado originario de una raíz que se corresponde con una mayor capacidad compositiva.

A pesar de estos intentos de delimitación, en la lengua china todavía está por determinar el número y el estatuto de los sufijoides. Quizá, porque, en nuestra opinión, el mandarín moderno proviene del monosilabismo del chino clásico, lengua en la que toda palabra consiste en un solo morfema léxico que aporta el significado semántico. Así, la delimitación entre raíz, morfema y palabra del mandarín moderno se convierte en una cuestión pendiente.

En resumen, la razón de la controversia para definir la frontera de estos elementos entre la composición y la derivación en ambas lenguas reside en que el formante parece tener cierta autonomía semántica y sintáctica. En español, los elementos llamados sufijoides, como -filo, -cronía, -algia, -cidio, -logía, -podo, -scopio, -terapia, -nauta, etc., presentan indudablemente un significado semántico muy distinto al de los sufijos convencionales, como-dad, -ción, -ería, -anza, -ón, -ito, -azo, etc., pues tal como describe la Nueva Gramática de la Real Academia Española (2010: 784), los sufijoides (o utemas neoclásicos»)) pueden aportar el significado del término primitivo de manera gradual y actúan como complementos argumentales al formar el significado final de los compuestos. Del mismo modo, en chino mandarín, la categoría del sufijoide se corresponde con un proceso de debilitación semántica de los 
Morfología contrastiva del chino mandarín y el español. Formas de gramaticalización y lexicalización

términos cuando son parte de una formación. Los sufijoides difieren de los verdaderos sufijos en que los sufijoides todavía aportan significado léxico cuando se agregan a los morfemas para formar palabras, aunque este queda debilitado. Pero los auténticos sufijos, como ér 兒, zi 子, tóu 頭, rán 然 y bā巴 solo desempeñan la función de favorecer la acusada tendencia hacia las formaciones polisilábicas de las palabras.

Respecto a la intervención del sufijoide en la formación léxica del chino y del español, los estudios morfológicos de una y otra lengua, a pesar de la distancia que las separa, recurren por lo general al mismo concepto de sufijoide para describir procesos de formación léxica que no pueden equipararse con la derivación mediante sufijos. En ambos códigos, se puede establecer una analogía entre los términos que pueden clasificarse como sufijoides o temas polimórficos cultos: todos ellos son elementos muy productivos en la formación de palabras y con una alta rentabilidad, es decir, se usan en diversos ámbitos de la comunicación. En realidad, estas nuevas formaciones nacen para cubrir nuevas necesidades expresivas. Como hemos mencionado antes, en ambas lenguas los sufijoides tienen origen culto: en español se trata de determinados elementos grecolatinos; en mandarín son unidades léxicas monosilábicas procedentes del chino clásico. Además, en las dos lenguas, se observa la debilitación del significado originario, al mismo tiempo que aumenta su capacidad combinatoria con otros elementos. Así, ambas lenguas cuentan con determinados formantes que, por un lado, desempeñan una función parecida a la de los sufijos, y por otro lado, presentan mayor capacidad para formar palabras nuevas.

Además de estos rasgos generales, se observan otras características morfológicas y semánticas que permiten describir los sufijoides en ambas lenguas. Estas propiedades se refieren al comportamiento de los sufijoides en Ios siguientes aspectos: 1) combinación con afijos y palabras, 2) posición libre, 3) aportación semántica específica y 4) alteración del significado primitivo. 
En español, los sufijoides no se consideran propiamente sufijos porque pueden formar palabras en combinación con otros temas cultos: centrífugo, psicópata, egolatría, telefonía, cardiopatía, trípode, telescopio, protozoo, etc. Además de combinarse entre sí, otra propiedad que aproxima los temas neoclásicos a las palabras compuestas consiste en su capacidad de formación con voces patrimoniales, como bolígrafo, raticida y otras muchas.

En mandarín, los sufijoides también se asemejan a las unidades léxicas más que a los sufijos, en el sentido de que se conserva el contenido semántico, a pesar de que el significado ha quedado debilitado con respecto a su sentido primitivo. En mandarín, los sufijoides son de uso cotidiano, se emplean en la lengua general y suelen aparecer junto a lexemas patrimoniales:

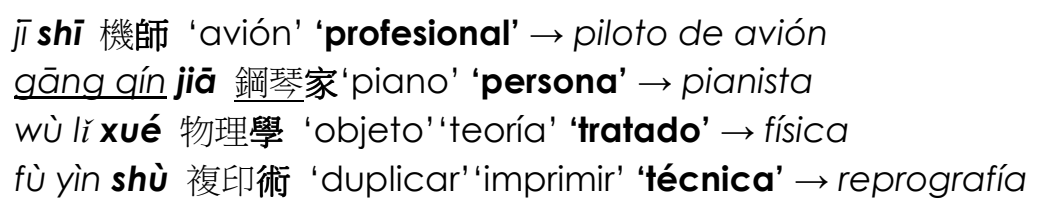

En cuanto a las posibilidades combinatorias, en mandarín se encuentran algunos ejemplos de sufijoides que pueden dar lugar a voces en combinación con prefijoides:

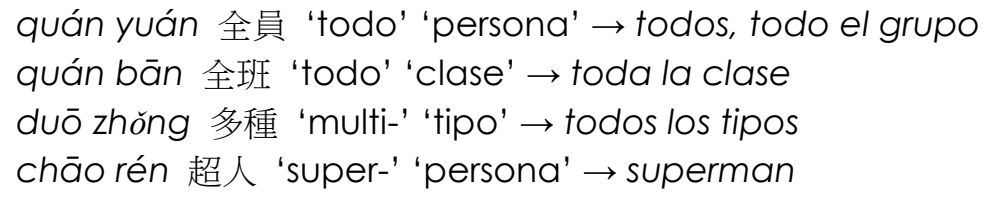

Por otra parte, en ambas lenguas, los sufijoides suelen mantener una relación argumental con la unidad con la que se combinan. En español, como ilustra la Gramática académica (2010: 784), una logopeda es una 'experta que enseña la fonación', fotófobo es 'alguien que teme a la luz' y un dipsómano es 'un adicto al alcohol'. Del mismo modo, en mandarín, tiě jiàng 鐵匠 'hierro' 'técnico' $\rightarrow$ herrero es 'el hombre que tiene por oficio labrar el hierro', yī shī 醫 師 'medicina' 'profesional' $\rightarrow$ médico es 'la persona que ejerce la medicina', wén xué 文學 'letra' 'estudio' $\rightarrow$ literatura es 'el arte de expresión de una lengua'. 
Otro aspecto que acerca los sufijoides a las palabras compuestas es la autonomía léxica. En español, un mismo elemento puede desempeñar funciones sustantivas al mismo tiempo que sirve de formante morfológico. Por ejemplo, grafo y -grafo: la base grafo se emplea como sustantivo en el vocabulario científico de términos matemáticos: grafo dirigido, grafo vacío, etc. y como sufijoide, en mecanógrafo, sismógrafo, telégrafo, etc. Lo mismo cabría decir de terapia, crono, agro, fobia, etc.

En mandarín, el sufijoide zú 族 (Hsieh y Hsu 2003) actúa de forma parecida. Zú 族 en chino clásico era un sustantivo que significaba 'familia, relación sanguínea'. En mandarín moderno, su significado léxico queda debilitado con respecto al significado primitivo y se usa para designar la agrupación de personas que comparten características sociales o culturales, como en 1). Pero además, en mandarín conversacional, zú 族 'raza,' puede utilizarse como sustantivo autónomo con el significado de 'clase de gente, tipo, estilo', como en 2):

1) yín fă zú 銀髮族 'plata' 'cabello' 'raza' $\rightarrow$ anciano gì chē zú 汽車族 'coche' 'raza' $\rightarrow$ persona con coche o aficionada al coche, automovilista

bù hūn zú 不婚族 'no' 'casarse' 'raza, clase' $\rightarrow$ persona que no tiene intención de casarse, soltero

ding kè zú 頂客族 'dinky' 'raza, clase' $\rightarrow$ dinky (pareja con doble sueldoy $\sin$ hijos)

2) 你是 哪一 族 ?

Nǐ shì nă yī zú

Tú ser cuál uno raza

¿De qué clase de gente eres?

Sobre la característica de la posición en español, mientras que los afijos presentan una posición fija, un mismo tema culto puede admitir las dos distribuciones: genotipo / hidrógeno, filoamericano / cinéfilo, grafología / ortografía, patógeno / alopatía, logotipo / mitólogo, metrónomo / kilómetro, morfología / alomorfo, etc. Incluso se forman palabras con los mismos 
elementos compositivos pero en orden distinto y con significado no coincidente, como fonograma / gramófono, logotipo / tipólogo, como señala la Gramática de la Real Academia (2010: 784). Esta propiedad es particular de estos formantes pues no se hace extensiva a los afijos. Sin embargo, una parte considerable de estos elementos compositivos solo admiten la posposición a otro tema o afijo, como -algia (gastralgia, neuralgia), -cracia (bancocracia, fisiocracia), -cida (herbicida, insecticida), -ésimo (millonésimo), -forme (arboriforme, vermiforme), -fagia (aerofagia, disfagia), -filia (bibliofilia, anglofilia), etc., que se comportan con auténticos sufijoides.

En mandarín, según el criterio de Ren (2002) y Chang (2003), los sufijoides no manifiestan tal libertad posicional, porque los morfemas que pueden aparecer al principio y al final de la palabra sin cambiar el significado no se clasifican como sufijoides, sino como constituyentes de una composición. Sin embargo, como se ha mencionado arriba, en mandarín todavía falta un consenso sobre la teoría de los sufijoides y además tampoco hay acuerdo en el inventario de estas unidades, que tiende a ser excesivo. Así, se observa que determinados elementos, por una parte, se asemejan a los sufijoides por su función morfológica y semántica, pero por otra parte, admiten la doble colocación en la formación compleja. Esta característica, escasamente observada, permite defender por nuestra parte la proximidad entre los temas cultos del español y los (mal llamados) sufijoides de la morfología china y, al mismo tiempo, reconocer el estatuto compositivo, más que derivativo, de estas formaciones en ambas lenguas. Así, por ejemplo, en Lü (1990 [1979]) y Liu (1996 [1983]), yuán 員 'persona' y guì 櫃 'armario' se agrupan como sufijoides quizá por su productividad, pero estos formantes también se anteponen, como se ilustra en los siguientes ejemplos:

Yuán 員 'persona'

Anteposición: yuán gōng 員工 'persona' 'trabajador' $\rightarrow$ empleado yuán jing 員警 'persona' 'policía' $\rightarrow$ policía

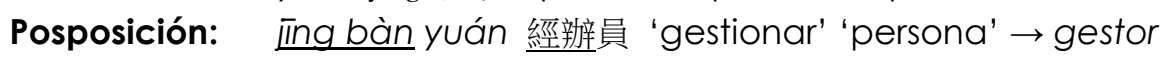
guăn lǐ yuán 管理員 'administrar' 'persona' $\rightarrow$ administrador 
Morfología contrastiva del chino mandarín y el español. Formas de gramaticalización y lexicalización

\section{Guì 櫃 'armario'}

Anteposición: guì tái 樌台 'armario' 'plataforma' $\rightarrow$ mostrador

Posposición: $\quad$ yī guì 衣櫃 'ropa' 'armario' $\rightarrow$ ropero

huò guì 貨櫃 'mercancía' 'armario' $\rightarrow$ contenedor

Respecto al significado de los sufijoides, tanto en chino mandarín como en español, muchas de estas raíces léxicas se utilizan de manera general en el vocabulario científico y técnico. En español, la aportación semántica específica de los sufijoides es de tipo léxico, similar a la de los sustantivos y adjetivos, diferente del significado gramatical de los afijos:-algia ('dolor'), -fono ('sonido'), -gamia ('unión'), -nomía ('ley'), -ptero ('que tiene alas'), -voro ('que come'), etc. Se usan principal, pero no exclusivamente, como parte de un léxico especializado de la ciencia y la técnica: bactericida, termómetro, mamografía, podólogo, etc.

Por su parte, en mandarín, muchos de los sufijoides son productos traducidos de una lengua extranjera que alcanzan una alta productividad para integrarse con otros elementos. Además de formar parte del léxico especializado de la ciencia, la técnica, la política, etc., estos sufijoides también se generalizan en la lengua común y son elementos transcategorizadores. Un ejemplo típico de la verbalización es el sufijoide huà 化, cuyo significado equivale a -ificar o -izar del español y se suele añadir a bases nominales:

$$
\begin{aligned}
& \text { yáng huà 洋化 'occidente' '-izar' } \rightarrow \text { occidentalizar } \\
& \text { IIx xiè huà 機械化 'máquina' '-izar' } \rightarrow \text { mecanizar } \\
& \text { gōng yè huà 工業化 'industria' '-izar' } \rightarrow \text { industrializar }
\end{aligned}
$$

Existen más sufijoides sustantivadores, como xing 性 'propiedad', lùn 論 'teoría', xué 學 'tratado', fă 法 'forma, regla', zhě 者 'persona', yuán 員 '-dor/-tor', etc., en los que se observan indicios de traducción de alguna lengua extranjera para la creación de palabras correspondientes a conceptos modernos. A continuación se muestran algunos ejemplos: 
kě shuò xìng 可朔性 'poder' 'plastificar' 'propiedad' $\rightarrow$ plasticidad xiāng duì lùn 相對論 'relativo' 'teoría' $\rightarrow$ teoría de la relatividad kăo gŭ xué 考古學 'investigar' 'antigüedad' 'tratado' $\rightarrow$ arqueología sù jì fă 速記法 'rápido' 'memorizar' 'forma' $\rightarrow$ taquigrafía jì zhě 記者 'apuntar' 'persona' $\rightarrow$ periodista qiú yuán 球員 'balón' 'persona' $\rightarrow$ jugador

En cuanto a la alteración del significado primitivo, como se ha mencionado arriba, los sufijoides adquieren otro contenido semántico diferente del que era su sentido primitivo. Tanto en español como en chino mandarín, existe cierta gradación respecto de esta debilitación del contenido semántico. Por ejemplo, elementos como -algia, -cido, -fono, -fobia, -terapia, -manía, entre otros, mantienen su significado del sustantivo original en las formaciones del tipo neuralgia, homicidio, teléfono, claustrofobia, hidroterapia, melomanía, etc. En cambio, dromo significa 'carrera' en griego, pero como tema culto forma tanto nombres que designan lugares en los que se celebran tales carreras, como hipódromo, canódromo, velódromo, como otros nombres locativos que simplemente designan espacios abiertos, como aeródromo y rockódromo(Real Academia Española 2010: 786).

En mandarín, del mismo modo, los sufijoides no se alejan del significado original de la palabra cuando forman compuestos. Los sufijoides pueden mostrar distintos grados de debilitamiento, pero nunca se pierde totalmente el significado del sustantivo original. Por ejemplo, en Wang (2007), se observa que los siguientes sufijoides sufren un grado mayor de debilitación semántica, pues los formantes xìng 性 'propiedad', shì 式 'forma' y rè 熱 'fiebre' se convierten en forma ligada con significado léxico abstracto y así alcanzan una alta productividad y rentabilidad al formar compuestos junto con cualquier tipo de palabras:

guàn xìng 慣性 'costumbre, hábito' 'propiedad' $\rightarrow$ inercia

liáng xìng 良性 'bondad' 'propiedad' $\rightarrow$ benigno

è xìng 惡性 'maldad' 'propiedad' $\rightarrow$ maligno

wā shì 蛙式 'rana' 'forma' $\rightarrow$ (nadar) a braza

dié shì 蝶式 'mariposa' 'forma' $\rightarrow$ (nadar) a mariposa

yăng shì 仰式 'mirar hacía arriba' 'forma' $\rightarrow$ (nadar) de espalda 
Morfología contrastiva del chino mandarín y el español. Formas de gramaticalización y lexicalización

chū guó rè 出國熱 'salir' 'país' 'fiebre' $\rightarrow$ moda de ir al extranjero dú shū rè 讀書熱 'estudiar' 'libro' 'fiebre' $\rightarrow$ moda de estudiar

En fin, tanto en chino mandarín como en español, los sufijoides son formantes morfológicos híbridos que oscilan entre la composición y la derivación. Este tipo de formantes presenta un estatuto intermedio que todavía plantea algunas dificultades de delimitación y definición. En ambas lenguas, estas unidades comparten cuatro características:

1) Presentan un contenido semántico debilitado con respecto al significado primitivo de origen culto.

2) Algunos de estos formantes también se usan como sustantivos plenos.

3) Se posponen a la unidad léxica, pero no se identifican con los sufijos.

4) Resultan muy productivos en la formación del lenguaje científico y técnico.

Sin embargo, por nuestra parte, hemos propuesto que determinados formantes con libertad posicional y autonomía léxica no deberían incluirse entre los sufijoides, como tradicionalmente se clasifican, sino más bien como unidades libres o temas que pueden intervenir en la composición, sea esta de tipo morfológico o sintagmático (locución). Se trata de elementos como los siguientes:

$\begin{array}{ll}\text { diàn 店 'tienda' } & \text { zú 族 'raza' } \\ \text { yuán 園 'jardín' } & \text { xué 學 '-logía' } \\ \text { tuán 員 'persona' } & \text { kǒng jù zhèng 恐懼症 'fobia' } \\ \text { guì 櫃 'armario' } & \text { liáo fă 療法 'terapia' } \\ \text { lùn 論 'tratado' } & j i \text { 機 'aparato, máquina' }\end{array}$

Las principales diferencias entre los sufijos y los sufijoides también se corresponden en ambas lenguas. En chino mandarín, los sufijoides aportan un significado léxico como en español. Sin embargo, los sufijos chinos no presentan ni significado léxico ni gramatical, pues el uso principal de los sufijos chinos se limita al plano morfonológico al facilitar la tendencia polisilábica de 
las palabras. Por otro lado, en español, los sufijoides pueden combinarse con otros temas cultos para formar palabras y pueden colocarse tanto en una como en otra posición. En cambio, los sufijos convencionales son morfemas ligados, carecen de autonomía léxica y solo se combinan con elementos léxicos.

Por nuestra parte, finalmente, sugerimos limitar el concepto de sufijoide en español solo a aquellos elementos compositivos que admiten únicamente la posposición a otro tema o afijo, como son, entre otros:

$$
\begin{array}{ll}
\text {-algia (neuralgia) } & \text {-fagia (aerofagia) } \\
\text {-cida (herbicida) } & \text {-fero (sanguífero) } \\
\text {-cola (fructícola) } & \text {-filia (anglofilia) } \\
\text {-cracia (fisiocracia) } & \text {-fobo (xenófobo) } \\
\text {-cultura (agricultura) } & \text {-forme (arboriforme) } \\
\text {-cefalia (dolicocefalia) } & \text {-foro (necróforo) } \\
\text {-ésimo (millionésimo) } & \text {-fugo (centrífugo) }
\end{array}
$$

Por el contrario, los elementos compositivos que admiten cualquier posición pueden ser considerados temas, como son:

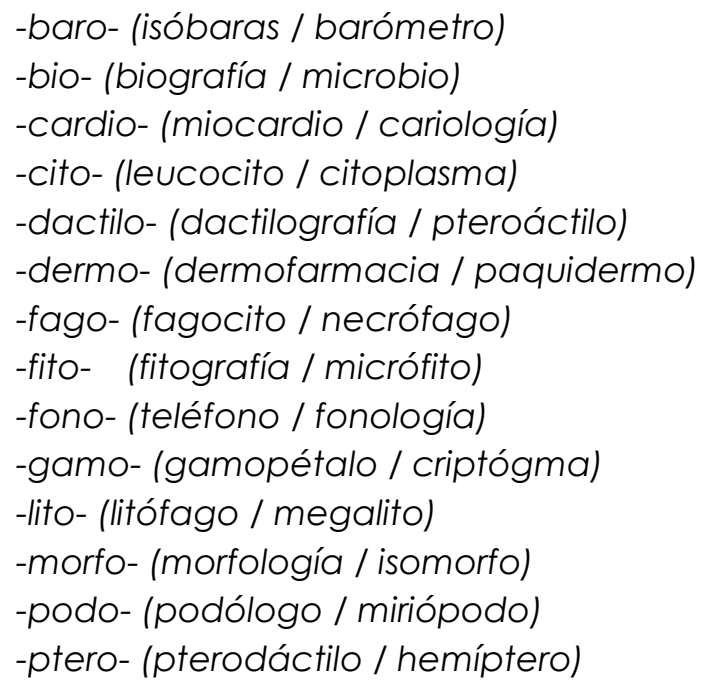

En definitiva, proponemos distinguir en la clase de los elementos compositivos dos tipos diferentes: los temas y los sufijoides, que se corresponden con estos mismos formantes de la morfología china. 
Morfología contrastiva del chino mandarín y el español. Formas de gramaticalización y lexicalización

\subsection{Otros aspectos comparables: los clasificadores, la abreviación y el extranjerismo}

Hemos dedicado anteriormente un apartado al análisis de los clasificadores del chino mandarín por tratarse de un rasgo muy característico de esta lengua que alcanza una amplia presencia en gramáticas y diccionarios (§ 4.6). Aunque no parece que todos los tipos de clasificadores se correspondan estrictamente con el componente morfológico del chino, su tratamiento resulta casi obligado en este trabajo, así como también se considera adecuado plantear aquí alguna posible comparación con fenómenos semejantes del español, a pesar de que estos tampoco puedan situarse propiamente en el ámbito morfológico.

Los clasificadores del chino pueden compararse a los sustantivos cuantificativos del español que suelen recibir en la bibliografía el término de «nombres de medida». En ambas lenguas, estos elementos clasificadores son sustantivos ${ }^{32}$. Mientras que en chino mandarín, se distinguen tres tipos de clasifcadores (los nominales, los individuales y los verbales), en español, según Bosque (1999: §1.2.3.4), se observan tres clases de sustantivos cuantificativos:

1) Sustantivos acotadores, que denotan una magnitud acotada 0 seleccionada, como un pedazo de pan, una rodaja de merluza, un grano de uva, un gajo de limón, un vaso de agua.

2) Sustantivos de medida, que aparecen impuestos por las características físicas de los objetos (peso, volumen, extensión, distancia, tiempo), como una tonelada de cieno, un kilo de lentejas, un galón de agua, un metro de terreno, un año de espera.

3) Sustantivos cuantificativos de grupo, que establecen el significado múltiple en virtud de las características dimensionales del objeto

\footnotetext{
32 Sin embargo, en chino mandarín, algunos de los clasificadores individuales no son sustantivos, pues carecen del significado léxico y equivalen a las llamadas "adjunciones numerales". Por ejemplo ge 個 en sì ge rén 四個人 cuatro personas.
} 
medido, como un ramo de flores, una partida de ladrones, una serie de preguntas, un rosario de escándalos.

Los principales aspectos comparables de ambas lenguas se limitan, en nuestra opinión, a un par de comportamientos. Por un lado, los clasificadores nominales del chino son los que más se aproximan al uso de los sustantivos cuantificativos del español, indicados anteriormente. Por otra parte, las dos lenguas mantienen la relación de hiperonimia-hiponimia, en el sentido de que el sustantivo utilizado para la cuantificación o clasificación de un término genérico se repite también con los términos específicos o particulares.

En español, los sustantivos cuantificativos pueden ser optativos, como en un (vaso de) café, una (prenda de) ropa, un (diente de) ajo, etc., mientras que en chino mandarín, es obligatorio el clasificador intercalado ente el numeral y el objeto cuantificado, como se ilustra en los siguientes ejemplos. En cierto modo, se puede decir que la interpretación discontinua de los sustantivos continuos la aportan obligatoriamente los clasificadores:

yī bēi shǔ 一杯水 'uno' 'vaso' 'agua' $\rightarrow$ un vaso de agua yī dào căi hóng 一道彩虹 'uno' 'carretera' 'arcoiris' $\rightarrow$ un arcoiris yīshēng shăn diàn 一聲閃電 'uno' 'sonido' 'trueno' $\rightarrow$ un trueno

Para terminar, se dedica cierta atención a otros fenómenos comparables en ambas lenguas, como son los procesos de formación de siglas, acrónimos y el tratamiento de los extranjerismos. A pesar de que no todos estos casos forman parte estrictamente de la morfología de las lenguas en contraste, parece aconsejable no eludir una breve revisión, pues no cabe duda de que estos resultados forman una parte importante del léxico -y de la formación léxica- de nuestros idiomas en la actualidad.

Con respecto al proceso de siglación, en español, tanto la siglación (SIDA, ONU) como la acronimia (secrefata, teleñeco), se consideran procesos combinatorios, ya que se caracterizan por el cruce de varios tipos. Parecido a este procedimiento, en mandarín, la abreviación es la simplificación de un 
Morfología contrastiva del chino mandarín y el español. Formas de gramaticalización y lexicalización

compuesto polisilábico, que puede responder a varios tipos. A continuación vemos la comparación de los procesos:

\begin{tabular}{|c|c|c|}
\hline & Chino mandarín & Español \\
\hline $\begin{array}{l}\text { a) } \\
\text { combinación } \\
\text { de los } \\
\text { primeros } \\
\text { componentes } \\
\text { o siglación }\end{array}$ & $\begin{array}{l}\text { gão shù tiè lù 高速鐵路 'alto' 'velocidad' 'hierro' } \\
\text { 'camino' } \rightarrow \text { gāo tiě 高鐵 ferrocarril de alta } \\
\text { velocidad } \\
\text { jiā yòng diàn qì 家用電 器 'casa' 'utilizar' } \\
\text { 'electricidad' 'instrumento' } \rightarrow \text { jiā diàn 家電 } \\
\text { electrodomésticos }\end{array}$ & $\begin{array}{l}\text { Red Nacional de } \\
\text { Ferrocarril } \\
\text { Españoles } \rightarrow \\
\text { RENFE } \\
\text { Alta Velocidad } \\
\text { Española } \rightarrow \text { AVE }\end{array}$ \\
\hline $\begin{array}{l}\text { b) } \\
\text { combinación } \\
\text { de los } \\
\text { morfemas } \\
\text { externos o } \\
\text { acronimia } \\
\end{array}$ & $\begin{array}{l}\text { huà xué zhì liáo 化學治療 'química' 'ordenar' } \\
\text { 'curar' } \rightarrow \text { huà liáo 化療 quimioterapia } \\
\text { ou zhōu lián méng 歐洲聯盟 'Europa' 'Unir' } \\
\text { 'alianza' } \rightarrow \text { ou méng 歐盟 Organización de la } \\
\text { Unión Europea }\end{array}$ & $\begin{array}{l}\text { pequeños }+ \\
\text { muñecos } \\
\rightarrow \text { pequeñecos } \\
\text { cristalería }+ \\
\text { española } \rightarrow \\
\text { cristañola }\end{array}$ \\
\hline $\begin{array}{c}\text { c) } \\
\text { formaciones } \\
\text { de apócope } \\
\text { con aféresis }\end{array}$ & $\begin{array}{l}\text { jīng jii jiàn shè wěi yuán huì 經濟建設委員會 } \\
\text { 'economía' 'construir' 'establecer' 'delegado, } \\
\text { miembro' 'unión' } \rightarrow \text { jīng jiàn huì 經建會 comité } \\
\text { de construcción económica } \\
\text { yào wù huà zhuāng pin shāng diàn 藥物 化妝品 } \\
\text { 商 店 'medicamento' 'objeto' 'química' } \\
\text { 'maquillaje' 'artículo' 'comecio' 'tienda' } \rightarrow \text { yào } \\
\text { zhuāng diàn 藥妝店 droguería }\end{array}$ & \\
\hline
\end{tabular}

Tabla 7: Procedimientos de abreviación

En español, generalmente, la siglación es una combinación del primer grafema de cada uno de todos los términos principales. El significado de la sigla depende del conocimiento de la expresión completa (SIDA, SOS, VIP). Por otro lado, en la acronimia, aunque también las palabras de base sufren transformaciones, su significado se puede deducir con cierta facilidad (informática < infor[mación] + [auto]mática, secrefata < secre[taria] + [aza]fata). En mandarín, en cambio, el significado determina el proceso de abreviación, pues se seleccionan para la abreviación aquellos elementos que permiten deducir el significado de la fórmula completa: zhuō zi yǐ zi 桌子椅子 'mesa' 'suf.' 'silla' 'suf.' $\rightarrow$ zhuō yi 桌椅 mesa y silla; diàn y̌nng míng xīng 電影明 星 'electricidad' 'film' 'claro' 'estrella' $\rightarrow$ y̌ng xing 影星 estrellas de película 
(actores).

En español, la siglación se lee según el valor fónico de la secuencia: RENFE (de Red Nacional de Ferrocarril Españoles), PSOE (leído [pé.sóe]). Cuando la secuencia fónica no es aceptable, se deletrean los grafemas: DNI leído [dé.éne.í]. Respecto a la abreviación, que ya tiene sus propias convenciones, como la reduplicación para señalar el plural en EEUU, se lee la expresión completa "Estados Unidos". El mandarín difiere del español en este aspecto. Dado que todos los morfemas son monosilábicos, su lectura no varía en forma abreviada, en la cual se seleccionan morfemas claves para formar la abreviación. De ahi, gāo tiě 高鐵 'alto' 'hierro' tiene la misma forma fónica y ortográfica que su procedencia gāo shū tiě lù 高速鐵路 'alto' 'velocidad' 'hierro' 'camino' $\rightarrow$ ferrocarril de alta velocidad; gōng chē 公車 'público' 'vehículo con ruedas' es igual fonética y ortográficamente que gōng gòng chì chē 公共汽車 'público' 'junto' 'al vapor' 'vehículo con ruedas' $\rightarrow$ autobús.

Tanto en español como en mandarín, la abreviación tiene un desarrollo amplio especialmente en los ámbitos periodísticos y publicitarios. Por medio del proceso abreviado se producen continuamente denominaciones relativas a todos los campos sociales, como la política, la economía, la cultura, la alta tecnología, el deporte, la administración, el transporte, etc.

Tanto el español como el mandarín reciben la influencia de otras lenguas para aumentar su vocabulario. Entre ellas, el anglicismo es en la actualidad el idioma que desempeña el papel más importante y evidente en ambas lenguas. Lan (2004: 358-374) indica que, a partir del Diccionario de la Real Academia Española (1992) y del Guo yu ri bao wai laiyu ci dian 國語日報外 來語詞典 (Diccionario de extranjerismos) (1981), la mayoría de los anglicismos en son sustantivos. La influencia del anglicismo en los dos idiomas se puede comparar desde el punto de vista fonético: las vocales simples inglesas no sufren muchos cambios en español, mientras que al traducirlas al mandarín, estas pueden ser simples o dobles: 
Morfología contrastiva del chino mandarín y el español. Formas de gramaticalización y lexicalización

1) Inglés > español: bingo > bingo, bikini > bikini

2) Inglés > mandarín: disco > dí sī kě 迪斯可, logic > luó jí 邏輯,

camera > kāi mài lā 開麥拉

Por otra parte, es muy frecuente sustituir las vocales dobles inglesas por las vocales simples españolas, mientras que en mandarín estas pueden ser simples o dobles:

1) Inglés > español: bluetooth > pronunciado «blutú», cyber-coffee > pronunciado «ciber-café»

2) Inglés > mandarín: Faust > fú shì dé 浮士德, nylon > ní lóng 尼龍

Otro aspecto interesante del anglicismo en español y en mandarín reside en la segmentación de sílabas. El español no siempre coincide con el inglés en el número de sílabas. En cambio, en mandarín no es difícil encontrar ejemplos que varían en la segmentación de sílabas con respecto al inglés:

1) Inglés > español: cheque > cheque, volt > votio, adrenaline > adrenalina

2) Inglés > mandarín: Hamlet > hā mǔléi tè 哈姆雷特, romantic > luó màn dì kè 羅 曼蒂克, sandwich > sān míng zhì 三明治, lace > léi sī 蕾絲

En muchos de ellos, la divergencia se basa en la traducción fonética de las consonantes del inglés, ya que en mandarín estas se pueden considerar como sílabas aunque no se presenten en compañía de las vocales.

Por último, los préstamos pueden clasificarse según los procesos de adaptación que han experimentado en la lengua de destino. Básicamente se distinguen tres tipos: a) se toma la palabra sin ningún tipo de adaptación; b) la nueva palabra sufre algún cambio fonético, morfológico o gráfico; c) la palabra tiene la forma de la lengua de destino pero representa el concepto de la lengua original (préstamo de significado). A continuación vemos algunos ejemplos: 


\begin{tabular}{|c|c|c|}
\hline a) sin & Inglés > mandarín & Inglés > español \\
\hline ninguna & Windows 2000 & hall \\
adaptación & b-mail & block \\
& DJ & clip \\
bikini
\end{tabular}

Tabla 8: Préstamos del inglés en chino mandarín y español

\subsection{Resumen y conclusiones}

En este capítulo se han puesto de manifiesto los principales aspectos de una morfología contrastiva entre dos lenguas aparentemente tan diferentes como el español y el chino mandarín. Hemos sugerido que, además de la distancia evidente entre estas dos lenguas, también conviene tener en cuenta que en ocasiones la descripción morfológica actual del chino mandarín puede mostrar determinados prejuicios que vienen repitiéndose desde hace décadas. Es indudable que los procesos flexivos no están ausentes en el chino mandarín, pues estas informaciones gramaticales se expresan mediante procedimientos analíticos, como marcas gramaticales, pero también como recursos léxicos. Así, en la flexión nominal, el caso gramatical se expresa a través de la preposición y el orden de palabras. Por otro lado, se encuentra la marca me 們 para expresar 
Morfología contrastiva del chino mandarín y el español. Formas de gramaticalización y lexicalización

la pluralidad de los pronombres personales y de determinados sustantivos que designan personas. En la flexión verbal, mientras que en español el verbo expresa las variaciones mediante las desinencias, el chino mandarín utiliza también particulas gramaticales, pero además se sirve de determinados adverbios y verbos auxiliares para expresar los cambios de persona, tiempo, aspecto, modo y voz. Así, la presencia obligatoria de pronombres personales para indicar la persona gramatical; la partícula le $了$ desempeña la función de marca flexiva de aspecto perfectivo y también expresa el tiempo pasado de un predicado télico; formantes como zài 在 'asp. progresivo', zhe 著 'asp. progresivo', guò 過 'pasado indefinido', qǔ laí 起來 'asp. incoativo' y xià qù 下去 'asp. continuativo' se usan como componentes morfológicos de la variación aspectual; la modalidad se representa mediante el elemento rú guó 如果 si; la marca bèi 被 expresa la voz pasiva y la marca gěi 給 equivale a la pasiva refleja del español.

En el proceso derivativo, se observa que en ambas lenguas los afijos se caracterizan por su estabilidad posicional en la formación de palabras, pues no hay ningún formante en las lenguas contrastadas que pueda desempeñar simultáneamente funciones prefijales y sufijales. En chino mandarín, mientras que todos los afijos convencionales (ér 兒，zi 子，tóu 頭，lăo 老，xiăo 小， di 第. etc.) sufren la gramaticalización, en español el debilitamiento semántico se refleja en menos casos (como el sufijo adverbializador-mente). Los sufijos apreciativos del español y algunos afijos convencionales del chino mandarín (como los prefijos xiăo 小, lăo 老 y los sufijos zi 子 y tóu 頭) comparten el valor afectivo, pero en el chino mandarín se observan menos efectos de uso que los del español. También se reconocen ciertos paralelismos entre las dos lenguas en los tipos generales de sustantivos que admiten la derivación afectiva, pues esta suele recaer en nombres con significados materiales, físicos o contables, frente a los de sentido abstracto y no contable. 
Con respecto a las diferencias en los procesos derivativos, se ha señalado que en chino mandarín algunos prefijos, sobre todo del tipo no convencional, alteran la categoría gramatical de la base léxica. Sin embargo, en español, la prefijación resulta fundamentalmente homocategorial. Por otra parte, el sistema de los sufijos apreciativos del español se caracteriza por una acusada morfología recursiva, mientras que en chino mandarín, solo el sufijo ér 兒 es el único que presenta esta capacidad recursiva, pues se comporta como un elemento no silábico que se amalgama a la base. Finalmente, en chino mandarín, algunos afijos convencionales se identifican más bien con los morfofonemas en determinadas combinaciones, pues sirven de elementos que contribuyen al bisilabismo del chino moderno. En este sentido, estos formantes se asemejan a algunos interfijos del español, pues tanto unos como otros ejercen únicamente funciones morfonológicas y carecen de significado léxico y de valor gramatical.

En cuanto a los procesos compositivos de ambas lenguas, es de notar que algunos esquemas que en una lengua resultan procesos habituales y productivos, pueden considerarse en la otra lengua como recursos defectivos o improductivos. Así, el esquema $N$ (sujeto) $\vee$ es una formación habitual del chino mandarín, pero ausente en el español, debido sobre todo a que la composición española no admite la lexicalización de esta relación sintáctica, que comprende a los dos constituyentes inmediatos de la estructura oracional. Otro aspecto divergente también se observa en el tipo formado por verbo y complemento predicativo. Mientras que en el chino mandarín el adjetivo de la combinación categorial verbo-adjetivo equivale sintácticamente a un complemento predicativo, en la composición española no se dan constituyentes de doble dependencia. Por lo tanto, aunque en ambas lenguas los compuestos muestran una sintaxis interna semejante a las relaciones estructurales que rigen la gramática, se ha mostrado que el chino presenta una mayor variedad de tipos compositivos, ya que es una lengua con una fuerte tendencia hacia la composición morfológica. Esta característica también se 
Morfología contrastiva del chino mandarín y el español. Formas de gramaticalización y lexicalización

muestra en los compuestos de estructura compleja, en los que la combinación de elementos de distintas categorías gramaticales presenta más variedad que las correspondientes del español.

En cuanto a las formaciones híbridas, existe un grupo de formantes polimórficos que se clasifican tradicionalmente como sufijoides (o pseudosufijos) por sus características morfológicas. En ambas lenguas, estos elementos muestran algunas semejanzas, pues son de origen clásico, presentan libertad de posición, incluso algunos alcanzan cierta autonomía léxica, gran capacidad combinatoria y admiten variaciones morfonológicas. Se trata de unidades morfológicas con un contenido semántico debilitado con respecto al significado primitivo de origen culto y resultan muy productivas en la formación del lenguaje científico y técnico. Hemos propuesto que la mayoría de los llamados sufijoides no interviene en procesos derivativos propiamente dichos, sino que más bien se comportan como formantes de la composición. Además, se ha planteado aquí una nueva clasificación entre los sufijoides o formantes compositivos propiamente dichos (que únicamente ocupan la segunda posición) y los temas (con doble posición). Esta reordenación creemos que puede ser común al español y al mandarín. Por otra parte, por influencia del extranjerismo, mientras que en el chino mandarín se encuentran más sufijoides que prefijoides, en el español parece que son más numerosos los temas antepuestos de origen culto.

En fin, se observa que el estudio del chino en contraste con el español puede aportar algunas novedades a la descripción tradicional del mandarín, pues los criterios que se adoptan del español para distinguir procesos morfológicos también pueden aplicarse a la lengua oriental con buenos resultados. En el caso de los afijoides. Concretamente, mediante el análisis contrastivo, se ha mostrado que determinadas formas híbridas chinas se identifican más bien con los elementos compositivos, ya que son unidades léxicas autónomas, capaces de entrar en la composición y de formar locuciones. Así, la práctica del contraste resulta positiva para reformular el 
tratamiento teórico y descriptivo de unidades morfológicas que habitualmente desde la perspectiva de una sola lengua llegan a indentificarse, pero quizá solo parcialmente. 

6

PROCESOS DE GRAMATICALIZACIÓN Y LEXICALIZACIÓN: MARCO TEÓRICO

En este capítulo se analizan las principales teorías propuestas acerca de los procesos de gramaticalización desde el siglo XIX hasta la actualidad. Se toman en consideración los presupuestos de la lingüística histórico-comparada y estructuralista y, posteriormente, las aportaciones pragmáticas y cognitivas. También se examinan los factores semánticos de estos cambios, que constituyen otro de los planos relevantes de la gramaticalización. Por otra parte, se realiza una revisión de los trabajos sobre los procesos de lexicalización, especialmente para explicar que este proceso puede identificarse con un mecanismo complementario que interactúa con la gramaticalización en el ámbito de la evolución lingüística.

\subsection{Gramaticalización}

\subsubsection{Principales definiciones}

A finales del siglo XIX Wilhelm von Humboldt y Georg von Gabelentz esbozaron los trabajos precursores en el estudio de la gramaticalización. Se mencionaban en sus obras las diferentes etapas de la formación de unidades gramaticales y se mostraba que los procesos de recreación gramatical son recurrentes. 
Morfología contrastiva del chino mandarín y el español. Formas de gramaticalización y lexicalización

Con todo, se reconoce generalmente a la obra de 1912, titulada Introduction à l'étude comparative des langues indo-européennes de Antoine Meillet el papel fundador del término "gramaticalización" (en el francés original grammaticalisation). Meillet (1973 [1912]: 131) define la gramaticalización como "le passage d'un mot autonome au role d'élément grammatical [...] I'attribution du caractère grammatical à un mot jadis autonome". Según esta definición, las formas gramaticales pueden tener su origen en elementos léxicos. Así, la gramaticalización puede interpretarse como un proceso histórico en el que las unidades léxicas perdieron autonomía conceptual y fueron adquiriendo contenido gramatical o funcional.

A partir de la obra de Meillet, empezó a despertarse el interés por el estudio de los procesos de gramaticalización. A mediados del siglo XX, algunos estructuralistas, como Roman Jakobson, Viktor M. Zirmunskij, Jerzy Kuryłowicz, Witold Mańczak y Émile Benveniste, realizan importantes contribuciones al análisis de los procesos de gramaticalización.

Según Lehmann (1982: 6), los estudios de Jakobson permitieron interpretar la gramaticalización como un proceso histórico en el que los ítems perdieron contenido léxico o conceptual y fueron adquiriendo contenido gramatical o funcional. Benveniste, por su parte, retoma muchas de las ideas expuestas en los trabajos de Meillet y asigna el nombre de auxiliation al concepto de gramaticalización. El trabajo de Kuryłowicz es muy destacado. El autor polaco contribuyó con aportaciones cruciales a la teoría de la gramaticalización y ofreció la que Heine y Hünnemeyer (1991a: 3) considera la definición clásica y más común de hoy:

La gramaticalización consiste en el aumento del rango de un morfema que avanza desde un plano léxico a otro plano gramatical, o de un estado menos gramatical a un estado más gramatical, por ejemplo a partir de un derivado a un formante flexivo (Kuryłowicz 1965 [1976]: 52) ${ }^{33}$.

\footnotetext{
33 Texto original en inglés "Grammaticalization consists in the increase of the range of a morpheme advancing from a lexical to a grammatical or from a less grammatical to a more gramatical status, e.g. from a derivative formant to an inflectional one".
} 
Asimismo, para Kuryłowicz, la gramaticalización es "lexical > grammatical and grammatical > more grammatical -or, more generally: any morpheme (lexical or grammatical) > a more grammatical morpheme". Esto es, una forma léxica, a partir del uso en contextos muy concretos, puede adquirir una función gramatical, o bien, una forma ya gramatical adquiere un significado aún más gramatical, con la consiguiente modificación de sus funciones.

Hasta hace unas décadas, la teoría de la gramaticalización solía quedar relegada a un segundo plano porque los procesos de gramaticalización solo eran analizados principalmente por la lingüística histórica indoeuropea y la tipología evolutiva. Sin embargo, la situación comienza a cambiar en la década de los sesenta, cuando se observa un interés creciente por los estudios de los universales lingüísticos y la tipología lingüística. Según Schwenter (1994: 105), se puede decir que la revitalización de estos trabajos crea una situación propicia para el desarrollo de las cuestiones relacionadas con la gramaticalización. Asimismo, resulta fácil establecer una conexión entre estas teorías generalistas y la gramaticalización porque numerosos procesos de gramaticalización siguen una línea evolutiva similar en lenguas diversas.

Tal paralelismo revela la existencia de mecanismos comunes que impulsan los cambios lingüísticos en lenguas distintas. De hecho, en algunos trabajos se aplica la idea de la gramaticalización para resolver problemas lingüísticos que surgen en el curso de las investigaciones sobre los universales lingüísticos (Hopper y Traugott 1993: 27). Por ejemplo, cabe destacar algunos trabajos de Givón $(1971,1979)$ en los que se relacionan cuestiones sintácticas sincrónicas del inglés con los estudios de los universales lingüísticos. En este contexto, se anuncia la famosa frase de "la morfología de hoy es la sintaxis de ayer (today's morphology is yesterday's syntax)" (Givón 1979: 209) para expresar la cadena de los procesos de gramaticalización:

Discurso $>$ sintaxis $>$ morfología $>$ morfonología $>$ zero . 
Morfología contrastiva del chino mandarín y el español. Formas de gramaticalización y lexicalización

Durante este periodo en que se recurre a la gramaticalización como parámetro explicativo de ciertas evoluciones en las estructuras lingüísticas, los estudios de Li y Thompson $(1974,1976)$ son especialmente influyentes en las cuestiones históricas (historical issues). Por ejemplo, estos autores tratan del cambio de un orden SVO a otro orden básico SOV en chino mandarín y otras lenguas, examinan la relación entre el sujeto y el fenómeno de la topicalización y describen la evolución de verbos a preposiciones y marcadores discursivas.

A partir de la perspectiva sintáctica, también se advierte un creciente interés por los fenómenos pragmáticos relacionados con el estudio de los procesos de gramaticalización. Se puede decir que los estudios de Meillet y Kuryłowicz ofrecen una visión originaria con enfoques provenientes de la pragmática y de los estudios discursivos. Asimismo, Givón sigue tomando el testigo para la revitalización metodológica desde la perspectiva pragmático-cognitiva de la gramaticalización. Algunos continuadores, como Traugott (1995b, 2003) y Company $(2001,2002,2003 a)$, siguen este concepto y aplican tal enfoque al estudio de casos de gramaticalización, donde el contexto pragmático adquiere gran relevancia en este proceso. Por ejemplo, Traugott (2003: 1) cree que "lexemes grammaticalized only in certain highly specifiable context, and under specifiable pragmatic conditions". Asimismo, Traugott (2003: 645) ofrece la definición de gramaticalización como:

El proceso por el cual se le asigna la función gramatical al material léxico en un contexto pragmático y morfosintáctico muy limitado, y si (el material es ya) gramatical, se le asigna la función de operador cada vez más gramatical34.

Company (2004a: 30) también considera estándar esta definición complementaria de la definición tradicional, pues señala que la gramaticalización consiste en la fijación de estrategias discursivas, de manera que los fenómenos lingüísticos operan en un nivel discursivo o textual que, de

34 Texto original en inglés: "The process whereby lexical material in highly constrained pragmatic and morphosyntactic context is assigned grammatical function, and once grammatical, is assigned increasingly grammatical, operator-like function". 
un estado de lengua dado a un nivel más pragmático, se convierten con el paso del tiempo en construcciones gramaticales convencionales, carentes ya de condicionamientos pragmáticos.

De acuerdo con lo anterior, se puede afirmar que los cambios lingüísticos no son arbitrarios ni son siempre predecibles a partir del significado y la forma. La gramaticalización puede derivar en diferentes concepciones según las implicaciones semánticas del proceso, entre las que se encuentran la pérdida de contenido léxico de la unidad gramaticalizada y la adquisición de significados gramaticales o funcionales. En el siguiente apartado se revisan estos mecanismos que se manifiestan como motivación para explicar los cambios semánticos de la gramaticalización.

\subsubsection{Gramaticalización y motivaciones pragmático-cognitivas}

Desde los primeros años de la década de los ochenta, muchos trabajos sobre gramaticalización han tomado en consideración criterios semánticos, pues se asume que los cambios de significado y la motivación cognitiva que los provoca se incluyen en el tratamiento de la gramaticalización. Las perspectivas que adoptan los autores están vinculadas al marco pragmático-cognitivo. Por ejemplo, Bybee y Pagliuca (1985) utilizan el concepto de cambio semántico para explicar el desarrollo del significado gramatical. Traugott y König (1991) destacan la función pragmática en el proceso de gramaticalización. Además, muchos autores aplican conceptos cognitivos a la evolución de los significados por los procedimientos de la metáfora y la metonimia. Generalmente, se puede establecer que los autores más vinculados a la Gramática Cognitiva justifican los cambios de significados a partir de metáforas (Claudi y Heine 1986; Sweetser 1990), mientras que los vinculados más a perspectivas funcionalistas prefieren adoptar la motivación metonímica (Traugott y König 1991; Heine, Claudi y Hünnemeyer 1991a) para 
Morfología contrastiva del chino mandarín y el español. Formas de gramaticalización y lexicalización

explicar los procesos de gramaticalización.

En el marco de la gramaticalización, las implicaciones semánticas consisten en una pérdida del contenido léxico de la unidad gramaticalizada y en la adquisición de un significado gramatical. Este debilitamiento semántico ha recibido la denominación de attribution (Lehmann 1985: 307) o bleaching (Heine y Reh 1984: 15). Sin embargo, otros autores como Bybee y Pagliuca han considerado que la gramaticalización no conlleva propiamente un desgaste semántico, sino una generalización (generalization) del significado del elemento que se gramaticaliza, lo que explica su polisemia y ambigüedad. Así pues, Company (2003a: 14) señala que la gramaticalización es un proceso:

[...] simultáneo de debilitamiento o pérdida y ganancia: pérdida de especificidades de significado y de privilegios de ocurrencia, y debilitamiento de iconicidad, pero al mismo tiempo es ganancia en polisemia, incremento de funciones adicionales gramaticales y aumento en la frecuencia $y$ generalización del signo, y por lo tanto ganancia en la aplicabilidad del signo.

Se entiende que, desde el punto de vista funcional, esta reducción semántica de un signo determina la pérdida de autonomía y su dependencia de otra unidad. Por consiguiente, se puede afirmar que en cualquier proceso de gramaticalización existe una interrelación entre el cambio semántico que experimenta la unidad lingüística que se gramaticaliza y las modificaciones que ese cambio provoca en el sistema funcional de la lengua.

Jacob (2004) apoya la tesis de que el cambio semántico no se considera como una pérdida arbitraria de rasgos semánticos. Las repercusiones semánticas de la gramaticalización consisten en el paso de lo concreto a lo abstracto, en la sustitución de rasgos más concretos por rasgos más abstractos. Por ello, la gramaticalización se considera un proceso de abstracción del significado.

Ahora bien, dado que resulta imprescindible establecer alguna conexión entre los cambios semánticos y los fenómenos metafóricos y metonímicos como instrumentos de motivación del cambio significativo, se han 
llegado a distinguir estas dos perspectivas de la Gramática Cognitiva, que han dado lugar a dos hipótesis teóricas para el estudio de la gramaticalización:

1) La hipótesis de las proyecciones metafóricas, según la cual el significado concreto de una expresión se aplica a un contexto más abstracto (Heine 1993 y Sweetser 1990).

2) El modelo contextual, o hipótesis de la implicatura, según el cual el mecanismo predominante para la creación de significados secundarios, que gradualmente sustituyen a los significados primarios, es la convencionalización de implicaturas conversacionales (Bybee y Pagliuca 1994; Hopper y Traugott 1993). En los estudios de Traugott y König (1991) y Hopper y Traugott (1993) se denomina a este mecanismo "inferencia metonímica", o simplemente "metonimia".

La metáfora se considera un instrumento cognitivo (Lakoff y Johnson 1980). Este tipo de cambio de significado se entiende como "un proceso metafórico que proyecta (o representa) el significado de una determinada unidad lingǘstica perteneciente a un dominio cognitivo en concreto a otro dominio más abstracto o gramatical" (Tornel Sala 2000: §2.4.1). Evidentemente, la "sustitución" de un dominio cognitivo por otro tiene que partir de la existencia de ciertos rasgos semánticos compartidos en ambos dominios. Por tanto, la metáfora se entiende como la representación de una unidad lingüística desde un dominio cognitivo a otro dominio cognitivo diferente de índole más abstracta, llegando incluso a establecer series de metáforas enlazadas en su proceso evolutivo. La siguiente figura, tomada de Cuenca y Hilferty (1999: 111 ), ilustra el mecanismo de la metáfora:

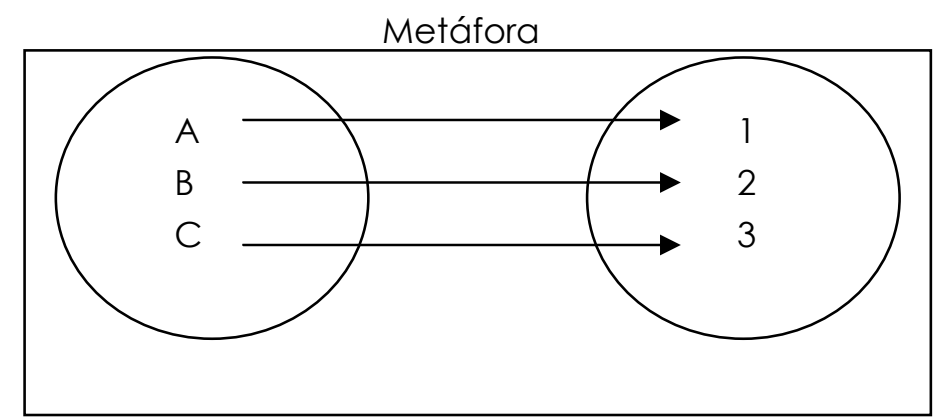

Dominio origen

Dominio destino 
Morfología contrastiva del chino mandarín y el español. Formas de gramaticalización y lexicalización

Estas transformaciones se desarrollan en cadenas de gramaticalización que siguen el orden básico, semejante a la jerarquía de abstracción metafórica esquematizada por Heine, Claudi y Hünnemeyer (1991a: 48):

persona > objeto > proceso > espacio > tiempo > cualidad

La interpretación de esta jerarquía es la siguiente: los elementos léxicos pueden desarrollar sentidos más abstractos si recorren la escala de izquierda a derecha y van adquiriendo los nuevos significados a medida que se gramaticalizan. La universalidad de esta jerarquía se demuestra actualmente en una considerable evidencia empírica. Además, los elementos gramaticalizados pueden obtener muchos de los significados de la jerarquía o bien solo uno, pero siempre tiene que ser uno de los que figuran a su derecha.

Un ejemplo en el que el proceso de gramaticalización se explica perfectamente a partir de la metáfora es la formación del conector aditivo encima. La noción física y espacial de este adverbio de lugar constituido por la preposición en y el sustantivo cima se proyecta en el plano discursivo, de modo que la idea de superioridad se sitúa en el nivel textual informativo. Así, encima funciona como conector textual que enlaza enunciados argumentativamente coorientados (Garachana 1997: 82-83).

Se han propuesto otros esquemas que tienen en cuenta categorías distintas a la de la escala anterior. Por ejemplo, en Cifuentes Honrubia (2003: 26) se señala la jerarquía presentada por Traugott y König (1991):

temporal > causal > concesivo

Difiere de la escala de Heine, Claudi y Hünnemeyer en que esta añade la categoría "concesivo". Una segunda jerarquía es la de Bat-Zeev Shyldkrot (1995: 89), en la que se tienen en cuenta unos dominios que Heine, Claudi y Hünnemeyer no habían considerado:

cantidad > cualidad > concesión 
De acuerdo con lo anterior, se recuerda que la otra hipótesis sobre los procesos de gramaticalización en los que el nivel léxico está implicado es la metonimia. Frente a la metáfora, la metonimia consiste en un proceso de transferencia del significado dentro de un único dominio de la experiencia. Dicho de otra manera, la metonimia se entiende como una asociación conceptual por la que se representa un elemento implícito a través de otro explícito, donde ambas entidades pertenecen a una misma contigüidad conceptual de un mismo dominio cognitivo. La siguiente figura, tomada de Cuenca y Hilferty (1999: 111), ilustra el mecanismo de la metonimia (PR: punto de referencia, ZA: zona activa):

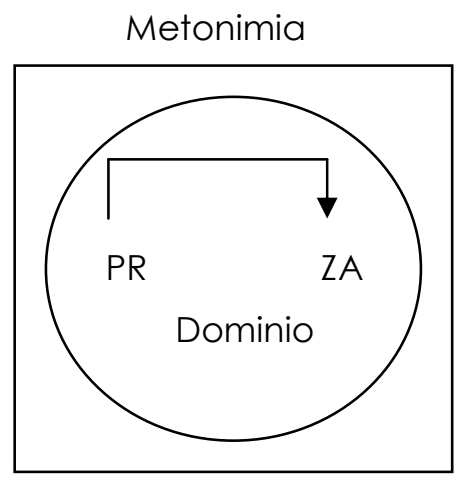

Un ejemplo de metonimia es el caso de luego como conector consecutivo. Garachana (1997: 84-85) indica que el valor originario de luego es el temporal (='después'), pero esta idea de secuencia está asociada al dominio de la causalidad. En efecto, los conceptos de causa y efecto se corresponden con los de anterioridad y posterioridad temporal. Por consiguiente, no es de extrañar que un valor consecutivo se infiera a partir de un significado de posterioridad. Otro ejemplo equivalente, más actual y no convencionalizado, sería el caso de después en enunciados como María se fue de casa, después (más tarde, como consecuencia de la marcha), Pedro se suicidó. En este contexto a la idea de posterioridad temporal expresada por después se añade un significado inferido de valor consecutivo. 
Morfología contrastiva del chino mandarín y el español. Formas de gramaticalización y lexicalización

Otro rasgo importante de la teoría de la metonimia se refiere a la necesidad de tomar en consideración aspectos de tipo pragmático. Normalmente la metonimia se considera una interpretación inducida por el contexto que trata de una modificación del significado gramatical y un incremento de los valores pragmáticos. De hecho, la metonimia se interpreta como un proceso de pragmaticalización del significado y se podría hablar de debilitamiento semántico. Sin embargo, la pérdida de significado no es la condición arbitraria que constituye el parámetro explicativo de los procesos de gramaticalización. En muchas ocasiones, aunque la gramaticalización se iguala al empobrecimiento semántico, parece más adecuado hablar de evolución hacia un nuevo significado que de desemantización.

Ejemplos de esta dependencia del significado contextual son algunos conectores, como pues, cuyo valor semántico en muchas ocasiones solo puede determinarse a partir del contexto, como causal de 1) o como consecutivo de 2) (Garachana 1997: 77):

1) Despidámonos ahora, pues no nos volveremos a ver jamás.

2) Él la mató, que sufra las penas, pues.

Por otra parte, a partir de los principios pragmáticos, en el mecanismo de la metonimia también se observan los principios de "economía" y "cooperación conversacional". Según indica Cifuentes Honrubia (2003: 27), el hablante tiende a no decir más que lo necesario para lograr la eficacia mediante las marcas formales que manifiesten los diferentes valores que se consideran relevantes, mientras que el receptor se inclina a seleccionar la interpretación más informativa de lo que se recibe. Es decir, se trata de un refuerzo de la informatividad basado en un proceso metonímico de carácter inferencial que, si acaba convencionalizado, puede sustituir al término originario o convivir con él. 
Hasta el momento se han considerado la metáfora y la metonimia como dos procesos cognitivos perfectamente delimitados. Sin embargo, no resulta fácil establecer un deslinde entre uno y otro. Esta dificultad obedece a que en numerosos procesos de gramaticalización la metonimia aparece como el condicionante básico para el proceso metafórico. Por ejemplo, la expresión metafórica estar por los suelos se entiende como "menos ánimo" porque corresponde al tipo de metáfora conceptual que desde la lingüística cognitiva se denomina "menos es bajo" (Lakoff y Johnson 1980 y Lakoff 1987). Por consiguiente, se constituye un estado mental a partir de la actitud corporal y se establece una asociación a otros conceptos de características metonímicas. Esta transferencia es precisamente la que ha determinado que la metáfora quede excluida como parámetro explicativo o descriptivo, ya que las metáforas están condicionadas por una base metonímica.

Además del plano sincrónico, la correlación entre la metáfora y la metonimia se observa también en el desarrollo diacrónico, de modo que ciertas evoluciones lingüísticas, que en conjunto suponen una proyección entre dominios distintos, están determinadas por relaciones de tipo metonímico. Por ejemplo, Garachana (1997: 87-90) indica en su trabajo que la evolución desde los valores espaciales de la construcción ir a + infinitivo hasta los temporales de futuro no se explica como un proceso metafórico sin más, puesto que se manifiesta un componente metonímico del tipo el todo por la parte en dicha evolución, cuando el sentido temporal acaba convencionalizándose y forma parte de la estructura semántica de la construcción. Por consiguiente, se confirma que existe una cadena metonímica que conduce a la metáfora.

En suma, la metáfora y la metonimia son dos mecanismos asociativos y complementarios en los procesos de gramaticalización. Según Hopper y Traugott (1993: 77), los procesos metafóricos son procesos de inferencia entre dominios conceptuales que se realizan mediante la proyección o asociación desde un dominio a otro. La asociación no es aleatoria, sino motivada por analogía y relaciones de iconicidad. Por ello, se relaciona perfectamente con 
Morfología contrastiva del chino mandarín y el español. Formas de gramaticalización y lexicalización

conceptos pragmáticos. La metonimia, por otra parte, depende de la contigüidad y el reanálisis. Hopper y Traugott (1993: 4.3.2) indican que Antilla (1989 [1972]: 141-2) sugiere que la metáfora es una transferencia semántica a través de percepciones sensoriales y, por tanto, es analógica e icónica, mientras que la metonimia es una transferencia semántica mediante la contigüidad y es más dependiente del contexto lingüístico. Asimismo, la metáfora actúa entre dominios conceptuales y la metonimia opera entre constituyentes gramaticales.

De cualquier forma, no se debe ver aquí un enfrentamiento radical, pues metonimia y metáfora son mecanismos complementarios y no excluyentes. Los dos funcionan como instrumentos cognitivos que forman los componentes del proceso de gramaticalización (Heine, Claudi y Hünnemeyer 1991b: 166; Hopper y Traugott 1993: 87). Además, en muchas ocasiones la clasificación de un proceso como metafórico o como metonímico depende del punto de vista adoptado: si se centra en el término originario y en el resultado del cambio, de forma que se analiza como un proceso de cambio de dominio cognitivo, se hablará de metáfora; pero si se analiza el cambio progresivamente, teniendo en cuenta las distintas etapas de su evolución, que son contiguas, se hablará de metonimia.

Normalmente, la noción de metonimia suele aplicarse también a la formación de inferencias pragmáticas y convencionales en contextos discursivos determinados:

Proponemos ampliar la noción de metonimia desde los contextos tradicionales concretos y abiertos a los contextos cognitivos y encubiertos, específicamente a los contextos pragmáticos de inferencia conversacional y convencional (Traugott y König 1991: 211)35.

Estos significados pragmáticos inducidos por el contexto se extienden posteriormente hasta llegar a convencionalizarse o rutinizarse (o ritualizarse),

35 Texto original en inglés "We propose extending the notion of metonymy from traditional concrete and overt contexts to cognitive and covert contexts, specifically the pragmatic contexts of conversational and conventional inference". 
dando origen al establecimiento de un nuevo significado gramatical 0 abstracto. Por consiguiente, la metonimia, frente a la metáfora, opera a través del contexto y de las relaciones de inferencia que los diferentes elementos del discurso pueden llegar a establecer por la contigüidad lingüística. Sin embargo, la metáfora no funciona a partir de las contigüidades lingüísticas, sino de los cambios de un dominio conceptual a otro por la transferencia de un significado más concreto a otro más abstracto que no aparece en el contexto (Tornel Sala 2000: 121-122).

Del mismo modo, Cifuentes Honrubia (2003: 28) señala que parece que la metáfora es un mecanismo de cambio semántico para el significado léxico de la escala del continuo de gramaticalización, mientras que la metonimia es uno de los mecanismos aplicables a los significados más gramaticalizados o más abstractos. La razón de esta diferencia podría ser que la metáfora requiere estructuras de imágenes esquemáticas que atraviesan dominios cognitivos. Tales estructuras son más accesibles cerca del polo léxico del continuo de gramaticalización. Como el significado gramatical llega a ser más abstracto y más erosionado, es menos deseable para la metáfora y más sujeto a las presiones contextuales que el cambio producido por inferencia.

\subsubsection{Unidireccionalidad}

La caracterización que se propone de la gramaticalización revela que este tipo de proceso se desarrolla en cadenas o clines, pues comprende el recorrido de un término desde su estadio más referencial hacia el más gramatical. En términos de Hopper y Traugott (1993), cualquier proceso de gramaticalización debería comportar el estadio de clitización (1) y de morfologización (2), como los dos tipos de cadenas según la naturaleza del elemento afectado por el proceso:

1) Clitización: Verbo pleno > Auxiliar > Clítico > Afijo 
Morfología contrastiva del chino mandarín y el español. Formas de gramaticalización y lexicalización

2) Morfologización: Nombre pleno > Nombre relacional > Preposición secundaria o locución prepositiva > Preposición primaria > Clítico > Afijo

Según Joseph y Janda (1988: 195-196), el proceso de clitización es: "the diachronic process whereby a lexical form becomes a clitic" (Hopper y Traugott 1993: 5), mientras que la morfologización es un morfema "form a derivative formant to an inflectional one" (Kuryłowicz 1965: 13) y un proceso que "describes any transition [...] from a state in which a generalization is nonmorphological in nature to a state in which the corresponding generalization is morphological in nature". Para Hopper y Traugott (1993: 55-56), los clíticos son unidades lingüísticas que dependen de otras unidades autónomas para poder funcionar en la cadena hablada, aunque no forman parte de otra palabra como los afijos. Pueden adoptar la forma proclítica o enclítica (como en inglés l'm, you're, we'll, we've). Un ejemplo clásico de evolución de una unidad léxica a clítico se encuentra en el verbo auxiliar hebere, que pasa de verbo pleno a verbo modal deóntico y, posteriormente, a una forma enclítica de futuro. Tras el estadio de clitización, la unidad lingüística se transforma en un morfema afijal que designa el tiempo, como se ilustra a continuación:

$$
\begin{aligned}
& \text { Habeo }>\text { cantare habeo }>\text { cantare he }>\text { cantar-é } \\
& \text { Verbo pleno Auxliliar } \quad \text { Afico }
\end{aligned}
$$

Un ejemplo de morfologización lo constituye el sufijo adverbial -mente. Según Cifuentes Honrubia (2003: 44), este sufijo en un principio es el sustantivo latino en caso ablativo. Después, se extiende contextualmente y se gramaticaliza hasta convertirse en un afijo con la consiguiente pérdida de funciones como categoría nominal plena.

Más adelante, otros lingüistas, como Pérez Saldanya (1997), resumen estas cadenas de gramaticalización en un proceso más general:

Categoría léxica mayor > categoría léxica menor > categoría funcional 
Estas caracterizaciones ponen de manifiesto que los procesos de gramaticalización se pueden considerar como fenómenos unidireccionales, de modo que se observa un proceso evolutivo que va desde palabras o construcciones pertenecientes a categorías léxicas hasta formas gramaticales, o desde formas gramaticales hasta otras más gramaticales. Así pues, en el momento en que una unidad lingüística inicia su evolución hacia la gramaticalización, el mecanismo que se desarrolla va en una única dirección y demuestra una fuerte tendencia hacia la unidireccionalidad. En este sentido, la unidireccionalidad constituye una de las hipótesis más frecuentes asociadas a la teoría de la gramaticalización (Heine, Claudi y Hünnemeyer 1991a: 212, 1991b: 150; Heine 1993; Hopper y Traugott 1993: 94; Pérez Saldanya 1997: 1-8).

Ahora bien, según lo que se ha señalado, parece que la unidireccionalidad de la gramaticalización implica una pérdida del contenido semántico, que ha sido descrito mediante la metáfora del debilitamiento (fading, weakening o bleaching, Heine y Reh 1984: 15). Tal planteamiento de la unidireccionalidad corresponde a lo que afirma Börjars (2011: 175): "la gramaticalización se considera generalmente una pérdida de fonología, de significado y de independencia". Sin embargo, Hopper y Traugott (1993: 88) advierten que en los estadios iniciales de los procesos de gramaticalización no se produce propiamente una pérdida o debilitamiento, sino una redistribución o cambio de significado. De estas observaciones, Candalija (2008: §1.3.2) indica que se derivan dos principios generales en los procesos de inferencia en la gramaticalización:

1) Los cambios de significado en la gramaticalización no son arbitrarios, dado que los significados se derivan desde el sentido léxico original mediante inferencias metafóricas o metonímicas.

2) La fase de la gramaticalización no supone la pérdida sino un cambio en el significado. No es probable que cualquier instancia gramaticalizada implique una repentina pérdida de significado. Los significados más prominentes tienden a persistir durante bastante 
Morfología contrastiva del chino mandarín y el español. Formas de gramaticalización y lexicalización

tiempo y condicionan los usos de las formas gramaticalizadas.

Se quiere considerar que la unidireccionalidad se caracteriza por la irreversibilidad, que se manifiesta en los cambios semánticos, sintácticos y fonológicos que se producen en los procesos de gramaticalización. En el plano semántico, se observa una evolución hacia significados cada vez más abstractos y relacionales; en el plano sintáctico, la unidireccionalidad representa una evolución hacia categorías gramaticales inferiores y se demuestra una frecuente pérdida de la capacidad de movilidad en las piezas gramaticalizadas; por último, en el plano fonológico, la unidireccionalidad implica la frecuente reducción del cuerpo fonético de las voces o elementos gramaticalizados. Estos cambios solo pueden ir en una única dirección y no son reversibles.

Un aspecto importante vinculado a la unidireccionalidad es la descategorización, que consiste en un proceso de recategorización o de transcategorización. Es decir, se trata de un proceso por el que se modifica la combinatoria sintáctico-semántica de una unidad lingüística, lo que conlleva una tendencia de esta unidad a transformarse desde una categoría gramatical más o menos abierta (mayor) hasta formar parte de una categoría más cerrada (menor).

En este desplazamiento sintáctico, las piezas afectadas pierden las propiedades morfológicas y sintácticas que las identificaban como miembros de una categoría gramatical. Así, algunas unidades de las categorías menores, como preposiciones, conjunciones, verbos auxiliares, pronombres, demostrativos, etc., tienen su origen en categorías mayores, como son el nombre y el verbo pleno. En ese sentido, la pérdida de la categoría gramatical original del elemento gramaticalizado explica la unidireccionalidad del proceso.

En cuanto al carácter irreversible, para explicar la generalización y la pérdida de significado como principio que parece seguir la gramaticalización, 
Cifuentes Honrubia se centra en el fenómeno de la iconicidad que se deriva de los cambios formales que se dan en el proceso. Para el autor, la interrelación de los diferentes cambios que tienen lugar en los aspectos semánticos, sintácticos y fonológicos permite otorgar a la gramaticalización un cierto carácter icónico. En este sentido, se puede afirmar que las formas gramaticalizadas presentan una mayor fijación, una mayor frecuencia de uso, un menor coste fonético y una mayor regularidad formal que las unidades de las que proceden.

En función de estas características, Cifuentes Honrubia (2003: §1.6.2) señala que existe un continuo entre el léxico y la gramática, en el que todos los niveles de análisis lingüístico siguen una evolución paralela. Asimismo, podría trazarse una línea evolutiva prototípica que podría esquematizarse de la siguiente manera:

LÉXICO $\longrightarrow$ GRAMÁTICA

a. Semánticamente rico $>$ más general> reducido o vacío

b. Lexema $>$ auxiliar, partículas $>$ desinencias

c. Polisílabo $>$ monosílabo $>$ segmento único

d. Clases abiertas $>$ clases cerradas

e. Posición libre $>$ posición +/- fija > posición fija

f. Poco frecuente > bastante frecuente > obligatorio Tabla 1: Evolución del plano léxico al gramatical

Así pues, la gramaticalización se define como un proceso dinámico y unidireccional por el cual los lexemas adquieren un nuevo estatuto gramatical y morfológico $y$, desde el punto de vista semántico, pasan a tener un significado más abstracto y general que el significado originario.

En el proceso de gramaticalización, la desaparición de la antigua alternativa puede ocurrir, pero no es imprescindible. Ridruejo (1989: 74) señala que la forma antigua y la forma nueva quedan como variantes o presentan la posibilidad de un nuevo cambio que afecta a la unidad antigua. Así, en español medieval y clásico, el sintagma constituido por el participio del verbo 
Morfología contrastiva del chino mandarín y el español. Formas de gramaticalización y lexicalización

poner, puesto, más la conjunción que sufre un proceso de gramaticalización que, vaciado el participio de su significado léxico, convierte el sintagma en un elemento de relación, en una conjunción concesiva o causal. Sin embargo, la gramaticalización de este sintagma no trae consigo el reemplazo total de otras conjunciones como porque, ya que, etc.

Para concluir este apartado, no se debe olvidar la importancia de los condicionamientos cognitivos que intervienen en relación con la unidireccionalidad y el cambio semántico. Según señala Traugott (1982), los dominios del significado más concretos tienden a derivar su vocabulario a los dominios más abstractos y no al contrario. Sweetser (1990: 19-20) también destaca que en algunos casos hay cierta predisposición cognitiva a que los dominios particulares más concretos pueden derivar hacia los dominios generales y abstractos. Por ejemplo, ciertos verbos de estado físico o movimiento son los orígenes del vocabulario de ciertas áreas del significado abstracto. En este sentido, parece confirmarse la hipótesis de que el cambio semántico puede ser explicado en términos de reestructuración metonímica y pragmática del significado (Candalija 2008: 44-45).

En el siguiente apartado, se introducirá el concepto de subjetivación que ha estado estrechamente ligado a la noción de unidireccionalidad. Según Traugott (1995a: 45), si bien la unidireccionalidad va acompañada de factores como la generalización de contextos sintácticos y morfológicos y la reducción fonológica, la subjetivación es uno de los factores semánticos esenciales de la gramaticalización.

\subsubsection{Subjetivación}

Además del mecanismo de la metáfora y la metonimia, existen otras tendencias subyacentes a los cambios semánticos que pueden guiar los procesos de gramaticalización, como la validez de la subjetivación. 
La subjetivación es una interacción hablante-oyente que se da en la gramaticalización. Company (2004a: 1) indica que ciertas construcciones convencionalizadas en la gramática de una lengua son el resultado de procesos de cambio lingüístico que incorporan a la gramática significados pragmáticos con los que se codifica la actitud y las valoraciones del hablante ante lo comunicado.

Más concretamente, Garachana (1997: 98-99) entiende la subjetivación como un fenómeno gradual a través del cual ciertas palabras que en un primer momento expresan significados léxicos y objetivos pasan a desempeñar funciones cada vez más abstractas, pragmáticas y basadas en la expresión de la opinión del emisor, mientras que el interlocutor coopera para interpretar la rutinización.

Otros autores como Traugott (1990, 1995a) y Langacker (1999) proponen que la noción de subjetivación está estrechamente ligada al proceso unidireccional de la gramaticalización. Sin embargo, los dos autores defienden esta relación de forma distinta. Cifuentes Honrubia (2003: 56) indica que, mientras que Langacker considera la subjetivación como el resultado de la atenuación, Traugott opina que la subjetivación se limita a las construcciones que afectan al sujeto sintáctico y se caracteriza por un enriquecimiento semántico. Para Traugott (1995a: 31), la subjetivación es un proceso que:

Se refiere a un proceso pragmático-semántico mediante el cual 'los significados se basan cada vez más en el estado/actitud de la creencia subjetiva del hablante hacia la proposición', en otras palabras, hacia lo que el hablante está diciendo36.

Es decir, la subjetivación es un proceso que supone una mayor participación del sujeto de la enunciación en el acto comunicativo, puesto que este pasa a expresar su actitud ante el enunciado. Más concretamente, la

\footnotetext{
36 Texto original en inglés "Refers to a pragmatic-semantic process whereby 'meanings become increasingly based in the speaker's subjective belief state/attitude toward the proposition', in other words, towards what the speaker is talking about".
} 
Morfología contrastiva del chino mandarín y el español. Formas de gramaticalización y lexicalización

subjetivación es un fenómeno gradual por el cual las palabras y las construcciones que en un primer momento expresan significados concretos, léxicos y objetivos, pasan a desempeñar luego, tras el uso repetido en contextos sintácticos concretos, funciones cada vez más abstractas, pragmáticas, interpersonales y basadas en la expresión de la opinión del emisor. De ahí, se puede afirmar que, la evolución semántica tanto en el plano léxico como en el gramatical siempre va acompañada de un incremento de la subjetividad de la construcción. Traugott (1990: 501) opina que el incremento de la subjetividad es una tendencia más o menos constante en el desarrollo del significado gramatical, que explica la propensión de las palabras a perder su valor referencial para expresar valores textuales, metatextuales o sentidos relacionados con el mundo de las vivencias personales.

A diferencia de Traugott, la definición de la subjetivación de Langacker (1999) no toma en consideración los detalles del proceso de cambio semántico ni los contextos específicos en que el cambio se produce. El autor, en cambio, se centra en el papel de la construcción para desarrollar una teoría de la gramática basada en una visión conceptualista de la semántica: la inclusión del hablante o conceptualizador en la escena, como punto de referencia, convierte las escenas en subjetivas. Así, entiende la subjetivación como un proceso gradual de atenuación progresiva.

Por otro lado, acerca del alcance de la subjetivación en la evolución semántica, conviene señalar que no todos los procesos de gramaticalización desembocan en significados subjetivos. Por ejemplo, Garachana (1997: 108) explica que la evolución de conectores contraargumentativos a partir de otros causales (per hoc > pero) no puede justificarse como el resultado de un incremento de subjetividad. Por consiguiente, no parece que todos los procesos de gramaticalización incluyan una forma gramatical con un significado "subjetivo". Incluso en Traugott (1995a: 45-49) se admite la posibilidad de que el grado de subjetividad de una palabra disminuya a lo largo del proceso de gramaticalización: "some counterexemples de existe, buł 
they all involve later stages of grammaticalisation". Y se llega a señalar que "of those paths of grammaticalisation in which subjectification is reduced or possibly reversed".

En consecuencia, la subjetividad no se revela como una tendencia general en la evolución del significado gramatical, sino como una tendencia vinculada, en la que algunos procesos de gramaticalización suponen una subjetividad del significado gramatical resultante.

\subsubsection{Reanálisis y analogía}

Los cambios sintácticos que tienen lugar con la gramaticalización responden a un mecanismo de cambio denominado reanálisis. El reanálisis se considera uno de los principales motores del cambio sintáctico en general, pero también es un mecanismo básico de actuación de la gramaticalización (Langacker 1977: 57-59; Heine y Reh 1984: 110; Ridruejo 1989; Heine Claudi y Hünnemeyer 1991b: 167; Hopper y Traugot† 1993: 32; Pérez Saldanya 1997: 8).

El reanálisis conlleva una reestructuración interna de los elementos implicados en el proceso de gramaticalización. Tal como afirma Traugott (201 1: 23), la gramaticalización se identifica con un tipo de reanálisis. Se trata de la transformación de una estructura dada en una estructura diferente sin que ello afecte a su configuración externa. Así, el reanálisis supone la descategorización de los términos gramaticalizados, de forma que ven alterados su alcance, su movilidad sintáctica y experimentan una reorganización de los límites entre sus constituyentes. Un ejemplo claro de este proceso es la perífrasis verbal ir a + infinitivo para expresar el valor del futuro.

En opinión de Ridruejo (1989: 87-89), dos procesos caracterizan el reanálisis: la resegmentación y la reformulación. La resegmentación es el resultado de la falta de transparencia entre los elementos significantes y los significados, bien porque se ha producido una modificación (evolución fónica 
Morfología contrastiva del chino mandarín y el español. Formas de gramaticalización y lexicalización

o morfológica) o bien por la dificultad de análisis de los significados (empleo de significados figurados). Por ejemplo, en Dios hay una secuencia de un lexema más el morfema de plural, lo que lleva a reconstruir un singular Dio. La reformulación se refiere a la incorporación de una unidad en oposiciones paradigmáticas diferentes de las que se integraba previamente. Atañe, por tanto, a la configuración más abstracta, a su categorización semántica. Por ejemplo, en la evolución de la forma verbal cantara < cantaveram, la expresión de la no realidad se atribuye a la forma en -ra, que pasa a ser el correlato anterior de cantaría.

A pesar de lo dicho, el concepto de reanálisis no está exento de problemas. Gran parte de los procesos de gramaticalización suelen implicar reanálisis $y$, por ello, hay autores que identifican como sinónimos la gramaticalización con el reanálisis o con una serie de reanálisis (Harris y Campbell 1995; Company 2003a: 48). Acerca de esta identificación, muchos autores reconocen que, aunque estén íntimamente relacionados, la gramaticalización y el reanálisis no son procesos idénticos, tal como señalan Heine, Claudi y Hünnemeyer (1991 a: 215-220) y Hopper y Traugott (1993: 48-50). Cifuentes Honrubia (2003: 39-40) indica que Haspelmath (1998) ha planteado algunas nociones de gramaticalización y reanálisis como dos clases de fenómenos distintos:

1) El reanálisis no necesita que un elemento llegue a gramaticalizarse como resultado de un cambio, mientras que en el proceso de la gramaticalización se produce la pérdida de autonomía o de sustancia.

2) En el reanálisis los elementos oracionales pueden desarrollar nuevas relaciones sintácticas con nuevos elementos sin relación directa, mientras que en la gramaticalización el cambio de relaciones jerárquicas es menor y se desarrolla en todo caso de manera gradual.

3) El reanálisis es potencialmente reversible, mientras que la gramaticalización es esencialmente irreversible.

4) En el reanálisis puede existir una ambigüedad potencial entre la 
estructura original y la estructura nueva, mientras que en los cambios de la gramaticalización este factor no suele ser frecuente.

Por consiguiente, se puede decir que las características diferenciales entre el reanálisis y la gramaticalización residen en que este último proceso supone una pérdida de autonomía o de sustancia, se considera un proceso gradual y unidireccional, y no conlleva ambigüedad estructural. El reanálisis, por su parte, no implica una perdida de autonomía o sustancia, el cambio de relaciones sintácticas se produce de forma abrupta e incluye la bidireccionalidad y la ambigüedad estructural.

En palabras de Cifuentes Honrubia (2003: 40), se puede afirmar que el reanálisis es uno de los mecanismos determinantes de la gramaticalización y que, sin su consideración, la gramaticalización no tiene poder explicativo por sí misma (Campbell y Janda 2001: 151).

La analogía, por otra parte, en palabras de Ridruejo (1989: 76), consiste en la imitación regular por parte de los hablantes de otras construcciones ya existentes en la misma lengua, de suerte que para acomodarse a este modelo se genera un cambio en una forma preexistente. Según Cifuentes Honrubia (2003: 40), la relación entre este fenómeno y la gramaticalización puede ser planteada desde una nueva perspectiva si se tiene en cuenta el proceso de reanálisis. El reanálisis y la analogía no están contrapuestos como procesos alternativos del cambio gramatical. El reanálisis se considera como un mecanismo en el cual se encuentra la acomodación o generalización sistemática que es consustancial a la analogía, tal como indica Itkonen (2002: 418):

La analogía también juega un papel en el reanálisis. Una generalización importante se logra al mostrar que los dos componentes de la gramaticalización, esto es, el reanálisis y la extensión, implican la noción súpercoordinada de la analogía ${ }^{37}$.

37 Texto original en inglés "Analogy plays a role in reanálisis as well. A significant generalization is achieved by showing that both components of grammaticalization, i.e. reanalysis and extension, involve the superordinate notion of analogy". 
Morfología contrastiva del chino mandarín y el español. Formas de gramaticalización y lexicalización

Así pues, en la actualización del reanálisis se producen los cambios analógicos. Ambos mecanismos se dan como diferentes facetas de un mismo proceso: la actualización de virtualidades sistemáticas en nuevos enunciados. Más concretamente, en opinión de Cifuentes Honrubia, la analogía puede ser concebida como un ejemplo de la capacidad cognitiva adoptadora del ser humano, que puede vincular cognitivamente los principales mecanismos del cambio lingüístico. El autor (2003: 41-43) indica que la analogía se relaciona con la explicación funcional de la prototipicidad como un rasgo estructural de la lengua. Lo prototípico reside en categorías conceptuales que funcionan como esquemas interpretativos de la realidad. La analogía crea nuevos paradigmas a partir de otros ya existentes.

\subsection{Lexicalización}

\subsubsection{Principales definiciones}

Según lo señalado anteriormente, la unidireccionalidad constituye una de las hipótesis más frecuentemente asociadas a la teoría de la gramaticalización. Sin embargo, existe la posibilidad de que una forma gramaticalizada experimente un proceso evolutivo por medio del cual vuelva a formar parte de una categoría superior. Este proceso, como se explicará a continuación, queda fuera de la gramaticalización, de manera que la hipótesis de la irreversibilidad de los procesos de gramaticalización no se ve afectada.

En efecto, algunos trabajos sobre gramaticalización reúnen contraejemplos a la tesis de la unidireccionalidad y niegan que estos casos sean productos insignificantes $O$ de un análisis inadecuado. Estos trabajos apuntan a procesos tales como la lexicalización, la desclitización o la regramaticalización (Fischer, Rosenbaum y Stein 2000; Hopper y Traugott 1993; Janda 2001: 291; Traugott y Heine 1991b: 6-7; Wischer y Diewald 2002). 
Concretamente, los problemas que plantean estos procesos obedecen a la falta de delimitación del concepto de gramaticalización y a la observación de que los cambios del significado gramatical no se ajustan totalmente a la unidireccionalidad. La mayoría de los contraejemplos aducidos responden a casos de lexicalización, dado que este proceso trata de la formación de unidades léxicas a partir de formas gramaticales y se caracteriza por presentar cadenas (o clines) inversas a las de la gramaticalización.

Este proceso inverso que constituye la lexicalización se manifiesta en la transferencia de información desde una dimensión sintagmática (la combinación de palabras) a otra dimensión paradigmática (un único elemento léxico). Según la definición de Bosque (1982) y Blasco Mateo (2002: 36-37), por una parte, el término lexicalización, en sentido amplio, es sinónimo de fosilización y, como tal, designa el fenómeno lingüístico que interviene, por ejemplo, en la composición de unidades léxicas o en la formación de acrónimos a partir de siglas. Por otra parte, en sentido estricto, el término lexicalización designa el fenómeno lingüístico por el cual ciertas unidades gramaticales se convierten en unidades léxicas con valor referencial, o bien el proceso lingüístico por el cual determinadas formas léxicas adquiere un significado más referencial del que presentaban originariamente. Por tanto, en ese último sentido, la lexicalización avanza desde el plano gramatical hasta el plano léxico o bien tiene lugar en un plano puramente léxico, desde ciertas unidades simples a otras complejas.

En la actualidad, los estudios que han utilizado el término lexicalización no han llegado a un acuerdo sobre su definición. La disparidad se debe, sobre todo, al empleo de este término con significados bien distintos. De hecho, Brinton (2000) y Brinton y Traugott (2005) clasifican las definiciones según los diferentes significados, que Buenafuentes (2007: 32-34) resume a continuación:

1) La lexicalización se caracteriza por ser un mecanismo de crecimiento del léxico. En ocasiones, equivale a los procesos de formación de palabras o de creación léxica. 
Morfología contrastiva del chino mandarín y el español. Formas de gramaticalización y lexicalización

2) Aunque la lexicalización se entiende como un proceso de fosilización o institucionalización, según la denominación de Lyons (1977) y Baver (1983)38, sigue manteniendo la capacidad de crear nuevas palabras. Es decir, la productividad es un índice claro de la culminación de la lexicalización.

3) La lexicalización es la transformación de una construcción sintáctica en un lexema o la conversión de un morfema (afijo derivativo) en lexema. Por ejemplo, Blasco Mateo (2002: 35-38, 63) distingue dos tipos de lexicalización en función del punto de partida hacia el plano léxico: el tipo morfológico y el sintáctico. En el plano morfológico, el caso sería el de los afijos que pierden la significación que les es pertinente para formar una palabra indivisible con el lexema al que se adjuntan. Por ejemplo, los sufijos -illo y -ón, en palabras como bolsillo o sillón, han perdido su valor diminutivo o aumentativo prototípico. En el plano sintáctico, se trata de determinados sintagmas y oraciones que sirven de base a la lexicalización. Tal como afirman Brinton y Traugott (2005: 48), "one of the commonest conception of lexicalization is the unification or univerbation, of a syntactic phrase or construction into a single word". Ejemplos de este tipo son los compuestos estructurados 'verbo + nombre' (cuentagotas, lavaplatos) y aquellos cuya estructura parte de una oración (nomeolvides, metomentodo).

\footnotetext{
38 Según Contreras (2004: 48-49), existen acepciones de la lexicalización en que se asume que se trata de un proceso que amalgama varios elementos. Por ejemplo, a partir de Lyons (1977) y Leech (1977), se concibe la lexicalización como un proceso más restrictivo que comprende únicamente la especialización semántica del complejo lexicalizado. Además, la lexicalización, entendida en los términos propuestos estos mismos autores, se denomina institucionalización en Baver (1983), mientras que el concepto lexicalización acuñado por este autor alude a la creación de nuevos lexemas y se corresponde con el concepto de fosilización de Lyons (1977: 547). Para un estudio pormenorizado de la complicada trama conceptual ligada a este fenómeno puede resultar útil consultar a Lipka (1992), Corpas (1996: §2), entre otros autores.
} 


\subsubsection{La cuestión de la direccionalidad}

Tanto los procesos que conducen del ámbito léxico al gramatical (gramaticalización) como los que parten del ámbito gramatical para desembocar en el léxico (lexicalización) forman parte del cambio lingüístico. Sin embargo, parece que estas dos líneas evolutivas suponen procesos distintivos cuyo único punto de unión es la implicación del significado gramatical. De hecho, está claro que no puede identificarse la lexicalización con la gramaticalización.

Ahora bien, como se ha definido que la lexicalización es un proceso lexicotélico (Moreno Cabrera 1998: 218), a través del cual se obtienen unidades léxicas a partir de unidades sintácticas, parece lógico que la mayoría de los contraejemplos a la unidireccionalidad de la gramaticalización se concreten en procesos de lexicalización. Sin embargo, en opinión de Garachana (1997), el fenómeno de la lexicalización es mucho más complejo de lo que parece, dado que la formación de elementos léxicos no necesariamente debe partir de una forma gramatical, sino que puede recaer sobre otros elementos como los sintagmas o incluso las siglas (DNI, AVE, ONU, etc.). De ahí que la lexicalización no pueda considerarse como un contraejemplo a la hipótesis de la unidireccionalidad, pues queda fuera del área de la gramaticalización, que se caracteriza por ser una evolución hacia posiciones gramaticales.

En efecto, para Cifuentes Honrubia (2003: 51), la lexicalización no contradice la hipótesis de la unidireccionalidad como característica distintiva de la gramaticalización, sino que forma parte de los mecanismos de formación de palabras o de condicionantes sintácticos particulares. Así pues, se puede afirmar que la evolución del significado presenta dos facetas diferenciadas, la gramaticalización y la lexicalización, y que estos dos procesos no se contradicen entre sí. 
Morfología contrastiva del chino mandarín y el español. Formas de gramaticalización y lexicalización

Moreno Cabrera (1998) señala que la direccionalidad no solo afectaría a la gramaticalización, sino que sería un principio relevante para explicar la evolución lingüística. En este sentido, el autor plantea que tanto la gramaticalización como la lexicalización se consideran procesos irreversibles y que la evolución de las lenguas es bidireccional, pues resulta una característica constante del cambio lingüístico tanto el movimiento del léxico a la sintaxis como el de la sintaxis al léxico. Un ejemplo de la bidireccionalidad de la evolución lingüística se manifiesta en el caso de los compuestos cultos que crean una segunda generación de compuestos. Algunos elementos como foto- 'luz' o tele- 'lejos' se lexicalizan a partir de su acortamiento (la foto, la tele) e intervienen en la formación de una segunda generación compositiva (fotomontaje, telebasura) donde se vuelve a gramaticalizar, dado que se convierten en elementos compositivos.

Más concretamente, Moreno Cabrera (1998: 223) señala que la lexicalización debe ser entendida como un proceso complementario que produce interacciones en los resultados de la evolución lingüística. Señala el autor que la lexicalización y la gramaticalización son dos fenómenos que no solo tienen direcciones opuestas, sino que ambos interactúan en algunos casos de la evolución lingüística:

Vemos de nuevo que existe una fuerte tendencia a los procesos de gramaticalización, de modo que existe una estrecha interacción entre ambos procedimientos. Esta interacción es crucial para tener una mejor comprensión de la dinámica evolutiva de los elementos léxicos y gramaticales ${ }^{39}$.

Un ejemplo de la interacción entre lexicalización y gramaticalización en la evolución lingüística vuelve a ser el caso de los compuestos constituidos por elementos grecolatinos. Según Buenafuentes (2007: 43), el elemento auto'por sí mismo' se concibe como un verdadero afijo tras sufrir un proceso de

\footnotetext{
39 Texto original en inglés "We see again a strong tendency exists for grammaticalization processes, and that there is a close interaction between both procedures. This interaction is crucial for having a better understanding of the evolutionary dynamics of lexical and grammatical elements".
} 
gramaticalización (autobiografía, autorretrato, automóvil). Sin embargo, la forma reducida auto- experimenta también la lexicalización cuando representa el significado de 'automóvil'. Pero interviene de nuevo, con este último sentido en una segunda serie de compuestos, como autopista, autoescuela, etc., en que auto- pierde el significado abstracto de su origen y se concreta en la designación de un objeto (el automóvil).

De acuerdo con lo señalado anteriormente, se puede afirmar que la lexicalización no se considera una excepción a la unidireccionalidad de los fenómenos gramaticalizados, ya que se trata de un mecanismo de creación léxica y de un proceso complementario que interactúa con la gramaticalización en el ámbito de la evolución lingüística.

Ahora bien, los casos que verdaderamente constituyen contraejemplos a la hipótesis de la unidireccionalidad son los cambios lingüísticos de sentido inverso a la gramaticalización tradicional. En este sentido, se deben citar los fenómenos que suponen una evolución hacia posiciones de derecha a izquierda en el continuo de la gramaticalización. A continuación se presentan los procesos de desgramaticalización/desclitización y regramaticalización que operan en el terreno del cambio lingüístico y que suceden en dominios y niveles diferentes.

\subsubsection{Desclitización}

Hasta el momento, según lo señalado, la lexicalización no se identifica con contraejemplos a la hipótesis de la unidireccionalidad, ya que se ha presentado como un proceso que tiene un recorrido simétrico respecto al de la gramaticalización. Ahora bien, según la opinión de Garachana (1997: 178-179), los contraejemplos a la unidireccionalidad se pueden concretar en los procesos como desclitización. En efecto, esta última evolución no se puede explicar como un caso de lexicalización, pues no supone una transformación 
Morfología contrastiva del chino mandarín y el español. Formas de gramaticalización y lexicalización

hacia categorías superiores y además los resultados de esta desclitización adquieren una independencia sintáctica que contrasta con la pérdida de autonomía en los procesos de gramaticalización.

Garachana (1997: 183) indica que la desclitización es el cambio de una unidad dependiente del acento de intensidad de otra hasta constituirse en una palabra independiente. Este proceso supone un contraejemplo a la noción de unidireccionalidad, tanto en el plano sintáctico como en el fonológico, ya que se produce la adquisición de movilidad sintáctica y se consigue la autonomía prosódica. Algunos ejemplos de este proceso de desclitización, según esta autora, son ciertos marcadores discursivos (sin embargo, no obstante), pues estos ganan autonomía fonológica y adquieren mayor movilidad sintáctica en un momento concreto de su evolución ${ }^{40}$.

Sin embargo, las implicaciones teóricas de la desclitización no están exentas de problemas, pues para estos marcadores discursivos, el resultado semántico de la evolución es un significado gramatical y la categoría resultante es una forma gramatical. Además, hay una fijación de los elementos que conforman el sintagma de partida. Por consiguiente, no parece adecuado excluir la desclitización de la gramaticalización, aun cuando en ciertos aspectos rompan con la unidireccionalidad sintáctica o fonológica característica de aquella. Por ello, en opinión de Garachana (1997: 191-193), la unidireccionalidad no ha de entenderse de forma absoluta, sino que se considera como el factor más prototípico de los procesos de gramaticalización. En este sentido, los casos de desclitización no constituyen excepciones a la hipótesis de la unidireccionalidad, sino que se sitúan en áreas menos representativas de los procesos de gramaticalización, ya que se ha desarrollado un significado gramatical.

\footnotetext{
40 En opinión de Hopper y Traugott (1993) y Traugott (1995a, 1995b), la gramaticalización de elementos temporales, aspectuales, modales o causales tiende a seguir el esquema de la unidireccionalidad, mientras que otros elementos, como los conectores, no siempre se adaptan a la unidireccionalidad. Sobre ejemplos de español y japonés, véase Garachana (1997: 184-186).
} 


\subsubsection{Desgramaticalización}

Se utiliza el término desgramaticalización, acuñado por Lehmann (1982), para describir los cambios inversos a la unidireccionalidad de la gramaticalización y para presentar las formas que adquieren una mayor autonomía e independencia en la estructura sintáctica, que apoyan la existencia de desclitización,

Según Company Company (2004b: 32), los fenómenos de desgramaticalización suelen causar una amplia polémica por su comportamiento huidizo y no se etiquetan fácilmente en una tipología de los cambios sintáctico-semánticos. La autora describe las diferentes posturas teóricas, que van desde ignorar su existencia hasta considerar estos fenómenos como casos de una gramaticalización tradicional:

1) Ignorar la existencia de la desgramaticalización o reducir sus efectos en la diacronía de las lenguas.

2) Aceptar que es un cambio posible y que la evolución de la lengua se mueve tanto en la gramaticalización como en la desgramaticalización, si bien se reconoce que la segunda es mucho menos frecuente.

3) Defender que los cambios que muestran esta direccionalidad inversa son peculiares y que se sustraen a algunas de las características de los procesos de gramaticalización.

4) Sostener que no es un proceso específico distinto de la gramaticalización, sino que difiere de esta en cuanto que pone el énfasis en el resultado del cambio.

Company Company (2004b: 29-66) se sitúa entre los lingüistas que defienden el tercer criterio. Menciona los marcadores discursivos formados a partir de verbos como ejemplos de una transformación simultánea a que son sometidos por los efectos de la gramaticalización y la desgramaticalización. En esta evolución, se advierte un debilitamiento del significado referencial 
Morfología contrastiva del chino mandarín y el español. Formas de gramaticalización y lexicalización

etimológico, un debilitamiento del control agentivo del sujeto, determinados cambios metafóricos y metonímicos y una pérdida de capacidad sintáctica. Las nuevas formas deverbales (andar > janda!) ilustran el proceso diacrónico de subjetivización del verbo a marcador discursivo, pues estos últimos adquieren emancipación sintáctica y autonomía, características acordes con la desgramaticalización.

Cifuentes Honrubia (2003: 53), por otro lado, se sitúa en la última postura con Nord, pues considera que la desgramaticalizción no es exactamente la imagen inversa del proceso de gramaticalización y tampoco puede ser una inversión completa de un continuo de gramaticalización. Para Nord (2001: 238), los cambios contra-direccionales no son contraejemplos a la gramaticalización, sino que se trata de otro tipo de cambio lingüístico menos común. Los cambios por desgramaticalización se deben distinguir de los cambios por gramaticalización, ya que los primeros son cambios graduales, como de clítico a partícula o de afijo a clítico (Nord 2001: 247-256; 2002: 49), mientras que en los cambios por gramaticalización el cambio gradual no es necesariamente unidireccional.

Para Haspelmath (2002), aunque constan ejemplos de desgramaticalización en la bibliografía, la mayoría de ellos no forma excepciones verdaderas respecto al proceso de gramaticalización, ya que el fenómeno de la desgramaticalización es de índole heterogénea y parece útil identificar subclases de desgramaticalización. En palabras de Nord (201 1: 477), la diferencia entre la gramaticalización y desgramaticalización es la siguiente:

La gramaticalización implica el desgaste semántico, mientras que la desgramaticalización puede implicar el fortalecimiento semántico. La gramaticalización implica la fijación sintáctica o la coalescencia morfológica, mientras que la desgramaticalización implica un aumento de la libertad sintáctica ${ }^{41}$.

\footnotetext{
${ }^{41}$ Texto original en inglés: "Grammaticalization involves semantic attrition, degrammaticalization may involve semantic strengthening, or where grammaticalization inviles syntactic fixation or morphological coalescence, degrammaticalization involves an increase in syntactic freedom".
} 
Por lo tanto, Haspelmath introduce el término antigramaticalización para dar cuenta de este proceso inverso al de la gramaticalización y destacar la existencia de fases intermedias. Haspelmath (2002: 28-29) ejemplifica con la evolución de una desinencia casual al lexema posposicional la existencia de la fase intermedia:

Con esto (antigramaticalización), me refiero a un cambio que va desde el extremo hasta el punto de partida de una gramaticalización potencial y también muestra las mismas etapas intermedias. Por ejemplo, un cambio de un sufijo de caso a una posposición libre con la etapa intermedia de un clítico posposicional sería una antigramaticalización [...]. Mi término antigramaticalización se destina a cubrir cualquier tipo de cambio que va en contra de la dirección general de la gramaticalización (es decir, discurso > sintaxis $>$ morfología) ${ }^{42}$.

Según Brinton y Traugott (2005: 104), los ejemplos de antigramaticalización son relativamente escasos frente a los de gramaticalización. La reversibilidad de la gramaticalización debe referirse a los cambios de formas menos gramaticales a las más gramaticales. El siguiente esquema ilustra las relaciones entre estos conceptos:

antilexicalización

\begin{tabular}{|c|c|c|c|c|}
\hline menos léxico & \multicolumn{4}{|c|}{ más léxico } \\
\hline (L1) sintagmas fijos & compuestos & $\overrightarrow{\text { formas derivadas }}$ & simples (L3) & \\
\hline $\begin{array}{c}\text { (G1)construcciones } \\
\text { gramaticales } \\
\text { menos gramatical }\end{array}$ & palabras funcionales & clíticos & $\begin{array}{l}\text { flexiones } \\
\text { tatical }\end{array}$ & (G3) \\
\hline
\end{tabular}

antigramaticalizacion

Tabla 2: Esquema de los fenómenos de antilexicalización y antigramaticalización

${ }^{42}$ Texto original en inglés: "By this (antigramaticalización) I mean a change that leads from the endpoint to the starting point of a potential grammaticalization and also shows the same intermediate stages. For instance, a change from a case suffix to a free postposition with the intermediate stage of a postpositional clitic would be an antigrammaticalization [...] My term antigrammaticalization is intended to cover any type of change that goes against the general direction of grammaticalization (i.e. discourse > sayntax > morphology)". 
Morfología contrastiva del chino mandarín y el español. Formas de gramaticalización y lexicalización

El esquema muestra que el resultado de los cambios de antigramaticalización es un movimiento de función gramatical que parte del nivel superior al inferior, se produce una creciente autonomía y se disminuye la productividad. En palabras de los autores:

Este tipo de cambio da como resultado una mayor autonomía de la forma y una disminución de productividad (de totalmente a semi-productivo). Esto es [...], el movimiento de un mayor a un menor grado de función gramatical. Los ejemplos de antigramaticalización son relativamente escasos, ya que incluyen cambios de la inflexión a clítico [...] y ejemplos infrecuentes de 'desclitización', o los cambios de clítico a palabra independiente ${ }^{43}$.

\subsubsection{Implicaciones semánticas de la lexicalización}

Tanto la gramaticalización como la lexicalización son mecanismos del cambio lingüístico que implican un cambio de significado. Este cambio semántico se puede explicar a partir de procesos de tipo metafórico o metonímico. Según se ha señalado en el apartado anterior, bastantes investigaciones ponen de manifiesto las relaciones entre la teoría de la gramaticalización y los procesos metafóricos y metonímicos. Sin embargo, parece que quedan marginados los estudios que implican a la metáfora y la metonimia como procesos imprescindibles del cambio semántico que se manifiesta en la lexicalización.

El trabajo de Moreno Cabrera (1998: 216) tiene en cuenta las evidentes relaciones entre lexicalización y metonimia. De acuerdo con Heine, Claudi y Hünnemeyer (1991a), afirma que "If the grammaticalization hierarchy tries to account for metaphorical abstraction process, the lexicalization hierarchy

\footnotetext{
43 Texto original en inglés "This type of change results in increased autonomy of the form and often decreased productivity (from fully to semi-productive). This is [...] movement from a higher to a lower degree of grammatical function. Examples of antigrammaticalization are relatively rare; they include shifts from inflection to clitic [...] and infrequent examples of 'declitization', or shifts from clitic to independent word".
} 
reflects metonymical concretion process". Es decir, si el proceso de gramaticalización se define por una abstracción de carácter metafórico, la lexicalización refleja un proceso de concreción de carácter metonímico. De este modo, el cambio semántico que implica una lexicalización se caracteriza por la contigüidad que se manifiesta a partir de la metonimia. Por consiguiente, el autor propone una jerarquía inversa de concreción metonímica (Metonymical Concretion Hierarchy) a la de la gramaticalización, en la que la unidad léxica va adquiriendo los valores que aparecen a la derecha. La jerarquía se representa del siguiente modo (Moreno Cabrera 1998: 218):

Quality > time > space > process > object > person

Posteriormente, Buenafuentes (2007: 70-71) opina que ni la metonimia se restringe a la lexicalización ni la metáfora solo se produce en los procesos de gramaticalización. La autora indica que tanto la metáfora como la metonimia se pueden dar en la gramaticalización y en la lexicalización, puesto que ambos recursos entran del mismo modo a formar parte de los cambios semánticos que conlleva una lexicalización. Se ejemplifica este cambio con los compuestos léxicos que proceden de la síntesis de una estructura oracional para demostrar el proceso metonímico que convierte un verbo en un sustantivo que designa 'objeto' o 'persona'. Este es el proceso que manifiestan todas las metonimias denominadas "la parte por el todo":

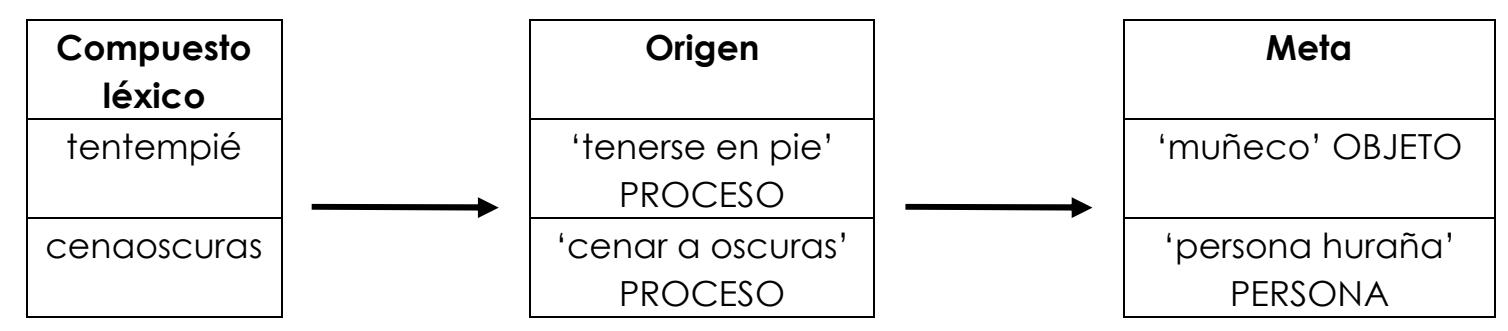

Tabla 3: Proceso de las metonimias de "la parte por el todo" 


\subsection{Relaciones entre gramaticalización y lexicalización}

Se entiende generalmente que la lexicalización y la gramaticalización son procesos diacrónicos que comparten algunos efectos como la fijación gramatical de los elementos afectados, la pérdida o modificación de su significado primigenio o su recategorización. Sin embargo, se trata también de procesos que actúan de forma direccionalmente distinta, pues favorecen a componentes lingüísticos distintos. En palabras de Contreras (2004: 60), la lexicalización parte de la sintaxis o de la morfología y concluye en el léxico, mientras que la gramaticalización afecta a piezas léxicas o a sintagmas que pierden parte de su contenido semántico y de sus características distintivas (referencia, estructura argumental, subcategorización, etc.) para adquirir funciones más relacionales llegando en el caso extremo a convertirse en categorías funcionales.

Para Varela (2005b: 1133), la gramaticalización es un proceso por el que una unidad sintácticamente independiente adquiere una función gramatical y llega a veces hasta a perder su independencia formal y a convertirse en parte de una palabra. La lexicalización, por su parte, es una operación léxica que entraña cambio o pérdida de rasgos gramaticales. Se considera una muestra de fosilización y se manifiesta, entre otros casos, en la fraseología, en los sintagmas fijos y en los constructos morfológicos desprovistos de motivación semántica.

Elvira (2006: 23-25), por otra parte, utiliza los conceptos de léxico y gramática para describir la relación entre gramaticalización y lexicalización. El autor indica que los conceptos de gramaticalización y lexicalización dependen en buena medida del sentido que apliquemos a las nociones de léxico y gramática, pues estos conceptos están explícitos en sus respectivas raíces morfológicas. El autor sitúa la oposición entre lo léxico y lo gramatical en dos perspectivas para describir su procedimiento: el domino semántico y el mecanismo mental en el que se producen las diferentes expresiones de la 
lengua. El contraste se manifiesta en el siguiente esquema:

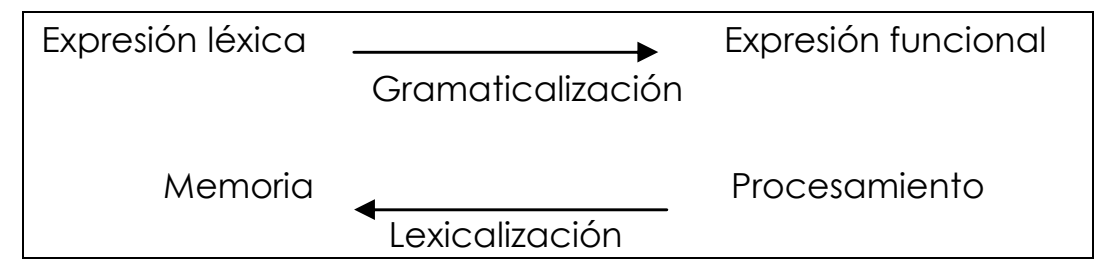

Tabla 4: Contraste entre gramaticalización y lexicalización

Según el esquema, los conceptos de gramaticalización y lexicalización no son en principio contrapuestos, pues están definidos en niveles o dominios conceptuales diferentes. La gramaticalización se sitúa en un nivel o dominio semántico y se interpreta como el proceso por el que un elemento con valor o significado léxico adquiere valor gramatical o funcional. Por lo tanto, la gramaticalización se identifica con una funcionalización. Por otro lado, el concepto de lexicalización no se sitúa en el dominio semántico, sino en el de los mecanismos de producción de expresiones y hace referencia a un cambio en el procedimiento que hace posible la existencia de una expresión. Más en concreto, la lexicalización es el proceso por el cual una expresión, que previamente se obtenía o recibía por medios gramaticales o analíticos, se archiva como un bloque en la memoria o diccionario mental y se utiliza de manera global sin necesidad de análisis previo.

Sin embargo, más que fenómenos opuestos, la relación entre los procesos de gramaticalización y lexicalización puede entenderse como complementaria. Como señala Moreno Cabrera (1998: 224), la evolución de las lenguas es bidireccional y la direccionalidad afecta tanto a la gramaticalización como a la lexicalización. Por lo tanto, la lexicalización se manifiesta como un proceso complementario a los procesos de gramaticalización, y como parte del cambio lingüístico presenta similitudes con la gramaticalización.

Wischer (2000: 364) también apoya la idea de que estos dos procesos son fenómenos paralelos que operan en el mismo terreno del cambio lingüístico, pero suceden en dominios o niveles diferentes: "it becomes obvious 
Morfología contrastiva del chino mandarín y el español. Formas de gramaticalización y lexicalización

that lexicalization and grammaticalization are not all contradictory process. They show come similarities, but operate on different levels of the language". Con el siguiente esquema se ilustra el paralelismo entre gramaticalización y lexicalización y su aplicación en distintos niveles lingüísticos ${ }^{44}$ :

\begin{tabular}{|l|l|}
\hline \multicolumn{1}{|c|}{ Lexicalización } & \multicolumn{1}{c|}{ Gramaticalización } \\
\hline $\begin{array}{l}\text { - un sintagma se convierte } \\
\text { en un nuevo elemento } \\
\text { léxico (nomeolvides) }\end{array}$ & $\begin{array}{l}\text { - un sintagma se convierte en un nuevo elemento } \\
\text { gramatical (ir a + infinitivo 'futuro') }\end{array}$ \\
\hline & $\begin{array}{l}\text { - un elemento léxico se convierte en un elemento } \\
\text { gramatical (haber como auxiliar) }\end{array}$ \\
\hline $\begin{array}{l}\text { - un lexema se hace más } \\
\text { léxico (esposos) }\end{array}$ & $\begin{array}{l}\text { - un elemento gramatical se hace más gramatical } \\
\text { (formación del futuro romance: decir lo hé > lo diré) }\end{array}$ \\
\hline
\end{tabular}

Tabla 5: Paralelismo entre lexicalización y gramaticalización

Respecto a las similitudes que comparten la lexicalización y la gramaticalización, desde el punto de vista formal, se ve que ambos procesos producen repercusiones parecidas en la pérdida de sustancia fónica o la fusión de elementos. De hecho, Wischer (2000: 365) indica lo siguiente:

Ambos procesos, la gramaticalización y la lexicalización, se acompañan de mecanismos sintácticos y fonéticos muy similares: la reducción fonética gradual, reanálisis sintáctico, la desmotivación, la fosilización, y la convencionalización ${ }^{45}$.

En relación con las diferencias, aunque la lexicalización y la gramaticalización forman un paralelismo de cambios graduales, el resultado en uno y otro proceso es diferente. En la lexicalización el resultado de los

\footnotetext{
44 Aquí se presenta el esquema y los ejemplos traducidos al español de Buenafuentes (2007: 42). Para la versión original de inglés véase Wischer (2000: 364).

45 Texto original en inglés "Both processes, grammaticalization and lexicalization, are accompanied by very similar syntactic and phonetic mechanisms: gradual phonetic reduction, syntactic reanalysis, demotivation, fossilization, and conventionalization".
} 
cambios siempre desemboca en el léxico y es de forma más abrupta debido al resultado del cambio semántico, tal como señala Wischer (2000: 364):

La gramaticalización y la lexicalización son acompañados por mecanismos sintácticos y fonéticos muy similares [...]. Los cambios semánticos, sin embargo, son diferentes: Cuando una colocación libre o una formación de palabras ordinaria se lexicaliza, se integra un componente semántico específico, de modo que el significado léxico nuevo difiere del significado de la composición anterior. Ambos están relacionados entre sí en un sentido metafórico o metonímico. Cuando un término lingüístico está gramaticalizado, se pierden los componentes semánticos específicos y se inserta un significado implícito categórico $u$ operacional ${ }^{46}$.

Así, las expresiones lexicalizadas tienen un significado que no se deduce necesariamente de la combinación de sus partes, y puede que los principios gramaticales que dan origen a la expresión retrocedan o desaparezcan. Del mismo modo, la regla o la categoría gramatical originaria pierde vigencia y, por consiguiente, se producen una fosilización, que a su vez provoca una constante irregularidad entre las expresiones lexicalizadas.

Del mismo modo, Varela (2005b: 1134) indica que la principal diferencia entre ambos procesos está en que la lexicalización produce un aumento de la 'irregularidad'. Con el factor de 'irregularidad', ambos procesos discurren en sentido contrario. La lexicalización sustrae unidades a la gramática y las incluye en el léxico, con lo cual se produce un aumento de la irregularidad y las unidades en cuestión han de ser listadas. En la gramaticalización, por el contrario, ciertos elementos quedan sometidos a la gramática y la irregularidad disminuye.

Para establecer las semejanzas y diferencias entre la gramaticalización y la lexicalización, Brinton y Traugott (2005: 110) resumen los paralelismos en la siguiente tabla:

\footnotetext{
46 Texto original en inglés "Grammaticalization and lexicalization are accompanied by very similar syntactic and phonetic mecanisms [...]. The semantic changes, however, differ: When a free collocation or an ordinary word formation is lexicalized, a specific semantic component is added, so that the new lexical meaning differs from the former compositional meaning. Both are related to each other in a metaphorical or metonymical sense. When a linguistic term is grammaticalized, specific semantic components get lost and an implied categorical or operational meaning is fore grounded".
} 


\begin{tabular}{|c|c|c|}
\hline & Lexicalización & Gramaticalización \\
\hline Gradualidad & + & + \\
\hline Unidireccionalidad & + & + \\
\hline Fusión & + & + \\
\hline Coalescencia & + & + \\
\hline Idiomaticidad & + & + \\
\hline Metáfora/Metonimia & + & + \\
\hline Descategorización & - & + \\
\hline Debilitamiento semántico & - & + \\
\hline Subjetividad & - & + \\
\hline Productividad & - & + \\
\hline Frecuencia & - & + \\
\hline Generalidad tipológica & - & + \\
\hline
\end{tabular}

Tabla 6: Paralelismo entre lexicalización y gramaticalización

Según se observa en la tabla, la lexicalización está menos obligada que la gramaticalización a asumir varios tipos de procesos lingüísticos. La respuesta para la cuestión de por qué la gramaticalización es tan sistemática reside en los mismos ítems (o resultados) gramaticales. En realidad, los ítems gramaticales son marcadores esquemáticos altamente abstractos, cuya función principal es representar la perspectiva del hablante. Del mismo modo, el ítem léxico ha de situarse en una posición relativamente no-específica en el contexto antes de que se incorpore a una función gramatical esquemática y abstracta.

\subsection{Resumen y conclusiones}

Según la definición clásica, la gramaticalización se interpreta como la evolución de una forma lingüística que pierde su contenido léxico o conceptual y adquiere un contenido gramatical 0 funcional. Los estructuralistas definen la gramaticalización de forma común: una forma léxica adquiere una función gramatical, o bien, una forma ya gramatical adquiere un significado aún más gramatical. Más tarde, se establece una conexión entre 
las teorías generalistas y la gramaticalización. Así, en la década de los sesenta se publican trabajos de los universales lingüísticos y la tipología lingüística relacionados con el proceso de la gramaticalización. A partir de la perspectiva sintáctica, se aplica el enfoque pragmático-cognitivo al estudio de la gramaticalización, de manera que este fenómeno adquiere una definición diferente a la tradicional, pues los cambios lingüísticos pueden derivar en resultados diferentes a la pérdida del contenido léxico y la adquisición de significado gramatical según las implicaciones semánticas del proceso. En la misma línea, en la década de los ochenta, las perspectivas que se adoptan están vinculadas al marco pragmático-cognitivo. De hecho, las implicaciones semánticas como la generalización, los fenómenos metafóricos y metonímicos se desarrollan en el marco de gramaticalización.

En los estudios recientes, la caracterización que se propone de la gramaticalización pone de manifiesto que este tipo de proceso se desarrolla en cadenas (o clines) que recorren desde el estadio más referencial hacia el más gramatical. Este fenómeno unidireccional constituye una hipótesis frecuente que se caracteriza por la irreversibilidad y la recategorización. Por la irreversibilidad, las formas gramaticalizadas presentan ciertos caracteres icónicos: una mayor fijación, una mayor frecuencia de uso, un menor coste fonético y una mayor regularidad formal. Por la recategorización, una unidad lingüística se transforma desde una categoría gramatical mayor hasta formar parte de una categoría menor.

Por otro lado, el reanálisis y la analogía son mecanismos cognitivos determinantes de la gramaticalización. Mientras que el reanálisis supone la descategorización de los términos gramaticalizados, la analogía crea nuevos paradigmas a partir de unidades lingüísticas ya existentes. En este sentido, ambos mecanismos se dan como diferentes facetas de un mismo proceso, pues en la actualización del reanálisis se producen los cambios analógicos. 
Morfología contrastiva del chino mandarín y el español. Formas de gramaticalización y lexicalización

Los procesos de lexicalización se definen como fenómenos lingüísticos que tratan de la formación de unidades léxicas a partir de formas gramaticales y se caracterizan por presentar cadenas inversas a las de la gramaticalización. En sentido amplio, la lexicalización es sinónimo de fosilización, por la cual ciertas unidades gramaticales se convierten en unidades léxicas con valor referencial. Así, la formación de palabras compuestas se considera un proceso de lexicalización, puesto que este cambio lingüístico avanza desde el plano gramatical hasta el plano léxico, es decir, desde ciertas unidades simples a otras complejas.

La lexicalización no se considera una excepción a la unidireccionalidad de los fenómenos gramaticalizados, ya que se trata de un mecanismo de creación léxica y de un proceso complementario que interactúa con la gramaticalización en el ámbito de la evolución lingüística. Por lo tanto, se puede afirmar que la evolución de las lenguas es bidireccional, pues recorre tanto el movimiento del léxico a la sintaxis como el de la sintaxis al léxico.

Pese a la actuación de forma direccionalmente distinta, se entiende por lo común que la lexicalización y la gramaticalización son procesos diacrónicos que comparten algunos efectos, como la fijación gramatical de los elementos afectados, la pérdida o modificación de su significado primitivo o su recategorización. También se asume que ambos procesos producen repercusiones parecidas en la pérdida de sustancia fónica o la fusión de elementos. La principal diferencia reside en que la lexicalización sustrae unidades a la gramática y las incluye en el léxico, con lo cual se produce un aumento de la irregularidad. En la gramaticalización, en cambio, ciertos elementos quedan sometidos a la gramática y la irregularidad disminuye. 
Formantes gramaticalizados y lexicalizados en la morfología del chino mandarín y el español

En este capítulo se analiza la incidencia de los procesos de gramaticalización y lexicalización en las formaciones morfológicas de las dos lenguas contrastadas, ya sea en los aspectos flexivos como en los derivativos $y$, sobre todo, en la fijación de compuestos léxicos. Por otra parte, se pone de manifiesto que los fenómenos de la generalización, la fusión, el reanálisis, la analogía y la recategorización son factores imprescindibles que intervienen en la formación léxica de ambas lenguas. Por último, se comprueba que los compuestos de ambas lenguas pueden explicarse desde algunas perspectivas semántico-cognitivas próximas a la teoría de la integración y la fusión conceptual (Conceptual Blending).

\subsection{Gramaticalización en el componente morfológico}

\subsubsection{Gramaticalización en la morfología del español}

Los principales procesos de gramaticalización que pueden observarse en la morfología española se relacionan, en primer término, con el uso como prefijos de las mismas unidades léxicas que se comportan de forma autónoma como preposiciones. Además, la evolución del sustantivo latino mĕnte (m) al sufijo adverbial -mente también constituye un efecto de la gramaticalización que tuvo lugar entre el léxico latino y la formación de los sufijos españoles. 
Morfología contrastiva del chino mandarín y el español. Formas de gramaticalización y lexicalización

Finalmente, la mayoría de los temas cultos de origen grecolatino que intervienen muy productivamente en la formación de neologismos en español también pueden ser considerados como casos de gramaticalización, puesto que las formas autónomas de las lenguas originarias se transforman en formantes morfológicos del español.

Un rasgo destacado de algunos prefijos españoles es su origen en determinadas preposiciones independientes, tales como a, ante, bajo, con, contra, de, en, entre, para, por, sin, sobre, tras. Según Varela (1999: §76.2.1.1) y Almela (1999: 53-56), este tipo de prefijos convive con la preposición en la etapa actual del español. La identificación entre preposiciones y prefijos solo puede entenderse diacrónicamente. Formalmente estos prefijos coinciden con las preposiciones, pero las funciones gramaticales son diferentes en cada caso. Las preposiciones significan una subordinación nominal y relacionan dos términos carentes de puntos comunes entre sí, mientras que la prefijación, por su parte, no produce una combinación sintáctica esperable: en algunos casos, el prefijo asume funciones preposicionales (sobrevolar 'volar sobre'), pero en otros casos también adopta representaciones adverbiales (sobrealimentar 'alimentar excesivamente'). Además, como prefijos, pueden alternar con diferentes alomorfos (en-/in-, entre-/inter-, etc.), mientras que esta alternancia no consta para las preposiciones. En suma, la interpretación actual más generalizada consiste en distinguir entre las funciones preposicionales y estas prefijaciones, a pesar de la semejanza formal, y en considerar estas últimas formaciones como resultado de procesos derivativos y no compositivos.

Morfológicamente, esta evolución se presenta como un proceso de clitización (Hopper y Traugott 1993), pues la transformación se manifiesta entre una forma léxica independiente, como la preposición, a una forma clítica como es el prefijo. De hecho, se puede afirmar que estos prefijos experimentan el proceso de gramaticalización, dado que comprenden el recorrido desde su estadio más referencial hacia el más gramatical. 
Formantes gramaticalizados y lexicalizados en la morfología del chino mandarín y el 279 español

Estas transformaciones de preposiciones a prefijos se desarrollan en cadenas de gramaticalización. Según la jerarquía de abstracción metafórica esquematizada por Heine, Claudi y Hünnemeyer (1991a): persona > objeto > proceso > espacio > tiempo > cualidad, las preposiciones desarrollan sentidos más abstractos en el proceso de recategorización en elementos prefijales, pues recorren la escala de izquierda a derecha y van adquiriendo los nuevos significados a medida que se gramaticalizan. Por ejemplo, la noción espacial de la preposición entre es sustituida por el significado de calidad del prefijo entre- que se proyecta en la formación derivativa, de modo que la idea de abstracción se sitúa en el nivel morfológico. Así, entreacto, entrecejo, entrefino, etc., son formas derivadas constituidas por elementos gramaticalizados que se transforman desde un dominio cognitivo a otro dominio cognitivo diferente de índole más abstracta. A nuestro modo de ver, el origen de este fenómeno es la presión lingüistica para representar nociones complejas a partir de los componentes gramaticales o léxicos ya existentes.

Otro caso del cambio lingüístico hacia la gramaticalización es el formante adverbial-mente. El sufijo-mente deriva de una palabra autónoma, el sustantivo latino mente en ablativo femenino, que a partir de construcciones de sentido adverbial, del tipo claramente ('con mente clara'), se extendió contextualmente y se gramaticalizó hasta convertirse en un morfema afijal, con la pérdida de su categoría nominal plena. Esta generalización (Company 2003a: 14) hace que el formante -mente presente un incremento de funciones gramaticales y de productividad en el uso del signo, pues el sufijo-mente sirve para formar adverbios de modo a partir de adjetivos.

Los formantes de origen grecolatino, como bio-, dermo-, hiper-, meta-, extra- hidro-, electro-, crono-, logo-, morfo-, -voro, -logía, -grafía, -podo, etc., también presentan una transformación en cadenas de gramaticalización, pues los sustantivos o adjetivos con significado léxico originarios se identifican con las unidades morfológicas ligadas en la morfología española. De hecho, se pone de manifiesto que estos elementos grecolatinos presentan la evolución 
Morfología contrastiva del chino mandarín y el español. Formas de gramaticalización y lexicalización

hacia la gramaticalización, según el modelo general (Pérez Saldanya 1997), es decir, de categoría léxica mayor a categoría léxica menor. Esta pérdida de la categoría gramatical originaria del elemento gramaticalizado constituye un desplazamiente sintáctico que pone de manifiesto la unidireccionalidad del proceso de gramaticalización.

Es evidente que los temas cultos adquieren una generalización del significado a través del proceso de gramaticalización, lo que explica su polisemia en las formaciones complejas. Por ejemplo, super- presenta varias denotaciones en distintas combinaciones, como 'encima de' en superestructura, 'excelencia' en superdotado, 'grado sumo' en superfino y 'exceso' en superproducción. Esta reducción semántica produce la polisemia del elemento gramaticalizado, de manera que se puede afirmar que en cualquier proceso de gramaticalización existe una interrelación entre el cambio semántico que experimenta la unidad lingüística que se gramaticaliza y las modificaciones que este cambio provoca en el sistema funcional de la lengua.

\subsubsection{Gramaticalización en la morfología del chino mandarín}

Los estudios de índole tipológica han demostrado que existe una tendencia universal (Heine 1993, 1997) de los morfemas libres a evolucionar hacia elementos clíticos o afijos. Así, los afijos convencionales de la lengua china pueden considerarse como elementos gramaticalizados, pues eran antiguas unidades léxicas que presentaban autonomía sintáctica y semántica en el chino clásico, pero en el uso actual estos elementos han sufrido la pérdida del contenido semántico y la adquisición de un valor gramatical. En nuestra opinión, se pueden distinguir tres tipos de gramaticalización según el significado semántico y la función gramatical que aportan los elementos gramaticalizados. 
Formantes gramaticalizados y lexicalizados en la morfología del chino mandarín y el 281 español

En primer lugar, los afijos que presentan significado semántico y función morfológica revelan un menor grado de gramaticalización, pues en la cadena de los procesos de gramaticalización propuesta por Givón (1979), discurso > sintaxis > morfología > morfonología > cero, este tipo de afijos se sitúa en la tercera escala correspondiente a la morfología, pues todavía desempeñan funciones morfológicas en las formaciones derivativas. Así, por ejemplo, el sufijo zi 子 en chino clásico significaba 'hijo', pero en la actualidad ha perdido este significado para convertirse en un sufijo que se pospone a determinados adjetivos de cualidad, especialmente negativa, a los que transforma en sustantivos que designan persona, como en shă zi 俊子 'tonto' 'suf.' $\rightarrow$ el tonto y fēng zi 瘋子 'loco' 'suf.' $\rightarrow$ el loco. Además, cuando se pospone a verbos suele designar el agente, como en piàn zi 騙子 'mentir' 'suf.' $\rightarrow$ el mentiroso. Se trata, por tanto, de la gramaticalización de un antiguo sustantivo que en la actualidad forma parte de los sufijos convencionales nominalizadores.

En segundo lugar, otros afijos convencionales, como lăo 老 'viejo', xiăo 小 'pequeño', zi 子 'hijo' y ér 兒 'hijo' expresan sentidos afectivos en determinadas formaciones, de manera que pueden definirse como elementos gramaticalizados, pero en un grado algo más elevado que el caso anterior, aunque todavía en el nivel morfológico. Estos afijos pierden su significado léxico originario y, sin embargo, no alteran la categoría gramatical de la base, pues su función morfológica se reduce a una extensión metafórica al ámbito afectivo. Por ejemplo, el prefijo xiăo 小 'pequeño', cuando desempeña funciones expresivas, añade el valor de familiaridad, como en xiăo zhāng 小張 'pref.' 'apellido' $\rightarrow$ (el amigo) Zhang, o el de atenuación o cortesía, como en xiǎo qinng qiú 小請求 'pref.' 'petición' $\rightarrow$ (pequeño) favor. Se trata de la evolución unidireccional que siguen los cambios lingüísticos de lo concreto a lo abstracto. El mecanismo fundamental de este proceso es la metáfora, que se encarga de ampliar o desplazar significados desde un ámbito concreto (prototipo) hacia ámbitos más abstractos (extensiones). De modo parecido, lăo 老 'viejo', zi 子 'hijo' y ér 兒 'hijo' extienden sus significados a ámbitos que 
Morfología contrastiva del chino mandarín y el español. Formas de gramaticalización y lexicalización

dependen del nivel de afectividad, como se muestra en los siguientes ejemplos. Se trataría de procesos de gramaticalización motivados desde la pragmática o, en líneas generales, desde el componente expresivo de la lengua:

\begin{tabular}{|l|c|}
\hline $\begin{array}{l}\text { Extensión } \\
\text { semántica }\end{array}$ & Ejemplos \\
\hline familiaridad & $\begin{array}{c}\text { lăo xiǒng 老兄 'pref.' 'hermano' } \rightarrow \text { apelativo } \\
\text { familiar al interlocutor (= tío) }\end{array}$ \\
\hline tamaño & $\begin{array}{r}\text { běn zi 本子 'tomo' 'suf.' } \rightarrow \text { agenda, libreta } \\
\text { cè zi 冊子 'cuaderno' 'suf.' } \rightarrow \text { agenda, } \\
\text { cuadernillo }\end{array}$ \\
\hline menosprecio & $\begin{array}{c}\text { chú zi 廚子 'cocinero' 'suf.' } \rightarrow \text { cocinero } \\
\text { qǔ ér 乞兒 'mendigo' 'suf.' } \rightarrow \text { mendigo }\end{array}$ \\
\hline despectivo & $\begin{array}{c}\text { lăo tǔ 老土 'pref.' 'vulgar, rústico' } \rightarrow \text { paleto } \\
\text { lăo nang 老娘 'pref.' 'madre' } \rightarrow \text { designación } \\
\text { del yo, si es mujer }\end{array}$ \\
\hline
\end{tabular}

Tabla 1: Ejemplos de afijos convencionales gramaticalizados

En un tercer lugar más elevado de la escala de gramaticalización se sitúan, en nuestra opinión, los afijos que en el chino actual no aportan ni significado léxico ni gramatical cuando se combinan con unidades léxicas en la formación compleja. Su función parece reducirse a la puramente morfonológica, pues sirven para cumplir con la tendencia prosódica del bisilabismo del chino moderno, a pesar de que desempeñaban funciones léxicas en el chino antiguo. Pueden adoptar las dos posiciones, como en hŭ 老虎 'morfofonema' 'tigre' $\rightarrow$ tigre, yàng ér 樣兒 'forma' 'morfofonema' $\rightarrow$ aspecto o forma, xié zi 鞋子 'zapato' 'morfofonema' $\rightarrow$ zapato, shí tóu 石頭 'piedra' 'morfofonema' $\rightarrow$ piedra, etc. Estos afijos se consideran en este trabajo como los elementos gramaticalizados del nivel más elevado, pues su función principal es morfonológica, de manera que se colocan en la cuarta posición en la cadena de gramaticalización de Givón (1979), discurso > sintaxis > morfología > morfonología > cero. 
Formantes gramaticalizados y lexicalizados en la morfología del chino mandarín y el 283 español

En nuestra opinión, los afijos convencionales de la lengua china presentan distintas escalas de gramaticalización (Hopper y Traugott 1993: 6). Así, cuando una unidad lingüística sufre un proceso de gramaticalización, la nueva categoría no surge de forma inmediata, sino que atraviesa diversas etapas hasta llegar a la unidad resultante con una determinada definición gramatical. En efecto, en los afijos convencionales se observan distintos estados de gramaticalización, e incluso en un mismo formante se presentan también distintos niveles de gramaticalización, como se muestra en el siguiente ejemplo:

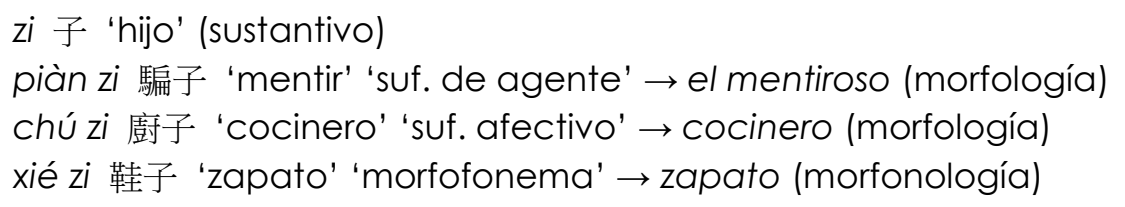

En suma, el análisis de la gramaticalización de los afijos convencionales del chino mandarín se define como un proceso dinámico y unidireccional que sigue una evolución del plano léxico al pleno gramatical.

Por otro lado, los denominados afijoides, que muestran claramente una influencia de la traducción de lenguas extranjeras, también son fruto de procesos de gramaticalización, puesto que producen el efecto de transferir información desde la dimensión léxica al plano gramatical. Así, el cambio desde palabras independientes del chino clásico a morfemas de contenido semántico debilitado en el chino moderno constituye un proceso de gramaticalización, pues se considera una evolución desde el significado léxico al significado gramatical. Por ejemplo, a partir del uso en contextos muy concretos del tipo liè yán 烈炎 'ardiente' 'fuego' $\rightarrow$ fuego ardiente, el sustantivo yán 炎 'fuego' llega a adquirir el significado general de 'inflamación', de manera que desempeña una función sufijal equivalente al -itis del español. Se forman así, por ejemplo, năo yán 腦炎 'cabeza' '-itis' $\rightarrow$ encefalitis y wèi yán 胃炎 'estómago' '-itis' $\rightarrow$ gastritis. Otro ejemplo semejante de gramaticalización reside en el antiguo verbo huà 化 
Morfología contrastiva del chino mandarín y el español. Formas de gramaticalización y lexicalización

'transformar' que carece en el chino actual de autonomía léxica, pero forma en el chino moderno algunos derivados con un valor más abstracto de acción, equivalente al español '-izar, -ificar'. Así, por ejemplo, en $\Perp$ xiè huà 機 械化 'máquina' '-izar' $\rightarrow$ mecanizar y gōng yè huà 工業化 'industria' '-izar' $\rightarrow$ industrializar.

En general, se observa que los afijoides presentan un estadio de morfologización, pues se extienden contextualmente a las palabras autónomas y se gramaticalizan hasta convertirse en elementos afijales con la consiguiente pérdida de las funciones propias de una categoría nominal plena. Desde el punto de vista funcional, esta extensión semántica de un signo determina la pérdida de su autonomía y también su dependencia de otra unidad.

Finalmente, la formación del género femenino de ciertos sustantivos de profesiones y de animales también puede considerarse, en nuestra opinión, como resultado de procesos de gramaticalización. En efecto, algunos sustantivos del chino mandarín sufren el debilitamiento semántico y se gramaticalizan en elementos con funciones solo gramaticales, y no léxicas. Así, el sustantivo nŭ女 'mujer o hija' pierde su significado originario y gana un valor genérico de referencia femenina cuando se une a nombres de profesiones para denotar el sexo femenino de la persona referida. Del mismo modo, el sustantivo mǔ 母 'madre' deja su especificidad de significado y se generaliza en un constituyente que designa la hembra de ciertos animales. Se observa en esta evolución un incremento de la aplicabilidad del signo a través de la gramaticalización, pues la mayoría de los sustantivos de profesiones y de animales puede admitir nŭ女 y $m \check{u}$ 母, respectivamente, para crear formaciones femeninas. Se ilustran estas formaciones con los siguientes ejemplos: 
Formantes gramaticalizados y lexicalizados en la morfología del chino mandarín y el 285 español

\begin{tabular}{|c|c|}
\hline Sustantivo con sigdo. léxico & Sustantivo con sigdo. gramatical \\
\hline mǔ 母 'madre' & $\begin{array}{l}\text { mǔ mă 母馬 'hembra' 'caballo' } \rightarrow \text { yegua } \\
\text { mǔ niú 母牛 'hembra' 'toro' } \rightarrow \text { vaca } \\
\text { mǔ goǔ 母狗 'hembra' 'perro' } \rightarrow \text { perra } \\
\text { mǔ lăo hǔ 母老虎 'hembra' 'tigre' } \rightarrow \text { tigresa }\end{array}$ \\
\hline nǔ 女 'mujer o hija' & 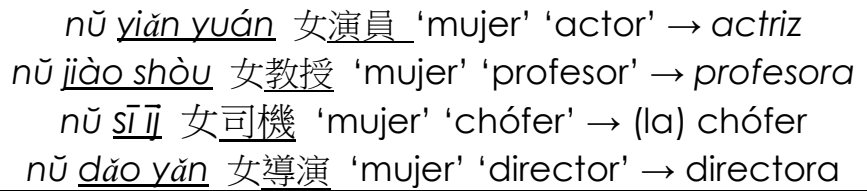 \\
\hline
\end{tabular}

Tabla 2: Formas gramaticalizadas para la formación del femenino

\subsection{Lexicalización en la morfología del chino mandarín y el español}

\subsubsection{Lexicalización de formas flexivas y derivativas}

Suelen distinguirse dos tipos de lexicalización según el punto de partida hacia el plano léxico que implica cualquier proceso de esta naturaleza: la lexicalización desde el plano morfológico y la lexicalización a partir del plano sintáctico (Blasco Mateo 2002: 38). En este apartado, se estudian, en general, los casos más representativos del primer tipo de lexicalización en las dos lenguas en contraste, mientras que las formaciones lexicalizadas procedentes de estructuras sintagmáticas serán objeto de atención en el capítulo siguiente.

Se reúnen aquí, en primer lugar, algunos resultados destacados de la lexicalización tanto de determinados procesos flexivos como de los derivativos en español. Se tratará de la lexicalización de compuestos morfológicos en los apartados siguientes.

Se habla de lexicalización de morfemas cuando un determinado afijo pierde la significación que le es pertinente y pasa a formar una palabra indivisible con el lexema al cual se adjunta (Contreras y Suñer 2004: 63), de modo que el resultado pierde el sentido composicional. Este proceso puede partir de determinados verbos o sustantivos acompañados de morfemas 
Morfología contrastiva del chino mandarín y el español. Formas de gramaticalización y lexicalización

flexivos que en la lengua actual no se prestan a este análisis composicional. Por ejemplo, pagaré es un sustantivo formado a partir de la lexicalización de la primera persona del singular del futuro de indicativo del verbo pagar, que significa 'papel de obligación por una cantidad que ha de pagarse a tiempo determinado'. Otros casos semejantes son los de abonaré, mentís y las formas interjectivas vamos, vale, vaya. También pueden incluirse en esta categoría las antiguas formas conjugadas del latín que en español resultan inanalizables, como lavabo, placebo.

Por otra parte, en algunos nombres propios la flexión de número también experimenta el proceso de lexicalización, como Carlos, Marcos, etc. Algunos nombres comunes distinguen varios significados a partir de la variación singular/plural, lo que también supone un tipo de lexicalización. Es el caso, entre otros, los siguientes sustantivos:

$\begin{array}{ll}\text { esposa/esposas } & \text { dote/dotes } \\ \text { celo/celos } & \text { hábito/hábitos } \\ \text { agujeta/agujetas } & \text { narizo/narizotas } \\ \text { almacén/almacenes } & \text { cocinilla/cocinillas } \\ \text { botón/botones } & \text { recuerdo/recuerdos }\end{array}$

También las formas no personales del verbo han experimentado procesos de lexicalización, tanto las formaciones originarias del latín como las formadas en español. Unas y otras no se interpretan como formas verbales sino como sustantivos léxicos. Es el caso, entre otros, de comando, considerando, doctorando, graduando, memorando, multiplicando, ordenando, vitando, aventura (del participio futuro de advenire), dividendo, hacienda, resultando, tremendo/a, vivienda, volandero/a, etc.

Con todo, el proceso más productivo de las formaciones lexicalizadas en español se encuentra en las derivaciones con los afijos afectivos, esto es, con el diminutivo y el aumentativo. Todas estas palabras, generalmente derivadas de otros sustantivos, pierden el significado del tamaño o la expresión afectiva y adquieren un nuevo significado léxico. 
Formantes gramaticalizados y lexicalizados en la morfología del chino mandarín y el 287 español

Véanse algunos ejemplos:

\begin{tabular}{llll} 
Diminutivo & & Aumentativo & \\
\hline alcantarilla & calzoncillo & medallón & espolón \\
artillo & camilla & pelotón & colchón \\
almohadilla & cartilla & peñón & balón \\
azucarillo & casilla & salón & canalón \\
barbilla & centralita & telón & frontón \\
barquillo & cepillo & almohadón & listón \\
bocadillo & coronilla & boquerón & barracón \\
bolsillo & cursillo & culebrón & cañón \\
bombilla & octavilla & jergón & jarrón \\
bordillo & panecillo & barcaza & pezón \\
botiquín & peseta & bodegón & mantón \\
balancín & sillín & & \\
boletín & sombrilla & & \\
boquilla & varilla & & \\
banderilla & ventanilla & & \\
palillo & mirilla & & \\
balandilla & gatillo & &
\end{tabular}

Otros casos de lexicalización se encuentran en las formas del participio, sobre todo, en las formas deverbales que designan personas, como el acusado, el interesado, el imputado, etc. En suma, el proceso de lexicalización que muestran estos datos se puede comprobar a partir de la transformación que se desarrolla en una dirección contraria al esquema de la jerarquía de abstracción propuesta para explicar la gramaticalización: persona > objeto > proceso > espacio > tiempo > cualidad. Se ilustra así en la práctica el fenómeno de la lexicalización como un proceso por el que determinados elementos con valor flexivo o derivativo adquieren un valor léxico al perderse sus significaciones primarias.

El concepto de lexicalización puede considerarse como un proceso de aumento de autonomía, pues son representativos de este fenómeno los casos en que un elemento se traslada desde el nivel morfológico (flexivo o derivativo) al nivel léxico. Además de los afijos afectivos, revisados anteriormente, otros afijos derivativos y sobre todo ciertos temas cultos también han alcanzado la 
Morfología contrastiva del chino mandarín y el español. Formas de gramaticalización y lexicalización

autonomía prevista en estos procesos de lexicalización. Se trata de evoluciones como -ismo > ismo, entre los sufijos, y de agro- > agro, crono- > crono, -terapia > terapia, -fobia > fobia, -logo > logo, etc., entre los elementos compositivos. En efecto, según Lázaro Mora (1986: 222) y Lang (1992: 178) -ismo se ha lexicalizado en la pieza léxica ismo, ismos como término independiente con significado pleno. La lexicalización del sufijo -ismo se debe a la influencia en el mundo cultural de los movimientos de vanguardia que alcanzaron un gran protagonismo en la primera mitad del siglo XX. Por esta razón, se origina un sustantivo a partir de la forma plural lexicalizada del sufijo, ismos o también los ismos, para designar cualquiera de los movimientos culturales de vanguardia. De modo parecido, el uso actual del prefijo crono- también experimenta la lexicalización, pues evoluciona desde un elemento dependiente hasta un elemento autónomo del léxico deportivo. Se registra en el DRAE como sustantivo con el significado de 'tiempo medido con cronómetro en pruebas de velocidad'. El cambio supone una transformación hacia categorías superiores.

Por el contrario, la lexicalización de formantes flexivos y derivativos no constituye un proceso representativo de la evolución del chino mandarín. Los escasos morfemas flexivos y los afijos convencionales suponen, en cambio, muestras de gramaticalización, pues unos y otros proceden de antiguos elementos léxicos autónomos del chino antiguo. Las formaciones lexicalizadas en mandarín tienen lugar en los diferentes esquemas de composición.

\subsubsection{Lexicalización de compuestos}

Desde una perspectiva sincrónica, el término lexicalización puede entenderse como la adopción de una palabra en el lexicón. También se refiere a un proceso en el cual las entidades lingüísticas nuevas, simples, complejas o con nuevos significados, se convencionalizan en el vocabulario (Blank 2001, en 
Formantes gramaticalizados y lexicalizados en la morfología del chino mandarín y el 289 español

Brinton y Traugott 2005: 21). De acuerdo con esta definición general, se puede afirmar que tanto en chino mandarín como en español la formación compositiva es el resultado de procesos de lexicalización, puesto que produce el efecto de transferir información desde la dimensión morfológica hacia el plano léxico.

En chino mandarín, desde que Baver (1983: 11) indicó que "los compuestos implican la unificación de dos o más morfemas autónomos a fin de formar una palabra"47, la formación compositiva puede considerarse una construcción lingüística que está en pleno proceso de lexicalización, pues las unidades gramaticales se convierten en unidades léxicas con un valor referencial o un significado más referencial del que presentaban en un principio. Tal propiedad se observa en cualquier tipo de compuesto:

$$
\begin{aligned}
& \text { xiōng dì 兄弟 'hermano mayor' 'hermano menor' } \rightarrow \text { hermanos (coordinación) } \\
& \text { năo zhōng 銿鐘 'perturbar' 'reloj' } \rightarrow \text { despertador (modificador-núcleo) } \\
& \text { chīlì 吃力 'gastar' 'fuerza' } \rightarrow \text { duro, difícil (verbo-objeto) } \\
& \text { rèn qīng 認 清 'conocer' 'claro' } \rightarrow \text { reconocer (verbo-complemento } \\
& \text { predicativo) } \\
& \text { dìzhèn 地震 'tierra' 'vibrar' } \rightarrow \text { terremoto (sujeto-predicado) } \\
& \text { En español, los tipos compositivos como cuentagotas, pelirrojo, }
\end{aligned}
$$
nochebuena, bienvivir (a partir de un sintagma) o nomeolvides (a partir de una cláusula) también son resultado de la lexicalización, pues estas estructuras, tanto del nivel morfológico como del nivel sintáctico, son aptas para generar unidades léxicas complejas con fijación sintáctica y significado unitario. Así, se observa que en ambas lenguas, la lexicalización es un proceso de fijación (o, como suele decirse, fosilización) por el que ciertas construcciones sintácticas se convierten en unidades léxicas con un valor referencial. De acuerdo con estas ideas, a continuación se analizan las características que comparten el chino mandarín y el español en la lexicalización de algunas construcciones compositivas.

47 Texto original en Baver (1983: 11): "compounding involves the unifying of two or more autonomous words to form a third, eg., blackboard, wallpaper". 
Morfología contrastiva del chino mandarín y el español. Formas de gramaticalización y lexicalización

\subsubsection{Carácter idiosincrásico}

En opinión de Brinton y Traugot† (2005: 33-34), el término lexicalización se ha venido asociando a los procesos rutinarios de formación de palabras, como la composición, la derivación y la conversión. Estos procesos pueden incrementar el vocabulario de una determinada lengua. Sin embargo, para muchos autores en los últimos años, tanto en chino como en español, la lexicalización, en su grado más alto, no aporta datos interesantes sobre los procesos de formación de palabras. Es decir, en los casos de lexicalización completa, las palabras compuestas dejan de ser morfológicamente analizables $y$, en consecuencia, no se constituyen en esquemas productivos (Lehmann, 2002: 14, Brinton y Traugott, 2005: 21 ).

En español, por ejemplo, la formación compositiva del tipo nomeolvides se incluye en este proceso máximo de lexicalización y se excluye de los procesos compositivos regulares. Lo mismo ocurre en el caso de terremoto, lexicalización del sintagma latino terrae motum, en el cual el genitivo latino de terra se vuelve opaco.

En chino mandarín, la forma lexicalizada de muchos compuestos tampoco puede entenderse por la aplicación de las reglas sincrónicas de la morfología. Por ejemplo, en los compuestos como shǒu shì 首飾 'cabeza' 'decoración' $\rightarrow$ joya, alhaja y xī shēng 犧牲 'ganado' 'vaca' $\rightarrow$ sacrificar, la pérdida de reglas de formación de palabras conlleva la creciente complejidad de análisis de estas formaciones. Esto es, como indica Brinton y Traugott (2005: 50), este tipo de lexicalización idiosincrásica se da cada vez que una forma compleja, por razones semánticas, morfológicas o fonológicas, se almacena por separado, en vez de ser generada libremente de acuerdo con unas reglas determinadas. 
Formantes gramaticalizados y lexicalizados en la morfología del chino mandarín y el 291 español

\subsubsection{Procesos de fusión}

Según indican Brinton y Traugott (2005: 47-49), desde la perspectiva histórica, la lexicalización se ha venido asociado al concepto de fusión, en el sentido de que un ítem léxico constituido por una secuencia compleja pasa a utilizarse como una unidad léxica simple con un considerable cambio de significado. Los dos autores apuntan como ejemplos de fusión el de la univerbación de un sintagma en una sola palabra, e indican que los procesos de lexicalización se ponen en marcha cuando una unidad léxica formada por más de una palabra llega a funcionar como una sola unidad gramatical:

Ing. handicap < hand in the cap (esp. 'mano en el sombrero' $\rightarrow$ discapacidad, dificultad)

Ing. topsy-turvy < top so turvy (esp. 'arriba muy desordenado' $\rightarrow$ patas arriba, desorden)

Fr. aujourd'hui < au jour d'hui (esp. 'al día de hoy' $\rightarrow$ hoy)

Al. langeweile < lange weile (esp. 'largo tiempo' $\rightarrow$ aburrimiento)

Del mismo modo, la formación compositiva del español y del chino mandarín también incluye la fusión entre sus características comunes. En efecto, las combinaciones libres de palabras pueden formar palabras únicas con significados deducibles o no deducibles de cada una de sus partes. Estas univerbaciones pueden implicar a menudo algún grado de reducción fonológica y pueden resultar morfológica o semánticamente opacas. Así los compuestos del español como helioterapia $(N+N)$, pelirrojo $(N+A)$, maniatar $(N+V)$, anchicorto $(A+A)$, salvoconducto $(A+N)$, quitapón $(V+V)$, salvavidas $(V+N)$, etc., se consideran formas lexicalizadas porque implican la pérdida de sustancia fónica y la fusión de elementos. Este proceso se corresponde con la afirmacion de Brinton y Traugott (2005: 44):

Históricamente, las palabras compuestas y derivadas son los casos más obvios de la lexicalización, pues implican los procesos de fusión que eliminan o borran las fronteras entre morfemas dependientes, de manera que se da 
Morfología contrastiva del chino mandarín y el español. Formas de gramaticalización y lexicalización

lugar a lexemas unificados a través del tiempo 48.

En chino mandarín, la lexicalización ha provocado que ciertas agrupaciones de palabras que responden a la fusión de una estructura sintáctica sean consideradas compuestas. De esta manera, la noción de palabra compuesta en chino mandarín es relativamente amplia y extensa, puesto que, como se ha mencionado anteriormente, por la inclinación al bisilabismo, los compuestos modernos son el resultado de la evolución de ciertas construcciones sintácticas del chino clásico. Se explica así que en chino mandarín la forma compositiva desempeña el papel principal en la formación de palabras. Desde la perspectiva de la lexicalización, entendida como fusión (Brinton y Traugott 2005: § 2.3.), la formación compositiva manifiesta algunos aspectos para completar tal aglutinación: juntura morfémica de elementos, fosilización en unidad léxica inseparable, imposibilidad de insertar, sustraer o permutar sus constituyentes, reducción o debilitamiento semántico de constituyentes y pérdida de la composicionalidad del significado. Véanse los siguientes ejemplos:

Compuesto coordinado: guó jiā 國家 'país' 'casa' $\rightarrow$ país

Compuesto sujeto-predicado: yăn hóng 眼紅 'ojo' 'rojo' $\rightarrow$ envidioso

Compuesto verbo-objeto: guà gōu 掛鈎 'colgar' 'gancho' $\rightarrow$ cambalache Compuesto verbo-compl. pred.: găi shàn 改善 'corregir' 'bueno' $\rightarrow$ mejorar Compuesto AN: chū huà 粗話 'vulgar' 'palabra' $\rightarrow$ palabrota

Sin embargo, no todos los compuestos en chino mandarín manifiestan estos aspectos formales y semánticos del proceso de lexicalización. Según Cai (2005: 38), existen muchos compuestos en los que se encuentra una transparencia semántica total, de modo que los constituyentes pueden ser analizados. Así, estos compuestos presentan un sentido semántico transparente para cada morfema y se halla con facilidad la motivación de la composición de palabras. Por ejemplo, los compuestos modernos como lí hūn 離婚 'separar' 'matrimonio' $\rightarrow$ divorciar y tóng jū 同居 'junto' 'vivir' $\rightarrow$ convivir (en pareja)

\footnotetext{
48 Texto original en inglés "Historically, compounds and derivations are most obviously cases of lexicalization because they involve processes of fusion which serve to erase or efface boundaries between independent morphemes and give rise to unified lexemes over time".
} 
Formantes gramaticalizados y lexicalizados en la morfología del chino mandarín y el 293 español

muestran la composicionalidad semántica y se reconoce la motivación. Por otro lado, Cai (2005) también indica que no son pocos los compuestos en los que se permite la intercalación de otros morfemas entre los constituyentes, a veces incluso la intercalación de elementos oracionales. Esta formación intercalada ocurre con más frecuencia en compuestos del tipo modificador-núcleo y verbo-objeto, donde residen los problemas de delimitación entre las palabras compuestas y las construcciones sintácticas. Véanse algunos ejemplos:

\section{1) Palabras compuestas sin intercalación}

\section{Modificador-núcleo}

dàn zhuāng 淡妝 'ligero' 'maquillaje' $\rightarrow$ maquillaje ligero

duè kàng 對看 'de frente' 'mirar' $\rightarrow$ mirarse (recíproco)

Verbo-objeto

jiàn miàn 見面 'ver' 'cara' $\rightarrow$ ver(se)

zhǔ fàn 者飯 'cocinar' 'arroz' $\rightarrow$ cocinar

\section{2) Construcciones sintácticas con intercalación}

\section{Modificador-núcleo}

dàn de zhuāng 淡的妝 'ligero' 'marc. de atribución' 'maquillaje' $\rightarrow$ maquillaje es ligero

duè zhe kàng 對著看 'de frente' 'partícula' 'mirar' $\rightarrow$ mirar de frente

\section{Verbo-objeto}

jiàn zù̀ hòu yĩ miàn 見最後一面 'ver' 'último' 'uno' 'cara' $\rightarrow$ verse la última vez zhǔ le yī dùn fàn 者了一頓飯 'cocinar' 'part. perfectiva' 'uno' 'clasificador' 'arroz' $\rightarrow$ haber cocinado una vez

Como se observa en los ejemplos de 2), debido a la transparencia semántica y al carácter analizable de los constituyentes, los compuestos del tipo modificador-núcleo y verbo-objeto conservan en parte el mismo significado semántico, pese a que se añaden elementos intercalados. Sin embargo, en nuestra opinión, la posibilidad de separación de los elementos muestra que estos compuestos no están totalmente lexicalizados, pues se 
Morfología contrastiva del chino mandarín y el español. Formas de gramaticalización y lexicalización

mantienen algunos rasgos sintácticos propios de los sintagmas.

En opinión de Shi (2003), se ha de establecer una escala de lexicalización en los compuestos de chino mandarín, pues el grado de fusión difiere según el significado semántico de la formación compositiva. Solo los compuestos que desarrollan el proceso metafórico o metonímico adquieren una lexicalización total. Este rasgo se manifiesta tanto en chino mandarín ${ }^{49}$ como en español:

\section{1) Compuestos totalmente lexicalizados en chino mandarín}

Coordinado: shǒu ling 首領 'cabeza' 'cuello' $\rightarrow$ líder

Modificador-núcleo: nián tǔ 秥土 'pegajoso' 'barro' $\rightarrow$ plastilina

Verbo-objeto: chī cù 吃醋 'comer' 'vinagre' $\rightarrow$ estar celoso

Sujeto-predicado: yăn hóng 眼紅 'ojo' 'rojo' $\rightarrow$ tener envidia

\section{2) Compuestos totalmente lexicalizados en español}

$\mathbf{N}+\mathbf{N}$ : donjuán, madreperla, carasol, baloncesto

$\mathbf{N}+\mathbf{A}$ : manirroto, boquidulce, nochebueno, aguardiente, vinagre

$\mathbf{A}+\mathbf{N}$ : altavoz, malapata, ciempiés

V + V: quitapón, pasapasa, picapica

$\mathbf{V}+\mathbf{N}$ : ganapán, tragahombres, saltamontes, sacapuntas

Oracionales: hazmerreír, nomeolvides, bienteveo

En fin, tanto en chino mandarín como en español el mecanismo de la fusión pone en marcha el proceso de lexicalización de una formación compositiva desde la construcción sintagmática. Pero, en comparación con el español, se observa que algunos compuestos del chino mandarín presentan un menor grado de lexicalización, pues revelan más claramente un origen sintáctico y muestran un grado menor de pérdida de composicionalidad.

\footnotetext{
49 Respecto al compuesto del tipo verbo-predicado, según Dong (2002a: 81), el grado de lexicalización no es muy elevado puesto que se encuentra una combinación libre entre el elemento verbal y predicativo y, además, la construcción interna tiene una estructura sintáctica estable. Dong indica que este tipo de compuestos en su fosilización tiene una interpretación transparente. Así, no hace falta aprender de memoria ya que no forma parte del lexicón mental.
} 
Formantes gramaticalizados y lexicalizados en la morfología del chino mandarín y el 295 español

\subsubsection{Idiomaticidad}

En opinión de Brinton y Traugott (2005: § 2.3.4), la fusión característica de la lexicalización explica algunos aspectos semánticos y pragmáticos que determinan la producción de nuevas formas léxicas. Se trata de la idiomatización y la desmotivación. Estos autores indican que la idiomaticidad está asociada a la rutinización, que conduce a la univerbación, entendida como el proceso que compacta las fronteras entre los componentes y los simplifica. En efecto, Brinton y Traugott señalan que la identificación de la lexicalización con la idiomaticidad encuentra consenso entre los autores consultados. Lehmann (2002: 14), por ejemplo, está de acuerdo en que la lexicalización es idiomatización pues se trata de un proceso unitario. Moreno Cabrera (1998 [1984]: 214-215) cita las idiomatizaciones como los mejores ejemplos de lexicalización, pues indica que la idiomatización y la desmotivación son los atributos semánticos y formales en el proceso de integración de una construcción sintáctica o un compuesto en el lexicón. Lipka (1992: 214) señala que algunos compuestos del inglés, como wheelchair (esp. silla de ruedas), pushchair (esp. silla plegable para bebé) y trousersuit (esp. traje pantalón) sirven de ejemplos de idiomatización, porque se representa un significado específico e impredecible. Bussmann (1996) considera que la idiomatización es el elemento diacrónico de la lexicalización, porque no se puede deducir el significado del conjunto desde sus elementos individuales y la motivación original de la unidad solo se reconstruye a través de conocimientos históricos. El autor cita los casos del inglés neighbor (esp. vecino), cupboard (esp. alacena) y mincemeat (esp. 'carne picada', picadillo de fruta o de otros ingredientes para relleno) como ejemplos.

Más recientemente, Blank (2001: 1599-1600) distingue tres grados de idiomaticidad en los compuestos, representados por casos como los siguientes:

a) Al. Hundekuchen (esp. galleta de perro)

b) Ing. wheelchair (esp. silla de ruedas) 
Morfología contrastiva del chino mandarín y el español. Formas de gramaticalización y lexicalización

c) It. bocca di leone (esp. boca de dragón)

El autor explica que el orden de c) > b) > a) ilustra los tres niveles de mayor a menor lexicalización del compuesto, pues se manifiesta un alto grado de idiomaticidad donde se observan la opacidad semántica y la fosilización gramatical. Blank explica que en el grupo a) se conserva el significado literal de los componentes, pero el valor semántico del conjunto no es siempre predecible. En el grupo b) el significado del compuesto se basa en el sentido general de los componentes, pero se trata de una representación no prototípica o una especificación semántica. En c), finalmente, se observa una transformación metonímica o metafórica en el significado de los constituyentes, de forma que el valor semántico de la forma compositiva ('un tipo de planta') se vuelve plenamente opaco.

De acuerdo con la clasificación de Blank, se observa que la escala de lexicalización para los compuestos del chino mandarín y el español presenta la idiomatización gradual parecida a este esquema, tal como se muestra en la tabla siguiente:

\begin{tabular}{|c|c|c|}
\hline $\begin{array}{l}\text { Agrupación } \\
\text { de Blank }\end{array}$ & Ejemplos de chino mandarín & $\begin{array}{c}\text { Ejemplos de } \\
\text { español }\end{array}$ \\
\hline $\begin{array}{l}\text { a) } \\
\text { Hundekuchen } \\
\text { (galleta de } \\
\text { perro) }\end{array}$ & $\begin{array}{l}\text { Coordinado: fù mǔ 父母 'padre' 'madre' } \rightarrow \\
\text { padres } \\
\text { Modificación-núcleo: niù ròu 牛肉 'vaca' } \\
\text { 'carne' } \rightarrow \text { ternera } \\
\text { Núcleo-modificador: èr lóng 耳壟 'oreja' } \\
\text { 'sordo' } \rightarrow \text { sordo } \\
\text { Verbo-objeto: chōu yān 抽煙 'sacar' 'humo' } \\
\rightarrow \text { fumar } \\
\text { Verbo-comp.: jiàng dī 降低 'bajar' 'bajo' } \rightarrow \\
\text { bajar }\end{array}$ & $\begin{array}{l}\mathbf{V}+\mathbf{N} \text { : cortaúñas } \\
\mathbf{N}+\mathbf{N} \text { : telaraña } \\
\mathbf{N}+\mathbf{A} \text { : pelirrojo }\end{array}$ \\
\hline
\end{tabular}


Formantes gramaticalizados y lexicalizados en la morfología del chino mandarín y el 297 español

\begin{tabular}{|c|c|c|}
\hline $\begin{array}{l}\text { b) wheelchair } \\
\text { (silla de } \\
\text { ruedas) }\end{array}$ & $\begin{array}{l}\text { Coordinado: guó jiā 國家 'país' 'casa' } \rightarrow \text { país } \\
\text { Modificación-núcleo: lún yǐ 輪 椅 'rueda' } \\
\text { 'silla' } \rightarrow \text { silla de ruedas } \\
\text { Sujeto-predicado: qì chuăn 氣 喘 'aire' } \\
\text { 'jadear' } \rightarrow \text { asma } \\
\text { Verbo-objeto: fáng daò 防盜 'prevenir' 'robo' } \\
\rightarrow \text { (dispositivo) antirrobo }\end{array}$ & $\begin{array}{l}\mathbf{N}+\mathbf{N} \text { : bocacalle } \\
\mathbf{N}+\mathbf{A} \text { : manirroto } \\
\mathbf{A}+\mathbf{N} \text { : malasangre } \\
\mathbf{A d v .}+\mathbf{A} \text { : } \\
\text { bienhechor }\end{array}$ \\
\hline $\begin{array}{l}\text { c) bocca di } \\
\text { leone (boca } \\
\text { de dragón) }\end{array}$ & $\begin{array}{l}\text { Coordinado: shǒu zú 手足 'mano' 'pie' } \rightarrow \\
\text { hermano } \\
\text { Modificación-núcleo: xiǎo mǐ 小米 'pequeño' } \\
\text { 'arroz' } \rightarrow \text { mijo } \\
\text { Sujeto-predicado: yuè shí 月 蝕 'Iuna' } \\
\text { 'corroerse' } \rightarrow \text { eclipse lunar } \\
\text { Verbo-objeto: chī cù 吃醋 'comer' 'vinagre' } \\
\rightarrow \text { estar celoso } \\
\text { Verbo-comp.: kàn tòu 看扁 'ver' 'plano' } \\
\rightarrow \text { despreciar, desdeñar }\end{array}$ & $\begin{array}{l}\mathbf{N}+\mathbf{N} \text { : donjuán } \\
\mathbf{V}+\mathbf{N} \text { : saltamontes } \\
\mathbf{A}+\mathbf{N} \text { : altavoz } \\
\text { Or: nomeolvides } \\
\text { Or: hazmerreír }\end{array}$ \\
\hline
\end{tabular}

Tabla 3: Grados de idiomaticidad

Como puede observarse, en la agrupación a) los compuestos del chino mandarín y del español presentan un claro sentido de la composicionalidad y su significado semántico es bastante predecible. En la agrupación b), los componentes conservan el significado literal pero el valor semántico del conjunto puede presentar cierta especificación. Algunos compuestos adquieren contenidos semánticos denotativos que deben ser explicados en función de la selección de un determinado constituyente (Bustos Gisbert 1986: 224-226). Finalmente, se encuentran en la agrupación c) tipos o patrones metonímicos y metafóricos en el proceso de lexicalización de los compuestos, de modo que se activan mecanismos de personificación, animalización, cosificación, factores culturales, temporales, relación parte-todo, etc., que bloquean el sentido composicional.

En suma, estos tres grados de lexicalización según los componentes de idiomaticidad pueden identificarse tanto en los compuestos del chino mandarín como en los del español sin apenas diferencias destacables. Se trata, por tanto, de un criterio bastante general que puede aplicarse con relativa facilidad al análisis de los tipos de compuestos de muchas lenguas. 
Morfología contrastiva del chino mandarín y el español. Formas de gramaticalización y lexicalización

\subsubsection{Gramaticalización y lexicalización como procesos complementarios}

Según se ha mencionado anteriormente, la gramaticalización y la lexicalización son procesos que operan en el mismo terreno, solo que suceden en dominios o niveles diferentes: el primero es un mecanismo de creación gramatical y el segundo es un mecanismo de creación léxica. Pero las diferencias entre el proceso de gramaticalización y de lexicalización no resultan siempre del todo claras, de modo que estos cambios pueden llegar a ser complementarios. Moreno Cabrera (1998: 223) indica, en efecto, que "existe una fuerte tendencia a que el proceso de gramaticalización complemente el proceso de lexicalización, de manera que hay una estrecha interacción entre ambos procesos" ${ }^{50}$. Así, en la evolución lingüística, la interacción de estos dos procesos es crucial para obtener un mejor conocimiento de la dinámica evolutiva de los elementos léxicos y gramaticales. Estos criterios se pueden observar en los trabajos de Wischer (2000), Lehmann (2002), Rostila (2004), Buenafuentes (2006a, 2006b), Haas (2007), entre otros. Es más, algunos autores como Brinton y Traugott (2005: 86) postulan una nueva cadena en la que se aúnan los procesos de gramaticalización y lexicalización.

Esta interacción de la gramaticalización y la lexicalización se manifiesta en buena parte de los procesos del cambio lingüístico. Así, se observa que tanto en chino mandarín como en español esta interrelación puede explicar la evolución que han experimentado algunos procesos compositivos. En español, la interacción de la gramaticalización y la lexicalización se aprecia claramente en algunos formantes cultos (fase de gramaticalización) que llegan a convertirse en unidades libres (fase de lexicalización). Pero estas, a su vez, intervienen en la formación de nuevos compuestos, aunque con distinto significado del que presentaban originariamente (fase de gramaticalización). En los siguientes ejemplos, se observa que los elementos grecolatinos cambian

50 Texto original en inglés: "A strong tendency exists for grammaticalization processes to feed lexicalization process, and that there is a close interaction between both procedure". 
Formantes gramaticalizados y lexicalizados en la morfología del chino mandarín y el 299 español

de significado cuando se constituyen en palabras independientes tras la creación léxica por acortamiento o acronimia (Casado Velarde 1999: §78.3). El proceso se completa cuando esta última unidad autónoma se utiliza como un nuevo elemento compositivo. En esta fase, Wischer (201 1: 364) señala que la formación del compuesto puede ir acompañada por un proceso de gramaticalización, que puede afectar al conjunto de la construcción o solo a una parte de ella. Normalmente, la segunda generación de compuestos suele ser incluso más productiva que aquella en la que el formante aportaba su significado originario ${ }^{51}$ :

\begin{tabular}{|c|c|c|c|c|}
\hline \multirow{2}{*}{\begin{tabular}{|l|} 
Gramaticalización \\
Sigdo. grecolatino \\
\end{tabular}} & \multicolumn{2}{|c|}{ Lexicalización } & \multicolumn{2}{|c|}{ Gramaticalización } \\
\hline & Ejemplos & & Sigdo. lexicalizado & Ejemplos \\
\hline Foto = 'Iuz' & $\begin{array}{l}\text { fotografía } \\
\text { fotoeléctrico } \\
\text { fotofobia }\end{array}$ & 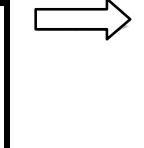 & Foto = 'fotografía' & $\begin{array}{l}\text { fotomatón } \\
\text { fotograma } \\
\text { fotocopia }\end{array}$ \\
\hline $\begin{array}{l}\text { Auto = 'por uno } \\
\text { mismo' }\end{array}$ & $\begin{array}{l}\text { automóvil } \\
\text { autografía } \\
\text { autorretrato }\end{array}$ & & Auto = 'automóvil' & $\begin{array}{l}\text { autopista } \\
\text { autoescuela } \\
\text { autovía }\end{array}$ \\
\hline Tele = 'lejos' & $\begin{array}{l}\text { televisión } \\
\text { telepatía } \\
\text { telescopio }\end{array}$ & & Tele = 'televisión' & $\begin{array}{l}\text { telebasura } \\
\text { teletienda } \\
\text { telecomedia }\end{array}$ \\
\hline Micro = 'pequeño' & $\begin{array}{l}\text { microscopio } \\
\text { micrómetro } \\
\text { microbio }\end{array}$ & & $\begin{array}{l}\text { Micro = } \\
\text { 'microscopio' }\end{array}$ & $\begin{array}{l}\text { microcirugía } \\
\text { microfotografía } \\
\text { microinyector }\end{array}$ \\
\hline $\begin{array}{l}\text { Euro = 'Europa, } \\
\text { europeo' }\end{array}$ & $\begin{array}{l}\text { eurocámara } \\
\text { euroasiático } \\
\text { euroescéptico }\end{array}$ & & Euro = 'moneda' & $\begin{array}{l}\text { euromercado } \\
\text { eurozona } \\
\text { eurobono }\end{array}$ \\
\hline $\begin{array}{l}\text { Eco = 'casa, } \\
\text { morada, hábitat' }\end{array}$ & $\begin{array}{l}\text { ecología } \\
\text { ecosistema }\end{array}$ & & Eco = 'ecología' & $\begin{array}{l}\text { ecoturismo } \\
\text { ecotasa } \\
\text { ecodesarrollo }\end{array}$ \\
\hline
\end{tabular}

Tabla 4: Interacción de procesos en la morfología española

51 García-Medall (1988) explica que el prefijo auto- ha sufrido procesos de eliminación, sustantivación y extensión intercategorial, por lo que se identifica con un elemento gramaticalizado que conduce a la lexicalización o a la re-lexicalización. 
Morfología contrastiva del chino mandarín y el español. Formas de gramaticalización y lexicalización

En chino mandarín, la interacción de la gramaticalización y la lexicalización se manifiesta en los elementos originariamente libres que se convierten en unidades dependientes e intervienen en la formación de nuevos compuestos. Por ejemplo, los siguientes elementos léxicos con autonomía semántica llegan a comportarse como elementos de la derivación: mantienen un significado conocido, adquieren una alta productividad, se unen a un radical y son creadores de una serie paradigmática. Así, estos componentes se gramaticalizan porque su resultado es una transformación en pseudoafijos. Sin embargo, la evolución de los compuestos no queda ahí. Posteriormente, estos elementos sufren un cambio semántico derivado de un proceso metafórico o metonímico, con el que pasan a la designación gramaticalizada de la persona o el agente. Este elemento vuelve a ser un formante dependiente que interviene en la formación de otros compuestos:

\begin{tabular}{|c|c|c|c|c|}
\hline Léxico - & $\rightarrow$ Gramaticalización & & Gra & naticalización \\
\hline $\begin{array}{l}\text { Sgdo. } \\
\text { original }\end{array}$ & Ejemplos & & $\begin{array}{l}\text { Marc. de } \\
\text { persona }\end{array}$ & Ejemplos \\
\hline $\begin{array}{l}\text { dàn 蛋 } \\
\text { huevo }\end{array}$ & $\begin{array}{l}\text { ji dàn 雞蛋 'gallina' } \\
\text { 'huevo' } \rightarrow \text { huevo } \\
\text { shēng dàn 生蛋 'crudo' } \\
\text { 'huevo' } \rightarrow \text { huevo sin cocer }\end{array}$ & & dàn 蛋 & $\begin{array}{l}\text { bèn dàn 笨蛋 'tonto' } \\
\text { 'marc.' } \rightarrow \text { tonto } \\
\text { huài dàn 壞蛋 'malo' } \\
\text { 'marc.' } \rightarrow \text { malo }\end{array}$ \\
\hline $\begin{array}{l}\text { jiā 家 } \\
\text { casa }\end{array}$ & $\begin{array}{l}\text { jiā rén 家人 'casa' 'gente' } \\
\rightarrow \text { familia } \\
\text { jiā tíng 家庭 'casa' 'patio' } \\
\rightarrow \text { familia }\end{array}$ & & $j i \bar{a}$ 家 & $\begin{array}{l}\text { huà jiā 畫家 'pintar' } \\
\text { 'marc.' } \rightarrow \text { pintor } \\
\text { zuò jiā 作家 'componer' } \\
\text { 'marc.' } \rightarrow \text { escritor } \\
\end{array}$ \\
\hline $\begin{array}{c}\text { shǒ } \text { 手 } \\
\text { mano }\end{array}$ & $\begin{array}{l}\text { zUǒ shǒu 左手 'izquierda' } \\
\text { 'mano' } \rightarrow \text { mano izquierda } \\
\text { yòu shǒu 右手 'derecha' } \\
\text { 'mano' } \rightarrow \text { mano derecha }\end{array}$ & $\Rightarrow$ & shǒ 手 & $\begin{array}{l}\text { xīn shǒ 新手 'nuevo' } \\
\text { 'marc.' } \rightarrow \text { principiante, } \\
\text { novato } \\
\text { lăo shǒ 老手 'viejo' } \\
\text { 'marc.' } \rightarrow \text { experto, } \\
\text { experimentado }\end{array}$ \\
\hline $\begin{array}{c}\text { chóng 蟲 } \\
\text { insecto }\end{array}$ & $\begin{array}{l}\text { huáng chóng 蝗蟲 } \\
\text { 'langosta' 'insecto' } \rightarrow \\
\text { langosta } \\
\text { zhù chóng 蛙蟲 'roer' } \\
\text { 'insecto' } \rightarrow \text { carcoma }\end{array}$ & & chóng 蟲 & $\begin{array}{l}\text { lǎn chóng 懶蟲 } \\
\text { 'perezoso' 'marc.' } \rightarrow \\
\text { perezoso, vago } \\
\text { dú chóng 毒蟲 'veneno' } \\
\text { 'marc.' } \rightarrow \text { drogadicto }\end{array}$ \\
\hline
\end{tabular}

Tabla 5: Proceso de doble gramaticalización en la morfología china 
Formantes gramaticalizados y lexicalizados en la morfología del chino mandarín y el 301 español

En definitiva, cabría tener en cuenta este tipo de relaciones semánticas como resultado de los procesos de lexicalización o gramaticalización para poder conocer exactamente el origen del elemento compositivo y su significación en la unidad compuesta. Además puede observarse que, a medida que se producen los procesos de lexicalización y gramaticalización, estos van hacia la concreción o abstracción semántica, es decir, hacia la designación de un objeto como el caso del español o del agente como el caso de chino mandarín.

Sin embargo, interesa destacar alguna diferencia en la dinámica de estos procesos complejos según se analicen los resultados en español o en mandarín. Se observa que no se produce en la morfología china el fenómeno del acortamiento que desemboca en la creación de un nuevo significado léxico para un sustantivo autónomo, que a su vez sustenta la segunda gramaticalización de los compuestos españoles. Probablemente, la tendencia manifiesta hacia el bisilabismo del mandarín no favorece la formación de palabras autónomas de una sola sílaba, pero tampoco impide que ciertos formantes compositivos adquieran un significado gramatical diferente del significado léxico originario.

\subsubsection{Debilitamiento sintáctico}

Como es bien sabido, y como señalan numerosos estudiosos de la morfología general y española (Benveniste 1977; Piera y Varela 1999) y también de la del chino mandarín (Chao 1994 [1980]; Hu 1992; Li y Thompson 2003 [1983]; Tang 1988), la formación compositiva coincide en presentar un origen sintáctico. Pero, este análisis del compuesto relacionado con la microsintaxis queda más claro y constante en chino mandarín, ya que desde una perspectiva diacrónica los compuestos del chino moderno se identifican con una transformación de las construcciones sintácticas del chino clásico. 
Morfología contrastiva del chino mandarín y el español. Formas de gramaticalización y lexicalización

Entre los distintos tipos de compuestos en ambas lenguas, el tipo de verbo más nombre es muy productivo y refleja una estructura sintáctica predicativa, donde el segundo elemento realiza la función de complemento directo del verbo al que acompaña. Ahora bien, durante este proceso de lexicalización en el que se crea una nueva pieza léxica a partir de un sintagma, aunque la fusión entre los componentes corresponde a una relación sintáctica, se produce el debilitamiento de la autonomía sintáctica de los elementos que favorece el proceso de lexicalización del complejo. Tal debilitamiento reduce la autonomía sintáctica de los elementos y posibilita su fusión, de modo que aumenta la autonomía morfológica de la estructura entera. Tal mecanismo corresponde a la jerarquía de abstracción propuesta por Heine, Claudi y Hünnemeyer (1991a) y Moreno Cabrera (1998), en el sentido de que un sintagma formado por verbo y nombre en la sintaxis libre que designa una actividad o un proceso (guardar algo, sacar algo, portar algo, etc.) pasa a denotar, convertido en compuesto, una persona o un objeto (guardarropa, sacacorchos, portalápiz, etc.).

Por su parte, Dong (2002a: 175-181) indica que en chino mandarín la formación compleja de verbo más objeto se lexicaliza con más facilidad cuando los componentes presentan una autonomía sintáctica débil, ya que este debilitamiento reduce la independencia de los componentes y favorece la aglutinación del conjunto. Tal supuesto puede generalizarse también al compuesto verbo más nombre del español.

Según señala Dong (2002b), de acuerdo con la teoría de Hopper y Thompson (1980: 252, en Taylor, 1995: 206-207), tal debilitamiento de la autonomía sintáctica consiste en el carácter "no prototípico" de los componentes: el verbo expresa el proceso o el estado, pero no la acción, mientras que el nombre denota el concepto genérico, pero no la individualidad del objeto. Así, en chino mandarín, los componentes verbales y nominales de los compuestos verbo-objeto presentan aspectos menos referenciales, debilitamiento de la acción y abstracción del sentido semántico. 
Formantes gramaticalizados y lexicalizados en la morfología del chino mandarín y el 303 español

De modo parecido, en la creación de compuestos $\mathrm{VN}$ del español, aunque los verbos que participan en la construcción designan acción (cortapuros, abrelatas, sacacorchos), los verbos más empleados como guardar o portar funcionan como paradigmas productivos que se integran en el proceso de lexicalización. Este cambio se caracteriza por el debilitamiento del sentido de la acción, pues el verbo deja de designar una acción concreta o acción terminada en un intervalo de tiempo. Véanse algunos ejemplos de ambas lenguas:

\begin{tabular}{|c|c|c|c|}
\hline & $\begin{array}{c}\text { Verbo con debilitamiento } \\
\text { de la acción }\end{array}$ & $\begin{array}{c}\text { Nombre con designación } \\
\text { genérica o abstracta }\end{array}$ & Compuestos \\
\hline $\begin{array}{l}\text { Chino } \\
\text { mandarín }\end{array}$ & $\begin{array}{c}\text { píng 貧 'faltar' } \\
\text { aó 鳌 'aguantar' } \\
\text { cún 存 'depositar' } \\
\text { fáng防 'prevenir' } \\
\text { miǎn 免 'quitar' } \\
\text { maò 冒 'coger' }\end{array}$ & $\begin{array}{l}\text { xiě 血 'sangre' } \\
\text { yè 夜 'noche' } \\
\text { kuăn 款 'dinero' } \\
\text { daò 盜 'robo' } \\
\text { fèi 費 'precio' } \\
\text { xiăn 險 'peligro' }\end{array}$ & $\begin{array}{l}\rightarrow \text { 'anemia' } \\
\rightarrow \text { 'trasnochar' } \\
\rightarrow \text { 'ahorro' } \\
\rightarrow \text { 'antirrobo' } \\
\rightarrow \text { 'gratis' } \\
\rightarrow \text { 'aventurar' }\end{array}$ \\
\hline Español & $\begin{array}{l}\text { portar } \\
\text { portar } \\
\text { guardar } \\
\text { matar } \\
\text { saltar } \\
\text { salvar }\end{array}$ & $\begin{array}{l}\text { retrato } \\
\text { bebé } \\
\text { brisa } \\
\text { suegra } \\
\text { pared } \\
\text { vida }\end{array}$ & $\begin{array}{l}\text { portarretratos } \\
\text { portabebés } \\
\text { guardabrisa } \\
\text { matasuegras } \\
\text { saltaparedes } \\
\text { salvavidas }\end{array}$ \\
\hline
\end{tabular}

Tabla 6: Lexicalización del compuesto verbo - objeto

En suma, se puede decir que tanto en chino mandarín como en español, los compuestos verbo más nombre se identifican con estructuras oracionales reducidas que configuran una especie de microsintaxis. Sin embargo, aunque la caracterización del origen sintáctico es fundamental, también resulta imprescindible el debilitamiento de la autonomía sintáctica de los componentes: el verbo reduce el sentido de acción y el nombre se particulariza. Los componentes pierden la independencia sintáctica y se facilita la fusión entre los elementos. Así, se realiza el proceso de lexicalización y el complejo adquiere autonomía morfológica. 
Morfología contrastiva del chino mandarín y el español. Formas de gramaticalización y lexicalización

\subsection{Mecanismos léxicos y gramaticales de la composición}

En la creación de palabras compuestas, tanto en chino mandarín como en español, se observan algunos mecanismos comunes que promueven los procesos de gramaticalización y lexicalización de la formación compositiva. Por los trabajos que hemos revisado, se deduce que Hopper y Traugott (1993) destacan la importancia de los mecanismos del reanálisis y la analogía en el proceso de gramaticalización. Haiman (1994), por su parte, señala que los cambios lingüísticos obedecen al mecanismo de la ritualización, al que contribuye la reiterada presencia de estos neologismos en la vida cotidiana y la automatización. Bybee (2003) también hace hincapié en la importancia de la frecuencia como mecanismo básico de la producción léxica. En los trabajos del chino mandarín, Shen (1994), Wen (1998), Hu (2003), Dong (2002a) y Chou (2004) explican la influencia de los mecanismos de generalización, subjetivación y diferenciación en los procesos de gramaticalización y lexicalización de las palabras compuestas. A partir de lo expuesto aquí, se puede decir que todos estos mecanismos que dan lugar a los procesos de gramaticalización y lexicalización de los compuestos son concepciones semánticas, mediante las cuales la estructura compleja manifiesta la pérdida de composicionalidad semántica y la adquisición de idiomaticidad. En este apartado se trata de exponer algunos mecanismos que se manifiestan como motivación para los cambios lingüísticos de la gramaticalización y la lexicalización en los compuestos de ambas lenguas. Se incluye el tratamiento de la generalización, la mezcla o fusión (mixture), el reanálisis, la analogía, y la recategorización. 
Formantes gramaticalizados y lexicalizados en la morfología del chino mandarín y el 305 español

\subsubsection{Generalización y fusión}

Según Sánchez Marco (2008), la generalización es un proceso que se caracteriza, de un lado, por el aumento de los significados de una forma y, por otro, por el aumento del alcance de un morfema al pasar de un estado léxico a otro más gramatical, o de uno menos gramatical a otro más gramatical. En los compuestos, esta desemantización (o semantic bleaching) se manifiesta en que uno de los componentes sufre un proceso de abstracción del significado y el otro mantiene el contenido del significado y su función gramatical. El componente que se gramaticaliza adquiere un sentido semántico más general y aumenta el rango de aplicación. En los siguientes ejemplos del chino mandarín y el español, el elemento subrayado es el componente que sufre la generalización al unirse con el otro componente, de modo que el significado del conjunto resulta una entidad más abstracta:

\section{Chino mandarín}

hóng bāo 紅包 'rojo' 'sobre' $\rightarrow$ sobre rojo (designa el dinero que se regala en año nuevo o celebraciones sociales y familiares)

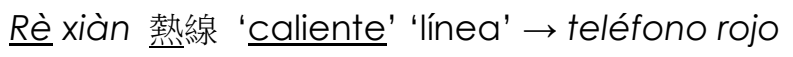

\section{Español}

malasangre, pintamonas, manirroto, carricoche

En opinión de Zhou y Dang (2004), a través del mecanismo de la fusión, las combinaciones de unidades lingüísticas sintáctica y semánticamente autónomas se integran en el vocabulario y adquieren un nuevo significado léxico. El significado del conjunto consiste en que uno de los componentes mantiene la función y el contenido semántico, mientras que el otro sufre un debilitamiento semántico y se convierte en elemento modificador, e incluso llega a perder su significado. Los compuestos subordinados de ambas lenguas presentan lexicalización formal mediante este mecanismo y suelen responder a la estructura endocéntrica. La mayoría de estos compuestos pertenece a la categoría nominal, como en los siguientes ejemplos de ambas lenguas: 
Morfología contrastiva del chino mandarín y el español. Formas de gramaticalización y lexicalización

\author{
Chino mandarín: \\ bái băn 白板 'blanco' 'tabla' $\rightarrow$ pizarra blanca \\ hóng ròu 紅肉 'rojo' 'carne' $\rightarrow$ carne roja \\ năo zhōng 閙鐘 'perturbar' 'reloj' $\rightarrow$ despertador
}

\title{
Español:
}

NN: aguanieve, bocamanga

NA: hierbabuena, pelirrojo

En chino mandarín, el tipo de compuesto coordinado manifiesta un grado de lexicalización muy elevado, pues a través de la fusión de los elementos, los componentes del complejo resultan sólidamente inseparables y el conjunto forma un concepto único, pero a partir de uno solo de los constituyentes. En los siguientes ejemplos, la parte subrayada muestra claramente esta tendencia a la fusión:

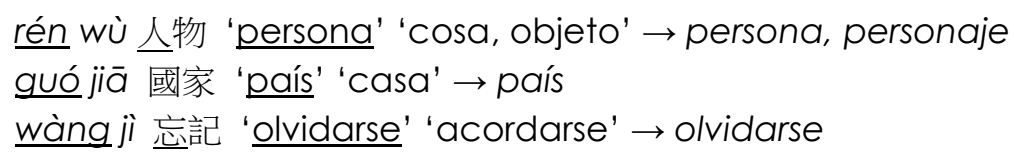

Respecto al préstamo o traducción, la incorporación de palabras procedentes de otras lenguas también constituye una fuente no desdeñable para enriquecer las formas compositivas del chino mandarín y el español. Actualmente, es el inglés la lengua moderna que representa la fuente principal. Los términos ingleses se traducen al chino mandarín y al español, pero estos términos sufren posteriormente procesos de gramaticalización o lexicalización y alcanzan una alta productividad. Véanse los siguientes préstamos lingüísticos que forman parte del acervo léxico de la composición del chino mandarín y el español:

\section{Chino mandarín:}

yìng tř 硬體 'duro' 'cuerpo' $\rightarrow$ disco duro (ing. hard-ware)

ruăn tǐ 軟體 'blando' 'cuerpo' $\rightarrow$ software

bái ling 白領 'blanco' 'cuello' $\rightarrow$ personas que se encargan de tareas de oficina, administrativos, ejecutivos, oficinistas, etc. (ing. white collar workers) lán ling 藍領 'azul' 'cuello' $\rightarrow$ obreros, operarios o mecánicos (ing. blue collar workers)

fěn linng 粉領 'rosa' 'cuello' $\rightarrow$ personas del sector de servicios (ing. pink collar 
Formantes gramaticalizados y lexicalizados en la morfología del chino mandarín y el 307 español

worker)

\section{Español:}

balon-: balompié (fútbol), baloncesto (básquetbol), balonvolea (voleibol), balonmano

ciber-52: cibercafé, cibernauta, ciberespacio, cibercultura

En la producción de unidades nuevas, la aglutinación o fusión hace que los términos distintos se encuentren juntos en una oración y que se suelden en una unidad léxica, a veces difícilmente analizable. La característica esencial de la aglutinación es la ausencia de análisis, de modo que en la creación de los compuestos, esta síntesis se hace por sí misma en virtud de una tendencia mecánica, tal como indicaba Saussure (1993 [1916]: 262):

Cuando un compuesto se expresa por medio de una secuencia de unidades significativas muy usuales, el espíritu, tomando -por sí decirlo- a campo traviesa, renuncia al análisis y aplica en bloque en concepto al grupo de signos, que se convierte en una unidad simple.

Así, en la formación compositiva del chino mandarín y el español, se observa claramente el origen sintáctico con el que opera el mecanismo de la aglutinación en varios tipos de compuestos:

\begin{tabular}{|c|c|c|}
\hline $\begin{array}{c}\text { Relación sintáctica } \\
\text { entre morfemas }\end{array}$ & Chino mandarín & Español \\
\hline Coordinación & sàng shī 喪失 'perder' 'perder' $\rightarrow$ perder & blanquinegro \\
\hline Modificación-núcleo & dỉ jí 低級 'bajo' 'clase' $\rightarrow$ nivel elemental & maleducado \\
\hline Verbo-objeto & $\begin{array}{c}\text { cái yuán 裁員 'cortar' 'personal' } \rightarrow \text { reducir } \\
\text { personal }\end{array}$ & quitasol \\
\hline Sujeto-predicado & dì zhèn 地震 'tierra' 'vibración' $\rightarrow$ terremoto & \\
\hline Preposición-objeto & zì cì 自此 'desde' 'esto' $\rightarrow$ desde & sobremesa \\
\hline
\end{tabular}

Tabla 7: Procesos de fusión en compuestos

52 En Rodríguez Segura (1999: 43) se señala que, a través de la influencia del neologismo, han alcanzado un gran desarrollo los compuestos en los que el elemento paradigmático es de raíz grecolatina, pero la creación compositiva del español está importada del inglés. 
Morfología contrastiva del chino mandarín y el español. Formas de gramaticalización y lexicalización

En chino mandarín y en español, los recursos más productivos para la creación de compuestos son la subordinación y la estructura VN. En ambas lenguas, la lexicalización se da porque la aglutinación de las entidades léxicas se produce con más facilidad. Los compuestos subordinados presentan las características del orden fijo, especificación semántica y transcategorización que motivan la fosilización del léxico. En español, como señalan Alvar (1984), Lang (1992) y Val Álvaro (1999), los componentes sintácticos de los compuestos verbo más nombre siguen el orden de palabras Sujeto-Verbo-Objeto y se fosilizan a menudo para remitir a realidades prácticas como la designación de aparatos, instrumentos y utensilios.

\subsubsection{Analogía y reanálisis}

Los mecanismos de analogía y reanálisis también permiten explicar la formación de compuestos. Como señala Pérez Vigaray (1994: 58), los compuestos y derivados responden a las creaciones analógicas de la lengua y no a meras soldaduras de palabras. En la formación compositiva del chino mandarín y el español, el mecanismo de la analogía no produce un cambio en la estructura, sino que representa la extensión o generalización de la regla modificada por el reanálisis en el sistema lingüístico. Es decir, la analogía es una generalización de la regla que supone la extensión de un esquema gramatical desde un dominio restringido hasta otro más amplio. Como se puede observar en los siguientes ejemplos, el proceso de la analogía permite la generalización de la nueva creación compositiva y esta innovación en el eje paradigmático a veces supone que el contenido semántico del constituyente adquiera el carácter abstracto: 
Formantes gramaticalizados y lexicalizados en la morfología del chino mandarín y el 309 español

\begin{tabular}{|c|c|}
\hline $\begin{array}{l}\text { Chino } \\
\text { mandarín }\end{array}$ & 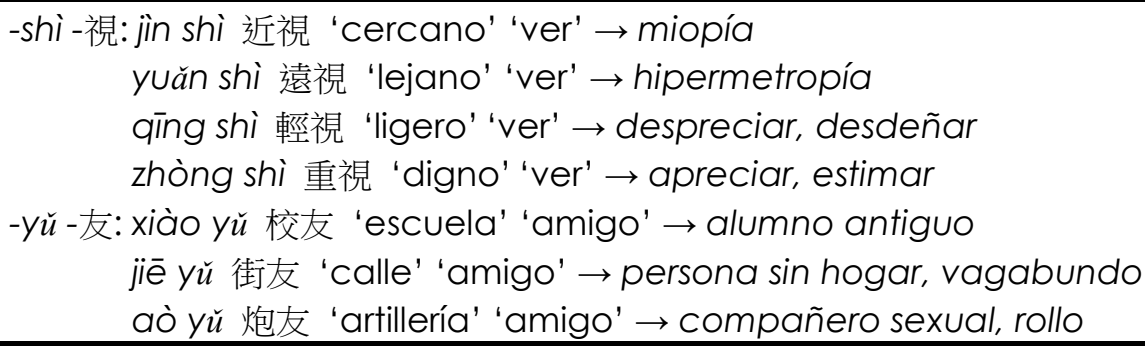 \\
\hline Español & $\begin{array}{l}\text { NA: manilargo, manicorto, manirroto, manivacío } \\
\text { VN: portalibros, portaplumas, portalira, portavoz }\end{array}$ \\
\hline
\end{tabular}

Tabla 8: Ejemplos de generalización en la composición

Como es bien sabido, el reanálisis y la analogía son procesos alternativos del cambio gramatical. En opinión de Cifuentes Honrubia (2003: 40), el reanálisis es uno de los mecanismos determinantes de la gramaticalización que también se da en otros tipos de cambios, como en la lexicalización y la desgramaticalización. En la lexicalización de los compuestos, el reanálisis se aplica a la transformación de una estructura dada en una estructura diferente sin que ello tenga que afectar a su configuración externa. Por ejemplo, Val Álvaro (1999: 4805) indica que los compuestos de [V+V $]_{\mathrm{N}}$ como alzaprima, picatoste, bullebulle, mordihuí, etc., pueden ser bien interpretados como el reanálisis de construcciones sintácticas, ya que en esta reestructuración interna de los elementos implicados se encuentra una coordinación de dos verbos. Los compuestos léxicos oracionales, como el tipo tentempié, también presentan un reanálisis, de forma que el resultado léxico se produce por la resegmentación que conlleva la lexicalización semántica de la construcción tente en pie.

En los compuestos del chino mandarín, el reanálisis siempre supone una modificación de la estructura sintáctica. El ejemplo más típico del efecto del reanálisis se encuentra en compuestos como kăi xúan 凱旋 'victoria' 'regresar'. En chino clásico, esta construcción sintáctica expresaba el significado de 'volver con victoria'. Sin embargo, cuando se lexicaliza en un compuesto del tipo modificador-núcleo en chino moderno, la estructura interna del compuesto se va oscureciendo hasta constituirse en una palabra lexicalizada 
Morfología contrastiva del chino mandarín y el español. Formas de gramaticalización y lexicalización

con el significado de 'victoria', sin el sentido de 'volver'. Otro ejemplo en el que interviene el mecanismo del reanálisis es la construcción del chino clásico guó ji 國際 'país' 'entre' $\rightarrow$ entre los países. En el uso moderno, se reanaliza la estructura interna del conjunto, de modo que se identifica con una palabra compuesta que significa 'país'. Así, aparece a menudo la expresión guó jì jiān 國際間 'país' 'entre' $\rightarrow$ entre los países.

En este patrón de creación de compuestos se han incluido también ejemplos del español. Así, los casos de hidalgo y trampantojo. Estos compuestos léxicos se acaban transformando en unidades léxicas simples, con lo que culmina el proceso de lexicalización formal de hijo de algo > hi(jo) (de) algo y trampa ante ojo > trampantojo.

\subsubsection{Recategorización}

Según señalan Brinton y Traugott (2005), la descategorización es la extensión de la unidireccionalidad a lo largo de la escala o camino (cline) de las propiedades estructurales: de ser una categoría mayor pasa a ser una categoría menor, y a la vez -en el nivel fonológico- de una unidad que suele ser fonológicamente más larga y acentuada, a una más corta y menos acentuada. Un ejemplo de la descategorización en español sería el cambio de sustancia fonética en los compuestos como manirroto, pelirrojo, boquiabierto, agridulce, telaraña, hojalata, etc. Sin embargo, este fenómeno no se da en chino mandarín, por ser una lengua tipológicamente aislante y monosilábica.

En chino mandarín, cabría más bien decir que la descategorización se manifiesta en la especialización semántica de los elementos compositivos. Es decir, en el proceso de gramaticalización, los constituyentes sufren la pérdida de las propiedades gramaticales características de las formas léxicas y disminuye la posibilidad de elección de formas gramaticales disponibles en cuanto los significados asumen una mayor generalización gramatical. Por 
Formantes gramaticalizados y lexicalizados en la morfología del chino mandarín y el 311 español

ejemplo, en chino clásico zhě 者 era un sustantivo que denotaba 'persona o agente', pero se ha transformado en un pseudosufijo con un significado gramatical (comparable al esp. -ista, -tor, -dor, etc.) que especifica algunos tipos de profesiones:

zoù zhě 作者 'escribir, hacer' 'marcador' $\rightarrow$ escritor

ji zhě 記者 'acordarse, apuntar' 'marcador' $\rightarrow$ periodista

xué zhè 學者 'escribir, hacer' 'marcador' $\rightarrow$ profesores académicos

Ahora bien, además de estos mecanismos comunes que promueven el cambio lingüístico, cabe tener en cuenta que estos procesos no funcionan aisladamente en la formación compositiva de ambas lenguas. Según Zhou y Dang (2005), en el proceso de gramaticalización y lexicalización de compuestos, pueden intervenir varios mecanismos que interactúan espontáneamente. Dicho de otra forma, a veces no se puede establecer un límite absoluto entre estos mecanismos, porque en la evolución de un elemento lingüístico compositivo, estas transformaciones entran del mismo modo a formar parte de los cambios gramaticales y semánticos que conlleva una gramaticalización y lexicalización. Por ejemplo, en la formación de rè xiàn 熱線 'caliente' 'línea' $\rightarrow$ teléfono rojo, no solo interviene el mecanismo de generalización para obtener la abstracción del significado, sino que también se observan los resultados del proceso metafórico y de la incorporación de préstamos. En manilargo y manicorto se observan los mecanismos de la generalización y del proceso metonímico, pero también se desarrolla el proceso analógico para la creación de compuestos con la misma estructura sintáctica.

\subsection{Mecanismos cognitivos de la composición}

Como resultado de los efectos interactivos de los principios cognitivos universales y del contacto incrementado entre lenguas (sobre todo, con el 
312 Morfología contrastiva del chino mandarín y el español. Formas de gramaticalización y lexicalización

inglés), se ha dado cuenta de la correspondencia que existe en la formación de palabras entre el chino mandarín y el español. Normalmente, el chino mandarín y el español se consideran dos lenguas extremadamente distintas. Sin embargo, hasta ahora se han encontrado muchas semejanzas morfológicas entre ambas lenguas, como se ha mostrado en los capítulos anteriores. Probablemente, los principios y mecanismos cognitivos universales de los humanos explican que estas dos lenguas no se diferencien en el procedimiento básico de formación de palabras.

Desde el punto de vista semántico, la explicación cognitiva en la formación compositiva es imprescindible, pues una estructura incorpora el contenido de sus componentes, pero el significado del compuesto no siempre está construido solo por estos constituyentes. Algunos compuestos muestran que el significado de la expresión compleja es más específico que el valor derivable de sus componentes (por ejemplo, en fàng yáng 放羊 'apacentar' 'oveja' $\rightarrow$ mentir, guà gōu 掛鈎 'colgar' 'gancho' $\rightarrow$ cambalache; y en altavoz, maniobra del español). La relación por la que un compuesto contiene a sus componentes puede ser arbitraria y a veces impredecible. Las estructuras componentes ofrecen algún grado de motivación para expresar la concepción compuesta, pero la estructura compuesta representa una entidad no reducible a sus componentes y puede presentar una construcción que se describe con estructuras simbólicas.

De acuerdo con esta observación, los compuestos de ambas lenguas pueden explicarse desde algunas perspectivas semántico-cognitivas de la teoría de la integración y la fusión conceptual (Conceptual Blending), propuesta por Fauconnier (1997), Fauconnier y Turner (2002), para comprobar que la categorización y el mecanismo cognitivo universal pueden determinar las características y los principios comunes entre nuestras dos lenguas en contraste. 
Formantes gramaticalizados y lexicalizados en la morfología del chino mandarín y el 313 español

En la teoría de prototipos y nivel básico53, según Ungerer y Schmid (1996), el mundo que conocemos existe solo a través de nuestra experiencia y de nuestro pensamiento. Dicha comprensión de la realidad es posible a partir de un conjunto de operaciones cognitivas complejas que denominamos categorización. La categorización es un mecanismo de organización de la información obtenida a partir de la aprehensión de la realidad. Mediante la categorización agrupamos elementos diferentes en conjuntos. Esta categorización se define como un proceso mental de clasificación cuyos resultados son las categorías cognitivas y los "conceptos mentales almacenados en nuestro cerebro", que, en conjunto y una vez convencionalizadas, "constituyen lo que se denomina lexicón mental" (Cuenca 1999: 32). En este sentido, la categorización fundamenta los procesos de comprensión y de producción lingüística, incluidos los que forman parte del el ámbito morfológico.

Desde la idea de la categorización, surge la cuestión de que no todos los miembros son iguales dentro de un grupo de entidades, pues siempre hay unos elementos más característicos que otros y aquellos obtienen alta puntuación en el reconocimiento de su categoría. Así, Rosch y Lioyd (1978) indica que dentro de una categoría o una clase existe un prototipo como el ejemplar que mejor se conoce, se considera el más representativo y distintivo entre otros miembros. Esta hipótesis se une a la concepción de las categorías como entidades difusas, y no como compartimentos delimitados y definidos. Por lo tanto, el paso de una categoría a otra es gradual y viene marcado por los miembros periféricos que comparten menos similitudes de la imagen central.

Así, Lakoff y Johnson (1998: 164) señalan que estas categorías, organizadas en torno a los ejemplares más prototípicos, se extienden y

53 Como introducción a estas nociones de la lingüística cognitiva, pueden valer los estudios de Ungerer y Schmid (1996), Cuenca y Hilferty (1999), etc. En este apartado solo se esboza una presentación general, pues existe abundante bibliografía que trata de estas teorías. Por ejemplo, desde 1990 se publica regularmente la revista Cognitive Linguistics, obra que explora especialmente la lingüística cognitiva. 
Morfología contrastiva del chino mandarín y el español. Formas de gramaticalización y lexicalización

completan con los miembros menos prototípicos o periféricos, relacionados entre sí por similitudes que se definen como parecidos de familia con el prototipo y cuya posición marginal genera límites difusos para las categorías (que Lakoff y Johnson terminan definiendo como "abiertas"). Véanse los ejemplos:

\begin{tabular}{|c|c|c|}
\hline Categoría & Ejemplar +prototípico & Ejemplar -prototípico \\
\hline flores & girasol & camelia \\
\hline animales domésticos & perro & iguana \\
\hline muebles & silla & perchero \\
\hline
\end{tabular}

Tabla 9: Categorías y prototipos

Sin embargo, al aplicarse a la gran diversidad de categorías de las entidades existentes, se ha demostrado insuficiente la categorización que deriva de esta definición del prototipo. Así, quedan preguntas como si cada categoría tiene solo un prototipo y cómo son sus características, etc. Por lo tanto, para completar el concepto de prototipo, otros autores como Kleiber (1990) y Lakoff (1987: cap. 3) proponen el concepto de efecto prototípico y el de semejanza de familia. En esta línea, Lakoff (1982: 165) indica:

El prototipo se define respecto a modelos cognitivos idealizados (simplificaciones y comprensiones esquemáticas de la realidad percibida), no respecto al mundo real o al conocimiento que de él pueda tener un individuo. Los efectos prototípicos surgen precisamente de interrelaciones imperfectas entre la realidad y el modelo cognitivo idealizado.

La aplicación de estos conceptos a la creación léxica puede dar buenos resultados. Así, por ejemplo, del concepto de madre se derivan compuestos sintagmáticos, como madre adoptiva, madre biológica, madre de alquiler, madre donante, etc., o más aún, surgen formaciones, como madre soltera, madre trabajadora, que reciben los efectos de la prototipicidad, en el sentido de que falta la correspondencia exacta entre el prototipo y la realidad. Estas mismas composiciones también se han formado en mandarín a partir de 
Formantes gramaticalizados y lexicalizados en la morfología del chino mandarín y el 315 español

constituyentes muy semejantes:

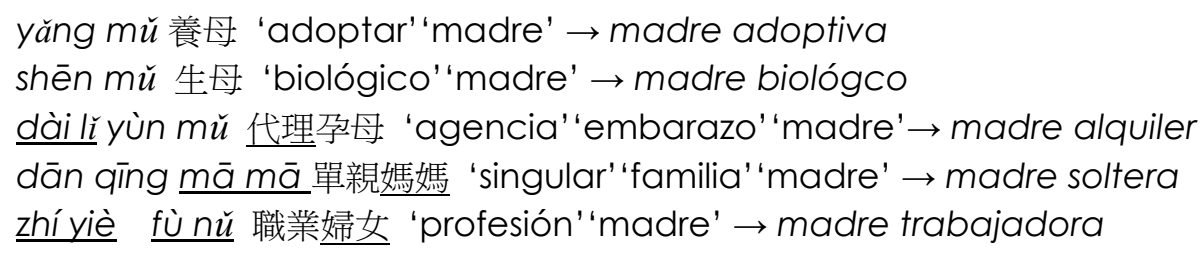

Respecto al concepto de semejanza de familia, en Ungerer y Schmid (1996: 38-40), se ha señalado que las categorías no son discretas y absolutas, sino difusas y contingentes. La relación entre los miembros de una categoría es como la que existe entre los miembros de una familia. Gráficamente se representa con la siguiente figura:

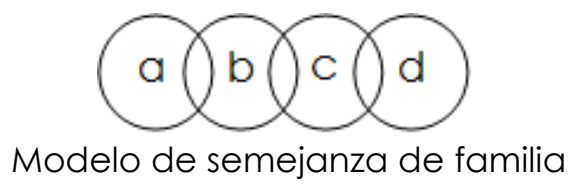

Un elemento se integra en la categoría por su semejanza con otro que presenta algún atributo común con la imagen mental del prototipo. Pero no es necesario que todos los miembros de una categoría tengan algún atributo común entre sí, ni tan siquiera algún atributo común con el prototipo, sino que las posibilidades asociativas son múltiples. Ponemos la categoría "chocolate" como ejemplo para explicar las características que definen el prototipo:

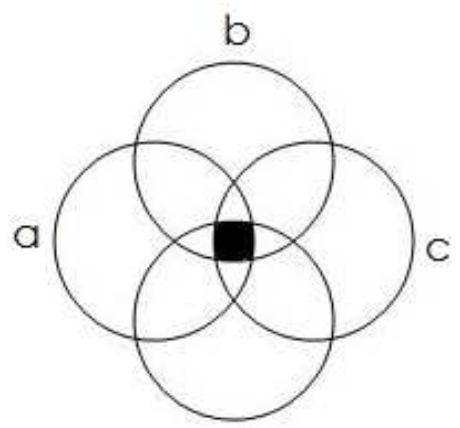

d

Estructura interna de una categoría 
316 Morfología contrastiva del chino mandarín y el español. Formas de gramaticalización y lexicalización

Si consideramos cuatro características que definen la categoría "chocolate": a) ser comestible, b) estar hecho a base de cacao, c) ser marrón y d) tener forma de tableta rectangular, la zona central representa los miembros que tienen las cuatro características del prototipo de "chocolate". A partir de este núcleo, el continuum categorial se caracteriza por dos gradaciones: cada característica se evalúa por la importancia relativa que tiene y cada miembro de la categoría se jerarquiza según el número y el tipo de características que presenta. De esta manera, es posible establecer el grado de prototipicidad de un elemento determinado. En el campo de las composiciones sintagmáticas o léxicas, podemos aportar, por nuestra parte, algunos ejemplos que muestran el alcance de la prototipicidad en las dos lenguas en contraste. Así, en español se forma cara de vinagre 'cara de pocos amigos', pero las características categoriales de "vinagre" (agrio, ácido, áspero, desapacible, etc.) también se manifiestan en compuestos del chino mandarín, como en el caso de chī cù 吃醋 'comer' 'vinagre' $\rightarrow$ estar celoso.

La interrelación entre la teoría del nivel básico y la teoría de los prototipos se manifiesta en que los miembros prototípicos se desarrollan más plenamente en el nivel básico y, complementariamente, las categorías de nivel básico funcionan como soportes de la categorización. El nivel básico incluye los ejemplares más fácilmente discriminables de la categoría y es equiparable al prototipo.

De acuerdo con la teoría de prototipos, uno de los pilares de la categorización es la capacidad de abstracción o, dicho de otro modo, la manifestación de diferentes niveles de especificidad. En líneas generales, se distinguen tres niveles según el esquema de la categorización: el nivel básico, el nivel superordinado y el nivel subordinado (Rosch 1976 y 1978; Lakoff 1982 y 1987; Kleiber 1990: 84-87; Ungerer y Schmid 1996: 74-76, entre otros). Cualquier objeto puede ser categorizado en cada uno de estos niveles. El mayor sería el superordinado, que contiene en su interior al básico y este a su vez incluye al subordinado. Tal jerarquía de las categorías conceptuales puede ilustrarse con 
Formantes gramaticalizados y lexicalizados en la morfología del chino mandarín y el 317 español

el siguiente gráfico:

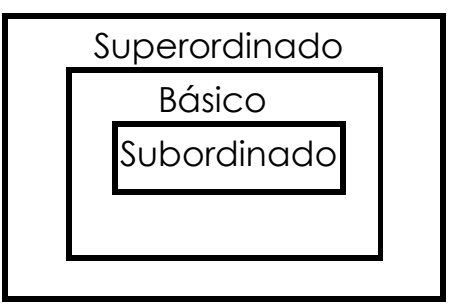

Jerarquía de las categorías conceptuales

Según indican estos autores, el nivel básico es el central y el más eficiente en el proceso de categorización. Los elementos de dicho nivel son los que se identifican de manera más rápida y suelen corresponden a palabras frecuentes en el uso. En la comunicación, su punto de referencia se representa en contextos neutros. En la organización del conocimiento, el nivel básico es el más informativo, pues a un esfuerzo cognitivo mínimo corresponde una cantidad de información elevada. El nivel superordinado, por su parte, es relativamente general e ineficiente en la jerarquía conceptual por incluir miembros que comparten un grado escaso de similitud entre ellos. Este nivel incluye la denominada categorización parasitaria respecto al nivel básico.

El nivel subordinado se basa en atributos diferenciales entre elementos del nivel básico y comprende miembros cuya similitud es muy alta entre ellos, lo que hace difícil su diferenciación. Este nivel ofrece solo un poco más de información, pero se requiere un procesamiento más costoso. Así, resultan más complicadas las palabras superordinadas, pues éstas se refieren a grupos de objetos o seres cuyos miembros son físicamente muy diversos, aunque sus funciones sean similares. En la tabla siguiente se presentan ejemplos de cada categoría con sus respectivos niveles:

\begin{tabular}{|c|c|c|}
\hline $\begin{array}{c}\text { Nivel de } \\
\text { categorización }\end{array}$ & Unidades léxicas & Unidades léxicas \\
\hline Superordinado & animal & mueble \\
\hline Básico & perro & silla \\
\hline Subordinado & perro gran danés & silla de tijera \\
\hline
\end{tabular}

Tabla 10: Niveles de categorización 
Morfología contrastiva del chino mandarín y el español. Formas de gramaticalización y lexicalización

En general, la noción de concepto superordinado y subordinado con respecto al nivel básico de categorización es consustancial a su misma naturaleza. Así, en términos generales, se puede afirmar que los términos de los lenguajes especializados pertenecen típicamente a planos de especificidad superordinados y subordinados al nivel básico de categorización.

La teoría de los niveles de categorización también puede aplicarse con facilidad a la creación morfológica. La semejanza de las unidades léxicas que representan estos tres niveles en nuestras lenguas contrastadas demuestra que, en efecto, las formaciones complejas responden a prinicipios cognitivos universales. Así, por ejemplo, las partes del cuerpo humano se constituyen a menudo en categorías superordinadas, que dan lugar a téminos simples de uso muy frecuente en el nivel básico de categorización (como, por ejemplo, boca, ojo; kŏU $\square$ 'boca', zUǐ bā 嘴巴 'boca', yăn 眼 'ojo'). Al mismo tiempo, estas unidades del nivel básico forman derivados o compuestos léxicos o sintagmáticos en ambas lenguas, que representan el nivel subordinado. La tabla siguiente reúne estos ejemplos de formaciones morfológicas que pueden explicarse de acuerdo con la teoría de los niveles de categorización, que efectivamente resultan comunes a las dos lenguas:

\begin{tabular}{|c|c|}
\hline $\begin{array}{l}\text { Nivel de } \\
\text { categorización }\end{array}$ & Unidades léxicas \\
\hline Superordinado & partes del cuerpo \\
\hline Básico & $\begin{array}{c}\text { esp.: boca, ojo } \\
\text { ch.: kǒu } \square \text { 'boca', zuǐbā 嘴巴 'boca', yăn 眼 'ojo' }\end{array}$ \\
\hline Subordinado & 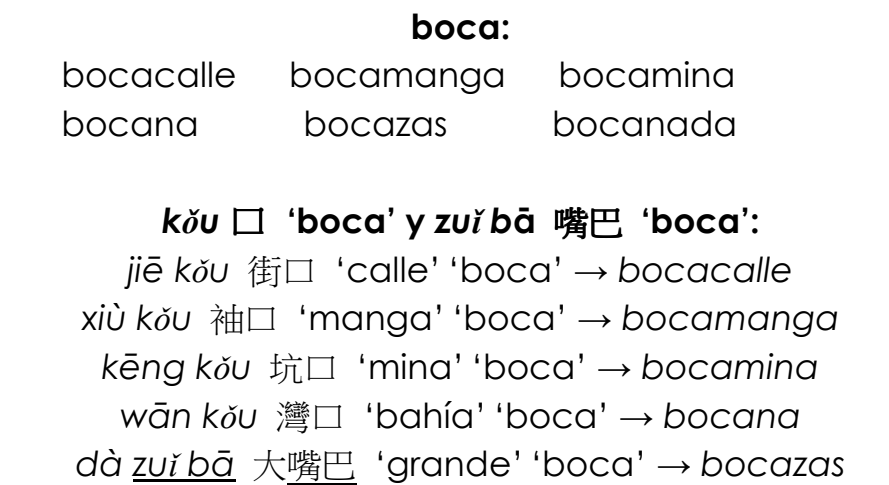 \\
\hline
\end{tabular}


Formantes gramaticalizados y lexicalizados en la morfología del chino mandarín y el 319 español

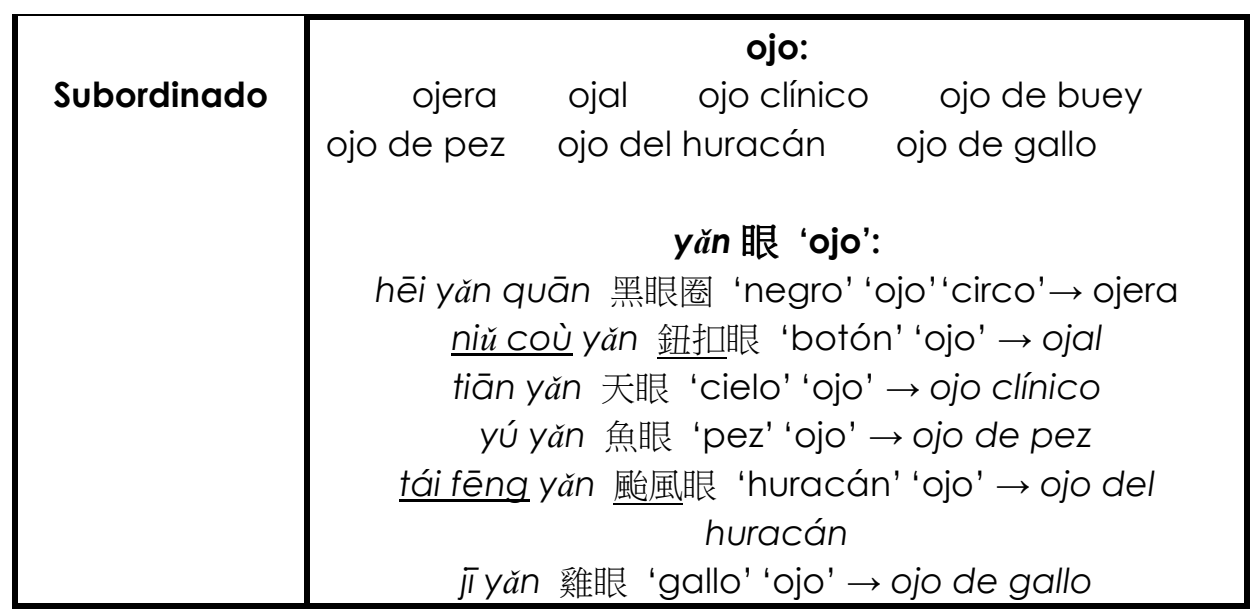

Tabla 11: Aplicación a la morfología de los niveles de categorización

Otra teoría que interviene en el formación morfológica es la de la metáfora, la metonimia y la integración conceptual ${ }^{54}$. Como se ha mencionado en apartados anteriores, la metáfora y la metonimia son concepciones cognitivas que tienen mucha importancia en la producción de los compuestos del español y el chino mandarín. En líneas generales, la metonimia se parece a la metáfora en la medida en que se basan en procesos conceptuales que relacionan entidades. Sin embargo, la metonimia opera dentro de los confines de un único dominio, mientras que la metáfora opera entre dos dominios. Es decir, la metáfora asocia entidades provenientes de dos dominios distintos; la metonimia, por el contrario, asocia dos entidades conceptualmente contiguas pertenecientes al mismo dominio.

Desde esta perspectiva semántico-cognitiva (Cuenca 1999: 114), la diferencia estructural entre metáfora y metonimia conduce a una puntualización importante: la metonimia es un mecanismo principalmente referencial con el que nos remitimos a una estructura implícita por medio de otra de mayor preeminencia; la metáfora, en cambio, es un proceso de analogía, por el que concebimos un concepto de un dominio en términos de otro.

54 Aquí tampoco desarrollamos con detalle la teoría de la metáfora, ya que es un tema que se desvía del objeto de este apartado. 
Morfología contrastiva del chino mandarín y el español. Formas de gramaticalización y lexicalización

A pesar de estas diferencias, es importante reconocer que la metonimia y la metáfora no son operaciones cognitivas mutuamente incompatibles, porque muchas formaciones se sirven de ambos procesos a la vez, de modo que la interpretación se fundamenta en la deducción de ambos cambios semánticos.

En la lingüística cognitiva, según Fauconnier $(1994,1998)$-de acuerdo con Lakoff y Johnson (1980)-, la metáfora consiste en un mapping (proyección) entre un dominio-origen (sourse domain o source) y un dominio-meta o destino (target domain o target; Lakoff 1987: 276). Así, según esta teoría, entran en juego dos dominios y una proyección entre ambos (source-to-target mapping). Más concretamente, Ibba (2008: 26) también indica que hay que analizar las metáforas teniendo en consideración el dominio-origen, pues este presta sus conceptos al dominio-meta sobre el que se superponen dichos conceptos. Pero la autora señala que no todos los atributos del dominio-origen se proyectan en el dominio-destino, sino las características más relevantes, las que más lo caracterizan. Así, la metáfora se produce mediante la proyección de unos conceptos desde un dominio conceptual (origen) hacia otro dominio conceptual (destino). La intervención de la metáfora y la metonimia en el proceso cognitivo puede esquematizarse del modo siguiente (lbba 2008: 27-28):

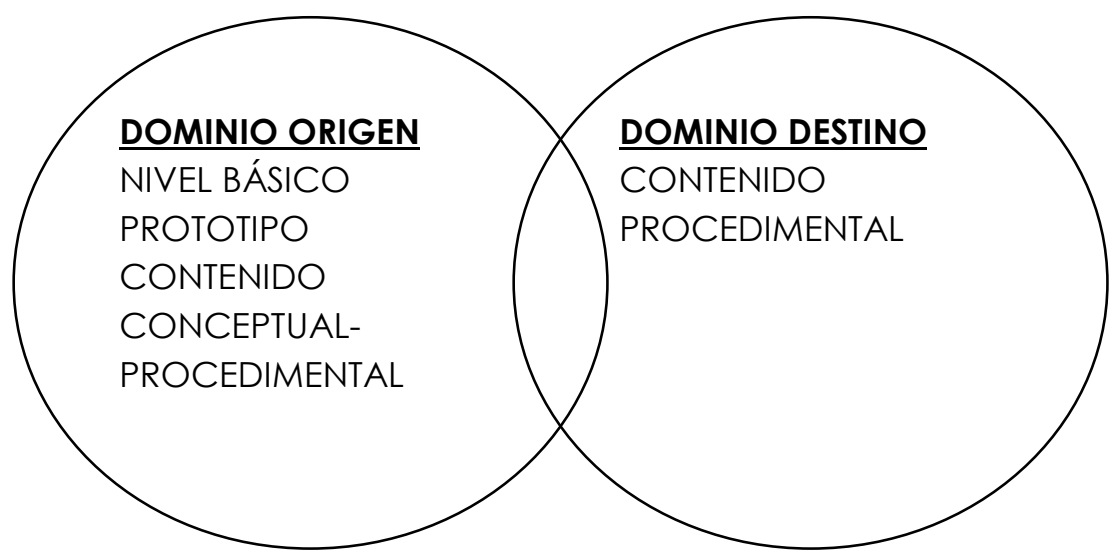

Intervención de la metáfora en el proceso cognitivo 
Formantes gramaticalizados y lexicalizados en la morfología del chino mandarín y el

Como se observa, en los procesos de gramaticalización basados en la metáfora, el dominio de origen seria un contenido conceptual (un elemento léxico) o procedimental (un ítem gramatical) de nivel básico o prototípico, una parte del cual se proyectaría al dominio de destino. En cambio, este último dominio solo podrá ser un contenido procedimental, dado que en la gramaticalización el resultado es siempre una pieza relacional.

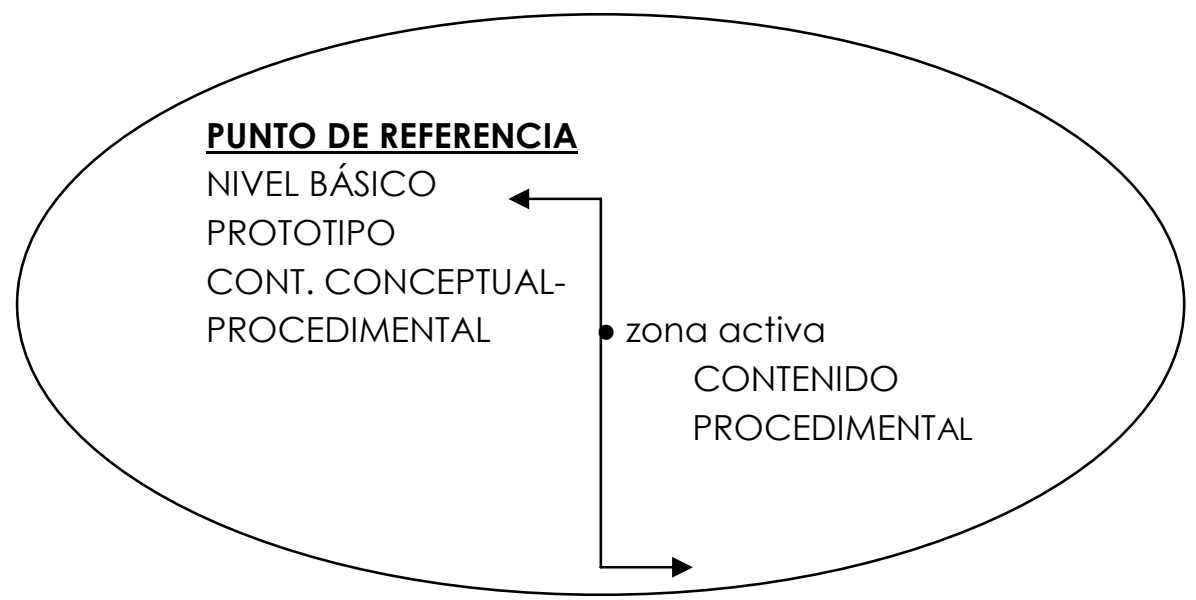

Intervención de la metonimia en el proceso cognitivo

Paralelamente, en la gramaticalización en la que interviene la metonimia, el contenido conceptual o procedimental inicial y el contenido procedimental final deberían pertenecer al mismo dominio. El punto de referencia -que podrá ser un contenido conceptual o procedimental (prototipo de su dominio) - muestra la zona activa del proceso metonímico y el referente lógico que se necesita para relacionarlo con el ítem "final". También en este caso, el resultado del proceso de gramaticalización podrá ser solo un contenido procedimental.

Así, tal esquema de mapping (proyección) entre el dominio-origen y el dominio-meta o destino es la idea fundamental de la teoría de la integración o fusión conceptual (Conceptual Blending). Con esta proposición se explican los mecanismos cognitivos que desarrollan la construcción de la formaciones compositivas en chino mandarín y español. Tal como señala Fauconnier (2005 : 
Morfología contrastiva del chino mandarín y el español. Formas de gramaticalización y lexicalización

155):

Dos dominios de entrada comparten la organización de una estructura marco. Se unen gracias a un espacio mixto y se proyectan partes de ellos en un espacio fundido. La proyección permite que emerja una estructura para desarrollar la base de la composición, para completar el patrón y para elaborarlo más.

En efecto, determinadas partes del cuerpo humano constituyen también buenos ejemplos de la teoría de la integración conceptual aplicada al ámbito morfológico de nuestras dos lenguas en contraste. Es bastante natural que nuestra propia experiencia se traslade a otros dominios cognitivos de la realidad, pues el antropocentrismo constituye un prinicpio de referencia común a casi todas las lenguas. La tabla siguiente ilustra estos mecanismos a partir de la designación de mano y pie, y su correspondencia en chino mandarín shǒ 手 'mano', jiăo 腳 'pie' y zú 足 'pie':

\begin{tabular}{|c|c|c|}
\hline & $\begin{array}{l}\text { Dominio } \\
\text { origen }\end{array}$ & Dominio meta \\
\hline \multirow{2}{*}{$\begin{array}{l}\overline{0} \\
1 \frac{1}{0} \\
0 \\
0 \\
0\end{array}$} & $\begin{array}{l}\text { mano } \\
\text { 'parte del } \\
\text { cuerpo' }\end{array}$ & $\begin{array}{ll}\text { manuscrito } & \text { pasamano } \\
\text { guardamano } & \text { balonmano } \\
\text { maniobra } & \text { mano de obra }\end{array}$ \\
\hline & $\begin{array}{c}\text { pie } \\
\text { 'parte del } \\
\text { cuerpo' }\end{array}$ & $\begin{array}{l}\text { piedemonte } \\
\text { pie de atleta } \\
\text { milpiés buscapié }\end{array}$ \\
\hline \multirow{2}{*}{ 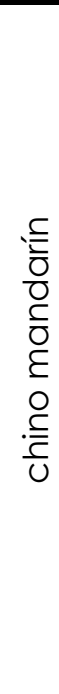 } & $\begin{array}{l}\text { shǒ 手 } \\
\text { 'mano' }\end{array}$ & $\begin{array}{l}\text { shǒ xiě băn 手寫本 'mano' 'escribir' 'libro' } \rightarrow \text { manuscrito } \\
\text { fú shǒu 扶手 'apoyar' 'mano' } \rightarrow \text { pasamano } \\
\text { hù shŏ 護手 'proteger' 'mano' } \rightarrow \text { guardamano } \\
\text { shǒu qiú 手球 'mano' 'balón' } \rightarrow \text { balonmano } \\
\text { èr shǒu 二手 'segundo' 'mano' } \rightarrow \text { segunda mano } \\
\text { u tuĩ chē 手推車 'mano' 'empujar' 'carro' } \rightarrow \text { carrito de compras }\end{array}$ \\
\hline & $\begin{array}{l}\text { jiăo 腳 } \\
\text { 'pie' } \\
\text { zú 足 } \\
\text { 'pie' }\end{array}$ & $\begin{array}{c}\text { jiăo tà băn 腳踏板 'pie' 'pisar' 'tabla' } \rightarrow \text { pedal } \\
\text { shē zú 失足 'perder' 'pie' } \rightarrow \text { traspié } \\
\text { shān jiăo 山腳 'montaña' 'pie' } \rightarrow \text { piedemonte } \\
\text { băi zú chóng 百足蟲 'cien' 'pie' 'bicho' } \rightarrow \text { ciempiés } \\
\text { píng dí zú 平底足 'plano' 'fondo' 'pie' } \rightarrow \text { pie plano } \\
\text { xiān găng jiăo 香港腳 'Hong Kong' 'pie' } \rightarrow \text { pie de atleta } \\
\text { jiăo tà chē 腳踏車 'pie' 'pisar' 'coche' } \rightarrow \text { bicicleta } \\
\text { shǒu zú 手足 'mano' 'pie' } \rightarrow \text { hermano }\end{array}$ \\
\hline
\end{tabular}

Tabla 12: Integración conceptual en la composición 
Formantes gramaticalizados y lexicalizados en la morfología del chino mandarín y el 323 español

Por último, la teoría del análisis semántico también conduce a algunas características de la composición en ambas lenguas. Como señala Bustos Gisbert (1986), la definición de los compuestos endocéntricos se funda en la relación existente entre el referente y el compuesto: un compuesto que representa una especialización con respecto a su núcleo referencial es considerado endocéntrico. Siguiendo la observación de Zeng (2008), los compuestos endocéntricos pueden dividirse en dos tipos según el orden del contenido semántico del modificador y del núcleo: núcleo pospuesto y núcleo antepuesto. Tanto en chino mandarín como en español, el compuesto endocéntrico puede presentarse en distintas estructuras morfológicas. Véanse los siguientes ejemplos:

\begin{tabular}{|c|c|c|}
\hline & Chino mandarín & Español \\
\hline $\begin{array}{c}\text { Núcleo } \\
\text { pospuesto }\end{array}$ & $\begin{array}{l}\text { tiě lù 鐵路 'hierro' 'camino' } \rightarrow \text { ferrocarril } \\
\text { năo zhōng 閙 鐘 'perturbar' 'reloj' } \rightarrow \\
\text { despertador } \\
\text { fěn suì 粉碎 'polvo' 'roto' } \rightarrow \text { pulverizado } \\
\text { 透明 'transparentar' 'claro' } \rightarrow \text { transparente }\end{array}$ & $\begin{array}{l}\mathrm{N}+\mathrm{N} \text { : bocateja, } \\
\text { casapuerta } \\
\mathrm{A}+\mathrm{N} \text { : altamar } \\
\mathrm{Adv}+\mathrm{N} \text { : malhumor }\end{array}$ \\
\hline $\begin{array}{c}\text { Núcleo } \\
\text { antepuesto }\end{array}$ & $\begin{array}{l}\text { pái duì 排隊 'ordenar, disponer' 'fila' } \rightarrow \\
\text { ponerse en filas } 55 \\
\text { aó yè 鳌夜 'aguantar, soportar' 'noche' } \rightarrow \\
\text { trasnochar } \\
\text { lǐ fă 理髮 'arreglar' 'pelo' } \rightarrow \text { cortar el pelo } \\
\text { jiàn miàn 見面 'ver' 'cara' } \rightarrow \text { verse } \\
\text { fáng daò 防盜 'prevenir' 'robo' } \rightarrow \text { antirrobo }\end{array}$ & $\begin{array}{l}\mathrm{N}+\mathrm{A} \text { : pelícano, } \\
\text { bancarrota } \\
\mathrm{N}+\mathrm{N} \text { : bocacalle } \\
\mathrm{N} \text { de } \mathrm{N} \text { : campo de } \\
\text { fútbol, centro de salud }\end{array}$ \\
\hline
\end{tabular}

Tabla 13: Composición endocéntrica

Tradicionalmente, la lingüística ha explicado la relación entre el núcleo y el modificador del compuesto a partir de varios facores, como el grado de fijación, la estructura sintáctica, los aspectos morfológicos de género, número y afijación y la coherencia existente entre el compuesto y su núcleo. En los compuestos endocéntricos, el modificador o el complemento con la

55 En Chao (1968: § 6.5.3), se define que la construcción $\vee+O$ se identifica con el compuesto endocéntrico con el verbo como núcleo del conjunto, pues el compuesto exocéntrico $\mathrm{V}+\mathrm{O}$ no tiene como núcleo el verbo. 
Morfología contrastiva del chino mandarín y el español. Formas de gramaticalización y lexicalización

preposición de en español forma un elemento que se subordina al núcleo. Este complemento preposicional desempeña la función principal de indicar la diferencia específica con respecto al conjunto y marcar el referente del compuesto.

Sin embargo, desde la perspectiva cognitiva, Fauconnier y Turner (1995) señalan que la explicación semántica de la composición ha demostrado que el compuesto no es simplemente una estructura de " $1+1 \neq 2$ ", pues el contenido semántico del complejo no siempre consiste en la composicionalidad del significado de los constituyentes. La formación compositiva se lleva a cabo mediante el uso de mecanismos cognitivos de carácter específico. Este proceso cognitivo genera la proyección de dos dominios de entrada y fusión conceptual. A través de los patrones y de elaboraciones dinámicas, se desarrolla una organización emergente por sí misma.

Desde el punto de vista cognitivo, el modificador adjetival o el complemento con de ofrecen explicaciones de la categorización semántica del compuesto. Además de la función de modificación y especificación, el constituyente modificador aporta las características semánticas que definen el núcleo. Por ejemplo, en el compuesto sintagmático cajero automático, aunque el núcleo es cajero 'máquina que realiza las funciones de la caja de los comercios o bancos', el modificador automático decide principalmente el contenido semántico del conjunto, que muestra las condiciones que definen la categoría semántica del núcleo y ofrece rasgos relativos sobre el significado léxico del complejo. Así, el constituyente automático 'perteneciente o relativo al autómata; dicho de un mecanismo: que funciona en todo o en parte por sí solo' aporta algunas características semánticas que se integran con el concepto de cajero y así se produce el contenido particular de esta lexicalización. Esta integración semántica puede explicarse a partir del foco cognitivo de blending de Fauconnier (1997) y Fauconnier y Turner $(1998,2002)$. 
Formantes gramaticalizados y lexicalizados en la morfología del chino mandarín y el 325 español

Como se ha mencionado arriba, básicamente la fusión (blending) consiste en un mecanismo cognitivo que opera simultáneamente sobre dos espacios mentales y forma un tercer espacio mental 56 a partir de una selección de estructuras de estos espacios. En palabras de Fauconnier y Turner (1998: 133), este tercer espacio es el blend, que tiene carácter emergente en el sentido de que desarrolla estructuras propias y no deriva del dato inicial o input -"not provided by the inputs". Independientemente del dominio conceptual del que se trate, el mecanismo de blending opera siguiendo estrictamente un conjunto uniforme de principios estructurales y dinámicos (Fauconnier 1997: 149 y Fauconnier y Turner 1998: 136 y 2002: 40).

Fauconnier (1997: 149) señala que todo el proceso de blending se inicia con un enlace parcial de elementos en la estructura fuente y contrapartes en la estructura meta. Este enlace es parcial en el sentido de que no afecta a todos los elementos integrantes de los dos espacios, sino solamente a aquellos que tienen la capacidad de ser enlazadas por esquemas abstractos. Estos esquemas están compartidos por elementos de la estructura fuente y su contraparte en la estructura meta y forman una nueva estructura denominada espacio genérico. Una vez establecidos los enlaces y formado un espacio genérico, el proceso blending procede a la construcción de un nuevo espacio, que es el blend (o espacio de fusión). Esta construcción se lleva a cabo mediante la proyección parcial de elementos de la estructura fuente y de la estructura meta. La parcialidad de la proyección puede seleccionar tan solo algunas características de un elemento y excluir otras. Tal proyección produce una fusión entre un elemento de la estructura fuente y otro de la estructura meta en el caso de la proyección fusionada (Fauconnier 1997: 155-159). La siguiente figura, basada en el esquema de Fauconnier (1997: 151) y Huelva (2007: 17), representa esquemáticamente este proceso cognitivo en el compuesto cajero automático:

56 Los espacios mentales son unidades conceptuales de una cierta complejidad formados por elementos individuales y modelos cognitivos. Fauconnier (1994) indica que los espacios mentales pueden pertenecer a diferentes dominios conceptuales. En nuestro caso equivalen al dominio-origen y al dominio-meta. 
Morfología contrastiva del chino mandarín y el español. Formas de gramaticalización y lexicalización

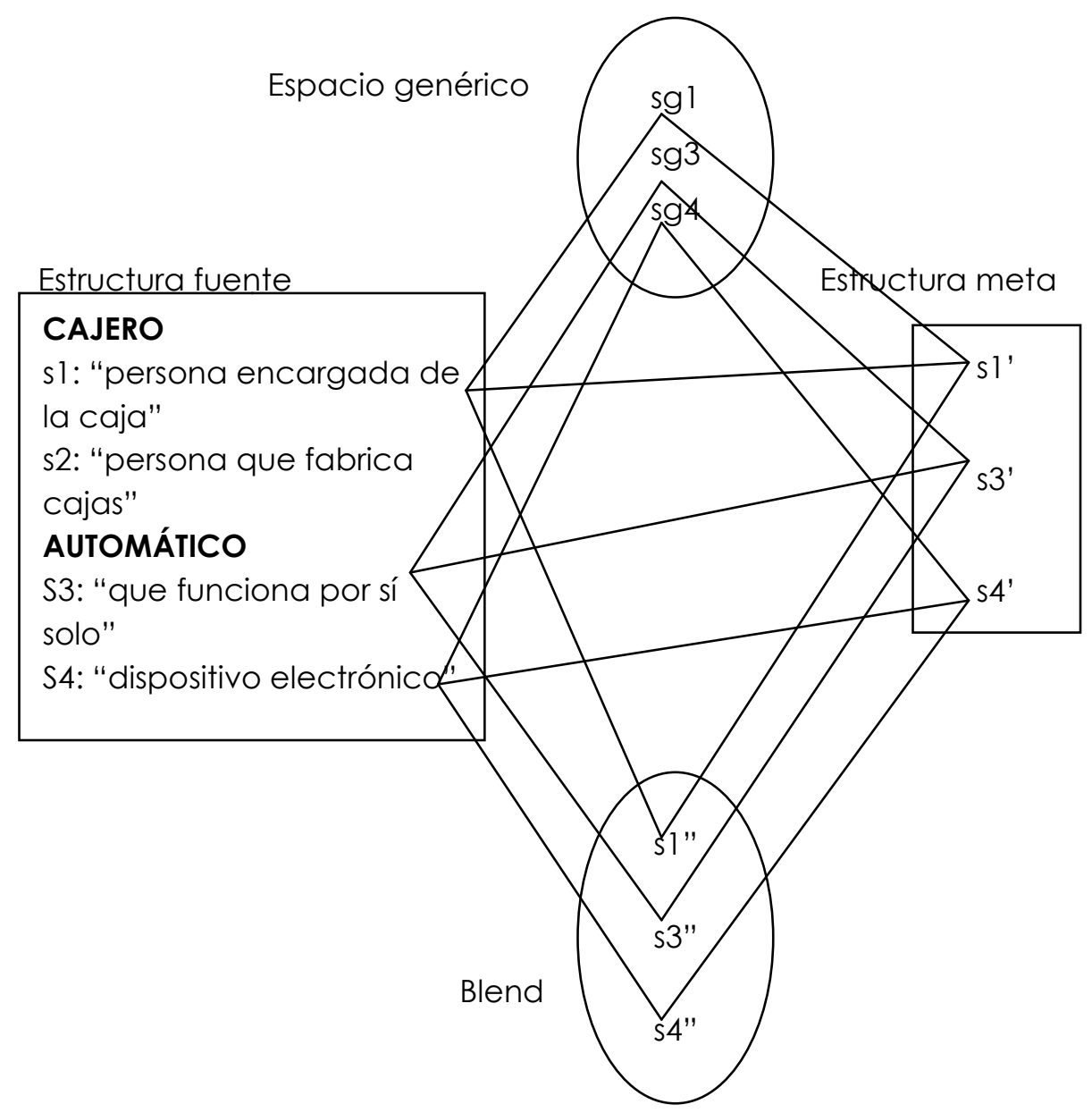

Construcción del Blend en la formación de cajero automático

Como se observa, tanto la estructura fuente como la estructura meta contienen los rasgos semánticos de 'persona encargada de la caja' y 'funciona por sí solo'. Entre s1, s3 y sl' y s3', se establecen enlaces que a su vez dan lugar a los elementos sg 1 y sg3, respectivamente. Los sg 1 y sg3 representan los rasgos de 'persona encargada de la caja' y 'funciona por sí solo' a un nivel genérico y no actualizados como parte constitutiva de un elemento lingüístico determinado. La construcción del compuesto se lleva a cabo cuando el proceso de blending se produce mediante la proyección parcial de elementos de la estructura fuente y de la estructura meta, y, como se ve, la proyección solecciona solo algunas características y excluyen otras. Así, en el blend emerge una estructura nueva con elementos, características y relaciones que 
Formantes gramaticalizados y lexicalizados en la morfología del chino mandarín y el 327 español

no existían ni en la estructura fuente ni en la estructura meta. Este proceso de emergencia se produce mediante el uso de mecanismos de la composición. Así, la composición de cajero automático significa que el blend junta elementos que, por pertenecer a estructuras diferentes, estaban separados, dando lugar con ello a relaciones anteriormente inexistentes. Este mecanismo de composición forma una unidad lingüística compleja mediante la junción de los elementos seleccionados de los que consta el blend.

Frente a los compuestos endocéntricos, los compuestos exocéntricos son, como señala Bustos Gisbert (1986: § 2.3.1), básicamente los que designan una realidad no referida por ninguno de los elementos componentes, de modo que la atribución semántica de contenidos de las unidades presentes en el compuesto no pertenece al campo nocional de su núcleo referencial.

En los compuestos exocéntricos, la relación semántica entre el compuesto y sus elementos componentes es menor, pues la formación no es simplemente un proceso que se lleva a cabo mediante el mecanismo de blending, sino que se activan otros mecanismos cognitivos que conceptúan tal proceso de composición: la metáfora y la metonimia. Por ejemplo, en el compuesto del chino mandarín gān xǐ 乾洗 'seco' 'lavar' $\rightarrow$ limpieza en seco, antes de que se produzca la junción entre los dos elementos, el adjetivo seco y el verbo lavar no solo presentan diferencias en aspectos sintácticos y semánticos, sino que además manifiestan contradicción de rasgos semánticos: seco representa el carácter semántico de [-usar agua] mientras lavar denota el carácter de [+usar agua] en la actuación de "lavar ropa". Sin embargo, con el desarrollo de la técnica, el sistema de lavado de prendas incluye el "lavado" sin el uso de agua, de modo que se necesita una nueva expresión para denotar el concepto de "lavar ropa + lavar sin agua". De los elementos léxicos existentes se encuentran dos que corresponden a este concepto: seco y lavar, cuyos caracteres semánticos constituyen dos espacios de "input" (o datos de entrada). Luego, tras la elaboración del proceso cognitivo, en el espacio genérico se conservan los rasgos semánticos de seco [-usar agua] y lavar 
Morfología contrastiva del chino mandarín y el español. Formas de gramaticalización y lexicalización

[+para limpiar] y se abandonan los aspectos semánticos de lavar [+usar agua]. Se forma así el blend compositivo estructurado gān xĭ gān x̌̃ 乾洗 'seco' 'lavar' $\rightarrow$ limpieza en seco. Cabe tener en cuenta que la formación compositiva no termina aquí en la selección y junción de los elementos semánticos, pues el mecanismo metafórico también participa en esta proyección fusionada. Como es sabido, la metáfora opera entre dos dominios distintos. En nuestro ejemplo, la actuación de "lavar (prendas) con agua" puede situarse en el dominio origen, mientras que "lavar (prendas) sin agua" puede colocarse en el dominio destino, tal como ilustra el siguiente cuadro:

\begin{tabular}{|c|c|c|}
\hline & $\begin{array}{c}\text { Metáfora conceptual } \\
\text { Fusión (Blending) }\end{array}$ & \\
\hline Dominio origen & lavar en seco & Dominio destino \\
$\begin{array}{c}\text { lavar (prendas) con } \\
\text { agua }\end{array}$ & & $\begin{array}{c}\text { lavar (prendas) sin } \\
\text { agua }\end{array}$ \\
\hline
\end{tabular}

Tabla 14: Dominios de la metáfora conceptual lavar en seco

Aunque estas dos actuaciones difieren en el tratamiento y el uso de líquido, tienen en común el proceso de "lavar" y el "resultado": quitar la suciedad, arreglar la prenda y hacer que quede limpia. Así, la composición se lleva a cabo tras el mecanismo de blending y la proyección de metáforas conceptuales.

Un ejemplo en el que se combinan los mecanismos de blending y la metonimia puede ser la lexicalización de un compuesto del español como ciempiés. Probablemente, esta composición se forma a partir de un proceso cognitivo en el que se conservan en el espacio genérico los rasgos semánticos de cien [+cantidad elevada] y pie [+extremidad para moverse] y se abandonan los aspectos semánticos de cien [+100 exactamente] y pie [+ humano]. Así en el blend se forma una unidad lingüística compleja mediante la junción de los elementos seleccionados producida por la proyección fusionada. Sin embargo, en este proceso compositivo, el elemento pie es una parte del cuerpo y hace referencia al movimiento de los seres. Así, se observa 
Formantes gramaticalizados y lexicalizados en la morfología del chino mandarín y el 329 español

el mecanismo metonímico de la parte por el todo en el que interviene una parte del cuerpo y la significación final del conjunto corresponde a una entidad [-humana]. El proceso puede ilustrarse en el siguiente cuadro:

\begin{tabular}{|c|c|l|}
\hline \multicolumn{2}{|c|}{ Dominio único } \\
\hline $\begin{array}{c}\text { Parte del cuerpo: } \\
\text { pie }\end{array}$ & $\begin{array}{c}\text { Metonimia } \\
\text { Fusión (Blending) }\end{array}$ & $\begin{array}{l}\text { Significación abstracta [+ } \\
\text { cantidad elevada]: un tipo } \\
\text { de gusano }\end{array}$ \\
\cline { 2 - 3 } & $\begin{array}{c}\text { la parte por el todo } \\
\text { ciempiés }\end{array}$ & \\
\hline
\end{tabular}

Tabla 15: Operación metonímica en el compuesto ciempiés

Así la composición de ciempiés se lleva a cabo tras el mecanismo de blending y la proyección de una metonimia conceptual.

Partiendo del análisis semántico de la formación de construcciones compositivas de la lengua china y española, se ha demostrado que la lexicalización del compuesto puede ser analizado como un caso de proceso cognitivo, sobre todo, por la participación del mecanismo de blending (Huelva 2007, Lin y Yang 2007, Muñoz Gutiérrez 2006, Zeng 2008). Los motivos principales que justifican este análisis son las propiedades emergentes que presentan las construcciones compositivas resultantes de procesos de lexicalización. Como un caso de blending, la lexicalización del compuesto es el producto de un conjunto complejo de operaciones cognitivas entre las que se encuentran:

1) La identificación de semejanzas entre elementos pertenecientes a dominios conceptuales diferentes y la formación de un espacio genérico donde se presentan estas semejanzas.

2) La proyección parcial de elementos a un nuevo espacio mental, el blend.

3) La estructuración del contenido de este nuevo espacio mediante la operación de composición y, al final, la formación de una nueva unidad lingüística compleja mediante la fijación del blend. 
Morfología contrastiva del chino mandarín y el español. Formas de gramaticalización y lexicalización

\subsection{Resumen y conclusiones}

En este capitulo se han analizado los principales formantes lexicalizados y gramaticalizados en la morfología de las dos lenguas contrastadas. En cuanto a la gramaticalización, se ha dado cuenta de que se cumplen en las dos lenguas las principales condiciones de este proceso. En síntesis, tanto en español como en chino mandarín, la gramaticalización supone el cambio de un elemento autónomo en un estado de lengua anterior a un elemento dependiente en el estado de lengua actual. Esta evolución conduce al debilitamiento semántico, al aumento de la productividad, al cambio desde un estadio referencial a otro gramatical, al desarrollo de sentidos abstractos (generalización del significado) y, en muchos casos, también a la tendencia hacia la polisemia, al incremento de funciones gramaticales y a la evolución desde de una categoría léxica mayor a otra categoría menor.

Conviene llamar la atención sobre la semejanza de los procesos que conducen en español, por un lado, a la formaron de temas polimórficos cultos desde formas originarias grecolatinos y a la formación en chino mandarín, por otro lado, de los llamados afijoides. También resultaría relativamente comparable la gramaticalización de las formaciones femeninas en chino mandarín a partir de las formas léxicas mŭ 母 'madre' y nŭ 女 'mujer o hija' con respecto a las formaciones españolas en las que los sustantivos madre, mujer, moza, etc., también son signos gramaticales del femenino, o de la idea de 'reproducción' (pez mujer, mujer objeto; madreselva, madreperla, célula madre, aeromoza, etc.). Finalmente también conviene resaltar en este resumen que el nivel de la gramaticalización que desciende hasta el plano

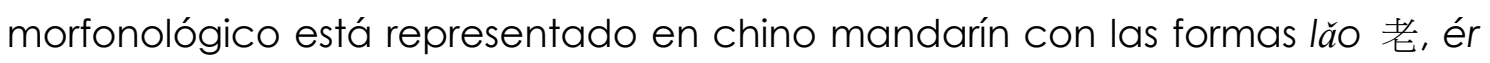
兒，zi 子 y tóu 頭. Sin embargo, este proceso de evolución desde una forma léxica plena hasta un elemento morfonológico no creemos que se produzca en español. 
Formantes gramaticalizados y lexicalizados en la morfología del chino mandarín y el 331 español

Otra diferencia destacable reside en la gramaticalización que experimentan los elementos léxicos del chino mandarín para expresar los sufijos afectivos. Sin embargo, este tipo de gramaticalización (común a otras lenguas, como el francés petit) no está desarrollado en español, que presenta un grupo numeroso de sufijos afectivos (-ito, -ico, -illo, etc.)

Puede decirse que algunos procesos de lexicalización del español no constituyen una característica de la evolución histórica de la lengua china, al menos, en los casos de formantes flexivos y derivativos, pues estos no se convierten en unidades léxicas con registro en el diccionario actual del mandarín. En efecto, la lexicalización consiste, en resumen, en el desarrollo de una evolución en sentido contrario al esquema jerárquico propuesto para la gramaticalización. La lexicalización conduce a la formación léxica a partir de una unidad dependiente con significado relacional. Los efectos más destacados de la lexicalización son la pérdida del sentido composiciónal (lavabo, pagaré, ventanilla, boletín, etc.) y el aumento de la autonomía sintagmática.

Un estudio aparte merece el tema de la lexicalización de compuestos. Tanto en chino mandarín como en español, puede decirse que la composición es el resultado del proceso de lexicalización, puesto que se transfiere información desde el plano morfológico hasta el plano léxico.

Se ha comprobado en los apartados correspondientes de este capítulo que las principales características de la composición, entendida como un tipo de lexicalización, se manifiestan con pocas diferencias en ambas lenguas. Se trata de aspectos como la fijación sintáctica, la adquisición de valor referencial unitario, la fusión de dos elementos simples en una sola unidad léxica con registro lexicográfico, la imposibilidad de intercalación de elementos y de cambios en la ordenación interna de los constituyentes. Por otra parte, también se ha comprobado la utilidad de considerar la lexicalización como un proceso gradual que permite establecer niveles o escalas de mayor o menor representatividad. En ambas lenguas, se constata el carácter idiosincrásico de 
Morfología contrastiva del chino mandarín y el español. Formas de gramaticalización y lexicalización

las composiciones que presentan un grado elevado de lexicalización. Al mismo tiempo, la aplicación de los diferentes grados de idiomaticidad a los compuestos también ha dado resultados comunes a las dos lenguas. En cuanto a la interacción entre la lexicalización y la gramaticalización, si bien esta interrelación se manifiesta en las dos lenguas, conviene advertir que el fenómeno del acortamiento (tipo tele, foto, etc.) no se da en chino mandarín.

En otro punto, se han tomado en consideración los mecanismos léxicos y gramaticales que favorecen la formación de compuestos. En este sentido, se han mostrado en las dos lenguas en contraste los principales resultados de la aplicación de las diferentes características que favorecen la gramaticalización y la lexicalización, como son la generalización, la fusión, el reanálisis, la analogía y la recategorización.

Finalmente, se han examinado los principales mecanismos cognitivos que propician la formación compositiva de nuestras dos lenguas. A partir de la idea de los principios cognitivos universales y con el reconocimiento del fuerte impacto del inglés en las lenguas contemporáneas, se muestra en este punto la proximidad entre el chino mandarín y el español en la formación de compuestos. Desde esta perspectiva, se aplican a las dos lenguas los principios básicos de la teoría de la integración y la fusión conceptual. La formación de esquemas de recategorización a partir de los tres niveles (el básico, el subordinado y el superordinado) se ha mostrado muy relevante para describir determinados compuestos comunes a las dos lenguas, especialmente los que incluyen partes del cuerpo humano entre las categorías superordinadas (como, por ejemplo, mano y pie). 
8

LEXICALIZACIÓN DE LOCUCIONES NOMINALES

El propósito de este último capítulo de nuestro trabajo consiste en extender el análisis contrastivo a determinados tipos de locuciones nominales que por sus especiales características formales y semánticas pueden ser comparadas en las dos lenguas que son objeto de nuestra atención. Se trata de examinar el comportamiento de la lexicalización en un grupo semejante de compuestos sintagmáticos del español y del chino. El estudio comprende además la selección de algunos factores que permitan distinguir las locuciones de los compuestos léxicos y también de los sintagmas en cada una de las lenguas en contraste.

\subsection{Características generales de la locución}

Julio Casares (1969 [1950]: 37, 75) definía la locución como una "combinación estable de dos o más términos, que funciona como elemento oracional y cuyo sentido unitario consabido no se justifica, sin más, como una suma del significado normal de los componentes". Se proporcionaban así las principales características de lo que posteriormente algunos morfólogos entienden por compuesto sintagmático: estabilidad o fijación, unidad funcional, falta de composicionalidad. No cabe duda de que este tipo de unidades puede definirse en relación con las expresiones fijas y estrechamente con las características de la lexicalización. En palabras de Lipka (1990: 97), la lexicalización es "el fenómeno en que los elementos léxicos complejos, a través 
Morfología contrastiva del chino mandarín y el español. Formas de gramaticalización y lexicalización

del uso frecuente, pueden perder su carácter sintagmático y tienden a convertirse en unidades formales con contenidos específicos" 57 . En este sentido, las locuciones se consideran formas lexicalizadas, pues son estructuras complejas que manifiestan una pérdida de composicionalidad semántica y una adquisición de idiomaticidad.

La clasificación de las locuciones comprende tipos muy variados que, en general, dependen de la categoría funcional resultante y de las clases gramaticales de las unidades constituyentes. Así, cabe distinguir entre locuciones nominales, verbales, adverbiales, etc., y entre locuciones formadas por nombres, verbos, preposiciones, etc. Sin embargo, para nuestro propósito de elaborar un primer estudio contrastivo de los procesos de lexicalización que conducen a la fijación de locuciones en nuestras dos lenguas, el análisis se limitará en este capítulo a los casos representativos que muestran más claramente las semejanzas de estos mecanismos por los que se transforman las combinaciones sintagmáticas en unidades denominativas complejas.

Así, por ejemplo, las locuciones nominales constituidas por nombres y adjetivos en español, del tipo zona verde, mercado negro, renta variable, estrella fija presentan sus equivalentes prácticamente idénticos en chino:

lù dì 綠地 'verde' 'tierra' $\rightarrow$ zona verde

hēi shì 黑市 'negro' 'mercado' $\rightarrow$ mercado negro

fú dòng lì lù 浮動 利率 'flotante' 'renta' $\rightarrow$ renta variable

héng xing 恆星 'perpetuo' 'estrella' $\rightarrow$ estrella fija

Se trata de una muestra que permite justificar nuestro análisis contrastivo, pues, como se ve en los ejemplos, el proceso de lexicalización consta de las dos mismas categorías gramaticales y el conjunto presenta un único significado denominativo comparable. Se observa así un proceso común desde las construcciones sintácticas hacia el plano léxico. Sin embargo, a pesar de las semejanzas, conviene recordar también que en mandarín apenas

57 Texto original en inglés "The phenomenon that complex lexical items, through frecuent usage, may lose their syntagmatic nature and tend to become formal units with specific content". 
es posible distinguir entre el compuesto léxico y el compuesto sintagmático (o locución), mientras que en español las diferencias se manifiestan en varios planos. Así, en el plano prosódico, las unidades de una locución suelen conservar su propio acento (cámpo sánto), frente a la unidad acentual de un compuesto léxico (camposánto). Además del diferente tratamiento lexicográfico, también se reflejan propiedades morfológicas específicas en cada caso: una locución suele admitir el plural de los dos constituyentes (aguas duras), en contraste con la pluralización única del segundo constituyente en el compuesto morfológico (*aguasardientes / aguardientes). Finalmente, los comportamientos en el caso de las referencias anafóricas también permiten distinguir entre algunos tipos de locuciones y compuestos: el adjetivo de una locución nominal, principalmente si esta designa seres humanos, admite la sustantivación (los civiles, por los guardias civiles), lo que resulta anómalo en el caso del compuesto morfológico (*el franco / el francotirador). Por el contrario, ninguna de estas pruebas -u otras semejantes- permitiría distinguir tipos de compuestos en chino mandarín. Sin embargo, una vez presentados los tipos de locuciones que se van a someter aquí al análisis contrastivo, se dedicará cierta atención al problema de las diferencias entre el compuesto morfológico y la locución (o compuesto sintagmático) en la lengua china.

Las estructuras locucionales que se han seleccionado en este capítulo para mostrar procesos de lexicalización convergentes en nuestras dos lenguas se limitan a tres tipos:

1) Locuciones nominales constituidas por nombres y adjetivos de color, del tipo huáng yiè 黃頁 'amarillo' 'página' $\rightarrow$ páginas amarillas.

2) Locuciones nominales formadas con nombres y adjetivos aspectuales, como măn yuè 滿月 'lleno' 'luna' $\rightarrow$ luna llena.

3) Locuciones nominales locativas, que se presentan en español con la forma $\mathrm{N}$ de $\mathrm{N}$ y en chino responden al tipo $\mathrm{NN}$, por ejemplo hăi găng 海港 'mar' 'puerto' $\rightarrow$ puerto de mar. 
Morfología contrastiva del chino mandarín y el español. Formas de gramaticalización y lexicalización

Estos tres tipos de locuciones se consideran formaciones muy productivas en las dos lenguas. Además, la semejanza formal y semántica de estas estructuras pone de manifiesto que el carácter idiomático e irregular, el sentido idiosincrásico e imprevisible, tradicionalmente atribuidos a estas formaciones complejas, resultan en cierto modo cuestionables. Una tercera característica común a estas locuciones en nuestras dos lenguas reside en la función que desempeñan los elementos no nucleares. En estas posiciones locucionales, los adjetivos y los complementos preposicionales, pese a su carácter de modificadores, no son atibutivos ni predicativos, porque no adscriben propiedades a los objetos ni son propiamente caracterizadores. Véanse algunos ejemplos que muestran que una locución no se interpreta en el mismo sentido que una construcción predicativa o atributiva:

las páginas amarillas / *las páginas son amarillas la luna llena / *la luna está/se pone llena

el puerto de mar / *el puerto es de mar

Por otra parte, aunque se observan casos tanto de endocentricidad como de exocentricidad en estas locuciones de ambas lenguas, parece que las locuciones locativas tienden a presentar una interpretación endocéntrica, pues rara vez el nombre nuclear aporta a la locución un sentido ajeno a su propia definición léxica. Por el contrario, las locuciones nominales constituidas por adjetivos de color y aspectuales se reparten con más facilidad entre el endocentrismo y el exocentrismo:

Endocentrismo

puerto de mar

salón de actos

té verde

Iuna llena

\section{Exocentrismo}

casa de citas

páginas amarillas

media naranja

En cuanto a la posibilidad de distinguir entre el compuesto y la locución en mandarín, a pesar de que los recursos utilizados para el español apenas pueden aplicarse al chino y de que la bibliografía especializada no 
parece que resuelva esta cuestión, se plantea aquí la siguiente explicación. Las locuciones nominales -al menos las examinadas en este apartado- en una y otra lengua se distinguen de los compuestos correspondientes porque el nombre cabecera (o nuclear) de una locución adquiere propiedades anafóricas en referencia a toda la locución si esta ha sido ya presentada en el discurso. Por el contrario, el sustantivo que forma parte de un compuesto morfológico semejante ha perdido su capacidad anafórica asociativa. Se puede comprobar el diferente comportamiento en los siguientes ejemplos:

\section{Ejemplos de español:}

1) En la plaza de toros de Valencia sigue el trasiego de animales y hierros. Hoy la corrida fue rechazada en su totalidad por el presidente y los veterinarios de la plaza (Consulta del CREA).

2) *Muchos periodistas se acercaron al camposanto. A las cuatro de la tarde se ofició una misa en la misma capilla del campo.

\section{Ejemplos de chino mandarín:}

1) 這 個 植物 園 很大，依植物 類型，

Zhè ge zhí wù yuán hăn dà yī zhí wù lèi xíng

Este clas. planta jardín muy grande, según planta clase,

園 內 分 為 六 區
yuán nèi fān wéi liò chū
jardín interior distinguir en seis zona

Este jardín botánico es muy grande. Se distiguen seis zonas en el jardín según las clases de plantas.

2) 白肉是一 種含較少飽和脂肪 Bái ròu shì ȳ̄ zhǒng hán jiào shăo băo hé zhē fáng Blanco carne ser un tipo contener menos satudado grasa

$\begin{array}{ll}\text { 的 } & \text { 肉 } \\ \text { de } & \text { ròu } \\ \text { part. relativa } & \text { carne }\end{array}$

La carne blanca es un tipo de carne que contiene menos grasa saturada.

3) *儘管 他是 新手，卻 是 優秀 的 手 Jǐn guăn tā shì xīn shǒu chuè shì yoū shiù de shǒu aunque él ser nuevo mano, pero ser bueno marc. de atribución mano *Aunque es un novato (nueva mano), es una buena mano. 
Morfología contrastiva del chino mandarín y el español. Formas de gramaticalización y lexicalización

\subsection{Locuciones nominales constituidas por nombres y adjetivos de color en chino mandarín y español}

\subsubsection{Los adjetivos de color}

Las locuciones nominales constituidas por nombres y adjetivos de color constituyen en las dos lenguas comparadas en este trabajo un caso muy representativo de un proceso de lexicalización común, como puede comprobarse en los siguientes ejemplos:

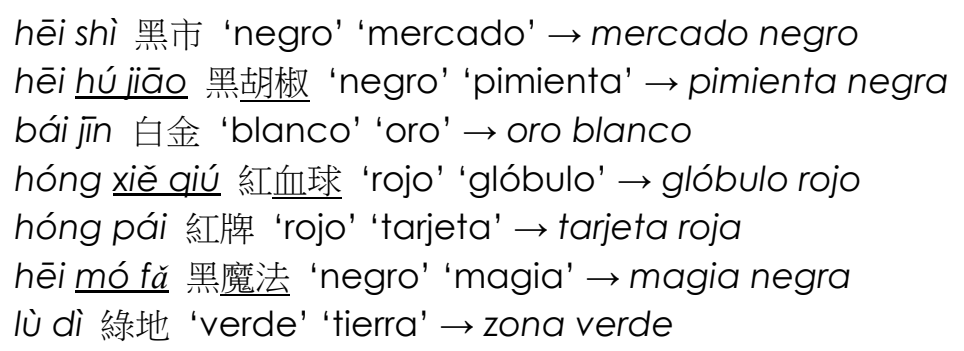

En ambas lenguas, la lexicalización de este tipo de formaciones depende en gran medida de las propiedades léxicas y gramaticales de los adjetivos. Así, por ejemplo, en un sintagma nominal del tipo coche amarillo, el adjetivo identifica por el color una clase de objetos que no dejan de ser coches. Sin embargo, en las locuciones nominales formadas por este adjetivo, el amarillo es algo más que un color que se atribuye al objeto representado por el nombre. En efecto, los adjetivos de color forman parte de los elementos semánticamente intersectivos (también llamados categoremáticos o absolutos), que asignan una propiedad no solo al nombre sino también a la clase hiperónima del nombre (las páginas amarillas son una clase de objetos de color amarillo) (Demonte 1999: 178). Es decir, el adjetivo de una locución nominal aporta la identidad relevante del objeto denotado, tanto si este se expresa mediante una construcción semánticamente endocéntrica como si la forma compleja no es completamente endocéntrica. 
La lexicalización de estas locuciones nominales en una y otra lengua se manifiesta en varios aspectos. En primer lugar, la fijación formal explica que los adjetivos de estas locuciones nominales rechacen el cambio de posición, como en 1); por lo mismo, estos adjetivos no son graduables ni aceptan construcciones comparativas, como en 2); finalmente, una locución nominal no se interpreta en el mismo sentido que una construcción atributiva o predicativa, como en 3), pues en español no suele admitirse la paráfrasis con un verbo atributivo y en chino tampoco se tolera la presencia del marcador de atribución de 的:

1) zona verde $=>*$ verde zona

mercado negro $=>*$ negro mercado

bái jiǔ 白酒 'blanco' 'vino' $\rightarrow$ vino blanco => *jiǔ bái 酒白 'vino' 'blanco'

hóng cháo 紅潮 'rojo' 'marea' $\rightarrow$ marea roja $=>{ }^{*}$ cháo hóng 潮紅 'marea' 'rojo'

2) zona (*tan) verde

*El mercado más negro de todos

(*hěn) bái jiǔ ("很)白酒 (*'muy') 'blanco' 'vino' $\rightarrow$ vino (*muy) blanco

*zuì hóng de hóng 最紅的潮 *'más' 'rojo' "part. superlativa' 'marea' $\rightarrow$ *marea más roja

3) La zona verde / *La zona es verde

El mercado negro / *el mercado es negro

bái jiǔ 白酒 'blanco' 'vino' $\rightarrow$ vino blanco / *jiǔ shì bái de 酒是白的 'vino' 'ser' 'blanco' "marc. de atribución' $\rightarrow$ *el vino es blanco

hóng cháo 紅潮 'rojo' 'marea' $\rightarrow$ marea roja / *cháo shì hóng de 潮是紅的 'marea' 'ser' 'rojo' 'marc. de atribución' $\rightarrow$ *la marea es roja

El segundo aspecto de la lexicalización de estas locuciones nominales consiste en la contracción o especialización semántica. Así, mercado negro no designa cualquier sitio público destinado al comercio, que además es de color negro; designa, como sabemos, 'la venta clandestina e ilegal de productos o servicios'. La restricción semántica se produce por la suma del valor intersectivo del adjetivo de color más el mecanismo metafórica que sufre el adjetivo negro ('ilegal, clandestino', etc.). 
Morfología contrastiva del chino mandarín y el español. Formas de gramaticalización y lexicalización

En suma, una locución nominal no designa un objeto, individuo o entidad, sino una clase particular de estos. A su vez, el adjetivo de la locución no es un predicado de propiedades o cualidades, sino un atributo adyacente clasificador.

\subsubsection{La estructura formal y la posición del adjetivo}

En este apartado, se toma como fuente del español el Diccionario de la lengua española de la Real Academia Española en su 22. ${ }^{a}$ edición de 2003 (edición electrónica) para el análisis de las locuciones nominales constituidas por nombres y adjetivos de color. Por otro lado, también se incluyen en el presente trabajo otras formaciones idiomáticas que aún no aparecen en el DRAE pero presentan en el uso actual la fijación en sus componentes, como marca blanca, páginas amarillas, ejército rojo, Navidades Blancas, cinturón negro, etc. Respecto a la fuente de las formaciones léxicas adjetivo-nombre del chino mandarín, se recogen las que figuran en el trabajo de Z.-B. Liu (2008), donde se considera la combinación adjetivo de color más nombre como un tipo sintagmático lexicalizado. También se toman como referencia las formaciones compuestas según el Diccionario Español de la Lengua China (2000), con el fin de realizar una traducción correspondiente al español. El corpus recopilado de tales estructuras en chino mandarín y el español constiuye la base del estudio contrastivo.

El análisis se centra en las combinaciones nominales de adjetivo más nombre, especialmente con adjetivos de color. En español, los adjetivos van adyacentes pospuestos al nombre, mientras que en chino mandarín los adjetivos aparecen por lo común en posición prenominal. Se muestran algunos ejemplos a continuación: 


\section{Español}

príncipe azul números rojos

arma blanca dinero negro

cenizas azules zona verde

\section{Chino mandarín}

hēi shì 黑市 'negro' 'mercado' $\rightarrow$ mercado negro

bái băn 白板 'blanco' 'tabla' $\rightarrow$ pizarra blanca

hóng dàn 紅蛋 'rojo' 'huevo' $\rightarrow$ huevo dibujado en color rojo que se da en celebraciones de boda o de nacimiento

húang niú 黃牛 'amarillo' 'buey' $\rightarrow$ persona que saca beneficio ilegal de la venta de entradas, reventa

lù chá 綠茶 'verde' 'té' $\rightarrow$ té verde

Tanto en chino mandarín como en español, la combinación de un nombre y un adjetivo de color es una estructura muy frecuente en la creación léxica. En español se denomina locución o compuesto sintagmático a esta estructura, mientras que en chino mandarín se analizan como compuestos o sintagmas lexicalizados. Pese a la diferencia de la denominación, en ambas lenguas esta combinación se considera una formación compositiva que presenta fijación estructural, carácter idiomático e especificidad semántica.

En chino mandarín, la locución adjetivo de color + nombre difiere del sintagma nominal ordinario en el uso de los determinantes. El rechazo del determinante suele denotar el nivel más elevado de lexicalización. Por ejemplo, mientras que las construcciones de 1) y 3) admiten el uso de determinante, resulta inadecuado el empleo del determinante en las locuciones de 2) y de 4):

1) hēi chē 黑車 'negro' 'coche' $\rightarrow$ coche negro nà tái hēi chē 那台 黑車 'aquel' 'negro' 'coche' $\rightarrow$ aquel coche negro

2) hēi shì 黑市 'negro' 'mercado' $\rightarrow$ mercado negro *nà ge hēi shì 那個黑市 'aquel' 'negro' 'mercado' $\rightarrow$ *aquel mercado negro

3) huáng qián 黃牆 'amarillo' 'pared' $\rightarrow$ pared amarilla tā jiā de huáng qián 他家的黃牆 'él' 'casa' 'part. posesiva' 'amarillo' 'pared' $\rightarrow$ la pared amarilla de su casa

4) húang tāng 黃湯 'amarilla' 'sopa' $\rightarrow$ bebida alcóholica *tā jiā de huáng tāng 他家的黄湯 'él' 'casa' 'part. posesiva' 'amarilla' 'sopa' $\rightarrow$ *la bebida alcólica de su casa 
Morfología contrastiva del chino mandarín y el español. Formas de gramaticalización y lexicalización

Frente a la indiferencia de las locuciones del chino en cuanto a la selección del número gramatical, en español hay locuciones constituidas por nombre y adjetivo de color que se usan tanto en singular como en plural sin cambio de significado, como el caso de carne blanca y carnes blancas. Pero, por lo común, la lexicalización en forma plural suele responder al carácter no contable, colectivo o abstracto del nombre:

$\begin{array}{ll}\text { aguas negras } & \text { cabos negros } \\ \text { armas blancas } & \text { moscas blancas } \\ \text { páginas amarillas } & \text { números rojos } \\ \text { cenizas verdes } & \text { habas verdes } \\ \text { cascos azules } & \text { diablos azules }\end{array}$

Las locuciones nombre + adjetivo de color son compuestos sintagmáticos no fusionados gráficamente en ambas lenguas. Se escriben separadamente sin el empleo de guion y se pronuncian con dos acentos fónicos, es decir, los elementos no pierden el acento al entrar en composición, como en los ejemplos anteriores. Sin embargo, también se forman combinaciones de nombre + adjetivo de color cuyo resultado final es un compuesto léxico con fusión gráfica entre sus miembros. Se trata de formaciones como pelirrojo, pelirrubio, barbicano, pelicano, etc., que presentan una -i- vocal de enlace por analogía con los compuestos que requieren este nexo vocálico (tipo sopicaldo). En español, estas formaciones son adjetivos compuestos que se diferencian claramente de las locuciones nominales, a pesar de que presentan la misma forma constitutiva del nombre y adjetivo de color. Sin embargo, su equivalencia en chino mandarín no se distingue de las locuciones nominales, puesto que este tipo de adjetivo compuesto y de locución nominal comparten la misma estructura formal constituida por un adjetivo de color más un nombre:

hóng fă [紅 a. 'rojo' 髮 n. 'pelo'] A o N. $\rightarrow$ pelirrojo o pelo rojo jin $f a ̆$ [金 a 'rubio'.髮 n. 'pelo'] A o N. $\rightarrow$ pelirrubio o pelo rubio bái hú [白 a 'blanco'髧n. 'barba'] A o N. $\rightarrow$ barbicano o barba blanca 
Como se observa, el adjetivo compuesto no se distingue formalmente de la locución nominal. Solo es posible la distinción en el uso contextual:

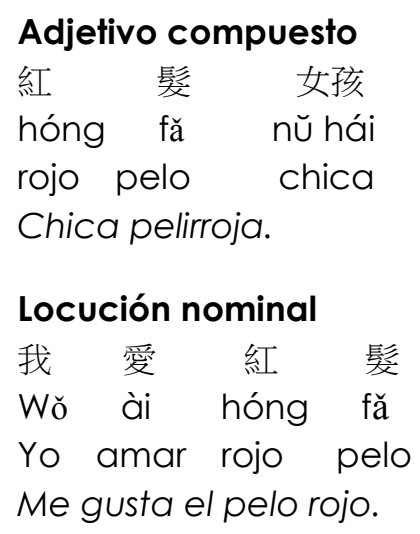

\subsubsection{Clasificación contrastiva}

Sin embargo, para contribuir a nuestro propósito de ofrecer un análisis contrastivo, se propone aquí una nueva clasificación que atiende, de una parte, a las locuciones que se corresponden en ambas lenguas y, de otra, a las formaciones que resultan incomparables, pues no comparten propiedades formales o de significado.

Así, las composiciones que resisten el análisis contrastivo presentan una estructura semejante, aunque cambia la posición del nombre y el adjetivo de color, como ya se ha señalado. Estas combinaciones designan un referente idéntico o similar en ambas lenguas, pero el significado final del conjunto puede o no responder a motivaciones metafóricas. En este último caso, sin necesidad de interpretaciones figuradas, el contenido semántico de la combinación es deducible de las partes constitutivas:

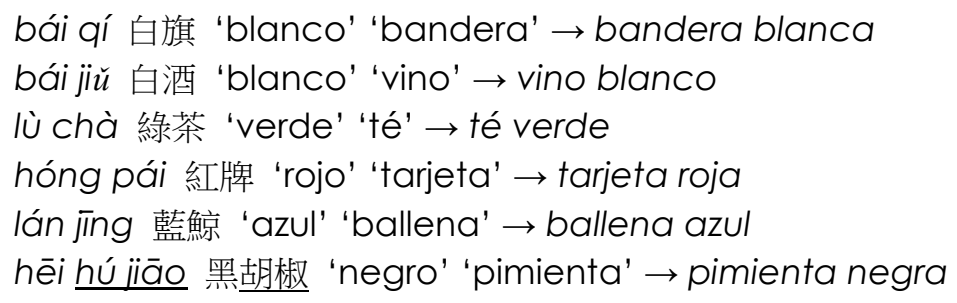


Morfología contrastiva del chino mandarín y el español. Formas de gramaticalización y lexicalización

bái jin 白金 'blanco' 'oro' $\rightarrow$ oro blanco

bái y y̌̌ 白蟻 'blanco' 'hormiga' $\rightarrow$ hormiga blanca

hóng xiě qiú 紅血球 'rojo' 'glóbulo' $\rightarrow$ glóbulo rojo

hóng cháo 紅潮 'rojo' 'marea' $\rightarrow$ marea roja

En algunos casos, los constituyentes no se corresponden exactamente en ambas lenguas, pero también resulta altamente deducible el significado final del conjunto:

běi jí xiang 北極熊 'norte' 'polo' 'oso' $\rightarrow$ oso polar (oso blanco) kòng bái zhǐ 空白紙 'vacío' 'blanco' 'papel' $\rightarrow$ papel blanco

hēi kā fēi 黑咖啡 'negro' 'café' $\rightarrow$ café solo

Por su parte, en las composiciones figuradas, el significado metafórico también es idéntico o similar en ambas lenguas, debido a que los hablantes comparten la misma filosofía, las mismas costumbres o las mismas ideas que sustentan la designación de un determinado concepto cognitivo a uno y otro lado del mundo. El significado de estas combinaciones no es semánticamente transparente, pues suele responder a motivaciones metafóricas. Esta falta de composicionalidad semántica puede venir dada por la totalidad del compuesto o bien por una sola de sus partes:

hēi mó fă 黑魔法 'negro' 'magia' $\rightarrow$ magia negra

hēi sè yōu mò 黑色 幽默 'negro' 'humor' $\rightarrow$ humor negro

hēi shì 黑市 'negro' 'mercado' $\rightarrow$ mercado negro

hēi jin 黑金 'negro' 'dinero' $\rightarrow$ dinero negro

hēi míng dān 黑名單 'negro' 'lista' $\rightarrow$ lista negra

bái pí shū 白皮書 'blanco' 'corteza' 'libro' $\rightarrow$ libro blanco (colección de documentos diplomáticos)

bái ròu 白肉 'blanco' 'carne' $\rightarrow$ carne blanca

húang rè bìng 黃熱病 'amarillo' 'calor' 'enfermedad' $\rightarrow$ fiebre amarilla

chì zì 赤字 'rojo' 'número' $\rightarrow$ números rojos

Respecto a las composiciones que no ofrecen puntos de encuentro en ambas lenguas, hay casos en los que a los elementos léxicos simples del español les corresponden formaciones locucionales en chino que tratan de describir la realidad mediante el carácter intersectivo del adjetivo de color: 
hēi guăn 黑管 'negro' 'tubo' $\rightarrow$ clarinete

hēi băn 黑板 'negro' 'tabla' $\rightarrow$ pizarra

lù zhōu 綠洲 'verde' 'continente, provincia' $\rightarrow$ oasis

hēi méi 黑莓 'negro' 'mora' $\rightarrow$ zarzamora

Estas formas complejas del chino, basadas en significados metafóricos muy distintos, se corresponden en español con elementos léxicos de morfología también muy variada (palabras simples, derivadas o compuestas). Generalmente, la fijación se produce a partir de un proceso metafórico que proyecta el significado concreto a otro más abstracto. Así, el significado del conjunto no es deducible a partir de los elementos que lo componen. Debido al fuerte sentido idiosincrásico, estas formas están muy lexicalizadas, de modo que pueden provocar malentendidos y han de ser memorizadas por los aprendices:

\author{
Ejemplos del español y su equivalencia en chino mandarín \\ aguas negras $\rightarrow$ fèi shŭi 廢水 'abandonado' 'agua' \\ garbanzo negro/ oveja negra $\rightarrow$ lăo shǔ shǐ 老鼠屎 'ratón' 'caca' \\ fiebre amarilla $\rightarrow$ húang rè bìng 黃熱病 'amarillo' 'calor' 'enfermedad' \\ novela rosa $\rightarrow$ yàn gíng xiăo shuō 愛情 小說 'amor' 'novela' \\ páginas amarillas $\rightarrow$ diàn huà bù 電話簿 'teléfono' 'libro' \\ Ejemplos del chino mandarín y su equivalencia en español \\ lán tú 監圖 'azul' 'dibujo' $\rightarrow$ dibujo técnico/papel carbón (de calco) \\ qīng lóu 青樓 'verde' 'edificio' $\rightarrow$ casa de prostitución \\ húang jin 黃金 'amarillo' 'dinero' $\rightarrow$ oro \\ bái fěn 白粉 'blanco' 'polvo' $\rightarrow$ heroína, cocaína \\ fěn hóng diàn yǐng 粉紅 電影 'rosa' 'película' $\rightarrow$ película porno \\ hóng shǔ 紅薯 'rojo' 'patata' $\rightarrow$ papa dulce (batata)
}

\title{
8.2.4 Principales diferencias de productividad
}

Tanto en el chino mandarín como en español, los adjetivos de color se sustantivan con facilidad siempre que el contexto sintáctico permita la elipsis del sustantivo implícito color. Así, en ambas lenguas son expresiones semejantes color rojo y rojo; hóng sè 紅色 'rojo' 'color' y hóng 紅 'rojo'. Del mismo modo, 
Morfología contrastiva del chino mandarín y el español. Formas de gramaticalización y lexicalización

en la construcción sintáctica, resultan intercambiables expresiones del tipo una falda roja y una falda de color rojo, y su equivalente en chino mandarín: hóng qún zi 紅裙子 'rojo' 'falda' $\rightarrow$ falda roja y hóng sè qún zi 紅色 裙子 'rojo' 'color' 'falda' $\rightarrow$ falda de color rojo.

Pues bien, en la formación de locuciones nominales, mientras que en español no interviene el sustantivo color en el proceso de lexicalización, en la lengua china el sustantivo 'color' y el adjetivo cromático correspondiente resultan productivos en la fijación de locuciones nominales. Se trata sobre todo de préstamos del inglés introducidos recientemente en chino, como los ejemplos siguientes:

hēi sè yōu mò 黑色 幽默 'negro' 'color' 'humor' $\rightarrow$ humor negro (/*humor (de) color negro)

hēi sè diàn ying 黑色 電影 'negro' 'color' 'cine' $\rightarrow$ cine negro/cine policíaco húang sè xīn wén 黃色 新聞 'amarillo' 'color' 'prensa' $\rightarrow$ prensa amarilla lù sè zhèng zhì 綠色政治 'verde' 'color' 'política' $\rightarrow$ política verde ('ecológica') lù sè wū dỉng 綠色屋頂 'verde' 'color' 'techo' $\rightarrow$ techo verde ('vegetal')

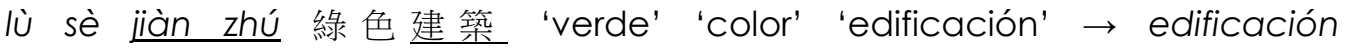
verde/bioconstrucción

Otra particularidad del mandarín reside en la productividad de determinados adjetivos cromáticos del chino clásico, pero solo en la formación de locuciones nominales, pues estas formas anticuadas han caído en desuso en las construcciones sintagmáticas. Así, los adjetivos arcaicos de color wū $⿹$ ⿹ negro, qīng 青 verde y chì 赤 rojo únicamente sobreviven en locuciones como las siguientes:

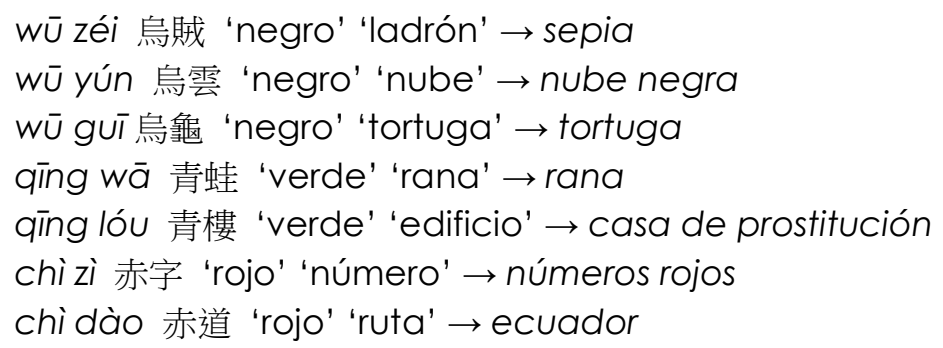


La productividad de este tipo de locuciones formadas con nombres y adjetivos de color resulta ciertamente elevada en cada una de nuestras dos lenguas en contraste. Aunque no es el propósito de este trabajo presentar de forma exhaustiva un registro léxico-semántico de estas locuciones, que en todo caso resultaría útil a la lexicografía bilingüe, pero escasamente representativo de los procesos morfológicos contrastivos, conviene mostrar brevemente la variedad de designaciones que alcanzan estas locuciones. Solo así se podrán deducir posteriormente las principales diferencias de productividad entre estas formaciones lexicalizadas del chino mandarín y el español. Entre estas, se encuentran referentes de personas, objetos artificiales y naturales, animales, plantas, comidas, fenómenos naturales, sociales y culturales, etc. Seguidamente, se ilustran ejemplos de locuciones nominales que corresponden a los principales adjetivos de color:

\begin{tabular}{|l|c|c|c|}
\hline no LN chino & LN chino & LN español & no LN español \\
\hline & $\begin{array}{c}\text { hēi xióng 黑熊 } \\
\text { 'negro' 'oso' }\end{array}$ & oso negro & \\
\hline & $\begin{array}{c}\text { hēi shì 黑市 'negro' } \\
\text { 'mercado' }\end{array}$ & mercado negro & \\
\hline & $\begin{array}{c}\text { hēi jin 黑金 'negro' } \\
\text { 'dinero' }\end{array}$ & dinero negro & \\
\hline & $\begin{array}{c}\text { hēi táng 黑糖 } \\
\text { 'negro' 'azucar' }\end{array}$ & azucar moreno & \\
\hline & $\begin{array}{c}\text { hēi dòng 黑洞 } \\
\text { 'negro' 'agujero' }\end{array}$ & agujero negro & \\
\hline & $\begin{array}{c}\text { hēi cháo 黑潮 } \\
\text { 'negro' 'ola' }\end{array}$ & corriente negra & \\
\hline & $\begin{array}{c}\text { hēi guă fù 黑寡婦 } \\
\text { 'negro' 'viuda' }\end{array}$ & viuda negra & \\
\hline & $\begin{array}{c}\text { hēi dòu 黑豆 } \\
\text { 'negro' 'legumbre' }\end{array}$ & soja negra & \\
\hline & $\begin{array}{c}\text { hēi hú jiāo 黑胡椒 } \\
\text { 'negro' 'pimienta' }\end{array}$ & pimienta negra & \\
\hline & $\begin{array}{c}\text { hēi mó fă 黑魔法 } \\
\text { 'negro' 'magia' }\end{array}$ & magia negra & \\
\hline & $\begin{array}{c}\text { hēi nú 黑奴 'negro' } \\
\text { 'esclavo' }\end{array}$ & & esclavo negro \\
\hline
\end{tabular}


Morfología contrastiva del chino mandarín y el español. Formas de gramaticalización y lexicalización

\begin{tabular}{|c|c|c|c|}
\hline & $\begin{array}{c}\text { hēi zăo 黑霜 } \\
\text { 'negro' 'azufaifa' }\end{array}$ & & azufaifa negra \\
\hline & $\begin{array}{l}\text { wū yún 烏雲 } \\
\text { 'negro' 'nube' }\end{array}$ & & nube negra \\
\hline & $\begin{array}{c}\text { wū zéi 烏賊 'negro' } \\
\text { 'ladrón' }\end{array}$ & & sepia \\
\hline & $\begin{array}{c}\text { wū gūi 烏龜 'negro' } \\
\text { 'tortuga' }\end{array}$ & & tortuga \\
\hline & $\begin{array}{c}\text { hēi yiè 黑夜 'negro' } \\
\text { 'noche' }\end{array}$ & & noche \\
\hline & $\begin{array}{l}\text { hēi guăn 黑管 } \\
\text { 'negro' 'tubo' }\end{array}$ & & clarinete \\
\hline & $\begin{array}{c}\text { hēi băn 黑板 'negro' } \\
\text { 'tabla' }\end{array}$ & & pizarra \\
\hline & $\begin{array}{c}\text { hēi méi 黑莓 'negro' } \\
\text { 'fresa' }\end{array}$ & & mora \\
\hline & $\begin{array}{c}\text { hēi méi 烏梅 } \\
\text { 'negro' 'cirvela' }\end{array}$ & & cirvela silvestre/endrina \\
\hline & $\begin{array}{l}\text { hēi zĭ 黑子 'negro' } \\
\text { 'mancha' }\end{array}$ & & mancha solar \\
\hline & $\begin{array}{c}\text { hēi mă 黑馬 } \\
\text { 'negro' 'caballo' }\end{array}$ & & $\begin{array}{c}\text { persona con } \\
\text { capacidad y potencia } \\
\text { inesperadas }\end{array}$ \\
\hline & $\begin{array}{c}\text { hēi huò 黑貨 } \\
\text { 'negro' 'artículo' }\end{array}$ & & $\begin{array}{l}\text { mercancía de } \\
\text { contrabando }\end{array}$ \\
\hline & $\begin{array}{c}\text { wū cù 烏醋 'negro' } \\
\text { 'vinagre' }\end{array}$ & & $\begin{array}{c}\text { vinagre de arroz y } \\
\text { especias }\end{array}$ \\
\hline & $\begin{array}{l}\text { hēi hán 黑函 } \\
\text { 'negro' 'carta' }\end{array}$ & & $\begin{array}{c}\text { carta de acusación } \\
\text { falsa }\end{array}$ \\
\hline & $\begin{array}{l}\text { hēi shǒu 黑手 } \\
\text { 'negro' 'mano' }\end{array}$ & & $\begin{array}{c}\text { mecánico de coche o } \\
\text { moto }\end{array}$ \\
\hline $\begin{array}{l}\text { huài míng shēn 壞 } \\
\text { 名聲'opinión' } \\
\text { 'desfavorable' }\end{array}$ & & leyenda negra & \\
\hline $\begin{array}{l}\text { 高級 火腿 ‘alto' } \\
\text { 'categoría' 'jamón' }\end{array}$ & & pata negra & \\
\hline
\end{tabular}

Tabla 1: Locuciones con el adjetivo negro 


\begin{tabular}{|c|c|c|c|}
\hline no LN chino & LN chino & LN español & no LN español \\
\hline & $\begin{array}{l}\text { bái rén 白人 'blanco' } \\
\text { 'persona' }\end{array}$ & raza blanca & \\
\hline & bái hǔ 白虎 'blanco' 'tigre' & tigre blanco & \\
\hline & $\begin{array}{c}\text { bái cài 白菜 'blanco' } \\
\text { 'verdura' }\end{array}$ & col china & \\
\hline & $\begin{array}{c}\text { bái tóng 白銅 'blanco' } \\
\text { 'bronce' }\end{array}$ & $\begin{array}{l}\text { cobre } \\
\text { blanco }\end{array}$ & \\
\hline & bái jin 白金 'blanco' 'oro' & oro blanco & \\
\hline & bái jiǔ 白酒 'blanco' 'vino' & vino blanco & \\
\hline & bái ròu 白肉 'blanco' 'carne' & $\begin{array}{l}\text { carne } \\
\text { blanca }\end{array}$ & \\
\hline & $\begin{array}{c}\text { bái pí shū 白皮書 'blanco' } \\
\text { 'corteza' 'libro' }\end{array}$ & libro blanco & \\
\hline & $\begin{array}{c}\text { bái táng 白糖 'blanco' } \\
\text { 'azucar' }\end{array}$ & $\begin{array}{c}\text { azúcar } \\
\text { blanquilla }\end{array}$ & \\
\hline & $\begin{array}{c}\text { bái gōng 白宮 'blanco' } \\
\text { 'palacio' }\end{array}$ & $\begin{array}{l}\text { Palacio } \\
\text { Blanco } \\
\end{array}$ & \\
\hline & bái mó fă $\frac{\text { 白魔法 'blanco' }}{\text { 'magia' }}$ & $\begin{array}{l}\text { magia } \\
\text { blanca }\end{array}$ & \\
\hline & 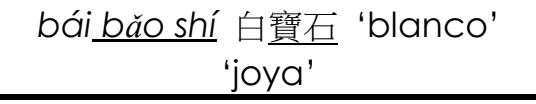 & $\begin{array}{l}\text { zafiro } \\
\text { blanco }\end{array}$ & \\
\hline & bái fěn 白粉 'blanco' 'polvo' & & heroína, cocaína \\
\hline & $\begin{array}{c}\text { bái jú 白菊 'blanco' } \\
\text { 'margarita' }\end{array}$ & & margarita \\
\hline & $\begin{array}{l}\text { bái luó bo 白羅葍 'blanco' } \\
\text { 'zanahoria' }\end{array}$ & & rábano \\
\hline & bái yín 白銀 'blanco' 'plata' & & plata \\
\hline & bái yún 白雲 'blanco' 'nube' & & nube \\
\hline & bái tiān 白天 'blanco' 'día' & & día \\
\hline & $\begin{array}{c}\text { bái tóu 白頭 'blanco' } \\
\text { 'cabeza' }\end{array}$ & & pelicano \\
\hline & bái fàn 白飯 'blanco' 'arroz' & & arroz cocido \\
\hline & bái tié 白鐵 'blanco' 'hierro' & & acero inoxidable \\
\hline & bái cù 白醋 'blanco' 'vinagre' & & vinagre de arroz \\
\hline $\begin{array}{l}\text { dāo xiè 刀械 'hoja } \\
\text { cortante" 'arma' }\end{array}$ & & $\begin{array}{l}\text { arma } \\
\text { blanca }\end{array}$ & \\
\hline $\begin{array}{c}\text { dī zhē yú 低脂魚 } \\
\text { 'poco' 'grasa ' } \\
\text { 'pescado' }\end{array}$ & & $\begin{array}{l}\text { pescado } \\
\text { blanco }\end{array}$ & \\
\hline
\end{tabular}

Tabla 2: Locuciones con el adjetivo blanco 
Morfología contrastiva del chino mandarín y el español. Formas de gramaticalización y lexicalización

\begin{tabular}{|c|c|c|c|}
\hline no LN chino & LN chino & LN español & no LN español \\
\hline & hóng jūn 紅軍 'rojo' 'ejército' & ejército rojo & \\
\hline & hóng méi 紅莓 'rojo' 'fresa' & $\begin{array}{l}\text { arándano } \\
\text { rojo }\end{array}$ & \\
\hline & hóng hăi 紅海 'rojo' 'mar' & Mar Rojo & \\
\hline & hóng chá 紅茶 'rojo' 'té' & té rojo & \\
\hline & hóng cháo 紅潮 'rojo' 'ola' & marea roja & \\
\hline & $\begin{array}{l}\text { hóng chăn 紅場 'rojo' } \\
\text { 'explanada' }\end{array}$ & $\begin{array}{l}\text { Plaza Roja } \\
\text { (de Moscú) }\end{array}$ & \\
\hline & hóng xiě qiú 紅血球 'rojo' & glóbulo rojo & \\
\hline & hóng pái 紅牌 'rojo' 'tarjeta' & tarjeta roja & \\
\hline & hóng ròu 紅肉 'rojo' 'carne' & carne roja & \\
\hline & hóng luó bo 紅羅蓄 'rojo' & & zanahoria \\
\hline & hóng tóng 紅銅 'rojo' 'cobre' & & cobre \\
\hline & chì dào 赤道 'rojo' 'eje' & & ecuador \\
\hline & hóng bǎo shí 紅寶石 'rojo' & & rubí \\
\hline & hóng fān 紅蕃 'rojo' 'indio' & & indio americano \\
\hline & hóng shǔ 紅薯 'rojo' 'patata' & & papa dulce \\
\hline & hóng lóng 紅龍 'rojo' 'dragón' & & pez dragón \\
\hline & hóng tiě 紅帖 'rojo' 'carta' & & tarjeta de boda \\
\hline & hóng yán 紅顏 'rojo' 'cara' & & mujer hermosa \\
\hline & hóng cù 紅醋 'rojo' 'vinagre' & & vinagre de vino \\
\hline & hóng bāo 紅包 'rojo' ‘sobre' & & $\begin{array}{c}\text { dinero que se da } \\
\text { en algunas } \\
\text { fiestas }\end{array}$ \\
\hline $\begin{array}{l}\text { zui hòu yīmíng } \\
\text { 最後 } \frac{\text { 二名 }}{\text { 'último' }} \\
\text { 'persona' (en la } \\
\text { competición) }\end{array}$ & & farolillo rojo & \\
\hline
\end{tabular}

Tabla 3: Locuciones con el adjetivo rojo 


\begin{tabular}{|c|c|c|c|}
\hline no LN chino & LN chino & $\begin{array}{c}\text { LN } \\
\text { español }\end{array}$ & no LN español \\
\hline & $\begin{array}{c}\text { huáng yiè 黃頁 'amarillo' } \\
\text { 'página' }\end{array}$ & $\begin{array}{l}\text { página } \\
\text { amarilla }\end{array}$ & \\
\hline & $\begin{array}{c}\text { huáng pái 黃牌 'amarillo' } \\
\text { 'tarjeta' }\end{array}$ & $\begin{array}{l}\text { tarjeta } \\
\text { amarilla }\end{array}$ & \\
\hline & $\begin{array}{c}\text { huáng yiú 黃油 'amarillo' } \\
\text { 'aceite' }\end{array}$ & & mantequilla \\
\hline & $\begin{array}{c}\text { huáng quán 黃泉 'amarillo' } \\
\text { 'manantial' }\end{array}$ & & inframundo \\
\hline & $\begin{array}{c}\text { húang fēng 黃蜂 'amarillo' } \\
\text { 'abeja' }\end{array}$ & & avispa \\
\hline & húang jin 黄金 'amarillo' 'oro' & & oro \\
\hline & $\begin{array}{c}\text { huáng băo shí 黃寶石 'amarillo' } \\
\text { 'joya' }\end{array}$ & & topacio \\
\hline & $\begin{array}{l}\text { húang niú 黃牛 } \\
\text { 'amarillo' 'buey' }\end{array}$ & & vaca/toro \\
\hline & $\begin{array}{c}\text { húang guā 黃瓜 'amarillo' } \\
\text { 'pepino' }\end{array}$ & & pepino \\
\hline & $\begin{array}{c}\text { húang doù 黃豆 'amarillo' } \\
\text { 'legumbre' }\end{array}$ & & soja \\
\hline & $\begin{array}{c}\text { húang dǎn 黃膽 ‘amarillo' } \\
\text { 'vesícula biliar' }\end{array}$ & & ictericia \\
\hline & $\begin{array}{c}\text { huáng huā 黃花 'amarillo' } \\
\text { 'flor' }\end{array}$ & & crisantemo \\
\hline & $\begin{array}{c}\text { húang tāng 黃湯 'amarilla' } \\
\text { 'sopa' }\end{array}$ & & $\begin{array}{c}\text { bebida } \\
\text { alcóholica }\end{array}$ \\
\hline & $\begin{array}{c}\text { húang paó 黃袍 'amarillo' } \\
\text { 'vestido' }\end{array}$ & & $\begin{array}{l}\text { manto amarillo } \\
\text { del emperador }\end{array}$ \\
\hline $\begin{array}{c}\text { mǒu zhǒng gōng huì } \\
\text { 某種公會 } \\
\text { 'agún' 'tipo' 'sindicato' }\end{array}$ & & $\begin{array}{l}\text { sindicato } \\
\text { amarillo }\end{array}$ & \\
\hline
\end{tabular}

Tabla 4: Locuciones con el adjetivo amarillo

\begin{tabular}{|c|c|c|c|}
\hline no LN chino & LN chino & LN español & no LN español \\
\hline & lù chá 綠茶 'verde' 'té' & té verde & \\
\hline & lù dì 綠地 'verde' 'tierra' & zona verde & \\
\hline & qiing wā 青蛙 'verde' 'rana' & & rana \\
\hline & qìng căo 青草 'verde' 'césped' & & césped \\
\hline
\end{tabular}


Morfología contrastiva del chino mandarín y el español. Formas de gramaticalización y lexicalización

\begin{tabular}{|c|c|c|c|}
\hline & $\begin{array}{c}\text { lù zhōu 綠洲 'verde' } \\
\text { 'continente' }\end{array}$ & & oasis \\
\hline & 綠帽 lù mào 'verde' 'gorro' & & marido cornudo \\
\hline & lù băo shí 綠寶石 'verde' 'joya' & & esmeralda \\
\hline & qīng lóv 青樓 'verde' 'edificio' & & $\begin{array}{c}\text { casa de } \\
\text { prostitución }\end{array}$ \\
\hline & $\begin{array}{c}\text { qīng chūn 青春 'verde' } \\
\text { 'primavera' }\end{array}$ & & juventud \\
\hline & qiing shǐ 青史 'verde' 'historia' & & historia \\
\hline & lu zăo 綠藻 'verde' 'alga' & & alga verde \\
\hline & lù doù 綠豆 'verde' 'soja' & & soja verde \\
\hline & qiing tóng 青銅 'verde' 'bronce' & & bronce \\
\hline $\begin{array}{l}\text { xǔ kě 許可 } \\
\text { 'permiso' }\end{array}$ & & luz verde & \\
\hline $\begin{array}{l}\text { ¿iāo tōng dēng } \\
\text { tóng bù 交通燈 } \\
\text { 同步 'semáforo' } \\
\text { 'sincronización' }\end{array}$ & & ola verde & \\
\hline
\end{tabular}

Tabla 5: Locuciones con el adjetivo verde

\begin{tabular}{|c|c|c|c|}
\hline no LN chino & LN chino & LN español & no LN español \\
\hline & lán jing 藍鯨 'azul' 'ballena' & ballena azul & \\
\hline & lán zăo 糮藻 'azul' 'alga' & & $\begin{array}{c}\text { alga } \\
\text { verdeazulada, } \\
\text { cianobacteria }\end{array}$ \\
\hline & lán dòng 藍洞 'azul’ 'agujero' & & $\begin{array}{l}\text { agujero azul } \\
\text { ('cueva } \\
\text { submarina') }\end{array}$ \\
\hline & $\begin{array}{c}\text { qīng guāng yăn 青光眼 'verde' } \\
\text { 'Iuz' 'ojo' }\end{array}$ & & glaucoma \\
\hline & lán bǐ 藍筆 'azul' 'lápiz' & & bolígrafo \\
\hline & lán tiā 監天 'azul' 'cielo' & & cielo \\
\hline & lán méi 藍䒯 'azul' 'fresa' & & arándano \\
\hline & lán yá 藍牙 'azul' 'diente' & & bluetooth \\
\hline & lán tú 藍圖 'azul' 'dibujo' & & dibujo técnico \\
\hline & lán băo shí 監寶石 'azul' 'joya' & & zafiro \\
\hline $\begin{array}{c}\frac{\text { 貴族 }}{\text { xiě tóng 血統 }} \text { 'nuì zú } \\
\text { 'linaje' }\end{array}$ & & sangre azul & \\
\hline
\end{tabular}

Tabla 6: Locuciones con el adjetivo azul 


\begin{tabular}{|c|c|c|c|}
\hline no LN chino & LN chino & LN español & no LN español \\
\hline & $\begin{array}{c}\text { huĩ shì 灰市 'mercado' } \\
\text { 'gris' }\end{array}$ & $\begin{array}{c}\text { mercado } \\
\text { negro }\end{array}$ & \\
\hline & huĩ xiang 灰熊 'gris' 'oso' & oso pardo & \\
\hline & huī gū nián 灰姑娘 & & Cenicienta \\
\hline & 'gris' 'jovencita' & & lobo \\
\hline & huĩng 灰狼 'gris' 'lobo' & & polvo 灰鹿 'gris' 'polvo' \\
\hline $\begin{array}{c}\text { mù hòu zhǔ năo } \\
\text { 幕後主腦 'telón' } \\
\text { 'detrás' 'liderar' } \\
\text { 'cerebro' }\end{array}$ & huījiă 灰甲 'gris' 'uña' & & tiña de las uñas \\
\hline
\end{tabular}

Tabla 7: Locuciones con el adjetivo gris

Aunque no pretendemos hacer un estudio exhaustivo, es necesario partir de un corpus representativo como el reflejado en las tablas anteriores para establecer alguna comparación entre el chino mandarín y el español, de la que se puedan extraer las principales generalizaciones descriptivas.

Pues bien, a la vista de las tablas anteriores, se presentan a continuación las siguientes propiedades diferenciales de productividad en las dos lenguas. En primer lugar, se observa una mayor productividad en el chino mandarín en la formación de este tipo de locuciones nominales. La elevada lexicalización ha de ponerse en relación con un tipo de lengua muy proclive a la composición como es el mandarín. Esta alta productividad relativa se refleja en la presencia de una locución nominal en chino frente a una formación no locucional del español. La locución nominal china explicita la relación de pertenencia de una entidad a una determinada clase de realidades, mientras que en español, este sentido de clasificación resulta en comparación más opaco. Como muestran los siguientes ejemplos, las locuciones nominales chinas equivalen en español a formas no locucionales:

húang fēng 黃蜂 'amarillo' 'abeja' $\rightarrow$ avispa

wū zéi 鳥賊 'negro' 'ladrón' $\rightarrow$ sepia

hóng băo shí 紅寶石 'rojo' 'joya' $\rightarrow$ rubí

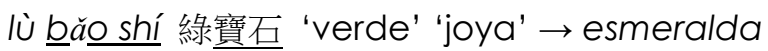


Morfología contrastiva del chino mandarín y el español. Formas de gramaticalización y lexicalización

\author{
huáng băo shí 黃寶石 'amarillo' 'joya' $\rightarrow$ topacio \\ qing guāng yăn 青光眼 'verde' 'Iuz' 'ojo' $\rightarrow$ glaucoma \\ huī gū nián 灰姑娘 'gris' 'jovencita' $\rightarrow$ Cenicienta \\ qīng chūn 青春 'verde' 'primavera' $\rightarrow$ juventud \\ lán bǐ 監筆 'azul' 'lápiz' $\rightarrow$ bolígrafo
}

En segundo lugar, frente a la improductividad de los adjetivos intensionales en la formación de locuciones nominales del español, resulta evidente que este sentido de los adjetivos contribuye muy frecuentemente a la lexicalización de las composiciones chinas. Como es sabido, los adjetivos intensionales no restringen la significación del nombre, como los extensionales, sino que evalúan la referencia (Demonte 1999: § 3.5.2.3). Por ejemplo, en hēi yiè 黑夜 'negro' 'noche' $\rightarrow$ noche, el adjetivo representa un atributo inherente de lo designado por el nombre que, como tal, carece de sentido clasificador, pues no se trata de seleccionar un tipo de noche, sino de valorar la denotación del nombre. Véanse más casos semejantes en los siguientes ejemplos:

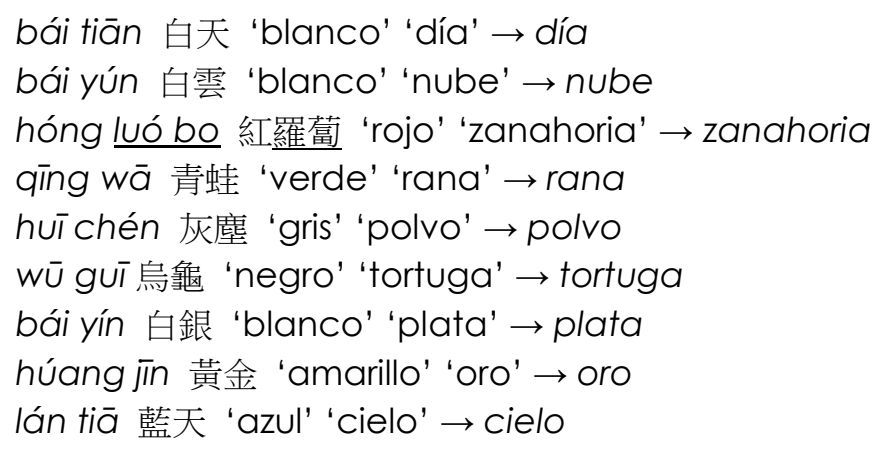

En tercer lugar, aunque en ambas lenguas no faltan locuciones que distinguen las clases de referentes con los adjetivos de color, como en los ejemplos de 1), la productividad más elevada para la designación de subclases de la realidad mediante adjetivos cromáticos corresponde al chino mandarín. Así, mientras que en el español se distinguen las subclases con otros adjetivos o sustantivos como modificadores, en el chino mandarín la distinción de los grupos taxonómicos se expresa frecuentemente con el adjetivo de color. Por ejemplo, en bái cài 白菜 'blanco' 'verdura' $\rightarrow$ col china, el adjetivo blanco se utiliza para designar una subclase de hortaliza, mientras que en español se 
usa el adjetivo china para distinguir esta especie según su origen. Se muestran más ejemplos de este caso en 2):

1) lán jing 藍鯨 'azul' 'ballena' $\rightarrow$ ballena azul bái hǔ 白虎 'blanco' 'tigre' $\rightarrow$ tigre blanco bái yॅ̆ 白蟻 'blanco' 'hormiga' $\rightarrow$ hormiga blanca

2) hóng fān 紅蕃 'rojo' 'indio' $\rightarrow$ indio americano hóng shǔ 紅薯 'rojo' 'patata' $\rightarrow$ papa dulce/batata lán tú 監圖 'azul' 'dibujo' $\rightarrow$ dibujo técnico hēi zĭ 黑子 'negro' 'azúcar' $\rightarrow$ mancha solar hēi méi 烏梅 'negro' 'cirvela' $\rightarrow$ cirvela silvestre bái cài 白菜 'blanco' 'verdura' $\rightarrow$ col china bái fàn 白飯 'blanco' 'arroz' $\rightarrow$ arroz cocido bái tié 白鐵 'blanco' 'hierro' $\rightarrow$ acero inoxidable húang tāng 黃湯 'amarilla' 'sopa' $\rightarrow$ bebida alcóholica bái cù 白醋 'blanco' 'vinagre' $\rightarrow$ vinagre de arroz wū cù 鳥醋 'negro' 'vinagre' $\rightarrow$ vinagre de arroz y especias hóng cù 紅醋 'rojo' 'vinagre' $\rightarrow$ vinagre de vino hóng lóng 紅龍 'rojo' 'dragón' $\rightarrow$ pez dragón

\subsubsection{Lexicalización formal y semántica}

Tanto en chino mandarín como en español, las locuciones constituidas por adjetivo de color y nombre presentan dos tipos de lexicalización: lexicalización formal y lexicalización semántica. De acuerdo con la distinción que efectúa Brinton (2000: 74) y la clasificación de Buenafuentes (2003), el primer tipo trata de combinaciones en las que se produce la aglutinación de los elementos y se crea una nueva unidad léxica, pero con un significado composicional. El segundo tipo hace referencia al proceso mediante el que se produce un cambio desde una estructura gramatical a una estructura léxica. Esta conversión de elementos sintácticos en una nueva unidad léxica con un nuevo significado implica cambios semánticos. Así, lù chá 綠茶 'verde' 'té' $\rightarrow$ té verde es lexicalización formal, ya que el adjetivo verde tiene la función de modificación respecto a las distintas clases de té. Sin embargo, qīng chūn 青春 
Morfología contrastiva del chino mandarín y el español. Formas de gramaticalización y lexicalización

'verde' 'primavera' $\rightarrow$ juventud es ejemplo de lexicalización semántica, pues mediante un proceso metafórico el color verde implica las propiedades de frescura e inmadurez de la juventud. El sustantivo primavera presenta un sentido figurado de la etapa inicial de los seres humanos. A continuación, se aportan más ejemplos de ambas lenguas que presentan estos dos tipos de lexicalización. Las combinaciones del grupo 1) presentan la lexicalización formal, pues los adjetivos de color ejercen una función clasificadora para expresar la variedad o característica de los referentes en su totalidad. Mientras tanto, las formas del grupo 2) presentan la lexicalización semántica, pues los adjetivos de color pueden hacer referencia a alguna de las características del referente o bien aluden a algún concepto abstracto asociado con el referente mediante mecanismos metafóricos:

\section{1) Español \\ oso negro ballena azul \\ Papel blanco glóbulo rojo \\ Chino mandarín \\ lán méi 藍莓 'azul' 'fresa' $\rightarrow$ arándano \\ bái băn 白板 'blanco' 'tabla' $\rightarrow$ pizarra blanca \\ húang Jin 黄金 'amarillo' 'oro' $\rightarrow$ oro}

\section{2) Español}

$\begin{array}{ll}\text { bestia negra } & \text { números rojos } \\ \text { libro blanco } & \text { príncipe azul }\end{array}$

\section{Chino mandarín}

huī gū nián 灰姑娘 'gris' 'jovencita' $\rightarrow$ Cenicienta (el gris refiere a la mancha y el polvo)

hēi huò 黑貨 'negro' 'artículo' $\rightarrow$ mercancía de contrabando (el negro genera el sentido ilegal)

hóng yán 紅顏 'rojo' 'cara' $\rightarrow$ mujer hermosa (el rojo implica la belleza natural de la cara)

En las voces que experimentan una lexicalización semántica, tanto en chino mandarín como en español, se pueden encontrar sentidos figurados en el primer elemento o en el segundo elemento. Los siguientes ejemplos son 
locuciones que presentan un significado específico para el adjetivo de color. En estos casos los adjetivos de color generan conceptos abstractos que modifican a los componentes nominales y añaden propiedades 0 características que no son propias del referente. Por ejemplo, el negro se relaciona con lo ilegal, clandestino, policiaco; el gris se asocia con algo sucio, empolvorado o ambiguo:

$\begin{array}{lll}\text { Español } & & \\ \text { dinero negro } & \text { arma blanca } & \text { agua roja } \\ \text { luz negra } & \text { zona azul } & \text { sindicato amarillo } \\ \text { novela rosa } & \text { prensa amarilla } & \text { magia blanca }\end{array}$

\section{Chino mandarín}

qīng lóu 青樓 'verde' 'edificio' $\rightarrow$ casa de prostitución

hēi huò 黑貨 'negro' 'artículo' $\rightarrow$ mercancía de contrabando

huĩ shì 灰市 'mercado' 'gris' $\rightarrow$ mercado negro

huīgū nián 灰姑娘 'gris' 'jovencita' $\rightarrow$ Cenicienta

Los siguientes ejemplos son locuciones lexicalizadas a partir del elemento nominal. El cambio metafórico afecta al sustantivo, de manera que la designación de la forma compleja no corresponde al significado estándar del elemento nominal:

\section{Español \\ cuerpo amarillo cerebro gris garbanzo negro}

\section{Chino mandarín}

hóng lóng 紅龍 'rojo' 'dragón' $\rightarrow$ pez dragón

bái fěn 白粉 'blanco' 'polvo' $\rightarrow$ heroína (droga)

hēi guăn 黑管 'negro' 'tubo' $\rightarrow$ clarinete

En ambas lenguas, se han hallado menos casos de combinaciones léxicas en las que se da una lexicalización parcial provocada por el elemento nominal. Según todos los ejemplos que se han expuesto, lo más frecuente es que la lexicalización semántica esté ocasionada por el adjetivo de color, o por otro lado, por la totalidad de los elementos que intervienen en el proceso compositivo. En el último caso se habla de lexicalización semántica total, en la que el significado final de la formación no está relacionado con la designación 
Morfología contrastiva del chino mandarín y el español. Formas de gramaticalización y lexicalización

de los elementos. Por ejemplo, en hēi mă 黑馬 'negro' 'caballo' $\rightarrow$ persona con potencialidad de triunfar, el adjetivo negro tiene el sentido generado de algo oculto, potencial o inesperado. Por otro lado, en el constituyente nominal mă 馬 'caballo' se produce la metáfora ontológica basada en la personificación, la que concibe el animal como si fuera una persona, a partir del siguiente esquema:

\begin{tabular}{|c|c|c|c|c|}
\hline \multicolumn{2}{|c|}{ Concepto origen } & \multirow{2}{*}{$\begin{array}{l}\text { sentido generado } \\
\text { y personificación }\end{array}$} & \multicolumn{2}{|c|}{ Concepto meta } \\
\hline Adj. de color & $\begin{array}{c}\text { Comp. } \\
\text { nominal }\end{array}$ & & Adj. de color & $\begin{array}{c}\text { Comp. } \\
\text { nominal }\end{array}$ \\
\hline hēi 黑 'negro' & $\begin{array}{c}\text { mă 馬 } \\
\text { 'caballo' }\end{array}$ & - & $\begin{array}{c}\text { hēi 黑 } \\
\text { 'capacidad } \\
\text { de triunfar' }\end{array}$ & $\begin{array}{c}\text { mă 馬 } \\
\text { 'persona' }\end{array}$ \\
\hline
\end{tabular}

Tabla 8: Ejemplo de lexicalización semántica total

En este tipo de lexicalización, las características del animal se proyectan sobre el ser humano. Así, el concepto de "correr rápido" del caballo hace referencia a la persona que tiene una gran capacidad para conseguir la victoria. Casos parecidos de lexicalización total son los siguientes:

\section{Español}

bestia negra oveja negra calor negro príncipe azul farolillo rojo sangre azul luz verde pata negra

\section{Chino mandarín}

hēi mù 黑幕 'negro' 'telón' $\rightarrow$ telón negro (la verdad oculta) huáng niú 黃牛 'amarillo' 'buey' $\rightarrow$ persona que saca beneficio ilegal de la venta de entradas, reventa

Con bastante frecuencia en ambas lenguas, la lexicalización semántica total parte de un constituyente nominal que designa una parte del cuerpo. Como es sabido, la designación de las partes del cuerpo es una de las parcelas del léxico más polisémicas. Estos sustantivos experimentan un proceso metafórico o metonímico por el que su significado pasa a designar otra realidad como, por ejemplo, la persona. Así, en sangre azul el sustantivo sangre 
significa 'linaje'. Lo mismo ocurre en el ejemplo hēi shǒu 黑手 'negro' 'mano' $\rightarrow$ mecánico de coche o moto, en el que el significado de 'mano' se ha lexicalizado desde 'parte del cuerpo humano' a 'empleo, facultad u oficio que alguien ejerce'. Así, cuando se combina con el adjetivo de color negro, el significado final de la combinación designa un tipo de ocupación.

\subsection{Locuciones nominales constituidas por nombres y adjetivos aspectuales en chino mandarín y español}

\subsubsection{Los adjetivos aspectuales}

En español hay un grupo de adjetivos que no indican propiedades de las entidades sino que distinguen la manera de aplicar el significado o concepto aludido por el sustantivo a un determinado referente. Estos adjetivos no admiten gradación ni comparación porque no designan propiedades. Según la clasificación de Demonte (1999: 205), estos adjetivos se denominan adjetivos adverbiales porque todos ellos estarían representados por el adverbio correspondiente en -mente. Como por ejemplo, posiblemente, principalmente, constantemente, únicamente, etc. Entre los adjetivos adverbiales, se encuentran los adjetivos aspectuales que modifican la estructura temporal interna de los nombres deverbales, especialmente los de acción y resultado (asiduas recriminaciones, constantes salidas). Los adjetivos aspectuales pueden anteponerse o posponerse sin que cambie ni su significado ni el de la frase de la que forman parte en la estructura sintáctica:

Las publicaciones periódicas del profesor

Los constantes viajes de mi familia

Las quejas permanentes de los empleados 
Morfología contrastiva del chino mandarín y el español. Formas de gramaticalización y lexicalización

En las locuciones nominales, según Lliteras (s.a), los adjetivos aspectuales expresan el carácter completo o incompleto del acontecimiento descrito por el nombre, su frecuencia y su progreso en el tiempo, su comienzo, desarrollo y fin. Los principales adjetivos aspectuales se encuentran entre los ofrecidos a continuación:

$\begin{array}{lllll}\text { asiduo } & \text { constante } & \text { ocasional } & \text { continuo } & \text { habitual } \\ \text { periódico } & \text { esporádico } & \text { permanente } & \text { frecuente } & \text { reiterado }\end{array}$

También en chino mandarín, los adjetivos aspectuales se consideran como adjetivos no descriptivos, que se distinguen de los calificativos en que no designan una cualidad del sustantivo al que acompañan, sino que se refieren a los objetos o procesos en cuanto entidades que tienen lugar en el tiempo, en el espacio y de una cierta manera. Se trata de adjetivos como los siguientes:

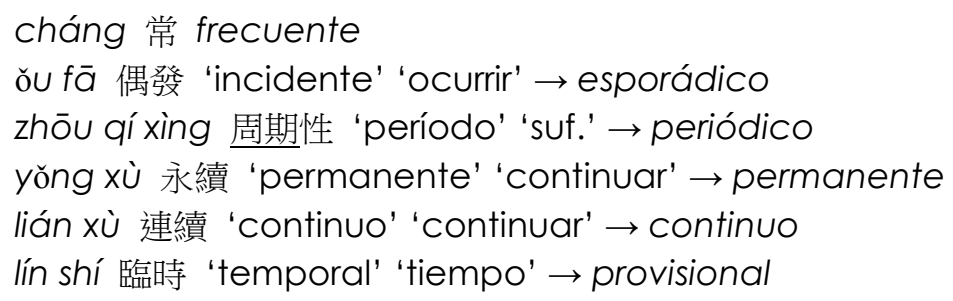

Pues bien, en ambas lenguas, algunos adjetivos de significado aspectual se muestran claramente improductivos en la formación de compuestos o locuciones nominales, lo que no quiere decir que la noción de aspecto léxico esté ausente de nuestras locuciones. En español, el grupo de adjetivos aspectuales sintagmáticos que no forman ninguna locución está constituido por:

$\begin{array}{ll}\text { asiduo } & \text { ocasional } \\ \text { esporádico } & \text { reiterado } \\ \text { frecuente } & \text { repetido }\end{array}$

Sin embargo, se encuentran expresiones, propias de lenguajes especializados, como gracia habitual, cantidad constante, cometa periódico, etc., a pesar de esta escasa productividad locucional. En chino mandarín, 
algunos adjetivos aspectuales también forman compuestos o locuciones nominales:

ŏu fā shì jiàn 偶發 事件 'esporádico' 'asunto' $\rightarrow$ incidencia yŏng xù fā zhăn 永續 發展 'permanente' 'desarrollo' $\rightarrow$ desarrollo sostenible lián xù jù 連續劇 'continuo' 'programa, serie' $\rightarrow$ serie (de TV)

\subsubsection{Clasificación aspectual de las locuciones nominales}

Sin embargo, otra serie de adjetivos parece especializarse en la formación de locuciones nominales aspectuales. Según Lliteras (s.a), los adjetivos como entero, pleno, lleno, medio, variable, fijo, entre otros, proporcionan pruebas evidentes de su productividad en la formación de locuciones nominales. Estos adjetivos reordenan el sistema de significación aspectual en torno a dos ejes: (i) el que se podría llamar de la 'variación' / 'estabilidad' y (ii) el de la 'perfectividad' / 'imperfectividad'. Así, los adjetivos que tienden a codificar en las locuciones la 'estabilidad' o ausencia de variación de la entidad designada por el nombre son fijo, permanente y único, mientras que continuo y variable tienden a lexicalizar la 'variación'. Por su parte, la 'perfectividad' aspectual en las locuciones suele quedar representada mediante los adjetivos completo, entero y pleno, y paralelamente, medio es el adjetivo aspectual de la 'imperfectividad'. Según la tabla siguiente que propone Lliteras (s.a), se observa que en la significación aspectual la mayor riqueza léxica corresponde a los polos de la 'variación' y la 'perfectividad':

\begin{tabular}{|c|c||c|c|}
\hline Variación & Estabilidad & Perfectividad & Imperfectividad \\
\hline renta variable $><$ & renta fija & luna llena $><$ & media luna \\
\hline estrella variable $><$ & estrella fija & pulso lleno & media luz \\
\hline fiesta variable $><$ & fiesta fija & aguas llenas & media naranja \\
\hline cantidad continua & & dedicación plena & medias palabras \\
\hline corriente continua & & dominio pleno & medias tintas \\
\hline
\end{tabular}


Morfología contrastiva del chino mandarín y el español. Formas de gramaticalización y lexicalización

\begin{tabular}{|c|c||c|c|}
\hline papel continuo & & pleno empleo & medio pelo \\
\hline sesión continua & & leche entera & media sonrisa \\
\hline & gas permanente & el mundo entero $><$ & medio mundo \\
\hline & tarifa plana & pensión completa $><$ & media pensión \\
\hline & precio único & dentición completa & medio luto \\
\hline
\end{tabular}

Tabla 9: Codificación del aspecto en las locuciones nominales

En chino mandarín, los adjetivos como quàn 全 'completo, entero, todo' y bàn 半 'medio, semi-' también proporcionan pruebas evidentes de su productividad en la formación de locuciones. Igual que en español, el sistema de significación aspectual sigue los dos ejes del español: 1) la 'variación' / 'estabilidad' y 2) la 'perfectividad' / 'imperfectividad'. Véanse algunos ejemplos representativos del primero de estos significados aspectuales en la siguiente tabla:

\begin{tabular}{|c|c|}
\hline Variación & Estabilidad \\
\hline$\frac{\text { fú dòng lì lù }}{\text { variable }} \frac{\text { 浮動 }}{><}$ 利率 'flotante' 'renta' $\rightarrow$ renta & $\begin{array}{l}\text { gù ding lì lù 固定 利率 'fijo' } \\
\text { 'renta' } \rightarrow \text { renta fija }\end{array}$ \\
\hline $\begin{array}{l}\text { biàn xing 變星 'cambiante' 'estrella' } \rightarrow \text { estrella } \\
\text { variable } \quad><\end{array}$ & $\begin{array}{l}\text { héng xīng 恆星 'perpetuo' } \\
\text { 'estrella' } \rightarrow \text { estrella fija }\end{array}$ \\
\hline $\begin{array}{l}\text { huó cún 活存 'vivo' 'depósito' } \rightarrow \text { depósito } \\
\text { normal } \quad><\end{array}$ & $\begin{array}{l}\text { ding cún 定存 'fijo' 'depósito' } \rightarrow \\
\text { depósito a plazo fijo }\end{array}$ \\
\hline $\begin{array}{l}\text { biàn shù 變數 'cambiante' 'número' } \rightarrow \text { variable } \\
\text { (mat.) } \quad><\end{array}$ & $\begin{array}{l}\text { cháng shù 常數 'frecuente' } \\
\text { 'número' } \rightarrow \text { constante (mat.) }\end{array}$ \\
\hline $\begin{array}{l}\text { liú dòng zī chăn } \text { 流動 資產 'flotante' 'capital' } \rightarrow \\
\text { activo corriente/circulante }\end{array}$ & $\begin{array}{l}\text { gù ding zīchăn 固定 資產 'fijo' } \\
\text { 'capital' } \rightarrow \text { activo fijo }\end{array}$ \\
\hline $\begin{array}{l}\text { liú dòng fù zài 流動 真債 'flotante' 'deuda' } \rightarrow \\
\text { pasivo circulante/ deuda flotante } \\
><\end{array}$ & $\begin{array}{l}\text { gù dìng fù zài 固定 負債 'fijo' } \\
\text { 'deuda' } \rightarrow \text { pasivo fijo }\end{array}$ \\
\hline $\begin{array}{l}\text { liú dòng rén kǒu 流動 } \text { 人口 'flotante' 'población' } \\
\rightarrow \text { población flotante } \\
><\end{array}$ & 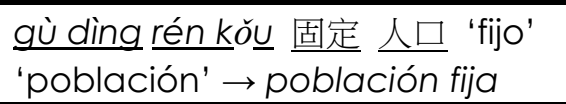 \\
\hline dān ȳ̄jiā 單一價 'exclusivo' 'prec & \\
\hline
\end{tabular}

Tabla 10: Locuciones aspectuales que expresan la 'variación' y la 'estabilidad'

Como se observa, la 'variación' aspectual queda representada mediante varios adjetivos, como fú dòng 浮動 'flotante', biàn 變 'cambiante', huó 活 'vivo', liú dòng 流動 'flotante' y dān yī 單一'fijo'. Entre ellos, liú dòng 
流動 'flotante' se muestra más productivo en la formación de locuciones. Por otra parte, la significación de la 'estabilidad' se establece con adjetivos como gù dìng 固定 'fijo', héng 恆 'perpetuo', dìng 定 'fijo' y cháng 常 'frecuente'. Entre ellos, gù ding 固定 'fijo' es el elemento más productivo en las formaciones lexicalizadas.

Por otra parte, la interpretación perfectiva e imperfectiva de las locuciones también resulta muy frecuente entre las locuciones del chino mandarín, como se ilustra en la tabla siguiente:

\begin{tabular}{|c|c|}
\hline Perfectividad & Imperfectividad \\
\hline $\begin{array}{c}\text { quàn tào 全套 'completo' 'conjunto, } \\
\text { serie' } \rightarrow \text { juego completo }><\end{array}$ & $\begin{array}{c}\text { bàn tào 半套 'medio' 'conjunto, serie' } \rightarrow \\
\text { medio juego }\end{array}$ \\
\hline $\begin{array}{c}\text { quàn zhī 全脂 'entero' 'grasa' } \rightarrow \text { grasa } \\
\text { entera }\end{array}$ & $\begin{array}{c}\text { bàn zhī niú năi 半脂 'medio' 'grasa' } \rightarrow \\
\text { media grasa }\end{array}$ \\
\hline $\begin{array}{c}\text { quàn sù 全宿 'completo' 'pensión' } \rightarrow \\
\text { pensión completa }\end{array}$ & $\begin{array}{c}\text { bàn sù 半宿 'medio' 'pensión' } \rightarrow \text { media } \\
\text { pensión }\end{array}$ \\
\hline $\begin{array}{c}\text { quàn xīn 全薪 'entero' 'sueldo' } \rightarrow \\
\text { sueldo entero }\end{array}$ & $\begin{array}{c}\text { bàn xīn 半薪 'medio' 'sueldo' } \rightarrow \text { medio } \\
\text { sueldo }\end{array}$ \\
\hline $\begin{array}{c}\text { quàn shí 全蝕 'total' 'eclipse' } \rightarrow \text { eclipse } \\
\text { total }\end{array}$ & $\begin{array}{c}\text { bàn shí 半蝕 'medio' 'eclipse' } \rightarrow \text { eclipse } \\
\text { parcial }\end{array}$ \\
\hline $\begin{array}{c}\text { quàn piào 全票 'total' 'billete' } \rightarrow \\
\text { billete de adulto }\end{array}$ & $\begin{array}{c}\text { bàn piào 半票 'medio' 'billete' } \rightarrow \text { billete } \\
\text { de niño o tarifa reducida }\end{array}$ \\
\hline $\begin{array}{c}\text { quàn shēn 全身 'entero' 'cuerpo' } \rightarrow \\
\text { cuerpo entero }\end{array}$ & $\begin{array}{c}\text { bàn shēn 半身 'medio' 'cuerpo' } \rightarrow \text { media } \\
\text { parte del cuerpo }\end{array}$ \\
\hline $\begin{array}{c}\text { quàn tiān 全天 'entero' 'día' } \rightarrow \text { jornada } \\
\text { entera }\end{array}$ & $\begin{array}{c}\text { bàn tiān 半天 'medio' 'día' } \rightarrow \text { media } \\
\text { jornada }\end{array}$ \\
\hline $\begin{aligned} \text { quàn chăng 全場 'entero' 'explanada' } \\
\quad \rightarrow \text { campo entero }\end{aligned}$ & $\begin{array}{c}\text { bàn chǎng 半場 'media' 'explanada' } \rightarrow \\
\text { medio campo }\end{array}$ \\
\hline $\begin{array}{c}\text { quàn zhí 全職 'entero' 'trabajo' } \rightarrow \\
\text { dedicación plena }\end{array}$ & $\begin{array}{c}\text { bàn zhí 半職 'medio' 'trabajo' } \rightarrow \text { trabajo } \\
\text { parcial }\end{array}$ \\
\hline $\begin{array}{c}\text { quàn máng 全盲 'total' 'ceguera' } \rightarrow \\
\text { ceguera total }\end{array}$ & $\begin{array}{c}\text { bàn máng 半盲 'medio' 'ceguera' } \rightarrow \\
\text { ceguera parcial }\end{array}$ \\
\hline $\begin{array}{c}\text { quàn nián 全年 'entero' 'año' } \rightarrow \text { todo } \\
\text { el año }\end{array}$ & $\begin{array}{c}\text { bàn nián 半年 'medio' 'año' } \rightarrow \text { medio } \\
\text { año }\end{array}$ \\
\hline $\begin{array}{c}\text { quàn qiú 全球 'entero' 'globo' } \rightarrow \\
\text { mundo entero }\end{array}$ & $\begin{array}{c}\text { bàn qiú 半球 'medio' 'globo' } \rightarrow \text { medio } \\
\text { mundo, hemisferio }\end{array}$ \\
\hline $\begin{array}{c}\text { quàn táng 全糖 'entero' 'azúcar' } \rightarrow \\
\text { cantidad normal de azúcar }\end{array}$ & $\begin{array}{c}\text { bàn táng 半糖 'medio' 'azúcar' } \rightarrow \text { media } \\
\text { porción de azúcar }\end{array}$ \\
\hline
\end{tabular}


Morfología contrastiva del chino mandarín y el español. Formas de gramaticalización y lexicalización

\begin{tabular}{|c|c|}
\hline $\begin{array}{c}\text { quàn sù 全素 'total' 'vegetarianismo' } \rightarrow \\
\text { vegetarianismo total }\end{array}$ & $\begin{array}{c}\text { bàn sù 半素 'medio' 'vegetariarismo' } \rightarrow \\
\text { vegetarianismo parcial }\end{array}$ \\
\hline $\begin{array}{c}\text { quàn kāi 全開 'total' 'apertura' } \rightarrow \\
\text { apertura total }\end{array}$ & $\begin{array}{c}\text { bàn kāi 半開 'medio' 'apertura' } \rightarrow \\
\text { apertura media }\end{array}$ \\
\hline $\begin{array}{c}\text { quàn zì dòng 全自動 'total' } \\
\text { 'automaticidad' } \rightarrow \text { automaticidad total }\end{array}$ & $\begin{array}{c}\text { bàn zì dòng 半自動 'medio' } \\
\text { 'automaticidad' } \rightarrow \text { automaticidad parcial }\end{array}$ \\
\hline $\begin{array}{l}\text { quàn yín mù 全銀幕 'entero' 'pantalla' } \\
\rightarrow \text { pantalla completa }\end{array}$ & $\begin{array}{c}\text { bàn yín mù } \begin{array}{c}\text { 半銀幕 'medio' 'pantalla' } \rightarrow \\
\text { pantalla normal }\end{array} \\
\end{array}$ \\
\hline $\begin{array}{c}\text { quàn guó 全國 'entero' 'nación' } \rightarrow \\
\text { toda la nación }\end{array}$ & $\begin{array}{c}\text { bàn yuán 半圓 'medio' 'círculo' } \rightarrow \text { medio } \\
\text { círculo }\end{array}$ \\
\hline $\begin{array}{c}\text { quàn chē 全車 'entero' 'coche' } \rightarrow \\
\text { todo el coche }\end{array}$ & $\begin{array}{c}\text { bàn kè 半刻 'medio' 'momento' } \rightarrow \text { ni un } \\
\text { minuto }\end{array}$ \\
\hline $\begin{array}{c}\text { quàn jiā 全家 'entero' 'familia' } \rightarrow \text { toda } \\
\text { la familia }\end{array}$ & bàn yīn 半音 'medio' 'tono' $\rightarrow$ semitono \\
\hline $\begin{array}{c}\text { quàn é 全額 'total' 'cuota, cantidad' } \rightarrow \\
\text { cuota/cantidad total }\end{array}$ & $\begin{array}{c}\text { bàn lù 半路 'medio' 'camino' } \rightarrow \text { medio } \\
\text { camino }\end{array}$ \\
\hline $\begin{array}{c}\text { quàn mián 全棉 'total' 'algodón' } \rightarrow \\
\text { algodón } 100 \%\end{array}$ & bàn zľ 半子 'medio' 'hijo' $\rightarrow$ yerno \\
\hline $\begin{array}{c}\text { quàn sù 全速 'total' 'velocidad' } \rightarrow \\
\text { velocidad máxima }\end{array}$ & $\begin{array}{l}\text { bàn yè 半夜 'medio' 'noche' } \rightarrow \\
\text { medianoche }\end{array}$ \\
\hline $\begin{array}{c}\text { quàn miàn 全面 'completo' 'lado' } \rightarrow \\
\text { por completo }\end{array}$ & $\begin{array}{l}\text { bàn dǎo tř 半導體 'semi-' 'conducir' } \\
\text { 'cuerpo' } \rightarrow \text { semiconductor }\end{array}$ \\
\hline $\begin{array}{c}\text { quàn yín 全銀 'total' 'plata' } \rightarrow \text { plata } \\
\text { pura }\end{array}$ & $\begin{array}{c}\text { bàn tòu míng 半透明 'medio' } \\
\text { 'transparencia' } \rightarrow \text { semitransparencia, } \\
\text { traslúcido }\end{array}$ \\
\hline $\begin{array}{c}\text { quàn nén 全能 'completo' } \\
\text { 'capacidad' } \rightarrow \text { todopoderoso, } \\
\text { omnipotencia }\end{array}$ & $\begin{array}{l}\text { bàn yuè kān 半月刊 'medio' 'mes' } \\
\text { 'publicación' } \rightarrow \text { publicación quincenal }\end{array}$ \\
\hline $\begin{array}{c}\text { quàn jí 全集 'completo' 'serie, } \\
\text { colección' } \rightarrow \text { colección completa }\end{array}$ & $\begin{array}{c}\text { bàn yì shì 半意識 'medio' 'consciencia' } \rightarrow \\
\text { semiinconsciencia, subconciencia }\end{array}$ \\
\hline $\begin{array}{l}\text { quàn shǒu gōng 全手工 'total' } \\
\text { 'artesanía' } \rightarrow \text { artesanía total }\end{array}$ & \\
\hline \multicolumn{2}{|l|}{$\begin{array}{l}\text { quàn fāng wèi 全方位 'total' 'dirección' } \\
\quad \rightarrow \text { multifunción, mucha capacidad }\end{array}$} \\
\hline \multicolumn{2}{|l|}{ măn yuè 滿月 'lleno' 'Iuna' $\rightarrow$ Iuna llena } \\
\hline $\begin{array}{c}\text { mǎn fēn 滿分 'completo' 'nota' } \rightarrow \\
\text { calificación máxima }\end{array}$ & \\
\hline
\end{tabular}

Tabla 11: Locuciones aspectuales de la 'perfectividad' y la 'imperfectividad' 
Así, los adjetivos que reordenan la significación aspectual de la 'perfectividad' y la 'imperfectividad' muestran una alta productividad en la formación de locuciones. El adjetivo que tiende a codificar la 'perfectividad' de la entidad designada por el nombre es quàn 全, cuyo significado varía entre 'total', 'completo', 'entero', 'pleno', etc., según el elemento con el que se combina para formar la lexicalización. Solo en algunos casos la significación aspectual de la 'perfectividad' se expresa mediante el adjetivo măn 滿 'lleno'. Por otra parte, bàn 半 'medio' tienden a lexicalizar la 'imperfectividad' o el sentido parcial de las entidades referidas.

En ambas lenguas, la mayor productividad de las locuciones aspectuales corresponde a la significación de 'perfectividad' 'imperfectividad'. Especialmente en chino mandarín, este procedimiento locucional alcanza una alta productividad sobre todo para la lexicalización de locuciones pareadas de significados opuestos.

\subsubsection{Análisis contrativo de la lexicalización}

Desde el punto de vista formal, la comparación de estas locuciones en español y en mandarín presenta alguna semejanza en la estructura interna: se establece una relación de tipo intersectivo entre el modificado (nombre-núcleo) y el modificador (el adjetivo). En los casos de oposición entre la 'variación' y la 'estabilidad', la 'perfectividad' y la 'imperfectividad', los adjetivos son modificadores que se posponen y se anteponen al núcleo de la combinación léxica del español y el chino mandarín, respectivamente. En el caso de la significación de la 'imperfectividad', ambas lenguas tienen los modificadores adjetivales antepuestos al núcleo nominal (en español, con el adjetivo medio). 
Morfología contrastiva del chino mandarín y el español. Formas de gramaticalización y lexicalización

Por otro lado, en ambas lenguas estas combinaciones no admiten la paráfrasis predicativa ni los modificadores de grado ni de comparación, como toda locución:

\section{Español}

La renta variable/ *La renta es variable/ * La renta muy variable La luna llena / *La luna es llena/ *La luna es más llena

\section{Chino mandarín}

1) liú dòng fù zài 流動負債 'flotante' 'deuda' $\rightarrow$ deuda flotante

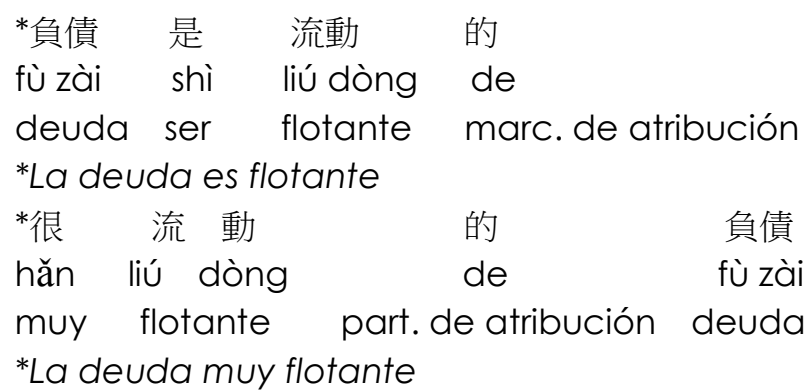

2) bàn piào 半票 'medio' 'billete' $\rightarrow$ tarifa reducida

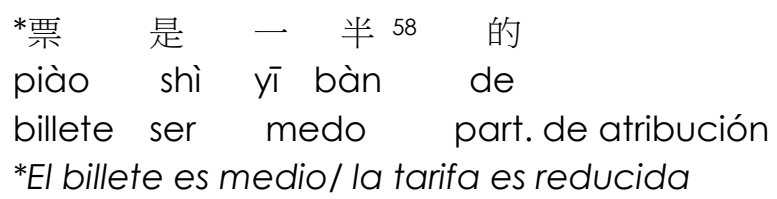

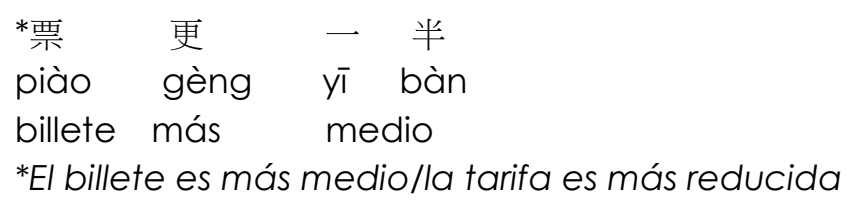

Junto a estas semejanzas, se observan también algunas diferencias entre las locuciones aspectuales del español y el mandarín desde una perspectiva morfológica y semántica. Así, en mandarín un mismo elemento como quàn 全 da lugar a un grupo numeroso de locuciones, todas relacionadas con el sentido 'perfectivo' de '†odo, máximo, completo', etc., como en los casos de quàn piào 全票 'total' 'billete' $\rightarrow$ billete completo,

\footnotetext{
58 Por la tendencia bisilábica del chino mandarín, muchas palabras monosilábicas suelen emplearse en forma de dos sílabas cuando aparecen en construcción predicativa. Así, la forma bisilábica de bàn 半 'medio' es 一半 yī bàn 'medio'.
} 
quàn sù 全速 'total' 'velocidad' $\rightarrow$ velocidad máxima, quàn yín 全銀 'total' 'plata' $\rightarrow$ plata pura, quàn zhí 全職 'entero' 'trabajo' $\rightarrow$ dedicación plena. Del mismo modo, el adjetivo bàn 半 denota la 'imperfectividad' en las locuciones aspectuales, pues se lexicaliza con el sentido de 'medio 'parcial', etc., como en los casos de bàn piào 半票 'medio' 'billete' $\rightarrow$ billete de niño, tarifa reducida, bàn zhí 半職 'medio' 'trabajo' $\rightarrow$ trabajo parcial, bàn tòu míng 半透 明 'medio' 'transparencia' $\rightarrow$ semitransparencia, traslúcido y bàn yuè kān 半月 刊 'medio' 'mes' 'publicación' $\rightarrow$ publicación quincenal.

Por otro lado, quàn 全 'total, entero, completo, lleno, pleno' y bàn 半 'medio' muestran en chino mandarín un sentido hacia la gramaticalización, pues en la formación de compuestos se consideran elementos que carecen de autonomía léxica y se convierten en formas ligadas que dependen de otros elementos. Tal cadena de gramaticalización es una descategorización que tiene como inicio un nombre pleno (en chino clásico) y como resultado un elemento de función afijal (en mandarín actual).

Respecto a la explicación semántica del endocentrismo y exocentrismo en estas combinaciones de adjetivos aspectuales y nombres, ambas lenguas coinciden en presentar más formas endocéntricas que exocéntricas. En las formas endocéntricas, los compuestos o las locuciones difieren de los sintagmas nominales en que a veces no resultan absolutamente composicionales, pues tanto el núcleo como el modificador pueden activar significados específicos. Así, una media cama es una cama de tamaño medio. Pero no cualquiera cama de este tamaño reducido es una media cama, sino que se trata específicamente de la compuesta solamente de un colchón, una sábana, una manta y una almohada (según la definición del DRAE 2007). Lo mismo cabría decir de media pensión o de leche entera. Paralelamente, biàn xing 變星 'cambiante' 'estrella' $\rightarrow$ estrella variable no describe simplemente el estado inconstante o mudable de una estrella, sino que se refiere a la especialización de contenidos del adjetivo modificador, de forma que el compuesto significa el tipo de estrella que aumenta y disminuye de claridad en 
Morfología contrastiva del chino mandarín y el español. Formas de gramaticalización y lexicalización

períodos más o menos largos.

Como indica Bustos Gisbert (1986), la calificación del endocentrismo o exocentrismo no es absoluta, sino que existe una cierta gradación en el exocentrismo semántico. Así se encuentran en español locuciones endocéntricas en las que la transferencia semántica se basa en valores asociativos no estrictamente estereotípicos. Por ejemplo, en media bata ('batín'), el adjetivo señala el carácter derivado del complejo con respecto al término simple e indica con frecuencia la menor importancia de la realidad compuesta. En bàn piào 半票 'medio' 'billete' $\rightarrow$ tarifa reducida, la transferencia se basa en el carácter valorativo del adjetivo, del que deriva el carácter positivo o negativo (en este caso positivo), en relación con la entidad referida por el elemento sustantivo.

Respecto a casos exocéntricos, en ambas lenguas, se encuentran combinaciones metonímicas y combinaciones metafóricas. Aguas llenas ('pleamar'), por ejemplo, es una locución metonímica en la que se selecciona el rasgo (llenas) que se considera más específico de la entidad designada (aguas) por el complejo, característico por responder a una cualidad real o figurada de la entidad, lo cual implica una transferencia semántica de importancia mayor. En chino mandarín, bàn piào 半票 'medio' 'billete' tiene dos significados: 'billete de niño' o 'tarifa reducida'. Cuando hace referencia al primer significado, se observa la metonimia de "la parte por el todo", en la que lo característico es la designación de la entidad referida por el compuesto mediante una cualidad característica de uno de sus elementos constitutivos. Es decir, el adjetivo medio es la representación de tamaño pequeño que hace referencia a la entidad niño.

En combinaciones metafóricas, la característica semántica esencial de estos complejos reside en la relación de similitud que el hablante establece entre dos realidades diferentes la una de la otra en función de un determinado rasgo, que para el hablante es común a ambas realidades y justifica la elección de la unidad léxica correspondiente a la realidad-imagen. Así, media 
naranja 'persona que se adapta perfectamente a otra, como si cada una fuera la mitad de una naranja' y bàn ž 半子 'medio' 'hijo' $\rightarrow$ yerno presentan tales relaciones metafóricas entre sus componentes y el referente.

Desde el punto de vista contrastivo, se encuentran en ambas lenguas formaciones léxicas de significación aspectual que se corresponden en la estructura formal y en la semántica. Entre estas, no faltan las combinaciones que forman correlaciones de polaridad, tal como ilustran los ejemplos siguientes:

1) biàn xīng 變星 'cambiante' 'estrella' $\rightarrow$ estrella variable héng xīng 恆星 'perpetuo' 'estrella' $\rightarrow$ estrella fija

2) fú dòng lì lù 浮動 利率 'flotante' 'renta' $\rightarrow$ renta variable gù ding li lù 固定 利率 'fijo' 'renta' $\rightarrow$ renta fija

3) quàn sù 全宿 'completo' 'pensión' $\rightarrow$ pensión completa bàn sù 半宿 'medio' 'pensión' $\rightarrow$ media pensión

4) quàn chăng 全場 'entero' 'explanada' $\rightarrow$ campo entero bàn chăng 半場 'media' 'explanada' $\rightarrow$ medio campo

Por otro lado, no faltan ejemplos de compuestos aspectuales cuyos equivalentes del español no coinciden en el proceso morfológico, puesto que a los compuestos adjetivo aspectual-nombre se suman los compuestos morfológicos (como en 1), las formaciones derivadas (como en 2), las palabras simples (como en 3) y los sintagmas nominales (como en 4):

1) quàn nén 全能 'total' 'capacidad' $\rightarrow$ todopoderoso, omnipotencia bàn yè 半夜 'medio' 'noche' $\rightarrow$ medianoche

2) bàn tòu míng 半透明 'medio' 'transparencia' $\rightarrow$ semitransparencia, tras/úcido bàn yì shì 半意識 'medio' 'consciencia' $\rightarrow$ semiinconsciencia, subconciencia quàn fāng wèi 全方位 'total' 'dirección' $\rightarrow$ multifunción, mucha capacidad

3) biàn shù 變數 'cambiante' 'número' $\rightarrow$ variable (mat.) bàn ž̌ 半子 'medio' 'hijo' $\rightarrow$ yerno

4) quàn nián 全年 'entero' 'año' $\rightarrow$ todo el año quàn zì dòng 全自動 'total' 'automaticidad' $\rightarrow$ automaticidad total bàn yuè kān 半月刊 'medio' 'mes' 'publicación' $\rightarrow$ publicación quincenal 
Morfología contrastiva del chino mandarín y el español. Formas de gramaticalización y lexicalización

También hay compuestos cuyo equivalente en español no se identifica con ningún tipo de formación léxica, sino que corresponde más bien a expresiones complejas e incluso a veces se encuentran ejemplos que necesitan alguna explicación descriptiva:

ding cún 定存 'fijo' 'depósito' $\rightarrow$ depósito a plazo fijo

bàn kè 半刻 'medio' 'momento' $\rightarrow$ ni un minuto

quàn táng 全糖 'entero' 'azúcar' $\rightarrow$ cantidad normal de azúcar

Sin embargo, conviene destacar que, a pesar de las diferencias estructurales entre ambas lenguas, los modificadores adjetivales de la locución aspectual del español (tanto los de la significación 'variación' / 'estabilidad' como los de la 'perfectividad' / 'imperfectividad') se corresponden en chino mandarín con los equivalentes de los mismos componentes, que igualmente resultan productivos en las formaciones compuestas. Así, tanto los formantes adjetivales españoles como lleno, completo, entero, pleno, medio, fijo, variable como los componentes adjetivales en mandarín quàn 全 'total, entero, completo, lleno, pleno', bàn 半 'medio', biàn 變 'cambiante, variable', dìng 定 'fijo' se constituyen en los elementos más productivos y frecuentes de este tipo de formaciones en una y otra lengua.

En definitiva, pese a la distancia estructural que separa ambas lenguas, hay cierta correlación entre unos procesos y otros. En general, los constituyentes como quàn 全 y bàn 半, los más frecuentes en el léxico para expresar la 'perfectividad' / 'imperfectividad', se corresponden con los adjetivos españoles del tipo entero, completo, lleno, pleno y medio en la formación de locuciones. Por su parte, en la significación de la 'perfectividad', cuando el componente adjetival chino coincide con los adjetivos españoles completo, entero y lleno, la forma compleja equivalente en español presenta un grado de lexicalización más elevado, tal como reflejan los compuestos o locuciones de 1); por otro lado, cuando el componente adjetival chino equivale al adjetivo español total, se suelen construir formas complejas cuyo nivel de lexicalización es menor, como en los sintagmas nominales de 2): 
1) quàn nén 全能 'completo' 'capacidad' $\rightarrow$ todopoderoso, omnipotencia quàn sù 全宿 'completo' 'pensión' $\rightarrow$ pensión completa quàn chăng 全場 'entero' 'explanada' $\rightarrow$ campo entero măn yuè 滿月 'Ileno' 'Iuna' $\rightarrow$ Iuna llena

2) quàn piào 全票 'total' 'billete' $\rightarrow$ billete de adulto quàn mián 全棉 'total' 'algodón' $\rightarrow$ algodón 100\% quàn zì dòng 全自動 'total' 'automaticidad' $\rightarrow$ (completamente) automático

\subsection{Locuciones nominales locativas}

\subsubsection{Los nombres de lugar en español y en mandarín}

El tercer y último tipo de locución que se selecciona en el presente trabajo para mostrar procesos de lexicalización semejantes entre el español y el chino mandarín está constituido por las locuciones nominales locativas o nombres complejos de lugar. Estas formaciones, en su conjunto, se pueden caracterizar semánticamente porque responden a los significados generales de 'lugar donde se vende o produce algo', 'sitio donde se guarda u ordena algo', 'espacio donde se ejerce alguna actividad', etc.

Pues bien, una clase de nombres locativos del español puede ser objeto de un análisis contrastivo con las formaciones correspondientes del chino mandarín. Se trata de las locuciones nominales que en español presentan la forma $\mathrm{N}$ de $\mathrm{N}$, con la particularidad de que el primer nombre (o nombre cabecera) aporta el sentido locativo. En chino, por su parte, la designación del lugar depende de un formante locativo nominal pospuesto a otro nombre (a veces, adjetivo o verbo). La semejanza entre las dos lenguas reside en la lexicalización de un sintagma nominal cuyo núcleo formal y semántico resulta equivalente en ambos idiomas. Se muestran seguidamente algunos ejemplos de estas lexicalizaciones comunes al español y al chino mandarín: 
Morfología contrastiva del chino mandarín y el español. Formas de gramaticalización y lexicalización

\begin{tabular}{|c|c|}
\hline $\begin{array}{c}\text { Locuciones locativas en } \\
\text { español }\end{array}$ & Locuciones locativas en chino \\
\hline cuarto de baño & yù shì 浴室 'bañarse' 'cuarto' $\rightarrow$ cuarto de baño \\
\hline salón de actos & $\frac{\text { biăo yăn tīng 表演廳 'actuación' 'salón' } \rightarrow \text { salón }}{\text { de actos }}$ \\
\hline puerto de mar & hăi găng 海港 'mar' 'puerto' $\rightarrow$ puerto de mar \\
\hline centro de salud & ïàn kāng zhōng xinn 健康中心 'salud' 'centro' $\rightarrow$ \\
& centro de salud \\
\hline
\end{tabular}

Tabla 12: Ejemplos de locuciones locativas equivalentes

Además de la identidad de los formantes locativos en nuestras dos lenguas (cuarto $\rightarrow$ shì 室, salón $\rightarrow$ tīng 廳, etc.), otros caracteres también semejantes permiten plantear un estudio contrastivo de estos nombres locativos. Así, la productividad de estos núcleos nominales en la formación de locuciones resulta relativamente elevada en ambos idiomas. Además, algunos de los formantes locativos más fecuentes alcanzan grados de gramaticalización comparables en cierto modo a los afijos, que tienden a favorecer el éxito de la lexicalización, ya sea endocéntrica o exocéntrica. Es el caso, para el español del sustantivo casa en locuciones como casa de beneficencia, casa de citas, casa de Dios, casa de socorro, etc., y para el chino, del formante fáng 房 'habitación' en locuciones como las siguientes:

yào fáng 藥房 'medicina' 'habitación' $\rightarrow$ farmacia chú fáng 廚房 'cocina' 'habitación' $\rightarrow$ cocina jiàn shēn fáng 健身房 'fortalecer' 'cuerpo' 'habitación' $\rightarrow$ gimnasio chăn fáng 產房 'parir' 'habitación' $\rightarrow$ paritorio

\subsubsection{Comparación estructural}

En español, según el proceso morfológico, los nombres de lugar se reparten en varios grupos. Además del tipo $\mathrm{N}$ de $\mathrm{N}$, que aquí se analiza, también forman la clase de los nombres locativos las palabras derivadas 
mediante un sufijo de significado locativo: zapat-ería, tana-torio, biblio-teca, cena-dor, inverna-dero, aparca-miento. Otros sustantivos locativos no coinciden con la estructura de los dos grupos anteriores, como los compuestos formados por verbo y nombre (guardarropa) y las aposiciones de dos nombres yuxtapuestos (café teatro) ${ }^{59}$.

En este apartado, nos interesamos especialmente por la formación de nombres de lugar que responden a la estructura $\mathrm{N}$ de $\mathrm{N}$. En estos compuestos sintagmáticos o locuciones, registradas como tales en los diccionarios, el primer sustantivo aporta el sentido locativo. En la tabla siguiente se reúne un corpus representativo de estos nombres de lugar formados mediante la secuencia $\mathrm{N}$ de N:

\begin{tabular}{|c|c|}
\hline Núcleo & Locución \\
\hline Banco & $\begin{array}{c}\text { banco de alimentos, banco de arena, banco de datos, banco de hielo, } \\
\text { banco de negocios, banco de niebla, banco de pruebas, banco de sangre }\end{array}$ \\
\hline Campo & $\begin{array}{c}\text { campo de batalla, campo de concentración, campo de fútbol, campo del } \\
\text { honor, campo de refugiados, campo de tiro }\end{array}$ \\
\hline Casa & $\begin{array}{c}\text { casa de acogida, casa de baños, casa de beneficencia, casa de campo, } \\
\text { casa de citas (casa de camas, casa de compromisos, casa de mancebía, } \\
\text { casa de putas), casa de comidas, casa de devoción, casa de Dios (casa de } \\
\text { oración, casa del Señor), casa de dormir, casa de empeños (casa de } \\
\text { préstamos), casa de expósitos, casa de fieras, casa de huéspedes (casa de } \\
\text { posada, casa de pupilos), casa de juego, casa de locos, casa de } \\
\text { maternidad, casa de moneda, casa de recreo, casa de socorro, casa de tía, } \\
\text { casa de vacas, casa de vecindad }\end{array}$ \\
\hline Centro & $\begin{array}{c}\text { centro de día, centro de gravedad, centro de menores, centro de } \\
\text { investigaciones, centro de recursos, centro de salud }\end{array}$ \\
\hline Cuarto & $\begin{array}{c}\text { cuarto de aseo, cuarto de banderas, cuarto de baño, cuarto de derrota, } \\
\text { cuarto de estar, cuarto de estandartes }\end{array}$ \\
\hline Patio & patio de butacas, patio de luces, patio de recreo \\
\hline Parque & parque de artillería, parque de atracciones, parque de bomberos \\
\hline Pista & pista de aterrizaje, pista de baile, pista de circo, pista de tenis \\
\hline Plaza & plabastos, plaza de armas, plaza de toros \\
\hline
\end{tabular}

59 Los nombres simples y primitivos de lugar (casa, tienda), que no comportan ningún proceso morfológico o sintagmático en su formación, no son objeto del presente trabajo. 
Morfología contrastiva del chino mandarín y el español. Formas de gramaticalización y lexicalización

\begin{tabular}{|c|c|}
\hline Sala & $\begin{array}{l}\text { sala de audiencia, sala de batalla, sala de estar, sala de fiestas, sala de } \\
\text { espera, sala de estudio, sala de exposiciones, sala de fiestas, sala de } \\
\text { gobierno, sala de justicia, sala de operaciones, sala de prensa, sala de } \\
\text { vacaciones }\end{array}$ \\
\hline Salón & salón de actos, salón de sesiones, salón de belleza \\
\hline Zona & zona de desastre, zona de ensanche, zona de influencia, zona de obras \\
\hline $\begin{array}{c}\text { Otras } \\
\text { formas }\end{array}$ & $\begin{array}{c}\text { circuito de carreras, depósito de cadáveres, edificio de oficinas, gabinete } \\
\text { de consultas, jardín de infancia, planta de reciclaje, torre de control }\end{array}$ \\
\hline
\end{tabular}

Tabla 13: Nombres de lugar de estructura $\mathrm{N}$ de $\mathrm{N}$ en español

Frente a las variedades morfológicas del español, los nombres de lugar en chino mandarín responden a un solo tipo, que es el formado por la adición del llamado pseudosufijo locativo a determinados morfemas léxicos o a palabras compuestas.

A continuación se presenta una selección de estos nombres locativos del mandarín. Se trata de una relación de los pseudosufijos locativos y de las formaciones a las que dan lugar en chino. Aunque sin pretensiones de exhaustividad, la tabla siguiente pretende ser representativa de las posibilidades combinatorias de tales formantes:

\begin{tabular}{|c|c|}
\hline $\begin{array}{c}\text { Formante } \\
\text { locativo }\end{array}$ & Nombres de lugar \\
\hline $\begin{array}{l}\text { diàn 店 } \\
\text { tienda }\end{array}$ & $\begin{array}{c}\text { huā diàn 花店 'flor' 'tienda' } \rightarrow \text { floristería } \\
\text { jing pǐn diàn 精品店 'delicado' 'artículo' 'tienda' } \rightarrow \text { boutique } \\
\text { fàn diàn 飯店 'arroz' 'tienda' } \rightarrow \text { hotel } \\
\text { shū diàn 書店 'libro' 'tienda' } \rightarrow \text { librería } \\
\text { zhū băo diàn 珠寶店 'joya' 'tienda' } \rightarrow \text { joyería } \\
\end{array}$ \\
\hline $\begin{array}{c}\text { háng 行 } \\
\text { tienda }\end{array}$ & $\begin{array}{c}\text { wǔ jin háng 五金行 'cinco' 'metal' 'tienda' } \rightarrow \text { ferretería } \\
\text { jiā jù háng 家具行 'casa' 'artículo' 'tienda' } \rightarrow \text { mueblería } \\
\text { biăo háng 鐘錶行 'campana' 'reloj' 'tienda' } \rightarrow \text { relojería } \\
\text { yín háng 銀行 'plata' 'tienda' } \rightarrow \text { banco } \\
\text { yăn jìng háng 眼鏡行 'gafas' 'tienda' } \rightarrow \text { óptica }\end{array}$ \\
\hline $\begin{array}{l}\text { féng 坊 } \\
\text { tienda }\end{array}$ & $\begin{array}{c}\text { miàn bāo féng 麵包坊 'pan' 'tienda' } \rightarrow \text { panadería } \\
\text { huā féng 花坊 'flor' 'tienda' } \rightarrow \text { floristería } \\
\text { mó féng 磨坊 'moler' 'tienda' } \rightarrow \text { molino } \\
\text { yú féng 油坊 'aceite' 'tienda' } \rightarrow \text { almazara } \\
\text { răn féng 染坊 'teñir' 'tienda' } \rightarrow \text { tintorería }\end{array}$ \\
\hline
\end{tabular}




\begin{tabular}{|c|c|}
\hline $\begin{array}{l}\text { pù 舖 } \\
\text { tienda }\end{array}$ & $\begin{array}{c}\text { dàng pù 當舖 'empeñar' 'tienda' } \rightarrow \text { casa de empeños } \\
\text { zhōng yào pù 中藥舖 'chino' 'medicina' 'tienda' } \rightarrow \text { herboristería } \\
\text { china } \\
\text { gāo diǎn pù 糕點舖 'pastel, tarta' 'tienda' } \rightarrow \text { pastelería } \\
\text { ròu pù 肉舖 'carne' 'tienda' } \rightarrow \text { carnicería } \\
\text { dă tiě pù 打鐵舖 'fundir' 'hierro' 'tienda' } \rightarrow \text { herrería }\end{array}$ \\
\hline $\begin{array}{l}\text { jiān 間 } \\
\text { cuarto }\end{array}$ & 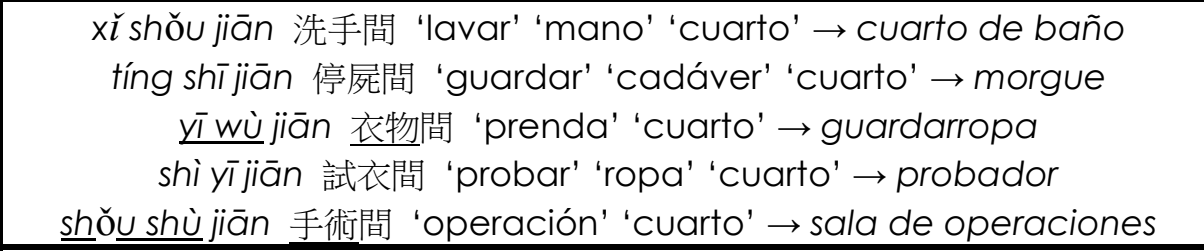 \\
\hline $\begin{array}{l}\text { shì 室 } \\
\text { cuarto }\end{array}$ & $\begin{array}{c}\text { shí yàn shì 實驗室 'experimentar' 'cuarto' } \rightarrow \text { laboratorio } \\
\text { wēn shi 溫室 'templado' 'cuarto' } \rightarrow \text { invernadero } \\
\text { bàn gōng shì 辦公室 'tratar' 'público' 'cuarto' } \rightarrow \text { despacho, oficina } \\
\text { yù shì 浴室 'bañarse' 'cuarto' } \rightarrow \text { cuarto de baño } \\
\text { wò shì 臥室 'tumbar' 'cuarto' } \rightarrow \text { dormitorio }\end{array}$ \\
\hline $\begin{array}{c}\text { táng 堂 } \\
\text { cuarto }\end{array}$ & $\begin{array}{c}\text { zăo táng 澡堂 'baño' 'cuarto' } \rightarrow \text { casa de baño } \\
\text { shí táng 食堂 'comer' 'cuarto' } \rightarrow \text { comedor } \\
\text { jiào táng 教堂 'religión' 'cuarto' } \rightarrow \text { iglesia, catedral } \\
\text { fó táng 佛堂 'Buda' 'cuarto' } \rightarrow \text { corte búdica } \\
\text { lǐ táng 禮堂 'ceremonia' 'cuarto' } \rightarrow \text { salón de ceremonias, salón de } \\
\text { actos }\end{array}$ \\
\hline $\begin{array}{c}\text { guăn 館 } \\
\text { casa }\end{array}$ & $\begin{array}{c}\text { bó wù guăn 博物館 'amplio' 'objeto' 'casa' } \rightarrow \text { museo } \\
\text { tú shū guăn 圖書館 'dibujo' 'libro' 'casa' } \rightarrow \text { biblioteca } \\
\text { lü guăn 旅館 'viajar' 'casa' } \rightarrow \text { hotel } \\
\text { kā fēi guăn 咖啡館 'café' 'casa' } \rightarrow \text { cafetería } \\
\text { cān guăn 餐館 'comida' 'casa' } \rightarrow \text { restaurante }\end{array}$ \\
\hline jiā 家 casa & 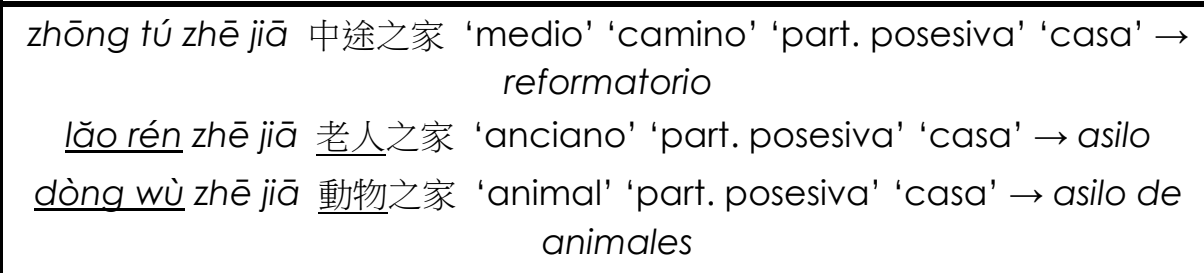 \\
\hline shè 舍 casa & $\begin{array}{l}\text { nóng shè 農舍 'agrícola' 'casa' } \rightarrow \text { casa de campo } \\
\text { xiào shè 校舍 'escuela' 'casa' } \rightarrow \text { edificio escolar } \\
\text { sù shè 宿舍 'alojarse' 'casa' } \rightarrow \text { residencia } \\
\text { Ji shè 雞舍 'gallina' 'casa' } \rightarrow \text { gallinero } \\
\text { lü shè 旅舍 'viajar' 'casa' } \rightarrow \text { hostal }\end{array}$ \\
\hline $\begin{array}{c}\text { chăng 廠 } \\
\text { fábrica, } \\
\text { taller }\end{array}$ & $\begin{array}{l}\text { hé néng chăng 核能廠 'nuclear' 'energía' 'fábrica' } \rightarrow \text { central nuclear } \\
\text { fā diàn chăng 發電廠 'producir' 'electricidad' 'fábrica' } \rightarrow \text { central } \\
\text { eléctrica } \\
\text { yìn shuā chăng 印刷廠 'imprimir' 'fábrica' } \rightarrow \text { imprenta } \\
\text { zhōng biăo chăng 鐘錶廠 'campana' 'reloj' 'taller' } \rightarrow \text { taller de relojería } \\
\text { yào chăng 藥廠 'medicamento' 'fábrica' } \rightarrow \text { laboratorio farmacéutico }\end{array}$ \\
\hline
\end{tabular}


Morfología contrastiva del chino mandarín y el español. Formas de gramaticalización y lexicalización

\begin{tabular}{|c|c|}
\hline $\begin{array}{c}\text { fáng 房 } \\
\text { habitación }\end{array}$ & $\begin{array}{c}\text { yào fáng 藥房 'medicina' 'habitación' } \rightarrow \text { farmacia } \\
\text { chú fáng 廚房 'cocina' 'habitación' } \rightarrow \text { cocina } \\
\text { jiàn shēn fáng 健身房 'fortalecer' 'cuerpo' 'habitación' } \rightarrow \text { gimnasio } \\
\text { wò fáng 臥房 'tumbar' 'habitación' } \rightarrow \text { dormitorio } \\
\text { chăn fáng 產房 'parir' 'habitación' } \rightarrow \text { paritorio }\end{array}$ \\
\hline $\begin{array}{l}\text { chăng 場 } \\
\text { explanada }\end{array}$ & $\begin{array}{c}\text { guăn chăng 廣場 'amplio' 'explanada' } \rightarrow \text { plaza } \\
\text { caō chăng 操場 'entrenar' 'explanada' } \rightarrow \text { campo de deporte } \\
\text { tíng chē chăng 停車場 'aparcar' 'vehículo' 'explanada' } \rightarrow \\
\text { aparcamiento } \\
\text { zú qiú chăng 足球場 'fútbol' 'explanada' } \rightarrow \text { campo de fútbol } \\
\text { Ji chăng 機場 'avión' 'explanada' } \rightarrow \text { aeropuerto } \\
\text { shāng chăng 商場 'comercio' 'explanada' } \rightarrow \text { centro comercial }\end{array}$ \\
\hline $\begin{array}{l}\text { yuàn 院 } \\
\text { edificio }\end{array}$ & $\begin{array}{c}\text { gū ér yuàn 孤兒院 'huérfano' 'edificio' } \rightarrow \text { orfanato } \\
\text { liăo yăng yuàn 療養院 'curar' 'edificio' } \rightarrow \text { sanatorio } \\
\text { lĭ fă yuàn 理髮院 'arreglar' 'pelo' 'edificio' } \rightarrow \text { peluquería } \\
\text { jì yuàn 妓院 'prostituta' 'edificio' } \rightarrow \text { casa de citas } \\
\text { găn huà yuàn 感化院 'reformar, corregir' 'edificio' } \rightarrow \text { reformatorio }\end{array}$ \\
\hline $\begin{array}{l}\text { yuán 園 } \\
\text { jardín }\end{array}$ & $\begin{array}{c}\text { huā yuán 花園 'flor' 'jardín' } \rightarrow \text { jardín } \\
\text { mù yuán 墓園 'tumba' 'jardín' } \rightarrow \text { cementerio } \\
\text { zhí wù yuán 植物園 'planta' 'jardín' } \rightarrow \text { jardín botánico } \\
\text { gōng yuán 公園 'público' 'jardín' } \rightarrow \text { parque } \\
\text { yú lè yuán 遊樂園 'viajar' 'feliz' 'jardín' } \rightarrow \text { parque de atracciones }\end{array}$ \\
\hline $\begin{array}{c}\text { tīng 廳 sala } \\
\text { (salón) }\end{array}$ & $\begin{array}{c}\text { cān tīng 餐廳 'comida' 'sala' } \rightarrow \text { restaurante } \\
\text { kā fēi tīng 咖啡廳 'café' 'sala' } \rightarrow \text { cafetería } \\
\text { kè tīng 客廳 'huésped' 'sala' } \rightarrow \text { salón } \\
\text { lì fă tīng 理髮廳 'arreglar' 'pelo' 'sala' } \rightarrow \text { peluquería } \\
\text { dà tīng 大廳 'grande' 'sala' } \rightarrow \text { hall, vestíbulo } \\
\text { 表演廳 biăo yăn tìng 'actuación' 'sala' } \rightarrow \text { salón de actos } \\
\end{array}$ \\
\hline $\begin{array}{c}\text { kù 庫 } \\
\text { almacén }\end{array}$ & $\begin{array}{l}\text { shuľ kù 水庫 'agua' 'almacén' } \rightarrow \text { embalse, presa } \\
\text { cāng kù 倉庫 'almacén' 'almacén' } \rightarrow \text { almacén } \\
\text { xiě kù 血庫 'sangre' 'almacén' } \rightarrow \text { banco de sangre } \\
\text { chē kù 車庫 'coche' 'almacén' } \rightarrow \text { garaje } \\
\text { jin kù 金庫 'oro' 'almacén' } \rightarrow \text { tesorería }\end{array}$ \\
\hline $\begin{array}{l}\text { suǒ 所 } \\
\text { oficina }\end{array}$ & $\begin{array}{c}\text { cè suǒ 廁所 'baño' 'oficina' } \rightarrow \text { aseo } \\
\text { zhěn suǒ 診所 'diagnosticar' 'oficina' } \rightarrow \text { clínica } \\
\text { xiāng gōng suǒ 鄉公所 'pueblo' 'público' 'oficina' } \rightarrow \text { ayuntamiento } \\
\text { wèi shēng suǒ 衛生所 'higiene' 'oficina' } \rightarrow \text { dispensario } \\
\text { shì wù suǒ 事務所 'asunto' 'oficina' } \rightarrow \text { oficina, despacho }\end{array}$ \\
\hline $\begin{array}{l}\text { jú 局 } \\
\text { oficina }\end{array}$ & $\begin{array}{c}\text { yào jú 藥局 'medicina' 'oficina' } \rightarrow \text { farmacia } \\
\text { yú jú 郵局 'correo' 'oficina' } \rightarrow \text { correos } \\
\text { jǐng chá jú 警察局 'policía' 'oficina' } \rightarrow \text { comisaría } \\
\text { xiāo fáng jú 消防局 'prevenirse del fuego' 'oficina' } \rightarrow \text { parque de } \\
\text { bomberos }\end{array}$ \\
\hline
\end{tabular}




\begin{tabular}{|c|c|}
\hline $\begin{array}{l}\text { zhàn 站 } \\
\text { parada }\end{array}$ & $\begin{array}{c}\text { chē zhàn 車站 'vehículo' 'parada' } \rightarrow \text { estación } \\
\text { xiū xí zhàn 休息站 'descansar' 'parada' } \rightarrow \text { área de descanso/ servicio } \\
\text { shōu fèi zhàn 收費站 'recibir' 'tasa' 'parada' } \rightarrow \text { peaje } \\
\text { yī liáo zhàn 醫療站 'medicina' 'curar' 'parada' } \rightarrow \text { botiquín }\end{array}$ \\
\hline $\begin{array}{c}\text { zhōng xīn 中 } \\
\text { 心 centro }\end{array}$ & $\begin{array}{c}\text { ¿iàn kāng zhōng xīn 健康中心 'salud' 'centro' } \rightarrow \text { centro de salud } \\
\text { gòu wù zhōng xīn 購物中心 'compra' 'centro' } \rightarrow \text { centro comercial } \\
\text { lĭ făzhōng xīn 理髮中心 'arreglar' 'pelo' 'centro' } \rightarrow \text { peluquería } \\
\text { yán jiù zhōng xīn 研究中心 'investigar' 'centro' } \rightarrow \text { centro de } \\
\text { investigaciones } \\
\text { yī xuézhōng xīn 醫學中心 'medicina' 'estudio' 'centro' } \rightarrow \text { hospital } \\
\text { clínico }\end{array}$ \\
\hline $\begin{array}{l}\text { shì chăng 市 } \\
\text { 場 mercado }\end{array}$ & $\begin{array}{l}\frac{\text { tiào zăo shì chăng 跳蚤市場 'pulga' 'mercado' } \rightarrow \text { mercadillo }}{\text { chāo jí shì chăng 超級市場 'superar' 'clase' 'mercado' } \rightarrow} \text { supermercado } \\
\text { huā huì shì chăng 花卉市場 'flor' 'mercado' } \rightarrow \text { mercado de flores } \\
\text { cài shì shì chăng 菜市場 'verdura' 'mercado' } \rightarrow \text { mercado }\end{array}$ \\
\hline $\begin{array}{c}\text { tái 台 } \\
\text { plataforma }\end{array}$ & $\begin{array}{c}\text { yáng tái 陽台 'sol' 'plataforma' } \rightarrow \text { balcón } \\
\text { jiǎng tái 講台 'hablar' 'plataforma' } \rightarrow \text { estrado } \\
\text { hòu tái 後台 'detrás' 'plataforma' } \rightarrow \text { bastidor } \\
\text { xǐ shǒu tái 洗手台 'lavar' 'mano' 'plataforma' } \rightarrow \text { lavabo } \\
\text { yuè tái 月台 'luna' 'plataforma' } \rightarrow \text { andén }\end{array}$ \\
\hline $\begin{array}{l}\text { láng 廊 } \\
\text { pasillo }\end{array}$ & $\begin{array}{c}\text { zǒu láng 走廊 'andar' 'pasillo' } \rightarrow \text { pasillo } \\
\text { huà láng 畫廊 'pintura' 'pasillo' } \rightarrow \text { galería de pinturas } \\
\text { shū láng 書廊 'libro' 'pasillo' } \rightarrow \text { librería } \\
\text { huí láng 迴廊 'girar' 'pasillo' } \rightarrow \text { corredor, pasillo } \\
\text { fă láng 髮廊 'pelo' 'pasillo' } \rightarrow \text { peluquería }\end{array}$ \\
\hline $\begin{array}{l}\text { chí 池 } \\
\text { fuente }\end{array}$ & $\begin{array}{l}\text { yú yǒng chí 游泳池 'nadar' 'fuente' } \rightarrow \text { piscina } \\
\text { wǔ chí 舞池 'baile' 'fuente' } \rightarrow \text { pista de baile } \\
\text { shuí chí 水池 'agua' 'fuente' } \rightarrow \text { fuente }\end{array}$ \\
\hline $\begin{array}{l}\text { tíng 亭 } \\
\text { porche }\end{array}$ & $\begin{array}{c}\text { diàn huà tíng 電話亭 'teléfono' 'porche' } \rightarrow \text { cabina telefónica } \\
\text { shoù piào tíng 售票亭 'vender' 'billete' 'porche' } \rightarrow \text { taquilla } \\
\text { liáng tíng 涼亭 'fresco' 'porche' } \rightarrow \text { cenador } \\
\text { bào tíng 報亭 'periódico' 'porche' } \rightarrow \text { quiosco }\end{array}$ \\
\hline $\begin{array}{c}\text { yín hán 銀行 } \\
\text { banco }\end{array}$ & 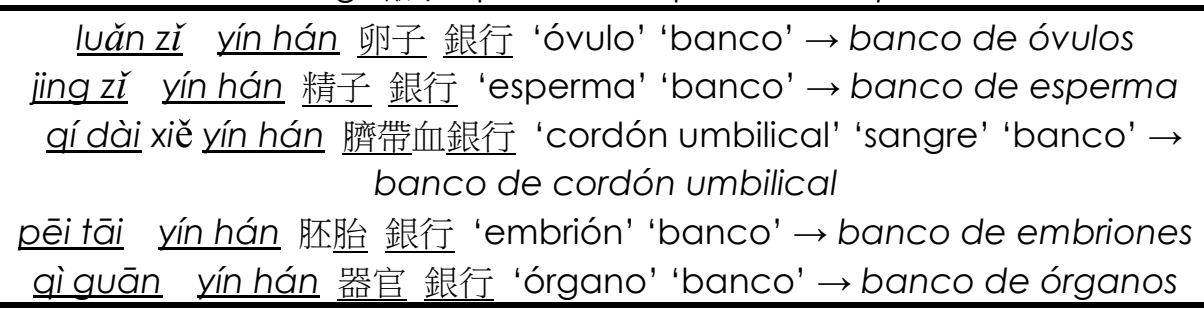 \\
\hline $\begin{array}{l}\text { găng 港 } \\
\text { puerto }\end{array}$ & $\begin{array}{c}\text { yú găng 漁港 'pesca' 'puerto' } \rightarrow \text { puerto pesquero } \\
\text { hăi găng 海港 'mar' 'puerto' } \rightarrow \text { puerto de mar }\end{array}$ \\
\hline $\begin{array}{l}\text { jiào 窒 } \\
\text { bodega }\end{array}$ & 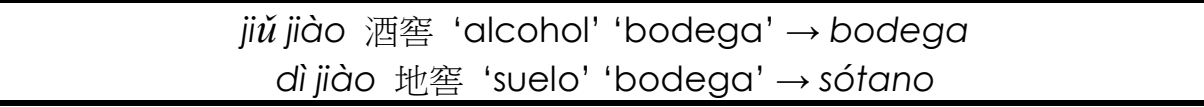 \\
\hline
\end{tabular}

Tabla 14: Nombres de lugar en chino mandarín 
Morfología contrastiva del chino mandarín y el español. Formas de gramaticalización y lexicalización

Los formantes locativos presentan, en general, una estructura monosilábica que se pospone a otros morfemas léxicos o a palabras compuestas de distintas categorías gramaticales, sobre todo sustantivos:

Sustantivo + locativo: yáng tái 陽台 'sol' 'plataforma' $\rightarrow$ balcón Adjetivo + locativo: wēn shì 溫室 'templado' 'habitación' $\rightarrow$ invernadero Verbo + locativo: wò fáng 臥房 'tumbarse' 'habitación' $\rightarrow$ dormitorio Adverbio + locativo: hòu tái 後台 'detrás' 'plataforma' $\rightarrow$ bastidor Compuesto verbal + locativo: shoù piào tíng 售票亭 'vender' 'billete' 'porche' $\rightarrow$ taquilla

Por otra parte, aunque son escasos en mandarín, existen morfemas locativos de forma bisilábica, como zhōng xīn 中心 centro. Sin embargo, algunos morfemas locativos monosilábicos son en realidad formas abreviadas de palabras bisílabas:

diàn 店 tienda < shāng diàn 商店 'comercio' 'tienda' chăng 廠 fábrica, taller < gōng chăng 工廠 'trabajo' 'fábrica, taller' găng 港 puerto < găng kǒu 港 $\square$ 'puerto' 'boca' shì 市 mercado < shì chăng 市場 'mercado' 'explanada'

La selección del formante abreviado monosílabo facilita la combinación con otros elementos léxicos para formar los nombres de lugar complejos. El fenómeno puede compararse a las formaciones del español con tele-, foto-, euro-, etc., que representan los acortamientos léxicos habituales en formaciones como teletienda, fotomatón, eurocopa, etc. Normalmente, resultan inusuales las combinaciones con las formas bisilábicas originarias, excepto en algunos casos con gōng chăng 工廠 fábrica, taller y shì chăng 市場 mercado:

\begin{tabular}{|l|l|}
\hline \multicolumn{1}{|c|}{$\begin{array}{c}\text { Formante locativo } \\
\text { abreviado }\end{array}$} & \multicolumn{1}{|c|}{ Selección de la forma abreviada } \\
\hline chăng 廠 fábrica, taller & yào chăng 藥廠 'medicina' 'fábrica' $\rightarrow$ laboratorio \\
\hline shì 市 mercado & chāo shì 超市 'súper' 'mercado' $\rightarrow$ supermercado \\
\hline
\end{tabular}




\begin{tabular}{|l|l|}
\hline $\begin{array}{l}\text { Formante locativo } \\
\text { pleno }\end{array}$ & \multicolumn{1}{|c|}{ Selección de la forma plena } \\
\hline $\begin{array}{l}\text { gōng chăng 工 廠 } \\
\text { fábrica, taller }\end{array}$ & $\begin{array}{l}\text { huà xué gōng chăng 化學 工廠 'química' 'fábrica' } \rightarrow \\
\text { fábrica química } \\
\text { sù jiāo gōng chăng 塑膠 工廠 'plástico' 'fábrica' } \rightarrow \\
\text { fábrica de plásticos }\end{array}$ \\
\hline shì chăng 市場 mercado & $\begin{array}{l}\text { cài shì shì chăng 菜市場 'verdura' 'mercado' } \rightarrow \text { mercado } \\
\text { tiào zăo shì chăng 跳蚤 市 場 } \\
\text { mercadillo }\end{array}$ \\
\hline
\end{tabular}

Tabla 15: Nombres de lugar en chino mandarín con formante locativo bisilábico

Otros nombres del chino mandarín que indican lugar, sin embargo, aunque también son formas compuestas, no se analizan propiamente a partir de la combinatoria de formantes locativos productivos. Por ejemplo, casos como shuǐ bà 水壩 'agua' 'dique' $\rightarrow$ presa, mă jiù 馬廐 'caballo' 'establo' $\rightarrow$ caballeriza, biè shù 別墅 'otro' 'cabaña' $\rightarrow$ casa de campo, jiān yù 監獄 'prisión' 'cárcel' $\rightarrow$ cárcel, etc. Son nombres de lugar formados por un formante locativo que suele restringir su productividad a un reducido número de casos, frente a la frecuencia de uso que alcanzan los formantes de la tabla 14.

Por otra parte, el mandarín también dispone de palabras de designación locativa que tienen su origen en otra lengua. Por ejemplo, dí sī kě 迪斯可 discoteca, jiǔ ba 酒吧 bar, jù lè bù 俱樂部 club, etc., que se introducen en mandarín con algún cambio fonético; pub (así escrito) es un préstamo directo del inglés; kōng găng 空港 'cielo' 'puerto' $\rightarrow$ aeropuerto es un préstamo del japonés cuyo significado puede deducirse en mandarín a partir de sus componentes.

Según lo expuesto, la formación de palabras locativas en español se produce a partir de los dos procesos principales, la derivación y la composición, que, a su vez, comprende la composición morfológica y la composición sintagmática. En cambio, los sustantivos locativos del chino se forman mediante un único proceso, que consiste en la adición de formantes locativos pospuestos a los morfemas léxicos o a las palabras compuestas. En español, 
Morfología contrastiva del chino mandarín y el español. Formas de gramaticalización y lexicalización

cada uno de los procesos incluye formaciones de distintas estructuras sintáctico-semánticas. Ilustramos las posibles combinaciones en la siguiente tabla:

\begin{tabular}{|c|c|c|c|}
\hline Derivación & $\begin{array}{l}\text {-ería: formación o } \\
\text { formación d } \\
\text { formación c } \\
\text {-teca: biblioteca } \\
\text {-ario: santuario } \\
\text {-dor: comedor } \\
\text {-ía: abadía }\end{array}$ & $\begin{array}{l}\text { ominal: acerería } \\
\text { rbal: refinería } \\
\text { oase en -ero: zapatería } \\
\text {-dromo: hipódromo } \\
\text {-ato: economato } \\
\text {-duría: expendeduría } \\
\text {-torio: laboratorio }\end{array}$ & $\begin{array}{l}\text {-ado: arzobispado } \\
\text {-dero: tendedero } \\
\text {-miento: aparcamiento }\end{array}$ \\
\hline $\begin{array}{l}\text { Composición } \\
\text { Sintagmática }\end{array}$ & \multicolumn{3}{|c|}{$\begin{array}{l}\text { N de N: núcleo + compl. singular: sala de espera, banco de sangre } \\
\text { núcleo + compl. plural: plaza de toros, centro de recursos } \\
\text { núcleo + compl. con determinación: campo del honor } \\
\text { estructura semántica endocéntrica: sala de visitas, cuarto de } \\
\text { baño } \\
\text { estructura semántica exocéntrica: casa de citas, sala de } \\
\text { batalla } \\
\mathrm{N}+\mathrm{N} \text { : café teatro, salón comedor }\end{array}$} \\
\hline $\begin{array}{l}\text { Composición } \\
\text { morfológica }\end{array}$ & \multicolumn{3}{|c|}{ V+ N: guardarropa, guardamuebles } \\
\hline
\end{tabular}

Tabla 16: Formaciones de nombres locativos en español

Por otro lado, los formantes locativos más frecuentes del mandarín incluyen: chăng 場 'explanada', chí 池 'fuente', féng 坊 'tienda', fáng 房 'habitación', găng 港 'puerto', háng 行 'tienda', suǒ 所 'oficina', jiān 間 'cuarto', jiào 窄 'bodega', jú 局 'oficina', kù 庫 'almcén', láng 廊 'pasillo', pù 舖 'tienda', shè 舍 'casa', shì 室 'habitación', táng 堂 'cuarto', tīng 廳 'sala (salón)', tíng 亭 'porche', yuán 園 'jardín', zhōng xīn 中心 'centro', shì chăng 市 'mercado', etc.

Ahora bien, la comparación de los nombres locativos en español y en mandarín presenta algunas semejanzas en cuanto a la estructura morfológica ${ }^{60}$. Por un lado, los sustantivos locativos derivativos del español

${ }^{60}$ Este párrafo constituye un resumen reelaborado de nuestro artículo, Liu (2009): "Morfología contrastiva de los nombres locativos en chino mandarín y español", Anuario de Lingüística Hispánica, voL. XXV, 49-64. 
(como los formados con -ería, -ado, -ario, -ato, -dero, -dor, -duría, -ía, -miento, -torio) coinciden con todos los sustantivos locativos del mandarín en estar constituidos por la agregación de un formante locativo pospuesto al elemento léxico:

\begin{tabular}{|c|c|c|c|c|c|}
\hline \multirow[b]{2}{*}{ Mandarín } & \multicolumn{2}{|l|}{ Elemento léxico } & \multicolumn{2}{|l|}{ Formante locativo } & \multirow{2}{*}{$\begin{array}{l}\text { Nombre locativo } \\
\text { 實驗室 laboratorio }\end{array}$} \\
\hline & $\begin{array}{l}\text { shí yàn 實驗 } \\
\text { 'experimentar' }\end{array}$ & + & shì 室 'cuarto' & $\rightarrow$ & \\
\hline & 花 'flor' & + & 店 'tienda' & $\rightarrow$ & 花店 floristería \\
\hline & aparcar & + & -miento & $\rightarrow$ & aparcamiento \\
\hline & agua & + & -ario & $\rightarrow$ & acuario \\
\hline
\end{tabular}

Ahora bien, se plantea en ambas lenguas el problema de la categoría sufijoide. En español los morfemas con designación locativa como -teca y -dromo (y, en cierto modo, también -landia) vacilan entre los sufijos y los temas de la composición culta, puesto que tiene un origen grecolatino y rechazan la combinación con elementos afijales. En mandarín, aunque para algunos autores los morfemas locativos se clasifican como pseudosufijos (Lü 1992a, Y. Wang 2001: 47, Pan 1993: 79, Liu 1996 [1983]: 20), hay autores (J. Chang 1994: 92-93, Li y Thompson 2003: 50 y J.-H. Chang 1994: 98-105) que sostienen la opinión de que algunos morfemas locativos, como guăn 館 casa, yuàn 院 edificio, chăng 廠 taller, fábrica, diàn 店 tienda, zhàn 站 parada, tái 台 plataforma, fáng 房 habitación, se deberían identificar con los elementos compositivos, puesto que estos formantes aportan un significado léxico y funcionan con autonomía en determinados contextos.

Aparte de las semejanzas, se observan también algunas diferencias entre los nombres de lugar del español y el mandarín desde una perspectiva morfológica y semántica. Así, en mandarín un mismo formante locativo, como es el caso de chăng 場 'explanada', da lugar a un grupo numeroso de nombres locativos. Pero algunos no están relacionados con el sentido literal de 'espacio de terreno allanado normalmente al aire libre', como ocurre en jù chăng 劇場 'teatro' 'explanada' $\rightarrow$ sala (salón) de actos o shāng chăng 商場 
Morfología contrastiva del chino mandarín y el español. Formas de gramaticalización y lexicalización

'comercio' 'explanada' $\rightarrow$ centro comercial. Por tanto, el formante locativo chăng 場 muestra en chino un marcado sentido hacia la gramaticalización como uno de los formantes genéricos que expresan 'lugar'. Sin embargo, los equivalentes en español no siempre coinciden ni en el proceso morfológico, puesto que a los compuestos sintagmáticos $\mathrm{N}$ de $\mathrm{N}$ se suman los compuestos morfológicos y las formaciones derivadas, ni tampoco en la selección de un núcleo nominal de la estructura $\mathrm{N}$ de $\mathrm{N}$ que pueda corresponder al sentido de 'explanada, terreno llano'. Veamos algunas equivalencias:

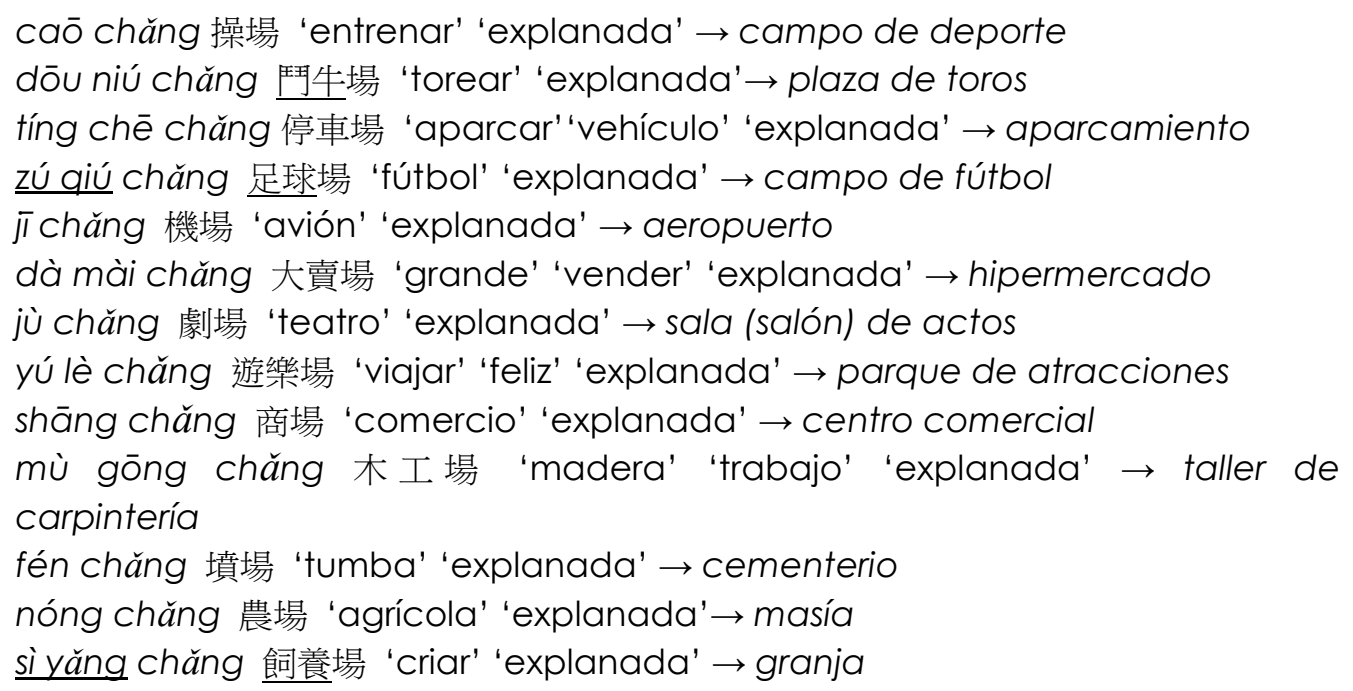

En mandarín todas estas palabras están constituidas por el mismo formante chăng 場 pospuesto al morfema léxico. Sin embargo, los correspondientes nombres españoles presentan estructuras morfológicas muy variadas, como sufijaciones (aparcamiento), prefijaciones (hipermercado), locuciones nombre + adjetivo (centro comercial), además de la estructura $\mathrm{N}$ de N, como en plaza de toros, parque de atracciones, campo de fútbol, sala (salón) de actos. Sin embargo, a pesar de las diferencias estructurales entre ambas lenguas, los núcleos nominales de la composición sintagmática del español (tanto los del tipo $\mathrm{N}$ de $\mathrm{N}$ como las combinaciones del nombre con adjetivos) se corresponden en chino mandarín con otros formantes locativos que igualmente resultan productivos en este tipo de formaciones. Así, el 
término equivalente a sala o salón, tīng 廳, se constituye en otro de los elementos más frecuentes, lo mismo que yuán 園 jardín o zhōng xīn 中心 centro.

Mediante el análisis contrastivo de estos nombres locativos en ambas lenguas, se observan otras convergencias interesantes. Así, en español no parece darse un caso claro de gramaticalización semejante al de chăng 場 'explanada' en chino, pues mientras este formante locativo adquiere un carácter genérico de 'lugar', los equivalentes en español se dispersan en compuestos morfológicos y formaciones derivadas, como se acaba de indicar. Además, la selección del núcleo nominal de la estructura $\mathrm{N}$ de $\mathrm{N}$ tampoco corresponde al significado literal de 'explanada, terreno llano'. No obstante, pueden observarse indicios de gramaticalización en otros nombres españoles que, sobre todo en otros periodos históricos, mostraron una alta productividad y una tendencia hacia el significado general de 'lugar'. Tal vez, sería el ejemplo de casa el más próximo a este proceso de gramaticalización en formaciones del tipo casa de socorro, casa de fieras, casa de citas, casa de beneficencia, casa de campo, casa de huéspedes, casa de juego, casa de maternidad, etc. Del mismo modo que el pseudosufijo chăng 場 'explanada' ha perdido en la actualidad su autonomía léxica, también se registran en español compuestos morfológicos con casa, que igualmente suponen algún grado de gramaticalización, como en casamata, casamuro, casapuerta, casatienda.

Parecido al caso del formante chino chăng 場 'explanada' es el de shì 室 'cuarto', pues la variedad de procesos morfológicos del español contrasta con la uniformidad de los compuestos chinos:

shí yàn shì 實驗室 'experimentar' 'cuarto' $\rightarrow$ laboratorio wēn shì 溫室 'templado' 'cuarto' $\rightarrow$ invernadero wò shi 臥室 'tumbar' 'cuarto' $\rightarrow$ dormitorio xiào zhăng shì 校長室 'rector' 'cuarto' $\rightarrow$ rectorado gēng yī shì 更衣室 'cambiar' 'ropa' 'cuarto' $\rightarrow$ vestuario huì kè shì 會客室 'recibir' 'huésped' 'cuarto' $\rightarrow$ sala de visitas yù shì 浴室 'baño' 'cuarto' $\rightarrow$ cuarto de baño shǒw shù shì 手術室 'operación' 'cuarto' $\rightarrow$ quirófano bàn gōng shì 辦公室 'tratar' 'público' 'cuarto' $\rightarrow$ despacho, oficina yī wù shì 醫務室 'medicina' 'asunto' 'cuarto' $\rightarrow$ botiquín 
Morfología contrastiva del chino mandarín y el español. Formas de gramaticalización y lexicalización

chú cáng shì 儲藏室 'ahorrar' 'esconder' 'cuarto' $\rightarrow$ almacén

En este caso, todos los sustantivos locativos del mandarín están constituidos por el formante shi 室 pospuesto al morfema léxico. En cambio, los nombres correspondientes del español presentan, en su mayoría, una forma derivativa, como dormitorio, laboratorio, invernadero, rectorado; pero también está representada la formación $\mathrm{N}$ de $\mathrm{N}$ en cuarto de baño, sala de visitas.

En definitiva, pese a las diferencias entre ambas lenguas, hay cierta correlación en unos procesos y otros. En general, los significados locativos más genéricos o inespecíficos de los formantes chinos, que también suelen ser los más frecuentes en el léxico, como chăng 場 'explanada', shì 室 'cuarto', diàn 店 'tienda', guăn 館 'casa' o yuàn 院 'edificio', se corresponden en español con derivados sufijales en -ería, -teca, -torio, -dero, etc. En cambio, las formaciones locativas chinas de componentes más específicos, particulares o técnicos se corresponden en español con la estructura morfológica más próxima al chino, que es la composición sintagmática del tipo $\mathrm{N}$ de $\mathrm{N}$. Los elementos que intervienen en estas formaciones complejas en una y otra lengua conservan su significado léxico, como en el caso de zhōng xīn 中心 'centro', găng 港 'puerto', yín háng 銀行 'banco'. Por tanto, tienden a interpretarse como compuestos endocéntricos en las dos lenguas. Por su parte, los compuestos exocéntricos alcanzan una mayor presencia entre los nombres locativos del español (especialmente, los formados con casa). Por el contrario, en mandarín dominan los esquemas endocéntricos. Además, conviene resaltar que, a pesar de una distribución no siempre coincidente, el conjunto de los formantes locativos chinos cuenta con equivalentes en español que también intervienen muy productivamente en la composición sintagmática como nombre cabecera de la fórmula $\mathrm{N}$ de $\mathrm{N}$ o $\mathrm{N}+$ Adjetivo, como por ejemplo en parque de atracciones, banco de pruebas, centro comercial, etc. 
Por otra parte, al margen de los casos de formantes libres chinos, como diàn 店 'tienda', yuàn 院 'edificio', guăn 館 'casa', zhàn 站 'parada', tái 台 'estrado', que alcanzan autonomía léxica en ciertos contextos, otros formantes como háng 行 'tienda', féng 坊 'tienda', pù 舖 'tienda', etc., se clasifican como afijos ligados (ejemplos de 1) que se corresponden funcionalmente con los elementos compositivos del español -teca y -dromo (y quizá también -landia), por presentar un origen culto y no admitir elementos afijales (ejemplos de 2), como se muestra a continuación. Tanto en una como en otra lengua, estos formantes pospuestos ligados se especializan únicamente en la designación de 'lugar' y, por tanto, son sufijoides específicos de la formación del léxico locativo:

1) *háng 行 'tienda'/ yín háng 銀行 'plata' 'tienda' $\rightarrow$ banco *féng 坊 'tienda' / huā féng 花坊 'flor' 'tienda' $\rightarrow$ floristería *pù 舖 'tienda' / dàng pù 當舖 'empeñar' 'tienda' $\rightarrow$ casa de empeños

2) *háng yuán 行員 'tienda' 'suf. -ero' $\rightarrow$ tendero *féng yuán 坊員 'tienda' 'suf. -ero' $\rightarrow$ tendero *pù yuán 舖員 'tienda' 'suf. -ero' $\rightarrow$ tendero

\subsubsection{Análisis contrastivo de la lexicalización de los nombres locativos en español y en chino mandarín}

Los nombres locativos del español y del mandarín se constituyen en formaciones lexicalizadas en el sentido de que en ambas lenguas representan unidades de designación que, como tales, se registran en los correspondientes diccionarios. Así, por ejemplo, campo de tiro o campo de concentración son expresiones que requieren una definición lexicográfica porque presentan un significado no completamente composicional, a diferencia de campo de trigo. Las mismas diferencias se observan en mandarín: jinn kù 金庫 'oro' 'almacén' $\rightarrow$ tesorería contrasta con shū kù 書庫 'libro' 'almacén' $\rightarrow$ almacén de libros. 
Morfología contrastiva del chino mandarín y el español. Formas de gramaticalización y lexicalización

Sin embargo, las pruebas de la lexicalización de estas formaciones locativas recorren caminos parcialmente diferentes en nuestras dos lenguas. Para el español, es importante demostrar que la lexicalización de los nombres locativos depende de la distancia que los separa de los sintagmas nominales como resultado de determinados comportamientos formales y semánticos. En cambio, la lexicalización de los nombres locativos en mandarín exige la identificación de los formantes locativos con los sufijos o pseudosufijos, la pérdida de autonomía léxica y, en consecuencia, el análisis del nombre locativo como un caso de derivación y no propiamente de composición.

\subsubsection{Lexicalización de las locuciones nominales locativas del español}

La lexicalización de formaciones del tipo casa de socorro, campo de tiro, banco de datos, patio de butacas, etc., requiere esencialmente justificar que los nombres locativos del español de forma $N$ de $N$ comparten propiedades con los compuestos al mismo tiempo que se distinguen de los sintagmas nominales.

Según Bustos Gisbert (1986: 72-73), para determinar qué elementos deben ser incluidos o excluidos en el sistema de la composición, se han de establecer las características fundamentales de estas unidades. Por consiguiente, es preciso formular algunas observaciones fonemáticas y morfofuncionales de los sustantivos locativos estructurados en $\mathrm{N}$ de $\mathrm{N}$ a fin de comprobar que se identifican con las locuciones o compuestos sintagmáticos.

Así, con relación al plano fonético, el comportamiento de los nombres de lugar de estructura $\mathrm{N}$ de $\mathrm{N}$ se caracteriza por la pluralidad acentual, como cualquier otra locución (como mecado negro, por ejemplo, o renta fija), porque cada elemento conserva su acento sin que llegue a formarse un compuesto morfológico: sála de visítas, cámpo de batálla, céntro de recúrsos. 
Por otra parte, desde el punto de vista morfológico, interesa analizar el comportamiento de estas formaciones como unidades léxicas. A este respecto, se observan las siguientes propiedades:

1) Normalmente los nombres de lugar $N$ de $N$ admiten sin dificultad un sufijo apreciativo en el primer constituyente, de forma que en este sentido no se pueden establecer diferencias entre los sintagmas nominales y los compuestos sintagmáticos: sala de visitas / salita de visitas, cuarto de baño / cuartito de baño, casa de campo / casita de campo son locuciones que se comportan como un sintagma del tipo cuartito de máquinas, salita de espera. Sin embargo, más interesante es la presencia de sufijos en el segundo constituyente del grupo, que implica la interpretación de un sintagma nominal. En este sentido, los sustantivos locativos $\mathrm{N}$ de $\mathrm{N}$ se parecen más a los compuestos sintagmáticos, dado que no aceptan la presencia de diminutivos en el segundo elemento: *sala de visitita, *parque de bomberitos, *casa de citillas.

2) El género del compuesto se identifica con el del núcleo o determinado: la sala de visita, el campo de batalla, el centro de recursos.

3) En líneas generales, puede decirse que la formación del número es idéntica en estos compuestos y en los sintagmas nominales correspondientes, de forma que recibe la determinación numérica el núcleo o determinado. Sin embargo, algunos ejemplos revelan una determinada fijación del plural en relación con el sintagma nominal. Esta fijación se manifiesta invariablemente en el segundo elemento de los componentes del grupo: sala de visitas, casa de citas, centro de recursos, parque de atracciones, taller de reparaciones, circuito de carreras, salón de actos, banco de órganos, etc. La presencia del plural puede deberse tanto al sentido de generalización que alcanza el grupo como a una evidencia presente en la realidad extralingüística, en la que el elemento que figura en segundo lugar suele hacer 
Morfología contrastiva del chino mandarín y el español. Formas de gramaticalización y lexicalización

referencia a una pluralidad de entidades (centro de recursos / *centro de recurso). De ahí, observamos un mayor grado de fijación morfológica en el caso de los nombres de lugar semejante a la de otros compuestos sintagmáticos (silla de ruedas; altos hornos, horas bajas).

En el plano léxico, puede examinarse la posibilidad de sustitución por unidades léxicas simples. Entre los nombres de lugar, se encuentran dos tipos de comportamientos:

1) Compuestos no sustituibles: Se trata de aquellos casos que presentan un significado no composicional, de modo que el nombre cabecera no puede representar a la locución: plaza de toros no es cualquier plaza donde hay toros; sala de visitas no es cualquier sala donde se reciben visitas; patio de luces tampoco es un patio relacionado con la luz.

2) Compuestos sustituibles por una unidad léxica: La lengua dispone a veces de un sinónimo simple que puede alternar en el uso con la formación compleja: casa de beneficencia y hospital o asilo, casa de citas y prostíbulo, casa de expósitos e inclusa, casa de fieras y zoo(lógico), casa de locos y manicomio, depósito de cadáveres y morgue, sala de operaciones y quirófano, etc.

Una característica que atañe al plano sintáctico es la complementación de los compuestos. En líneas generales, puede decirse que todos estos grupos locucionales se caracterizan por la posibilidad de recibir el artículo o los demostrativos: la sala de visitas, un campo de batalla, aquel centro de recursos; pero no admiten la determinación del segundo constituyente sin alterar el sentido: *sala de su visita, *campo lujoso de fútbol, *plaza de toros bravos. Tampoco admiten el uso del artículo en el segundo elemento del compuesto: *sala de una visita, *campo de la batalla, *centro de los recursos. Cuando se presenta la modificación, solo es posible aquella 
complementación que afecta al compuesto en su totalidad: nuestra sala de visitas, gran campo de fútbol, salvo en un número muy reducido de compuestos que se caracterizan por su especial fijación: centro de investigaciones sociológicas. Tampoco es esperable que estos compuestos admitan la coordinación del sintagma adnominal con otro de la misma naturaleza *sala de espera y de visita, *campo de fútbol y de baloncesto, *centro de estudios y de investigación.

Por último, el plano semántico adquiere una gran importancia porque debe considerarse la relación de significado que se establece entre la entidad referida por el compuesto sintagmático y el contenido semántico actualizado de cada uno de los componentes. Así, resulta útil aplicar al análisis semántico -y no ya al sintáctico- las nociones de endocentrismo y exocentrismo, tal como se ofrecen en Bustos Gisbert (1986: 95):

Todas las definiciones se fundan en la relación existente entre el referente y el compuesto: un compuesto que representa una especialización con respecto a su núcleo referencial es considerado endocéntrico, mientras que aquel que designa una realidad no referida por ninguno de los elementos componentes es considerado exocéntrico.

En este sentido, muchos de los sustantivos locativos de estructura $\mathrm{N}$ de $\mathrm{N}$ pertenecen a la clase de los endocéntricos, dado que se caracterizan por la coherencia semántica entre el compuesto y su núcleo. Es decir, la modificación y especialización del compuesto procede del complemento, que adquiere un contenido particular en este contexto. Su relación se puede representar mediante el esquema de Bustos Gisbert (1986: 97):
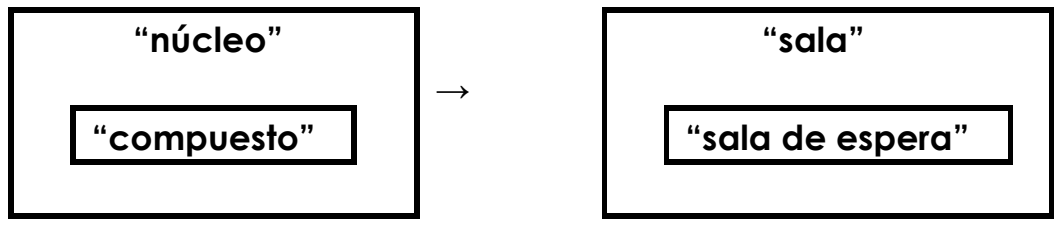

Tabla 17: La relación de los componentes del compuesto endocéntrico 
Morfología contrastiva del chino mandarín y el español. Formas de gramaticalización y lexicalización

Así, por ejemplo, en plaza de toros, la diferencia de este compuesto con respecto a los sintagmas nominales se basa en el hecho de que el compuesto no se refiere a utodo X (complejo) tal que X es B (núcleo) y posee la cualidad $Y$ (complemento)», sino tan solo a alguna de las realidades que cumplen esta condición de ser B y poseer la cualidad Y. Así, una plaza de toros es una B (plaza) donde hay toros (Y) y se celebran las corridas de toros, pero no cualquier plaza donde haya toros es una plaza de toros, sino tan solo aquella en la que se lidian. Por lo mismo, un campo de fútbol no es cualquier campo donde se pueda jugar al fútbol; una sala de espera no es cualquier sala donde haya gente que espere; un parque de bomberos tampoco es cualquier parque donde haya bomberos. En todos estos casos, aunque hay cierta gradación de endocentrismo, existe una limitación de la extensión semántica del significado del núcleo para concretar la referencia.

Sin embargo, en los compuestos exocéntricos, la denotación del grupo no se corresponde con el significado del primer constituyente, a pesar de que ambos referentes participen de los rasgos semánticos comunes que definen todo el campo nocional. Más concretamente, este tipo de núcleo del compuesto representa el archilexema del campo léxico. Por archilexema aquí no se entiende aquel lexema cuyo contenido es el más general, sino aquel que por su valor semántico puede sustituir a los demás en un contexto cualquiera. Así por ejemplo, en la composición agua de azahar el archilexema del campo semántico 'líquido' no es el lexema líquido sino el núcleo agua, común a todo el campo: agua de cal, agua de palo, agua de cepas. Obsérvese que existen diferencias entre estos y otros formalmente parecidos como agua de lluvia, agua de nieve, agua de manantial, que son endocéntricos y se comportan como hipónimos o tipos de agua (Bustos Gisbert 1986: §2.3.1.2).

Pues bien, también son frecuentes los compuestos exocéntricos entre los nombres de lugar del tipo $\mathrm{N}$ de $\mathrm{N}$. Se trata de los casos en los que el primer elemento del grupo no puede considerarse propiamente como el núcleo referencial porque no se interpreta en su acepción estricta sino más bien como 
equivalente del término genérico o archilexema. Así, por ejemplo, casa de socorro es un compuesto exocéntrico, pues casa representa al archilexema edificio, establecimiento, y no propiamente al término casa. Sin embargo, casa de huéspedes se interpreta como un compuesto endocéntrico, en el que casa conserva su acepción genuina. Las diferencias entre ambos tipos de compuestos se reflejan claramente en las definiciones lexicográficas. En términos generales, un compuesto endocéntrico admite una definición mediante un elemento anafórico, que remite a la denotación del núcleo. Sin embargo, la referencia deíctica no es posible en la definición lexicográfica de un compuesto exocéntrico, que normalmente debe comenzar, en cambio, con la repetición del archilexema o término más general. En efecto, casa se define como 'edificio', casa de socorro se define como 'establecimiento', mientras que casa de huéspedes admite el elemento anafórico 'aquella en que...'.

No obstante, téngase en cuenta que el contenido semántico del complemento puede haberse especializado también, con lo cual existe una restricción en la motivación. Así, en casa de citas se trata de un tipo de citas muy concreto; en casa de fieras, el valor de fiera es generalizante; en sala de audiencia la palabra audiencia se refiere al tipo judicial. En este sentido, la calificación del endocentrismo o exocentrismo de los compuestos locativos no es absoluta, puesto que existe una cierta gradación en el exocentrismo semántico. Tal gradación se deriva esencialmente de la modificación semántica del contenido del conjunto con el contenido semántico del núcleo.

Además del análisis de los nombres locativos españoles del tipo plaza de toros, cuarto de estar, etc., según los diferentes planos revisados hasta aquí, también cabe incluir un breve estudio sobre el grado de fijación que alcanzan estas locuciones. En este sentido, los estudiosos de la lexicalización (Lehmann 1989, Pawley 1986, Lipka, 1992, Lipka y Günther 1981, Baver 1983, 1988, Bustos Plaza 2005), suelen distinguir tres niveles que reflejan el proceso de fijación de las formas lingüísticas. El nivel más bajo de fijación corresponde a la llamada 
Morfología contrastiva del chino mandarín y el español. Formas de gramaticalización y lexicalización

formación ocasional; un nivel intermedio está representado por los efectos de la institucionalización; finalmente, el grado de fijación más elevado coincide con la lexicalización.

Bustos Plaza (2005: 130-131), de acuerdo con Ryder (2000), trata de explicar los conceptos de formación ocasional, institucionalización y lexicalización. Para ello, propone las siguientes características:

1) La formación ocasional representa una innovación que no le resulta familiar al oyente. Es una forma morfológicamente transparente cuyo significado exacto se delimita contextualmente. Esta formación carece de entrada en el diccionario.

2) La forma institucionalizada se crea mediante procesos morfológicos productivos. El significado, relativamente independiente del contexto, se reduce a un subconjunto de los significados posibles a partir de la estructura compositiva. Esta forma se percibe como unidad léxica conocida por los hablantes, de manera que puede estar recogida en el diccionario con los significados genéricos o específicos.

3) La forma lexicalizada presenta un significado no complementamente predecible a partir de la estructura morfológica y resulta completamente independiente del contexto. Es una forma aceptada como conocida por los hablantes y está incluida en el diccionario con los significados específicos que ha desarrollado.

Ahora bien, nos preguntamos si resulta posible explicar los compuestos locativos de estructura $\mathrm{N}$ de $\mathrm{N}$ a partir de estas teorías de la lexicalización. Se trata de contrastar estos compuestos sintagmáticos con las características anteriores con la finalidad de determinar su condición entre las formaciones ocasionales, institucionalizadas o lexicalizadas.

Los nombres de lugar del tipo campo de batalla, sala de estar, cuarto de baño, salón de actos, patio de butacas, sala de fiestas, etc., no se interpretan como formaciones ocasionales, pues presentan un significado no 
completamente composicional pero que resulta independiente del contexto. Se registran como tales en el diccionario, aunque, en nuestra opinión, algunas de estas locuciones también deberían figurar en los repertorios lexicográficos, como, por ejemplo, puerto de mar, patio de luces, banco de sangre, parque de bomberos, centro de día, punto de información, pista de baile, casa de acogida, entre otras.

Una vez descartados nuestros nombres locativos de las formaciones ocasionales, sería interesante examinar su clasificación entre las estructuras institucionalizadas o lexicalizadas. En nuestra opinión, este aspecto depende del grado de exocentrismo que haya alcanzado la locución, de modo que las formas decididamente exocéntricas se corresponden más directamente con las características de las composiciones lexicalizadas. Así, los nombres locativos del tipo casa de citas, jardín de infancia, campo de concentración, plaza de armas, zona de influencia, sala de vacaciones, banco de pruebas, etc., cumplen con los requisitos del significado no composicional, autonomía contextual, registro lexicográfico con una acepción específica. En opinión de Zuloaga (2002: 62), este uso particular, al aislarse mediante la fijación, contiene el germen de una ulterior especialización semántica, esto es, la idiomaticidad. Numerosos hablantes aceptan estas formas como unidades léxicas conocidas. Corpas (1996 y 2000) señala que los hablantes reconocen estas combinaciones como expresiones familiares y las emplean adecuadamente como unidades léxicas.

En efecto, es posible distinguir de algún modo entre las formaciones institucionalizadas y las lexicalizadas por el nivel de idiomaticidad. Así, por ejemplo, campo de tiro y casa de citas son dos locuciones locativas registradas en el diccionario, reconocidas por el hablante e independientes del contexto. Sin embargo, campo de tiro, por su carácter endocéntrico, se identifica con la formación institucional, pues significa un tipo de campo donde se realizan prácticas de tiro con armas de fuego. En cambio, casa de citas, por su condición exocéntrica, no significa propiamente un tipo de vivienda donde se 
Morfología contrastiva del chino mandarín y el español. Formas de gramaticalización y lexicalización

celebren reuniones previamente acordadas. Lo mismo cabría apuntar del préstamo del alemán jardín de infancia 'colegio de párvulos', locución que por su exocentrismo entraría en el grupo de las formaciones lexicalizadas.

En conclusión, los aspectos aquí estudiados de los nombres de lugar formados por dos sustantivos unidos por la preposición de, permiten apreciar las diferencias esenciales de estos compuestos con respecto a los sintagmas nominales. Estas formaciones de significado locativo se corresponden en gran medida con el comportamiento que cabe esperar de un compuesto sintagmático. Además, según las características a las que responden, se observa que la fijación de estas formaciones locativas no es ocasional. Se puede decir que los compuestos locativos de tipo endocéntrico suelen comportarse como las formaciones institucionalizadas, mientras que los de tipo exocéntrico se corresponden más bien con las formaciones lexicalizadas. Los compuestos exocéntricos presentan la fijación de una secuencia léxica a partir de una configuración sintáctica. Esta fijación es el resultado de un proceso de lexicalización más avanzado que el de la formación ocasional o institucionalizada, de forma que su carácter de sintagma se pierde para dar lugar a una unidad léxica.

\subsubsection{Lexicalización de las locuciones nominales locativas del chino mandarín}

La lexicalización de los nombres locativos del chino mandarín debería mostrar claramente el comportamiento del formante locativo como un sufijo o pseudosufijo capaz de formar unidades léxicas derivadas. Por el contrario, los formantes locativos del chino más próximos a los elementos compositivos, que dan como resultado un compuesto morfológico, mostrarian un nivel más bajo de lexicalización. 
Ha de tenerse en cuenta que, en este apartado, nuestro trabajo no intenta reunir todas las disertaciones divergentes sobre la discusión teórica de que los pseudosufijos podrían depender hasta cierto punto de la delimitación entre la sufijación y la composición. Solo se pretende desarrollar un análisis básico para explicar el desarrollo de la lexicalización cuando estos formantes locativos intervienen en distintos tipos morfológicos, como la pseudoafijación y la composición.

La clasificación de los nombres de lugar como palabras derivadas formadas por pseudosufijos o como palabras compuestas se basa en la identificación de estos componentes locativos bien como sufijos (o pseudosufijos) o bien como elementos compositivos. Si se clasifican como elementos pseudosufijales, se representa un estado más avanzado en el proceso de lexicalización, por lo que el grado de fijación es mayor. Ahora bien, para examinar si estos elementos se comportan como pseudosufijos, se pueden aplicar los criterios de Ren (2002) y Chang (2003) -ya presentados anteriormente en §5.4- en relación con el estatuto del pseudosufijo:

1) La posición determinada

2) La autonomía léxica

3) La determinación de la categoría gramatical

4) La productividad

5) La debilidad semántica

En primer lugar, la mayoría de los formantes locativos solo pueden colocarse al final de la palabra. Por tanto, según esta característica, tales formantes locativos se clasificarían entre los pseudosufijos. En cambio, la mayoría de los elementos compositivos admite el cambio de posición.

En segundo lugar, los morfemas que presentan autonomía léxica y pueden identificarse con las palabras independientes no se clasifican como pseudosufijos. Así, algunos morfemas locativos, como shi 室 'cuarto', shè 舍 'casa', jiān 間'cuarto', láng 廊 'pasillo', pù 舖 'tienda', háng 行 'tienda', se 
Morfología contrastiva del chino mandarín y el español. Formas de gramaticalización y lexicalización

identifican sin duda como pseudosufijos, puesto que no presentan autonomía léxica ni pueden reemplazar anafóricamentes a formas complejas ya enunciadas. Sin embargo, no todos los formantes locativos cumplen esta condición. J. Chang (1994: 92-93) indica que, en algunos contextos, determinados morfemas locativos, como guăn 館 'casa', yuàn 院 'edificio', chăng 廠 'fábrica, taller', diàn 店 'tienda', zhàn 站 'parada', tái 台 'plataforma', etc., pueden considerarse como formas abreviadas de las palabras complejas que forman con otro constituyente. Por tanto, estos formantes alcanzan cierta independencia contextual y pueden identificarse con las raíces. A continuación se muestran tres ejemplos del uso autónomo de un formante locativo:

1) diàn 店 sustituye a shū diàn 書店 'libro' 'tienda' $\rightarrow$ librería en kaī diàn shí jiān 開店時間 'abrir' 'librería' 'tiempo' $\rightarrow$ horario de apertura.

2) yuàn 院 sustituye a yī yuàn 醫院 'medicina' 'casa' $\rightarrow$ hospital en rù yuàn shóu xù 入院手續 'entrar' 'hospital' 'trámite' $\rightarrow$ trámites de hospitalización

3) tái 台 sustituye a jiăng tái 講台 'hablar' 'estrado' $\rightarrow$ estrado en shàng tái yăn iiăng 上台演講 'subir' 'estrado' 'dar discurso' $\rightarrow$ dar un discurso en el estrado.

En este sentido, se puede decir que no todos los morfemas locativos se clasifican como pseudosufijos, dado que la correspondencia con esta característica es solo parcial.

En tercer lugar, los pseudosufijos son transcategorizadores, pues pueden alterar la categoría gramatical de los elementos a los que se adjuntan. En este sentido, los morfemas locativos cuando se agregan a otros morfemas o palabras, siempre transforman la categoría gramatical de las palabras en sustantivos:

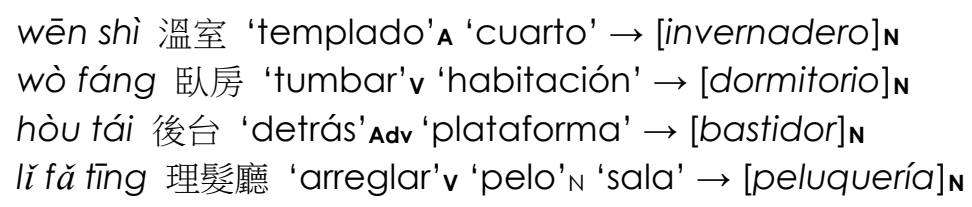


Por su parte, la productividad de estos formantes ha quedado suficientemente reflejada en la tabla 14. Por último, los pseudosufijos pierden en mayor o menor grado su significado original y tienden hacia la designación genérica de un tipo de 'lugar'. Por ejemplo, táng 堂 'cuarto' en jiào táng 教堂 'religión' 'cuarto' $\rightarrow$ iglesia, catedral no tiene otra función semántica que la propia designación locativa. Esta característica revela claramente la lexicalización que experimentan estos nombres locativos del mandarín, lo mismo que otros casos como:

yào fáng 藥房 'medicina' 'habitación' $\rightarrow$ farmacia shāng chăng 商場 'comercio' 'explanada' $\rightarrow$ centro comercial lı̆ fă yuàn 理髮院 'arreglar' 'pelo' 'edificio' $\rightarrow$ peluquería xiāo fáng jú 消防局 'prevenirse del fuego' 'oficina' $\rightarrow$ parque de bomberos huà láng 畫廊 'pintura' 'pasillo' $\rightarrow$ galería de pinturas

Para identificar los pseudosufijos, Ren (2002) y Chang (2003) coinciden en la propiedad de la reducción semántica, esto es, recorren un proceso de gramaticalización. Desde el punto de vista funcional, la gramaticalización y la lexicalización son procesos paralelos y complementarios. En mandarín la gramaticalización de los morfemas consiste principalmente en la reducción del contenido semántico. Estos elementos pierden el significado léxico, se convierten en marcadores de determinadas palabras y adquieren capacidad combinatoria. En el caso de los sustantivos locativos, la lexicalización está relacionada con la gramaticalización de los pseudosufijos. Es decir, la gramaticalización de estos morfemas locativos se manifiesta en una reducción del valor semántico originario y, por lo tanto, en un aumento de la capacidad combinatoria de estos elementos con otros morfemas. En este sentido, se puede decir que la productividad da lugar a la lexicalización. En otras palabras, la gramaticalización de estos morfemas locativos en pseudosufijos es favorable a la lexicalización de la palabra, dado que esta autoriza la combinación de estos morfemas locativos con otros morfemas y la productividad aumenta. 
Morfología contrastiva del chino mandarín y el español. Formas de gramaticalización y lexicalización

Así pues, se ha defendido hasta aquí que determinados formantes locativos del mandarín se comportan como verdaderos sufijos o pseudosufijos, que dan como resultado un sustantivo locativo derivado. En efecto, tales formantes, como chăng 場 'explanada', chí 池 'fuente', féng 坊 'tienda', fáng 房 'habitación', găng 港 'puerto', háng 行 'tienda', suǒ 所 'oficina', jiān 間 'cuarto', jiào 䆜 'bodega', jú 局 'oficina', kù 庫 'almacén', láng 廊 'pasillo', pù 舖 'tienda', shè 舍 'casa', shì 室 'habitación', táng 堂 'cuarto', tīng 廳 'sala (salón)' y tíng 亭 'porche' presentan una posición determinada, carecen absolutamente de autonomía léxica, alcanzan una alta productividad como nombres de lugar y muestran algún grado de gramaticalización.

Sin embargo, algunos gramáticos no están de acuerdo en que los nombres de lugar sean palabras formadas por pseudosufijos $y$, en consecuencia, puedan considerarse como derivadas. Así, J. Chang (1994: 92-93) y Li y Thompson (2003: 50), entienden que, en vez de pseudosufijos, estos elementos son morfemas léxicos (o raíces), puesto que en realidad funcionan como formas abreviadas de las palabras y, por tanto, presentan la propiedad de comportarse como unidades independientes. A los ejemplos 1), 2), 3), anteriores sobre el uso autónomo del formante locativo, se podrían añadir los siguientes:

\begin{tabular}{|c|c|c|}
\hline Forma plena & Forma abreviada & Autonomía léxica \\
\hline $\begin{array}{c}\text { gōng chăng 工廠 } \\
\text { 'trabajo' 'taller' } \rightarrow \text { taller }\end{array}$ & chăng 廠 & $\begin{array}{c}\text { jin chăng weí xiū 進廠維修 'entrar' } \\
\text { 'taller' 'reparar' } \rightarrow \text { reparación en el } \\
\text { taller. }\end{array}$ \\
\hline $\begin{array}{c}\text { tú shū guăn 圖書館 } \\
\text { 'dibujo' 'libro' 'casa' } \\
\text { biblioteca }\end{array}$ & guăn 館 & $\begin{array}{c}\text { kāi guăn shí jiān 開館時間 'abrir' } \\
\text { 'casa, edificio' 'tiempo' } \rightarrow \text { horario } \\
\text { de apertura de la biblioteca }\end{array}$ \\
\hline $\begin{array}{c}\text { huǒ chē zhàn 火車站 } \\
\text { 'dibujo' 'libro' 'casa' } \rightarrow \\
\text { estación de tren }\end{array}$ & zhàn 站 & $\begin{array}{c}\text { huǒ chē daò zhàn 火車到站 'tren' } \\
\text { 'llegar' 'estación' } \rightarrow \text { el tren llega a } \\
\text { la estación de tren }\end{array}$ \\
\hline
\end{tabular}

Tabla 18: Ejemplos de elementos locativos como formas libres 
J.-H. Chang (1994: 98-105) también cuestiona la naturaleza pseudosufijal de los formantes locativos. El autor indica que los pseudosufijos son elementos que se hallan en los límites de la composición y la derivación. Pero advierte que las palabras constituidas por medio de estos morfemas locativos deberían clasificarse como palabras compuestas, puesto que estos elementos no se comportan como los verdaderos sufijos, que -en opinión de este autor- desempeñan el papel de morfemas vacíos y funcionales, sino que actúan como constituyentes de los compuestos, que son morfemas independientes y aportan algún valor semántico.

Al margen de una opinión tan tradicional como la anterior, aquí podemos valorar también la formación de nombres locativos mediante procesos compositivos, cuyo nivel de lexicalización consideramos menos elevado que en las formaciones derivadas mediante sufijos.

Los autores que se han ocupado de esta cuestión, como Y.-S. Chang (2000), Shi (2002), W.-S. Wu (2003) y Dong (2002a, 2002b), consideran que la lexicalización depende, en última instancia, de factores como los siguientes:

1) La fusión semántica

2) El sentido genérico o metafórico

3) La fosilización

Ahora bien, para verificar la lexicalización de los nombres de lugar, deben aplicarse a estos sustantivos locativos las características de la lexicalización que atribuyen estos autores.

En primer lugar, según Y.-S. Chang (2000), la fusión semántica se refiere a una mezcla (mixture) de significados de los componentes y a la producción de un significado nuevo del conjunto. En este sentido, los nombres de lugar cumplen con esta característica, puesto que el significado del conjunto suele ser un referente único y constante. Por ejemplo, en yào chăng 藥廠 'medicamento' 'taller' $\rightarrow$ laboratorio farmacéutico, por la fusión semánica, el significado del conjunto no es simplemente la suma de medicamento 'la 
Morfología contrastiva del chino mandarín y el español. Formas de gramaticalización y lexicalización

sustancia que cura o alivia la enfermedad' más taller 'lugar donde se trabaja una obra con manos', sino un valor semántico innovado que consiste en 'el establecimiento donde se realiza el análisis clínico y la elaboración de productos medicinales' y 'la empresa donde produce medicamentos y los comercializan'. En cambio, en el sintagma nominal como 修配廠 xiū pèi chăng 'reparación' 'taller' $\rightarrow$ taller de reparación, el significado es totalmente transparente o composicional, pues el conjunto no hace más referencia que a un 'lugar donde se realiza obras de reparación'.

En segundo lugar, el significado del formante locativo evoluciona hacia un sentido genérico o metafórico. Pues bien, los nombres de lugar obtienen la especialización semántica a base de la gramaticalización de los formantes locativos, pues los elementos que designan lugar pierden su significado original específico cuando se combinan con otros lexemas para formar nombres de lugar. Por ejemplo, en 1), yuán 園 'jardín' deja su significado de 'terreno donde se cultivan plantas' y alcanza un sentido más genérico de lugar, que también puede designar al cementerio y al parque de atracciones. En 2), jiā 家 'casa' pierde su significado específico de 'vivienda o familia' y sufre un cambio para designar metafóricamente un tipo de 'establecimiento benéfico':

1) mù yuán 墓園 'tumba' 'jardín' $\rightarrow$ cementerio zhí wù yuán 植物園 'planta' 'jardín' $\rightarrow$ jardín botánico

gōng yuán 公園 'público' 'jardín' $\rightarrow$ parque yú lè yuán 遊樂園 'viajar' 'feliz' 'jardín' $\rightarrow$ parque de atracciones

2) zhōng tú zhē jiā 中途之家 'medio' 'camino' 'part. posesiva' 'casa' $\rightarrow$ reformatorio

lăo rén zhē jiā 老人之家 'anciano' 'part. posesiva' 'casa' $\rightarrow$ asilo dòng wù zhē jiā 動物之家 'animal' 'part. posesiva' 'casa' $\rightarrow$ asilo de animales

En tercer lugar, según Dong (2002a, 2002b), la fosilización es una transformación de los sintagmas libres en palabras compuestas. En tal proceso de transformación, la unidad lexicalizada presenta un significado propio y unitario, y su estructura formal no permite la intercalación de otros elementos. 
En este sentido, la lexicalización de los nombres de lugar se comprueba por la imposibilidad de intercalar elementos entre los componentes. En los siguientes ejemplos, se muestra la agramaticalidad de los resultados si se intercala la partícula posesiva de 的 'de' entre el núcleo y el modificador, pues tal inserción solo es posible en los sintagmas nominales, en los que la relación subordinada entre el núcleo y el complemento se introduce mediante esta marca de relación, pertenenecia o posesión:

lUăn zǐ yín hán 卵子銀行 'óvulo' 'banco' $\rightarrow$ banco de óvulos

*luăn zǐ de yín hán 卵子的銀行 'óvulo' 'de (part. posesiva)' 'banco' $\rightarrow$ banco de óvulos

hăi găng 海港 'mar' 'puerto' $\rightarrow$ puerto de mar

*hăi de găng 海的港 'mar' 'de (part. posesiva') 'puerto' $\rightarrow$ puerto de mar

mù yuán 墓園 'tumba' 'jardín' $\rightarrow$ cementerio

'mù de yuán 墓的園 'tumba' ‘de (part. posesiva)' 'jardín' $\rightarrow$ cementerio

gū ér yuàn 孤兒院 'huérfano' 'edificio' $\rightarrow$ orfanato

'gū ér de yuàn 孤兒的院 'huérfano' 'de (part. posesiva)' 'edificio' $\rightarrow$ orfanato

Por útimo, además de estos criterios, en nuestra opinión, cabe considerar que la presencia de una forma monosilábica como constituyente de un nombre locativo también puede considerarse un indicio de lexicalización. La forma monosilábica de una palabra polisilábica se identifica con una forma abreviada que contiene el significado nocional. Por ejemplo, guǒ zhī 果汁 'fruta' 'jugo' $\rightarrow$ zumo es una unidad lexicalizada, pues no permite la intercalación de la partícula posesiva de 的 que introduce la relación de pertenencia: *guǒ de zhī 果的汁 'fruta' 'part. posesiva' 'jugo' $\rightarrow$ jugo de fruta. Sin embargo, el primer constituyente guó 果 fruta es la forma monosilábica seleccionada a partir de shŭi guř 水果 'agua' 'fruta' $\rightarrow$ fruta, que admite la composición. Del mismo modo, en los siguientes ejemplos, se presenta la forma monosílaba de los constituyentes nominales en la formación lexicalizada, pues la forma original bisílaba de los nombres daría resultados agramaticales en la formación de nombres de lugar. 
Morfología contrastiva del chino mandarín y el español. Formas de gramaticalización y lexicalización

mù yuán 墓園 'tumba' 'jardín' $\rightarrow$ cementerio

*fén mù yuán 墳墓園 'tumba' 'jardín'

shuì fáng 睡房 'dormir' 'habitación' $\rightarrow$ dormitorio

‘suhìiiào fáng 睡覺房 'dormir' 'habitación'

wēn shì 溫室 'templado' 'cuarto' $\rightarrow$ invernadero

*wēn nuăn shì 溫暖室 'templado' 'cuarto'

En fin, según las características a las que responden estos nombres de lugar, se observa que algunos elementos locativos, como yuán 園 'jardín', diàn 店 'tienda', guăn 館 'casa', jiā 家 'casa', chăng 廠 'fábrica, taller', yuàn 院 'edificio', zhàn 站 'parada', tái 台 'plataforma', shì chăng 市場 'mercado', yín hán 銀行 'banco', zhōng xīn 中心 'centro', se comportan como elementos compositivos que, por un lado, difieren de los formantes locativos pseudosufijales por su autonomía léxica, y por otro lado, difieren de los sintagmas libres por su fijación estructural, pues, al reunirse con otros lexemas, la forma compleja presenta un nivel medio de lexicalización: el conjunto presenta un significado léxico que proviene de la mezcla del valor semántico de los componentes. En esta fusión semántica, se observa que el significado de los componentes puede sufrir algún cambio metafórico para proporcionar al conjunto un valor semántico más específico. Además, los componentes no permiten la intercalación de otros morfemas y la forma monosilábica del componente polisílabico conduce a la fijación.

En nuestra opinión, un nivel más avanzado de lexicalización presentan los nombres de lugar constituidos en mandarín por formantes locativos que, por sus características especiales, pueden clasificarse adecuadamente entre los pseudosufijos, de modo que la formación puede equipararse a los casos de nombres derivados.

Estos formantes pseudosufijales, como se ha adelantado, son principalmente los siguientes: chăng 場 'explanada', chí 池 'fuente', féng 坊 'tienda', fáng 房 'habitación', găng 港 'puerto', háng 行 'tienda', suǒ 所 'oficina', jiān 間 'cuarto', jiào 空 'bodega', jú 局 'oficina', kù 庫 'almacén', 
láng 廊 'pasillo', pù 舖 'tienda', shè 舍 'casa', shì 室 'habitación', táng 堂 'cuarto', tīng 廳 'sala (salón)', tíng 亭 'porche'.

A diferencia de los formantes locativos composicionales, estos de tipo derivativo se caracterizan por la posposición permanente y la función de sustantivador en la formación de nombres de lugar. Además, Estos formantes son elementos gramaticalizados que faltan la autonomía léxica y así presentan la debilidad semántica.

\subsection{Resumen y conclusiones}

Tanto en chino mandarín como en español, las locuciones nominales formadas por adjetivos de color y nombres, adjetivos aspectuales y sustantivos y nombres de lugar según el esquema español $\mathrm{N}$ de $\mathrm{N}$ se consideran formaciones muy productivas que muestran procesos de lexicalización convergentes, pues son estructuras complejas que manifiestan cierta pérdida de composicionalidad semántica y, al mismo tiempo, adquieren algún grado de idiomaticidad.

En ambas lenguas, estos tres tipos de locuciones comparten algunas semejanzas. En primer lugar, los modificadores de estas formaciones locucionales, como los adjetivos y los complementos preposicionales del español o nominales del chino, no se comportan como atibutivos ni predicativos, porque no son propiamente caracterizadores que adscriban propiedades a los objetos. Este rasgo resulta en mandarín especialmente interesante, pues la lexicalización de las locuciones analizadas se puede comprobar por la imposibilidad de intercalar el formante de 的 'marcador de atribución', característico de la atribución entre el adjetivo y el sustantivo. Del mismo modo, el verbo atributivo (ser o estar) en español resulta incompatible con estas estructuras lexicalizadas. 
Morfología contrastiva del chino mandarín y el español. Formas de gramaticalización y lexicalización

En segundo lugar, mientras que las locuciones locativas tienden a presentar una interpretación endocéntrica, las locuciones nominales constituidas por adjetivos de color y adjetivos aspectuales se reparten con más facilidad entre el endocentrismo y el exocentrismo semánticos tanto en español como en mandarín. Sin duda, en las locuciones locativas la pertenencia del núcleo a una clase léxica restringida a la designación del 'lugar', aunque admite también la gramaticalización, conserva en mayor grado el sentido composicional, lo que favorece el endocentrismo semántico. En cambio, los núcleos de las otras locuciones analizadas en este capítulo no se limitan a un solo tipo léxico.

En tercer lugar, las propiedades léxicas y gramaticales de los adjetivos de color y de los aspectuales favorecen el proceso de lexicalización, pues se trata en ambas lenguas de adjetivos intersectivos, que asignan una propiedad no solo al nombre sino también a la clase hiperónima del sustantivo. El otro factor que propicia la lexicalización de los tres tipos de locuciones examinadas se refiere a la reducción o generalización del significado léxico de los núcleos. Este cambio semántico favorece la capacidad combinatoria de estos elementos y contribuye a la fijación del conjunto.

Con respecto a las locuciones nominales constituidas por adjetivos aspectuales y nombres, cabe destacar aquí que el eje de la 'perfectividad' - 'imperfectividad' se muestra codificado en ambas lenguas y además, la fijación recae en el mismo tipo de adjetivos, pues elementos como quàn 全 'total, entero, completo, lleno, pleno' y bàn 半 'medio', y sus equivalentes en español dan lugar a un grupo numeroso de locuciones. Por otra parte, en chino mandarín, las locuciones nominales aspectuales de la significación 'perfectividad' presentan un grado de lexicalización más elevado cuando el componente adjetival coincide con los adjetivos españoles completo, entero y lleno. Sin embargo, cuando el componente adjetival chino se corresponde con el adjetivo español total, las formas complejas presentan un menor grado de lexicalización. 
Frente a estas semejanzas, hay que tener en cuenta las principales diferencias. En primer lugar, en chino mandarín, las locuciones nominales formadas con nombres y adjetivos de color resultan muy productivas, especialmente porque explicitan la relación de pertenencia de una entidad a una determinada clase de realidades, mientras que en español esta tendencia hacia la clasificación explícita no resulta tan preferente, pues con frecuencia la locución china se corresponde con un sustantivo simple y primitivo en español (hóng băo shí 紅寶石 'rojo' ‘joya' $\rightarrow$ rubí; lù băo shí 綠寶石 'verde' ‘joya' $\rightarrow$ esmeralda).

Por otro lado, frente a la improductividad de los adjetivos intensionales en la formación de locuciones nominales del español, en las locuciones nominales chinas se integran también estos adjetivos de color con valor intencional que representan un atributo inherente de lo designado por el nombre y carecen de sentido clasificador (huĩ chén 灰塵 'gris' 'polvo' $\rightarrow$ polvo). La lexicalización en mandarín se extiende incluso a la fijación del sustantivo 'color' junto al adjetivo cromático correspondiente, especialmente en los anglicismos recientes (hēi sè diàn yĭng 黑色 電影 'negro' 'color' 'cine' $\rightarrow$ cine negro). Además, determinados adjetivos cromáticos anticuados también se prestan a las lexicalizaciones (chì zì 赤字 'ant. rojo' 'número' $\rightarrow$ números rojos). En suma, todas estas características explican la mayor productividad del chino mandarín en la formación de locuciones nominales constituidas por adjetivos de color y nombres.

Por último, se observa que en español la lexicalización de los compuestos locativos de estructura $\mathrm{N}$ de $\mathrm{N}$ comprende dos tipos desde el punto de vista semántico. Por un lado, los compuestos locativos endocéntricos suelen comportarse como las formaciones institucionalizadas, mientras que los de tipo exocéntrico se corresponden más bien con las formaciones lexicalizadas que presentan un nivel más avanzado de fijación y de pérdida del sentido composicional. Por su parte, los nombres de lugar en chino también pueden clasificarse en dos tipos según la autonomía léxica del formante 
406 Morfología contrastiva del chino mandarín y el español. Formas de gramaticalización y lexicalización

locativo, que actúa o bien como un pseudosufijo o bien como un elemento compositivo. El primer tipo representa un estado más avanzado en el proceso de lexicalización. Aquí se ha defendido la proximidad de estas formaciones altamente lexicalizadas con las palabras derivadas cuyo grado de fijación es mayor que en las composiciones. 


\section{RESUMEN Y CONCLUSIONES}

En este trabajo se ha intentado realizar un estudio contrastivo sobre los procesos fundamentales de la formación de palabras en chino mandarín y español, que comprende el análisis de los principales tipos productivos y la incidencia de las formas de gramaticalización y lexicalización en los resultados morfológicos de las dos lenguas contrastadas. A partir de una descripción de los rasgos comunes y específicos en los procedimientos morfológicos de ambas lenguas, se examina la gramaticalización en el componente morfológico de cada idioma, se analizan los esquemas compositivos y se seleccionan tres clases representativas de locuciones nominales para determinar el paralelismo de su proceso de formación y describir los principales factores que intervienen en la lexicalización de estructuras sintagmáticas. El trabajo se ha dividido en ocho capítulos que pueden resumirse a partir de las siguientes conclusiones.

El primer capítulo contiene una descripción general de las principales propiedades tipológicas de la lengua china. Según la mayoría de los estudios consultados, el chino se define como una lengua tonal, de escritura logográfica y típicamente aislante y analítica. Sin embargo, aquí se plantean algunas dificultades para admitir sin reservas estos últimos rasgos, sobre todo si se comparan con la estructura gramatical del español. Aunque el debate sobre estas cuestiones se desarrolla más ampliamente en los capítulos siguientes de esta tesis, interesa adelantar ahora que -en nuestra opinión- el chino se presta a un análisis morfológico, y no solo por la variedad de esquemas compositivos, sino también porque dispone de un sistema de afijos que desempeñan funciones gramaticales y léxicas comparables a las 
Morfología contrastiva del chino mandarín y el español. Formas de gramaticalización y lexicalización

desinencias de las palabras variables y a los formantes de la derivación, característicos de las lenguas consideradas tipológicamente como sintéticas y flexivas.

En el segundo capítulo se presentan las principales definiciones y clasificaciones del morfema. En ambas lenguas, la aplicación de los cinco principios de Nida (1965) ha permitido comprobar que un morfema se caracteriza por mantener el mismo significado al reunirse con otro elemento 0 bien por resultar productivo en combinación con formas libres o raíces. Por otra parte, en español la relación entre los morfemas libres y ligados o morfemas derivativos y funcionales viene determinada por una morfología en la que cada formante presenta una estructura regularizada y jerárquica. En cambio, en chino mandarín la relación entre estos morfemas es menos estricta debido a que es una lengua en la que predomina la morfología compositiva.

Frente a los rasgos comunes, se observan algunas diferencias en la estructura morfológica de nuestras dos lenguas en contraste. En primer lugar, la polisemia, sobre todo en la lengua china, explica la divergencia en las dos lenguas de la relación entre el significado y el significante. En segundo lugar, mientras que en español los morfemas pueden presentar alomorfos, en chino mandarín todos los morfemas son relativamente unidades invariables. Por último, mientras que la lengua china admite la doble composición como un recurso muy habitual en la formación de palabras, el español se caracteriza por el proceso de derivación compleja. En cuanto a las categorías morfológicas comparables, se ha defendido que los llamados morfemas libres ligados del chino mandarín se asemejan a los temas polimórficos cultos del español, ya que se trata de formantes que fueron autónomos en las lenguas originarias, pero en la lengua actual se comportan como unidades morfológicas sin autonomía léxica que oscilan entre la derivación y la composición. Además, los llamados afijos convencionales del mandarín, que carecen de significado pero favorecen el polisilabismo del chino moderno en formaciones complejas, resultan próximos -en nuestra opinión- a los infijos e 
interfijos del español.

En el tercer capítulo se reúnen algunas propiedades que caracterizan la morfología española. Así, aunque todavía no se ha hallado una unanimidad con respecto al inventario de los afijos, es indudable que el español es una lengua fructífera en la morfología derivativa, en particular muy productiva en la sufijación. En segundo lugar, la parasíntesis se identifica con un modelo muy particular de la morfología española, pero defectivo en otras lenguas. En tercer lugar, las principales discusiones de la morfología española giran en torno a algunos temas: la distinción entre flexión y derivación, la clasificación de los temas polimórficos cultos en la composición o la derivación y la definición del proceso morfológico mediante prefijos idénticos a las preposiciones.

En el cuarto capítulo se analizan los principales procedimientos de formación de palabras en chino mandarín mediante la complementación de las descripciones ofrecidas por la lingüística china con la teoría morfológica del español. Se ha observado que los procesos morfológicos de derivación y composición del español son comparables en alguna medida a las formaciones léxicas del chino mandarín. Sobre todo, la composición se revela como un recurso teórico imprescindible para explicar las formaciones léxicas de la lengua china.

Para el tratamiento de la derivación en mandarín, resulta de utilidad distinguir entre los afijos convencionales y los afijoides. Así, algunos afijos convencionales chinos, como ér 兒，zi 子，tóu 頭，lǎo 老， $\bar{a}$ 阿，no aportan significado léxico ni significado gramatical al agregarse a los morfemas léxicos para formar palabras. La utilización de estos elementos parece servir principalmente para facilitar la acusada tendencia hacia las formaciones polisilábicas de las palabras, en sustitución del monosilabismo del chino clásico. Por otra parte, el planteamiento tradicional de la ausencia de flexión en la lengua china tampoco está exento de problemas. En nuestra opinión, se reconocen algunas marcas flexivas que expresan la flexión nominal, tales como los marcadores de la pluralidad, del género y del genitivo, aunque 
Morfología contrastiva del chino mandarín y el español. Formas de gramaticalización y lexicalización

algunas tienen además autonomía léxica y funcionan como palabras independientes. Por su parte, la lengua china dispone de recursos léxicos, pero también de algunas marcas morfológicas de función gramatical que expresan las flexiones verbales, de modo que las variaciones de tiempo y aspecto se codifican mediante la anteposición o posposición de estos marcadores al elemento léxico verbal.

Además de la derivación y la composición, se observa que la reduplicación y los clasificadores son procesos léxicos propios del chino mandarín. La reduplicación es un fenómeno frecuente en lenguas aislantes. En este sentido, el chino mandarín dispone de este recurso para expresar el aspecto delimitado de la acción y aumentar la intensidad de las cualidades que describe el nombre. Respecto a los clasificadores, aunque tanto el chino mandarín como el español presentan este recurso para describir la propiedad de los elementos de un conjunto, en mandarín los elementos de clasificación son más variados y su uso es más habitual que en español.

En el quinto capítulo, a partir del análisis contrastivo de los fenómenos comunes y específicos de la morfología de nuestras dos lenguas, hemos reconsiderado algunos aspectos tanto teóricos como descriptivos que hasta ahora permanecían confusos o solo parcialmente examinados. En la derivación y la flexión, se proponen dos novedades para el tratamiento de los rasgos desemejantes. En primer lugar, la flexión no es un fenómeno defectivo en el chino mandarín, dado que las informaciones gramaticales se expresan con la adición de marcas gramaticales, aunque también interviene el uso de elementos léxicos y el orden de palabras. Así, la marca men 們 expresa la pluralidad de los pronombres personales y de determinados sustantivos que designan personas. Con respecto a la flexión verbal, en lugar de usar las desinencias como el español, el chino mandarín utiliza algunas partículas gramaticales que, además de servirse de determinados adverbios y verbos auxiliares, pueden expresar los cambios de persona, tiempo, aspecto, modo y voz. Así, son representativas algunas partículas, como le 了 'predicado télico o 
asp. perfectivo', zài 在 'asp. progresivo', zhe 著 'asp. progresivo', guò 過 'pasado indefinido', qǔ laí 起來 'asp. incoativo', xià qù 下去 'asp. continuativo', 如果 si 'marc. de modalidad', bèi 被 'marc. pasiva' y gěi 給 'marc. pasiva refleja'.

En segundo lugar, mientras que todos los afijos convencionales del chino mandarín sufren el proceso de gramaticalización, en español el debilitamiento semántico se refleja en menos casos (como el sufijo adverbializador -mente). Desde el punto de vista funcional, algunos afijos convencionales chinos se identifican más bien con los morfofonemas en determinadas combinaciones, ya que solo contribuyen al bisilabismo del chino moderno. En este sentido, estos elementos se asemejan a algunos interfijos del español, pues tanto unos como otros carecen de significado léxico y de valor gramatical y solo ejercen funciones morfonológicas. Por otra parte, algunos afijos convencionales chinos son comparables a los sufijos apreciativos del español, pues unos y otros expresan valores afectivos. En ambas lenguas, algunos sustantivos tienden a admitir la derivación afectiva, pues esta suele recaer en nombres con significados materiales, físicos o contables, frente a los de sentido abstracto y no contable. Finalmente, son destacables dos diferencias en las dos lenguas contrastadas: mientras que algunos prefijos chinos alteran la categoría gramatical de la base léxica, la prefijación del español resulta fundamentalmente homocategorial. Por otra parte, el sistema de los sufijos apreciativos del español se caracteriza por una morfología recursiva, mientras que el único sufijo chino que presenta esta capacidad recursiva es ér 兒, dado que se comporta como un elemento no silábico que se amalgama a la base.

En la composición, se destacan aquí dos puntos innovadores. En primer lugar, ambas lenguas disponen de un grupo de formantes polimórficos de origen clásico que se clasifican tradicionalmente como afijoides (o pseudoafijos) por sus características morfológicas. Estas unidades aportan significado léxico, pero su contenido semántico está más debilitado con 
412 Morfología contrastiva del chino mandarín y el español. Formas de gramaticalización y lexicalización

respecto al significado primitivo. Al mismo tiempo, estos elementos admiten variaciones morfonológicas y alcanzan una gran capacidad combinatoria en la formación del lenguaje científico y técnico. Asimismo, a fin de identificar estos formantes híbridos en ambas lenguas, hemos planteado una nueva clasificación entre los sufijoides o formantes compositivos propiamente dichos (que únicamente ocupan la segunda posición) y los temas (con doble posición).

En segundo lugar, tanto la composición del español como la del chino mandarín presentan un origen sintáctico $y$, en particular, una palabra compuesta china parece una proposición abreviada. Sin embargo, en mandarín el origen sintáctico de los compuestos alcanza un mayor grado de generalización, pues la estructura interna de los compuestos representa un proceso que consiste en transformar construcciones sintácticas y no solo en sumar elementos morfológicos. Esta tendencia se refleja en dos tipos de compuestos que resultan productivos en chino mandarín, pero defectivos en español. El primer tipo se corresponde con el esquema $N$ (sujeto)- $V$ y el segundo tipo es el formado por verbo y complemento predicativo. Así, se puede decir que aunque en ambas lenguas se reconoce una relación sintáctica entre los componentes, en los compuestos chinos de estructura compleja la combinación de elementos de distintas categorías gramaticales presenta más variedad que las correspondientes del español.

En fin, mediante el análisis contrastivo, se observa que el estudio morfológico del chino mandarín en contraste con el español puede aportar algunas novedades a la descripción tradicional de la lengua china. En primer lugar, los criterios que se adoptan del español para distinguir procesos morfológicos son también aplicables al chino mandarín con resultados positivos. Por ejemplo, en el caso de las formas híbridas, se ha demostrado que los afijoides chinos se identifican más bien con los elementos compositivos, ya que son unidades léxicas autónomas capaces de entrar en la composición y de formar locuciones. El método contrastivo, en suma, da buen resultado en el 
sentido de que desde la perspectiva de dos lenguas diferentes se puede reformular complementariamente el tratamiento teórico y descriptivo de las unidades morfológicas.

Por otra parte, se ha defendido también un criterio innovador con respecto a los problemas tradicionales de la clasificación tipológica de la lengua china. Mediante el procedimiento contrastivo, hemos puesto en duda la excesiva dependencia que se observa en el chino mandarín con respecto al chino escrito. Tradicionalmente, se ha construido la gramática china a partir del código escrito, como si el chino hablado no tuviera suficiente prestigio para la investigación científica. De hecho, los estudios lingüísticos del chino basados en la lengua oral se encuentran poco desarrollados en la actualidad. Con la obsesión por la lengua escrita, se ha llegado a rechazar la existencia de flexiones gramaticales en la lengua china. Se define así el chino como una lengua absolutamente analítica, pues cada carácter (signo gráfico) tiene una silaba, cada sílaba representa un morfema libre y cada morfema es una palabra independiente. Todos estos planteamientos se construyen a partir del estudio del chino escrito.

Pues bien, en nuestro trabajo hemos cuestionado esta posición y hemos afirmado que la lengua china dispone de flexiones gramaticales, de manera que la clasificación tipológica se convierte en una cuestión gradual. En realidad, la excesiva dependencia hacia el chino escrito hace que los desajustes de la morfología china no sean casos aislados. Es decir, muchas cuestiones conflictivas están relacionadas entre sí, debido a la inclinación hacia el código gráfico, como el planteamiento de la carencia de flexión, la improductividad de la derivación, la indefinición entre afijoides y elementos compositivos. Por nuestra parte, hemos aportado algunos criterios nuevos para tratar de aclarar ciertas ideas que hasta ahora se veían confusas o claramente equivocadas.

Hemos dedicado el capítulo sexto a revisar los principales marcos teóricos de los procesos de gramaticalización y lexicalización. En los estudios 
414 Morfología contrastiva del chino mandarín y el español. Formas de gramaticalización y lexicalización

recientes, la gramaticalización puede resumirse como un fenómeno lingüístico en el que el enfoque pragmático-cognitivo desempeña un papel importante. Las implicaciones semánticas como la generalización, los mecanismos metafóricos y metonímicos se desarrollan en el marco de la gramaticalización y la definen como un cambio lingǘstico que puede derivar en resultados diferentes a la pérdida del contenido léxico y la adquisición de significado gramatical. Así, el proceso de gramaticalización se desarrolla en cadenas (clines) que recorren un trayecto desde el estadio más referencial hacia el más gramatical. De este modo, se plantea la hipótesis de la unidireccionalidad en la que la irreversibilidad y la recategorización caracterizan el proceso de la gramaticalización. Por otra parte, el reanálisis y la analogía también son mecanismos cognitivos determinantes en la gramaticalización. Ambos se dan como diferentes facetas de un mismo proceso, pero difieren en que el reanálisis trata de una reestructuración interna de los elementos gramaticalizados, mientras que la analogía crea nuevos paradigmas a partir de unidades lingüísticas ya existentes.

Frente a la gramaticalización, la lexicalización se considera un proceso complementario que interactúa con la gramaticalización en el ámbito de la evolución lingüística. Se trata de un mecanismo de creación léxica que se desarrolla de forma direccionalmente contraria a la gramaticalización, pero se asemeja al proceso de gramaticalización en presentar algunos rasgos: la fijación gramatical de los elementos afectados, la pérdida o modificación de su significado primitivo o su recategorización y la pérdida de sustancia fónica o la fusión de elementos. Pese a las semejanzas, se observa una diferencia destacable entre los dos procesos: mientras que la gramaticalización somete ciertos elementos a los paradigmas de la gramática, por lo que la irregularidad disminuye, la lexicalización, por el contrario, provoca una constante irregularidad entre las expresiones lexicalizadas, pues se sustraen unidades de la gramática y se incluyen en el léxico.

A partir de las descripciones más asentadas sobre los procesos de 
gramaticalización y lexicalización del capítulo anterior, en el capítulo séptimo se analiza la incidencia de ambos mecanismos en las formaciones morfológicas de las dos lenguas contrastadas. En el caso de gramaticalización, los temas polimórficos cultos del español y los llamados afijoides del chino mandarín se consideran formas gramaticalizadas, pues presentan las principales características de esta evolución: debilitamiento semántico, aumento de productividad, cambio desde un estadio referencial a otro gramatical y desarrollo de sentidos abstractos (generalización del significado). En ambas lenguas, la gramaticalización conduce a estos elementos hacia la polisemia, al incremento de funciones gramaticales y a la evolución desde de una categoría léxica mayor a otra categoría menor. En el caso de la lexicalización, la composición constituye un caso representativo del proceso de lexicalización en ambas lenguas contrastadas, dado que se transfiere información desde el plano morfológico hasta el plano léxico. En ambas lenguas, la composición se caracteriza por la fijación sintáctica, la adquisición de valor referencial unitario, la fusión de dos elementos simples en una sola unidad léxica con registro lexicográfico, la imposibilidad de intercalación de elementos y de cambios en la ordenación interna de los constituyentes.

Frente a estos paralelismos, destacamos también algunas divergencias interesantes. La pérdida del sentido composicional en palabras como pagaré, doctorando, considerando, ventanilla, interesado, etc., y el aumento de la autonomía sintagmática en casos como crono, logo, etc., constituyen fenómenos defectivos en el chino mandarín, pues la lengua china se caracteriza por la evolución histórica de unidades autonómas a elementos morfológicos dependientes, pero carece de formantes lexicalizados en el caso de los afijos flexivos y derivativos. Por otro lado, se observa que no se produce en la morfología china el fenómeno del acortamiento que desemboca en la creación de un nuevo significado léxico para un sustantivo autónomo, como el tipo tele, foto, etc., que a su vez sustenta la segunda gramaticalización de los compuestos españoles. Se supone que en el chino moderno la tendencia 
Morfología contrastiva del chino mandarín y el español. Formas de gramaticalización y lexicalización

hacia el polisilabismo conduce a la formación léxica de constituyentes que se someten al proceso de gramaticalización, -o doble gramaticalización en algunos casos-, ya que el debilitamiento semántico y el aumento de la capacidad combinatoria de los formantes favorecen la creación de palabras polisilábicas.

En ambas lenguas, los mecanismos léxicos y gramaticales que regulan la formación de compuestos son la generalización, la fusión, el reanálisis, la analogía y la recategorización. Por otra parte, se observa que los principios cognitivos también constituyen factores importantes en la formación compositiva. Entre ellos, los principios básicos de la teoría de la integración y la fusión conceptual constituyen un principio de referencia común a las dos lenguas contrastadas. Por su parte, se ha demostrado que la categorización y el mecanismo cognitivo universal pueden describir determinados compuestos comunes a las dos lenguas en distintos niveles de prototipicidad y de especificidad.

En el último capítulo se ha comprobado que el comportamiento de la lexicalización es productivo en un grupo semejante de locuciones nominales del español y del chino: las locuciones nominales formadas por adjetivos de color y nombres, adjetivos aspectuales y sustantivos, y nombres de lugar según el esquema español $\mathrm{N}$ de $\mathrm{N}$. Estos tres tipos de locuciones presentan algunas semejanzas en la estructura formal y el plano semántico. En primer lugar, los adjetivos y los complementos preposicionales del español o nominales del chino no son modificadores que describan propiedades de los objetos, pues no se comportan como elementos atributivos ni predicativos. En chino mandarín, este rasgo puede comprobarse por la imposibilidad de intercalación del formante de 的, que se define como un 'marcador de atribución', característico de la atribución entre el adjetivo y el sustantivo. Del mismo modo, en español el verbo atributivo (ser o estar) resulta incompatible con estas estructuras lexicalizadas. En segundo lugar, los núcleos de las locuciones locativas se limitan a la clase léxica de la designación de 'lugar'. Aunque 
admiten también la gramaticalización, estas locuciones conservan en mayor grado el sentido composicional, lo que favorece el endocentrismo semántico. En cambio, las locuciones nominales constituidas por nombres y adjetivos de color o adjetivos aspectuales se reparten con más facilidad entre el endocentrismo y el exocentrismo semánticos, ya que los núcleos de estas locuciones analizadas tienden a denotar tipos léxicos muy variados.

En tercer lugar, se observan dos factores que favorecen el proceso de lexicalización de estas locuciones nominales. En ambas lenguas, los adjetivos de color de las locuciones nominales formadas por nombres y esta clase de adjetivos se comportan como elementos intersectivos, que asignan una propiedad no solo al nombre sino también a la clase hiperónima del sustantivo. Por otra parte, los núcleos de estas locuciones nominales presentan reducción o generalización del significado léxico, de manera que este cambio semántico favorece la capacidad combinatoria de estos elementos y contribuye a la fijación del conjunto.

Merece una mención especial que el eje de la 'perfectividad' - 'imperfectividad' de las locuciones nominales constituidas por adjetivos aspectuales y nombres se muestra codificado en ambas lenguas. Además, la fijación recae en el mismo tipo de adjetivos, ya que algunos adjetivos, como quàn 全 'total, entero, completo, lleno, pleno' y bàn 半 'medio', y sus equivalentes en español dan lugar a un grupo numeroso de locuciones.

Frente a estas semejanzas, se observa una diferencia muy destacable en las locuciones nominales formadas con nombres y adjetivos de color en las dos lenguas contrastadas. En chino mandarín, esta forma léxica presenta una productividad relativamente mayor que la del español, debido a que las locuciones nominales explicitan la relación de pertenencia de una entidad a una determinada clase de realidades. Sin embargo, en español esta tendencia hacia la clasificación explícita no resulta tan preferente, ya que los equivalente se corresponden con un sustantivo simple y primitivo (hóng băo shí 
Morfología contrastiva del chino mandarín y el español. Formas de gramaticalización y lexicalización

紅寶石 'rojo' ‘joya' $\rightarrow$ rubí). Por otro lado, mientras que en español se observa la improductividad de los adjetivos intensionales en la formación de locuciones nominales, en el chino mandarín estos adjetivos de color con valor intensional representan un atributo inherente de lo designado por el nombre y carecen de sentido clasificador (húang jinn 黃金 'amarillo' 'oro' $\rightarrow$ oro). En el chino mandarín, la lexicalización se extiende incluso a dos formaciones: la fijación del sustantivo 'color' junto al adjetivo cromático correspondiente, especialmente en los anglicismos recientes (hēi sè diàn yĭng 黑色 電影 'negro' 'color' 'cine' $\rightarrow$ cine negro); el uso de determinados adjetivos cromáticos anticuados, como chì dào 赤道 'ant. rojo' 'ruta' $\rightarrow$ ecuador.

Finalmente, se ha comprobado que en español la lexicalización de los compuestos locativos de estructura $\mathrm{N}$ de $\mathrm{N}$ se agrupa en dos tipos semánticos: los endocéntricos se corresponden con las formaciones institucionalizadas por la fijación estructural y la pérdida de composicionalidad parcial. Por otro lado, los de tipo exocéntrico se comportan como las formaciones lexicalizadas, pues además de la fijación estructural elevada y la pérdida del sentido composicional, se observa una plena idiomaticidad. En los nombres de lugar del chino mandarín, la autonomía léxica del formante locativo permite distinguir dos tipos de lexicalización: el tipo pseudosufijal y el tipo compositivo. En los primeros se percibe un alto nivel de lexicalización, pues el conjunto funciona como un derivado cuya fijación es mayor que en las composiciones.

Las conclusiones de este trabajo tal vez puedan aplicarse a otros esquemas léxicos cuyo proceso morfológico se relacione con las formas de gramaticalización y lexicalización. Con nuestra aportación, hemos pretendido dar un pequeño paso hacia el desarrollo de los estudios contrastivos entre la morfología del chino mandarín y la del español, a sabiendas de que este trabajo es simplemente una iniciación por uno de los posibles enfoques que pueden seguirse para el análisis de estas dos lenguas, a veces no tan diferentes como cabría pensar. Son muchos los problemas que a partir de aquí se plantean y somos conscientes de las dificultades de su resolución. 


\section{BIBLIOGRAFÍA}

\subsection{Estudios de lingüística general y de lingüística española}

AITCHISON, J. 1987. Words in the mind, Oxford: Basil Blackwell.

ALARCOS LLORACH, E. 1974. Gramática estructural, Madrid: Gredos.

ALARCOS LLORACH, E. 1976. Fonología española, Madrid: Gredos.

ALARCOS LLORACH, E. 1983. "Consideraciones sobre la formación léxica", Serta Philológica Fernando Lázarro Carreter: Estudios de Lingüística y Literatura, vol. I, Madrid: Cátedra, 11-16.

ALARCOS LLORACH, E. 1994. Gramática de la lengua española, Madrid: Espasa Calpe.

ALBA de DIEGO, V. 1983. "Elementos prefijales y sufijales: ¿derivación o composición?", Serta Philológica Fernando Lázarro Carreter: Estudios de Lingüística y Literatura, vol. I, Madrid: Cátedra, 17-22.

ALCÁZAR LÓPEZ, J. 1984. Cuaderno de morfología española, Granada: Editorial Don Quijote.

ALCINA, J. y J. M. BLECUA. 1975. Gramática Española, Barcelona: Ariel.

ALCOBA, S. 1988. "Categoría léxica de las palabras compuestas", Verba, 15, 109-146.

ALCOBA, S. 1991. "Morfología del verbo español: conjugación y derivación deverbal", C. Martín Vide (ed.), Lenguajes naturales y lenguajes formales, VI. 1, Barcelona: Universidad Autónoma de Barcelona, 87-119.

ALCOBA, S. 1993. "Los parasintéticos: constituyentes y estructura léxica", S. Varela Ortega (ed.), La formación de palabras, Madrid: Taurus, 360-379. 
ALCOBA, S. 1999. "La flexión verbal", I. Bosque y V. Demonte (dirs.), Gramática descriptiva de la lengua española, Madrid: Espasa Calpe, 4915-4991.

ALEMANY BOLUFER, J. 1917. "De la derivación y composición de las palabras en la lengua castellana", Boletín de la Real Academia Española, IV, 564-579.

ALEMANY BOLUFER, J. 1920. Tratado de la formación de la lengua castellana: la derivación y la composición, Madrid: Victoriano Suárez.

ALEZA-IZQUIERDO M. y A. LÓPEZ-GARCÍA (coord.). 2000. Estudios de filología, historia y cultura hispánicas, Valencia: Universidad de Valencia.

ALMELA PÉREZ, R. 1999. Procedimientos de formación de palabras en español, Barcelona: Ariel.

ALONSO-CORTÉS, A. 1992. Lingüística General (2a edición corregida y aumentada), Madrid: Cátedra.

ALVAR, M. y B. POTTIER, 1983. Morfología histórica del español, Madrid: Gredos.

ALVAR EZQUERRA, M. 1978. "Notas para el estudio del formante foto-", Analecta Malacitana, I, 2, 313-326.

ALVAR EZQUERRA, M. 1983a. "El acortamiento de palabras", M. Alvar Ezquerra y A. Miró Domínguez (eds.), Diccionario de siglas y abreviaturas, Madrid: Alambra.

ALVAR EZQUERRA, M. 1983b. "Vitalidad y pervivencia del sufijo nominalizador «O॥", Serta philologica F. Lázaro Carreter, Madrid: Cátedra, 47-58.

ALVAR EZQUERRA, M. 1983c. Diccionario de siglas y abreviaturas, Madrid: Editorial Alambra, S. A.

ALVAR EZQUERRA, M. 1984. "De nuevo sobre los compuestos de verbo + sustantivo", M. Alvar Ezquerra (coord.), Actas del II Simposio Internacional de Lengua Española, Las Palmas: Cabildo Insular, 83-97.

ALVAR EZQUERRA, M. 1993. La formación de palabras en español, Madrid: Arco Libros.

ALVAR EZQUERRA, M. 1995. "El elemento tele, formante de palabras en español", Homenaje a Félix Monge. Estudios de Lingüística Hispánica, Madrid: Gredos, 55-64. 
ALVAR EZQUERRA, M. 2006. "Tendencias en los neologismos en español actual", G. Adamo y V. Della Valle (eds.), Che fine fanno i neologismi? A cento anni Della pubblicazione del Dizionario moderno di Alfredo Panzini, Roma: Leo S Olschki editore, 33-53.

ÁLVAREZ GARCÍA, M. 1979. Léxico-génesis en español: los morfemas facultativos, Sevilla: Publicaciones de la Universidad de Sevilla.

AMADOR R. y L. ALEXIS. 2009. La derivación nominal en español: nombres de agente, instrumento, lugar y acción, Frankfurt am Main: Peter Lang.

AMBADIANG, T. 1993. La morfología flexiva, Madrid: Taurus.

AMBADIANG, T. 1999. "La flexión nominal. Género y número", I. Bosque y V. Demonte (dirs.), Gramática descriptiva de la lengua española, Madrid: Espasa Calpe, 4843-4913.

ANTILLA, R. 1989 [1972]. Historical and Comparative Linguistics. Amsterdam: John Benjamins

ARONOFF, M. 1976. Word formation in generative grammar, Cambridge (Mass): The MIT Press.

ARONOFF, M. 1980. "The relevance of productivity in a synchronic description of word formation", J. Fisiak (ed.), Historical morphology, The Hague: Mouton Publishers, 71-82.

ARRIZABALAGA, C. 2010. Gramaticalización en español americano: la perífrasis concomitante norperuana, Pamplona: Eunsa.

BAT-ZEEV SHYLDKROT, H. 1995. "Tout- polysémie, grammaticalisation et sens prototipique", Langue français, 107, 72-93.

BAJO PÉREZ, E. 1997. La derivación nominal en español, Madrid: Arco Libros.

BAUER, L. 1983. English Word formation, Cambridge: Cambridge University Press.

BAUER, L. 1988. Introducing linguistic morphology, Edinburgh: Edinburgh University Press.

BEARD, R. 1995. Lexeme-Morpheme base Morphology: general theory of inflection and word formation, Albany: State Universityof New York Press.

BENVENISTE, E. 1977. Problemas de lingüística general, Madrid: Siglo, XXI. 
BERNAL, E. 2007. "Nuevos prefijos: implicaciones para la morfología y la lexicografía", M. Iliescu, H. Siller-Runggaldier y P. Danler (eds.), Actes du XXVe Congrès International de Linguistique et de Philologie Romanes, Innsbruck: De Gruyter, 361-373.

BISETTO, A. y S. SCALISE. 2005. "The classification of compounds", Lingue e Linguaggio, IV , 2, 319-332.

BLANK. A. 2001. Einführung in die lexikalische Semantik für Romanisten, Tübingen: Niemeyer.

BLASCO MATEO, E. 2002. "La lexicalización y las colocaciones", Lingüística Española Actual, XXIV, 35-61.

BLECUA, J. M. y G. CLAVERÍA. 1999. "La Lexicografía Castellana, antes y después de Joan Coromines", J. Solà (ed.), L'obra de Joan Coromines. Cicle d'estudi i homenatge, Sabadell: Fundació Caixa Sabadell, 29-43.

BÖRJARS, K. y N. VINCENT. 2011. "Grammaticalization and directionality", H. Narrog, y B. Heine (eds.), The Oxford handbook of grammaticalization, Oxford: Oxford University Press, 163-176.

BLOOMFIELD, L. 1950 [1933]. Language, London: Henderson and Spalding.

BORN, J. 2006. "O confixo euro- nos países românicos e germânicos", M. F. Athayde (coord.), Estudio sobre léxico e gramática (Cadernos do Centro Interuniversitario de Estudos Germânicos, 23), 111-138.

BOSQUE, I. 1982. "Más allá de la lexicalización", Boletín de la Real Academia Española, LVII, 103-158.

BOSQUE, I. 1983. "La morfología", A. Yllera et alii (eds.), Introducción a la lingüística, Madrid: Alambra, 115-153.

BOSQUE, I. 1999. "El sintagma adjetival. Modificadores y complementos del adjetivo. Adjetivo y participio", I. Bosque y V. Demonte (eds.), Gramática descriptiva de la lengua española, Madrid: Espasa Calpe, 217-310.

BOSQUE, I. 2001. "Sobre el concepto de 'colocación' y sus límites", Lingüística Española Actual, XXIII, 9-40. 
BOSQUE, I. y J. A. MAYORAL. 1979. "Formación de palabras. Ensayo bibliográfico", tirada aparte de los Cuadernos bibliográficos, 38.

BOSQUE, I. y V. DEMONTE (dirs.). 1999. Gramática descriptiva de la lengua española. Madrid: Espasa Calpe.

BOSQUE, I. Y M. PEREZ FERNÁNDEZ. 1987. Diccionario inverso de la lengua española, Madrid: Gredos.

BOTHA, R. P. 1984. Morphological Mechanisms: Lexical Analysis of Synthetic Compounding, Oxford: Oxford University.

BRINTON, L. J. 2000. "Grammaticalization versus lexicalization reconsidered: on the 'late' use of temporal adverbs", T. Fanego, M. J. López-Couso y J. Pérez-Guerra (eds.), English historical syntax and morphology: selected papers from 11 ICEHL, Amsterdam: John Benjamins, 67-97.

BRINTON, L. J. y E. C. TRAUGOTT. 2005. Lexicalization and Laguage Change, Cambridge: Cambridge University Press.

BRIZ GÓMEZ, A. 1989. Sustantivación y lexicalización en español, Valencia: Universidad de Valencia.

BRIZ GÓMEZ, A. 1998. El español coloquial en la conversación. Esbozo de pragmagramática, Barcelona: Ariel.

BRUYNE, J. de. 2000. "La función multidimensional de los sufijos patemáticos", M. Alvar (ed.), Introducción a la lingüística española, 255-267.

BUENAFUENTES, C. 2001-2002. "Procesos de gramaticalización en el estudio de los compuestos del español: el caso del elemento mal/a (-)", Anuari de Filología, vol. XXIII-XXIV, secció F, 11-12, 17-29.

BUENAFUENTES, C. 2003. Estudio diacrónico de las formaciones compuestas del español Procesos de gramaticalización y lexicalización (Proyecto de investigación inédito), Bellaterra: Universitat Autònoma de Barcelona.

BUENAFUENTES, C. 2006a. "Evolución de las formaciones compuestas del español: de la composición sintagmática a la composición léxica", J. J. de Bustos Tovar, y J. L. Girón Alconchel (eds.), Actas del VI Congreso Internacional de Historia de la Lengua Española, vol. I, Madrid: Arco Libros, 545-556. 
BUENAFUENTES, C. 2006b. "Estudio evolutivo de la composición culta a partir de procesos de gramaticalización y lexicalización", J. Rodríguez Molina y D. M. Sáez de Rivera (coords.), Diacronía, lengua española y lingüística, Madrid: Síntesis, 211-224.

BUENAFUENTES, C. 2007. Procesos de gramaticalización y lexicalización en la formación de compuestos en español, Tesis Doctoral, Universidad Autónoma de Barcelona.

BUENAFUENTES, C. y M. PRAT. 2008. "Evolución del paticipio de presente latino español: procesos de gramaticalizción y lexicalización", C. Company Company, y J. G. Moreno de Alba (eds.), Actas del VIl Congreso Internacional de Historia de la Lengua Española, vol. I, Madrid: Arco Libros, 413-429.

BUSSMANN, H. (ed.). 1996. Routledge Dictionary of Language and Linguistics, London: Routledge.

BUSTOS GISBERT, E. 1986. La composición nominal en español, Salamanca: Universidad de Salamanca.

BUSTOS PLAZA, A. 2005. Combinaciones verbonominales y lexicalización, Frankfurt am Main: Peter Lang.

BUSTOS TOVAR, E. de, 1966. "Algunas observaciones sobre las palabras compuestas", Revista Filología Española, XLIX, 255-274.

BYBEE, J. 1985. Morphology: A study of relation between Meaning and form, Amsterdam: John Benjamins.

BYBEE, J. 1988. "Morphology as Lexical Organización", M. Hammond y M. Noonan (eds.), Theoretical Morfology, Londres: Academia Press.

BYBEE, J. 2003. "Mechanisms of change in grammaticalization: the role of frequency", B. D. Joseph y R. D. Janda (ed.), Handbook of Historical Linguistics, Oxford: Blackwell, 602-623.

BYBEE, J. Y W. PAGLIUCA. 1985. "Cross-Linguistics Comparison and the Development of Grammatical Meaning", J. Fisiak (ed.), Historical Semantics. Historical Word-Formation, Berlín: Mouton de Gruyter, 59-83. 
BYBEE, J. y W. PAGLIUCA. 1987. "The evolution of future meaning", A. Giacalone Ramat, O. Carruba y G. Bernini (eds.), Papers from the $7^{\text {th }}$ International Conference on Historical Linguistics, Amsterdam: John Benjamins, 109-122. BYBEE, J., R. PERKINS y W. PAGLIUCA. 1991. "Back to the future", B. Heine y E. C. Traugott (eds.), Approaches to grammaticalization, vol. II, Amsterdam: John Benjamins, 17-58.

BYBEE, J., R. PERKINS y W. PAGLIUCA. 1994. The Evolution of Grammar. Tense, Aspect, and Modality in the Languages of the World, Chicago: University of Chicago Press.

CALVO PÉREZ, J. 1986. Adjetivos puros: estructura léxica y topología, Valencia: Universidad de Valencia.

CAMPA, H. de la. 1987. Diccionario inverso del español: su uso en el aula, Madrid: Narcea.

CAMPBELL, L. y R. JANDA. 2001. "Introduction: Conceptions of Grammaticalization and their Problems", Language Sciences, 23, 93-112.

CAMPOS, H. 1999. "Transitividad e intransitividad", I. Bosque y V. Demonte (dirs.), Gramática descriptiva de la lengua española, Madrid: Espasa Calpe, 1520-1574.

CANDALIJA REINA, J. A. 2008. Preposiciones Vacías del español: complemento de régimen preposicional, Alicante: Biblioteca virtual Miguel de Cervantes.

CASADO VELARDE, M. 1985. Tendencias en el léxico español actual, Madrid: Editorial Coloquio.

CASADO VELARDE, M. 1999. "Otros procedimientos morfológicos: acortamientos, formación de siglas y acrónimos", I. Bosque y V. Demonte (dirs.), Gramática descriptiva de la lengua española, Madrid: Espasa Calpe, 5075-5096.

CASARES, J. 1969 [1950]. Intoducción a la lexicografía moderna, Anejo LII de REF, Madrid: CSIC. 
CASTAÑER MARTÍN, R. M. y V. LAGÜÉNS GRACIA (eds.). 2010. De moneda nunca usada. Estudios filológicos dedicados a José M. a Enguita Utrilla, Zaragoza: Institución Fernando el Católico.

CAStillo CARBAllo, M. A. 1988. "¿Compuestos o locuciones?", M. Alvar Ezquerra y G. Corpas Pastor (coords.), Diccionarios, frases, palabras, Málaga: Universidad de Málaga.

CAStillo CARBAlLO M. A. y J. M GARCíA PLATERO (coords.). 2010. La lexicografía en su dimensión teórica, Málaga: Universidad de Málaga.

CHICAGO 1972. The Chicago Manual of Style, 12 th Edition completely revised, Chicago / London: The University of Chicago Press.

CHOMSKY, N. 1970. "Observaciones sobre la nominalización", V. Sánchez de Zavala (comp.), Semántica y sintaxis en la lingüística transformatoria, vol. I, Madrid: Alianza, 133-187.

CIFUENTES HONRUBIA J. L. 1994. Gramática cognitiva, Fundamentos críticos, Madrid: Eudema.

CIFUENTES HONRUBIA J. L. 2003. Locuciones prepositivas. Sobre la gramaticalización preposicional en español, Alicante: Universidad de Alicante.

CIFUENTES HONRUBIA J. L. 2010. Clases semánticas y construcciones sintácticas: Alternancias locales en español, Lugo: Editorial Axac.

CLAVERÍA NADAL, G. 2003. "Procesos de lexicalización con sufijos diminutivos en los nombres de plantas", F. Sánchez Miret (ed.), Actas del XXIII Congreso Internacional de Lingüística y Filología Románticas, vol. III, Tübingen: Max Niemeyer, 69-81.

CLAUDI, U. y B. HEINE. 1986. "On the metaphorical base of grammar", Studies in Language, X/2, 297-335.

COMPANY COMPANY, C. 2001. "Gramaticalización, debilitamiento semántico y reanálisis. El posesivo como artículo en la evolución sintáctica del español", RFE 81, 49-87. 
COMPANY COMPANY, C. 2002. "Reanálisis en cadena y gramaticalización. Dativos problemáticos en la historia del espñol", Verba, 29, 31-69.

COMPANY COMPANY, C. 2003a. "(¿¿De?) Gramaticalización, subjetivización y reanálisis. La flexibilidad categorial del verbo en la historia del español", ponencia leída en The $7^{\text {th }}$ Hispanic Linguistics Symposium, University of New México, octubre de 2003.

COMPANY COMPANY, C. 2003b. "La gramaticalización en la historia del español", Medievalia, 35. 3-61.

COMPANY COMPANY, C. 2004a. "Gramaticalización por subjetivación como prescindibilidad de la sintaxis", Nueva Revista de Filología Hispánica, Tomo 52, n. 1, 1-28.

COMPANY COMPANY, C. 2004b. “¿Gramaticalización o desgramaticalización? El reanálisis y subjetivación de verbos como marcadores discursivos en la historia del español", RFE 84, 1, 29-66.

COMPANY COMPANY, C. 2009. "Entre el bien y el mal. Una pauta de lexicalización en la lengua española", Revista de Historia de la lengua española, 4, 29-46.

COMRIE, B. 1981. Language Universals and Linguistic Typology, Oxford: Basil Blackwell.

CONDE SAIZ, M. V. et al. 1978. Estudios ofrecidos a Emilio Alarcos Llorach (con motivo de sus XXV años de docencia en la Universidad de Oviedo), 3 , Oviedo: Universidad de Oviedo.

CONTRERAS, J. M. y A. SUÑER. 2004. "Los procesos de lexicalización", E. Pérez Gaztelu, I. Zabala y L. Gràcia (eds.), Las fronteras de la composición en las lenguas románticas y en vasco, San Sebastián: Universidad de Deusto, 47-108.

CORPAS PASTOR, G. 1996. Manual de fraseología española, Madrid: Gredos.

CORPAS PASTOR, G. (ed.). 2000. Las lenguas de Europa: estudios de fraseología, fraseografía y traducción, Granada: Comares. 
CORRIENTE, F. 1999. Diccionario de arabismos y voces afines en iberorromance, Madrid: Gredos.

COSERIU, E. 1977. "Introducción al estudio estructural del léxico", Principios de semántica estructural, Madrid: Gredos, 87-142.

COWIE, A. P. 2001. Phraseology: Theory, Analysis and Applications, Oxford: Oxford University Press.

CRESPO, A. 2002. Cognición humana: mente, ordenadores y neuronas, Madrid: Centro de Estudios Ramón Areces.

CROFT, W. 1990. Typology and Universals, Cambridge: Cambridge University Press,

CRUSE, D. 2008. "Antonimia y complementariedad", William Croft y D. Alan Cruse, Lingüística cognitiva, Madrid: Akal, 217-252.

CRYSTAL, D. 2000. Diccionario de lingüística y fonética, Barcelona: Octaedro.

CUADRADO CAMPS, S. y K. V. ALSINA. 2002. "Lexicografía y lingüística cognitiva: lexicalización de metáforas y metonimias", IV Congreso de Lingüistica General, Cádiz del 3 al 6 de abril 2000, Vol. 2, 63-74.

CUENCA, M. J. y J. HILFERTY. 1999. Introducción a la lingüística cognitiva, Brcelona: Ariel.

DEMONTE, V. 1999. "El adjetivo: clases y usos. La posición del adjetivo en el sintagma nominal", I. Bosque y V. Demonte (dirs.), Gramática descriptiva de la lengua española, Madrid: Espasa Calpe, 129-215.

DEMONTE, V. 2000. "Configuración e interpretación de los adjetivos del español: un enfoque minimista", Wotjak, Gerd (ed.), En torno al sustantivo y adjetivo en español actual. Aspectos cognitivos, semánticos, (morfo) sintánticos y lexicogenéticos, Frankfurt am Main: Verwuert Verlag, 261-273.

DEMONTE, V. 2011. "Adjectives", K. von Heusinger, C. Maienborn y P. Portner (eds.), Semantics: An International Handbook of Natural Language Meaning, Berlín: De Gruyter-Mouton, Vol. 2, Cap. 52, 1314-1340.

DEMONTE, V. y P. J. MASULLO. 1999. "La predicación: Los complementos predicativos", I. Bosque y V. Demonte (dirs.), Gramática descriptiva de la lengua española, Madrid: Espasa Calpe, 2461-2523. 
DÍAZ HORMIGO, M. a T. 2003. Morfología, Cádiz: Servicio de Publicaciones y Universidad de Cádiz.

DOBROVOLSKIJ, D. 2009. "La variación léxico-sintáctica en la fraseología: la introducción del atributo en la estructura de la locución idiomática", Language Design: Journal of Theoretical and Experimental Linguistics, 11, 29-65.

DYER, N. J. 1972. "Old Spanish adverb in -mente", Hispanic Review, 40, 303-308.

ELVIRA, J. 2006. "Aproximación al proceso de lexicalización", J. Rodríguez Molina y D. M. Sáez de Rivera (coords.), Diacronía, lengua española y lingüística, Madrid: Síntesis, 21-41.

ESCANDELL VIDAL, M. V., M. LEONETTI y C. SÁNCHEZ LÓPEZ (eds.). 2011. 60 problemas de gramática: dedicados a Ignacio Bosque, Madrid: Tres Cantos.

FÁBREGAS, A., I. GIL y S. Varela. 2011. “¿Existen los prefijos categorizadores en españole , M. V. Escandell Vidal et al. (eds.), 2011, 360-365.

FÁBREGAS, A. 2012. "Entre kufa y Basora: nombres, verbos y raíces", J. L. Mendívil Giró y M. del C. Horno Chéliz (eds.), La sabiduría de mnemósine. Ensayos de historia de la lingüística ofrecidos a José Francisco Val Álver, Zaragoza: Prensas Universitarias de Zaragoza, 169-179.

FAITELSON-WEISER, S. 1980. Les suffixes quantificateurs de l'espagnol (La suffixation augmentative et diminutive: essai de systématisation), Paris: Éditions Hispaniques.

FAITELSON-WEISER, S. 1993. "Sufijación y derivación sufijal: sentido y forma", S. Varela Ortega (ed.), La formación de palabras, Madrid: Taurus, 119-161.

FAUCONNIER, G. 1994. Mental Spaces. Aspects of Meaning Construction in Natural Languages, Cambridge: Cambridge University Press.

FAUCONNIER, G. 1997. Mappings in Thought and Language, Cambridge: Cambridge University Press. 
FAUCONNIER, G. 1998. "Mental spaces, language modalities, and conceptual integration", M. Tomasello (ed.), The new psychology o f language: Cognitive and functional approaches to language structure, Mahwah NJ: Erlbaum, 251-279.

FAUCONNIER, G. 2001. "Conceptual Blending and Analogy", k. Dedre Gentner, J. Holyoak y N. K. Boicho (eds.), The analogical mind: perspectives from cognitive science, Cambridge: MIT Press, 255-287.

FAUCONNIER, G. 2005. "Fusión conceptual y analogía" (trad. Eva Aladro), revista CIC, Cuadernos de Información y Comunicación, n. 10, 151-182.

FAUCONNIER, G. y M. TURNER. 1994. Conceptual projection and middle spaces, San Diego: University of California.

FAUCONNIER, G. y M. TURNER. 1995. "Conceptual integration and formal expression", Journal of Metaphor and Symbolic Activity, vol. 10, n. 3, 103 -204 .

FAUCONNIER, G. y M. TURNER. 1996. "Blending as a central process of grammar", A. Goldberg (ed.), Conceptual structure, discourse, and language, Stanford: Center for the Study of Language and Information, 113-129.

FAUCONNIER, G. Y M. TURNER. 1998. "Conceptual integration networks", Cognitive Science, 222, 133-187.

FAUCONNIER, G. y M. TURNER. 2002. The Way We Think, New York: Basic Books.

FELÍU ARQUIOLA, E. 2003. Morfología derivativa y semántica léxica: la prefijación de auto-, co-, e inter-, Madrid: Ediciones Universidad Autónoma de Madrid.

FELÍU ARQUIOLA, E. (ed.). 2006. La morfología a debate, Jaén: Universidad de Jaén.

FELÍU ARQUIOLA, E. 2009. "Palabras con estructur interna", E. de Miguel (ed.), Panorama de la lexicología, Barcelona: Ariel, 51-82.

FERNÁNDEZ DE CASTRO, F. 1999. Las perífrasis verbales en el español actual, Madrid: Gredos. 
FERNÁNDEZ PÉREZ, M. 1993. Las categorías gramaticales (morfológicas) en español, Santiago de Compostela: Universidad de Santiago de Compostela.

FERNÁNDEZ RAMÍREZ, S. 1951. Gramática española (Los sonidos, el nombre y el pronombre), Madrid: Revista de Occidente.

FERNÁNDEZ RAMÍREZ, S. 1986. La derivación nominal, Madrid: Boletín de la Real Academia.

FERNANDO, C. 1996. Idioms and Idiomaticity, Oxford: Oxford University Press.

FERRANDO ARAMO, V. 2002, "Colocaciones y compuestos sintagmáticos: dos fenómenos léxicos colindantes", A. Veiga et alii (eds.), Léxico y gramática, Lugo: Tris Tram, 99-107.

FISCHER. D., A. ROSENBACH y D. STEIN (eds.). 2000. Pathways of change: gramamticalizationin English, Amsterdam: John Benjamins.

FISIAK, J. (ed.). 1981. Contrastive Linguistics and the Language Teacher, Oxford: Pergamon.

FOSTER, D. W. 1976. "Exocentric N [NN] Nous in Spanish", Orbis, 25, 44-75.

GALLARDO PAÚLS, B. 2000. Evolución de lenguas y tipología, Valencia: Tirnt lo Blanch.

GARACHANA CAMARERO, M. 1997. LOS procesos de gramaticalización: Una aplicación a los conectores contraargumentativos, Tesis doctoral, Universidad de Barcelona.

GARCÍA-LOZANO, F. 1993. "Los compuestos de sustantivo + adjetivo del tipo «pelirrojo»", S. Varela Ortega (ed.), La formación de palabras, Madrid: Taurus, 205-214.

GARCÍA-LOZANO, F. 1993. "Wortbildung", N. Cartagena y H. M. Gauger, Vergleichende Grammatik Spanih-Deutsch, Mannheim: Duden, vol. II, 73-330.

GARCÍA-MEDALL, J. 1988. "Diversificación y desarrollo del prefijo auto- en español actual", Homenatge a José Belloch Zimmermann, Valencia: Universidad de Valencia, 119-134. 
GARCÍA-MEDALL, J. 1992. "Sobre repetición léxica y sintaxis prepositiva", Estudio de lingüística, 8, 67-84.

GARCÍA-MEDALL, J. 1994. La prefiajación verbal: un estudio de morfología integrada del español, Valladolid: Universidad de Valladolid.

GARCÍA-MEDALL, J. 1995a. Casi un siglo de formación de palabras del español 1900-1994). Guís bibliográfica, Valencia: Cuadernos de Filología (Anejo $\mathrm{XIII).}$

GARCÍA-MEDALL, J. 1995b. "Sobre la innovación morfológica del español americano", Español Actual, 63, 53-62.

GARCÍA-MEDALL, J. 1997. "Neología y productividad morfológica", Thesaurus, Boletín del instituto Caro y Cuervo, tomo 52, 1-3, 94-116.

GARCÍA-MEDALL, J. (ed.). 2002. Aspectos de morfología derivativa del español, Lugo: Tris Tram.

GARCÍA-PAGE SÁNCHEZ, M. 2006. Cuestiones de morfología española, Madrid: Editorial Centro de Estudios Ramón Areces, S. A.

GARCÍA PALACIOS, Joaquín. 2000-2001. "La quimera del euro", Revista de lexicografía, VII, 33-62.

GARCÍA PLATERO, J. M. 1995. "Los compuestos sustantivos en español", Español Actual, 64, 98-100.

GARCÍA PLATERO, J. M. 1998. "Los seudoprefijos. Su importancia para la creación léxica", II Simposio de Historiografía Lingüística. Estudios de Lingüística Genaral. Simposio de Historiografía Lingüística. Estudios de Lingüística Genaral. n. 2. Córdoba, 291-301.

GARCíA PLATERO, J. M. 1998. "Presencia de las voces seudosufijadas en los diccionarios del español", S. Ruhstaller y J. Prado Aragonés (eds.) Tendencias en la investigación lexicográfica del español. El diccionario como objeto de estudio lingüístico y didáctico, Huelva: Servicio de Publicaciones Universidad de Huelva, 425-432.

GARCÍA SÁNCHEZ, J. J. 2007a. Altas toponímico de España, Madrid: Arco Libros. 
GARCÍA SÁNCHEZ, J. J. 2007b. "Derivados regresivos de formas en -ĀTUS en español", M. Iliescu, H. Siller-Runggaldier y P. Danler (eds.), Actes de XXVe Congrès International de Linguistique et de Philologie Romanes, Innsbruck: De Gruyter, 435-444.

GARCÍA, S., A. MEILÁN y H. MARTíNEZ. 2004. Construir bien en español la forma de las palabras, Oviedo: Ediciones Nobel.

GENTNER, D., K. J. HOLYOAK y B. N. KOKINOV (eds.). 2001. The analogical mind: perspectives from cognitive science, Cambridge: MIT Press.

GILI GAYA. S. 1943. Curso superior de sintaxis española, Barcelona: Bobliograf, S. A.

GINEBRA, J 2002. "Las unidades del tipo dinero negro y dormir como un tronco: ¿naturaleza léxica o gramatical?", A. Veiga et alii. (eds.), Léxico y gramática, Lugo, Tris Tram, 147-154.

GINNOULOPOULOU, G. 2006. "On the borderline between lexicon and grammar: confixes in Modern Greek and Italian", STUF, 59, 3, 270-238.

GIURESCU, A. 1972. "El método transformacional en el análisis de los nombres compuestos del español moderno", Revue Roumaine de Linguistique, 17, 5 , 407-414.

GIVÓN, T. 1971. "Historical Syntax and Synchronic Morphology: An Archaeologist's Field Trip", Proceedings of the annual Meeting of the Chicago Linguistics Society, 7, 394-415.

GIVÓN, T. 1979. On Understanding Grammar, Nuw York: Academic Press.

GÓMEZ SOLÍS, F. 1987. "Acerca de un tipo de composición nominal en español (estudio lexicográfico)", Estudios Humanísticos, 9, 31-52.

GÓMEZ TORREGO, L. 1994. "La polisemia del sufijo -logía", Español Actual, 62, p.104.

GÓMEZ TORREGO, L. 1999. "LOS verbos auxiliares. Las perífrasis verbales de infinitivo", I. Bosque y V. Demonte (dirs.), Gramática descriptiva de la lengua española, Madrid: Espasa Calpe, 3323-3389. 
GONZÁLEZ ARANDA, Y. 2002. Lexicología y lexicorafía del español. Repertorio bibliográfico (1990-2002), Almería: Servicio de publicaciones y Universidad de Almería.

GONZÁlez CALVO, J. M. 2000. "Morfología nominal", M. Alvar Ezquerra (ed.), Introducción a la lingüística española, 177-193.

GONZÁLEZ GARCÍA, E. 2007. "Los neologismos en tres diccionarios actuales", M. Campos Souto, M. Muriano Rodríguez y J. I. Pérez Pascual (eds.), El nuevo léxico, A Coruña: Universidad de Coruña.

GONZÁLEZ OLLÉ, F, y M. CASADO VELARDE. 1991. "Formación de palabras", G. Holtus, M. Metzeltin y C. Schmitt, (coords.), Lexikon der Romanistischen Linguistik, vol. VI, 1, Tubinga: Niemeyer, 91-109.

GONZÁLEZ PÉREZ, R. 2002. "El tratamiento lexicográfico de las raíces sufijas y prefijas", J. I. Pérez Pascual y M. Campos Souto (eds.), Cuestiones de Lexicografía, Lugo: Tris Tram, 107-117.

GRÀCIA SOLÉ, L. 1995. Morfología lexica. L'herència de l'estructura argumental, Valencia: Universidad de Valencia.

GRÀCIA SOLÉ, L. 2002. "Formació de mots: composición", J. Solà et al. (eds.), Gramàtica del català contemporani (3 voll.), Brcelona: Empúries, I, 777-829.

GRÀCIA SOLÉ, L. et al. 2000. Configuración morfológica y estructura argumental: Léxico y diccionario, Zarautz: Universidad del País Vasco.

GRÀCIA SOLÉ, LL. y M. CABRÉ CASTELLVÍ. 2000. Configuración morfológica y estructura argumental: léxico y diccionario, Bilbao: Universidad del País Vasco.

GREENBERG, J. H. 1963a. "Some Universals of Grammar with Particular Referente to the order of Meaningful Elements", J. H. Greenberg (ed.), Universals of language, London: MIT Press, 73-113.

GREENBERG, J. H. (ed.). 1963b. Universals of Language, Cambridge: MIT Press.

GUERRERO RAMOS, G. 1995. Neologismos en el español actual, Madrid: Arco Libros. 
GUEVARA, E. y S. SCALISE. 2008. "Searching for Universals in Compounding", S. Scalise, E. Magni y A. Bisetto (eds.), Universals of language, The Netherlands: Springer, 101-128.

GUILBERT, L. 1975. La créativité lexicale, París: Larousse

GUTIÉRREZ ORDÓÑEZ, S. 1978. "Grupos sintagmáticos N de N: Sintaxis y Semántica", Estudios ofrecidos a Emilio Alarcos Llorach (con motivo de sus 25 años de docencia en la Universidad de Oviedo), 3, Oviedo: Universidad de Oviedo, 133-159.

GUTIERREZ ORDÓÑEZ, S. 1986. Variaciones sobre la atribución, León: Universidad de León.

GUTIERREZ ORDÓÑEZ, S. 1997. Temas, remas, focos, tópicos y omentarios, Madrid: Arcos Libros.

HAAS, F. 2007. "The development of English each other: grammaticalization, lexicalization o both?", English Language and Linguistics, 1 1, 31-50.

HAIMAN, J. 1985a. Iconicity in Syntax, Amsterdam: John Benjamins.

HAIMAN, J. 1985b. Natural Syntax: Iconicity and Erosion, Cambridge: Cambridge University Press.

HAIMAN, J. 1994. "Ritualization and the development of language", W. Pagliuca (ed.), Perspectives on Grammaticalization, Amsterdam: John Benjamins, 3-28.

HALLEBEEK, J. 1994. Morfología y sintaxis del español: introducción al análisis oracional, Madrid: Playor.

HALLIDAY, M. A. K. 1985. An Introduction to Functional Grammar, Oxford: Oxford University Press.

HARRIS, Z. S. 1942. "Morpheme alternats in linguistic analysis", Language, 18, 169-180.

HARRIS, A. C. y L. CAMPBELL. 1995. Historical syntax in cross-linguistic perspective, Cambridge: Cambridge University Press.

HASPELMATH, M. 1998. "Does grammaticalization need reanalysis?", Studies in Language, 22.2, 315-351. 
HASPELMATH, M. 1999. "Why is grammaticalization is irreversible?", Linguistics, 37, 1043-68.

HASPELMATH, M. 2002. "On directionality in language change with particular reference to grammaticalization", O. Fischer, M. Norde y H. Perridon (eds.), Up and Down the Cline--the Nature of Grammaticalization, Amsterdan: John Benjamins, 17-44.

HEINE, B. 1993. Auxiliaries: cognitive forces and grammatiealization, Oxford: Oxford University Press.

HEINE, B. 1997. Possession: cognitive sources, forces and grammatiealization, Cambridge: Cambridge University Press (Cambridge Studies in Linguistics, vol. 83).

HEINE, B. 2003. "On degrammaticalization", B. J. Blake, K. Burridge y J. Benjamins (eds.), Historical Linguistics 2001, Amsterdam: John Benjamins, 163-180.

HEINE, B., U. CLAUDI y F. HÜNNEMEYER. 1991a. Grammaticalization: A Conceptual Framework, Chicago: The University of Chicago Press.

HEINE, B., U. CLAUDI y F. HÜNNEMEYER. 1991b. "From Cognition to Grammar. Evidence from African Languages", B. Heine y E. C. Traugott (eds.), Approaches to grammaticalization, vol. I, Amsterdam: John Benjamins, 149-187.

HEINE, B. y M. REH. 1984. Gramaticalization and Reanalysis in African Languages, Hamburg: Helmut Buske.

HERNÁNDEZ ALONSO, C. 2000. "Morfología del verbo, La auxiliaridad", M. Alvar (dir.), Introducción a la lingüística española, Baeclona: Ariel, 195-211.

HERNANDO CUADRADO. L. A. 2005. "El orden de palabras en español", Revista de Filología, 23, 161-178.

HIDALGO NAVARRO, A. y M. QUILIS MERÍN. 2002. Fonética y fonología españolas, Valencia: Tirant lo Blanch.

HILFERTY, J. 1993, "Semántica lingüística y cognición", Verba, XX, 29-44.

HIMMELMANN, N. P. 2002. "Lexicalization and grammaticalization: oppsite or orthogonoal", W. Bisang, N. P. Himmelmann y B. Wiemer (eds.) 2004, What makes grammaticalization, Berlín: mouton de Gruyter, 1-15. 
HIMMELMANN, N. P. 2004. "Lexicalization and grammaticization: opposite or orthogonal", W. Bisang, N. P. Himmelmann y B. Wiemar (eds.), What makes grammaticalization: a look from ist firnges and ist components, Berlin: de Gruyter, 21-42.

HOCKETT, CH. F. 1947. "Problems of morphemic analysis", Language, 18, 321-343.

HOPPER, P. y S. A. THOMPSON. 1980. "Transitivity in grammar and discourse", Language, 56, n. 2, 251-299.

HOPPER, P. y S. A. THOMPSON. 1984. "The discourse basis for lexical categories in universal grammar", Language, 60, 703-753.

HOPPER, P. y S. A. THOMPSON. 1985. "The iconicity of the universal categories 'Noun' and 'Verb'", J. Haiman (ed.), Iconicity in Syntax, Amsterdam: John Benjamins, 151-183.

HOPPER, P. y E. C. TRAUGOTT. 1993. Gramaticalización, Cambridge: Cambridge University Press.

HUELVA UNTERNBÄUMEN, E. 2007. "Metáfora cognitiva y blending en el proceso de gramaticalización de construcciones nominales cuantificativas del español", Studies in Hispanic and Lusophone Linguistics, v. 1, 55-104.

IACOBINI, C. 2004. "Composizione con elementi neoclassici", M. Grossmann y F. Rainer (eds.), La formazione delle parole in italiano, Tübingen: Niemeyer, 69-95.

IBBA, D. 2008. Los procesos de gramaticalizacion de algunos conectores del castellano medieval, Tesis Doctoral, Universidad Autónoma de Barcelona. ILIESCU, M, SILLER-RUNGGALDIER H. y P. DANLER (eds.). 2007. Actes de XXVe Congrès International de Linguistique et de Philologie Romanes, Innsbruck: De Gruyter.

IORDAN, I. y M. MANOLIU. 1972. Manual de lingüística románica (revisión, reelaboración parcial y notas por Manuel Alvar), 2 tomos, Madrid: Gredos.

ITKONEN, E. 2002. "Grammaticalization as an analogue of hipothetico-deductive thinking", I. Wischer y G. Diewald (eds.), New Reflections on Grammaticlization, Ansterdam: John Benjmins Co., 413-422. 
JACOB, D. 2004. "De la gramática histórica a la teoría de la gramaticalización: hacia una perspectiva más amplia sobre el cambio gramatical", Ponencia inédita presentada en el Seminario La gramática histórica cien años después (1904-2004) celebrado en la Sede de la Fundación Duques de Soria, Soria, del 5 al 9 de julio de 2004.

JANDA, R. D. 2001. "Beyond 'phathways' and 'unidirectionality': on the discontinuity of language transmission and the counterability of grammaticalization", Language Sciences, 23, 2-3, 265-340.

JIMÉNEZ RÍOS, E. 2001. "¿Existe asignación y marca de caso en los compuestos de verbo nombre?", Nueva Revista de Filología Española, 49, 2, 307-338.

JIMÉNEZ RÍOS, E. 2002. "Tratamiento lexicográfico de los compuestos nominales de verbo + nombre", Lingüística Española Actual, XXIV, 2, 253-276.

JOHNSON, M. 1990 [1987]. The body in the mind: the Bodily Basis of Meaning, Imagination, and Reason, Chicago: University of Chicago Press.

JOVER, G. 1999. Formación de palabras en español (curiosidad por el lenguaje), Barcelona: Octaedro.

JOSEPH, B. D. Y R. D JANDA. 1988. "The How and Why of Diachronic Morfologization and Demorphologization", M. Hammond y M. Noonan (eds.), Theoretical Morphology: Approaches in Modern Linguistics, San Diego: Academic Press, 193-210.

KATAMBA, F. 1993. Morphology, Houndmills, Basingstoke, Hampshire: Palgrave. KIEFER, F. 1998. "Morphology and Pragmatics", Spencer and Zwicky (eds.), The Handbook of Morphology, Blackwell: Coronel-Molina, S., 272-279.

KLEIBER, G. 1990. La sémantique de prototype. Catégories et sens lexical, Paris: Presses Universitaires de France [Trad. esp.: Semántica de los prototipos, Madrid: Visor, 1994].

KLINGEBIEL, K. 1989. Noun and Verb Compounding in Western Romance, Berkeley: University of California publications in linguistics.

KOIKE, K. 2001. Colocaciones léxicas en el español actual: estudio formal y lexicosemántico, Madrid: Universidad de Alcalá - Takushoku University. 
KOOIJ, J. G. 1968. "Compounds and Idioms", Lingua, 21, 250-268.

KURYŁOWICZ, J. 1965 [1976]. "The evolution of gramatical categories", Enquisses Linguistiques, II, 38-45.

LACA, B. 1993. Las nominalizaciones orientadas y los derivados españoles en -dor y -nte, S. Varela (ed.), La formación de palabras, Madrid: Taurus, 180-204.

LAKOFF, G. 1982. "Categories: an essay in Cognitive Linguistics", The Linguistics Society of Korea, 139-193.

LAKOFF, G. 1987. Women, Fire, and Dangerous Things. What Categories Reveal about the Mind, Chicago: The University of Chicago Press.

LAKOFF, G. y M. JOHNSON. 1980. Metaphors We Live, Chicago: The University of Chicago Press.

LAKOFF, G. y M. JOHNSON. 1998. Metáforas de la vida cotidiana, Madrid: Cátedra.

LANG, M. F. 1992. Formación de palabras en español (trad. De Alberto Miranda Poza), Madrid: Cátedra.

LANGACKER, R. W. 1977. "Syntactic reanalysis", C. Li (ed.), Word Order and Word Order Change, Austin: University of Texas Press, 57-139.

LANGACKER, R. W. 1987. Foundations of Cognitive Grammar, Standford: Standford University Press.

LANGACKER, R. W. 1999. "Losing control: gramaticalización, subjection and transpsrency", y P. Koch, Mouton de Gruyter (eds.), Historical semantics and cognition, Berlin-New York: Mouton de Gruyter, 147-175.

LANGACKER, R. W. 2000. "Subjectification and grammaticlization", R. W. Langacker (ed.), Grammar and conceptualization, Berlin-New York: Mouton de Gruyter, 297-315.

LÁZARO CARRETER, F. 1980. "sobre el problema de los interfijos: ¿̇Consonantes antihiaticas en español?", Estudios de Lingüística, Barcelona: Crítica, 1 1-26. LÁZARO MORA, F. A. 1976. "Compatibilidad entre lexemas nominales y sufijos diminutivos", Revista de Filología Española, XXXI, 41-57. 
LÁZARO MORA, F. A. 1986. "Sobre la parasíntesis en espñaol", Dicenda, 5, 221-235.

LÁZARO MORA, F. A. 1999. "La derivación apreciativa", I. Bosque y V. Demonte (dirs.), Gramática descriptiva de la lengua española, Espasa Calpe, Madrid: 4646-4682.

LEECH, G. 1977. Semantics. Middlesex: Penguin.

LEHMANN, C. 1982. Thoughts on Grammaticalization, München-Newcastle: Lincom Europa.

LEHMANN, C. 1985. "Grammaticalization and Linguistic Typology", General Linguistics, 26, 3-23.

LEHMANN, C. 1989. "Grammatikalisierung und Lexikalisierung", Zeitschrift für Phonetik, Sprachwissenschaft und Kommunikationsforschung, 42, 1, 11-19.

LEHMANN, C. 2002. "New reflections on grammaticalization and lexicalization", I Wischer y G. Diewald (eds.), New reflections on grammaticalization, Amsterdam: John Benjamins, 1-18.

LI CHARLES N. y S. A. THOMPSON. 1974. "Co-verbs in Mandarin Chinese: Verbs or Prepositions?", Journal of Chinese Linguistics, 2, 3, 257-278.

LI CHARLES N. y S. A. THOMPSON. 1976. "Development of the Causative In Mandarin Chinese: Interaction of Diachronic Processes in Syntax", M. Shibatani (ed.), The Grammar of Causative Constructions. Syntax and Semantics, VI, New York: Academic Press, 477-492.

LI, CHARLES N. y S. A. THOMPSON 2003 [1983]. Mandarin Chinese: A Functional Reference Grammar, California: University of Califormia Press.

LIPKA, L. 1983. "A multi-Level Approach to Word-Formation: Complex Lexemes and Word Semantics", S. Hattori y K. Inove, (eds.), Proceedings of the XIIIth International Congress of Linguistics, Tokio: The Committee, 926-928.

LIPKA, L. 1990. An Outline of English Lexicology, Tübingen: Max Niemeyer Verlag.

LIPKA, L. 1992. "Lexicalization and institutionalization in English and German, or: Piefke, Wendehals, Smog, Perestroika, AIDS etc.", Zeitschrift für Anglistik und Amerikanistik, 40, 2, 101-111. 
LIPKA, L. y H. GÜNTHER (eds.). 1981. Wortbildung, Darmstadt: Wissenschaftliche Buchgesellschaft.

LLITERAS, M. 2000. "Las locuciones prepositivas en español", A. Englebert et al. (eds.), De la grammaire des formes à la grammaire du sens, Tübingen: Max Niemeyer, 319-326.

LLITERAS, M. 2002. "Concurrencia histórica de los derivados en -ción y -miento", J. García-Medall (ed.), Aspectos de morfología derivativa del español, Lugo: Tris Tram, 69-77.

LLITERAS, M. 2007. "Lexicalización de adjetivos en locuciones nominales y en nombres compuestos (de luna llena a plenilunio)", M. lliescu, H. Siller-Runggaldier y P. Danler (eds.), Actes du XXVe Congrès International de Linguistique et de Philologie Romanes, Innsbruck: De Gruyter, 759-767.

LLITERAS, M. 2009. "Adjetivos deícticos en procesos de lexicalización", G. Haßler y G. Volkmann (coord.), Deíxis y modalidad en textos narrativos, Münster. Nodus, 31-46.

LLITERAS, M. 2010a. "Productividad de los adjetivos locucionales y compositivos", R. M.a Castañer Martín y V. Lagüéns Gracia (eds.), De moneda nunca usada. Estudios filológicos dedicados a José M. a Enguita Utrilla, Zaragoza: Institución Fernando el Católico, 359-371.

LLITERAS, M. 2010b. "Problemas de codificación de los nombres personales en los siglos XIX y XX", C. Assuncão, G. Fernandes y M. Loureiro (eds.), Ideias Linguísticas na Península Ibérica. Münster: Nodus Publikationen, 513-523.

LLITERAS, M. s.a. El adjetivo en las locuciones nominales, Trabajo de investigación inédito.

LLOYD, P. M. 1968. Verb-Complement Compounds in Spanish, Tübingen: Max Niemeyer.

LÓPEZ, S. y C. MAYORAL et al. 2002. "Dos formants pejoratius: el prefix pseudo -i el sufix -oide", Observatori de Neologia (ed.), Lèxic i neologia, Barcelona: Institut Universitari de Lingüística Aplicada - Universitat Pompeu Fabra, 251-264. 
LORENZO, E. 1995. "La derivación nominal en español actual", Donaire, 4, 35-41. LÜDTKE, J. 1996. "La diacronía en la semántica de la formación de palabras", M. do C. Henríquez y A. Rifón (eds.), Estudios de Morfología, Vigo: Universidad de Vigo, 77-90.

LYONS, J. 1977. Semantics, Cambridge-New York: Cambridge University Press. MARCOS MARÍN, F. A. 2000. "Introducción a la gramática", M. Alvar Ezquerra (ed.), Introducción a la lingüística española, Barcelona: Editorial Ariel, 23-49.

MATEOS, F. 1975. Los caracteres chinos: lexicografía y romanización, Madrid: Barcelona: Asociación Española de Orientalistas.

MALKIEL, Y. 1958. "Los interfijos hispánicos. Problema de lingüística histórica y estructural", Miscelánea Homenaje a André Martinet "Estructuralismo e Historia", II, La laguna: Universidad, 107-199.

MALKIEL, Y. 1966 [1993]. "El análisis genético de la formación de palabras", S. Varel Ortega (ed.), La formación de palabras, Madrid: Taurus, 71-115.

MANTECA, A. 1987. "Sintaxis del compuesto", Lingüística Española Actual, IX, 333-346.

MARTÍN GARCÍA J. 1998. La morfología léxico-conceptual, las palabras derivadas con re-, Madrid: Universidad Autónoma de Madrid.

MARTíN MUNICIO, A. 1992. "La metáfora en el lenguaje científico", Boletín de la Real Academia Española, 72, 221-249.

MARTÍN VIDE C. (ed.). 1990. Lenguajes naturales y lenguajes formales: Actas del VI congreso de lenguajes naturales y lenguajes formales, Tarragona: Promociones y Publicaciones Universitarias.

MARTINELL, E. 1984. "De la complementación a la composición en el sintagma nominal", Revista Española de Lingüística, 14, 2, 223-244.

MARTÍNEZ CELDRÁN, E. 1978. "En torno a los conceptos de interfijos e infijo en español", Revista Española de Lingüística, 8, 447-460.

MARTÍNEZ CELDRÁN, E. 1995. Bases para el estudio del lenguaje, Barcelona: Octaedro. 
MARTíNEZ CELDRÁN, E. 1997. Bases para el estudio del lenguaje, Barcelona: Octaedro.

MATHEWS, P. H. 1974. Morphology: an introduction to the theory of Word-structure, Cambridge: Cambridge University.

MATHEWS, P. H. 1980. Morfología. Introducción a la teoría de la estructura de la palabra, Madrid: Paraninfo.

MCCARTHY, J. J. y A. PRINCE. 1993. Prosodic Morphology: Constraint Interaction and Satisfaction, University of Massachusetts: Amherst.

MCCARTHY, J. J. y A. PRINCE. 1990. "Prosodic Morphology and Templatic morphology", M. Eid y J. McCarthy (eds.), Perspectives on Arabic Linguistics II, Amsterdam: John Benjamins, 1-54.

MEILLET, A. 1973 [1912]. "L'évolution des formes gramaticales", Linguistique histroique et linguistique général, 131-148.

MEIRAMA, B. L. 1997. "Aportaciones de la tipología lingüística a una gramática particular: el concepto orden básico y su aplicación al castellano", Verba, $24,45-82$.

MENDÍVIL GIRÓ, J. L. y M. del C. HORNO CHÉLIZ. (eds.), 2012. La sabiduría de mnemósine. Ensayos de historia de la lingüística ofrecidos a José Francisco Val Álver, Zaragoza: Prensas Universitarias de Zaragoza.

MENDIKOETXEA, A. 1999. "Construcciones inacusativas y pasivas", I. Bosque y V. Demonte (dirs.), Gramática descriptiva de la lengua española, Madrid: Espasa Calpe, 1575-1629.

MIGHETTO, D. 1981. "Ajuste morfosemántico y determinación morfológica: ¿-ión o -miento?", Studia Neophilológica, vol. 53, 347-354.

MIGHETTO, D. 1992. "Notas sobre la noción de aspecto en un marco de clasificación de verbos (Vb) y sustantivos verbales (SV)", Voz y Letra, III-1,69-100.

MIGUEL, E. de. 1999. "El aspecto léxico", I. Bosque y V. Demonte. (dirs.), Gramática descriptiva de la lengua española, Madrid: Espasa Calpe, 2977-3060. 
MIRANDA, J. A. 1994. La formación de palabras en español, Salamanca: Ediciones Colegio de España.

MOGORRÓN HUERTA, P. y S. MEJRI (dirs.). 2008. Las construcciones verbo-nominales libres y fijas: aproximación contrastva y taductología, Alicante: Universidad de Alicante, D. L.

MOLINER, M. 2004. Diccionario de uso del español, Madrid: Gredos.

MONGE CASAO, F. T. 2012. "Aspectos de la sufijación en español", J. L. MENDÍVIL GIRÓ y M. del C. HORNO CHÉLIZ (eds.), La sabiduría de mnemósine. Ensayos de historia de la lingüística ofrecidos a José Francisco Val Álver, Zaragoza: Prensas Universitarias de Zaragoza, 129-143.

MONROY CASAS, R. 1980. Aspectos fonéticos de las vocals españolas, Madrid: Sociedad General Española de Librería.

MONTERO, M. L. 1999. La prefijción negativa en español, Cáceres: Universidad de Extremadura.

MORENO CABRERA, J. C. 1991. Curso universitario de lingüística general. Tomo 1: Teoría de la gramática y sintaxis general, Madrid: Sintesis.

MORENO CABRERA, J. C. 1997. Introducción a la lingüística. Enfoque tipológico y universalista, Madrid: Sintesis.

MORENO CABRERA, J. C. 1998 [1984]. "On the relationships between grammaticalization and lexicalization", A. G. Ramat y P. Hopper (eds.), The Limits of grammaticalization, Amsterdam: John Benjamins, $211-227$.

MORERO CABRERA, J. C. 2002 [1994]. Curso universitario de Lingüística General. Vol. 2: Semántica, Pragmática, Fonología y Morfología, Madrid: Síntesis. MORENO CABRERA, J. C. 2005. Las lenguas y sus escrituras. Tipología, evolución e ideología, Madrid: Síntesis.

MORENO CABRERA, J. C. 2003. "Síntesis y análisis en las lenguas. Crítica de la tipología morfológica clásica y de algunas de sus aplicaciones sincrónicas y diacrónicas", Estudios de Lingüística de la Universidad de Alicante, 17, 465-504. 
MORENO CABRERA, J. C. 2005. "Evolución y Tipología de los sistemas lingüísticos: observaciones críticas: Palabras, norma y discurso", Memoria de Fernando Lázaro Carreter, Ediciones de la Universidad de Salamanca, 843-857.

MORENO DE ALBA, J. G. 1977. "Sobre la formación de palabras en español" Anuario de Letras, Universidad Nacional Autónoma de México, XV, 69-94.

MOYNA, M. I. 2011. Compound words in Spanish: theory and history. Amsterdam: John Benjamins.

MUÑOZ GUTIÉRREZ, C. 2006. "Semántica cognitiva: modelos cognitivos y espacios mentales", Revista de Filosofía, 43, 1-28.

NARROG, H. y B. Heine. 2011. The Oxford handbook of grammaticalization, Oxford: Oxford University Press.

NARVÁEZ, R. A. 1970. An outline of Spanish Morphology. Formation of words, inflectional and derivational. St. Paul, Minnesota: EMC Corporation.

NIDA, E. A. 1965 [1944]. Morphorlogy: the descriptive analysis of words, Ann Arbor: Unoversity of Muchigan Press.

NIETO JIMÉNEZ, L. y M. ALVAR EZQUERRA. 2007. Nuevo tesoro lexicográfico del español (s. XIV-1726), Madrid: Arco Libros.

NORD, M. 2001. "Deflexion as a counterdirectional factor in grammatical change", Language Sciences, 23, 2-3, 231-264

NORD, M. 2002. "The final stages of grammaticalization: Affixhood and beyond", I. Wischer y G. Diewald (eds.), New Reflections on Grammaticalization, Amsterdam: John Benjamins, 45-65

NORD, M. 2003. "Dgrammaticalization: Process or result?", Comunicación leída en el $16^{\text {th }}$ International Conference on Historical Linguistics, Copenhagen: Universidad de Copenhagen.

NORD, M. 2011. "Degrammticalization", H. Narrog, y B. Heine (eds.), The Oxford handbook of grammaticalization, Oxford: Oxford University Press, 475-487.

OCAMPO, F. 1990. "The pragmatics of Word order in constructions with a verb and a subject", Hispanic Linguistics, 4, 1, 87-129. 
PACKARD, J. L. (ed.). 1998. New Approaches to Chinese Word Formation: Morphology, Phonology and the Lexicon in Modern and Ancient Chinese, Berlin: Mouton de Gruyter.

PAWLEY, A. 1986. "Lexicalization", T. Deborah y J. E. Alatis (eds.), Languages and Linguistics: the interdependence of theory, data and application, Washington D.C: Georgetown University Press, 98-120.

PAZÓ. J., I. GIL y. M. a Á. CANO (eds.). 2011 . Teoría morfológica y morfología del español, Madrid: Servicio de Publicaciones de la Universidad Autónoma de Madrid

PAZÓ. J., I. GIL y. M. a Á. CANO (eds.). 2011. "Diez años de teoría morfológica en España", J. PAZÓ, I. GIL y M. Á. CANO (eds.), Teoría morfológica y morfología del español, Madrid: Servicio de Publicaciones de la Universidad Autónoma de Madrid, 19-58.

PENA SEIJAS, J. 1980. La derivación en español: verbos derivados y sustantivos verbales, Santiago de Compostela: Universidad de Santiago.

PENA SEIJAS, J. 1990. "Sobre los modelos de descripción en morfología", Verba, $17,17,5-75$.

PENA SEIJAS, J. 1991. "La palabra: estructura y procesos morfológicos", Verba, $18,69-128$.

PENA SEIJAS, J. 1993. "La formación de verbos en español: la sufijación verbal", S. Varela Ortega (ed.), La formación de palabras, Madrid: Taurus, 217-281. PENA SEIJAS, J. 1995. "Sobre la definición de morfema", Lingüística Española Actual, XVII, 2, 129-141.

PENA SEIJAS, J. 1999. "Partes de la morfología. Las unidades del análisis morfológico", I. Bosque y V. Demonte (dirs.), Gramática descriptiva de la lengua española, Madrid: Espasa Calpe, 4305-4366.

PENA SEIJAS, J. 2002. Morfología derivativa y diccionario, A. VEIGA, M. GONZÁLEZ PEREIRA y S. G. Montserrat (eds.), Léxico y gramàtica, Lugo: Tris Tram, 285-298. 
PENA SEIJAS, J. 2003. "Los estudios de morfología del español en España durante los últimos 25 años (1979-2003)", Lingüística Española Actual, XXV, 1 y $2,7-38$.

PENA SEIJAS, J. 2012. "El elemento cero como recurso morfológico en el modelo Item and arrangement", J. L. MENDÍVIL GIRÓ y M. del C. HORNO CHÉLIZ (eds.), La sabiduría de mnemósine. Ensayos de historia de la lingüística ofrecidos a José Francisco Val Álver, Zaragoza: Prensas Universitarias de Zaragoza, 145-156.

PENADÉS, I. et al. 1999. Lingüística contrastiva y análisis de errores: (Español-Portugués y Español-Chino), Madrid: Editorial Edinumen.

PENSADO, C. 1999. "Morfología y fonología. Fenómenos morfológicos", I. Bosque y $\vee$. Demonte (dirs.), Gramática descriptiva de la lengua española, Madrid: Espasa Calpe, 4423-4504.

PÉREZ CINO, W. 2002. Manual práctico de formación de palabras en español, Vol. I, Madrid: Verbum.

PÉREZ LAGOS, M. F. 1985. "Un nuevo «elemento compositivo» en el DRAE: radio-", Español Actual, 14, 87-94.

PÉREZ LAGOS, M. F. 1986. "Composición de verbo más nombre en el DRAE", Lingüística Española Actual, VIII, 21-57.

PÉREZ LAGOS, M. F. 1996a. Formación de palabras. La composición culta en los diccionarios (DRAE-VOX), Tesis doctoral, Universidad de Málaga.

PÉREZ LAGOS, M. F. 1996b. "Euro-: un nuevo elemento compositivo", Español Actual, 65, 74-75.

PÉREZ LAGOS, M. F. 1997. “¿Entre composición y afijación? Naturaleza de los elementos de formación culta", J. A. Molina Redondo y J. de D. Luque Durán (eds.), Estudios de Lingüística General (Conferencias de II Congreso Nacional), vol. III, Granada: Universidad de Granada, 361-369.

PÉREZ LAGOS, M. F. 2001. "Nuevos elementos compositivos en el Diccionario de la Real Academia", Analecta Malacitana, XXIV, 2, 439-447. 
PÉREZ SALDANYA, M. 1997. "Entre el lèxic i la gramàtic: els procesos de gramaticalització", Cabré, M. ${ }^{a}$ T. (ed.), Cicle de conferències 95-96: Lèxic, corpus i diccionaris, Barcelona: IULA, 91-111.

PÉREZ VIGARAY, J. M. 1994. La composición nominal en español, Tesis doctoral, Universidad de Las Palmas.

PHARIES, D. A. 2002. Diccionario etimológico de los sufijos españoles y de otros elementos finales, Madrid: Gredos.

PHARIES, D. 2002b. "Historia de los sufijos españoles -ajo, -ejo, -ijo y -ujo", J. García-Medall (ed.), Aspectos de morfología derivativa del español, Lugo: Tris Tram, 95-101.

PIERA, C. y S. VARELA ORTEGA. 1999. "Relaciones entre morfología y sintaxis", I. Bosque y $\vee$. Demonte (dirs.), Gramática descriptiva de la lengua española, Madrid: Espasa Calpe, 4367-4422.

PILLEUX, M. 1983. Formación de palabras en español, Valdivia: Alborada.

PÖCKL, W. 2007. "Le confixe: élément rebelle à vocation internationale", Maria lliescu, Heide Siller-Runggaldier y Paul Danler (eds.), Actes du XXVe Congrès International de Linguistique et de Philologie Romanes, Innsbruck: De Gruyter, 471-476.

PORTOLÉS LÁZARO, J. 1993. "Sobre los interfijos en español", S. Varela Ortega (ed.), La formación de palabras, Madrid: Taurus, 339-359.

PORTOLÉS LÁZARO, J. 1999. "La interfijación", I. Bosque y V. Demonte (dirs.), Gramática descriptiva de la lengua española, Madrid: Espasa Calpe, 5042-50473.

PRĆIĆ, T. 2005. Prefixes vs initial combining forms in English: A lexicographic perspective, en International Journal of Lexicography 18, 3, 313-334.

PRINCE, E. 1981. "Toward a taxonomy of given-new information", P. Cole (ed.), Radical Pragmatics, New York: Academic Press, 223-225.

PUJOL PAYET, I. 2000. Numerales y morfología léxica: del latín al español, Tesis doctoral digitalizada, Universidad Autónoma de Barcelona. [Disponible en http://www.tdx.es] 
QUILIS, A. 2000. Principios de fonología y fonética, Madrid: Arco Libros.

RAINER, F. 1993. Spanische Wortbildungslehre, Tubinga: Max Niemeyer.

RAINER, F. 1993. "Setenta años (1921-1990) de inverstigación en la formación de palabras del español moderno: bibliografía crítica selectiva", S. Varela Ortega (ed.), La formación de palabras, Madrid: Taurus, 30-70.

RAINER, F. 1999. "La derivación adjetival", I. Bosque y V. Demonte (dirs.), Gramática descriptiva de la lengua española, Madrid: Espasa Calpe, 4595-4643.

RAINER, F. 2004. "Del nombre de agente al nombre de instrumento y de lugar en español: ¿̇cuándo y cómo?", Iberoromania, 59, 97-122.

RAINER, F. 2005. "Semantic change in word formation", Linguistics, 43-2, 415-442.

REAL ACADEMIA ESPAÑOLA. 1984 [1771]. Gramática de la lengua castellana, edición facsímil, Madrid: Editora Nacional.

REAL ACADEMIA ESPAÑOLA. 1991. Esbozo de una nueva gramática de la lengua española, Madrid: Espasa-Calpe.

REAL ACADEMIA ESPAÑOLA. 1992. Diccionario de la lengua española $\left(21^{a}\right.$ edición), Madrid: Espasa Calpe.

REAL ACADEMIA ESPAÑOLA. 2001. Nuevo Tesoro Lexicográfico de la Lengua Española (ed. en DVD), Madrid: Espasa Calpe.

REAL ACADEMIA ESPAÑOLA. 2006. Diccionario esencial del español, Madrid: Espasa Calpe.

REAL ACADEMIA ESPAÑOLA. 2007. Diccionario de la lengua española $\left(22^{\mathrm{a}}\right.$ edición), Madrid: Espasa Calpe.

REAL ACADEMIA ESPAÑOLA. 2010. Nueva gramática de la lengua española, Madrid: Espasa-Libros.

REAL ACADEMIA ESPAÑOLA. 2011. Nueva gramática de la lengua española: fonética y fonología, Madrid: Espasa-Libros.

REBOLLO TORÍO, M. A. 1997. "Precisiones sobre los llamados temas", Anuario de Estudios Filológicos XX, 357-366. 
REYES, G. 1985. "Orden de palabras y valor informativo en español", Philologica Hispaniensia: in honoren Manuel Alvar, vol. 2, Lingüística, Madrid: Gredos, 567-588.

RIBEIRO, S. 2006. Com ostos Nominais en Português: As Estruturas VN, NN, NperpN e NA, Dissertação de Mestrado em Linguística Portuguesa, Coimbra: Faculdade de Letras da Universidade de Coimbra.

RIBEIRO, S. y G. RIO-TORTO. 2007. "Denominações compositivas de estructura VN, NN, NprepN e NA: nexos intralexicais", M. lliescu, H. Siller-Runggaldier y P. Danler (eds.), Actes de XXVe Congrès International de Linguistique et de Philologie Romanes, Innsbruck: De Gruyter, 477-485.

RICHARDS, J. C. et al. 1998. Longman Dictionary of Language Teaching and Applied Linguistics, Hong Kong: Addison Wesley Longman China Ltd.

RIDRUEJO, E. 1989. Las estructuras gramaticales desde el punto de vista histórico, Madrid: Síntesis.

RIDRUEJO, E. 2002. "El sufijo -dumbre en español medieval", C. Saralegui Platero, y M. Casado Velarde (eds.), Pulchre, bene, recte: Homenaje al prof. Fernando González Ollé, Navarra: EUNSA, 1161-1175.

RIO-TORTO, G. 2006. "O Léxico: semântica e gramática das unidades lexicais", M. F. Athayde, (ed.), Estudios sobre léxico e gramática. Cadernos do Cieg 23, Coimbra: FLUC. Centro Interuniversitário de Estudos Germanísticos $11-34$.

RODRÍGUEZ SEGURA, D. 1999. Panorama del anglicismo en espanol, Almeria: Universidad de Almería.

RODRÍGUEZ GONZÁLEZ, F. 1982. "Variaciones fonotácticas en siglas: condicionamientos lingüísticos y sociolingüísticos", Revista Española de Lingüística, 12, 2, 357-374.

RODRÍGUEZ GONZÁLEZ, F. 1984. "El género de las siglas", Revista Española de Lingüística, 14, 2, 311-366.

RODRÍGUEZ GONZÁLEZ, F. 1987. "Naturaleza sintáctica de la sformas siglares. El cambio funcional", Estudios de Lingüística, 4, 139-148. 
ROSENBLAT, Á. 1953. "El género de los compuestos", Nueva Revista de Filología Hispánica, 7, 95-112.

RUIZ GURILLO, L. 2001. Las locuciones en español actual, Madrid: Arco-Libros.

RUIZ GURILLO, L. 2002. "Compuestos, colocaciones, locuciones: intento de delimitación", A. Veiga. et alii (eds.), Léxico y gramática, Lugo: Tris Tram, 327-339.

ROSCH, E. et al. 1976. "Basic objects in natural categories", Cognitive Psychology, 8, 382-493.

ROSCH, E. y B. B. LIOYD (eds.). 1978. Cognition and Categorization, Hillsdale (N. J.): Erlbaum.

ROSTILA, J. 2004. "Lexicalization as a Way to Grammaticalization", F. Karlsson (ed.), Proceedings of the 20th Scandinavian Conference of Linguistics, Helsinki: University of Helsinki, Department of General Linguistics, January 7-9, Publications N. 36.

RYDER, M. E. 2000. "Complex -er nominals: Where Grmmaticalization and Lexicalization Meet?", E. Contini-Morava y Y. Tobin (eds.), Between grammar and lexicon, Amsterdam: John Benjamins, 291-331.

SALA CAJA, L. 1995-1996. "Verbos parasintéticos formados con el prefijo e-" Revista de Lexicografía, II, 99-132.

SALVADOR, G. 1989-1990. "Las solidaridades lexemáticas", Revista de Filología, 8-9, 339-365.

SÁNCHEZ HERNÁNDEZ, P. 2004. "Sobre la consideración del sufijoide sustantivo como categoría independiente entre la composición y la derivación", Revista de filología alemana, 12, 165-175.

SÁNCHEZ HERNÁNDEZ, P. 2005. "¿Es la expresión de colectividad un rasgo inherente al fenómeno del sufijoide sustantivo?: análisis contrastivo alemán-español", Estudios filológicos alemanes: revista del Grupo de Investigación Filología Alemana, 9, 31-40.

SÁNCHEZ HERNÁNDEZ, P. 2008. "Estudio comparativo sobre la categoría del sufijoide en alemán y sus equivalencias en español", Germanística y enseñanza del alemán en España, vol. 1, 285-292. 
SÁNCHEZ LANCIS, C. 2006. "La desgramaticalización del partitivo indefinido en español", C. Concepción Company y J. G. Moreno de Alba (eds.), Actas del VII Congreso Internacional de la Lengua Española: Merida (Yucatán), vol. 1, 2008, 1105-1124.

SÁNCHEZ MARCO, C. 2008. "La diversidad metalingüística de la gramaticalización", Actas del VIII Congreso de Lingüística General, Madrid: Universidad de Autónoma de Madrid.

[Disponible en http://www.llf.uam.es/clg8/actas/pdf/paperCLG106.pdf]

SÁNCHEZ LÓPEZ, C. 1999. "Los cuantificadores: clases de cuantificadores y estructuras cuantificativas", I. Bosque y V. Demonte, (dirs.), Gramática descriptiva de la lengua española, Madrid: Espasa Calpe, 1025-1128.

SANDRU-OLTEANU, T. 1972. "Bibliografía de los trabajos relativos a la formación de palabras en los idiomas iberorrománicos (1920-1970)", Boletín de Filología Española, 42-45: 13-35.

SANTIAGO LACUESTA, R. y E. BUSTOS GISBERT. 1999. "La derivación nominal", I. Bosque y $\vee$. Demonte, (eds.), Gramática descriptiva de la lengua española, Madrid: Espasa Calpe, 4505-4594.

SANTANA SUÁREZ, O., F. J. CARRERAS RIUDAVETS y J. R. PÉREZ AGUIAR. 2004. Relaciones morfoléxicas sufijales para el procesamiento del lenguaje natural, Madrid: Mileto.

SANTANA SUÁREZ, O., F. J. CARRERAS RIUDAVETS y J. R. PÉREZ AGUIAR. 2005. Relaciones morfoléxicas prefijales para el procesamiento del lenguaje natural, Madrid: Mileto.

SANTANA SUÁREZ, O., F. J. CARRERAS RIUDAVETS y J. R. PÉREZ AGUIAR. 2006. Relaciones morfoléxicas parasintéticas para el procesamiento del lenguaje natural, Madrid: Mileto.

SANTOS GARGALLOS, I. 1993. Análisis contrastivo, análisis de errores e interlengua en el marco de la lingúistica contrastiva, Madrid: Síntesis. 
SAUSSURE, F. D. 1993[1916]. Curso de linguistica general (publicado por C. Bally y A. Sechehaye con la colaboracion de A. Riedlinger; traduccion, prologo y notas de Amado Alonso), Madrid: Alianza.

SCALISE, S. 1987. Morfología generativa, Madrid: Alianza.

SCHWENTER, S. A. 1994. "The Grammaticalización of an Anterior in Progress: Evidence from a Peninsular Spanish Dialect", Studies in Language, 18, 1, 71-111.

SECO, M. 1972. Gramática esencial del español: introducción al estudio de la lengua, Madrid: Aguilar.

SECO, M. 1987. Estudios de lexicografía española, Madrid: Paraninfo.

SECO, M., O. ANDRÉS y G. RAMOS. 1999. Diccionario del español actual, Madrid: Aguilar.

SECO, M. 1989. Gramática esencial del español. Introducción al estudio de la lengua, $2^{a}$ edición revisada y aumentada, Madrid: Espasa Calpe.

SEIJO CASTROVIEJO, M. a A. 1982. "Algunas observaciones sobre las formaciones compuestas", Anuario de Estudios Filológicos, 5, 201-210.

SERRANO-DOLADER, D. 1995. Las formaciones parasintéticas en español, Madrid: Arco Libros.

SERRANO-DOLADER, D. 1999. "La derivación verbal y la parasíntesis", I. Bosque y V. Demonte (dirs.), Gramática descriptiva de la lengua española, Madrid: Espasa Calpe, 4683-4755.

SERRANO-DOLADER, D. 2009. "La morfología léxica y el españl como lengua extranjera (selección bibliográfica comentada)", D. Serrano-Dolader, M. ${ }^{a}$ A. MARTíN ZORRAQUINO y J. F. VAL ÁLVARO (eds.), Morfología y español como lengua extranjera (E/LE), Zaragoza: Prensas Universitarias de Zaragoza, 177-195

SERRANO-DOLADER, D., M. ${ }^{a}$ A. MARTíN ZORRAQUINO y J. F. VAL ÁLVARO (eds.) 2009. Morfología y español como lengua extranjera (E/LE), Zaragoza: Prensas Universitarias de Zaragoza. 
SERRANO-DOLADER, D. 2012. "Noventa años de descripción de la morfología léxica española: tratados de formación de palabras en español (1920-2010)", J. L. MENDÍVIL GIRÓ y M. del C. HORNO CHÉLIZ (eds.), La sabiduría de mnemósine. Ensayos de historia de la lingüística ofrecidos a José Francisco Val Álvaro, Zaragoza: Prensas Universitarias de Zaragoza, 113-127.

SEZMERENYI, O. 1987. Introducción a la lingưistica comparativa, [versión española de Adelino Álvarez], Madrid: Gredos.

SGROI, S. C. 2003. "Per una ridefinizione di 'confisso': Composti confissati, derivati confissati, parasintetici confissati vs. Etimi ibridi e incongrui", Qsem $24,1,81-153$.

SHAW, P. (ed.). 1991. Morpgology, Santa Cruz: University of California.

SOSA, J. M. 1999. La entonación del español: su estructura fónica, variabilidad y dialectología, Madrid: Cátedra.

STEELE, S. 1978. "Word order variation: a typological survey", H. Joseph (ed.), Universals of human language, vol. 4. Stanford: Standford University Press, 585-623.

SWEETSER, E. 1988. "Grammaticalization and Semantic Bleaching", Berkeley Linguistics Society, 14, 389-405.

SWEETSER, E. 1990. From Etymology to Pragmatics. Metaphorical and Culture Aspects of Semantic Structure, Cambridge: Cambridge University Press.

TALMY, L. 1985. "Lexicalization patterns: Semantic Structure in lexical forms", T. Shopen (ed.), Language Typology and Syntactic Description, III, Cambridge: Cambridge University Press, 57-149.

TAYLOR, J. 1995 [1989]. Linguistic Categorization: Prototypes in Linguistic Theory, Oxford: Oxford University Press.

THIELE, J. 1992. Wortbildung der spanischen Gegenwartssprache, Leipzig: Langenscheidt.

TORNEL SALA, J. L. 2000. "Gramaticalización y cognición: pautas definitorias e interrelación", Letras de Deusto, 30, 88, 111 1-140. 
TORRES MARTíNEZ, M. 2008. "Tratamiento de los elementos compositivos en la lexicografía académica y extraacadémica del siglo XX", D. Azorín Fernández (dir.), El diccionario como puente entre las lenguas y culturas de mundo, Actas del Il Congreso Internacional de Lexicografía Hispánica, Alicante: Universidad de Alicante, 393-401.

TRAUGOTT, E. C. 1982. "From propositional to textual and expressive meaning; Some semantic-Pragmatic Aspects og Hrammaticalization", W. P. Lehmann y Y. Malkiel, (eds.), Perspectives on Historical Linguistics. Adsterdam: John Benjamins, 245-271.

TRAUGOTT, E. C. 1990. "From Less to More Situated in Language: The Unidirectionality of Semantic Change", S. Admson; V. Law; N. Vincent y S. Wright (eds.), Pepers from the 5th International Conference on English Historical Linguistics, Amsterdam: John Benjamins, 497-517.

TRAUGOTT, E. C. 1994. "Gramaticalización and lexicaliztion", Enciclopedia of Language and Linguistics, Oxford/New York/Seoul/Tokyo: Pergamon Press, 1481-1486.

TRAUGOTT, E. C. 1995a. "Subjectivification in grammaticalization", D. Stein y S. Wright (eds.), Subjectivity and subjectivisation. Linguistic perspectives, Cambridge: Cambridge University Press, 31-54.

TRAUGOTT, E. C. 1995b. "The role of the development of discourse markers in a theory of grammaticalization", Comunicación presentada en el $12^{\text {th }}$ International Conference on Historical Linguistics, Manchester.

[Disponible en www.stanford.edu/ traugott/papers/discourse]

TRAUGOTT, E. C. 2001. "Legitimate counterexamples to unidirectionality" Comunicción presented en Freiburg University, October 17. [Disponible en http://www.stanford.edu/ traugott/papers/Freiburg.Unidirect.pdf]

TRAUGOTT, E. C. 2002 [1994]. "Lexicalization and Grammaticalization", Encyclopedia of Language and Linguistics, Oxford/New York/Seoul/Tokyo: Pergamon Press, 1481-1486. 
TRAUGOTT, E. C. 2003. "Constructions in Grammaticalization", B. D. Joseph y R. D. Janda (eds.), Handbook of Historical Linguistics, Blackwell: Londres, 624-647.

TRAUGOTT, E. C. 2011. "Grammaticalization and mechanisms of change", H. Narrog y B. Heine (eds.), The Oxford handbook of grammaticalization, Oxford: Oxford University Press, 19-30.

TRAUGOTT, E. C. y B. HEINE (eds.). 1991a. Approaches to Grammaticalization, 2 vols, Amsterdam: John Benjamins.

TRAUGOTT, E. C. y B. HEINE. 1991b. "Introduction", E. C. Traugott y B. Heine (eds.), Approaches to Grammaticalization, vol. I, Amsterdam: John Benjamins, $1-14$.

TRAUGOTT, E. C. Y E. KÖNIG. 1991. "Semantics - pragmatics of grammaticalization revisited", E. C. Traugott y B. Heine (eds.) Approaches to Grammaticalization, I, Amsterdam: John Benjamins, 189-218.

TUTIN, A. y F. GROSSMANN. 2002. "Collocations régulières et irrégulières: esquisse de typologie du phénomène collocatif", Revue Français de Linguistique Appliquée 7-1, 7-25.

ULLOA, A. 2006. "Aplicación del componente morfológico a la enseñanza del léxico", I Encuentro de innovación en el aula E/LE, Universidad de Valladolid: Facultad de Filosofía y Letras, 3-5 de junio de 2006.

ULLOA, A. 2007. "Concurrencia histórica de los derivados agentivos en -dor y -nte", M. Iliescu, H. Siller-Runggaldier y P. Danler (eds.), Actes de XXVe Congrès International de Linguistique et de Philologie Romanes, Innsbruck: De Gruyter, 536-545.

ULRICH, M. 1985. Thetisch ubd kategorisch, Tübingen: Romanica Monacensia 24.

UNGERER, F. y H.-J. Schmid. 1996. An introduction to Cognitive Linguistics, Londres: Longman.

VAL ÁlVARO, J. F. 1999. "La composición", I. Bosque y V. Demonte (dirs.), Gramática descriptiva de la lengua española, Madrid: Espasa Calpe, 4757-4841. 
VARELA. F. y H. KUBARTH. 1994. Diccionario fraseológico del español moderno, Madrid: Gredos.

VARELA ORTEGA, S. 1990a. Fundamentos de morfología, Madrid: Síntesis.

VARELA ORTEGA, S. 1990b. "Composición nominal y estructura temática", Revista Española de Lingüística, 10, 1, 55-81.

VARELA ORTEGA， S. 1990c. "Condicionamientos sintácticos en procesos morfológicos de afijación y composición", V. Demonte y B. García Cuarón, (eds.), Estudios lingüísticos de España y México, México: UNAM Y Colegio de México, 95-114.

VARELA ORTEGA, S. (ed.) 1993. La formación de palabras, Madrid: Taurus.

VARELA ORTEGA, S. 1999. "Sobre las relaciones de la morfología con la sintaxis", Revista Española de Lingüística, 29, 257-282.

VARELA ORTEGA, S. 2000. "25 años de morfología española: la formación de palabras", M. Bargalló y C. Garriga, (eds.), 25 años de investigación en lengua española, Tarragona: Universitat Rovira i Virgili, 81-110.

VARELA ORTEGA, S. 2005a. Morfología léxica: La formación de palabras, Madrid: Gredos.

VARELA ORTEGA, S. 2005b. "Lexicalización y cambio categorial", Luis Santos Río (coord.), Palabras, norma, discurso: en memoria de Fernando Lázaro Carreter, Salamanca: Universidad de Salamanca, 1133-1146.

VARELA ORTEGA, S. y J. MARTíN GRACÍA. 1999. "La prefijación", I. Bosque y V. Demonte (dirs.), Gramática descriptiva de la lengua española, Madrid: Espasa Calpe, 4993-5040.

VEIGA, A. 2002. El subsistema vocálico español, Santiago de Compostela: Universidad de Santiago de Compostela.

VEIGA, A. 2002. Estudios de fonología funcional, Noia: Toxosoutos.

WELTE, W. 1985. Lingüística moderna: terminología y bibliografía (versión española de Francisco Merro Blanco), Madrid: Editorial Gredos, S.A. 
WISCHER, I. 2000. "Grammaticalization versus lexicalization: 'methinks' there is some confusion.", O. Fischer, A. Rosenbach y D. Stein (eds.), Pathways of change: gramamticalizationin English, Ámsterdam: John Benjamins, 355-370.

WISCHER, I. 2011 1. "Grammticalization and word formation", H. Narrog, y B. Heine (eds.), The Oxford handbook of grammaticalization, Oxford: Oxford University Press, 356-364.

WISCHER, I. y G. DIEWALD (eds.). 2002. New Reflections on Grammaticalization, Amssterdam: John Benjamins.

ZACARÍAS PONCE DE LEÓN, R. F. 2009. "Posesión inalienable en los compuestos N+i+A del tipo pelirrojo", Lingüística, 21, 31-49.

ZUBIZARRETA, M. a L. 1999. "Las funciones informativas: tema y foco", I. Bosque y V. Demonte (dirs.), Gramática descriptiva de la lengua española, Madrid: Espasa Calpe, 4215-4244.

ZULOAGA, A. 1975. "La fijación fraseológica", Thesaurus, XXX, 225-248.

ZULOAGA, A. 1980. Introducción al estudio de las expresiones fijas, Frankfurt: Peter Lang.

ZULOAGA, A. 2002. "Los 'enlaces frecuentes' de María Molinar. Obsevaciones sobre las llamadas colocaciones", Philologie im Netz, 22, 65-74. [Disponible en http://web.fu-berlin.de/phin/phin22/p22ł3.htm (enero 2003)]

\subsection{Estudios de lingüística descriptiva y contrastiva del chino}

Al, R.-X. 2006. Elliptical Predicate Constructions in Mandarin, Tesis doctoral, Harvard University.

BIEN，C.-L. (市成林) 2000. Hàn yǔ gōng chén cí luàn 漢語工程詞論 [Teoría del mecanismo morfológico de la lengua china], Shandong: Shandong da xue. 
CAI, J.-G. (蔡基剛) 2005. “Ying hàn cí huà duì bǐ yǔ zòng hé biăo dá fă 英漢詞化對 比與綜合表達法 [Estudio contrastivo de lexicalización y expresión sintética del chino e inglés]", Shān dōng wài yǔ jiāo xué 山東外語教學 [Enseñanza de lengua extranjera de Universidad Shan Dong], 5, 35-40.

CAO, B.-P. (曹保平) 2004. "Hàn yǔ lèi cí zhuì yán jiù shù píng 漢語類詞綴研究述評 [Comentario del estudio de los pseudosufijos en la lengua china]", Qu Jing Shi Fan Xue Yuan Xue Bao 曲靖師範學院學報 [Revista de Universidad Normal de Qu Jing], 1, 69-72.

CHAl, J.-S. (蔡佳珊) 2004. Indagaciones lexicográficas de las voces inglesas novedosas de los Diccionarios de la Real Academia Española, Tesis de Máster, Universidad Católica Fu-Jen.

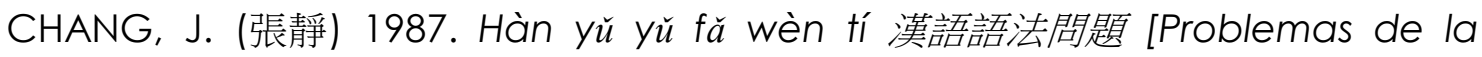
gramática china], Beijing: Zhong Guo She Hui Ke Xue.

CHANG，J. (張靜) 1994. Hàn yǔ yǔ fă yí náng tàn jiě 漢語語法疑難探解 [Explotación a los problemas de la gramática china], Taipei: Wen Shi Zhe.

CHANG, J.- H. (張嘉潇) 1994. Xiàn dài hàn yǔ hòu zhuì jí qí gòu cí wèn tí zhī yán jiù 現代漢語後経及其構詞問題之研究 [Estudio de los sufijos del chino moderno y sus problemas morfológicos], Tesis de Máster, National Chung Cheng University.

CHANG, J.-J. (張致靜) 2004. Estudio comparativo de los tiempos pasados en español, inglés y chino, Tesis de Master, Universidad Católica Fu-Jen.

CHANG, S.- K. (張壽康) 1981. Gòu cí fă hàn gòu xíng fă 構詞法和構形法 [Morfología léxica y morfología flexiva], Wuhan: Hu Bei Ren Ming.

CHANG, X.-P. (張小平) 2003. “Dāng dài hàn yǔ lèi cí zhuì biàn XĪ 當代漢語類詞緅辨 析 [Análisis de los pseudosufijos del chino actual]", Ning Xia Da Xue Xue Bao 寧夏大學學報 [Revista de Universidad Ning Xia], 5, 22-25.

CHANG, Y.-S. (張誼生) 2000. "Lùn yǔ hàn yǔ fù cí xiāng guān de xū huà jī zhì - jiān lùn xiàn dài hàn yǔ fù cí de xìng zhí, fēn lèi yǔ fàn wéi 論與漢語副詞相關的虛 化機制 - 兼論現代漢語副詞的性質、分類與範圍 [El mecanismo de reducción semántica relacionado con los adverbios de chino mandarín - también un tratamiento de los adverbios de chino moderno acerca de sus 
propiedades, su clasificación y su delimitación]", Zhong Guo Yu Wen 中國 語文 [Lengua y gramática chinas], 1, 3-15.

CHANG, Z.-G. (張志公) 1999. Hàn y̌̌ yǔ fă cháng shì 漢語語法常識 [Conocimiento común de la gramática china], Hong Kong: San Lian.

CHAO, J.-M. (趙金銘) 1997. Xin shì jiăo hàn yǔ yŭ fă yán jiù 新視角漢語語法研究 [Nueva perspectiva sobre el estudio de la gramática china], Beijing: Yu Yan Wen Hua.

CHAO, S.-Y. (趙士鈺) 1998. Hàn yǔ Xī bān yá yǔ shuāng yǔ bǔ jiào 漢語西班牙語雙 語比較 [Estudio comparativo del chino mandarín y el español], Beijing: Wai Yu Jiao Xue Yu Yan Jiu.

CHAO, Y.-R. (趙元任) 1968. A Grammar of Spoken Chinese, Los Angeles: Universidad de California.

CHAO，Y.-R. (趙元任) 1994 [1980]. Zhōng guó huà de wén fă 中國話的文法 [Gramática del chino], Taipei: Taiwán Xue.

CHEN, G.- L. (陳光否) 2001. Hàn yǔ cí fă lùn 漢語詞法論 [Proceso morfológico de lengua china], Shanghai: Xue Lin.

CHEN, J. J. 2003. Método de chino: nivel elemental (trad. C. Marco Martínez), Paris: Ediciones You-Feng.

CHEN, L 2005. The acquisition and use of motion event expressions in Chinese, tesis doctoral, University of Georgia.

CHEN, P. (陳平) 1987. "Jiě shì hàn yǔ zhōng yǔ míng cí xìng chén fèn xiāng guān de sì zŭ gài niàn 解釋漢語中與名詞性成分相關的四組概念 [cuatro conceptos relacionados con los componentes sustantivos en chino mandarín]", Zhong Guo Yu Wen 中國語文 [Lengua y gramática chinas], 2, 81-92.

CHEN, Y.-L. (陳雅伶) 2005. El estudio comparativo del pronombre personal en español y chino, Tesis de Master, Universidad Providence.

CHENG, X.-H. (程祥徽) 1992. Xiàn dài hàn yǔ 現代漢語 [El chino moderno], Taipei: Shu Lin.

CHI, T.-R. 1984. A lexical analysis of verb-noun compounds in Mandarin Chinese, Tesis doctoral, UCLA. 
CHOU, G.-G. (周國光) (ed.) 2004. Xiàn dài hàn yǔ Yǔ fă lǔ lùn yŭ fāng fă 現代漢語語 法理論與方法 [La teoría y el método de la gramática moderno del chino mandarín], Guang Zhou: Guang Dong Gao Deng Jiao Yu.

CHOU, M.-K. (周敏康) 1995. Estudio comparativo del chino y el español, Aspectos lingüísticos y culturales, Tesis doctoral, Universidad Autónoma de Barcelona.

CHU, C.-L. (朱進良) 2006. La comparación de las oraciones compuestas de español y chino, Tesis de Máster, Universidad Católica Fu-Jen.

CHU, C.-Q. (朱成器) (ed.) 2002. Xiàn dài hàn yǔ Yǔfă jiào chéng 現代漢語語法教程 [Enseñanza del curso de chino moderno], Beijing: Dui Wai Jing Ji Mau Yi.

CHU, C.-X. (屈承喜) 1983. Yǔ Yáng xué lùn jí: lǐ lùn, yìng yòng jí hàn yǔ Yŭ fă 語言學 論集：理論、應用及漢語語法 [Linguistics: Theory, Application and Chinese Syntax], Taipei: Crane.

CHU, C.-X. (屈承喜) 1993. Lì shǔ Yǔ fă XUé lǐ lùn yǔ hàn yǔ lì shǐ yǔ fă 歷史語法學理論 與漢語歷史語法 [Historical Syntax-Theory and Application to Chinese], Beijini: Beijin Yu Yan Xue Yan.

CHU, C.-X. (屈承喜) 1999a. Jiăn yì huá yŭ yŭ fă 簡易華語語法 [A Concise Grammar of Mandarin Chinese], Taipei: Wunan.

CHU, C.-X. (屈承喜) 1999b. Hàn yǔ rèn zhī gōng néng yǔ fă 漢語認知功能語法 [A Cognitive-Functional Grammar of Mandarin Chinese], Taipei: Crane.

CHU, D.-X. (朱德熙) 1980. Xiàn dài hàn yǔ yŭ fă yán jiù 現代漢語語法研究 [Estudios de gramática de chino moderno], Beijing: Shang Wu.

CHU, D.-X. (朱德熙) 1982. Yǔ fă jiăng yì 語法講義 [Estudios de gramática], Beijing: Shan Wu.

CHU, Y. (朱彥) 2004. Hàn yũ fù hé cí yì gòu cí fă yán jiù 漢語複合詞義構詞法研究 [Estudio de formaciones semánticas de palabras compuestas de la lengua china], Beijing: Beijing Da Xue.

CHU, Y.-J. (朱亞軍) 2001. "Xiàn dài hàn yǔ cí zhuì de xìng zhí jí qí fēn lèi yán jiù 現 代漢語詞綴的性質及其分類研究 [Estudio de propiedades de los afijos de chino moderno y su clasificación]", Han Yu Xue Xi 漢語學習, 2, 24-28. 
CHUNG, M.-H (鐘明祥) 2006. Estudio comparativo de las oraciones escindidas y pseudos-escindidas en español y chino, Tesis de Máster, Universidad Católica Fu-Jen.

DENG, Y.-S. (鄧英樹) 2002. Xiàn dài hàn yǔ yǔ fă lùn 現代漢語語法論 [Teoría de gramática china comtemporánea], Chengdu: Bashu.

DIAO, Y.-B. ( 宴斌) 1999. Chū qí xiàn dài hàn yǔ yŭ fă yán jiù 初期現代漢語語法研 究 [Estudios de gramática china contemporánea], Taipei: Sociedad limitada de industria cultural de Hongye.

DONG, X.-F. (董秀芳) 2002a. Cí huì huà: hàn yǔ shuāng yīn cí de yăn shēng hàn fā zhăn 詞彙化：漢語雙音詞的衍生和發展 [Lexicalización: la derivación y el desarrollo de las palabars bisilábicas en la lengua china], Chengdu: $\mathrm{Si}$ Chuan Ming Zu.

DONG, X.-F. (董秀芳) 2002b. “Lùn jù fă jié gòu de cí huì huà 論句法結構的詞彙化 [ La lexicalización en las construcciones sintácticas]", Yu Yan Yan Jiu 語言 研究 [Estudio de la lengua], 3, 57-65.

DONG, X.-F. (董秀芳) 2004. Hàn yŭ de cí kù yŭ cí fă 漢語的詞庫與詞法 [Corpus de vocabularios y lexicología de la lengua china], Beijing: Universidad de Beijing.

FANG, X. (方希) 1999. “Yǒu ding yǔ xiòng xīn jié gòu de yǔ xù 有定與向心結構的語序 [el orden de las construcciones endocéntricas y construcciones subordinadas]", Yu Yan Yan Jiu 語文研究 [Estudio de lengua y gramática], $1,1-10$.

FENG, S.-L. (馮勝利) 1996. "Lùn hàn yǔ de yùn lù cí 論漢語的韻律詞 [La palabra prosódica del chino mandarín]", Zhong Guo She Hui Ke Xue 中國語文 [Lengua y gramática chinas], 1, 161-176.

FENG, S.-L. (馮勝利) 1997. Interactions between morphology syntax and prosody in Chinese, Beijing: Universidad de Beijing.

FENG， S.-L. (馮勝利) 1998. “Lùn hàn yǔ de zì rán yīn bù 論漢語的自然音步 [Morfología prosódica del chino mandarín]", Zhong Guo She Hui Ke Xue 中國社會學科 [Ciencia social de China], 1, 40-48. 
FENG, S.-L. (馮勝利) 2000a. "hàn yǔ shuāng yīn huà de lì shǐ lái yuán 漢語雙音化 的歷史來源 [El origen histórico de la bisilabilidad del chino mandarín]", Zhong Guo She Hui Ke Xue 中國社會科學 [Ciencia social de China], 1, 123-138.

FENG，S.-L. (馮勝利) 2000b. Hàn yǔ yùn lù jù fă xué 漢語韻律句法學 [La sintaxis prosódica del chino mandarín], Shanghai: Shan Hai Jiao Yu.

FENG, Z.-Y. (馮志宇) 2003. Aproximación al anglicismo -desde el punto de vista del préstamo lingüístico, Tesis de Máster, Universidad Católica Fu-Jen.

FU, X.-L. y Z.-H. CHEN (eds.) (傅興嶺, 陳章煥) 1999. Cháng yòng gòu cí zì diăn 常 用構詞字典 [El diccionario habitual de formación de palabras], Beijing: Zhong Guo Ren Ming Da Xue.

GAO, H.-J. (高鴻經) 1984. Zhōng guó zì lì 中國字例 [Ejemplos de los caracteres chinos], Taipei: Sanming.

GONG, Q.-X. (壟千襲) 1984. "Dòng jié shì fù hé dòng cí jí qí gòu chéng de dòng cí wèi yǔ jù shì 動結式複合動詞及其構成的動詞謂語句式 [Compuesto resultativo del chino mandarín y su predicado verbal ]", An Hui Shl Da Xue Bao 安徽師大學報 [Revista de la Universidad Normal de An Hui], 3, 95-105.

GUO, F.-J. y Y. QIAO (郭鳳杰 y 喬雲) 2007. "Xiàn dài hàn yŭ zhōng zhuì yán jiū 現 代漢語中緅研究 [Estudio del interfijo del chino moderno]", Nei Meng Gu Gong Ye Da Xue Xue Bao 內蒙古工業大學學報 [Revista de la Universidad de tecnología de Mongolia Interior], 16 (1), 59-63.

GUO, L.-F. (郭良夫) 1999. Cí huì yǔ cí diăn 詞匯與詞典 [Vocabularios y lexicografía], Beijing: Shang Wu.

GUO YU RI BAO (國語日報 Diario del chino mandarín) 1981. Guó yư rì baò wài lái yŭ cí diăn 國語日報外來語詞典 [diccionario de extranjerismo], Taipei: Guo Yu Ri Bao She.

GUO YU RI BAO (國語日報 Diario del chino mandarín) 1986. Guó yŭ rì baò wài láiyŭ cí diăn, Taipei: Guo Yu Ri Bao She. 
HAN, C.-Q. (韓陳其) 2002. “Hàn yǔ cí zhuì xīn lùn 漢語詞綴新論 [Estudio del afijo del chino moderno]", Yang Zhou Da Xue Xue Bao 揚州大學學報 [Revista de la Universidad Yang Zhou] , 4, 42-46.

HE, J. (何杰) 2001. Xiàn dài hàn yŭ liàn cí yán jiù 現代漢語量詞研究 [Estudio de los clasificadores actuales], Beijing: Ren Ming Wen Xue.

HE, Y.-Q. (何永清) 2005. Xiàn dài hàn yŭ yŭ fă Xīng tàn 現代漢語語法新探 [Nueva explotación a la gramática china moderna], Taipei: Taiwán Shang Wu.

HE, Z. (賀重) 1956. Hàn yǔ de cí lèi wèn tí 漢語的詞類閣題 [Cuestiones sobre las categorías gramaticales de chino mandarín], Beijing: Zhong Hua.

HER, O.-S. (何萬順) 1990. Grammatical Functions and Verb Subcategorization in Mandarin Chinese, Taipei: Crane Pub

HER, W.-I, (何萬儀) 2002. La formación de palabras en chino y en español, Tesis Doctoral, Madrid: Universidad Complutense.

HSIEH, C.-Y. y J.-F. HSU (謝菁玉 y 許瑞峰) 2003. “Hàn yǔ yǔ liào kù lǐ de 'zú': zǒU zài shū huà lù shàng de lèi cí sui 漢語語料庫裡的「族」: 走在虛化路上的類詞綴 [Corpus-Based Study of '-Zu': Its Grammaticalization as a Quasi-affix]", Tsing Hua Xue Bao 清華學報 [Revista de estudios chinos de Tsing Hua], 331， 131-152.

HU, P.-S. 1991. Comparación sobre expresiones proverbiales de chino y español, Tesis doctoral, Madrid: Universidad Complutense.

HU, Y.- S. (胡裕樹) 1992. Xiàn dài hàn y̌̌ 現代漢語 [El chino moderno], Taipei: Xin Wen Feng.

HU, Z.-L. (胡壯麟) 2003. “Yǔ fă huà yán jiù de ruò gān wèn ti 語法化研究的若干問題 [cuestión sobre el estudio de gramaticalización]", Xan Dai Wai Yu 現代外語 [Lengua extranjera contemporánea],1, 86-91.

HUANG, C.-W. (黃成穩) 2003. Shí yòng xiàn dài hàn yǔ yŭ fă 實用現代漢語語法 [Gramática práctica del chino moderno], Beijing: Zi shi.

HUANG, T.-H. (黃太華) 2006. Hàn yǔ shù cí zhī gòu cí yǔ xiū cí yán jiù 漢語數詞之構 詞與修辭研究 [Estudio de la retórica y la formación de los numerales], Tesis de Master, Hsuan Chuang University. 
HUANG, TOMÁS H. T (黃輝達) 1984. XI bān yá wén zào jù fă 西班牙文造句法 [Sintaxis española], Taipei: Shin Lou Book.

JIANG, J.-D. (江正達) 2004. Hàn yǔ fù hé dòng qū jié goù de cí huì huà xiàn xiàng 漢語複合動趨結構的詞彙化現象 [Predicate Patterns in Mandarin Complex V-D Constructions: with the perspective of lexicalization], National Chengchi University.

JIANG, L.-S. (江監生) 2000. Jìn dài hàn yǔ tàn yuán 近代漢語探源 [Explotación al chino moderno], Beijing: Shang Wu.

JIANG, Z.-X. (蔣宗許) 2009. Hàn yǔ cí zhuì yán jiū 漢語詞綴研究 [Estudio de los afijos del chino mandarín], Sichuan: Ba Shu Shu She.

KU, M.-H. (古孟玄) 2002. Principales correspondencias entre las conjunciones temporales del español y del chino, Tesis de Máster, Universidad Católica Fu-Jen.

KE，P. (柯平) 1999. Duì bǐ y̌̌ yáng xué 對比語言學 [Lingüística contrastiva]， Nanjing: Universidad Normal de Nanking.

LAN, C.-H. (監翠華) 1995. Estudio morfológico de la formación de verbos en español, Tesis de Máster, Universidad Católica Fu-Jen.

LAN, W.-C. (監文君) 2004. El anglicismo en el léxico chino mandarín y en el léxico español: su incidencia en la enseñanza-aprendizaje de español como lengua extranjera, Tesis doctoral, Universidad Complutense.

LI, CHARLES N. y S. A. THOMPSON 2003 [1983]. Mandarin Chinese: A Functional Reference Grammar [trad. X.-F. HUANG, (黃宣範) 2003. Hàn y ǔ yŭ fă 漢語語 法], Taipei: Crane.

LI, C 2007. Mandarin resultive verb compounds: where syntax, semantics, and Pragmatics meet, Tesis doctoral, The City University of New York.

LI, G.-Y. (李高英) 1989. Zhōng wén jí Xī bān yá wén de cí xù bǐ jiào 中文及西班牙文 的詞序比較 [Comparación sobre el orden de palabras entre chino mandarín y español], Tesis de Máster, Universidad Católica Fu-Jen.

LI, Y.-C. y R. L. CHENG et al. 1978. Mandarin Chinese: A Practical Reference Grammar for Students and Teachers, Taipei: Crane Pub. Co. Chinese Materials Center Publications. 
LI, Z.-Y. (李知沅) 2004. Xiàn dài hàn yŭ wài lái cí yán jiù 現代漢語外來詞研究 [Estudio de préstamos en el chino moderno], Taipei: Wen He.

LIAN， J.-F. (連金發) 2000. “Gòu cí xué wèn ti tàn tăo 構詞學問題探討 [Investigación sobre los problemas de morfología]", en Han Xue Yan Jiu 漢 學研究 [Estudio de Sinología], 18, 61-78.

LIN, J.-J. (林娟娟) 1988. Zhōng xī y̌u yīn bř jiào 中西文語音比較 [Estudio comparativo de sistema fonética entre chino mandarín y español], Tesis de Máster, Universidad Católica Fu-Jen.

LIN, J.-J. (林娟娟) 2003. Xī bān yá wén zì de xíng chén 西班牙文字的形成 [la formación de palabras en español], Taipei: Guan Tang Guo Ji.

LIN, W.-J. (林萬菁) 1994. Yŭ fă xiū cílùn jí 語法修辭論集 [Estudio de la gramática y la retórica], Hong Kong: Centro de estudio de lengua china de Wuduotai.

LIN, Y.-C. (林怡君) 2001. La preposición "A" como nexo en los sintagmas preposicionales del español y su correspondencia general en los sintagmas de la oración en chino, Tesis de Máster, Universidad Católica Fu-Jen.

LIN, Z.-J. y Z. YANG (林正軍 y 楊忠) 2007. “Jiàn gòu yīng yǔ fù hé cí de rèn zhī lĩ jù 建構英語複合詞的認知理據 [motivación cognitiva en la construcción compuesta de inglés]", Dong Bei She Da Xue Bao 東北师大學報 [Revista de Universidad Normal Noreste], 2, 226, 124-128.

LIU, C.-H. (劉朝華) 2005. “Xíng míng zǔ hé yǔ xíng de míng zǔ hé 形名組合與形的名 組合 [Dos formas de combinaciones de adjetivo más sustantivo]", Chu Xiong Shi Fan Xue Yuan Xue Bao 楚雄師範學院學報 [Revista de Universidad Normal Xiong Shi], 21, 5, 19-24.

LIU, C.-L. (劉珍綾) 2006. El estudio comparativo de las construcciones pasivas en chino y en español, Tesis de Máster, Universidad Providence.

LIU, C.-L. (劉珍綾) 2008. Morfología contrastiva del español y el chino mandarín: Procesos de formación de los nombres de lugar, Trabajo de investigación inédito. 
LIU，C.-L. (劉珍綾) 2009. "Morfología contrastiva de los nombres locativos en chino mandarín y español", Anuario de Lingüística Hispánica, Vol. XXV, 49-64.

LIU, C.-L. (劉珍綾) 2010. "Formantes morfológicos híbridos en contraste: los pseudosufijos del chino y los sufijoides del español" en IX Congreso Internacional de Lingüística General celebrado en Valladolid del 21 a 23 de junio de 2010.

LIU, D.-W. (劉大為) 1998. "Guān yú dòng bīn dài bīn yǔ xiàn xiàng de yī xiē sī kăo 關於動賓帶賓語現象的一些思考 [Consideración sobre el objeto del compuesto verbo-objeto]", Yu Wen Jian She 語文建設 [Construcción de la lengua], 1 y 3, 22-27 y 28-30.

LIU, J.-Y. (劉吉豐) 2010. Hàn yǔ Xīn cí quán yán jiù 漢語新詞群研究 [Estudio del neologismo chino], Shanghai: Xue Lin Chu Ban She.

LIU, L.-Y. y Y.-F. MA (劉連元, 馬亦凡) (eds.). 1997. Xiàn dài hàn yǔ shēng diào jié gòu 現代漢語聲調結構 [Construcción de los sonidos y tonos del chino moderno], Chengdu: Si Chuan Ci Shu.

LIU, Y. (劉雲) 2003. "Yi gè XĪn de néng chăn de qián zhuì - líng 一個新的能產的前経 -零 [Un nuevo prefijo productivo -cero]", Ci Shu Yan Jiu 辭書研究 [Estudios lexicográficos ], 5, 136-139.

LIU, Y.-H. (劉月華) et al. 1996 [1983]. Shí yòng xiàn dài hàn yǔ yǔ fă 實用現代漢語語 法 [Gramática práctica del chino moderno], Taipei: Shi Da Shu Yuan.

LIU, Z.-B. (劉宗保) 2008. Xíng míng yǔ sù gòu chén fù hé cí de yǔ yì zǔ hé fēn XĪ 形 名語素構成複合詞的語義類組合分析 [Análisis semántico de los constituyentes del compuesto adjetivo-nombre]. Tesis de Máster, Universidad Nan Jing She Fang.

LU, Y. (路雲) 2009. Xiàn dài hàn yǔ shuāng yīn jié xíng míng zǔ hé fù hé cí gòu cí fă yán jiù 現代漢語雙音節形名組合複合詞構詞法研究 [El Estudio del compuesto bisilábico AN en chino moderno], Yu Yan Wen Zi Ying Yong 語言文字應用, 1. $1-144$.

LU, Z.-W. (陸志偉) 1957. Hà yǔ gòu cí fă 漢語構詞法 [Morfología del chino mandarín], Beijini: Ke Xue. 
LU, Z.-W. et al. (陸志偉) 1975. Hàn yǔ de gòu cí fă 漢語的構詞法 [Formación de palabras del chino mandarín], Hong Kong: Zhong Hua Shu Ju.

LU, Y.-S. (盧英順) 2007. Xiàn dài hàn y ǔ yǔ huì xué 現代漢語語匯學 [Estudio de los vocabularios de chino moderno], Shanghai: Fu Dan Da Xue.

LU, J.-S. 1999. "Un estudio contrastivo del sistema morfológico entre chino y español" en Actas del Simposio Internacional de Hispanistas 98 de Beijing, Shanghai: Wai Yu Jiao She Yu Yan Jiuh.

LÜ, R.-H. (呂仁煌) 1991. A study of Mandarin compounding morphology, Tesis de Máster, National Taiwan Normal University.

LÜ，S.-X. (呂叔湘) 1954. “Guān yú hàn yǔ cí lèi de ȳ̄ xiē yuán zé xìng wèn ti 關於漢 語詞類的一些原則性問題 [Algunas cuestiones de principios sobre las categorías gramaticales de la lengua china]", Zhong Guo Yu Wen 中國語 文 [Lengua y gramática chinas], 9, 131-173.

LÜ，S.-X. (呂叔湘) 1963. "Xiàn dài hàn yŭ shuāng yīn jié wèn ti chū tàn 現代漢語雙 音節問題初探 [Explotación de la cuestión bisilábica del chino moderno]", Zhong Guo Yu Wen 中國語文 [Lengua y gramática chinas], 1, 347-360.

LÜ，S.-X. (呂叔湘), 1990 [1979]. Hàn y ǔ yǔ fă fēn XĪ wèn tí 漢語語法分析問題 [Análisis gramatical del chino mandarín], Beijing: Shan Wu.

LÜ, S.-X. (呂叔湘) 1992a [1942]. Lü shú xiāng wén jí: zhōng guó wén fă yào lüè 号 叔湘文集: 中國文法要略 [Acta de Lü, Shu-Xiang: plan de la gramática china], Taipei: Wen Shi Zhe.

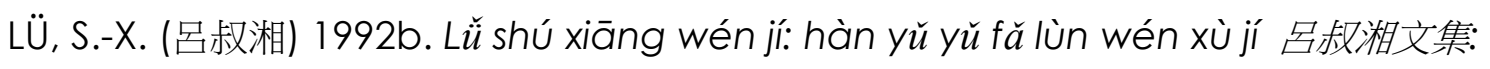
漢語語法論文續集 [Acta de Lü, Shu-Xiang: estudios sobre gramática china]， Beijing: Shan Wu.

LÜ, S.-X. (呂叔湘) 1995. Lü shú xiāng wén ji: hàn yǔ yǔ fă lùn wén jí 吕叔湘文集: 漢語 語法論文 [Acta de Lü, Shu-Xiang: estudios sobre gramática china], Beijing: Shan Wu.

LÜ, W.-H. (呂文華) 1994. Duì wài Hàn y̌̌ jiào xué yŭ fă tàn sUǒ 對外漢語教學語法探 索 [Explotación de la enseñanza de gramática china a alumnos extranjeros], Beijing: Yuwen. 
LUO, X.-R. (羅盺如) 1998. "Dòng bīn shì dòng cí + bīn yǔ guī lü tàn jiù 動賓式動詞 + 賓語規律探究 [Exploración de la regla de la composición verbal verbo más objeto]", Yu Wen Jian She 語文建設 [Construcción de la lengua], 5, 27-30.

LUO, X.-T. (駱小所) 1999. Xiàn dài hàn yǔ Yǐn lùn 現代漢語引/論 [Introducción de la gramática del chino moderno], Kuenming: Yun Nan Ren Ming.

MA, Q.-Z. (馬慶株) 1988. "Zì zhǔ dòng cí hé fēi zì zhǔ dòng cí 自主動詞和非自主動詞 [Verbo automático y no automático]", Zhong Guo Yu Yan Xue Bao 中國語 言學報 [Anuario de la lengua china], 3, 13-46.

MA, Q.-Z. (馬慶株) 1995. "Xiàn dài hàn yǔcí zhuì de xìng zhí fàn wéi hàn fēn lèi 現 代漢語詞経的性質,範圍和分類 [Las propiedades, la delimitación y la clasificación y de los sufijoides del mandarín moderno]", Zhōng guó yŭ yáng xué baò 中國語言學報 [Anuario de la lengua china], 6, 101-137.

MARCO MARTíNEZ, C. 1987. Estructura oracional del chino mandarín, Madrid: Asociación Española de Orientalistas

MARCO MARTíNEZ, C. 1988. La categoría de aspecto verbal y su manifestación en la lengua china, Madrid: Editorial de la Universidad Complutense.

MARCO MARTíNEZ, C. 1999. Esquemas de chino, Madrid: Palas Atenea.

MARCO MARTíNEZ, C. y W.-T. LEE (馬康淑、黎萬棠) 1991. Forma no marcada O signo cero en chino mandarín, Madrid: Asociación Española de Orientalistas.

MARCO MARTíNEZ, C. y W.-T. LEE (馬康淑、黎萬棠) 1992. Estructura morfológica de las palabras en chino mandarín, Madrid: Asociación Española de Orientalistas.

MARCO MARTÍNEZ, C. y W.-T. LEE (馬康淑、黎萬棠) 1998. Gramática de la lengua china,Taipei: Editorial Nacional de Taiwán.

MATEOS, F. et al. 2000. Diccionario español de la lengua china, Madrid: Espasa-calpe.

MEl, Z.-L. (梅祖麟) 1989. "Cóng hàn yǔ de 'dòng shā' hé 'dòng sǐ' lái kàn dòng bǔ jié gòu de fā zhăn 從漢語的 '動殺' 和 ‘動死' 來看動補結構的發展 [Desde 'mover, matado' y 'mover, muerto' del chino para ver el desarrollo del compuesto verbo-complemento]", Yu Yan Xue Lun Cong 語言學論叢 [Estudios de Lingüística], 16, 112-136. 
PAN, W.-G. et al. (潘文國) 1993. Hàn y ǔ de gòu cí fă yán jiù 漢語的構詞法研究 [Estudio sobre formación de palabras en la lengua china], Taipei: Tai Wan Xue Seng Shu Ju.

QI, F.-D. (礽峰定) 2003. Dìng zhòng shì A dān + N zhōng xíng míng zǔ hé de xuăn zé xing yán jiū 定中式 $A$ 單+N 中形名組合的選擇性研究 [Mecanismo de selectividad de la combinación bisilábica AN], Tesis de Máster, Shanghai Normal University.

QIEN, N.- R. (錢乃榮) (ed.) 2002. Xiàn dài hàn yǔ gài lùn 現代漢語概論 [Esbozo del chino moderno], Taipei: Shi Da Shu Yuan.

QIEN, Y.-L. (錢玉蓮) 2006. Xiàn dài hàn yǔ cí hui jiăng yì 現代漢語詞匯講義 [Estudio sobre vocabularios de chino moderno], Beijing: Beijing Da Xue.

REN, Z.-P. (任志萍) 2002. "Xiăo yì lèi cí zhuì de pàn bié biāo zhǔn 小議類詞綴的判別 標準 [Acercamiento sobre el criterio para calificar los pseudosufijos]", en Xing Jiang Shi Yiu Jiao Yu Xue Yuan Xue Bao 新疆石油教育學院學報 [Revista del Instituto de Educación Xinjiang] , 2, 48-50.

SHEN，J.-X. (沈家煊) 1994. "Yǔ fă huà yán jiù zòn guān 語法化研究綜觀 [Una investigación de estudios en gramaticalización]", Wai Yu Jiao Xue Yu Yan Jiu 外語教學與研究 [Estudio y enseñanza de la lengua extranjera] , 4, 17-26.

SHEN, M.-Y. (沈孟珼), 1986. "Hàn yǔ Xīn de cí zhuì huà qĩng xiàng 漢語新的詞緅化 傾像 [Formación de nuevos afijos en chino mandarín]", Nan Jing Shi Da Xue Bao 南京所大學報，4,93-98.

SHEN, M.-Y. (沈孟瓔) 1996. "Zài tán hàn yǔ xīn de cí zhuì huà qĩng xiàng 再談漢語 新的詞経化傾向 [Más allá las nuevas tendencias afijales de la lengua china]", Cí huì xué xīn yán jiù -shǒu jiè quán guó xiàn dài hàn yǔ cí huì xué shù tăo lùn huì xuăn ji 詞彙學新研究 - 首屆全國現代漢語詞彙學術討論會選集 estudio nuevo de lexicología - el primer simposio nacional de lexicología de chino moderno, 195-205.

SHI, Y.- Z. (石毓智) 2002. "Hàn yŭ fā zhăn shǐ shàng de shuāng yīn huà qū shì hàn dòng bǔ jié gòu de dàn shēng - yǔ yīng biàn huà duì yŭ fă fā zhăng de yǐng xiăn 漢語發展史上的雙音化趨勢和動補結構的誕生 - 語音變化對語法發展的影響 
[La tendencia polisilábica y el nacimiento de construcción verbo-complemento en el desarrollo de la lengua china - la influencia de los cambios fonéticos al desarrollo de la gramática]" en Yu Yan Yan Jiu 語 言研究 [Estudio de la lengua], 1, 1-14.

SHI, Y.-Z. (石毓智) 2003. Xiàn dài hàn yǔ yǔ fă xì tǒng de jiàn lì 現代漢語語法系統的 建立 [El establecimiento del sistema sintáctica del chino moderno], Beijing: Beijing Tu Yan Da Xue.

SHI, Y.-W. (史有為) 2000. Hàn yǔ wài lái cí 漢語外來詞 [Las palabras del extranjerismos en la lengua china], Beijing: Shan Wu.

SHI, Y.-W. (史有為) 2004. Wài lái cí: yì wén huà de shǐ zhě 外夾詞. 異文化的使者 [Palabra del extranjerismo: el enviado de cultura extranjera], Shanghai: Shanghai Ci Shu.

SU, K.-R. (蘇寬仁) 1989. Xi wén yǔ zhōng wén xíng róng zhī de bǐ jiào 西文與中文形 容詞之比較 [Comparación de los adjetivos entre chino mandarín y espñaol], Tesis de Máster, Universidad Católica Fu-Jen.

SUN, Y.-X. (孫銀新) 2003. Xiàn dài hàn yǔ cí sù yán jiū 現代漢語詞素研究 [Estudio de morfemas del chino moderno], Beijini: Zhong Guo Wen Shi Chu Ban She.

SUN, Y.-W. (孫玉文) 2007. Hàn yǔ biàn diào gòu cí yán jiù 漢語變調構詞研究 [Estudio de formación de palabras con cambio tonal en la lengua china], Beijing: Shan Wu.

TANG, T.-C. (湯廷池) 1981. Y̌̌ yáng xué y̌̌ y̌̌ wén jiào xué 語言學與語文教學 [Linguistics and Language Teaching], Taipei: Student Book.

TANG, T.-C. (湯廷池) 1988. Hàn yǔ cí fă jù fă lùn jí 漢語詞法句法論集 [Studies on Chinese Morphology and Syntax: 1], Taipei: Student Book.

TANG, T.-C. (湯廷池) 1989. Hàn yǔ cí fă jù fă xù jí 漢語詞法句法續集 [Studies on Chinese Morphology and Syntax: 2], Taipei: Student Book.

TANG, T.-C. (湯廷池) 1992a. Hàn yǔ cí fă jù fă sān jí 漢語詞法句法三集 [Studies on Chinese Morphology and Syntax: 3], Taipei: Student Book. 
TANG, T.-C. (湯廷池) 1992b. Hàn yǔ cí fă jù fă sì ji 漢語詞法句法四集 [Studies on Chinese Morphology and Syntax: 4], Taipei: Student Book.

TANG，T.-C. (湯廷池) 1994. Hàn yŭ cí fă jù fă w w̌ jí 漢語詞法句法五集 [Studies on Chinese Morphology and Syntax: 5], Taipei: Student Book.

TANG, T.-C. (湯廷池) 1996a. Guó yǔ yǔ fă yán jiù lùn jí 國語語法研究論集 [Studies in Chinese Syntax], Taipei: Student Book.

TU, T-M (杜東璊) 1993. Semántica contrastiva de los campos léxicos en español y en chino, Tesis doctoral inédita, Universidad Complutense.

WANG, D.-Z. (王德貞) 1994. Mandarin lexical phonology: [r] suffixation and particle [a] suffixation, Tesis de Máster, National Kaohsiung Normal University.

WANG, H. J (王洪君). 2005. "Lùn xiàn dài hàn yǔ de lèi cí zhuì 論現代漢語的類詞緅 [Los sufijoides en el mandarín moderno]", en hàn yǔ yáng wén zì xué 漢語 言文字學 [Estudio de la lengua y la grafía del chino mandarín], 5, 3-17.

WANG, H.-Y. (王鶴巘) 1994. Comparación de las oraciones compuestas en español y en chino, Tesis de Máster, Universidad Católica Fu-Jen.

WANG, H.-Y. (王鶴巘) 2003. La negación en chino y en español, Tesis doctoral, Universidad Complutense.

WANG, J. (王潔) 2008. "Xiàn dài hàn yǔ cí zhuì yán jiū zhōng de jĩ gè wèn ti 現代 漢語詞緅研究中的幾個問題 [Algunas preguntas sobre el estudio de afijos del chino moderno]", Hua Dong She Fang Da Xue Wai Guo Yu Xue Yan 華東励 範大學外國語文學院 [Revista de la Universidad Normal de Hua Dong], 8, 115-116.

WANG, J.-H. (王吉輝) 2001. Xiàn dài hàn yǔ luè suō cí yán jiù 現代漢語略縮詞研究 [Estudio de las palabras abreviadas en el chino moderno], Tianjin: Tian Jin Ren Ming.

WANG, L. (王力) 1956. “Guān yú hàn yǔ yǒu wú cí lèi wèn ti 關於漢語有無詞類問題 [Sobre la cuestión de si existen las categorías gramaticales en la lengua china]" en Z. He (賀重) 1956. Hàn yǔ de cí lèi wèn tí 漢語的詞類問題 [Cuestiones sobre las categorías gramaticales de chino mandarín], Beijing: Zhong Hua. 
WANG, L. (王力) 1977. Zhōng guó yǔ fă lŭ lùn 中國語法理論 [Teoría del a gramática china, Tomos I y III, Taipei: Shang Wu.

WANG, L. (王力) 1989. Hàn yǔ yŭ fă shǐ 漢語語法史 [Historia de la gramática china], Beijing: Shang Wu.

WANG, L. (王力) 1996. Hàn yǔ shǐ găo 漢語史稿 [Manuscrito histórico de la lengua Han], Beijing: Editorial Shang Wu.

WANG, L. (王力) 2000a [1947]. Zhōng guó xiàn dài yŭ fă 中國現代語法 [Gramática moderna china], Shanghai: Shang Wu.

WANG, L. (王力) 2000b. Wáng lì yǔ yáng xué lùn wén jí 王力語言學論文集 [Colección de estudios de lingüistica de Wang, L.], Beijing: Shang Wu.

WANG, Y. (王珏) 2001. Xiàn dài hàn yŭ míng cí yán jiù 現代漢語名詞研究 [Estudio de los nombres en el chino moderno], Shang Hai: Universidad Normal de Hua Dong.

WANG, L. (王玲) 2006. "wài lái yǔ sù de cí zhuì huà 外來語素的詞綴化 [La tendencia afijal de los morfemas de extranjerismo]", Chang Chun Da Xue Xue Bao 長春大學學報 [Revista de la Universidad Chang Chun], 17/2， 34-35.

WANG, X.-M. (王雪梅), 2007. "Hàn yǔ lèi cí zhuì duì dāng dà hàn yŭ cí huì xì tǒng de yinng xiăn 漢語類詞経對當代漢語詞匯系統的影響 [La influencia de los sufijoides en el sistema léxico del mandarín moderno]", Chang Chun Da Xue Xue Bao 長春大學學報 [Revista de la Universidad Chang Chun], 17/2, 34-35.

WEI, Y.-C. (魏郁真) 2006. Zũ de yǔ fă huà yǔ cí huì huà yán jiù 子的語法化與詞彙化研 究 [Estudio de la gramaticalización y lexicalización de zi], Tesis de Máster, Universidad Providence.

WEN， S. (文旭) 1998. “Yǔ fă huà jiăn jiè 語法化簡介 [introducción de gramaticalización]", Dang Dai Yu Yan Xue 當代語言學 [Lingüística contemporánea], 3, 47-48.

WU, Q.-Z. (吳啟主) 2003. Xiàn dài hàn yŭ jiào chéng 現代漢語教程 [Curso de la enseñanza del chino moderno], Changsha: Hu Nan Shi Fan. 
WU, W.-S. (吳為善) 2003. "Shuāng yīn huà yŭ fă hàn yùn lù cí de zài fēn xī 雙音化語 法和韻律詞的再分析 [Reanálisis del fenómeno bisilábico y las palabras prosódics]", Han Yu Xue Xi 漢語學習 [Aprendizaje de la lengua china], 2, $8-20$.

WU, X.-L. (吳琇鈴) 1995. Neutral Tone Sandhi in Mandarin Chinese: A Perspective of the Connection Between Phonology and Three Linguistic Components, Syntax, Semantics and Morphology, Tesis de Máster, National Chengchi University.

WU, Y.-X. (吳又熙) 1994. Yìng yòng yǔ yán xué ľ̃ lùn jí qí zài wài yǔ jiāo xué shàng de gōng néng yón jiù 應用語言學理論及其在外語教學上的功能研究 [Teoría de Lingüística Contrastiva y estudio de sus función de aplicación en la enseñanza de lenguas extranjeras], Taipei: Zheng Zhong.

XIANG, L. (向烈) 1993. "Xiàn dài hàn yǔ cí zhuì de jiè dìng 現代漢語詞緅的界定 [La delimitación de los afijos del chino moderno]", Chang Zhou Jiao Yu Xue Yuan Xue Kan 常州教育學院學刊 [Revista de Facultad de Pedagogía de Chang Zhou], 1, 1-10.

XIE, M.-H. (謝妙宏) 1990. Zhōng wén jí xī bān yá wén guò qù shí tài de biăo dá fāng shì 中文及西班牙文過去時態的表達方式 [Expresiones del tiempo pasado entre chino mandarín y español], Tesis de Máster, Universidad Católica Fu-Jen.

XIE, G.-P. (謝國平) 2004. Yǔ yáng xué gài lùn 語言學概論 [Introducción de la lingüística], Taipei: Sanming.

XIN, Z.-Q 2003. Grammaticalization of verbs in mandarin Chinese, tesis doctoral, Western Washington University.

XU, S.-X. (徐世璇), 1999. "Hàn zàng yǔ yán de pài shēng gòu cí fāng shì fēn XĪ 漢 藏語言的派生構詞方式分析 [El análisis de la morfología derivativa de lenguas sibetinotanas]", Ming Zu Yu Wen 民族語文 [Filología étnica]，4, 23-31.

XU, S.-Y. (許世瑛) 1996. Zhōng guó wén fă jiăng huà 中國文法講話 [El habla de la gramática china], Taipei: Taiwán kai ming. 
XU, S.-Y. (徐時儀) 2004. “Cí zǔ cí huì huà yǔ cí diăn shì yì kăo chá 詞組詞匯化與辭典 釋義考察 [La palabra que origina de sintagmas y sus explicaciones en el diccionario]", Hu Zhou Shi Fan Xue Yuan Xue Bao 湖州師範學院學報 [Revista de la Universidad Normal de Hu Zhou], 26 (3), 1-6.

XU, Y.-L. (許余龍) 2001. Duì bǐ Yǔ yáng xué gài lùn 對比語言學概論 [Conceptos de lingüística comparativa], Shanghai: Educación de lenguas extranjeras de Shanghai.

XU, W.-Y. 2007. A study of Chinese color terminology, Tesis doctoral, Australian National Univrsity.

XU, Z.-H. y M.-K. ZHOU 1997. Gramática china, Barcelona: Universidad Autónoma de Barcelona.

XU, Z.-M. y L. CAI (徐志敏 y 蔡亮) 2007. “Hàn yǔ qián zhuì yǔ wài lái yǔ sù de qián zhuì tí qǔ 漢語前綴與外來語素的前綴提取 [Prefijo tradicional y prefijo de origen extranjero del chino mandarín]", Huai Bei Mei Tan She Fan Xue Yan Xue Bao 淮北煤炭启範學院學報 [Revista de la Universidad Normal de Industria del Carbón de Huai Bei] , 28 (6), 133-136.

XU, Z.-Y. (徐芷儀) 1999. A Comparative Study of the Syntactic Systems of

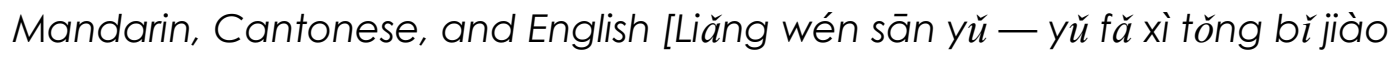
兩文三語 一 語法系統比較, Taipei: Student Book.

YAN, H.-J (顏紅菊) 2008. “Lí Xīn jié gòu fù hé cí de yǔ yì rèn zhī dòng yīn 離心結構複 合詞的語義認知動因 [La motivación cognitiva semántica del compuesto exocéntico]", Shou du shi fan da xue xue bao 首都仰範大學學報 [Revista de la Universidad Normal de Shou Du ], 4, 91-97.

YANG, J. (楊杰) 1999. È hàn xíng tài gòu cí duì bǐ yán jiù 漢俄形態構詞對比研究 [Estudio contrastivo de la morfología y formación de palabras entre chino mandarín y ruso], Ha Er Bin: Hei Long Jian Ren Ming.

YANG, M. M. 2006. Introduction to Chinese dialectology, Munich: Lincom Europa.

YANG, X.- L. (楊錫苓) 2006. Dāng dài yīng yǔ gòu cí tè diăn yǔ dú yīn 當代英語構詞 特點與讀音 [Características morfológicas y pronunciación del inglés en la actualidad], Beijing: Ji Xie Gong Ye. 


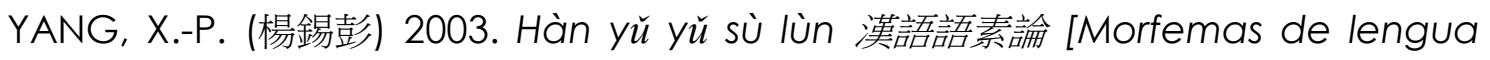
china], Nan Jing: Nan Jing Da Xue

YANG, X.- P. (楊錫彭) 2006. Xiàn dài hàn yǔ yán jiù dăo yĭn 現代漢語研究導引 [Introducción al chino moderno], Nanking: Nan king Da Xue.

YU, J.-C. (余建成) 1999. On Chinese derived nominals: interface between morphology and semantics, Tesis de Máster, Universidad Nacional de Taiwán.

YUAN, C.-F. y C.-N. HUANG (苑春法 y 黄昌寧) 1998. “JT yú yŭ sù shù jù kù de hàn yŭ yŭ sù jí gòu cí yán jiù 基於語素數據庫的漢語語素及構詞研究 [Estudio basado en corpus sobre morfemas y morfología del chino mandarín]" , Shi Jie Han Yu Jiao Xue 世界漢語教學 [Enseñanza del chino en el mundo] 2, 7-12.

ZENG, J.-C. (曾錦程) 2008. "Ying yŭ fù hé cí yǔ yì jí aí jiàn gòu de rèn zhī jiě shì 英語 複合詞語義及其建構的認知解釋 [La semántica y la motivación cognitiva en el compuesto del inglés]", Culture and History Vision, 9, 26-27.

ZHANG, B.-J. (張柏江) 1994. "Cí lèi huó yòng de gōng néng jiě shì 詞類活用的功能 解釋 [Funcionamiento de las categorías gramaticales]", Zhong Guo Yu Wen 中國語文 [Lengua y gramática chinas], 5, 339-346.

ZHANG G.-X. (張國憲) 2005. "Xíng míng zǔ hé de yùn lü zǔ pèi tú shì jí qí yùn lü de yǔ yán dì wèi 形名組合的韻律組配圖式及其韻律的語言地位 [Las configuraciones prosódicas de la estructura Adj+N]", Dan ai Yu Yan Xue 當代語言學 [Lingüística contemporánea], 1, 35-52.

ZHONG GUO SHE HUI KE XUE YUAN XUE JE WEN XUAN (中國社會科學院學者文選) 2001. Lü shú xiāng jí 吕叔湘集 [Selección de artículos de Shu-Xiang Lü], Beijing: Zhong Guo She Hui Ke Xue.

ZHONG GUO SHE HUI KE XUE YUAN YU YAN YAN JIU SUO CI DIAN BIAN JI SHI (中國 社會科學院語言研究所詞典編輯室 Ediciones del Instituto de la Academia china de Ciencias Sociales y Lingüística) 2001 [1987]. Daò xù xiàn dài hàn yǔ cí diăn 倒序現代漢語詞典 [Diccionario inverso del chino moderno], Beijini: Shang Wu. 
ZHONG GUO SHE HUI KE XUE YUAN YU YAN YAN JIU SUO CI DIAN BIAN JI SHI (中國 社會科學院語言研究所詞典編輯室Ediciones del Instituto de la Academia china de Ciencias Sociales y Lingüística) 2005. Xiàn dài hàn yǔ cí diăn 現代 漢語詞典 [Diccionario del chino moderno], Beijini: Shang Wu.

ZHOU, J. (周薦) 1991. Fù hé cí cí sù jiān de yì yì jié gòu guān xì 複合詞詞素間的意義 結構關係 [Relación semántica entre los morfemas de la composición]， Tianjing: Jiao U.

ZHOU, G.-H. y DANG, J.-Q. (周國輝 y 黨俊卿) 2005. "Hà yīng fù hé cí gòu cí jìn chéng zhōng de yǔ fă huà ji zhì 漢英複合詞構詞進程中的語法化機制 [El mecanismo de gramaticalización en la composición del chino e inglés]", Wai Yu Yu Wai Yu Jiao Xue 外語與外語教學 [Lengua extranjera y su enseñanza], 4, 35-37.

ZHU, H.-J. (祝鴻杰) 1991. “Hàn yǔ cí zhuì yán jiū guăn jiàn 漢語詞綴研究管見 [Opiniones sobre estudio de los afijos del chino mandarín]", Yu Yan Yan Jiu 語言研究 [Estudio de la lengua], 2, 11-16. 